2.

$x^{2}<-5$

,

Ixis?

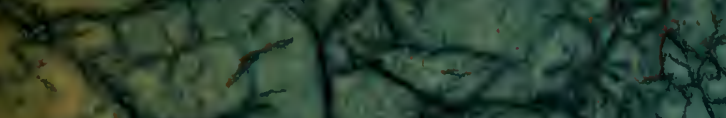

$x+1-296324$

(8) (o)

ex

4

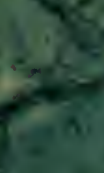

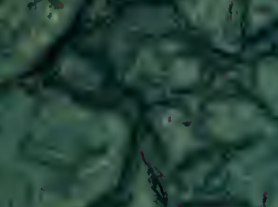

30.72

miseseses

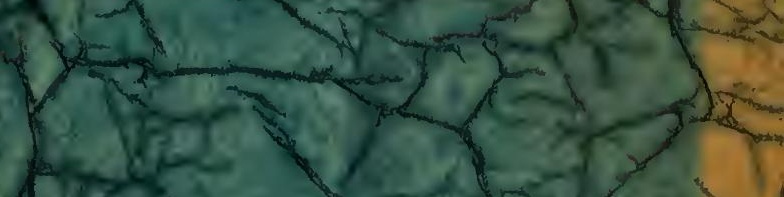

$342 \pi 25$

$3 x+20$.

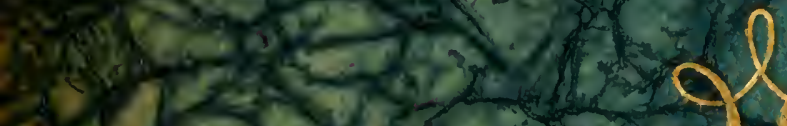

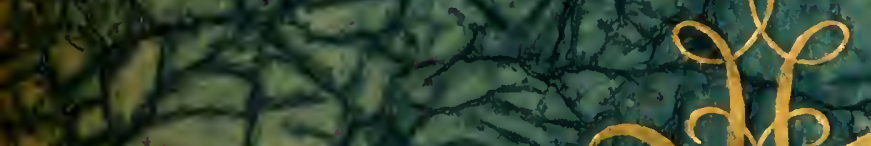

$+2025$

miser.

15)

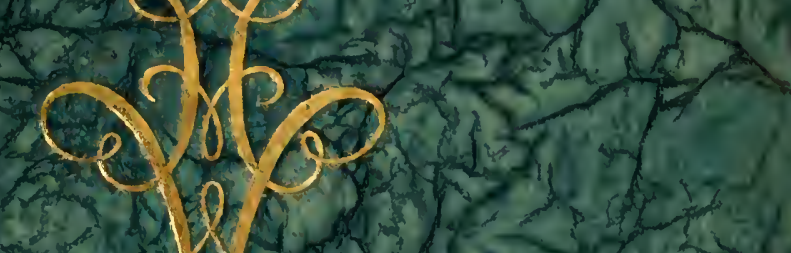

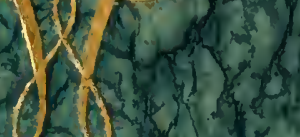

Exts $x+1$

60.12

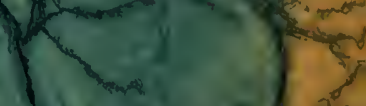

(u)

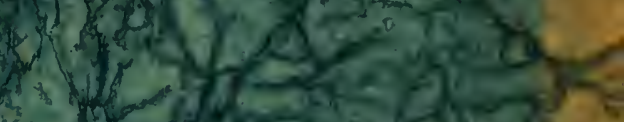

$1+2 \cdot 1$.

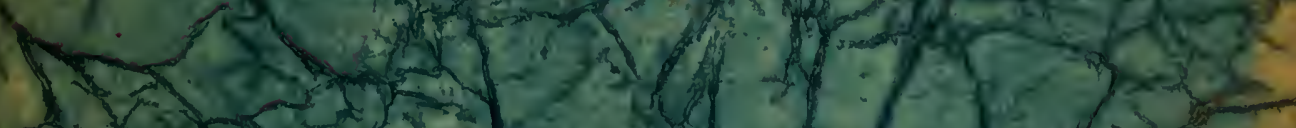

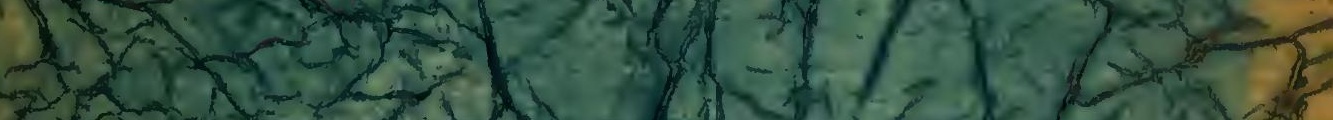

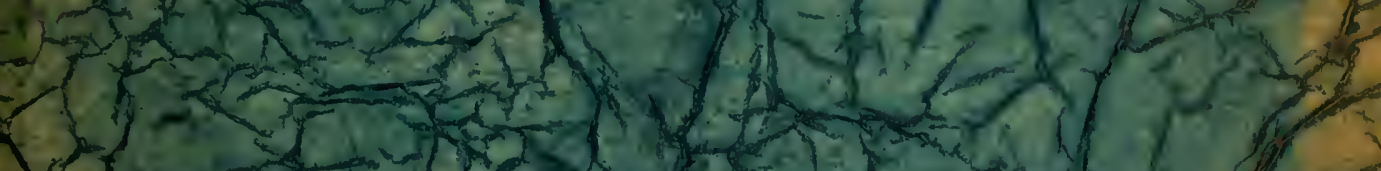

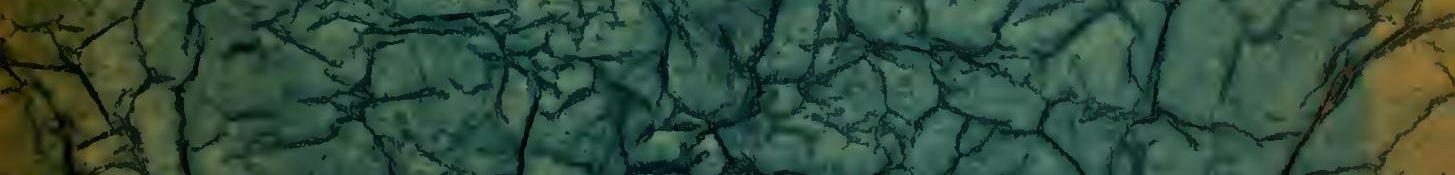
I)

(x) 1,32 4.
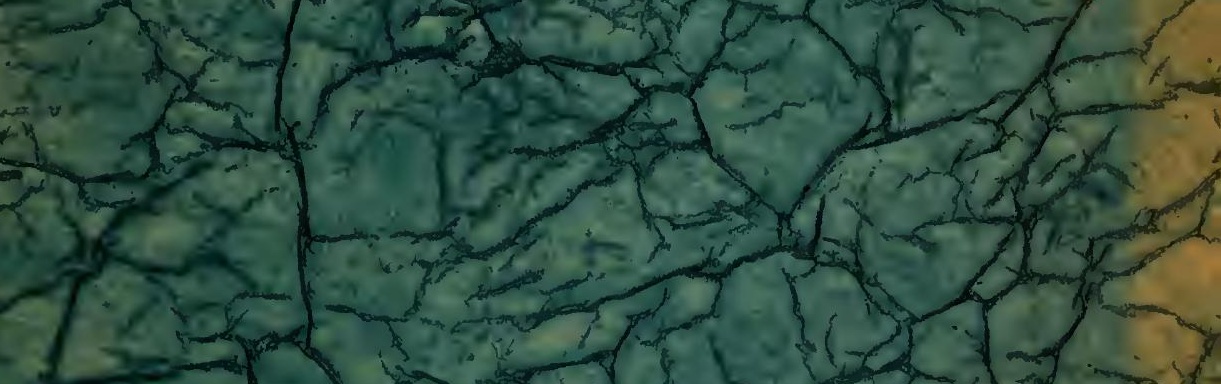

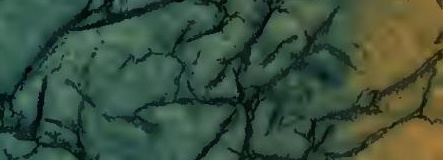

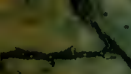

1)

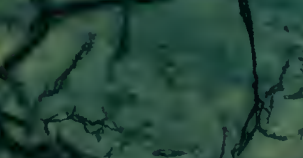

it ${ }_{1}{ }_{2}$

aris

$8=2 x+1>19$

11) $=2 x+13$

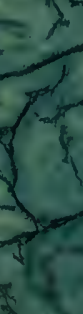


RECEIVID

\section{FEd 11970}

WEST VIRGINIA UNNIVERSITY MEDICAL CENTER LIBRARY

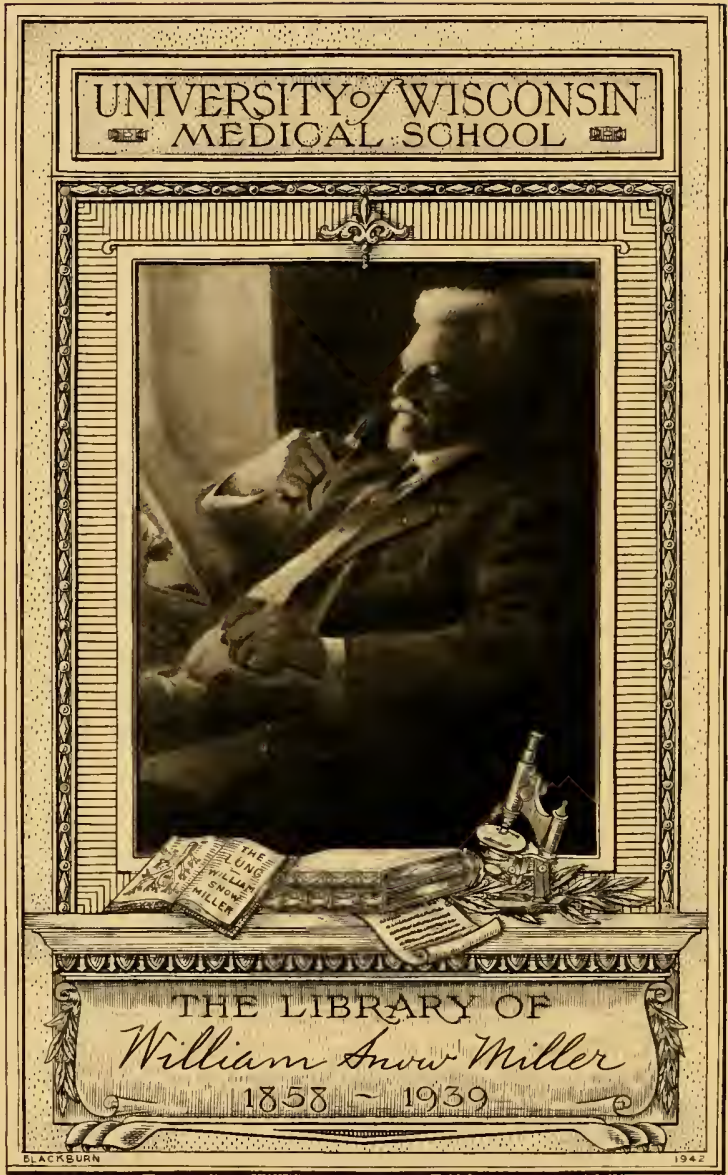


WVU - Medical Center Library
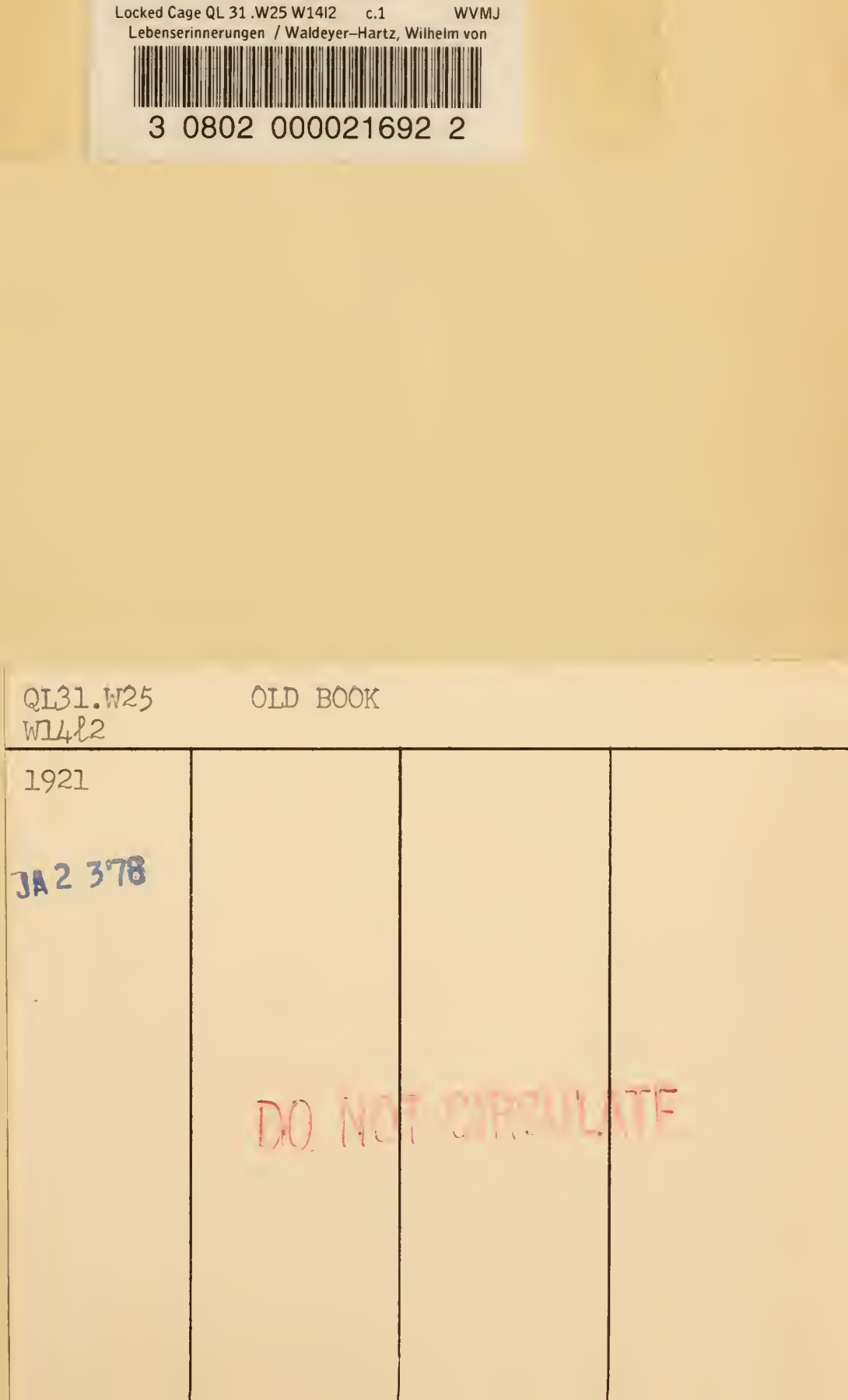

Digitized by the Internet Archive in 2011 with funding from LYRASIS Members and Sloan Foundation 


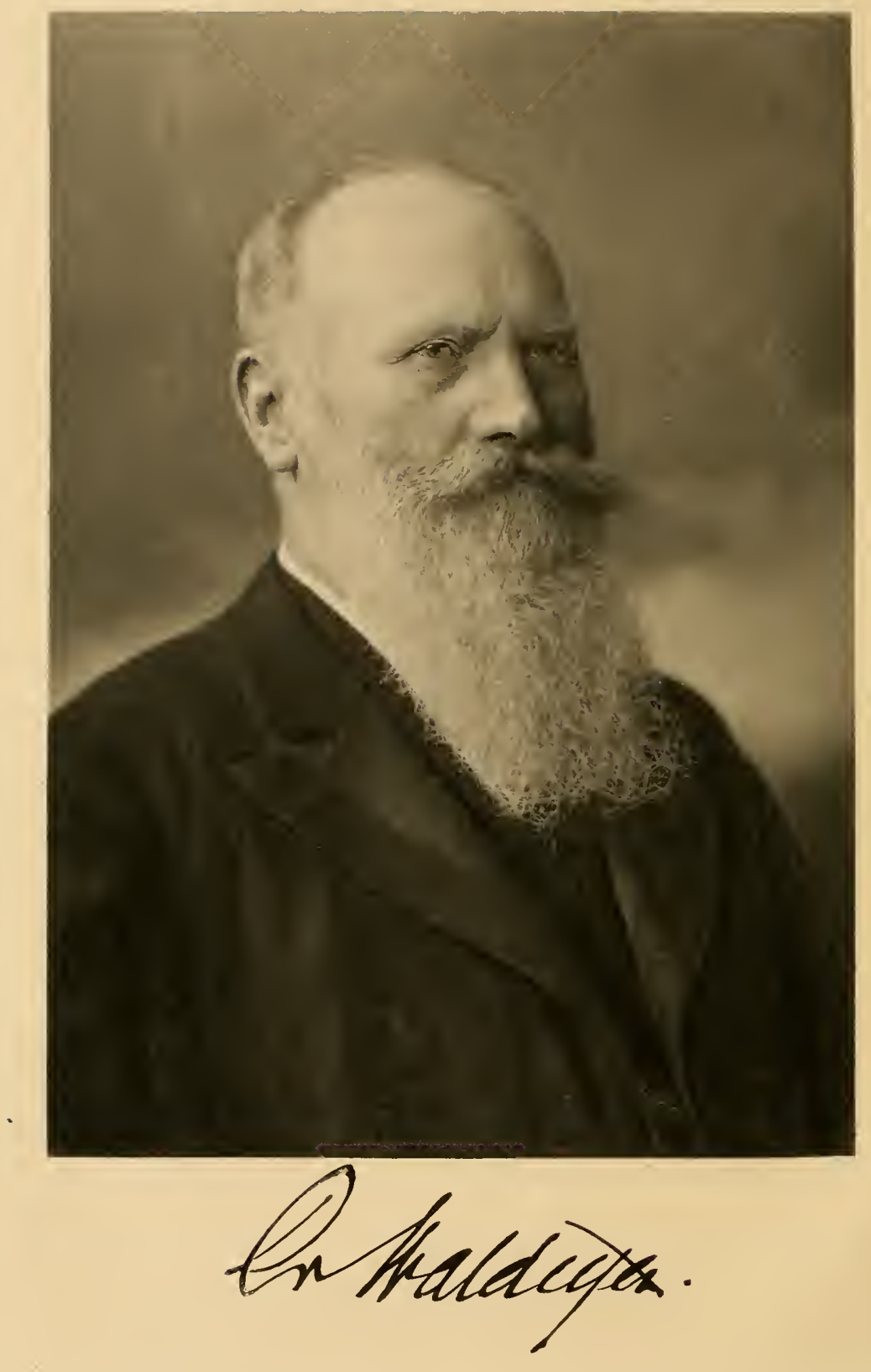




\section{LEBENS- \\ ERINNERUNGEN}

VON

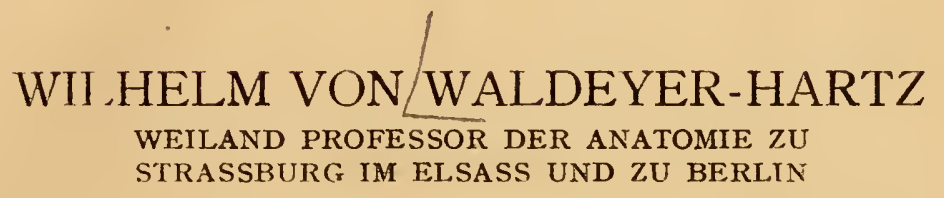

ZWEITE AUFLAGE

I 92 I

VERLAG VON FRIEDRICH COHEN IN BONN 
OLD POOKS

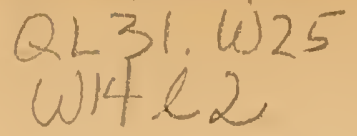

Alle Rechte vorbehalten

Copyright by Friedrich Cohen in Bonn, Germany r92I

Ohlenrothsche Buchdruckerei

Georg Richters

Erfurt 


\section{Vorwort.}

In der Annahme, daß die noch in großer Zahl lebenden Mitglieder meiner Familie, die ihren alten Großvater und Großonkel - von allen den übrigen, schwierig auszudrückenden Verwandtenbeziehungen zu schweigen - gut gekannt haben, gern etwas Näheres über dessen Leben und Treiben erfahren möchten, begann ich diese Erinnerungen niederzuschreiben. Während die Feder sie zu Papier brachte, kam mir der Gedanke, da $B$ auch von den rund 20000 Schülern, zu deren medizinischer Ausbildung ich während einer mehr als 5ojährigen Lehrtätigkeit habe beitragen können, manche den gleichen Wunsch haben möchten. So kam ich zu dem Entschlusse, meine Niederschrift in Druck zu geben. Und, zum dritten, schien es mir von Interesse auch für Alle, die gern der Entwicklung von Welt und Menschheit folgen, darzulegen, wie in einer rund Ioojährigen Spanne Zeit, einer Zeit, in der die größten Wandlungen in der politischen Geschichte sowohl wie in der Entwicklung der Wissenschaft und Technik vor sich gegangen sind, das Leben einst und jetzt sich gestaltete. Um so mehr wurde ich zur Festlegung meiner Lebenserinnerungen veranla Bt, als gerade jetzt, wie es scheint, besonders große Änderungen - Reformen beliebt man sie zu nennen - sich vorbereiten und namentlich Deutschland, vielleicht aber auch das ganze alte Europa, vor einem Wendepunkte seiner Geschichte steht, wie es ihn bedeutungsvoller noch nicht erlebt hat. Da scheint mir eine getreue Schilderung der Zeit, wie sie ehemals war und jetzt, vor dieser Wende, sich darstellt, fast geboten. Eine solche Schilderung zu geben, wie sie sein soll, dazu bin ich freilich nicht imstande, das ist Sache der Historiker vom Fach.

Aber auch ein bescheidenes, anspruchsloses Lebensbild eines Menschen, der diese Zeit in einer langen Reihe von Jahren durchschritten hat und einen großen Teil der Welt durch eigene Anschauung, im Verkehr mit den verschiedensten Berufen und Ständen, kennen lernte, mag nicht wertlos erscheinen. 
Wenn der Verfasser dieses Buches bei einigen Dingen, wie in der Besprechung seiner eigenen Lehrtätigkeit, Vielen zu sehr ins Einzelne sich verlierend erscheinen mag, so hat er dabei vorzugsweise seine Schüler im Auge gehabt und daran gedacht, daß gerade jetzt so viel von Reformen der Universitäten die Rede ist.

Ich habe in meinem Buche versucht, dem unübertrefflichen Werke meines Kollegen und Freundes Adolf $\mathrm{KuBmaul}$ möglichst nahe zu kommen und in den gleichmäßigen Fluß der Darstellung durch eingestreute Anekdoten nach wirklichen Erlebnissen einige belebende Wirbel hineinzubringen. Dabei bin ich auch vor derberen Dingen, die man dem Anatomen, dem alles Menschliche menschlich vorkommt, zu Gute halten muB, nicht zurückgeschreckt, hoffe aber meine Leser und selbst meine Leserinnen, wenn es solche geben sollte, damit doch nicht $z u$ erschrecken.

$\mathrm{KuBmaul}$ ist mir gegenüber im Vorteil. Er koṇnte in der Zeit, als er seine Jugenderinnerungen schrieb, seine Einleitung mit den Sätzen enden:

,,Uns Deutschen gebietet die Pflicht, dem scheidenden Jahrhundert ein doppelt feuriges Danklied zu singen. Den patriotischen Sinn, der lins in der langen Zerrissenheit und dem unseligen Hader der Stämme, Fürsten und Konfessionen verloren gegangen war, hat es dem deutschen Volke wieder gegeben. Es schenkte uns zur rechten Stunde den Fürsten von unerschütterlichem Pflichtbewußtsein und klarem Urteil, der mit sicherem Blick die genialen Helfer zu dem großen Werke der Wiederherstellung des Reiches fand, den Staatsmann und den Feldherrn, um die uns die Welt beneidet. In treuer Hingebung und felsenfestem Vertrauen folgte die Nation den herrlichen Führern und erkämpfte auf den blutgetränkten Schlachtfeldern Frankreichs die ersehnte Einheit und die Deutschland gebührende Stellung im Rate der Völker.

„,Möchten die Söhne und glücklichen Erben den heiligen Besitz, den sie ebensowohl der klugen Besonnenheit als dem Wagemut und Genie der Väter verdanken, treu schirmen und fernen Geschlechtern wahren!“"

So Adolf Kußmaul noch 1899 in der dritten Auflage seiner , Jugenderinnerungen eines alten Arztes“.

Welches Begleitwort kann ich meinen Lebenserinnerungen mit auf den Weg geben? 


\section{Vorwort.}

Mit Beschämung und Trauer müssen wir gestehen, da $B$ die Söhne und Erben den Wunsch KuBmauls nicht haben in Erfüllung gehen lassen. Zwanzig Jahre später war Alles, was in der großen Zeit, von der mein Freund schreibt und die ich mit denselben gehobenen Gefühlen wie er durchlebt habe, gewonnen war und noch mehr als das, wieder verloren und die alte innere Zerrissenheit, schlimmer noch als früher, ist wieder da.

Das Verkehrteste, was wir tun könnten, wäre: Klagen, Anklagen und Verzagen; das Rechte ist: Ertragen, Lernen und Mut behalten! Deutschland hat sich schon wiederholt aus ähnlichen schweren Unglückszęiten, wie sie zum guten Teil seiner zentralen Lage entspringen, erhoben; es wird auch wieder gelingen! 



\section{Inhalt.}

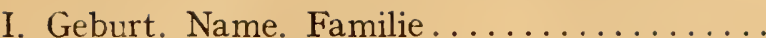

II. Kindheit und erste Jugendzeit .............. 4

Volksschule. - Vorbereitung zum Gymnasium. - Schilderung des Lebens auf einem westfälischen Landgute und Dorfleben vor roo Jahren. - Weiteres über die Familie meiner Eltern. Ein Wort über ehelichen Kindersegen, Säuglings- und Mutterschutz.

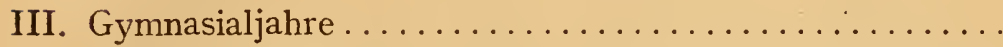

Das Gymnasium zu Paderborn. - Das Latein in der Medizin. Promotionen. - Habilitationen. - Doktordiplome. - Gymnasium und Realschule. - Musikübungen. - Erste Bekanntschaft mit der Eisenbahn. - Ferienwanderungen.

IV. Universitäts-Studentenjahre.

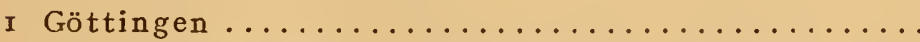

Fahrt nach Göttingen. - Mathematische Studien. - Ubergang zur Medizin. - Studentenleben. - Vorlesungen bei Stern, bei Wöhler, bei Wilhelm Weber, bei Henle. Erlebnisse bei Rudolf Wagner und bei Baum. - Bauchrednerei. $-Z$ wei Hinrichtungen; Bemerkungen zur Todesstrafe.

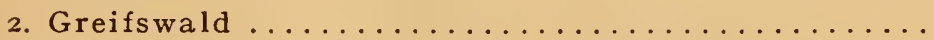

Abenteuer auf der Fahrt dorthin. - Greifswalder Studentenleben. - Beschäftigung mit Normaler und Pathologischer Anatomie. - Entschluß zum Verfolg einer akademischen Lehrtätigkeit. - Meine Lehrer: Budge, Sommer, Niemeyer, v. Bardeleben, Pernice. - Mißgeschicke beim geburtshilflichen Unterricht.

3. Berlin

Berlin im Jahre I86I.. - Im Hause meines Onkels. - Meine Lehrer: Reichert, Jüngken, v. Frerichs. - Doktorpromotion. - Medizinische Staatsprüfung. - Medizinische SchluBprüfung; mein Examinator Ehrenberg. - Ernste Stimmung nach bestandener Schlußprüfung. 
V. Universitäts-Dozentenjahre; Wanderjahre.

I. Königsberg

Freundliche Aufnahme in der Universität. - Förderung durch die Pathologische Anatomie. - Assistententätigkeit bei Professor v. Wittich. - Erste anatomische Vorlesung. Erlebnisse mit Papageien. - Etwas über Tierpsychologie. Eigene Erfahrungen mit Äther- und Chloroformnarkose. Der Anatom August Müller. - Meine Verlobung.

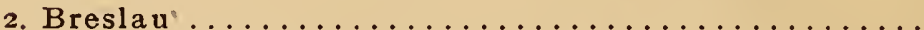

Assistententätigkeit bei Rudolf Heidenhain. - Der Anatom K. L. Barkow. - Weitere Förderung durch die Pathologische Anatomie; in drei Jahren vom Privatdozenten zum Professor ordinarius. - Tätigkeit als Pathologischer Anatom. - Bakteriologische Pläne. - Vergleichend anatomische Studien in Triest und Neapel. - Erste Bekanntschaft mit Rudolf Virchow. - Vier Wochen im Berliner Pathologischen Institute. - Julius Cohnheim, Willy Kühne. Berufung nach Straßburg.

3. Stra Bburg ...................... I4I

Eröffnung der neuen Universität; der Zwischenfall v. AufseßBinding. - Freiherr v. Roggen bach. - Erste Einrichtungen der Universität und ihrer Anstalten; akademisches Lagerleben. - Die medizinische Fakultät; mein Kollege und Freund G. Joessel. - Neubau der Anatomischen und Pathologisch-anatomischen Anstalt. - Freundschaftliches Zusammenleben und Zusammenwirken mit Friedrich v. Recklinghausen. - Von anderen Straßburger Kollegen, insbesondere von Adolf $\mathrm{KuBmaul}$. - Tätigkeit im Anatomischen Institute; meine Assistenten und Laboranten. - Vom Straßburger Bürgerspital. - Berufungen von Straßburg aus. - Vom Deutsch- und Französischsprechen im Elsaß. Politische Stellung Eisaß-Lothringens. - Oberpräsident v. Moeller, Statthalter v. Manteuffel. - Gespräch mit französischen Kollegen über Elsaß-Lothringen. - Unbeliebtheit der norddeutschen, namentlich der preußischen Beamten; ihre Ursache. - Der Zaberner Zwischenfall. - Die elsässische Bevölkerung. - Friedrich Alth off. - Berufung nach Berlin. - Einigung mit Reichert. - Reicherts Tod.

VI. Universitäts-Dozentenjahre; Schlußjahre. - Berlin ..... I78

I. Universität: Dozenten, Ordinarien, Extraordinarien. Medizinischer Unterricht. - Medizinische Fortbildung. Akademien für praktische Medizin. - Prüfungswesen. - 
Universitätsreform. - Gründung neuer Universitäten. Seite Köln und Bonn.

2. Frauenstudium und Frauenfrage.

3. Einrichtung meiner Lehrtätigkeit: Vorlesungen. Praktische Ubungen in der Mikroskopischen Anatomie. Präparierübungen.

4. Unterricht an den Militärärztlichen Bildungsanstalten.

VII. Beziehungen zu Akademien der Wissenschaften und Ge-

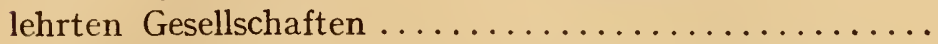

Stellung in der Preußischen Akademie. - Einrichtung der Preußischen Akademie. - Geschichtliche Bemerkungen; die preußischen Könige und die Akademie. - Bedeutung und Aufgaben der Akademien überhaupt; Akademien und Universitäten. - Die Preußische Akademie und die KaiserWilhelms-Gesellschaft. - Tätigkeit der Preußischen Akademie. - Internationale Beziehungen der Akademie. Association des Académies. - Tagungen in Paris, London, Wien, Rom und St. Petersburg. - Z wischenfall in Paris. - Mein Abschied von Rom und Italien. - König Eduard VII., Zar Nikolaus II. - Hirnforschungs-Institute. - Die Akademien und der Weltkrieg. - Arthur v. Auwers.

VIII. Mitgliedschaft in wissenschaftlichen, geselligen und gemeinnützlichen Vereinen. Außeramtliche Tätigkeit. Kongreßreisen . . . . . . . . . . . . . . .

In Königsberg, Breslau und Straßburg. - Deutsche Anthropologische Gesellschaft und Berliner Gesellschaft für Anthropologie, Ethnologie und Urgeschichte. Rudolf Virchow. - Tagung in Trier. - Dr. Hans Virchow. - Tagungen in Breslau, Karlsruhe, Nürnberg, Bonn, Wien und Budapest, Münster in Westfalen, in Westund Ostpreußen. - Abenteuer eines Arztes in Ruß. - Tagung in Ulm. - Vom Reich der Töne. - Tagungen in Innsbruck, Kassel und in der Pfalz. - Vom Pfälzer Wein. - Tagungen in Lübeck, in Braunschweig, in Lindau, in Halle an der Saale und in Metz; letzte Versammlung mit Rudolf Virchow; dessen Lebensende. - Tagung in Worms. - Liebfrauenmilch. - Tagung in Greifswald, Ausflug nach Bornholm, Gotland, Stockholm, Kristiania und Kopenhagen. - Tagungen in Görlitz, Heilbronn und Posen. - Nullum vinum, nisi hungaricum. - Anatomische Gesellschaft. - Besuch in Bordeaux. - Weinprobe. - Deutsche Ärzte-und Natur- 


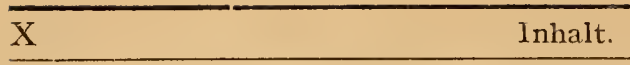

forscherversammlungen. - Internationale medizinische Kongresse: I. in Moskau. - Vom Reisen in Rußland. - 2. in Rom. - Gefahren der Staatsoberhäupter. - 3. in Madrid. - Vom Reisen in Spanien. - Hygienische Einrichtungen in unseren Eisenbahnwagen. - 4. in Berlin I890. - Meine Reisen im Jahre 1890. - 5. Letzter Internationaler medizinischer Kongreß in London I9r3. - Gesellschaft naturforschender Freunde in Berlin. - Gesellschaft für Natur- und Heilkunde. - Karl Asmund Rudolphi. Die Berliner Mittwochs-Gesellschaft. - Der Berliner Montags-Klub. - Die Heimia. Vom "Alten Heim". Akademischer Verein für Medizin und Naturwissenschaften. - Einiges über Mitgliedschaften in auswärtigen Vereinen. - Verein für volkstümliche Kurse von Berliner Hochschullehrern. - Verein für Volkshygiene. - Zentralstelle für die ärztliche Fortbildung in Preußen. - Litterarische Sachverständigenkammer. - Deutscher Sprachverein

IX. Von einigen Berliner und auswärtigen Kollegen ...... 280

Theodor v. Frerichs. - Ernst v. Leyden. - Karl Gerhardt. August Kundt. - Robert Koch. - Wilhelm His senior. Karl Ludwig. - Meine Assistenten und Laboranten.

X. Von meinen Reisen und Wanderungen........... 29I

Schwarzwald und Vogesen. - Frankreich: Annecy, Carcassonne, Lourdes, Marseille-Toulon-Nizza, St. Malo-Jersey. - Italien! Drei größere Reisen: Rom, Neapel, der Vesuv, die Zoologische Station, Sizilien, Taornina und der Ätna. Über Tunis und Frankreich heim. - Zwei Mittelmeerfahrten. - Türkei, Kleinasien, Griechenland, Ägypten. - Rumänien, Jassy. König Carol I. und Königin Elisabeth. - Zwei Reisen nach den Vereinigten Staaten und Mexiko. - Über die U. S. A. Die Todesfahrt der russischen Flotte r904. - Die Kämpfe um die Weltmacht. - Ausblick in die politische Zukunft.

XI. Beziehungen zum Preußischen Königshause $\ldots \ldots \ldots \ldots 320$

Kaiser und König Wilhelm I. - Kaiser und König Friedrich III. - Kaiser und König Wilhelm II.

XII. Politische und Kriegs-Erlebnisse $\ldots \ldots \ldots \ldots \ldots \ldots 336$

Das Jahr I848. - Der kurhessische Verfassungsstreit. - Olmütz. - Der Krimkrieg. - Der Österreichisch-französische Krieg. - Die Kämpfe um Deutschlands Einigung: I864, I866, I $870 / 7$ I. - Bemerkungen über die späteren Kriege: 
Peru-Chile, Vereinigte Staaten-Spanien, Russisch-türkiSeite scher Krieg, Boxerkrieg in China, Russisch-japanischer Krieg, Balkankriege r912/13.

XIII. Der Weltkrieg und dic Revolution ........... 355

Gespannte politische Lage. - Der Fürstenmord von Serajewo. - Vereitelte Reise nach Straßburg und Lyon. - Berlin in den ersten Kriegswochen. - Die heimische und gegnerische Presse. - Zwei Kriegsgedichte. - Annexionsgelüste; Verurteilung derselben. - Ein Brief von mir aus dem Jahre I9I5 und das Auswärtige Amt. - Anklagen und Verleumdungen unserer Gegner; Steigerung des Völkerhasses; Krriegspsychose. - Meine Veröffentlichung I914: "Frieden im Kriege“. - Beteiligung meiner Familie am Kriege. - Die deutsche Revolution von I9I 8. - Plünderungen im Gebäude der Akademie der Wissenschaften. - Spartakistische Unruhen; Streiks; Ursachen des Weltkrieges und der Revolution. Die Schuldfrage. - Ursachen unseres Zusammenbruches. Der Luftkrieg. - Der Unterseebootkrieg. - Unterlegen, aber nicht besiegt.

XIV Bild Deutschlands vor und nach dem Weltkriege..... 385

Wie kann Deutschland politisch einig werden? - Was mich aufrecht erhielt.

XV. Fortschritte in den Wissenschaften und in der Technik und deren Verwertung für unsere Lebensführung seit meiner Geburt. Schlußwort ............. 393

XVI. Anmerkungen, Zusätze, litterarische Nachweise ...... 403

Namen-Register ...................... 409 



\section{Ka pitel. \\ Geburt, Name, Familie.}

Das Kirchenbuch der Dorfgemeinde Hehlen besagt, da $B$ ich dort am 6. Oktober 1836 geboren sei. Ich selbst weiß davon Nichts, denn die Natur ist barmherzig. Sie läßt uns ins Leben treten und aus dem Leben scheiden, ohne da $B$ wir dessen gewahr werden. Für den Eintritt ins Leben ist dies sicher; ich halte es für ebenso sicher beim $\mathrm{Ab}$ schied. Wenn man von Diesem oder Jenem auch sagen hört, er sei bei vollem Bewußtsein gestorben, so ist das doch nur so $\mathrm{zu}$ verstehen, da $B$ der Betreffende mit vollem Bewußtsein sein Ende herannahen fühlte; vom Akt des Sterbens selbst wird er nichts gewahr, da schwindet vorher das Bewußtsein.

Das Kirchdorf Hehlen gehört zum Kreise Holzminden des Herzogtums Braunschweig; es liegt malerisch zusammen mit der Tochtergemeinde Daspe zu beiden Seiten des echtesten deutschen Großstromes, der Weser( ${ }^{(1)}$, unweit Hameln. Die beiden niedrigen runden Türme der Kirche und das Schloß der dort ansässigen Grafen von der Schulenburg-Hehlen bieten dem von der Weser Nahenden ein charakteristisches Bild.

Mein Vater, einer alten westfälischen Landwirtsfamilie angehörig, war zu der Zeit Oberverwalter des Schulenburgischen Gutes. Er verehelichte sich I835 mit der fünften Tochter, Wilhelmine, des derzeitigen Schullehrers und Kantors der Gemeinde Hehlen, Wilhelm Gabriel v. Hartz und so wurde ich, obwohl väterlicherseits Westfale, auf braunschweigischem Boden geboren.

Meines Aufenthaltes in diesem gesegneten Lande, welches ich wie eine zweite Heimat liebe, war zunächst nicht von langer Dauer. Schon ein Jahr nach meiner Geburt nahm mein Vater eine Oberverwalterstelle auf dem alten Klostergute Corvei, gleichfalls an der Weser bei der preußischen Kreisstadt Höxter gelegen, an und kam damit in seine Heimat zurück. Bald darauf übernahm er die ihm

${ }^{1}$ Die eingeklammerten Ziffern beziehen sich auf die Anmerkungen am Schlusse des Buches.

v. Waldeyer-Hartz, Lebenserinnerungen. 
angebotene Oberverwaltung des dem Freiherrn Friedrich v. Haxthausen gehörigen Gutes Abbenburg, gleichfalls im Kreise Höxter belegen und blieb in dieser Stellung fast $30 \mathrm{Jahre}$, bis er die Pachtung des daneben gelegenen kleineren v. Haxthausenschen Gutes Bökerhof bekam. So habe ich denn meine ganze Kindheit und Jugendzeit auf einem allein gelegenen schönen, großen westfälischen Landgute zubringen dürfen, zusammen mit meinen beiden Brüdern. Nicht genug kann ich das günstige Geschick preisen, welches unserem brüderlichen Dreikleeblatt damit zuteil wurde. Ehe ich davon weiter erzähle, noch einiges über meine Vorfahren väterlicher und mütterlicher Seite.

Der in meinem Besitze befindliche Stammbaum der Familie Waldeyer reicht bis zur Zeit des Dreißigjährigen Krieges und stützt sich auf die Kirchenbücher der in Betracht kommenden Orte. In diesem Kriege sind bekanntlich viele solcher Urkunden verloren gegangen, so daß über dessen Zeit hinaus, namentlich für ländliche Familien, vielfach keine Nachrichten zu beschaffen sind. Eine Familienüberlieferung besagt, daß der erste Träger des Namens Waldeyer aus dem Fürstentum Waldeck in das Paderborner Land eingewandert und dort als „Waldecker" bezeichnet sei. Daraus sei später die niederdeutsche Form „Waldegger" und weiterhin „Waldeyer" entstanden. „Egger" ist in der plattdeutschen Mundart dasselbe wie hochdeutsch ,Eier", früher auch wohl „Eyer" geschrieben. Soweit nachweisbar, wurde mein Familienname stets mit "y“ geschrieben und mit dem Ton auf der ersten Silbe = „Wáldeyer" gesprochen, was mit der Familienüberlieferung ,Wáldecker"stimmt. Das Rätsel also, welches die damals sechsjährige Else v. Wittich verfaßte, als ich im Jahre I86I Assistent ihres Vaters in Königsberg wurde und in dessen Familie freundliche Aufnahme fand: ,Im Ersten stehen viele Bäume, das $Z$ weite legen die Hühner“ und das ganze ist . . ? , ,der Dr. Waldeýer" sprudelte sie triumphierend heraus, wenn der Gefragte nicht sofort die von ihr gewünschte Lösung fand, - das Rätsel, worauf sie nicht wenig stolz war, stimmt nicht ganz.

Meine Vorfahren väterlicherseits waren fast sämtlich gutgestellte westfälische Bauern, ansässig in dem ehemaligen Fürstbistum Pa derborn, in den jetzigen preußischen Kreisen Höxter und Warburg des Regierungsbezirkes Minden. Zweite und weitere Söhne der Familien 
verließen oft die väterlichen Höfe und suchten sich andere Lebensberufe. So wählten mehrere den geistlichen Stand - die Familie ist katholischer Konfession. Unter diesen war einer, Philipp Waldeyer, Pastor in Völsen; er begründete eine Stiftung, die einem Angehörigen der Familie, falls er das Gymnasium in Paderborn besuchte, zugute kommen sollte; sie ist mir verliehen worden. Der Stiftungsurkunde ist auch der vorhandene Stammbaum entnommen.

Mein Großvater, Philipp Heinrich Waldeyer, war Bauerngutsbesitzer und Gemeindeförster in dem Dorfe Hembsen bei der Amtsstadt Brakel. Da er früh starb, habe ich ihn nicht kennen gelernt, ebensowenig meine Großmutter väterlicher Seite. Sie hatte in zwei Ehen - mein Großvater war ihr zweiter Gatte - I2 Kinder, unter denen mein Vater, Johann Gottfried, I796 geboren, das älteste der zweiten Ehe war. Er starb I878 im Alter von 82 Jahren, kurz nachdem er noch einen Abdominaltyphus überstanden hatte, eines sanften Todes, einem Einschlummern gleich, I4 Tage nach dem Tode meiner Mutter, die, 66 Jahre alt, der gleichen Krankheit erlag. Der jüngere Bruder meines Vaters, der alte Onkel Franz, wie wir ihn nannten, erreichte ein Alter von 94 Jahren, bis zuletzt bei guter Gesundheit. Ich erinnere mich auch nicht, da $B$ mein Vater bis zu seinem letzten Leiden jemals krank gewesen wäre. Es sei hier gleich angefügt, da $\beta$ die Langlebigkeit auch in der Familie meiner Mutter häufig vorkam. Mein Urgroßvater v. Hartz, auch Volksschullehrer wie mein Großvater mütterlicherseits, erreichte ein Alter von 92 Jahren, mein Großvater wurde 78 Jahre alt, dessen Frau 8o Jahre, ihr einziger Sohn, Superintendent in Hasselfelde im Harz die Familie meiner Mutter ist protestantischer Konfession - 9I Jahre. Er hätte sicher ein noch höheres Alter erreicht, wenn er nicht den bekannten Altersbruch des Oberschenkelhalses erlitten hätte. Die dadurch erzwungene Ruhelage ertrug er nicht, wie ja solche Traumen dem höheren Alter fast stets gefährlich werden. Außer diesem einzigen Sohne wurden meinem Großvater noch 7 Töchter geboren, von denen 3 auch ein ansehnliches Alter erreicht haben. Sonach darf ich von mir wohl sagen, da $B$ ich in der Wahl meiner Stammeltern vorsichtig gewesen sei. Das hat sich auch bewährt, denn ich schreibe diese Zeilen in meinem 84. Lebensjahre, ohne an den Schwächen des Alters fühlbar zu leiden. Dankbar gedenke ich meiner Vorfahren, 
die, soweit ich weiß, alle durch ein wohlgehaltenes, mäßiges, aber auch tätiges Leben ihren Nachkommen den kostbaren Schatz der Gesundheit als Erbe vermacht haben. Dieses Erbe ist weit mehr wert als Geld und Gut, von dem uns drei Söhnen kaum etwas hinterlassen werden konnte.

\section{K a pitel. \\ Kindheit, Jugendzeit.}

Volksschule, Vorbereitung zum Gymnasium. - Das Leben auf einem westfälischen Landgute und Dorfe vor hundert Jahren. - Weiteres über die Familien meiner Eltern. - Ein Wort über ehelichen Kindersegen, Säuglings- und Mutterschutz.

Wenn ich im folgenden Abschnitt von meiner Kindheit und ersten Jugendzeit erzähle, so geschieht dies nicht, um viel von mir zu berichten. Hauptziel meiner Schilderung soll eine getreue Darstellung davon sein, wie die Zustände auf einem westfälischen Edelhofe und in den westfälischen Dörfern meiner Heimatsgegend zur Zeit meiner Kindheit waren und wie das Leben dort sich damals gestaltete. Wenn ich in der Überschrift dieses Abschnittes von rund hundert Jahren spreche, obwohl ich nur etwa 75 Jahre mit gutem Bewußtsein zurückdenken kann, so hat sich einerseits in den 25 fehlenden Jahren von I820 bis I845, die für Deutschland und insbesondere für meine Heimat volle Friedensjahre waren, das Leben genau so abgespielt, wie es von $\mathrm{r} 845$ bis $\mathrm{r} 848$ war, welche Zeit mir gut im Gedächtnisse geblieben ist. Außerdem ergänzen die Erzählungen meiner Eltern das Selbsterlebte und Selbstbeobachtete dahin, daß ich mit gutem Grunde hundert Jahre zurückgreifen darf.

Zuerst eine kurze Schilderung der Örtlichkeit, eine beschreibende und topographische Anatomie der Gegend, wie man von meinem Berufsstandpunkte aus sagen könnte. Die Landschaft im Kreise Höxter macht durch ihre hügelige Beschaffenheit, ihre gesegneten Fluren, ihre grünen Weiden, Wiesen und Wälder, zwischen denen zahlreiche Bäche, die der Weser zufließen, das belebende Geäder darstellen, auf den Besucher einen wohltuenden, angenehmen Eindruck. Sie ist reich belebt, denn fast jede Viertelmeile weiter trifft man beim Wandern auf ein Dorf oder ein Gehöft. Damals gab es 
reichliche Hausviehzucht an Rindern, Pferden, Schafen, Schweinen und Geflügel und in der Weidezeit trugen die zahlreichen Herden viel zum Schmuck des Landschaftsbildes bei. Sehr zu bedauern ist, daß schon lange vor dem jetzigen Kriege die Schafzucht sehr zurückgegangen ist; wir haben jetzt darunter zu leiden.

Abgesehen von der nächsten größeren Stadt Paderborn, auf die ich später bei der Schilderung meines Gymnasiastenlebens noch zurückkomme, finden sich im Bereiche meiner engeren Heimat vier Städte, alles richtige Landstädte mit Ackerbau: die weit über tausenn Jahre alte Kreisstadt Höxter, die auch in der Geschichte ihred Namen hat, insbesondere durch die erwähnte dicht dabei gelegene altberühmte Benediktinerabtei Corvei (Corbeja), unter Ludwig dem Frommen 823 gegründet, dann die Amtsstadt Brakel mit ihrem weithin sichtbaren, schlanken, spitzen Kirchturme, den ich erbauen sah und die beiden kleineren Städte Nieheim und Steinheim. Nahe bei Brakel schaut man das malerisch auf einer schön bewaldeten Anhöhe gelegene, der gräflichen Familie Asseburg gehörige Schloß Hinnenburg.

Die Ausläufer des Teutoburger Waldes reichen bis in meine Heimat hinein, die den Stätten, wo einst Arminius den Römern siegreich entgegentrat, nicht fern liegt. Oft habe ich auf Fußwanderungen diese geschichtlich so bedeutsamen Wald- und Feldfluren durchstreift.

Das der Freiherrlich v. Haxthausenschen Familie gehörige Gut Abbenburg ist das größte ihres Besitzes mit etwa 400 Hektaren Acker- und Wiesengelände. Außerdem gehören der Familie noch die in der Nähe gelegenen, je etwa halb so großen Güter Bökerhof, Vörden und Thienhausen. Abbenburg und Bökerhof grenzen unmittelbar aneinander. Bei Bökerl of liegt das kleine Dorf Bökendorf (Buchendorf), jetzt durch des Mediziner-Dichters F. W. Weber, der in Nieheim wohnte, episches Werk „Dreizehnlinden“ unter dem Namen „Bodinkthorpe“" bekannt geworden(2). Abbenburg liegt gänzlich allein, fast genau in der Mitte des Kreises. Vier Dörfer umgeben es in je 1/4 Meile Entfernung: das genannte Bökendorf, und die Kirchdörfer Bellersen, Altenbergen und Bredenborn, dieses das größte. Das Arbeitspersonal Abbenburgs: Tagelöhner, Knechte und Mägde, kam von diesen Dörfern. Es hat mich bis auf den heutigen Tag stets interessiert, daß die Bewohner dieser 
vier Dörfer, die sich alle ganz genau kannten, desselben Stammes, derselben Konfession und vielfach verwandt und verschwägert untereinander waren, doch in ihren Mundarten sich so voneinander unterschieden, da $ß$ man, wenn man sie sprechen hörte, sofort sagen konnte, aus welchem Dorfe sie stammten. Freilich, die Bellerser und Bökendorfer sprachen gleich; Bökendorf ist ein Tochterdorf von Bellersen. Kein Mensch spricht allerdings genau so wie ein anderer und wie man Jeden an der Handschrift erkennen kann, so auch an der Sprache. Immerhin ist es, so viel ich weiß, unerklärt, wie alle Menschen eines Ortes dieselbe Mundart haben, während in einem dicht daneben liegenden Orte mit Bewohnern gleicher Rasse, gleicher politischer und sozialer Lage, gleichen religiösen Bekenntnisses, unter gleichem Klima, bei gleichem Schulunterricht und bei vielfacher Verwandtschaft sich diese Verschiedenheiten herausbilden und durch die Jahrhunderte hindurch erhalten können. $\mathrm{Da} B$ jeder Mensch seine eigene Sprechart hat, erklärt sich anstandslos aus den kleinen, aber unendlich wechselnden Verschiedenheiten, die im anatomischen Bau der Sprech- und Stimmorgane bestehen, so wie es nicht zwei Menschen gibt, die ein Haupthaar von völlig gleichem mikroskopischem Bau haben. Das Abänderungsvermögen der.Lebewesen ist schier unendlich!

Der Abbenburger Hof ist regelmäßig und schön gebaut. Die großen Gebäude, Verwaltungshaus und Wohnung für den Oberverwalter oder Pächter, die großen Scheunen und Viehstallungen liegen der Länge nach zu beiden Seiten einer breiten Fahrstraße, die den Hof mitten durchsetzt; an der einen Stirnseite, der Wetterseite, schließt ein schönes kleines Eichengehölz ab, gegenüber das Herrenhaus, dem die Fahrstraße ausweicht, um ihm und einem kleinen Fischteiche Platz zu lassen. - Unmittelbar an die eine Längsseite schließt an ein mehrere Morgen großer Gemüsegarten, an die andere ein ebenso großer Obstgarten; dieser ist durch einen großen Laubengang von den angrenzenden Wiesenfluren abgetrennt. Etwas abseits lagen derzeit mit einem großen Teiche eine Mahl- und Sägemühle und eine Schmiede, sowie nach dem Obstgarten hin eine Werkstatt zur Anfertigung und Ausbesserung der landwirtschaftlichen Holzgeräte: Wagen, Pflüge, Eggen u.a., genannt die „Rademacherei“, im Volksmunde die ,.Räkerei“", wo der „Rademacher" oder „Räker“ sein Handwerk be- 
trieb. Es ist nicht ohne Interesse festzustellen, daß dies Handwerk seinen Namen vom „Rade ${ }^{66}$ hat. Ist doch die Erfindung des Rades zweifellos eine der bedeutsamsten, die jemals gemacht worden sind; sie reicht in das älteste Altertum. Anderwärts spricht man vom „Wagner", vom , Tischler" u. a. Beim landwirtschaftlichen Betriebe ist aber das Rad eines der wichtigsten Dinge. So war für alles gut gesorgt. Es versteht sich wohl von selbst, daß die Räkerei, die Schmiede und die Mühle uns Kindern die liebsten Orte waren und ich weiß ganz gut, warum Schuberts Müllerlieder mich immer so gefesselt haben; abgesehen von ihrer unverwelklichen melodischen Schönheit stecken für mich liebe Erinnerungen aus der Kinderzeit darin. Eine andere etwas mehr materielle Erinnerung knüpft sich an den Räker; dieser war zugleich der Bäcker. Jede Woche wurde frisches Brot gebacken. Die Mägde bereiteten den Teig, den der Bäcker dann in den vorher gut geheizten Ofen, in die Brotlaibe zerteilt, zu bringen hatte. An den Vortagen der großen Feste, Weihnachten, Ostern und Pfingsten, wurden Kuchen gebacken, zu denen meine Mutter den Teig bereitete nach dem alten Rezept:

Wer will guten Kuchen machen,

Der muß haben sieben Sachen:

Eier und Salz,

Butter und Schmalz,

Milch und Mehl -

Safran macht den Kuchen gel.

Dann blieb sie beim Backen dabei und mein Vater kam wohl auch dazu; wir Kinder, vom angenehmen Kuchenduft gefesselt, fehlten sicher nicht und verfolgten den Backvorgang mit dem größten Interesse; wußten wir doch, was die nächsten Tage brachten, gebührend zu schätzen. Dann kamen auch wohl, da die Kuchen abends in der Feierstunde gebacken wurden, die jüngeren Verwalter und Landwirtschaftslehrlinge - Ökonomieeleven wurden sie genannt - und die Wirtschafterinnen und Lehrtöchter hinzu und es entwickelte sich eine gemütliche Plauderstunde um den angenehm warmen und duftenden Ofen. Da meine beiden Eltern in dem Rufe standen, als Landwirt und Hauswirtin sehr tüchtig zu sein, was ich ihnen vollauf nachrühmen kann, so hatten sie stets junge Zöglinge, die bei ihnen lernen wollten, um sich. Viele später selbst ihre Wirtschaft führende Besitzer, 
Verwalter kleinerer und größerer Güter, Wirtschafterinnen und Hausfrauen, die eigenen größeren Haushalt führten, sind aus ihrer Schule hervorgegangen.

In der Schmiede gab es genug des Merkwürdigen zu sehen, wenn der Blasebalg das Feuer anfachte, wenn das weiBglühende Eisen aus dem Feuer gezogen und auf den $A m b o ß$ gelegt wurde und dann die Hämmer im Takt darauf niedersausten, daß die Funken weit umherspritzten. Oder wenn abends die Pferde beschlagen wurden, wobei wir gern genau zusahen und uns alles, was da nötig war, merkten; ein guter Hufbeschlag ist keine leichte, einfache Sache.

Nun vollends die Mühle: die Räder vom rauschenden Wasser getrieben, das Klappern des Mahlkastens, das Aufschütten des Getreides, die Sonderung von Kleie und Mehl, die Entnahme des Mehles, wobei dann der Rock des Müllers immer weißer wurde. Am liebsten sahen wir aber der Arbeit der Säge in der Sägemühle zu, wie sie sich knirschend in den starken Block, der ihr langsam und sicher entgegengetrieben wurde, hineinfra $B$. Wir Kinder pflegten uns dann wohl auf den Block zu setzen und so lange zuzuwarten, bis wir ganz nahe an der Säge waren. Wir wußten genau, wann es Zeit war, aufzuspringen. Man ließ uns das Spiel treiben und ängstigte uns nicht mit übertriebenen Warnungen und Verboten.

Unsere Eltern hatten stets genug zu tun; als wir ins schulpflichtige Alter kamen, begleitete uns Niemand mehr zur Aufsicht. Wir streiften in den Freistunden zwanglos umher in Feld, Wald und Flur, an den Teichen und Bächen, kletterten auf die höchsten Bäume, kurz, taten, was wir wollten. Man hatte uns auf die Gefahren einfach aufmerksam gemacht, ohne uns aber übertriebene Vorsichtigkeit oder gar Ängstlichkeit beizubringen. Ich halte dies Verfahren meiner Eltern bei der Erziehung für durchaus richtig. Wir wußten ganz genau, daß man einen Baumast $\mathrm{zu}$ prüfen hat, ehe man sich hinaufschwingt, wir kannten die gefährlichen tiefen Wasserlöcher - „Kolke“ hießen sie bei uns - in den Wiesen und mieden ihre nachgiebigen unterhöhlten Ufer.

Neben dem Herrenhause lag noch die Rentei, in der der Rentmeister wohnte und seine Geschäftszimmer hatte. Ihm waren alle Rechtsgeschäfte, die Verhandlungen mit den Behörden und die Prüfung der von den landwirtschaftlichen und forstwirtschaftlichen Verwaltungen 
und von der Mühle abgelegten Jahresrechnungen übertragen. Der damalige Rentmeister Meyer war verwitwet und führte keinen eigenen Haushalt; so war er zu den Mittags- und Abendmahlzeiten unser täglicher Tischgast. Er war ein sehr unterrichteter, kluger Mann, der uns Kindern manche geistige Anregung gab, namentlich mir, der ich frühzeitig Neigung zum Erlernen alles wissenswert Erscheinenden zeigte. Er und der Müllermeister Runge, sowie die Verwalter, Ökonomiezöglinge und Lehrtöchter bildeten unsern geselligen Umgang, der sich namentlich Sonntags und an den Sommerabenden, nach getaner Arbeit, vor der Haustür im Freien oder im Garten angenchm gestaltete. An den Sonntagabenden im Winter verkürzte ein mit geringem Einsatz geführtes Whistspiel die Zeit, an dem wir Knaben, als wir älter waren, von unserem Vater unterrichtet, teilnehmen durften. Keiner von uns hat sich irgendeinem Spiel mit Leidenschaft hingegeben, doch war es uns im späteren Leben angenehm, dieses feinste aller Kartenspiele zu kennen. War Besuch da von den Nachbargütern oder von den Städten und Dörfern der Umgegend, so kam es, wenn Jugend dabei war, auch wohl zu einem lustigen Pfänderspiel. Ich erinnere mich, da $B$ auch das ,,Tischrücken“ und „Hutrücken“ eine Zeitlang, wie in aller Welt, so auch auf unserem einsamen Gutshofe viel in Übung war und zu manchen Scherzen Veranlassung bot.

Meine Eltern waren nicht musikalisch beanlagt und wir besaßen nicht das übliche Hausinstrument, das Klavier. Erst später, als sich bei mir Neigung und Begabung zur Musik entwickelte, ließ mir mein Gönner, der Freiherr August v. Haxthausen, von dem ich später noch mehr zu erzählen haben werde, einen Flügel aus seinem Besitze in die Wohnung meiner Eltern hinüberschaffen. Bis dahin beschränkten sich unsere musikalischen Genüsse auf die Guitarre und die Ziehharmonika, die einige von den jungen Verwaltern und Zöglingen leidlich spielten. Ich lernte bald beide Instrumente handhaben. Sie reichten aus, um die junge Welt auch manchmal zu einem Tänzchen zu verlocken.

Zur guten Jahreszeit gab es im Frühjahr bei der Ackerbestellung, bei dem Jungvieh: Kälbern, Lämmern, Fohlen, Ferkelchen und bei dem jungen Geflügel, welches zu Hunderten heranwuchs, viel Interessantes und Anziehendes, auch Belehrendes zu sehen. Mein Vater 
übergab auch jedem von uns Knaben ein Stück Gartenland, welches wir selbst bepflanzen und in Ordnung halten mußten. Auch wurden wir angehalten, in Wald und Feld nützliche Früchte, Beeren und Samen zu sammeln, wie Kümmel und Buchnüsse, für die er uns dann eine kleine Summe Geldes gab, von der wir einen Teil in Sparpfennigen anlegen mußten, den anderen aber nach unserem Gutdünken frei verwenden durften. Zumeist verwendeten wir ihn auf dem Kirchweihfeste in Brakel, auf dem St. Annentage, für das Karussellreiten, welches ja wohl für alle Kinder und auf dem Lande auch noch für die Erwachsenen eine sehr beliebte Unterhaltung bietet.

Im Hochsommer, zur Erntezeit, halfen wir beim Einscheuern des Getreides und beim Heuen. Besonderes Vergnügen bot uns dabei das Bauen der großen Getreideschober, der Dimmen, wie sie in der Gegend genannt wurden. Es war ein Ehrenpunkt, eine recht stattliche Dimme regelmäßig und in schöner Form zu bauen. Schief und krumm geratene Dimmen wurden, wenn sie auf den Nachbargütern sich vorfanden, bespöttelt. Selbstverständlich saßen wir beim Einfahren fast unsere ganze freie Zeit auf den Pferden und lernten das Reiten von frühester Kindheit an. Später, als Gymnasiast und Student, habe ich mit meines Vaters Reitpferd manche Tagesritte zum Besuche befreundeter und verwandter Familien gemacht und mich dabei von der Sicherheit, mit der ein Pferd seinen Pfad unter schwierigen Verhältnissen in völliger Dunkelheit findet, überzeugt. Es sei hier ein solcher Fall eigener Erfahrung erzählt:

Ich kam als Göttinger Student zu den Ferien heim und hatte mit der Eisenbahn den Weg nach Höxter genommen. Von dort holte mich mein jüngster Bruder Friedrich mit meines Vaters Reitpferd $\mathrm{ab}$; es war noch ein Weg von etwa $I \frac{1}{2}$ Meilen zurückzulegen. Es hatte andauernd stark geregnet und als wir von der Landstraße zur letzten Wegstrecke abbogen, trafen wir auf dem nassen, schlüpfrig gewordenen Lehmboden auf mehrere Wasserpfützen. Am Rande einer solchen Pfütze glitt mein Pferd aus, stürzte in die Kniee und RoB und Reiter trennten sich voneinander. Ich verschwand für einen Augenblick in dem Lehmloche und als ich dann wieder auf meinem Pferde sa $B$, muß ich in einer sehr merkwürdigen Bekleidung erschienen sein. Mittlerweile war die Nacht angebrochen und wir ritten in einen dunklen Wald hinein, der uns noch in einer Viertelmeilenstrecke von 
unserem Ziele trennte. Je tiefer wir in den Wald auf einem sehr unregelmäßigen, mit Baumwurzeln reichlich durchsetzten Pfade hineinkamen, desto finsterer wurde es; bald erkannte man nichts mehr. Ich weiß genau, da $\beta$ ich, des Wortes eingedenk: ,man kann keine Hand vor Augen sehen", wiederholt versucht habe, meine emporgehobene Hand zu sehen, sie jedoch nicht wahrzunehmen vermochte. Da riet mir mein Bruder, der mit diesen Dingen Bescheid wußte und sich dicht hinter dem Pferde hielt, ich solle die Zügel freigeben und mich ganz der Führung des Pferdes überlassen. Das geschah und das Tier brachte mich mit absolut sicherem Schritt, ohne zu zögern und Unsicherheit $\mathrm{zu}$ verraten, ohne störend an eine Baumwurzel zu stoßen, heim. Meine gute Mutter erschrak nicht wenig, als ich ihr in dem Lehmschmucke entgegentrat.

Im Herbst gab die zweite Heuernte, die Grummeternte, wie sie hieß, und die Obsternte reichliche und angenehme Beschäftigung. Besonderen Genuß bereitete es uns, wenn wir im Felde aus zusammengeholtem Reisig ein Feuer anzünden und in der Asche frischgerodete Kartoffeln backen konnten. Mit frischer Landbutter, die wir zu solchem Tun mitnahmen, genossen, geben solche kurz vorher aus der Erde geholte Kartoffeln ein leckeres Mahl, wie man es sich auf andere Weise nicht verschaffen kann. Wenigstens fand ich, als ich später auf meinen beiden Amerikafahrten mir die auf der Speisenkarte als „baked potatoes" bezeichneten Kartoffeln bestellte, daß sie merklich hinter den früher selbst bereiteten zurückstanden. Freilich war ich inzwischen an gastronomischen Erfahrungen reicher geworden und jede aufgewendete eigene Mühe erhöht auch den Genuß.

Nicht vergessen will ich, daß wir auch, älter geworden, an den Jagden in der wildreichen Gegend teilnahmen. Obwohl ich bei ruhigem Zielen auf die Scheibe sehr gut und sicher mit der Büchse umgehen konnte, so war ich auf lebendes und rasch fliehendes Wild kein gefährlicher Schütze, wenn ich auch gute Lehrmeister hatte: unseren schon genannten Müller Runge und einen unserer Ökonomie-Zöglinge, den Freiherrn Max v. Droste-Hülsh off. Was diesen beiden Meistern vor das Feuerrohr kam, war geliefert. Besonders eindrucksvoll ist mir ein Büchsenschuß geblieben, den der junge Droste auf einen Fischreiher abgab. Wir Beide hatten eine Jagdstreife gemacht mit wenig Glück. Auf dem Heimwege erspähte mein Begleiter einen hoch 
in den Lüften dahinsegelnden Fischreiher, der, in der Höhe kaum gut sichtbar, auf uns zuflog. ,,Siehst du den Vogel," sagte mein Begleiter zu mir, ,den hole ich mir mit der Kugel, wenn er über uns ist." $\mathrm{Er}$ hob die Büchse, zielte genau, der Schuß krachte und der große Vogel fiel wie ein Stein tot zu unseren Füßen nieder. - Ein anderes Jagderlebnis, welches mir in Erinnerung geblieben ist und wobei der Müller Runge die Hauptperson war, sei gleichfalls erzählt: Der Revierförster der v. Haxthausenschen Forsten hatte Runge und mich nebst einigen Anderen $\mathrm{zu}$ einer Jagd auf Hasen eingeladen. Wir hatten einige zur Strecke gebracht und befanden uns auf dem Heimwege; die Gewehre bereits über die Schulter gehängt. Schon dicht beim Gutshofe angelangt, sagte Runge, als wir an einer Kohlpflanzung vorbeigingen: „Wir könnten ja noch einmal durch den Kohl gehen, da findet sich vielleicht noch etwas." "Ja, " meinte der Revierförster, , ,aber ich glaube kaum, hier so dicht beim Hofe." Runge winkte mir, machte sein Gewehr schußfertig und schritt voran. Mit einem Male sehe ich ihn das Gewehr anlegen, ein Hase springt auf und in der nächsten Sekunde hatte ihn Runges totsicherer SchuB erlegt. Runge setzte das Gewehr ab und sagte in westfälischem Plattdeutsch: „Dei häww’ ick et oll lange wicket!“ „Dir habe ich es schon längst prophezeit !“ Die Aussprache des, ,Dei“ ist schwer anzugeben; es lautet fast wie „Di“،, es klingt aber, während der Hauptton auf dem i ruht, ein kurzes e, mit dem i nicht zusammen gesprochen, vorher an $=$ Dĕi. Runge kannte fast jedes Hasenlager in der Umgegend und wußte, daß der ihm jetzt zugefallene Hase in diesem Kohlhofe lagerte. Er hätte ihn jedoch allein, ohne die Einladung zur Jagd, nicht schießen dürfen, da der Hof nicht zu seinen Jagdgründen gehörte; aber es verdroß ihn, daß ihm der Hase so vor der Nase lag und er ihn nicht vor sein Rohr bringen konnte; da war ihm diese Gelegenheit so recht erwünscht gekommen.

Ein Hauptvergnügen, welches den Körper stählte und zu Mut und rascher Entschlossenheit erzog, war uns ein Discusspiel. Eine Scheibe aus hartem Holze gesägt vom Umfange eines gewöhnlichen Tellers und etwas über Daumenbreite dick, wurde von zwei gegnerischen Spielgruppen abwechselnd geschleudert. Die eine Gruppe, meist 2-3 Spieler, stellte sich zu Anfang des Spieles nahe dem westlichen Ende der den Abbenburger Hof der Länge nach durchziehenden 
Straße auf, die andere nahe dem östlichen. Nun wurde die Scheibeabwechselnd von der einen Gruppe der anderen entgegengeworfen. Zum Scheibenwerfer wurde meist der Stärkste gewählt. Die Scheibe rollte sausend die Straße entlang und es galt nun, sie in ihrem Laufe aufzuhalten; das hatte die Gruppe zu besorgen, der die Scheibe entgegengeschleudert worden war. Man sprang zu und streckte ihr starke mit keulenförmig verdickten Enden versehene Stangen entgegen. Die Scheibe, wenn sie kräftig genug geworfen worden war, sprang beim festen Entgegenstemmen der Stange oft mehrere Meter in die Höhe. $\mathrm{Da}$, wo sie zur Ruhe kam, stellte sich die Gruppe, welche sie aufzuhalten hatte, hin und hatte nun die Scheibe der ersten Gruppe entgegenzuwerfen. So ging das Spiel hin und her, bis eine der Gruppen, entweder infolge ungeschickten Aufhaltens der Scheibe oder infolge besonders kräftiger Würfe der Gegenpartei, aus dem ihrem Anfangsstandort benachbarten Hoftore hinausgedrängt war. Das galt als Niederlage.

Der Winter bot gleichfalls seine mannigfachen Vergnügungen für die Kinderzeit: In den warmen Ställen der Haustiere, namentlich der Schafe, wo dann auch die jungen Lämmer kamen, draußen im Schnee mit Schneeballen und Schneemännern, deren wir immer eine Menge herstellten, den einen größer als den anderen, das Eisvergnügen, das Schlittenfahren und manches andere, wie das Arbeiten in der Räkerei, das Dreschen mit seinem anheimelnden Taktgeklapper, welches man jetzt gar nicht mehr kennt, wie vieles andere. Wir scheuten uns nicht, nasse Füße zu bekommen oder uns im Schnee herumzubalgen. Erkältet haben wir uns dabei nicht, sondern tüchtig abgehärtet. Auf dem halbstündigen Schulwege blieben wir im Winter, wenn's heimging, oft die dreifache Zeit, um an geeigneten Stellen das Eis zu probieren. Hier ein Beispiel, wie abgehärtet wir waren und wie wenig ängstlich man zu sein braucht: Wir brachen einmal an einem recht kalten Wintertage auf dem Heimwege in das Eis ein und wurden völlig durchnäßt. Bis wir nach Hause kamen, waren wir in unseren nassen Kleidern förmlich zu Eissäulen erstarrt. Wir fürchteten aber von unseren Eltern Strafe, mochten sie auch nicht erschrecken, schlichen durch den Garten ins Haus, winkten einer der Mägde und baten sie, uns trockene Kleider auf den Getreideboden zu bringen, dessen Fenster offen standen. Hier kleideten wir uns in der kalten 
Zugluft um, waren vergnügt, $\mathrm{da} B$ unsere Eltern nichts gemerkt hatten, blieben frisch und gesund, beschlossen aber doch, nächstens vorsichtiger $\mathrm{zu}$ sein.

Wenn uns auf dem Schulwege nichts Besonderes beschäftigte, pflegte ich meinen mehr oder minder aufmerksam lauschenden Brüdern ein Märchen zu erzählen, welches ich jahrelang fortzuspinnen wußte. Die Hauptrolle darin spielte ein mit Zauberkräften begabter Kater, das „Lorck" genannt. Natürlich fehlten Könige, Prinzen und Prinzessinnen nicht, denen das Lorck entweder wohl oder übel wollte, was zu allerhand Verwicklungen führte. Offenbar hatte das Märchen vom gestiefelten Kater seinen Einfluß geübt.

Hier mögen noch zwei mir lebhaft im Gedächtnisse gebliebene Begebnisse aus unserer Kinderzeit Platz finden. Zunächst ein schauriges: Eines Tages, in der Hundszeit - wir Kinder spielten vergnügt vor der Haustür - erschien ein fremder Hund auf dem Hofe; die Hof- und Jagdhunde, die bei uns gehalten wurden, versammelten sich um den fremden Genossen, aber mit einer eigentümlichen Scheu; der fremde Hund biß sie alle und anstatt wieder zu beißen, liefen sie von ihm weg. Glücklicherweise hatte dies meine Mutter vom Fenster aus gesehen; sie wußte, um was es sich handelte, eilte schnell herbei, ergriff uns und konnte uns eben ins Haus in Sicherheit bringen, als der fremde Hund uns schon nachlief, aber eine verschlossene Tür fand. Er verließ dann den Hof, ohne da $B$ man ihn erlegen konnte und mag noch weiteres Unheil angerichtet haben. Meine Mutter meldete den Vorgang sofort dem Freiherrn; dieser ließ die Hunde einsperren; sie wurden leider sämtlich toll. Schaurig klang das Geheul der wutkranken Tiere aus ihrem Verließ, bis man sich entschloß, sie zu erschießen, was man wegen des Wertes der Hunde nicht eher vornehmen wollte, bis ihre Tollwut von sachverständiger Seite festgestellt war. Noch einmal bin ich in Gefahr gewesen, von einem tollen Hunde gebissen zu werden, als Schüler des Paderborner Gymnasiums. Es war an einem dunklen Herbstabend, als dort ein toller Hund die Westernstraße, in der ich wohnte, entlang lief und mehrere Personen biß, unter anderen einen Schulkameraden von mir, der gerade zu mir kommen wollte. Auch ich war erst kurze Zeit vorher nach Hause gekommen. Das Tier konnte eingefangen werden, so da $B$ man die Wutkrankheit festzustellen vermochte. Als mein Mitschüler mir seine 
Wunde am Bein zeigte und wir auch von der Straße her Rufe vernahmen, die von anderen Gebissenen herrührten, riet ich meinem Kameraden, sich sogleich die Wunde mit dem Glüheisen ausbrennen zu lassen. Er ging darauf ein und ein in der Nähe wohnender Arzt führte das sofort recht gründlich aus. Mein Mitschüler ist gesund geblieben; auch von den übrigen Gebissenen, die sich gleichfalls alsbald in Behandlung begaben, ist glücklicherweise keiner erkrankt.

Mit einer anmutigen Begebenheit möchte ich diese Erinnerungen aus meinem Kinderleben in Haus und Hof schließen; mit einer Erinnerung an die große westfälische Dichterin Annette v. Droste$H$ ülshoff, unzweifelhaft eine der bedeutendsten deutschen Dichterinnen. Sie war zum Besuche ihres Onkels, des Freiherrn v. Haxthausen, nach Abbenburg gekommen und blieb einige Wochen dort. So lernte sie uns Kinder, damals etwa im Alter von 7, 5 und 2 Jahren, kennen. Sie rief uns dann gewöhnlich des Morgens unter ihre im ersten Stock des Herrschaftshauses gelegenen Zimmerfenster und erzählte uns unten im Grase lagernden Buben selbsterfundene Märchen. Das machte ihr augenscheinlich selbst viel Vergnügen, denn wenn wir, namentlich meine jüngeren Brüder, uns vorzeitig entfernen wollten, so warf sie uns einige Zuckerplätzchen hinab, um unsere Aufmerksamkeit aufs neue zu fesseln, was ihr auch gelang, wobei nicht näher untersucht werden soll, ob die neugeweckte Aufmerksamkeit mehr den Märchen oder den Süßigkeiten galt.

Als ich das siebente Lebensjahr erreicht hatte, wurde ich zusammen mit meinem nächstjüngeren fünfjährigen Bruder in die Volksschule nach Bökendorf geschickt. Sommer wie Winter wanderten wir, wie vorhin erwähnt, unsere Ränzel auf dem Rücken, dorthin, nahmen uns Milch und Butterbrot mit, das wir zur Mittagszeit bei dem Lehrer verzehren konnten und kamen nach Schluß der Nachmittagsstunde gegen $4 \mathrm{Uhr}$ nach Hause, wo unserer dann ein gutes Mittagessen wartete. Während meines ersten schulpflichtigen Jahres war ich bei meinem Großvater mütterlicher Seite, dem Kantor v. Hartz in Hehlen gewesen und hatte von ihm und seinem Adjunkten und Schwiegersohne, meinem Onkel Lohmann, der später der Nachfolger meines Großvaters wurde, den ersten Unterricht erhalten. Die Familie meines Großvaters war, wie ich bereits anführte, protestantischer Konfession; wir Kinder wurden in der katholischen Kon- 
fession, der meines Vaters, erzogen. Ich widme der Familie meiner Mutter, der, wie auch mein Vater, wir Kinder besonders nahe traten, später ein besonderes Kapitel. Konfessionelle Schwierigkeiten ergaben sich nicht. Meine Mutter begleitete uns oft in die katholische Kirche zu Bellersen, die wir regelmäßig mit unseremVater Sonntags besuchten, blieb jedoch ihrer Konfession treu. Sie war eine echt fromme Frau. Ihre Kirche hatte sie in der Amtsstadt Brakel; sie begab sich, so oft es anging, zu Wagen dorthin; dann und wann begleiteten wir sie auch dorthin; doch hielt sie darauf, daß wir bei der einmal für uns bestimmten Konfession blieben.

Unser Lehrer in Bökendorf war ein junger, eben erst aus dem Seminar entlassener Mann, Rohrbach mit Namen; ich kann ihn auch heute noch, nachdem 70 Jahre vergangen sind, seit ich seinem Unterricht entwuchs, nur mit treuer Dankbarkeit und in ehrender Erinnerung nennen. Er erwies sich bald als ein seinem schweren Berufe völlig Gewachsener. Man möchte wünschen, daß unsere Volksschullehrer alle so wären; ich habe aus dieser meiner Schulzeit eine große Achtung vor dem Berufe eines Volksschullehrers und vor der Wichtigkeit dieses Amtes mir bewahrt. Rohrbach behandelte alle seine Schüler und Schülerinnen in dem, was die Aufgabe der Volksschule ist, völlig gleich. Sah er aber, daß unter den Kindern solche waren, die Neigung hatten, mehr zu lernen, so gab er gerne weiteren Unterricht und regte zum Verfolg dieser Bestrebungen an. Als ich die Oberklasse der Schule besuchte, gab er mir aus seinem Privatbesitz passende Bücher zu lesen über Naturkunde und anderes Wissenswerte, gab mir Anleitung zum Zeichnen und den ersten Klavierunterricht, lehrte mich und meine Brüder in seinem Garten pfropfen und okulieren, sowie manches andere zur Gartenpflege gehörige. So oft ich später als Gymnasiast, Student und Universitätslehrer Gelegenheit hatte, ihn $\mathrm{zu}$ besuchen, um ihm meine Anhänglichkeit und Dankbarkeit zu erweisen, tat ich es gern. In den letzten Jahren seines Lebens erblindete Rohrbach, verlor aber seinen Lebensmut und seine heitere Stimmung, die ihn immer ausgezeichnet hatte, durch dieses Mißgeschick nicht. Dieselbe Erfahrung habe ich bei mehreren meiner Bekannten, die ihr Augenlicht verloren, gemacht, so unter anderen bei meinem späteren Berliner Kollegen, dem berühmten Chirurgen v. Langenbeck. Die beiden Genannten traf 
der Verlust ihres Sehvermögens erst im höheren Alter; aber auch jüngere Leute lassen sich durch dies traurige Geschick meist nicht entmutigen. So versicherte mich noch jüngst mein Kollege Kr ückmann in Berlin, der eine große Anzahl unserer im jetzigen Weltkriege erblindeter Krieger zu behandeln hatte, daß die meisten von ihnen ihr schweres Geschick mit großer Fassung ertrügen, in guter Stimmung verblieben und von der Hoffnung auf Lebensglück nicht Abschied nähmen. Es ist mir dies, der ich mit Erblindeten stets ein großes Mitleid gehabt habe, ein lieber Trost gewesen.

Die Schule begann früh um 8 Uhr; einige Stunden lagen vormittags, andere nachmittags. Mittwochs und Sonnabends fielen die Nachmittagsstunden aus. Als ich II Jahre alt war und mein Vater auf Anraten des Freiherrn August v. Haxthausen den Entschluß gefaßt hatte, mich für ein Universitätsstudium vorbereiten zu lassen, bekam ich Lateinunterricht bei dem damaligen Kaplan der Gemeinde

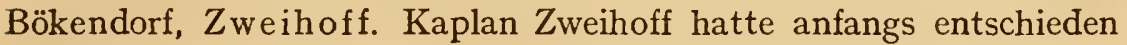
abgelehnt, den Unterricht zu übernehmen; er habe keine Gabe zu unterrichten, noch irgendwelche Neigung dazu, versicherte er mit voller Bestimmtheit und das war richtig. Nur auf inständiges Bitten meines Vaters entschloß er sich endlich dazu, sich meiner anzunehmen; aber ich kam bei seinem sehr fragmentarischen Unterrichte, bei dem ich fast ganz allein auf den alten ,Broeder ${ }^{6\left({ }^{3}\right)}$ angewiesen war, kaum vorwärts. Ich kann aber gegen Zweihoff heute noch keinen Vorwurf erheben, nachdem ich so manche Erfahrung darin gemacht habe, daß zum guten Lehren eine besondere Veranlagung gehört, viel mehr noch, als zum Lernen. Diese Gabe hatte Kaplan Zweihoff nicht; er hatte das ja auch vorher selbst gesagt. Fast zwei Jahre blieb ich Zweihoffs Schüler, dann ging dieser nach den Vereinigten Staaten Nordamerikas, wo er es zu einer hohen Würdenstellung in seiner Kirche brachte.

Der Nachfolger Zweihoffs in der Kaplanei hieB Fischer. Mit Eifer und Geschick nahm dieser sich meines Unterrichts an und es schien nun alles gut zu gehen; da, nach wenigen Monaten, wurde der junge Mann irrsinnig und mußte seine Stelle verlassen. So kam eine Hinderung nach der anderen. Nun aber wendete es sich zum Besseren und ich bekam in dem neuen Kaplan Köring einen ausgezeichneten Lehrer, der mich in einem Jahre - den Unterricht vorher kann ich 
18 Vorbereitung zum Gymnasium. Kaplan Köring. Pfarrer Schrader.

gar nicht rechnen - in allen Gymnasialfächern bis zur Untertertia brachte, in die ich im Januar 185I, I4 Jahre alt, aufgenommen wurde. Für den Kaplan Köring wurde der Unterricht, den er mir erteilt hatte, auch bedeutungsvoll. Er selbst hatte großes Interesse an dieser Tätigkeit gewonnen und bald kamen ihm neue Zöglinge $z u$; sein Ruf als tüchtiger Lehrer wuchs von Jahr zu Jahr und es entstand bei ihm eine förmliche Präparandenschule, die er bis in sein hohes Alter beibehielt; er wurde später Pfarrer in Altenbergen, wo er sein Leben beschloß. Ebenso wie meinen Elementarlehrer Rohrbach habe ich Pfarrer Köring, so oft ich in meiner Heimat weilte, besucht. Ein Wiedersehen war für uns Beide stets eine große Freude.

Im Anschluß an diese Mitteilung über meine ersten Lehrer gedenke ich auch gern des Pfarrers der Kirchgemeinde Bellersen, zu der wir gehörten, Christian Schrader. Er gehörte zu den Freunden meines Elternhauses. Sonntags nach dem Gottesdienste pflegten wir auf ein Stündchen $\mathrm{zu}$ ihm in die Pfarrei zu gehen, wie er auch uns gelegentlich besuchte. Er war ein stattlicher, großer, korpulenter Mann, energisch und welterfahren, der denen, die seine Hilfe heischten, gern mit Rat und Tat zur Seite stand. Er verstand Garten und Acker, aus denen die meisten Einkünfte der Pfarrei gewonnen werden mußten, gut zu pflegen, hatte auch einige medizinische Kenntnisse, die er in verständiger Weise verwertete und den Ärzten manchen Dienst bei Operationen oder bei der Überwachung ihrer Verordnungen leistete. Kurpfuscherei zu treiben lag ihm fern. In dieser Weise kann ein Pfarrer oder ein Lehrer in Ortschaften, zu denen ein Arzt nicht immer rasch gelangen kann, segensreich, ja mitunter lebensrettend wirken.

Zum. Vergleich des Wirtschaftsbetriebes vor Ioo Jahren und des ganzen Lebens auf dem Lande in der damaligen Zeit mit dem heutigen gebe ich noch folgende Erinnerungen: Der ganze Kreis Höxter sowie seine Nachbarkreise und die angrenzenden Teile des Königreichs Hannover, des Herzogtums Braunschweig, des Kurfürstentums Hessen-Kassel, der beiden Fürstentümer Lippe-Detmold und Schaumburg-Lippe und des Fürstentums Waldeck waren fast ausschließlich dem landwirtschaftlichen Betriebe gewidmet und sind es auch heute noch. Eine große Anzahl fiskalischer und in adligem Privatbesitz befindlicher Güter, jedoch alle nur in der Größe von rund 200-500 Hektaren, selten mehr, liegen zwischen den bäuer- 
lichen Besitzungen zerstreut. Die meisten Bewohner, selbst die, welche sich durch Tagelohn ihren Lebensunterhalt verdienen mußten, hatten ein kleines Haus mit Gärtchen und konnten sich wenigstens ein paar Ziegen, ein Schwein und etwas Federvieh halten, so daß es nur wenige eigentlich arme Leute gab. Von diesen ärmeren Bewohnern legten sich aber vor Ioo Jahren immer einige auf Bettelei; das hat jedoch schon seit vielen Jahren ganz aufgehört. Die Tagelöhner auf den größeren Gütern bekamen dort meist jeder ein Stück Ackerland, worauf sie für sich Kartoffeln und Flachs bauen konnten. Die Düngung und Beackerung des Landes wurde von der Gutsverwaltung getragen und nötigenfalls, gegen mäßiges Entgelt, auch die Verbringung der Ernte in die Wohnungen der Landarbeiter.

Wo viele große Güter zusammen lagen, gab es natürlich weniger Kleinbesitz und mehr Tagelöhnerfamilien; die Dörfer mit einem blühenden, kräftigen Bauernstande waren die, welche entfernter von den größeren Gütern lagen, und so ist es auch noch heute.

Es war und ist in der ganzen Gegend ein großer, schöner Laubwaldbestand vorhanden, von dem der größte Teil in fiskalischem und Adelsbesitze sich befindet. Doch gibt es auch einzelne ansehnliche Gemeindewaldungen. Meine ersten Erinnerungen kennen nur die Heizung mit vorzüglichem Buchenholz, welches zu billigem Preise überall zu haben war. Eine schönere Heizung gibt es nicht. Abends wurden in die großen eisernen Öfen ein paar mächtige Buchenklötze geschoben; diese glimmten die ganze Nacht weiter und man hatte früh am anderen Morgen angenehm warme Zimmer. Die Holzscheite wurden im Spätherbst aus den Wäldern herangefahren und zerkleinert, wobei auch wir Kinder unsere Unterhaltung und Beschäftigung hatten. Aufgestapelt wurden die handlich hergerichteten Stücke vielfach in Form der bei der Getreidebergung erwähnten Dimmen, die an einem geschützten Orte in der Nähe der Häuser aufgebaut wurden. Ich erinnere mich noch, da $B$ mein Großvater v. Hartz bei seinem Schulhause einen schönen großen Walnußbaum stehen hatte. Drei Seiten des Baumes wurden mit den Holzscheiten umbaut und zwischen Baum und der als Rückenschutz dienenden Holzwand wurden eine Bank und ein Tisch angebracht. Wie manche angenehme Stunde habe ich mit der Familie meines Großvaters unter diesem Walnußbaume im Schutze der behaglich wirkenden Holzscheite zugebracht! 
Das Personal, welches die Verwaltung und die Geschäfte des Abbenburger Hofes zu besorgen hatte, setzte sich zusammen aus meinem Vater als Oberverwalter, meiner Mutter als Wirtschaftsführerin und einem oder zwei Verwaltern. Der Rentmeister gehörte nicht notwendig zum Personal dieses bestimmten Gutes; er hatte auch die betreffenden Geschäfte der anderen v. Haxthausenschen Güter zu versehen. Weiterhin gehörten zum Hofe der Hofmeister; er hatte die Oberaufsicht über den Pferdestall, der Kuhhirt im Kuhstall, der Schafmeister mit drei Schäfern im Schafstall, der Schweinemeister im Schweinestall. Der Hof hatte vier Viergespanne Arbeitspferde, zu jedem Gespann gehörte ein Großknecht und ein Kleinknecht. Zum männlichen Personal zählten dann noch der Müller, der Rademacher und der Schmied mit einem Gehilfen.

Das weibliche Personal bestand außer meiner Mutter aus einer Unterwirtschafterin, „Mamsell“ tituliert, wie diese Umprägung des französischen „Mademoiselle“ damals vielfach in Deutschland üblich war, und aus sechs Mägden - sie wurden wirklich so genannt und nicht , Mädchen“ oder ,Stützen“ oder gar ,Fräulein“ —, der Küchenmagd und der Viehmagd (bei den Rindern), die auch den Sondertitel „Meyersche“ hatte; diese beiden waren die Obermägde und hatten höheren Lohn. Dazu kamen vier Hausmägde. Wenn die genannten Männer Familie hatten und das war meist bei dem Hofmeister, Schafmeister, den Großknechten, dem Rademacher, dem Schmied, dem Schweinemeister und dem Müller der Fall, so wohnte diese in einen der benachbarten Dörfer; nur der Müller hatte seine Familie bei sich in der Mühle. Das meiner Mutter unterstellte weibliche Personal war unverheiratet.

Bemerkenswert im Vergleich mit den heute gezahlten Bezügen sind die ,Gehälter", wie es bei den höheren Beträgen hieß, oder ,Löhne“, welche derzeit üblich waren. Mein Vater bezog an barem Gelde jährlich $5_{50}$ Taler, meine Mutter 50 Taler. Dazu kamen sechs Schafe, deren Wolle ihnen zustand und ein reichliches Maß von Flachs; außerdem ein Reitpferd und die Berechtigung, die Ackerpferde auch als Kutschpferde $\mathrm{zu}$ benutzen. Die Verarbeitung der Wolle und des Flachses zu Leinen war frei; etwaiger Überschuß konnte verkauft werden. Hinzu traten sogenannte Meßgelder bei Verkäufen der landwirtschaftlichen Produkte. Man konnte die Einnahme meiner Eltern 
im Jahre auf rund Iooo Mark nach unserer bisherigen Währung vor dem Weltkriege annehmen. Dazu kam völlig freier Unterhalt für die ganze Familie mit allem, was das Gut selbst bot und mit allem, was an Zutaten wieZucker, Kaffee, Gewürzen und anderem dergleichen gekauft werden mußte. An Getränken waren freilich, abgesehen vom Kaffee, nur Milch, Wasser und ein guter, alter Kornbranntwein, von dem mein Vater und die Verwalter regelmäßig zum Frühstück ein kleines Gläschen tranken, frei. Als ich älterer Gymnasiast und Student war, bekam auch ich davon und kann nur sagen, da $B$ ein solcher alter westfälischer Kornbranntwein, wie man ihn damals noch herstellte, mit den besten fremdländischen nund iländischen .Schnäpsen den Vergleich aushalten konnte.

Meine Mutter verspann den Flachs für ihren Familienbedarf selbst. Ich sehe sie noch vor mir, wie sie jede freie Zeit an ihrem Spinnrade $\mathrm{sa} B$ und das Rädchen unermüdlich schnurren ließ. Sie verstand auch einen äußerst feinen und gleichmäßigen Faden zu spinnen und das so leicht, als wenn der Faden von selbst sich entwickelte. Spinnen können unsere heutigen Frauen in den bürgerlichen Familien kaum mehr; das Spinnrad kommt allmählich zur Klasse der geschichtlichen Geräte, wie seine Vorläuferin, die Kunkel. Es war mir interessant, noch einmal mit der Kunkel spinnen zu sehen, und das war in der Bretagne. Ich war damals einige Wochen in St. Malo im Seebade; da sah ich öfter auf einer Brücke eine alte Frau sitzen, die mit der Kunkel spann; bis dahin hatte ich mir keine rechte Vorstellung davon machen können, wie das mit einem so einfachen Geräte geschehen könnte. Mein damaliger Aufenthalt in der Bretagne und in der Normandie bot übrigens noch manches der Aufzeichnung werte; ich komme darauf zurück.

Die Verwalter erhielten, abgesehen von dem völlig freien hauswirtschaftlichen Unterhalt, jährlich 24-30 Taler Gehalt. Je 50 Taler erhielten der Hofmeister und der Schafmeister, 36 Taler der Rademacher, der Schmied und der Schweinemeister. Der Müller stand besser. Die Großknechte erhielten 24 Taler, die Kleinknechte I2 Taler. Ebensoviel erhielten die Küchenmagd und die Viehmagd, während der Lohn der Hausmägde nur ro Taler jährlich betrug. Den Dienstboten, welche Familie hatten, stand aber ein gewisses Ma $B$ von Land ،um freien Kartoffel- und Flachsbau zu, den Schäfern auch Wolle. 
Mit diesen nach heutigen Verhältnissen äußerst bescheiden zu nennenden Bezügen kam man damals gut aus; in den ganzen 30 Jahren, in denen mein Vater den Hof von Abbenburg verwaltete und - später Pächter des Bökerhofes war, ist an diesen Bezügen nichts geändert worden.

Die Tagelö hner, Männer und Frauen, in der Ferienzeit wohl auch die älteren Kinder, kamen von den vier Dörfern, im Sommer um $6 \mathrm{Uhr}$, im Winter um $8 \mathrm{Uhr}$. Sie stellten sich auf dem Hofe um den in dessen Mitte auf einer Anhöhe neben der Straße befindlichen großen und schönen Lindenbaume auf. Dort wurden die Erschienenen festgestellt und mein Vater erteilte ihnen persönlich die Arbeit für den Vormittag. Die Arbeitszeit dauerte bis II Uhr bei einer halbstündigen Frühstückspause, in welcher den Arbeitern bei anstrengender Tätigkeit, insbesondere in der Erntezeit, ein Gläschen guten Branntweins gereicht wurde; Brot, Butter und Käse dazu, wie sie es hatten, brachten sie sich selbst mit; die Menge des Branntweins ist dadurch hinreichend gekennzeichnet, daß die Gabe allgemein dort als , ,Schluck“6 bezeichnet wurde. Dann waren 2 Stunden Ruhe. Angehörige brachten in dieser Zeit in Henkeltöpfen von den Dörfern her das Mittagessen, gewöhnlich eine dicke nahrhafte Suppe, öfters mit Fleisch, Wurst, Schinkenspeck oder Ei; dazu wieder Brot, Butter und Käse, nach den Mitteln jedes Haushaltes, besser oder geringer. Jedenfalls aßen die westfälischen Landarbeiter damals besser, als in den beiden jetzigen letzten Kriegsjahren und im Jahre IgI9 die meisten Deutschen.

Um I Uhr wurde unter der Linde die Nachmittagsarbeit angesagt, die im Sommer bis um $6 \mathrm{Uhr}$, im Winter bis um $5 \mathrm{Uhr}$ währte, wieder mit einer halbstündigen Ruhepause, während der gewöhnlich zu Brot und Butter auch ein „Schluck" gereicht wurde; das nannte man ,vespern". Es ist da ein völlig deutschklingendes Wort direkt aus dem Lateinischen herausgeholt und in die Sprache des Landvolkes hinübergenommen worden. Wenn in der Erntezeit gutes Wetter benutzt werden mußte, um das Getreide $z u$ bergen, dann wurden oft bis spät in den Abend hinein, so lange das Dämmerlicht reichte, Überstunden gehalten, die besonders bezahlt und außerdem mit einem Glase Branntwein belohnt wurden. Alle Leute fügten sich willig in diese Anordnungen und arbeiteten stets mit doppelter Anstrengung 
bei solchen Gelegenheiten. Damals nahmen noch die Arbeiter ein persönliches Interesse an den Geschicken des Hofes, auf dem sie arbeiteten; wußten sie doch, wie viel darauf ankam, daß die Ernte gut geborgen wurde! Der Tagelohn war sehr bescheiden; er betrug für den Mann 6o Pfennige, für die Frau 40 Pfennige. Er ist in der vorhin erwähnten Zeit meiner Kinder- und Jugendjahre auch nicht erhöht worden. Bei einzelnen Arbeiten, vor allem beim Mähen oder bei größeren Erdarbeiten, war ein Akkordlohn üblich, bei dem die Leute sich einen größeren Verdienst verschaffen konnten. Sonntags ruhte alle Feldarbeit, nur die notwendige häusliche wurde verrichtet. War bei ungünstigem Wetter zur Erntezeit eine Notlage eingetreten, so wurde ausnahmsweise auch der Sonntag für die Feldarbeit zu Hilfe genommen; es war üblich, dazu die Erlaubnis des Ortspfarrers einzuholen.

Die Beköstigung des Verwaltungs- und Dienstpersonals auf dem Gutshofe war eine einfache, aber sehr gute. Ich brauche nur daran zu erinnern, da $B$ uns bei einem reichen Bestande an Federvieh während des größten Jahresteiles täglich frischgelegte Eier in Mengen zur Verfügung standen, sowie die jungen Hähnchen, Enten und Gänse; auch die Putenbraten fehlten nicht. Da in den ersten Jahren nur der unverheiratete Major und Domherr Friedrich v. Haxtha usen auf dem Gute wohnte, der nur wenig für sich in Anspruch nahm, später aber die Mitglieder der Freiherrlichen Familie in Bökerhof, Vörden und Thienhausen lebten, so stand uns alles reichlich zu Gebote, zumal damals bei den noch sehr mangelhaften Verkehrseinrichtungen ein Verkauf kaum lohnend und möglich war, denn die nächstgelegenen Landstädte hatten selbst keinen Mangel an solchen Lebensmitteln, wie die Güter sie boten. Dazu kam nun die täglich dreimal frisch gemolkene Milch von 30-40 Kühen, dann die saure Milch mit ihrem dicken süßen Rahm, an dem es bei vortrefflicher Fütterung nicht fehlte. Wir Kinder tranken bis zu unserem I4. Jahre nur Milch; erst von da ab wurde uns etwas Kaffee zugegeben.

Häufig gingen wir zur Melkzeit in den Stall, wo die Mägde beim Melken ihre Lieder sangen; wir tranken dann von der kulswarmen noch schäumenden Milch. Bei einer dieser Gelegenheiten erfuhr ich auch, wie man in Westfalen einem Melkmädchen ein artiges Kompliment macht. Die Mägde mußten sich beim Melken in dem Stalle aus 
Reinlichkeitsrücksichten ihrer Strümpfe entledigen. Nachher wuschen sie ihre Beine in einem Eimer. Als nun eines schönen Tages die Meyersche, eine dralle Dirne, ihr Bein in den Eimer steckte, sah der dabei stehende alte Wollarbeiter, der die Wolle zum Spinnen herrichtete - diese Leute wurden ,Wollkratzer" genannt - mit seiner kurzen Pfeife im Munde dem zu, schmunzelte und sagte: „Mäken, wenn Díu den Hals brekkest, Diẽne Beine häwwet'er keine Schuld an."

Viel Wert wurde auf die Bereitung eines eigenartigen würzigen harten Käses gelegt, der unter dem Namen ,Nieheimer Käse“ in der Provinz und auch darüber hinaus wohlbekannt war und es bis zu einem Handelsartikel gebracht hat. Rinder, Kälber, Hammel und Schweine, alle gut gemästet, lieferten eine vortreffliche Fleischnahrung, zu der auch noch die Jagdbeute in Hasen, Rehen und Rebhühnern beitrug. Die Teiche lieferten reichlich Hechte und in den Bächen fehlten die Forellen nicht.

Das in allen guten Arten reichlich vorhandene Gemüse kam stets frisch zur Tafel und hat dann einen Wohlgeschmack und Nährwert, von dem sich der Stadtbewohner, der gezwungen ist, es erst durch den Markt oder durch den Laden des Händlers gehen zu lassen, nicht leicht eine Vorstellung bilden kann. Besonders gilt dies von den Spargeln. Diese wurden erst unmittelbar, bevor sie aufs Herdfeuer kamen, gestochen. Wir Kinder besorgten das gern und nahmen nur die, welche eben ihre Köpfchen aus der Erde gesteckt hatten und stachen sie auch nur fingerlang; es gab ja genug. Und dann die Fülle des Obstes! Wir durften, wenn es reif war, es uns selbst von den Bäumen pflücken; die I4 großen Kirschbäume des Obst- und Gemüsegartens machte uns Niemand streitig und wir verspeisten die Kirschen fast stets auf den Bäumen selbst.

Zur Mittags- und Abendtafel gab es aber stets nur ein einziges Gericht, Braten fast nur Sonntags; dazu als Getränk klares Wasser. Ein Glas Wein wurde nur bei besonderen festlichen Gelegenheiten gereicht. Das Wasser, stets frisch aus der Quelle geholt, so da $\beta$ es in beschlagener Flasche auf dem Tische stand, war ein überaus rein und erquickend schmeckendes. Ich habe es auch später, wenn ich als Student die

1 ,Mädchen, wenn Du den Hals brichst, Deine Beine haben daran keine Schuld." Dĩu und Diene müssen diphthongisch gesprochen werden. 
Ferien zu Hause verbrachte, obwohl an Biergenuß gewöhnt, stets wieder gern getrunken und bei diesem frischen Tranke das Bier nicht vermißt.

Eine Art Festlichkeit war es jedesmal für uns Kinder, wenn es an das Wurstmachen ging. Es wurden etwa Io-r2 Fettschweine im Laufe des Winters geschlachtet. Bei der Wurst- und Schinkenbereitung überwachte meine Mutter persönlich alles aufs genaueste; ich darf aber auch wohl sagen, da $B$ es besseres in diesen beiden Dingen wohl kaum gegeben hat, noch geben wird als das, was der Schlächter Kreimeyer, der von meiner Mutter angelernt worden war, auf dem Abbenburger Gute lieferte.

Bei dem Namen „Kreimeyer" will ich einer Eigentümlichkeit gedenken, die in den Landgemeinden Westfalens damals bestand. Der Mann hieß Kreimeyer und hatte den Vornamen ,JJustus“. Von den Dörflern wurde er aber niemals mit seinem richtigen Namen bezeichnet, sondern wenn von ihm die Rede war, so hieß es: „Hellekröiers Justus“, d. i. „Hellekrügers Justus“. Das kam daher, daß viele Jahre zuvor, ehe Kreimeyer Eigentümer wurde, in seinem Hause eine Krugwirtschaft gewesen war unter dem Namen „Hellekrug“. Diesen Namen behielt nun das Haus im Munde der Dörfler und jeder, der später in dem Hause wohnte, erhielt den Volksnamen ,der Hellekrüger". Diese Beinamen, Vulgo-Namen genannt, waren so üblich, $\mathrm{da} B$ sie in den Lohnregistern des Hofes immer mit aufgeführt wurden.

Die Beköstigung des Hofgesindes war selbstverständlich auch eine sehr gute. Wenn auch kein Braten vorgesetzt wurde, so bekamen die Leute doch dieselbe Milch, Butter, Eier und Käse, dasselbe frische Gemüse, Rind-, Hammel- und Schweinefleisch wie der Verwaltertisch. Für alle kochte die Küchenmagd immer unter der persönlichen Aufsicht meiner Mutter, die die Speisen, bevor sie aufgegeben wurden, stets selbst prüfte, in einem großen Topfe, dem "Leutetopfe“, wie er hieB. Zweimal in der Woche gab es Fleisch oder Wurst zu der dicken kräftigen Suppe des Leutetopfes, von der wir selber oft mit dem größten Behagen aßen. Mittags und abends wurde in dieser Weise gespeist; morgens nahm das Gesinde, anstatt des Kaffees, eine tüchtige Portion Milchmehlsuppe, wozu sie von dem ihnen wöchentlich zugemessenen Brot mit Butter und Käse aßen. Jede Woche wurde frisch gebacken. Das Brot war reines Roggenbrot, ähnlich dem Kommißbrot. Es schmeckte uns ebenso gut wie das, was wir bekamen, 
Feldfrüchte. Erstes Auftreten der Kartoffelkrankheit.

dem eine gewisse Menge Weizen zugesetzt war. Reines Weizenbrot in Form von Semmeln wurde damals auf dem Lande nicht bereitet. Ihre Suppen nahmen die Leute in runden hölzernen Gefäßen, größer und erheblich tiefer als Teller, in den sogenannten ",Setten“ oder ,,Satten".

Auf den Feldern von Abbenburg sowie auf denen der benachbarten Güter wurden vornehmlich angebaut Roggen, aber auch reichlich Weizen, Gerste, Hafer und die verschiedenen Hülsenfrüchte: Erbsen, Bohnen, Linsen, Wicken. Eine besondere Mischfrucht von Hülsenfrüchten ging unter dem Namen „Rauhzeug“; sie wurde besonders als Viehfutter verwendet, namentlich in Form von Schrot. Als Grünfutter und auch als Trockenfutter kam besonders der gewöhnliche dreiblättrige Klee in Betracht, daneben die Esparsette und, erst später in Aufnahme kommend, die Lupine. Gute und große Wiesen gaben in zwei Ernten reichlich Heu. Da in den September ein Teil unserer Schulferien fiel, so nahmen wir Kinder besonders an der Bearbeitung der zweiten Heuernte, des Grummets, teil; es machte uns viel Vergnügen. Auf Äckern, wo sowohl Roggen wie Weizen gedieh, wurde eine Mischung von Roggen und Weizen gezogen unter der Bezeichnung: Mengkorn; diese gab dann das feinere Brot.

Reichlich wurden Kart offeln gebaut, deren Haupternte in den Monat Oktober fiel. Lebhaft ist mir in Erinnerung geblieben das Jahr, in welchem die sogenannte Kartoffelkrankheit ( ${ }^{4}$ ) zuerst auftrat. Es war ein trauriger Anblick, die großen Kartoffelfelder der Güter mit schwärzlichen, faulenden, niedergesunkenen Krautmassen bedeckt zu sehen, die einen üblen Geruch verbreiteten. Allgemein wurde damals im Landvolke der Rauch der die Fluren durcheilenden Lokomotiven - kurz vorher war eine Eisenbahn durch den Kreis gelegt worden - als Ursache der Erkrankung angesehen; auch mein Vater ließ sich lange Zeit von dieser Meinung nicht abbringen. Man hatte ja damals von der außerordentlich großen Bedeutung der Pilze als Krankheitserreger noch keine rechte Vorstellung. Selbst als die Pilze gefunden wurden, sagte man: ,Ja, die Pilze sind da, aber sie sind in den faulenden Massen entstanden oder haben sich dort angesiedelt, die Erreger sind sie nicht, wie sollen auch so unsichtbar kleine Wesen so ungeheure Verwüstungen anrichten!?“، 
Eine der wichtigsten Früchte für den Landwirt auf großen Gütern war damals die Ölf rucht. Sie wurde von zwei Pflanzen, dem Raps und dem Rübsamen gewonnen. Der Raps hatte die größeren Samenkörner, der Rübsamen gab das feinere Öl. Mein Vater pflegte zu sagen, daß aus dem Rapsbau und dem Ertrage der Wolle bei einem Pachtgute die Pachtsumme bestritten werden müsse. Aus den übrigen Erträgnissen müßten die Wirtschaftskosten und der Gewinn des Pächters sich ergeben. Bei einem verwalteten Gute, wie Abbenburg, war der Ertrag aus dem Verkauf von Raps und Wolle sicherer Reingewinn des Besitzers. Aus den übrigen Erzeugnissen wurden die Wirtschaftskosten bestritten; dabei blieb für den Besitzer auch aus dem Ertrage dieser Erzeugnisse immer noch ein namhafter Betrag übrig, so daß er bei einer Verwaltung seiner Güter sich besser stand, als bei einer Verpachtung. Ich führe dies hier an, weil die Frage oft besprochen wird, was vorteilhafter sei, eine Verpachtung von Landgütern oder eine Verwaltung? Inzwischen haben sich, wenigstens in Westfalen, die landwirtschaftlichen Betriebe in manchen Dingen geändert. Mit der Einführung des Erdöls und der gesteigerten Wollzufuhr aus dem Auslande, namentlich aus Australien, ging der Bau von Ölfrüchten und die Haltung von Schafherden zurück. Die Landwirtschaft ging mit der Errichtung von Zuckerfabriken und Spiritusbrennereien $\mathrm{zu}$ industriellen Betrieben über. Das Fehlen von Öl und Wolle hat sich im jetzigen Kriege sehr fühlbar gemacht. Freilich war uns der Zucker und der Spiritus ebenso wertvoll. Der Weltkrieg hat uns auch für die Landwirtschaft manche Lehre gegeben, die hoffentlich zu. unserem Besten benutzt werden wird, denn auf einen ewigen Weltfrieden ist nicht zu rechnen.

Von Vieh wurden außer den erwähnten vier Gespannen Arbeitspferden und 30-40 Milchkühen einige Reitpferde, ein Zuchtstier, zwölf Arbeitsochsen und etwa ro junge Rinder und Kälber gehalten, ferner rund I200 Schafe. Von Federvieh über Ioo Hühner, 30 Gänse und Enten und einige Puter, dazu über Ioo Tauben. Für das Rindvieh und die Pferde bestand im größten Teile des Jahres Stallfütterung; nur kurze Zeit kamen sie zur Weide. Vor den Stieren mußte man sich, namentlich wenn die Weidegänge begannen, in acht nehmen. Ich möchte dazu zwei Erlebnisse mitteilen, die mir in Erinnerung sind: Auf dem Hofe stand eines Tages ein mit frischem Klee hochbe- 
ladener Wagen, an dem der zum Weidegange herausgelassene Zuchtstier eine Weile stehen blieb. Da kam ein Arbeiter, nichts Arges von seiten des Stieres vermutend, an den Kleewagen heran, vermutlich um ihn abzuladen. Ehe sich der Mann dessen versah, hatte das Tier ihn mit den Hörnern erfaßt und wie einen Ball in die Höhe geworfen, in Bereitschaft stehen bleibend, um den Mann wieder mit den Hörnern aufzufangen, wie es die Stiere mit ihren Gegnern zu machen pflegen, wenn sie diese werfen können. Der Mann fiel aber auf den Kleewagen hinauf und kam so mit dem Schrecken davon. Ich stand in der Nähe und es kam mir so vor, als ob der Stier ein ganz verdutztes Gesicht gemacht hätte, als er von seinem vermeintlichen Gegner nichts mehr gewahr wurde. Es machte einen geradezu komischen Eindruck, als das Tier nach einer Weile vergeblichen Zuwartens langsam abtrollte, hinter der übrigen Herde her.

Bei dem zweiten Falle war ich selbst der Bedrohte. Ich begab mich eines Tages von Bökerhof nach Abbenburg und schritt über eine Wiese, auf der die Bökerhofer Rinderherde friedlich weidete. Nichts Arges vermutend ging ich mitten durch die zerstreute Herde, als ich plötzlich den Stier in drohender Haltung auf mich zukommen sah. Der Hirt mit seinem Hunde hätte mich schützen können, aber ich sah mich vergebens nach ihnen um. Da rettete mich ein vielhundertjähriger Eichbaum, der in der Wiese stand und in dessen Nähe ich mich glücklicherweise befand. Der alte Stamm hatte einen Umfang, daß ihn zwei Männer eben umspannen konnten; er fiel Jedermann, der ihn sah, durch seine gewaltige Größe auf. Schnellen Schrittes stellte ich mich hinter den Baum, so daß ich, völlig verdeckt, von dem Stier nicht gesehen werden konnte. Das Tier lief bis nahe an den Baum heran, ich hörte sein Schnaufen ganz in der Nähe. Eine Weile merkte ich ihn dicht am Baume, offenbar auf der Suche nach mir. Ich hielt mich still und paßte scharf auf, daß er mich nicht sah. Übrigens war ich ja auch in Sicherheit, denn der Stier konnte mich hinter dem Baume, auch wenn er um ihn herumgegangen wäre, nicht erreichen, so lange ich nur darauf bedacht blieb, den Baum immer zwischen uns zu lassen und dabei war ich, als der Kleinere, im Vorteil. Als das Tier eine Zeitlang vergebens versucht hatte, mich zu Gesicht zu bekommen, ging es langsam zur Herde zurück; ich nahm meinen $\mathrm{W}^{\top}$ eg so, da $B$ ich, so lange ich auf der Wiese war, mich durch den Baum 
gegen den Bullen decken lie $\beta$; ich wußte, da $\beta$ er außerhalb der Wiese mich nicht mehr verfolgen würde. Ich irrte mich darin nicht.

Das Leben des auf den Gutshöfen gehaltenen gefiederten Völkchens bietet viel des Unterhaltenden und Merkwürdigen. Einiges von meinen Beobachtungen und Erfahrungen darüber möge hier mitgeteilt sein. $\mathrm{Zu}$ den etwa Ioo Hennen wurden vier Hähne gehalten. Jeder dieser Hähne hatte aber sein bestimmtes Gebiet auf dem Hofe, wie das augenscheinlich unter ihnen selbst abgemacht worden war; es hatte sich Niemand vom Personal darum gekümmert. Die Gebiete jedes einzelnen Hahnes waren gut abgegrenzt; verirrte sich einer der anderen Hähne hinein, so wurde er sofort vom dort regierenden Hahn angegriffen und über die Grenze gejagt; er versuchte meist auch nicht, dem Angreifer ernstlichen Widerstand entgegenzusetzen. Abends mit beginnender Dämmerung gingen nun alle Hühner und Hähne auf einer kleinen Leiter hinauf in ihr Nachtquartier, den sogenannten ,Hühnerwiem“. Dabei herrschte vollkommener Burgfriede. Morgens in der Frühe, wenn die Tiere den Wiem verließen, flog meist zuerst der Hahn heraus, der sein Revier zunächst beim Wiem hatte; dieses Revier fiel gewöhnlich auch dem stärksten Hahne zu. Sowie nun die anderen Hähne herabkamen, war dieser Haupthahn eifrigst darum bekümmert, daß sie schleunigst das Weite suchten und sich in ihre Reviere begaben. Die Hennen zerstreuten sich in die verschiedenen Gebiete; es war nicht festzustellen, ob immer dieselben Hennen demselben Hahne folgten.

Nicht minder merkwürdige Dinge bietet das Leben der Gänse. Vor allem ist festzustellen, da $B$ das Beiwort „dumm" auf diese Tiere durchaus nicht paßt. Sie haben vielleicht von allen Tieren die ausgebildetste Art, durch Stimmlaute, die man geradezu Sprechlaute nennen könnte, einander Mitteilungen zu machen. Es ist nicht ein bloßes nichtssagendes Geschnatter, welches man von ihnen hört. Bei aufmerksamer Beobachtung entdeckt man bald ganz verschiedene Laute, die mit anderen abwechseln und wiederkehren. Weiden Gänse in kleinen Trupps zusammen, so kann man bei ihnen nicht ein lautes Geschnatter, sondern mehr leise Laute, die verschieden sind, vernehmen und die bald von dieser, bald von jener Gans hervorgebracht werden; das Ganze nimmt sich völlig wie eine Unterhaltung aus. Es geht dies nach dem Eindrucke, den ich davon gewonnen habe, über 
etwaige Warnungs- oder Locklaute hinaus, wie sie ja bei den Vögeln weit verbreitet sind. Will man die Gänse vom Betreten eines Grundstückes, etwa eines Gartengrundstückes, wo sie Schäden anrichten würden, fernhalten, so genügt es, wie mir berichtet wurde, eine Gans an einem Pfahle auf diesem Grundstücke einige Stunden anzubinden. Man werde sehen, daß sie, losgelassen, nichts eiligeres zu tun habe, als zu ihren Gänsegenossen zu laufen und ihnen ihr Mißgeschick zu erzählen. Keine Gans gehe mehr dorthin. Eigene Erfahrung habe ich freilich darüber nicht.

Wenn im Frühjahre die Paarungszeit beginnt, dann kämpfen die Gänseriche miteinander um die Gänse, ähnlich wie die Hirsche in der Brunftzeit. Der Sieger in den sehr erbitterten Kämpfen geht mit ausgebreiteten Flügeln auf den Trupp der Gänse los und berichtet ihnen in hellen Trompetentönen von seinem Siege, während der Besiegte scheu davongeht. Es scheint, daß der Sieger sich dann seine Gefolgsgänse aussucht, die für die Sommerzeit $z u$ ihm halten. Schließlich sind nach mehreren solcher Kämpfe die Gänse in einzelnen Trupps zu den Gänserichen verteilt und dann bleibt der ganze Trupp meist ruhig zusammen. Immerhin kommen ab und zu noch weitere Kämpfe zwischen den Männchen vor. Es kann auch sein, daß einer der Gänseriche bei diesen Kämpfen von allen übrigen besiegt wird und ohne weibliches Gefolge als Zölibatär übrig bleibt. Mit einem solchen erlebte ich ein höchst merkwürdiges Ereignis, welches mitgeteilt zu werden verdient: Eine Zeitlang war dieser Ausgestoßene still und, wie es schien, traurig für sich allein geblieben, als er eines schönen Tages begann, ohne da $B$ der Mann das Tier angelockt hätte, sich an den Kuhhirten des Hofes zu halten und ihm auf Schritt und Tritt zu folgen. Dem Manne wurde das schließlich lästig und er jagte das Tier mehreremal von sich. Endlich, von der Beharrlichkeit seines Gänsefreundes milder gestimmt, wurde er freundlich $\mathrm{zu}$ ihm. Ich habe es mehreremal gesehen, wie der Gänserich, wenn der Hirt vor seinem Stalle saß, zu ihm kam und sich streicheln ließ. Das Merkwürdigste aber war, da $B$ das Tier von da an seine Furcht vor den übrigen Gänserichen, die ihn besiegt hatten, verlor. Kamen diese in die Nähe des Hirten, so stürzte dessen Begleiter auf sie los, es kam zum Kampfe, in welchem dieser meist siegte. Dann eilte er mit ausgebreiteten Flügeln auf den Hirten, seinen Freund, zu und verkündete ihm in 
derselben Fanfarenweise, wie es die Gänseriche nach ihren siegreichen Kämpfen den Weibchen gegenüber tun, seinen Sieg. Mehreremal war ich Zeuge einer solchen Szene. Mit Abschluß des Sommers löste sich nach und nach das Verhältnis und der Gänserich blieb wieder bei der Herde.

Außer dem Federvieh des Hofes beobachteten wir Kinder auch aufmerksam die Vögel in Feld, Wiese und Wald; wir kannten sie alle und ihre Nester in der ganzen Umgegend, haben aber nie ein Vogelnest zerstört. Auch hierzu sei etwas Merkwürdiges berichtet. Als ich eines Tages an einem kleinen Buschwerk vorbeiging und in dieses einzutreten mich anschickte, flog mir ein kleiner Vogel in etwas ungeschickter Weise, wie wenn er aus einem der Büsche herausgefallen wäre, vor die Füße. Ich bückte mich, um nach ihm zu greifen, da flatterte er, immer am Boden bleibend und in derselben ungeschickten Weise, eine kleine Strecke weiter, ich, in der Meinung, ihn jetzt fangen zu können, hinterher. Dieses Spiel wiederholte sich einige Male, wobei ich, dem Wege des Tierchens folgend, immer weiter von dem Buschwerke fortkam. Mit einem Male war der Vogel verschwunden, ich war aber vom Buschwerke abgekommen. Ich konnte mir das Verhalten des Tieres gar nicht deuten, bis ich später die Erklärung in einem Buche über Vogelkunde fand. Der Vogel hatte sein Nest gerade in dem Busche, an der Stelle, der ich bei meinem Wege nahe kam; um mich nun von da fortzulocken, schlug er das berichtete Verfahren ein. Es gibt mehrere Vogelarten, von denen diese Sache bekannt ist. Mit einigen Worten möchte ich, um den Unterschied zwischen einst und jetzt möglichst klar hervortreten zu lassen, noch auf diejenigen Betriebe eingehen, die damals auf den Gütern selbst geübt wurden. Ich erwähnte bereits der Rademacherei, der Schmiede und der Mühle, die in Abbenburg nur einen Mahl- und Sägegang hatte, auf anderen Gütern aber auch noch einen Ölgang. Ferner wurde vom Flachs und von der Wolle gesprochen. Die Leinenbereitung aus dem Flachs wurde vollständig auf dem Gutshofe durchgeführt. War der Flachs auf dem Acker zur Verarbeitung reif, so wurde er von den Arbeiterinnen und Hofmägden aus dem Boden gezogen. Dann wurden die Stengel von den Samenkapseln befreit, indem man sie durch eiserne Zinken, die kammartig auf einem Gestell befestigt waren, hindurchzog; bei dieser Arbeit sangen gewöhnlich die Arbeiterinnen ihre Lieder. Die so bearbeiteten Stengel wurden in kleinen Bündeln 
in stehendes Wasser gelegt, wo sie einem Fäulnisprozeß unterworfen waren, durch den sich der festere nutzbare Teil der Stengel, der sogenannte Bast, von dem weicheren schied. Dieser Proze $B$ hieß das „Rotten“. Die Zeit des Flachsrottens war in Westfalen, wo damals viel Flachs gebaut wurde und die Leinenindustrie blühte, an den üblen Gerüchen, die von den mit Flachs beschickten Tümpeln ausgingen, sehr zu merken. War der Fäulnisprozeß hinreichend weit gediehen, dann wurden die Bündel auf einem sonnigen Weideplatze in dünnen Lagen zum Trocknen ausgebreitet. Die getrockneten Stengel wurden dann mit einfachen hölzernen Maschinen, den „Flachsbraken“ oder schlichtweg „Braken“, gebrakt, das heißt ,gebrochen“. Die Braken waren auf vier Füßen stehende Holzgestelle, woran ein fester, mit den Füßen verbundener Unterteil und ein in einem Gelenk gegen den Unterteil $\mathrm{zu}$ bewegender Oberteil $\mathrm{zu}$ unterscheiden war. Beide hatten einige scharfe Längsleisten, so gestellt, daß beim Niederdrücken des Oberteiles gegen den Unterteil die oberen Leisten zwischen die unteren zu liegen kamen. Beim Braken wurden nun eine Handvoll Stengel auf den Unterteil gelegt und langsam mit der einen Hand durchgezogen, während die andere den Oberteil in raschen Schlägen klappernd gegen den Unterteil bewegte. Dadurch wurden die durch die Fäulnis veränderten, beim Trocknen brüchig gewordenen Teiles des Bastes von den Fadenteilen des Flachses getrennt, indem sie in kleinen Splittern absprangen. Wenn eine Reihe Arbeiterinnen mit dem Braken beschäftigt war, so gab das ein eigenartiges Taktgetöse, ähnlich wie beim Dreschen. Auf das Braken folgte das Hecheln, wobei die fädigen Flachssträhne durch feinere und dichter stehende Stahlzinken, die auf festgestellten Brettern befestigt waren, die „Hecheln", so lange sorgfältig durchgezogen wurden, bis die letzten etwa noch anhaftenden Bastsplitter entfernt und die feinen Flachsfäden regelmäßig der Länge nach geordnet waren. Damit war der Flachs für den Spinnrocken reif.

Wie ich bereits schilderte, wurde das Spinnen von den Mägden unter Beteiligung meiner Mutter besorgt; es war die Hauptwinterarbeit. Im Frühjahr kam dann der Leineweber auf mehrere Wochen; sein Webstuhl stand in der Weberstube schon bereit. Da wurde nun das gesponnene Flachsgarn zu Leinen verwoben. Das grau aussehende Leinen kam dann in großen langen Stücken auf eine dafür 
geeignete Wiese in der Nähe eines Wasserlaufes mit reinem klarem Wasser zur Bleiche (s. die Strophe F. W. Webers Anmerkung 2), wo es durch die abwechselnde Einwirkung des darüber ausgesprengten Wassers und des Sonnenlichtes zu dem bekannten schneeweißen Leinen oder „Linnen“ wurde. Irgendwelche künstliche Bleichmittel wurden damals nicht verwendet; der BleichprozeB dauerte mit dieser reinen Naturbleiche zwar lange, lieferte aber ein äußerst haltbares Leinen. Leinene Wäsche von Abbenburger Flachs, selbst von meiner Mutter gesponnen, dort gewebt und gebleicht, habe ich länger als 30 Jahre tragen können. Es ist mir nicht bekannt, ob die Herstellung von Leinen auf den Gutshöfen noch so im Betriebe ist, wie ich sie von der Zeit meiner Jugend geschildert habe.

Ein weiteres Fabrikat der Landwirtschaft auf den Gutshöfen war die Seife. Auch deren ländliche Herstellung verdient wohl einige Worte: Zunächst gab es da eine ,Seifentonne"; diese stand in der Küche und hatte alle Abfälle von Fett aufzunehmen. War hinreichend Fett gesammelt und gleicherweise reingesiebte Asche von dem verbrannten Buchenholz, dann konnte zur Seifenfabrikation geschritten werden. Das aufgesammelte Fett wurde geschmolzen und möglichst gereinigt. Aus der Asche wurde mit Hilfe von ungelöschtem Kalk eine Lauge hergestellt und wie das geschah, machte uns Jungen immer viel Vergnügen. Reiner ungelöschter Kalk wurde auf einem mit Steinfließen hergestellten Boden $\mathrm{zu}$ einem kegelförmigen Haufen aufgestapelt ; rings um diesen Kalkhaufen wurde nun von der Buchenasche ein ziemlich dicker Aschenmantel gelegt, so daß das Ganze wie ein Aschenkegel erschien von mehr als Meterhöhe und am Grunde von entsprechender Breite. Mit einem passenden Holzstiel, wie er zur Hand war, etwa einem Besenstiel, wurde dann von der Spitze aus der Aschenkegel durchstoßen bis auf den Kalkhaufen und durch das Loch vorsichtig Wasser eingegossen. Nun setzten sich 2-3 Mägde je nach der Größe des Kegels in die Kniee um den Kegel herum und hatten darauf zu achten, daß die beim Löschen des Kalkes sich entwickelnden heißen Dämpfe den Aschenmantel nicht durchbrachen. Der Kegel verwandelte sich geradezu in einen kleinen Vulkan. Wo ein Durchbruch drohte, wurde von den benachbarten Stellen Asche herangeschoben und mit den Händen fest angedrückt. Wenn der Kalk in der richtigen Löschbewegung war, hatten alle Hände voll zu 
tun. $\mathrm{Da} ß$ uns Kindern dies viel Vergnügen gewährte, kann man sich leicht vorstellen; wir halfen auch fleißig mit, die Löcher zu stopfen. War der Kalk gelöscht und das Ganze erlkaltet, so wurde die Asche mit dem gelöschten Kalk gemischt und daraus eine Lauge gewonnen. Mit dieser zusammen wurde dann das Fett in großen Kesseln erhitzt ; nach dem Erkalten setzte sich oben auf der Mischung eine dicke feste Seifenschicht $\mathrm{ab}$, die für den Hausgebrauch völlig genügte. Auch die Talgkerzen, welche wir im Hause gebrauchten, wurden in besonderen gläsernen Formen aus Hammeltalg auf dem Hofe selbst hergestellt.

Viel zu sehen gab es für uns auch bei der Bearbeitung der Wolle. Zunächst mußten die I200 Schafe gewaschen werden. Das geschah beim Eintritt der warmen Jahreszeit. In einem ausgemauerten Wasserbette von passender Breite, durch das in Metertiefe reines weiches Flußwasser floß, stellten sich 6-8 Männer, je zwei in gewissen Abständen gegenüber, auf. Dieses Wasserbett, die sogenannte „Schafwäsche“, lag in einer sauber gehaltenen sonnigen Weide. Nun wurde ein Schaf nach dem andern in die Wäsche hineingebracht, von dem ersten Wäscherpaare ergriffen und tüchtig in dem Wasser gewaschen, wobei es darauf ankam, daß das Wasser durch die Wolle hindurch bis zur Haut durchdrang. Das erste Wäscherpaar übergab das Schaf dem zweiten und nahm selbst ein neues Schaf in Empfang. So mußte jedes Tier 3-4 Waschungen durchmachen, bis es freigelassen wurde. Dann aber sprang es davon, schüttelte sich energisch und lief weit weg, in die Weide hinein, froh, seinen Peinigern entronnen zu sein. Waren die Tiere trocken geworden, so wurden sie geschoren, die Wolle wurde in Ballen verschnürt und auf einem großen Leiterwagen zum Wollmarkte nach Paderborn gefahren. Mein Vater fuhr dann mit; ich und meine Brüder wurden auch, als wir älter waren, mitgenommen, um uns die Stadt, die damals für uns eine Großstadt ersten Ranges war, zu zeigen. Mein Vater hielt sehr darauf, in uns Kindern frühzeitig das Interesse für andere Dinge, als die, welche das Landleben bot, zu wecken und Paderborn bot in seinen Kirchen, in den Paderquellen und in seinen geschichtlichen Erinnerungen manches Interessante. Meist war die Abbenburger Wolle, da auf möglichst gute Wäsche gehalten wurde, sehr bald verkauft.

Die Wolle, die meinen Eltern zustand und die, welche für den Hof verbraucht wurde, kam auf dem Hofe selbst zur Bearbeitung. Die 
Ländliche Unterhaltungen und Vergnügungen. Donati's Komet 1858. 35

Arbeiter hierfür, die S. 24 bereits genannten „,Wollkratzer“, kamen damals aus dem Eichsfelde.

So war die Ordnung der Dinge und das Arbeitsleben auf einem westfälischen Gutshofe in der damaligen Zeit. Aber es gab nicht nur Arbeit, sondern auch gemütliche Unterhaltungen, Scherze, Spiele und Festlichkeiten im Kreise der Verwaltenden sowohl, wie in dem der Dienenden, bei den Knechten und Mägden. Ich erwähnte bereits die gemütlichen Plauderstunden an den schönen Sommerabenden vor der Haustür. Einen ganz besonderen Reiz hatten sie im Herbst 1858 , als der mächtige Donatische Komet am Himmel erschien; es war ein wundervolles Schauspiel, welches wir an vielen Abenden, da wir in der Zeit gerade andauernd schönes Wetter hatten, genießen konnten; die großartige Erscheinung dieses prächtigen Gestirns ist eine der eindrucksvollsten Erinnerungen meiner Jugendzeit. $\mathrm{Zu}$ den erfreuenden Belebungen des ländlichen Lebens auf dem einsamen Hofe gehörte auch der Gesang der Mägde, den meine Mutter sehr förderte. Sie sangen, wie erwähnt, bei der Flachsbereitung, bei dem Melken und bei den Abendarbeiten, namentlich beim Spinnen und bei der Herrichtung der Gemüse für den folgenden Tag. Viele der Lieder waren in Text und Melodie in den Dörfern selbst entstanden und wurden nur von Mund zu Mund überliefert. Dann gab es allerlei Erzählungen und Rätselaufgaben, oft von ungenierter Derbheit, die aber gar nicht weiter beachtet wurde. Auf dem Lande gilt der Satz: Naturalia non sunt turpia! Auch allerlei Spiele, wie Blindekuh und Pfänderspiele wurden in den Freistunden von den Knechten und Mägden gespielt und man konnte auch hier oft sagen: „Ländlich, sittlich." Hin und wieder wurde von den älteren Leuten auch politisiert und da kamen manchmal wunderbare Dinge heraus. So, wenn der alte Gärtner Kreilos, der den Feldzug Napoleons in Rußland mitgemacht hatte, von seinen Erlebnissen erzählte, oder wenn der Schafmeister Eickermann, der in großem Ansehen stand, während des Krimkrieges von den türkischen Soldaten erzählte. Ich entsinne mich, $d a \beta$ er damals unter anderem sagte: Dei Türke, dei hett Schnabelkerels, dei häwwet en isernen Schnabel, damit künnt se alles daud hacken"1. Das wurde ihm aufs Wort geglaubt; auch er selbst war

1 Der Türke, der hat Schnabelkerle, die haben einen eisernen Schnabel, damit können sie Alles tothacken. 
davon überzeugt; woher er diese Mär hatte, ist mir unbekannt geblieben. Die Schäfer, welche während der Weidezeit tagsüber einsam bei ihrer Herde stehen, werden vielfach stille, nachdenkliche Leute und man hört von ihnen nicht selten treffende und eigenartige Aussprüche. So soll hier noch eines dieser Dicta mitgeteilt werden: Der zweite Schäfer, Korte, hatte sich verlobt; er war noch ein ganz junger Mann und einer der Verwalter neckte ihn, daß er in so jungen Jahren sich schon ins Ehejoch einspannen lassen wolle. Korte hörte das eine Weile ruhig mit an, dann sagte er: „Meint Sei, ick sull up de Kinner mit de Brille kieken? ‘1.

Drei größere Festlichkeiten sollen besonders erwähnt werden: Der Nikolausabend, die Fastnachtsspiele und das Erntefest. Der Nikolausabend, einige Zeit vor Weihnachten, bringt ja eine weitverbreitete Sitte. Einer der Verwalter übernahm gewöhnlich die Rolle des heiligen Nikolaus und kam in völlig ihn unkenntlich machender Verkleidung mit einem Beutel, worin Nüsse und Äpfel lagen und mit einer Rute zu uns Kindern und ließ sich ein Sprüchlein sagen. Dem, der es gut machte, gab er von seinen Nüssen und Äpfeln, dem, der es schlecht machte, gab er einen leichten Rutenstreich. Origineller und wohl weniger verbreitet war das Fastnachtsspiel. Dabei wurde einer der Knechte, auf den das Los fiel, dicht mit Erbsenstroh umwickelt und ihm der Kopf vermummt. An eine lange eiserne Kette gebunden, trieb man ihn als einen Brummbären auf dem Hofe herum, wobei er möglichst getreu das Brummen eines Bären nachmachen mußte. Machte er es nicht ordentlich, so gabs Peitschenhiebe, die ihm natürlich nicht weh taten, da er durch seinen Strohmantel hinreichend geschützt war. Den Leuten wurden, das war alter Brauch, an dem Tage einige Gläser Branntwein mehr verabreicht; aber es wurde in allem, auch im Spiel, so lustig man dabei war, immer Maß gehalten.

Das Hauptfest und das schönste Fest war das Erntefest. War im Herbst alles Getreide eingescheuert, gewöhnlich Ende September oder Anfang Oktober, dann wurde ein Wochentag zum Erntefest bestimmt. Vier Erntewagen wurden mit Blumen und Laubgewinden geschmückt, jeder mit vier Pferden bespannt. Die Holzfigur eines Hahnes, des Erntehahnes, an einer Stange, schmückte man mit bunten Tüchern, Korallenschnüren und Goldflittern; alle Bewohner

${ }^{1}$ Meinen Sie, ich solle auf die Kinder mit der Brille sehen? 
des Hofes kleideten sich festlich und auch die Pferde wurden geschmückt. Die Leute bestiegen die Wagen. Auf dem vordersten sa $B$ die Küchenmagd, die den Erntehahn trug, nebst den anderen Mägden und den Dorfmusikanten, gewöhnlich ihrer fünf, die übrigen Hofleute und auch Arbeiter auf den anderen Wagen. So zog man hinaus zu einem naheliegenden Getreideacker, wo man noch einige Garben für diesen Tag hatte liegen lassen; diese wurden auf die Wagen verladen und so fuhr nun der stattliche Zug mit dem letzten Erntesegen unter Musik auf den Hof zurück. Die Gutsherrschaft, die, wie erwähnt, nach dem Tode des Domherrn Friedrich in Bökerhof residierte, die benachbarten Pfarrer und Lehrer und gelegentlich auch einige sonstige Gäste waren eingeladen und stellten sich, den Zug erwartend, vor dem Verwaltungsgebäude auf, von meinen Eltern, als den Festgebenden, begrüßt. Der Hofmeister verließ seinen Wagen und nahm seinen Platz auf der S. 22 schon genannten Erhöhung unter der großen Linde. Dann setzte sich der Wagenzug wieder in Bewegung und umfuhr die Linde, während die Insassen unter Musikbegleitung einen Choral sangen. Nach einer Umfahrt hielten die Wagen und der Hofmeister brachte ein Hoch aus auf die Gutsherrschaft, nach einer zweiten Umfahrt auf meine Eltern, und so ging es weiter; auch die Dienerschaft des Hofes und die Arbeiter wurden nicht vergessen. Dann begaben sich alle Geladenen in das größte Zimmer des Verwaltungsgebäudes und die Magd, die den Hahn trug, trat ein, verneigte sich vor den Gästen und sagte jedem ein Sprüchlein, die zum Teil von den Mägden selbst verfaßt waren. Auch meine Mutter, von der ich nach dem Goetheschen Spruche sagen kann:

„Vom Mütterchen die Frohnatur

und Lust zu fabulieren",

hatte mehrere dieser Reimereien gemacht. Die folgende, auf die Geistlichkeit gemünzte, die jedes Jahr wiederkam, war aber ein altes Erbstück. Sie lautete:

„Die Herren Geistlichen sind von Gott gesandt, $\mathrm{Zu}$ künden Gottes Wort im ganzen Land;

Drum sollen sie heut haben einen goldenen Tisch,

An allen vier Ecken einen gebratenen Fisch

Und in der Mitte eine Flasche Wein,

Dabei sollen sie denn recht fröhlich sein!“ 
Nun, meine Eltern hatten ein Einsehen: bei dem Festmahle, welches sich dann anschloß, gab es etwas Herzhafteres, als nur gebratene Fische und bei einer Flasche Wein blieb es nicht.

Während die Sprüche hergesagt wurden, begann auf einem der großen Böden der Tanz, an dem nun alle als Tänzer oder Zuschauer teilnahmen und da tat sich das junge Volk gütlich, bis der neue Tag dämmerte. Auch die jüngeren Mitglieder der Gutsherrschaft tanzten mit den Mägden, und wenn junge Freifräulein und Gräfinnen anwesend waren, so verschmähten sie es nicht, sich mit den Verwaltern und selbst mit dem einen oder dem anderen der jungen Knechte im Tanze zu drehen. Es herrschte bei diesen Festen in Abbenburg immer eine frische, zwanglose Fröhlichkeit, wie man sie kaum mehr antrifft, wenigstens will es mir so scheinen; freilich bin ich nicht mehr so jung wie damals, als ich die Erntefeste mitmachte. Es waren wirklich schöne Feste!

Bei einem dieser Feste war es auch, wo sich mein künftiges Lebensgeschick entschied. Ich war II Jahre alt, als meine Mutter mich veranlaßte, ein passendes längeres Gedicht zum Beginn der Sprüche aufzusagen. Ich muß meine Sache wohl gut gemacht haben, denn noch während des Festes fragte der S. 9 erwähnte damalige Majoratsherr, Geheimer Regierungsrat August v. Haxthausen (5) meinen Vater, welchen Lebensberuf er wohl für mich ins Auge gefaßt habe. Mein Vater erwiderte, er habe gedacht, seine Söhne sollten Landwirte werden nach seinem Beispiel. Darauf riet ihm der Freiherr, er möge mich studieren lassen. Mein Vater meinte, das möchte für ihn zu kostspielig sein, worauf Herr v. Haxthausen entgegnete, er möge es nur ruhig angehen, im Notfalle werde er aushelfen. Mein Vater nahm sich die Sache zu Herzen und da er ja wußte, wie sehr ich immer hinter den Büchern saß, während meine Brüder sich draußen umher tummelten, so suchte er für mich den Vorbereitungsunterricht für das Gymnasium einzuleiten, wovon ich S. I7 berichtet habe.

Auf dem Gymnasium kam mir das gerade freigewordene S. 3 erwähnte Waldeyersche Stipen dium zugute und auf den Universitäten Freitische und Honorarstundung. Auf die höheren Kosten der Doktor- und Staatsprüfung hatte ich meinen Vater schon gleich bei Beginn meiner Universitätsstudien aufmerksam gemacht, so da $B$ durch größere Sparsamkeit vorgesorgt werden konnte und die freund- 
lich angebotene Beihilfe nicht erforderlich war. Zum Ausgleich mit meinen Brüdern, deren Ausbildung nicht so viel gekostet hatte wie die meinige, verzichtete ich auf meinen Anteil an dem kleinen Kapital, welches meine Eltern hinterließen.

Nicht ohne Absicht habe ich bei der Schilderung des Lebens und Treibens auf einem westfälischen Gutshofe länger verweilt. Vieles hat sich seitdem geändert in dem Anbau des Getreides, in der Viehzucht, in der Selbsterzeugung vieler Dinge, wie des Brotes, des Leinens, der Seife, der Lichte. Und wo sind die schönen ländlichen Feste geblieben, wo das gute Einvernehmen zwischen der Gutsherrschaft und der Dienerschaft, den Landarbeitern und den Verwaltungsbeamten? Gewiß wird dies noch an manchen Stellen bestehen; aber vieles ist anders geworden - ob besser? ob schlechter? Ich will es nicht entscheiden, da man in Jugenderinnerungen leicht ,Laudator temporis acti" wird. Es lag mir aber daran, eine getreue Schilderung zu liefern von Dingen, die immerhin ein gewisses kulturhistorisches und soziales Interesse haben und leicht der Vergessenheit anheimfallen.

DenZuständen, wie sie damalsin den DörfernundLandstädten meiner Heimatsgegend herrschten, möchte ich im Interesse eines Vergleiches zwischen einst und jetzt noch ein kurzes Wort widmen. Im Kreise Höxter gab es damals nur eine gute Kreisstraße; die meisten Dörfer waren durch schlecht gehaltene, vielfach tief ausgefahrene Landwege, die man als „Hohlwege" bezeichnete, verbunden. Bei anhaltendem Regenwetter waren sie kaum zu befahren. Wolkenbruchartige Gewitterregen verwandelten sie wohl für einige Zeit in Flußbetten. Es kam hier und da vor, da $B$ an abhängigen Stellen, wo die plötzlich sich bildenden Wasserläufe zu tiefen, reißenden Bächen wurden, Menschen und Tiere, die sich nicht schnell in Sicherheit brachten, Gefahr liefen zu ertrinken. Wir verloren auf diese Weise bei einem solchen Gewitter einmal einige Schafe. Die Fahrer auf diesen Wegen waren angewiesen, in kurzen $Z$ wischenzeiten mit den Peitschen zu knallen, um entgegenkommenden Fuhrwerken ein Zeichen zu geben, an Stellen, wo ein Ausweichen möglich war, zu halten, denn auf den meisten Strecken war auf diesen tiefen, engen Wegen ein Vorbeifahren unmöglich.

Weit besser waren damals Wege und Stege in den angrenzenden nichtpreußischen Ländern, namentlich im Herzogtum Braun- 
schweig. Wir freuten uns immer, wenn wir bei den öfteren Besuchen, die wir unseren Verwandten im Braunschweigischen abstatteten, erst die Grenze überschritten hatten.

In den Ortschaften, namentlich in den Dörfern des Kreises Höxter, herrschte noch vielfach Unsauberkeit; der Straßenschmutz blieb liegen, bis er einmal von einem tüchtigen Regen weggeschwemmt war; in manchen Dörfern gab es überhaupt noch keine mit Steinschlag belegte Straße. Die Häuser wurden vernachlässigt, an den Fenstern sah man keine Vorhänge. In den Dorfwirtshäusern war von Getränken nur Branntwein zu haben. Ein kleines Erlebnis meines Vaters mag hier mitgeteilt sein, welches auf den gesellschaftlichen Bildungsgrad der damaligen ländlichen Bevölkerung ein Licht wirft: An der nach Paderborn führenden Landstraße stand ein Wirtshaus, in welchem vorzugsweise die Fuhrleute verkehrten. Auf seinen häufigen Dienstreisen nach Paderborn kehrte mein Vater öfters in dieser Wirtschaft ein, hauptsächlich der Fütterung der Pferde wegen, nahm aber auch selbst wohl eine kleine Erfrischung. Zur Familie des Wirtes gehörte auch ein alter Großvater, der bei der Bedienung der Gäste half. Er hatte, als mein Vater eines Tages wieder dort einkehrte, kurz vorher einen Zahn verloren; die ungewohnte Lücke belästigte ihn und er hatte sich ein fingerlanges Hölzchen, welches mit einem etwas dickeren Ende gerade die Lücke füllte, mit dem anderen aber zwischen den Lippen vorragte, in den Mund gesteckt. So stand er im Gespräch mit meinem Vater, als in dessen Kaffeetasse eine Fliege hineinfiel. Mein Vater suchte nach einem passenden Gegenstande, womit er die Fliege herausbefördern könnte, als der Alte sagte: „Teuben s'en biten" ' 1 , das Hölzchen aus dem Munde nahm und die Fliege damit herausfischte. $\mathrm{DaB}$ mein Vater den Kaffee nicht austrank, brauche ich wohl nicht erst zu erwähnen.

Auch die Schulen waren weniger gut als besonders die braunschweigischen; die Lehrer waren schlechter gestellt, die Kinder kamen in unsauberen Anzügen und mit bloßen Füßen - jetzt müßte dies ja entschuldigt werden - in die Schule, wie auch zum Gottesdienste in die Kirche. Wir hatten in der Bellerser Pfarrkirche zusammen mit der Gutsherrlichen Familie unsere besonderen Kirchenbänke auf dem Chore neben dem Hochaltare; vor diesen Banksitzen war der

" „Warten Sie ein bißchen." 
Platz der Schulmädchen. An der gegenüberliegenden Seite war der Banksitz des Küsters und vor diesem saßen die Schulknaben. So konnten wir die Schulkinder gut übersehen. Es fiel uns auf, wie häufig sie sich mit unzweideutigen Bewegungen auf ihren Köpfen zu tun machten, so da $B$ kein $Z$ weifel darüber bestehen konnte, da $B$ viele von ihnen dort ein Insektarium unterhielten. Von Kindern kann man kaum rechte Andacht während eines länger dauernden Gottesdienstes erwarten, insbesondere nicht während einer Predigt; sie sollen sich aber wenigstens ruhig verhalten. Darin blieb nun damals, namentlich auf der Knabenseite, manches zu wünschen übrig. Wenn's zu arg wurde, erhob sich der Küster langsam, verließ bedächtig seinen Sitz und trat unter die Knaben, um den ärgsten Störenfried recht fühlbar und eindringlich am Ohr zu zupfen; die Feierlichkeit, mit der er diese Strafakte ausführte, hatte etwas ungemein Komisches.

Zweier kirchlicher Bräuche, die damals bestanden, mag hier noch Erwähnung geschehen. Am Charfreitag fand von den Gemeinden Bellersen und Bökendorf aus eine Prozession statt, die an den Leidensweg Christi erinnern sollte, wobei an einzelnen Stationen Halt gemacht wurde. Diese Charfreitagsprozessionen bestehen ja in den meisten katholischen Ländern; insbesondere in Italien kann man sie mit viel uns Nordländern wenig anmutendem Zeremoniell verknüpft sehen. Etwas von diesem Zeremoniell war auch in meiner Heimatskirchengemeinde erhalten. In der genannten Prozession ging damals ein Mann in einer Art Mönchsgewand mit einer Dornenkrone auf dem Haupte, ein großes Holzkreuz, welches auf dem Boden nachschleifte, auf der Schulter tragend. Das Kreuz war so gro $B$, da $B$ er es, wäre es massiv gewesen, den langen Weg nicht hätte tragen können; es war jedoch aus leichten Brettern zusammengezimmert. Die biblische Erzählung besagt, da $B$ Christus, den dieser Kreuzträger darstellen sollte, dreimal unter der Wucht des schweren Kreuzes, welches er zu tragen hatte, zusammengebrochen sei. Dies wurde auch bei dieser Prozession nachgeahmt, indem der Mann bei drei bestimmten Stationen des Kreuzweges in die Kniee sinken mußte. Ich habe als Schulknabe diese Prozession öfters mitgemacht, zur Erbauung hat mir aber der Kreuzträger nicht gedient. Diese Empfindung ist später die herrschende geworden; seit vielen Jahren wird die Prozession ohne Kreuzträger gehalten. 
Die zweite kirchliche Übung, die damals noch bestand - ob jetzt noch, ist mir nicht bekannt - schloß sich zeitlich an die eben geschilderte Prozession an; sie wurde in der Osternacht, oder wenn man will, in aller Frühe des Ostermorgens, um 4 Uhr etwa, ausgeführt. In der Charwoche, das heißt in der Woche vor Ostern, schweigen bekanntlich in den katholischen Ländern die Glocken; in den Kirchen werden bei der heiligen Messe die sonst gebräuchlichen Glockenzeichen mit kleinen hölzernen Klappern gegeben. Nun gingen in der Osternacht die Schulkinder um die angegebene Zeit mit solchen Klappern im Dorfe herum und kamen auch auf den Gutshof, machten mit den Klappern ein gewaltiges Getöse und sangen dann die Worte: „Nah der Kerken, nah der Kerken, nah der Kerken!“" dann folgte wieder eine Klapperei, dann der Gesang und so ging es fort, bis daß die ganze Gemeinde abgeklappert war. Am Ostersonntag und Ostermontag erschienen dann die Schulkinder einzeln oder zu zweien auf den Gehöften, wo ihnen kleine Geschenke in Geld oder in Naturalien verabfolgt wurden.

Kommt man heute durch den Kreis Höxter und in die Gemeinden, die ich aus meiner Knabenzeit am besten kenne, so ist vieles anders und besser geworden. Ich besuche fast jedes Jahr meine liebe westfälische Heimat. Jetzt sind alle Dörfer und Städte durch gute Straßen verbunden, die Hohlwege brauchen nicht mehr benutzt zu werden oder sind in Straßen umgebaut, die Dorfstraßen sind besteint und sauber, die Häuser sehen freundlicher aus, vor den Fenstern stehen Blumen und die Vorhänge fehlen nicht. In den Dorfkrügen kann man jetzt auch Bier und Wein haben. Dieselbe vorteilhafte Veränderung sieht man bei den Kindern; die Schulen geben jetzt den braunschweigischen nichts mehr nach.

Fragt man nach der Ursache, warum zu meiner Jugendzeit die Sache anders war, so finde ich nur die eine Antwort: das Land war noch nicht lange genug unter der preußischen Verwaltung gewesen, und die frühere fürstbischöfliche Verwaltung von Paderborn hatte nicht Schritt gehalten mit den Verbesserungen, die in den Nachbarländern bereits eingeführt worden waren. Ein altes Wort sagt freilich : „Unter dem Krummstabe ist gut wohnen.“ Ich bestreite das nicht; aber unter weltlicher Verwaltung wohnt sichs besser. Gewiß, einzelne

1 „Nach der Kirche!" 
kleinere Landbezirke, Abteien und Bistümer sind unter der Herrschaft kluger und tüchtiger Bischöfe und Äbte musterhaft verwaltet worden; aber in den unter geistlicher Oberhoheit stehenden größeren Staaten blieb doch im allgemeinen die Entwicklung etwas zurück. Das ist auch begreiflich. Jede Religion und Konfession ist naturgemäß konservativ; sie wird an ihren Lehren und kirchlichen Einrichtungen unentwegt festhalten, so lange das irgend möglich ist. Dieser Zug überträgt sich selbstverständlich und sozusagen unbewußt auch auf die Führung der weltlichen Geschäfte, wenn sie in der Hand geistlicher Obern sind.

Die Rückständigkeit in vielen Dingen bei der Verwaltung der weltlichen Geschäfte des Bistums Paderborn wurde auch empfunden, als es 1807 , nach kurzer Zugehörigkeit - seit $\mathrm{I}^{803}$ - zu Preußen, durch Napoleons Machtwillen als Bestandteil des Königreichs Westfalen unter die ephemere Herrschaft des Königs Jerome kam. Mein Vater war damals II Jahre alt und lebte bis zu seinem I7. Jahre unter dieser Herrschaft. Er sagte öfters, daß man unter der französischen Verwaltung eine bessere Ordnung verspürt habe, als zur fürstbischöflichen Zeit. Dasselbe Urteil hörte ich später in Paderborn von einem Herrn, der, erheblich älter als mein Vater, in reiferen Jahren den Übergang von der einen Herrschaft zur anderen erlebt hatte. Im Jahre $18 \mathrm{r} 3$ kam das Land dauernd unter preußische Verwaltung, unter der es also zur Zeit, von der diese Erinnerungen sprechen, sich erst zo Jahre befunden hatte.

Zur Ergänzung des Bildes, welches ich hier von meiner Heimat entworfen habe, seien noch der üppig wuchernde Schmuggel und die Schwierigkeiten des Geldverkehrs erwähnt, die sich in der Nachbarschaft so vieler weder in einem Zollverein, noch in einem Münzverein mit Preußen befindlicher Kleinstaaten: Hannover, Braunschweig, Kurhessen, Waldeck und die Fürstentümer Lippe, ergaben. Man konnte in einem Tage zu Fuß fast sämtliche genannten Gebiete berühren.

Die lebhaftesten Beziehungen verbanden meine Eltern mit der Familie meiner Mutter. Es war eine Lehrerfamilie in mehreren Generationen. Mein Großvater, der S. I5 bereits genannte Kantor Wilhelm Gabriel von Hartz war ein großer, stattlicher Mann, geistig hochstehend und heiteren Temperaments. Er war ein aus- 
gezeichneter Lehrer, der 42 Jahre in der Gemeinde Hehlen-Daspe wirkte. So waren denn in beiden Dörfern nur wenige alte Leute, die, als er sein 50 jähriges Amtsjubiläum feierte, nicht durch seine Schule gegangen wären. Meine Eltern ließen mich, als ich 5 Jahre alt war, auf seinen Wunsch ein Jahr bei ihm und so habe ich, wie bereits erwähnt, dort den ersten Schulunterricht genossen. Lebhaft steht mir dieses Jahr noch in Erinnerung. Schon damals beschäftigten sich beide Männer, mein Großvater und sein Schwiegersohn, mein Onkel Lohmann, viel mit mir. Es verging dann kaum ein Jahr, ohne da $B$ ich längere Zeit in Hehlen geweilt hätte. Jedesmal, wenn ich dort war, brachte ich neue Anregungen zurück. Ich habe die Empfindung, da $\beta$ ich beiden Männern viel zu danken habe, wenn ich auf meinem Lebenswege gut voran gekommen bin.

Meine Großmutter, Karoline geb. Cassel, war das Muster einer echten deutschen Hausfrau und Mutter, von allen, die sie kannten und besonders von ihren zahlreichen Kindern und Enkeln verehrt und geliebt. Sie überlebte ihren Mann um zwei Jahre. Als mein Großvater von seinen. Amte zurückgetreten war, bewohnte er mit seiner Frau ein kleines Stübchen mit einem anstoßenden Schlafzimmer im Oberstocke der Hehlener Lehrerwohnung. Sein Nachfolger, mein Onkel Lohmann, bewohnte mit seiner Gattin, der jüngsten der v. Hartzschen Töchter, der Tante Doris, die übrigen Räume. Das kleine, mit Weinreben umrankte Haus dient noch heute als Lehrerwohnung; ich habe es als 8Ijähriger noch einmal besucht. Es war mir eine Herzenserquickung, als ich die Stätte wiedersah, wo ich als Knabe so viele glückliche Tage verlebte und so manche Anregung empfing. Ich ließ vor meinem geistigen Auge die Bilder der Entschlafenen, meiner Großeltern und meines Onkels, der sein Leben auf 86 Jahre brachte, und seiner Frau wieder lebendig werden, wie die beiden Alten auf ihrem Stübchen saßen, einträchtiglich zusammen, wie Philemon und Baucis, dabei mein Großvater behaglich seine lange Pfeife schmauchend - Zigarren kannte man damals dort noch nicht. Wie oft habe ich diese Pfeife mit einem sorgfältig von mir zurechtgestutzten Fidibus anzünden dürfen, wobei es mir besonderes Vergnügen machte, wenn mein Großvater, wozu ich ihn eifrigst ermahnte, dabei tüchtige Dampfwolken von sich blies. Mein Großvater ist nicht mehr zur Zigarre übergegangen, wohl aber mein Vater, der 
Mein Großvater v.Hartz. Konkurrenz zwischen Pfeife, Zigarre u.Zigarette. 45

anfangs, als die Zigarren mehr und mehr in Aufnahme kamen, nichts von ihnen wissen wollte. Zigarren auf einem Hofe, wo sich viel Heu und Stroh befinde, zu rauchen, sei zu feuergefährlich, es könne auch nicht der Gesundheit zuträglich sein, den Tabak, selbst wenn man sich der Zigarrenspitze bediene, so nahe an den Mund zu bringen; so ein Glimmstengel im Gesicht sähe auch nicht gut aus, so argumentierte er manches Jahr gegen diese Rauchform. Er sah es ungern, wenn wir als erwachsene junge Männer Zigarren rauchten. Endlich, als wir ihm einmal zu Weihnachten ein Kistchen gute Zigarren schenkten, ließ er sich, durch dies Geschenk gerührt, durch unser $\mathrm{Zu}$ reden und Beispiel bewegen, eine Zigarre zu rauchen und da war es um die Pfeife geschehen! Vor allem war es die Bequemlichkeit der neuen Rauchweise, die die Pfeife in die Ecke wandern ließ. Die Verdrängung der Pfeife durch die Zigarre ist ein interessantes Beispiel, wie und aus welchen Gründen sich Änderungen vollziehen. Jetzt ist in der Verwendung des Tabaks wieder ein neuer Änderungsvorgang im Werden; es scheint fast, als ob die Zigarette die Zigarre verdrängen werde. Ich stehe der Zigarette heute ebenso feindlich gegenüber, wie seiner Zeit mein Vater der Zigarre; ob ich noch kapitulieren werde?

Die Ehe meiner mütterlichen Großeltern war mit 8 Kindern gesegnet, 7 Töchtern und I Sohne. 6 der Töchter waren verheiratet, die älteste, Melusine, an den Schullehrer und Kantor Tellgmann in dem braunschweigischen Städtchen Eschershausen. Wilhelm Raabe ( $\left.{ }^{\circledR}\right)$, ein Kind dieser Stadt, hat seinen ersten Unterricht bei ihm erhalten. Die zweite, Minette, verehelichte sich mit ihrem Onkel mütterlicher Seite, dem Konditor Cassel in Braunschweig. Beide waren tüchtige Leute, die sich mit Sorgfalt und Umsicht ihrem Geschäfte widmeten, so da $B$ sie es bald zu einem ansehnlichen Vermögen brachten. Sie gaben dann das Geschäft auf, kauften ein an der Hohentorpromenade gelegenes Haus mit schönem Garten, das sie mit ihrer einzigen Tochter bewohnten. Dies Haus, von meiner Tante schlicht bürgerlich, aber in vornehmer Weise geführt, war gastfrei allen Verwandten und Freunden geöffnet; manches Jahr, bis zum Tode der Tante, die ihren Mann überlebte, bildete es eine Art Mittelpunkt für die Familie. Auch für mich knüpfen sich viele angenehme, aber auch eine traurige Erinnerung daran. Von dieser sei hier berichtet: Die Tochter, meine Base, verlobte sich mit einem jungen 
46 Die Familie meiner Mutter. Eine Hochzeit. Erste Eisenbahnfahrt.

Kaufmann in Braunschweig; zur Hochzeit wurden alle Verwandten geladen. Die meisten erschienen auch zum Feste, man wußte ja, da $B$ man den Wirten nur eine Freude machte, wenn man kam. So entschlossen sich auch meine Eltern zur Fahrt nach Braunschweig und nahmen mich, den damals I6jährigen Sekundaner und meinen älteren Bruder Leonhard, der in Braunschweig eine landwirtschaftliche Schule besuchen und während dieser Zeit Onkel Cassels Hausgast sein sollte, mit. In Alfeld wurde der Eisenbahnzug, der uns über Hannover nach Braunschweig brachte, kestiegen. Es war unser Aller erste Eisenbahnfahrt; stolz fuhren wir dritter Klasse. Das Zusammentreffen in Braunschweig mit allen unseren lieben Verwandten war ein hocherfreuliches Ereignis und so gestaltete sich das Hochzeitsfest zu einem frohen, allgemein befriedigenden. Das Hochzeitsmahl wurde bei herrlichem Wetter im Garten eingenommen. Ich hatte meinen Platz neben meiner klugen und schönen Base, Luise Tellgmann, die ich besonders gut kannte, da sie öfters bei uns in Abbenburg zu Besuch war und ich, ebenso wie meine beiden Brüder, bei ihren Eltern in Eschershausen. Sie starb unvermählt im hohen Alter von fast go Jahren in Braunschweig, wo sie nach dem Tode ihrer Eltern ihren Wohnsitz genommen hatte. Noch wenige Monate vor ihrem Tode hatte ich sie in Braunschweig besucht und sie noch völlig rüstig und frisch angetroffen. Ich hatte mich damals bei diesem Besuche mit meinen Braunschweiger Verwandten zu einer gemeinsamen Familientafel verabredet und wieder, wie vor vielen Jahren bei der Hochzeit, saßen wir beiden Alten zusammen und gedachten der vergangenen Zeiten frohen Sinnes, wenn auch, wie es bei lang zurückreichenden Familienerinnerungen nicht anders sein kann, bald hier, bald da, ein wehmütiger Einschlag nicht fehlte. Damals, beim Hochzeitsmahle, wo der junge Schüler zum ersten Male an einer solchen Festtafel sa $B$, war von einem wehen Einschlage nichts zu spüren; aber er sollte bald kommen: acht Wochen nach ihrer Hochzeit starb die junge, blühende Frau. - Man hatte damals den Wurmfortsatz, bei den Laien gewöhnlich und fälschlich „Blinddarm“ genannt, als Erreger von lebensgefährlichen Unterleibsentzündungen noch nicht erkannt, sonst würde sie das Messer des Chirurgen wohl sicher gerettet haben, während die innere Behandlung in solchen Fällen oft versagt. So legte sich eine betrübende Erinnerung in unserer ganzen Familie auf die 
vorangegangene schöne Zeit. Mein guter alter Onkel Cassel überlebte den Tod seines einzigen Kindes nicht lange. Die Trauer der Mutter blieb tief in ihr; sie fuhr aber fort in dem Bestreben - es gereichte ihr zum Troste - einen Mittelpunkt der ganzen Familie zu bilden und, wo es nötig war, wohlzutun.

Die dritte Tochter meiner Großeltern, Karoline, war mit dem Schullehrer und Kantor Persuhn in Holzminden vermählt. An dessen freundliches und gastliches Heim - es lag Abbenburg am nächsten - sowie an Hehlen und Eschershausen knüpfen sich für mich und meine Brüder die meisten und liebsten verwandtschaftlichen Jugenderinnerungen. Kein Jahr ging hin, ohne da B wir uns auf Tage oder auf Wochen gegenseitig besuchten; wir trafen dort unsere gleichalterigen Vettern und Basen, mit denen allen wir in bestem Einvernehmen standen. Die guten Tanten sorgten - alle Hartzschen Töchter hatten das von ihrer Mutter - ausgezeichnet für unser leibliches Wohl und unsere Onkels wußten uns in belehrender, aber niemals pedantischer, sondern in anregender und fesselnder Unterhaltung auf langen Spaziergängen durch die schönen Auen und Wälder der Wesergegend die Zeit angenehm und nutzbringend zu kürzen. Das Beste dabei war, da $B$ man es bald merkte, wie ihnen diese Wanderungen mit der heranwachsenden und empfänglichen Jugend selbst Vergnügen machten. Der Holzmindener Onkel Persuhn, eine stattliche Hünengestalt, hatte aber für uns noch einen Lockvogel zu den Spaziergängen in Bereitschaft, der sich besonders für die jüngeren unter uns wirksam erwies. Er pflegte den Heimweg so einzurichten, daß er über Altendorf, einen Vorort Holzmindens, führte; dort gab es eine vorzügliche Kuchenbäckerei, von deren Erzeugnissen der gute Onkel uns zu kosten gab. So wußte er das Angenehme mit dem Nützlichen $z u$ verbinden!

Die vierte Tochter, Luise, blieb unvermählt; es hat ihr nicht an Heiratsanträgen gefehlt, selbst als sie schon älter an Jahren war, hatte sie Bewerber; sie mochte sich indessen nicht entschließen, da sie sich nicht recht gesund zur Ehe fühlte, wie sie meinte. Sie war ein rührend gutes und sorgendes Wesen, von uns allen geehrt und geliebt; sie hat kein hohes Alter erreicht.

Die fünfte Tochter, Wilhelmine, war meine Mutter. Die sechste, Friederike, die Lieblingsschwester meiner Mutter, war verheiratet 
mit dem Kantor Meyer in Allrode am Harz. Ich habe sie kaum kennen gelernt; sie starb als junge Frau zum großen Schmerze meiner Mutter.

Von der siebenten und jüngsten Schwester meiner Mutter, der Tante Doris, habe ich bereits kerichtet. Ich erwähnte auch des einzigen Sohnes der Familie v. Hartz, des Superintendenten August v. Hartz in Hasselfelde am Harz und seines hohen Alters. Außer zwei Töchtern, von denen die eine an den als Dipterologen bekannten Baron v. Roeder in Hoym (Herzogtum Anhalt), die andere an den Kaufmann Wöhler in Braunschweig vermählt war, hatte er einen einzigen Sohn, der als Gymnasialschüler an Abdominaltyphus starb. Damit erlosch im Mannesstamme die Familie meines Großvaters. In dankbarer und ehrender Erinnerung an den Mann, von dem ich mir bewußt bin, daß ich ihm vieles verdanke, habe ich, als mir der erbliche Adel verliehen wurde, den Wunsch geäußert, seinen Namen dem meinigen anfügen $z u$ dürfen; dieser Wunsch ist mir gewährt worden.

Wenn man das Glück hat lange zu leben, so muß man sich damit abfinden, viele vor sich ins Grab sinken zu sehen, mit denen man einst in lieber Verwandtschaft und treuer Freundschaft, in Jugendlust und Mannesarbeit vereint war. Von meinen Vettern und Basen, die dem Hehlener Ehepaare v. Hartz ihr Leben verdankten - es waren I7 -, leben heute nur noch zwei, die verwitwete Frau Kantor Brüdern, geb. Persuhn in Braunschweig und der Kaufmann Karl Lohmann, früher in Hannover, der sich jetzt einen behaglichen Ruhesitz in Hehlen, seinem Geburtsorte, geschaffen hat.

Die Nachkommen meiner Vettern und Basen mütterlicherseits sind nicht sehr zahlreich, während sich die Familie meiner Eltern reich versproßt hat. Meiner Frau und mir wurden 6 Kinder geboren. 2 davon, I Sohn und I Tochter, starben im ersten Lebensjahre, 4, 2 Söhne und 2 Töchter, leben im Ehestande und haben mir I3 Enkel geschenkt, 7 Söhne und 6 Töchter. Mein verstorbener Bruder Leonhard, Gutspächter von Bökerhof, später Gutsbesitzer in Alhausen bei Bad Driburg im Kreise Höxter, hatte 6 Kinder, welche sich alle noch des Lebens erfreuen: 2 Söhne und 4 Töchter, sämtlich verehelicht. Aus diesen sechs Ehen sind 28 Kinder entsprossen, von denen heute 25 leben. Mein jüngster Bruder Friedrich, Bauernguts- 
besitzer in Ovenhausen, Kreis Höxter, hatte 9 Kinder, von denen 3 gestorben sind, 2 in jungen Jahren, I Sohn noch jüngst in Frankreich seinen Wunden erlegen. Enkel kamen von ihnen, die alle, bis auf einen Sohn, verheiratet sind und waren, 26 lebende, so da $B$ im ganzen 64 lebende Urenkel meines Elternpaares vorhanden sind; in den betreffenden Familien ist also noch im Durchschnitt die richtige Kinderzahl gegeben.

Hiermit schließe ich das, was ich gern über meine Familienbeziehungen niederschreiben wollte, $a b$. Diejenigen meiner freundlichen Leser, die diesen Abschnitt vielleicht zu weit ausgesponnen finden möchten, wollen bedenken, $d a B$ ich in erster Linie mein Buch für meine Familie und deren Freundes- und Bekanntenkreis gedacht habe. Ich füge hier noch einige Bemerkungen an über das, was ich als die richtige Kinderzahl bezeichnet habe. Diese muß auf jede Ehe mindestens drei betragen, wie ohne weiteres einleuchtet. Deutschland ist jetzt leider auf dem besten Wege, in seiner Bevölkerungsbewegung es England und Frankreich nachzumachen. Müßten sich diese beiden Staaten auf ihren eigenen Nachwuchs beschränkt haben, sie hätten uns nicht zu dem demütigenden Frieden von Versailles zwingen können. Nur mit Hilfe der aus allen Enden und Ecken der Welt herbeigeholten Hilfsvölker, weißen, gelben, braunen und schwarzen, ist es ihnen gelungen, den Krieg so lange hinzuziehen, um uns endlich matt zu setzen. Denken wir an die Zukunft! So sehr es wünschenswert ist, daß dieser Krieg der letzte wäre, der auf Europas alten Kulturfluren sich abspielte, so wenig Gewißheit haben wir davon. Wer weiß, ob Deutschlands Söhne nicht noch mehrere Male gezwungen sein werden in den Kampf zu ziehen? Da gilt es, Söhne zu haben, so traurig es ist, sie zum Opfer bringen zu müssen. Aber ein Volk, welches dazu nicht fähig und entschlossen ist, ist nicht wert, fortzuleben und wird auch nicht fortleben. Und wenn uns auch auf Jahrhunderte hinaus ein glücklicher Friede beschert wäre, bei fortwährend abnehmender Bevölkerung müßte die Volkskraft sinken, die sich nur im Fortschreiten erhält. Stillstand ist Rückgang! — Und dann, welche Sorge macht ein einziges oder auch nur zwei Kinder! Es ist nicht nötig, das hier auszumalen. Wie viel besser werden durchschnittlich die Kinder in den Familien, wo sie zahlreicher sind, erzogen. Nur nicht ängstlich! so möchte ich jedem Ehepaare, welches befürchtet, nicht mehr 
als ein oder zwei Kinder gut durchbringen zu können, zurufen. Es ist begreiflich, wenn jedes Elternpaar wünscht, daß seine Kinder mindestens zur selben Lebensstellung gelangen, die es selbst erreicht hat, ja wenn irgend möglich, darüber hinaus. Aber dieser Wunsch darf nicht die ultima ratio für den Familienstand bilden. Alle die Bestrebungen, die darauf hinzielen, uns die einmal geborenen Kinder zu erhalten, wie sie sich in der rühmenswerten Säuglingsfürsorge, im Mutterschutz, in der Sorge für die unehelichen Kinder kundgeben, sind ja sehr anzuerkennen. Aber sie bilden doch nur einen sehr unvollkommenen Ersatz für den Nachwuchs, der in gesunden Ehen unter der Sorge der Mutter aufwächst. Es kommt nicht so sehr darauf an, da $B$ uns schwächliche Kinder erhalten werden, als da $\beta$ gesunde genug da sind, um auch einmal Todesfälle in dem Kindersegen einer Familie ertragen zu können und es ist viel wichtiger, da B die Bevölkerungsziffer durch hinreichende Geburten wächst, als durch Verlängerúng der Lebenșdauer der Älteren.

\section{Ka p it el.}

\section{Gymnasialjahre.}

Das Gymnasium zu Paderborn. Latein in der Medizin. Promotionen, Habilitationen. Doktordiplome. Gymnasium und Realschule. - Musikübungen. Erste Bekanntschaft mit der Eisenbahn. Ferienwanderungen.

In den ersten Tagen des Januar I85I trat ich in das Gymnasium Theodorianum zu Paderborn ein. Die ungewöhnliche Zeit meines Eintrittes erklärte sich daraus, daß gerade zu Neujahr das Waldeyersche Familienstipendium, von dem ich S. 3 berichtete, frei geworden war, ich es jedoch nicht eher beziehen konnte, als bis ich tatsächlich Schüler des Paderborner Gymnasiums geworden war. Ich erhielt die nachgesuchte Erlaubnis, legte meine Prüfung beim Ordinarius der Untertertia, Professor Bäumker, ab und bestand sie mit der Zensur ,genügend“.

Morgens früh um $7 \frac{1}{2}$ Uhr begann täglich unser Pensum mit Anhörung einer Messe für die katholischen Schüler, welche bei weitem die Mehrzahl ausmachten, in der Gymnasialkirche, der ehemaligen Jesuitenkirche. Um 8 Uhr begann der Unterricht in den 9 Gym- 
nasialklassen, Sexta bis Oberprima; Gymnasial-Vorschulen gab es nicht. Man hat diese, glaube ich, erst später eingeführt. Es ist mir sehr zweifelhaft, ob solche Vorschulen eine gute Einrichtung sind; dadurch werden manche weniger gut veranlagte Schüler veranlaßt, beim Gymnasialunterricht zu verbleiben, dem sie nur mit Mühe folgen können und der sie nicht befriedigt, während sie in einfacheren Lebensstellungen, für die ein Volksschul- oder Mittelschulunterricht genügt, Tüchtiges, sie vollkommen Befriedigendes geleistet hätten. Der Überfüllung unserer Gymnasien, Realschulen, Oberrealschulen und Realgymnasien, zu der die Einrichtung von Vorschulen beiträgt, sollte möglichst wenig Vorschub geleistet werden.

Der Unterricht wurde, wie jetzt noch üblich, in den Vor- und Nachmittagsstunden erteilt. Mittwochs und Sonnabends Nachmittags war freie Zeit. Im Sommer wurde dann Turnunterricht gegeben, Turnlehrer war Professor Bäumker für alle Klassen. Eine besondere Einrichtung war das sogenannte Silentium. Die Schüler der fünf unteren Klassen mußten täglich von 5 bis 7 Uhr unter Aufsicht eines der jüngeren Hilfslehrer in den Klassenzimmern ihre Schularbeiten anfertigen. Die vier oberen Klassen hatten sie in derselben Zeit in ihren Wohungen zu machen. Jedenfalls waren sie gehalten, in diesen beiden Stunden zu Hause zu bleiben. Wenn man nun schon zu Hause bleiben mußte, machte man dann auch seine Arbeiten. Von Zeit zu Zeit besuchten die Klassenlehrer, ohne daß man den Besuch vorher ahnen konnte, ihre Schüler, um zu sehen, ob sie auch in ihren Wohnungen das Silentium innehielten. Im Winterhalbjahre durfte man nach 7 Uhr das Haus nicht mehr verlassen, im Sommer noch bis 9 Uhr abends. Da der Unterricht des Nachmittags von 2 bis 4 Uhr dauerte, so war im Winter an vier Wochentagen nur eine Stunde Zeit zum Nachmittagsspaziergange, wenn man nicht die Zeit von I bis 2 Uhr benutzt hatte. Das Gymnasium hielt, wie man sieht, auf strenge Ordnung. Ich beklage das nicht. Man war daran gewöhnt und empfand das nicht als drückend; um so wohltuender empfand man dann auch die Freiheit der Ferien.

Der Schwerpunkt des Unterrichts lag in den beiden alten Sprachen: Latein und Griechisch, ferner im Deutschen und in der Mathematik. Außerdem wurde unterrichtet im Französischen von Quarta an, im Hebräischen, jedoch nur fakultativ, von Unterprima an, in Logik 
und Psychologie - diese auch in den beiden oberen Klassen - in Physik, in den Anfangsgründen der Himmelskunde, in Religionslehre, Geschichte und Geographie und in den beschreibenden Naturwissenschaften. Der Unterricht wurde auch in den mit weniger Stunden bedachten Fächern so ausreichend erteilt, da $B$ jeder Schüler, der es an Fleiß nicht fehlen ließ, eine gute Ausbildung erhielt. Nur vermißte ich schon als Schüler den Unterricht im Englischen und in der Chemie. Das Englisclee lernte ich später auf der Universität in Göttingen, wo ich die Bekanntschaft des Studierenden der neueren Philologie Marheineke machte, der mir Unterricht gab; dann noch in Königsberg, wo ich mit dem mir befreundeten Zoologen Dr. Reinhold Buchholz, dem das afrikanische Klima auf einer Forschungsreise einen frühzeitigen Tod brachte, abends die Werke Shakespeares und Boz' und Bulwers las. Die Anfangsgründe der Chemie machte ich mir bereits in Paderborn zu eigen. Ich lernte dort den Sohn eines im Nachbarhause wohnenden Uhrmachers kennen, der im Geschäfte seines Vaters tätig war und der Interesse für Chemie an den Tag legte. Wir schafften uns Stöckhardts ,Schule der Chemie“ an und experimentierten in meinem Zimmer in den freien Stunden, auch wohl in den Stunden des Silentiums darauf los, wobei wir denn auch einmal einen Fenstervorhang in Brand steckten, den Brand aber mit der Kaltblütigkeit erfahrener Chemiker bald löschten.

Der Unterricht in den Hauptfächern war ein sehr guter und gründlicher. In der Prima mußten wir lateinische Aufsätze liefern. Die Meisten unter uns brachten es doch so weit, daß sie diese sofort lateinisch niederschrieben, ohne sie vorher deutsch verfaßt und etwa übersetzt zu haben. Der Ordinarius der Oberprima, Professor LeBmann, war ein ausgezeichneter Lateiner. Er hielt mit uns wöchentlich einmal lateinische Sprechübungen ab, wobei er es liebte, seine große Gewandtheit in der lateinischen Wiedergabe von Gesprächsstoffen aus dem täglichen Leben über moderne Dinge zu zeigen. Mir sind die lateinischen Aufsätze und diese Gesprächsübungen später noch auf den Universitäten zu gute gekommen, denn damals mußten noch die Doktordissertation und die Habilitationsschrift in lateinischer Sprache verfaßt werden. Ich konnte sie fast ebenso rasch niederschreiben, als wenn ich sie deutsch hätte abfassen müssen. Als ich in Breslau mich habilitierte, mußte ich noch nach altem Zopf eine öffentliche 
Disputation mit Opponenten und Respondenten durchmachen. Da diese Sitte schon prähistorisch geworden ist, mag sie in ihrem Verlaufe hier geschildert werden. Ich, der Habilitandus, hatte in der großen Aula Leopoldina der Universität als Doctor medicinae meinen Platz auf dem oberen Katheder (Cathedra quae est doctorum). Auf dem niederen Katheder nahm der Respondent Platz, der die Aufgabe hatte, den drei bestellten Opponenten, welche meine Habilitationsschrift und meine Thesen zu kritisieren und anzugreifen hatten, zunächst als mein Verteidiger zu antworten. Ich kam nur an die Reihe, wenn er mit ihnen nicht fertig werden konnte, hatte aber auch einzutreten, wenn mir aus der sogenannten Corona, der $\mathrm{Zu}$ hörerschaft, ein Gegner erstand. Das Wortgefecht zwischen Opponenten und dem Respondenten verlief wie gewöhnlich harmlos und ich fragte nun - alles in lateinischer Sprache - ob Jemand aus der Corona noch etwas einzuwenden habe? Da erhob sich an der entferntesten Stelle des großen Saales ein junger Kollege, Privatdozent an der Universität und sprach mich im schönsten Latein, so flüssig, wie wenn er seine deutsche Muttersprache geredet hätte, in längerer Rede an. Ich war außer stande, dieser ungewöhnlichen lateinischen Beredsamkeit, die der meinigen weit überlegen war, zu folgen und war in keiner geringen Verlegenheit darüber, was ich ihm erwidern sollte. Da rettete mich ein Lastwagen, der mit großem Getöse auf der anliegenden Straße vorbeifuhr. Schnell gefaßt, sagte ich zu meinem Gegner, als er geendet hatte: „Propius accedas, quaeso, nam propter magnum strepitum in via publica exortum non satis intellexi, quod dixisti" und brachte seine Bedenken gegen eine meiner Thesen noch einmal vor. Ich hatte vorher auch schon einiges, was er sagte, richtig erfaßt und konnte mir nun eine Antwort überlegen, die ihn denn auch befriedigte und mich befreite. Einige Jahre später, als ich zum Professor ordinarius ernannt war, hatte ich dann noch eine fast einstündige lateinische Antrittsrede in der Aula zu halten, die ich leicht erledigte. So kam mir meine gute Schulung im Latein wohl zu statten.

Jetzt sind alle diese Dinge abgeschafft: die Promotion in lateinischer Sprache mit Opponenten, die Habilitation in derselben

' "Treten Sie, bitte, näher, denn wegen des großen Geräusches auf der StraBe habe ich nicht gut verstanden, was Sie sagten." 
Sprache mit Opponenten und Respondenten, die lateinischen Antrittsreden sind verschwunden und haben deutschen Reden Platz gemacht. Auch die Doktordiplome, die meist noch in lateinischer Sprache abgefaßt werden, sowie die Einladungen zu den Festakten der Almae matres beginnt man an einzelnen Universitäten bereits in deutscher Sprache zu drucken. Mit den meisten dieser Neuerungen bin ich durchaus einverstanden. Früher hatte es einen guten Sinn, wenn Jemand, der die Doktorwürde erwerben oder sich habilitieren wollte, in einer öffentlichen Disputation bestehen und seine Gelehrsamkeit zeigen mußte. Alle Wisenschaften, auch die Naturwissenschaften und die zu ihnen gehörige Medizin, waren fast rein theoretisch; da ließ sich gut disputieren. Jetzt aber, wo auch die sogenannten Geisteswissenschaften, geschweige denn die Naturwissenschaften, sich auf Tatsachen, Beobachtungen und Versuche gründen, hat ein langes Disputieren weniger Wert. Falls in den vorzulegenden Dissertationen und Habilitationsschriften gute Beobachtungen und Beschreibungen von Tatsachen mitgeteilt sind, die zeigen, da $\beta$ der zu Promovierende oder zu Habilitierende die nötigen Kenntnisse, eine gute Beobachtungs- und Darstellungsgabe mit gutem Urteil besitzt, so wird das als genügend angesehen. Nur mit zwei Neuerungen kann ich mich nicht einverstanden erklären: mit dem Fortfall eines festlichen Promotionsaktes in der Aula der Universität und mit dem Ersatz der ehrwürdigen, lapidaren lateinischen Sprache auf den Doktordiplomen durch die deutsche, beziehungsweise die sonstigen Landessprachen. Leicht ließe sich, auch bei dem Fortfall der Disputation mit den Opponenten, eine würdige Form finden, in der den Doktoranden durch den Dekan der Fakultät in der Aula der Universität in Gegenwart seiner befreundeten Kommilitonen und etwa anwesenden Angehörigen das Doktordiplom öffentlich mit einer Ansprache überreicht würde. Jetzt, da dieser Akt in Werktagskleidung der Mitwirkenden im Sprechzimmer des Dekans stattfindet oder dem Doktoranden das Diplom gar durch die Post zugeschickt wird, hat er allen Wert für den Jünger der Wissenschaft verloren. Wenn wir fortfahren, akademische Würden zu verleihen, so sollen wir auch dafür sorgen, sie hoch zu halten; ohne eine gewisse angemessene und würdige Form geht das nicht an. Das Doktordiplom ist ein Dokument für's Leben, ja oft ein geachtetes Erbstück in der Familie. Es soll Jedermann, der den gleichen Bildungs- 
Vorbildung für das medizinische Studium; Wert des Lateinischen. 55

grad hat wie der Inhaber eines solchen Dokumentes, klar verständlich sein, auch wenn er die betreffende Landessprache nicht beherrscht. Da eignet sich die lateinische Sprache, ein Schatz, wie Edelmetall, welcher vom Rost der Zeiten nicht berührt wird. -

Bei Besprechung dieser Dinge möchte ich auch mein Glaubensbekenntnis vorbringen in der Frage, welche Vorbildung für die Mediziner die bessere sei, die gymnasiale oder die reale - so will ich kurz die Ausbildung auf den Realschulen, Oberrealschulen und Realgymnasien bezeichnen. Eine 50 jährige Erfahrung an vielen Tausenden von jungen Medizinern hat mir gezeigt, da $B$ die Gymnasialschüler in keiner Weise den Realschülern nachstehen, ja, ich möchte sagen, da $B$ sie mir durchschnittlich als die besser Vorgebildeten erschienen sind und jedenfalls den Vorteil haben, daß sie die medizinische Kunstsprache, die sich doch für alle absehbare Zukunft auf das Griechische und Lateinische stützen wird, leicht verstehen. Dazu kommt, daß sie durch ihre Kenntnis der beiden größten Kultursprachen, die wir haben, einen unverlierbaren Schatz besitzen, den ein Mediziner, der ihn später etwa noch erwerben will, nur mit vieler Mühe und Störung für seine medizinischen Studien sich aneignen kann. Der Gymnasialabiturient, der seine Kenntnisse in der Chemie, Physik und in den beschreibenden Naturwissenschaften zu vervollkommnen hat, $\mathrm{mu} B$ das auf der Universität ohnedies tun und bleibt dabei in seinem Fahrwasser. Meiner Meinung nach ist der Gymnasialabiturient für das medizinische Studium dem Realabiturienten gegenüber im Vorteil.

Zur Schilderung meines Gymnasiallebens zurückkehrend, betone ich, da $\beta$ das Paderborner Gymnasium unter seinem damaligen Direktor, Professor Dr. Ahlemeyer, in vorzüglichster Ordnung war. Die Mehrzahl der älteren Lehrer in den oberen Klassen waren katholische Geistliche. Die später hinzugetretenen, die zunächst die unteren Klassen übernehmen mußten, waren Laien. Jeder der Lehrer der unteren Klassen brachte seine Schüler von der Sexta bis zur Obertertia einschließlich, lernte sie also gründlichst kennen. Die beiden hervorragendsten unteren Klassenlehrer waren der meinige, Fr. Bäumker und Dieckhoff, der bei meinem Eintritt die Obertertia leitete. Einer der Söhne Bäumkers ist der jetzige Professor der Philosophie und Akademiker in München, auch korrespondierendes Mit- 
glied der Preußischen Akademie der Wissenschaften in Berlin, Klemens Bäumker, so da $B$ ich dadurch meinem alten verehrten Lehrer wieder näher gekommen bin. Dr. Fr. Bäumker war ein vorzüglicher, äußerst anregender Lehrer; er wußte seine über 50 Schüler zählende Klasse in Ordnung zu halten, nicht minder aber auch die mehrere Hunderte betragende Gesamtzahl aller Gymnasiasten in den Turnstunden, die er gleichfalls meisterhaft zu leiten verstand. Dieckhoff gab uns in etwas trockener Weise, jedoch sehr gründlich, den mathematischen Unterricht; er lehrte uns die euklidische Geometrie.

In Untersekunda kam ich glücklicherweise in die Hände desjenigen Lehrers, der meiner Ansicht nach die damalige bedeutendste Kraft des Gymnasiums war, des Professors Dr. Roeren. Er gab uns den lateinischen, griechischen und deutschen Unterricht, später in Prima den physikalischen und mathematischen; er erwies sich in allen diesen Fächern als Meister im Lehren. Später wurde er Direktor des Gymnasiums in Brilon. Als Klassenlehrer hatte ich ihn zwei Jahre, in Unter- und Obersekunda. Er wechselte in der Führung der beiden Sekundaklassen ab mit Professor Dr. Schmidt, ebenfalls einer bedeutenden Kraft. Dieser gab uns den Geschichtsunterricht bis Oberprima einschließlich. Schmidt wurde später Direktor des Gymnasiums in Osnabrück und zuletzt in Paderborn. In der Unterprima war Professor Schwubbe Klassenlehrer, ein etwas trockener, aber tüchtiger Lehrer mit manchen kleinen liebenswürdigen Eigenheiten. Wegen seiner Herzensgüte, Sorge und Liebe, die er seinen Schülern zeigte, genoß er die allgemeine Verehrung des ganzen Gymnasiums. Der Ordinarius der Oberprima war der von mir als tüchtiger Lateiner schon erwähnte Professor Dr. Leßmann. Ich kann aber nicht sagen, daß wir ihn als Lehrer besonders schätzten. Dagegen war der Direktor Ahlemeyer, der in der Unter- und Oberprima den Horaz mit uns in meisterhafter Weise durchnahm, eine von uns Allen verehrte Persönlichkeit. Roeren, Schmidt, Schwubbe, LeBmann und Ahlemeyer waren katholische Geistliche.

Aus den Schulerlebnissèn auf den Bänken der Klassenzimmer wäre mancherlei, was alten Paderborner Schülern liebe und erheiternde Erinnerungen wecken würde, zu erzählen. Ich gehe darüber hinweg mit Ausnahme eines Vorkommnisses beim deutschen Unterrichte Roerens in der Untersekunda. Einer von uns mußte Schillers 
Gedicht ,Die Teilung der Erde“ deklamieren, und hob nun mit einem Blick auf Roerens Priesterrock den Vers: „Der Abt wählt sich den edlen Firnewein" besonders deutlich hervor. Ein leises Lächeln ging durch die Klasse, da sagte Roeren, in behaglichem Tone der Stimmung Rechnung tragend: „Die Andern spucken'er auch nich 'rein" und hatte nun die Lacher auf seiner Seite.

Die jungen Freunde, die ich auf dem Gymnasium gewann, sind alle schon seit Jahren den Weg in die Ewigkeit gewandert. Mein bester Freund wurde und blieb bis zu seinem Tode Joseph Rochell aus Beverungen an der Weser, Sohn eines dortigen Gutsbesitzers Wir verstanden uns so gut, daß wir die beiden letzten Gymnasialjahre eine gemeinsame Wohnung nahmen. Er war besonders gut für Sprachen veranlagt, während ihm die Mathematik und Physik, die mich besonders interessierten und mir sehr leicht wurden, Schwierigkeiten machten. Als er von der mündlichen Schlußprüfung des Abiturientenexamens mit der Zensur , ,bestanden“ zurückkehrte, sagte er zu mir, der ich ihn vor dem Gymnasium erwartet hatte, auf dem Heimwege zu unserer Wohnung: ,.Jetzt ist mir, als wäre ein eiserner Reifen, der mir um den Kopf gelegt war, gesprungen und alle die Sinus und Cosinus samt Tangenten und Cotangenten wären mir aus dem Kopfe geflogen, wo sie mich so lange gedrückt haben!" In den Ferien pflegte ich gewöhnlich zu Pferd oder zu Fuß mich nach Beverungen zum Besuch meines Freundes $\mathrm{zu}$ begeben und er kam dann zum Gegenbesuche nach Abbenburg. Rochell studierte Theologie und ist vor einigen Jahren als Stadtpfarrer und Dechant in der Kreisstadt Höxter gestorben. Wir bewahrten einander treue Freundschaft, obwohl er über den Freidenker, zu dem sein Freund geworden war, öfters den Kopf schüttelte.

Andere mir lieke Schulgenossen übergehend, gedenke ich noch meines Freundes Julius Ber endes aus Paderborn, der den Apothekerkeruf erwählte, sich aber als Herausgeber verschiedener älterer einschlägiger Schriftsteller, wie des Dioskorides, einen geachteten Namen erwarb - schon auf dem Gymnasium war er in den alten Sprachen stets einer der Besten gewesen. Er erhielt den philosophischen Doktor- und Professortitel; in Goslar ist er vor wenigen Jahren gestorben. Ich habe ihn dort noch kurz vor seinem Tode besucht. An Berendes knüpfen sich für mich die angenehmsten Erinnerungen 
Musikpflege am Gymnasium.

aus dem Gebiete derjenigen Kunst, welche mir von allen die liebste geworden ist und mir stets die föchsten Genüsse verschafft, der Musik. Ich erwähnte bereits, daß mir mein Elementarlehrer Rohr bach darin den ersten Unterricht gab; er lehrte mich.die Noten kennen und den Fingersatz und erlaubte mir, auf seinem Klavier $\mathrm{zu}$ üben. Sonntags in der Kirche beim Orgelspiel sah ich meinem Lehrer zu, lernte die Orgelregister kennen und habe ihn später als älterer Elementarschüler und als Gymnasiast während der Ferien öfter als Organist vertreten. Noch heute ist mir die Orgel das mich am meisten musikalisch entzückende und ergreifende Instrument. Aber es muß ein gutes Werk sein und muß von Jemandem gespielt werden, der es zu meistern versteht; beides findet sich nicht häufig. Im Dom zu Ulm habe ich einst von einem Orgelspiel den höchsten GenuB gehabt; ich komme darauf zurück.

Unter den zahlreichen Schülern des Paderborner Gymnasiums, es waren damals über 500, gab es nun genug, die, mit guten Stimmmitteln und Lust am Gesange begabt, sich zur Bildung eines Gesangchors eigneten und ein solcher war auch auf besonderes Betreiben des Direktors Ahlemeyer geschaffen worden. In den unteren Klassen bis Obertertia einschließlich hatten wir obligatorischen Gesangunterricht und bei diesem wählte dann der Gesanglehrer seine Leute für den Chor, der aus etwa 30 Schülern bestand, aus. Wir sangen vierstimmig mit zwei Knabenstimmen, die den Sopran und Alt, und zwei Männerstimmen, die den Tenor und $\mathrm{Baß}$ vertraten. Der Chor leistete Vorzügliches. Er sang jeden Morgen zur Messe und bei den Schulfesten. Ferner zu einer Prozession, die an einem besonderen Feiertage rings um die Stadt auf dem Wallgange einherzog und an der die katholischen Schïler teilnahmen. Bei jedem der zu passierenden Stadttore waren mit Blumen geschmückte Altäre errichtet, bei denen die Priester Gebete sprachen und, die Monstranz erhebend die Feldfluren, auf die man weit hinausschaute, segneten, den Segen des Himmels für die Ernte erflehend. Diese Prozession, an der sich die ganze Stadt beteiligte, hatte etwas ungemein Feierliches, Schönes und Erhebendes. Ich habe ihr stets mit wahrer Andacht beigewohnt.

Ich war noch nicht lange in der Obertertia, als der Gesanglehrer fand, da $B$ meine Stimme zum Tenor des Gesangchores tauge und ich kam hinein. Mein Freund Berendes, der besonders musikalisch be- 
gabt war, leitete gewöhnlich den Chorgesang. Der Gesanglehrer trat nur bei besonderen festlichen Gelegenheiten ein. Dies genügte aber Berendes nicht. Er wollte noch Vollkommeneres und brachte aus besonders dafür veranlagten Schülern ein Quartett zustande, I. und II. Tenor, I. und II. BaB, das er dirigierte. Ich wurde darin zum II. Tenor bestimmt. Wir kamen Sonntags am Nachmittag regelmäßig auf meinem Zimmer - ich hatte mir inzwischen ein Klavier gemietet, Berendes brachte eine Geige mit - zusammen und dann ging's munter darauf los. Da wir alle Lust und Liebe zur Sache hatten und Berendes unermüdlich übte und besserte, so brachten wir es so weit, daß wir selbst schwierige Sachen leidlich gut vom Blatt weg singen konnten, und, wenn etwas einige Male geübt war, dann konnten wir uns hören lassen. Aber wir blieben für uns; hatten wir doch selbst hohe Freude daran, die schönen Lieder, an denen Deutschland so reich ist, uns zu Gehör bringen zu können und dabei ihre Schönheiten genau kennen zu lernen. Die edle Frau Musica hat mir auch später noch viel Gutes gebracht, von dem ich noch zu berichten haben werde und sie ist mir darin bis auf den Tag, an dem ich diese Zeilen niederschreibe, getreu geblieben. Dankbar habe ich mich ihr dadurch zu erweisen gesucht, daß ich als Anatom das Organ, durch dessen Vermittelung wir die Töne und deren Harmonie empfinden, in den Bereich meiner besonderen Studien gezogen und einen meiner späteren Schüler, Professor Dr. Gottstein in Breslau, veranlaßt habe, das Cortische Organ zum Gegenstande seiner Habilitationsschrift $\mathrm{zu}$ machen. Ein wenig zur besseren Kenntnis dieses wunderbaren Organs glauben wir beigetragen $\mathrm{zu}$ haben.

Außer diesem Quartettverein bestand bei den Primanern noch ein Verein für wissenschaftliche Unterhaltung, der von mir ins Leben gerufen war. Wir kamen etwa alle I4 Tage zusammen. Jeder war verpflichtet, wenn die Reihe an ihn kam, einen Vortrag über ein selbstgewähltes Thema zu halten. Ich entsinne mich, daß mein erster Vortrag dem Hildesheimer Dome galt, dessen Geschichte und Bauart ich, so gut ich es damals vermochte, darlegte. Ich hatte einige Zeit vorher Gelegenheit gehabt, den Dom zu sehen und sprach also z. T. aus eigener Anschauung.

Eine angenehme Erinnerung aus dieser Zeit bleiben für mich die öfteren Besuche, die ich bei meinen Verwandten väterlicherseits in 
dem Städtchen Lichtenau, I Meile von Paderborn gelegen, in der Sommerzeit abzustatten pflegte. Es waren drei Brüder Flörcken, Gutsbesitzer dort und Verwalter der Posthalterei. Einer der drei war verheiratet, die beiden anderen, deren jeder einen besonderen Beruf hatte, wohnten mit ihm zusammmen. Es war eine Freude zu sehen, wie diese drei Brüder, alle drei liebe und prächtige Menschen, einträchtig zusammenhielten. Sie waren Vettern meines Vaters; meine Großmutter väterlicherseits stammte aus diesem Hause. Diesen Verwandten väterlicherseits bewahre ich dieselbe liebe Erinnerung wie denjenigen mütterlicherseits, von denen vorhin die Rede war.

$\mathrm{Zu}$ den Ferien ging's nach Hause. Wir Schüler aus dem Kreise Höxter mieteten uns gewöhnlich einen großen Leiterwagen; darauf wurden ein Paar Bunde Stroh gelegt und dann vorwärts. In jedem Dorfe, welches wir durchfuhren, wurde Gesang angestimmt und bald dieser, bald jener harmlose Ulk getrieben. Man freute sich über das muntere junge Volk. Ein Hauptlied war das von der Kuh des Pastors in Buke, einem auf der Strecke gelegenen Dorfe; der erste Vers lautete:

Kenn Ji woll dat nigge Leid, nigge Leid,

Wat tau Buke iss passeirt, iss passeirt,

Van Pastaur sine Kau?

Triala, Triala, 't'iss jo van Pastaur sine Kau,

Van Pastaur sine Kau ${ }^{1}$

Die folgenden Verse besagen nun, da $B$ die gemästete Kuh geschlachtet war und verteilt wurde, an den Pastor selbst, an den Lehrer, den Küster usw. Jede Verteilung wurde durch einen zum Teil recht drolligen Vers zur Kenntnis gebracht. Solcher Verse gab es eine ganze Menge, und wer Anlage zur Poetasterei hatte, gab einen oder den anderen neuen zum Besten. Einer, ein etwas derber, sei hier zum Scherz noch mitgeteilt:

1 Kennt Ihr wohl das neue Lied, neue Lied,

Was zu Buke ist passiert, ist passiert,

Vom Pastor seiner Kuh?

usw. 
Dat Kinneken makte kékkĕrĕkĕkétt, kékkěrĕkěkétt,

Dat kamm van't schöne Nierenfett, Nierenfett

Van Pastaur sine Kau!

Triala usw. ${ }^{1}$

Den habe ich aber nicht verfaßt, er ist fast prähistorisch. -

Eine dieser Fahrten, bei der ich beinahe das „Gruseln“ gelernt hätte, steht mir noch lebhaft vor Augen. Es war am 24. Dezember, am Tage vor Weihnachten. Wir konnten erst an diesem Tage von Paderborn abreisen. In der Nähe der Stadt Brakel trennte ich mich von meinen Gefährten, um in der Richtung des großen v. Asseburgschen Gutes Schäferhof über Bellersen nach Abbenburg zu gelangen. Es war ein kalter Wintertag und eine tiefe Schneedecke breitete sich über den Boden aus. Mir war die Gegend bekannt und ich verließ bald, im Vertrauen auf meine Ortskenntnis, die Landstraße, um querfeldein, des tiefen Schnees nicht achtend, auf einem näheren Wege nach Abbenburg zu gelangen. Der Weihnachtsbescherung ging ich an dem Abende nicht aus dem Wege, denn es war bei uns Sitte, diese erst am ersten Weihnachtstage vorzunehmen. Ich ging, wie ich meinte meiner Richtung sicher, auf den Weg wenig achtend, munter fürbaß. Ehe ich es merkte, war die Nacht hereingekommen, freilich mit klarem Mondlicht. Als der Mond hervorgekommen war und die Gegend beleuchtete, blieb ich einen Augenblick stehen, um Umschau zu halten, wo ich wäre und wie ich weiter wandern müsse. Siehe da, ich stand mitten in einer im Mondlicht glänzenden Schneefläche, die sich nach drei Seiten dem Auge unbegrenzt ausdehnte und kein Wegemerkmal darbot; nirgends eine Spur, daß etwa dort Jemand gegangen sei. Die einzige Spur war die meinige. Nach der vierten Seite sah man einen dunklen Streifen, augenscheinlich einen Wald. Man hörte auch von da die Füchse bellen und $\mathrm{ab}$ und $\mathrm{zu}$ einen Eulenschrei. Zum Walde hatte ich mich nicht zu wenden, das war mir klar; aber nach welcher der drei anderen Richtungen mußte ich meinen Weg nehmen? Ohne die alles verhüllende, wie in eine Unendlichkeit auslaufende gleichmäßige Schneedecke hätte ich mich wohl, auch bei Mondenschein und selbst bei

${ }^{1}$ Das Kindchen machte kekkerekekett, kekkerekekett,

Das kam vom schönen Nierenfett,

Vom Pastor seiner Kuh! 
Sternenlicht, zurechtgefunden; aber es ist eigentümlich, wie sehr eine solche Eintönigkeit das Zurechtfinden erschwert. Da stand ich nun in der kalten Winternacht, wie man sagt, mutterseelenallein; es war mir doch ein wenig bang zu Mute. Endlich, nach längerem Überlegen und Umherschauen, wobei mich der Wald leitete, glaubte ich der Richtung sicher zu sein und schritt nun vorsichtig weiter, immer zurückschauend, ob meine Fußspur auch bei der Richtung blieb und nicht etwa zu einer Kreislinie wurde. Ich hatte mich nicht getäuscht; nach einer guten Viertelstunde tauchten vor mir die dunklen Gebäude des Schäferhofes auf und ich sah auch noch einzelne Lichter. Als ich den Hof erreicht hatte, es mochte 9 Uhr abends sein, ging ich auf eines der Lichter zu; es führte in den Rinderstall, wo der Hirt noch wach war; sonst war es still auf dem Hofe. Man geht, namentlich im Winter, auf dem Lande früh zu Bett. Da ich noch einen Weg vor mir hatte, der durch ein Gehölz an einem Bache entlang führte, wo man, ungeachtet des Mondlichts, nicht so gut sah, so bat ich den Hirten nachzufragen, ob nicht Jemand von den Hofleuten mich gegen eine Belohnung diese Wegstrecke geleiten wolle. , Jo, "sagte er, ,, da iss de olle Heinrich, dei schlöppet doch nich, dei sall dat woll geren daun". Der Genannte lag auf seinem Strohlager in dem Stalle, schlief aber in der Tat noch nicht und war bereit, mit mir $\mathrm{zu}$ gehen. Kaum waren wir aber einige Schritte unter den Bäumen am Bache vorsichtig entlang gegangen, da stieß der alte Mann recht kräftig mit dem Kopfe gegen einen Baumstamm, so $\mathrm{da} B$ es mir leid tat, ihn verlanlaßt zu haben mitzugehen. Ich nahm mir vor, ihn bald zu entlassen, damit er nicht noch zu Schaden komme. Wir kamen auch gut durch die dunkle Strecke, und nachdem ich meinen Begleiter durch ein gutes Trinkgeld erfreut hatte, ging ich allein weiter. Hundegebell belehrte mich bald, da B unser Kirchdorf Bellersen in der Nähe sei. Man hört dieses Gebell, ebenso wie einen Hahnenschrei, in stillen Nächten auf dem Lande schon aus weiter Ferne; es war mir ein angenehmer Laut. Der Weg wurde wieder heller und gegen II Uhr in der Nacht war ich, zwar durch die mehrstündige Wanderung im tiefen Schnee etwas ermüdet, aber froh, $\mathrm{da} B$ alles gut abgelaufen war, daheim.

$1 \mathrm{Ja}$, da ist der alte Heinrich, der schläft doch nicht, der soll (wird) das wohl gern tun. 
Als ich I85I ins Gymnasium eintrat, brachte mich mein Vater dorthin. Ich wohnte bei einem Kaufmann Buse und hatte für ein gutes Zimmer bei vortrefflicher voller Beköstigung am Familientische jährlich 90 Thaler $=270$ Mark zu zahlen. Dies war genau der Betrag, den ich aus dem Familienstipendium erhielt. Es mag diese Mitteilung als Wertmesser des Geldes damals gegen die Zeit unmittelbar vor dem Kriege dienen. Die enormen Preise, die jetzt am Ende der Kriegszeit zu zahlen sind, können als Wertmesser nicht herangezogen werden. Am Abend meiner Ankunft lud uns Herr Buse ein, den Bahnhof zu besuchen, der eben eröffnet worden war. Da weder mein Vater noch ich einen Eisenbahnzug gesehen hatten, so gingen wir mit Freuden darauf ein und erwarteten klopfenden Herzens den einfahrenden Zug, den wir aus der Ferne heranrollen hörten. Als die Lokomotive mit den blendenden Lichtern auf uns zufuhr, meinte ich nicht anders, als sie würde uns überfahren. Der Eindruck, namentlich in der dunklen Abendstunde, war ein überwältigender. Noch oft in meinem ersten Paderborner Jahre richtete ich mit mehreren Mitschülern, die auch zum ersten Male die Bekanntschaft eines Eisenbahnzuges gemacht hatten, unsere Nachmittagsspaziergänge so ein, $d a ß$ wir gerade an einer Wegschranke standen, wenn der Nachmittagszug Berlin-Köln den Weg kreuzte. Wir stellten uns dann dicht an die Schranke und ließen staunend und bewundernd den mit Schnellzugsgeschwindigkeit fahrenden Zug an uns vorbeisausen. Unsere Jugend wird das kaum begreifen, da $B$ man einen Bahnzug so anstaunen kann und wird sich darüber wundern, wenn sie vielleicht erfährt, da $B$ ich es der Mühe für wert erachtet habe, in diesem Buche davon als von etwas Besonderem zu schreiben. Aber sie ist mit dem Fahren in den Eisenbahnen von ihrer ersten Lebenszeit an vertraut gewesen, hat die ersten Eindrücke davon schon in ihr noch unbewußtes Leben aufgenommen. Ganz etwas anderes ist es, wenn man derartige weltumwälzende Dinge zum ersten Male in reiferem Alter zu Gesicht bekommt. Noch einmal wurde mir, und zwar in höherem Alter, ein solcher Eindruck von der Bedeutung einer großartigen technischen Leistung, als ich in Berlin vor einigen Jahren zum ersten Male ein Zeppelin-Luftschiff hoch über der Stadt durch die Lüfte steuern sah. -

Die Gymnasialjahre gingen so im Gleichschritt vorüber. Nur 
mit guten und angenehmen Erinnerungen kann ich an diese Zeit und an die alte Stadt Paderborn, in der ich fünf Jugendjahre verlebte, zurückdenken. Sechzig Jahre später kehrte ich noch einmal in die Gymnasialräume und in die Gymnasialkirche zurück, um der Feier des 300 jährigen Bestehens des Gymnasiums beizuwohnen und die Schule, der ich soviel verdankte, mit einer Ansprache zu begrüßen. Warmen Herzens sprach ich meine Worte. Mancher Feier der Art, die mich auch persönlich anging, habe ich beigewohnt - ich nenne nur die 200 jährige Stiftungsfeier der Preußischen Akademie der Wissenschaften, zu deren ständigen Sekretaren ich damals, I900, schon gehörte, seit I884 ihr Mitglied, und das Ioo jährige Jubiläum der Berliner Universität, I9ro, an der ich seit I883 als ordentlicher Professor tätig war - keiner jedoch mit so innerer Anteilnahme, wie der schlichten Gedenkfeier des Paderborner Gymnasiums. Es ist ein eigen Ding um die glücklichen Erinnerungen aus der Jugendzeit!

Ich besah mir damals alle die Räume des Gymnasiums, in denen ich als Schüler einst die Bänke gedrückt hatte und ging nach dem Festgottesdienst in der Kirche auch zur Orgelbühne hinauf, auf der ich so manchen Tag im Gymnasialchore mitgesungen hatte. Da stand in der Ecke noch der alte zerschlissene Lederstuhl, auf dem der Direktor Ahlemeyer, der sich so sehr für unseren Chorgesang interessierte, jeden Tag zu sitzen pflegte, um seinem Sängerchore zu lauschen. Man sah es ihm an, wie wohl ihm die frischen Jugendstimmen taten und leise bewegte sich oft seine Hand im Takt des Chorals. Lebhaft trat mir das Bild des feinen, von uns allen verehrten Mannes wieder vor die Augen. -

Als die Reifeprüfung nahte, mußten wir angeben, welchem Berufe wir uns zu widmen gedächten. Bei mir stand seit langem fest, da $B$ ich ein Lehrfach wählen wollte, um später als Gymnasiallehrer zu wirken. Ich gab damals an, daß ich Mathematik und Naturwissenschaften zu studieren beabsichtige. Es sollte anders kommen. Davon später. Die mündliche Prüfung wurde mir in allen Fächern erlassen. Meine Mutter wohnte dem feierlichen Akte der Abiturienten-Entlassung bei; über 50 Schülern der Oberprima konnte das Reifezeugnis erteilt werden. Stolz, mit dem Gefühle, nun ein frei über sich verfügender Mensch zu sein, verließ ich die altc Paderstadt. 
Die Ferien zwischen Gymnasium und Universität verbrachte ich damit, zu botanisieren und die Antigone des Sophokles, von der wir auf der Schule nur etwa den vierten Teil durchgenommen hatten, bis $\mathrm{zu}$ Ende $\mathrm{zu}$ lesen. Die Chorgesänge lernte ich auswendig und freute mich daran, sie zu rezitieren. Als Universität wählte ich Göttingen, weil es meiner Heimat am nächsten lag und mir auch von einem Göttinger Studiosus juris, den ich in Paderborn kennen gelernt hatte, empfohlen war. Er hatte mir einen guten Rat gegeben.

\section{Ka pit el. \\ Universitäts-Studienjahre.}

I. Göttingen.

Fahrt nach Göttingen. - Mathematische Studien. - Ubbergang zur Medizin. Studentenleben. - Vorlesungen bei Stern, bei Wöhler, bei Wilhelm Weber, bei Henle. - Erlebnisse bei Rudolf Wagner und bei Baum. - Bauchrednerei. - Zwei Hinrichtungen; Bemerkungen zur Todesstrafe.

Ende Oktober des Jahres I856 zog ich als junger Musensohn, 20 Jahre alt, zur Leinestadt. Zunächst war ich in Beverungen an der Weser eingekehrt, um mit meinem Freunde Rochell noch einige Tage zusammen zu sein. Mit der Post fuhr ich an einem schönen Herbstmorgen nach der nächsten Bahnstation. Die Straße berührt das große Waldgebiet des Sollings. Ich war der einzige Reisende. Als wir in den prächtigen Laubwald mit seiner schönen Herbstfärbung einlenkten und ich von der Höhe, die wir langsam hinanfuhren, den Blick rückwärts in das heimische Wesertal wendete, ging mir das Herz auf. Ich bat den Postillon, uns ein lustiges Lied zu blasen. Gern ging er darauf ein und es blieb nicht bei dem einen. Ich machte zwar damit gleich einen unvorhergesehenen Eingriff in meinen bescheidenen Wechsel, dem selbst die kleine Gabe an den Postillon fühlbar war; aber ich freue mich noch heute darüber, da $B$ ich es getan habe. Niemand, der es nicht selbst erlebt hat, wei $B$, wie einem jungen Mulus bei der Eigenart des deutschen Studentenlebens, die ihm ja doch schon mehr oder minder bekannt ist und die ihm sicherlich noch viel schöner vorschwebt als sie wirklich ist, zumute ist, wenn er sich zum ersten Male auf dem Wege zur erwählten Musenstadt befindet. Und v. Waldeyer-Hartz, Lebenserinnerungen. 
66 Ein Wort für das deutsche Studentenleben. Vorlesungen in Göttingen.

wenn er, gesund und frisch an Leib und Seele, nicht mit der rasselnden, schrill schreienden, qualmenden Eisenbahn durch die Gelände raset, sondern gemütlich und gemächlich reist, wie ehedem zu FuB, zu Pferd oder auch, wie ich damals, allein, Herr im Postwagen, zusammen mit einem verständnisvollen und gemütlichen Schwager ${ }^{1}$, der seinem Posthorn lustige Weisen $\mathrm{zu}$ entlocken wußte. Da gehört einem die ganze Welt und man versteht Schillers Lied an die Freude!

Beim Niederschreiben dieser Zeilen kommt mir der innige Wunsch, daß doch die Eigenart unseres deutschen Universitäts- und Studentenlebens uns erhalten bleiben möge. Es liegen so viele unschätzbare Imponderabilien darin, die auf das ganze spätere Leben ihren bedeutsamen und guten Einfluß üben, daß man sie nicht schwinden sehen mag. Dieser Wunsch drängt sich jetzt in der Zeit dieses Weltkrieges, der alles Bestehende über den Haufen geworfen hat, doppelt auf. Wird nach diesem Kriege, fragt man sich, das deutsche Leben so weiter geführt werden, wie bisher? Gewiß, wir werden manches gern fallen lassen und vergessen, aber unsere deutschen Universitäten und die deutschen Studenten sollten uns erhalten bleiben, wie sie jetzt waren und sind! -

In Göttingen wurde ich durch den angesehenen Juristen Hofrat Dr. Kraut unter die akademischen Bürger aufgenommen. Ich belegte in meinem ersten Semester die Vorlesungen über Analysis und analytische Geometrie bei Stern, Physik bei Wilhelm Weber, Chemie bei Wöhler, Vulkanologie bei Hausmann, Logik und Psychologie bei Lotze. Im Sommersemester Differential- und Integralrechnung und höhere Gleichungen bei Stern, Mechanik bei Ulrich, den zweiten Teil der Physik bei W. Weber, und Metaphysik bei Lotze. $\mathrm{Zu}$ Hause arbeitete ich alle Vorlesungen sorgfältig lehrbuchmäßig aus; die meisten Hefte besitze ich noch jetzt. Nur das besonders genau bearbeitete Heft über Differential- und Integralrechnung, welches ich einem Bekannten geliehen hatte, ist mir abhanden gekommen; er verließ Göttingen und nahm das Heft mit sich. $\mathrm{Da}$ er erfuhr, da $\mathrm{B}$ ich vom Studium der Mathematik zurückgetreten sei, nahm er an, da $B$ ich keinen Wert mehr auf den Besitz lege. Ich unterließ es, ihn zu mahnen.

In der Vorlesung bei Wöhler hatte ich einen jungen Hildesheimer

1 Mit dem Namen ,Schwager" wurden die Postillone angeredet. 
Kommilitonen, Josef Koch, Studenten der Medizin, kennen gelernt. Wir gefielen einander; er wurde absichtslos die äußere Veranlassung, daß ich mich dem Studium der Medizin, speziell dem der Anatomie zuwendete. Er schwärmte mir viel von der Vorlesung J. Henles über Anatomie vor und sagte, wenn ich wirklich einmal einen ausgezeichneten Dozenten hören wolle, der seine Zuhörer fessele, dann müsse ich zu Henle ins Kolleg gehen. Ich tat das. Der Eindruck, den Henle und wohl auch der Gegenstand seiner Vorlesung, die Anatomie, auf mich machte, war ein überwältigender. Ich hatte keine ruhige Stunde mehr; immer sagte ich mir, das mußt du studieren, das ist dir zum Lebensberufe bestimmt! Es war gegen Ende meines zweiten Semesters, des Sommersemesters I857.

Mittlerweile war in mir auch der Wunsch aufgetaucht, zwar dem Lehrerberufe treu zu bleiben, jedoch alles daran zu setzen, Universitätslehrer zu werden. Dabei sagte ich mir, wenn ich das werden wolle, müsse ich mich auch schöpferisch in dem gewählten Lehrfache betätigen, nicht bloß Lehrer, sondern auch Forscher sein. Mehrere Male besuchte ich noch Henles Vorlesungen und es wurde mir klar, daß ich in den anatomischen Disziplinen wohl eigene Arbeit würde leisten können, während ich in der Mathematik und Physik zwar spielend leicht den Vorlesungen folgen konnte, Cauchys Analyse algébrique und einen Teil von Eulers Werken ohne Mühe und mit vielem Interesse durchgearbeitet hatte und Lust und Liebe zur Sache bewahrt hatte, aber in dem ersten Jahre meiner mathematischen Studien mir noch keine neue mathematische Aufgabe gestellt hatte. Da kamen mir $Z$ weifel, ob meine mathematische Veranlagung hinreichend sei, um mit Erfolg den Weg zu einer Hochschuldozentur in diesem Fache betreten zu dürfen. Ohne genaue Prüfung wollte ich jedoch mein bisheriges Studienfach, welches mir lieb und wert geworden war, nicht verlassen. Ich entschloß mich, meines Lehrers Stern Rat einzuholen. Ich ging zu ihm und legte ihm die Frage vor, ob er mir rate, beim Studium der Mathematik zu verbleiben, wenn ich beabsichtigte, Hochschullehrer zu werden, bis jetzt, nach einjährigem Studium, mir aber noch keine eigene Aufgabe gestellt hätte. Stern unterhielt sich längere Zeit mit mir über diese Frage, erkundigte sich nach meiner Stellung zur Mathematik auf dem Gymnasium und nach allem, was ich bisher in Göttingen in meinem Fache gearbeitet 
hätte und gab mir dann den Rat, nicht die Universitätslaufbahn ins Auge $\mathrm{zu}$ fassen, wenn ich beim Studium der Mathematik bleiben wolle. Die ganze Art, in der Stern mit mir über diese gewiß nicht leicht zu nehmende Sache verhandelte, flößte mir volles Vertrauen ein, so daß seine Meinung, die ja auch mit meinem inneren Empfinden zusammenstimmte, ausschlaggebend für mich wurde. Noch heute bin ich Stern, den ich als einen ausgezeichneten Lehrer stets verehrt habe, von Herzen dankbar für seinen Rat. In den Herbstferien teilte ich meinen Eltern meinen Entschluß mit, ,umsatteln"6 zu wollen, wie der studentische Ausdruck lautet. Sie würdigten meine Gründe und gaben ihre Zustimmung.

Es ist mir stets wertvoll erschienen, auch für mein Fach als Anatom eine gute mathematische Vorbildung genossen zu haben. Die organischen und entwicklungsgeschichtlichen Vorgänge erfahren durch die Funktionslehre und die Differentialrechnung eine Beleuchtung, die zu ihrem Verständnis beiträgt, und ohne gute mathematische Vorkenntnisse ist eine voll befriedigende Einsicht in die Knochen- und Gelenklehre, wie sie ja der Anatom haben muß, nicht zu gewinnen. Für die Physiologie ist eine gute mathematische Vorbildung vollends unerläßlich.

Manche von den Vorlesungen, die ich als Student der physikalischmathematischen Wissenschaften bereits gehört hatte, wie Chemie, Physik und die Vorlesungen bei Lotze, hätte ich auch als Mediziner hören müssen und so hatte ich die beiden Semester für mein späteres Studium nicht ganż verloren. Ich kehrte zum Wintersemester I857/58 als Student der Medizin nach der Georgia Augusta, vor allem Henles wegen, zurück, hörte bei ihm Knochen- und Bänderlehre, die er als besondere Vorlesung gab, dann den ersten Teil der übrigen systematischen Anatomie, der die Muskel- und Eingeweidelehre umfaßte und nahm an den Präparierübungen teil. Im Sommersemester r 858 hörte ich bei Henle Allgemeine Anatomie und den zweiten Teil der systematischen Anatomie, die Gefäß- und Nervenlehre. Außerdem hörte ich bei Bartling Botanik und bei Sartorius v. Waltershausen Mineralogie, und wagte es in diesem zweiten Semester bereits, ein Publicum über Knochenbrüche und Verrenkungen bei Baum zu hören; konnte auch, mit der Anatomie der Knochen und Gelenke schon vertraut, recht gut folgen. 
Bedenklicher Ausspruch König Georgs V.von Hannover. Göttinger Erlebnisse. 69

Da ich als Preuße demnächst an einer preußischen Universität die medizinische Vorprüfung, derzeit als „Tentamen philosophicum" bezeichnet, abzulegen hatte, mußte ich die damals Hannoversche Universität Göttingen verlassen. Ich tat es schweren Herzens, nicht ahnend, daß 8 Jahre später Göttingen zur preußischen Krone gehören würde. Bei der Niederschrift dieser Zeilen erinnere ich mich des Eindrucks, den seiner Zeit - es war im Jahre I865 - ein Satz aus einer Ansprache des Königs Georg V. von Hannover auf mich machte. Irre ich nicht, so war es bei irgendeiner Festlichkeit in Göttingen, wo der blinde Monarch den Aufschwung seines Landes mit einem ,glänzenden Meteor" verglich. Ich sagte mir damals, da $\beta$ dies ein höchst bedenklicher Vergleich sei und die Ereignisse des Jahres I866, von denen mich diejenigen, welche Hannover betrafen, namentlich die Schlacht von Langensalza, insbesondere wegen meiner Göttinger Beziehungen und wegen der zahlreichen in Hannover und Braunschweig lebenden Verwandten, am tiefsten berührten, gaben dem Recht.

Aus meinen zwei Göttinger Studienjahren mögen hier noch einige Mitteilungen über das Studentenleben der damaligen Zeit, über meine Lehrer dort, über meine dort gewonnenen Freunde und einige andere Erlebnisse Platz finden:

Die Vorlesungen über die theologischen und philosophisch-historischen Fächer fanden in einem sehr bescheidenen Kollegienhause statt und die Hörsäle - Säle konnte man sie kaum nennen - waren in der einfachsten Weise hergerichtet. Ich hörte dort die Vorlesungen Sterns, Ulrichs und Lotzes. Für Chemie, Physik, Botanik, Zoologie und Anatomie gab es besondere Anstalten; das Anatomische Institut wird noch heute benutzt, hat aber einen Erweiterungsbau erfahren. Mehrere Professoren lasen in ihren Privatwohnungen, so Sartorius v. Waltershausen, Hausmann, der Mediziner Marx u. a.

Es war allgemeine Sitte bei den Studenten, aus kurzen Pfeifen zu rauchen; ich dachte, da $B$ ich kcin richtiger Bruder Studio wäre, wenn ich nicht die Lustwandelei auf der Weenderstraße mit der kurzen Pfeife im Munde mitmache, den sogenannten ,,Weender Bummel“, und es war eine meiner ersten Sorgen, mir eine solche Pfeife anzuschaffen; Zigarren wurden damals noch wenig geraucht. Man ging auch allgemein mit der Pfeife ins Kolleg und es wurde so lange geraucht, bis der 
Professor eintrat. In den kleinen Zimmern war dann bei gutbesuchten Vorlesungen oft ein dichter Qualm. Am meisten war das der Fall beim Physiker Weber, der zwar einen geräumigen Vorlesungssaal hatte, der aber auch bis auf den letzten Platz gefüllt war. Nun las Weber nachmittags zwei Stunden hintereinander mit einer Viertelstunde $Z$ wischenpause. Sobald Weber nach der ersten Stunde das Auditorium verlie $B$, um in seinem anstoßenden Privatzimmer den Kaffee $\mathrm{zu}$ nehmen, setzten wir Zuhörer wie auf Kommando unsere Pfeifen wieder in Brand und wenn Weber zur zweiten Stunde erschien, war der Saal manchmal wie mit einem dichten Nebel gefüllt, der auch bei einzelnen Experimenten sich störend erwies. Weber sagte das auch, aber er verbat sich das Rauchen nicht, denn er rauchte selbst gern. Ich hatte meinen Platz so, da $B$ ich die Tür, welche vom Hörsaale in Webers Privatzimmer führte, gut übersehen konnte. Ich bemerkte, daß, wenn Weber eintrat, er noch rasch ein paar $Z$ üge aus seiner $Z$ igarre tat, die er regelmäßig vor der Vorlesung zu rauchen pflegte, und sie dann in ein kleines Schälchen legte, welches neben der Tür angebracht war. Wenn er nun nach SchluB der ersten Stunde den Hörsaal verließ und die Tür zum Privatzimmer öffnete, dann war sein erster Griff nach dem Zigarrenreste und sein getreuer Diener Michelmann war schon mit dem brennenden Streichholz zur Stelle.

Von Michelmann möge hier eine kleine Anekdote Platz finden. Er hatte neben der Tafel im Hörsaale seinen Platz und erhob sich still und langsam von Zeit zu Zeit, um Weber irgend etwas vom Instrumentarium zu reichen oder die Tafel, wenn sie Weber beschrieben hatte, abzuwischen. Weber brauchte nie etwas zu sagen, Michelmann wußte genau Bescheid, wenn'sZeit war; es klappte, wie bei einem Automaten. Nur einmal habe ich es erlebt, da $B$ Michelmann sich irrte. Er war, nachdem Weber die Tafel mit einer längeren mathematischen Auseinandersetzung beschrieben hatte und dann, der Tafel den Rücken kehrend, an seinem Experimentiertische im Vortrage fortfuhr, langsam und bedächtig aufgestanden und hatte die Tafel gereinigt. Niemand hatte weiter darauf geachtet, da wir vermeinten, da $\beta$ dies so, wie gewöhnlich, der Ordnung gemäß sei. Mit einem Male sagt Weber: „Also, meine Herren, ich hatte Ihnen auf der Tafel die Formel für diesen Vorgang entwickelt, Sie sehen hier...", er drehte sich nach der Tafel um und stand eine Weile sprachlos, als er nichts sah, breitete 
beide Arme aus und sagte in seiner unverfälschten sächsischen Mundart mit klagendem Tone: „Michelmann hats ausgewischt!“" Michelmann war, als sich Weber zur Tafel wendete, aufgestanden und sank nun völlig geknickt wieder auf seinem Stuhle zusammen. Weber sagte weiter nichts und beendete in gewohnter Weise seinen Vortrag. Ich war, als sich der Saal leerte, ein wenig zurückgeblieben und stand gerade neben der Tafel, als Michelmann mich anredete und sagte: „Was sollen die Herren von mir denken! Aber der Herr Professor hat es dieses Jahr ganz anders vorgetragen wie früher, das konnte ich doch nicht ahnen; ich weiß doch Bescheid." - Ich habe es dem braven Michelmann gern geglaubt.

Das Korpsleben stand in Göttingen in hoher Blüte. Es gab die Roten Hannoveraner, von der Farbe ihrer Mützen so genannt, die Altbraunschweiger, die Bremenser, die Westfalen, die Sachsen, in welchem Korps die meisten Adligen waren und die Teutonen. Aber auch die Burschenschaften waren durch drei gutbesetzte und in Ansehen stehende Verbindungen vertreten, die Grünen Hannoveraner, von den Korps „Teejungen“ genannt, die Neubraunschweiger und die Hercynen, zu denen meist Theologen gehörten, die grundsätzlich die Mensuren ablehnten. Unter der gesamten Studentenschaft herrschte ein hochanständiger, vornehmer Ton, wie ich ihn an keiner anderen Universität wieder gefunden habe. Die Korps pflegten in ihrer Weise die Mensurpraxis, aber keineswegs in übertriebener Art und es wurde gut gefochten, nicht darauf losgeschlagen, wie ich es wohl anderwärts gesehen habe. Es heißt ja auch so in dem Studentenliede:

\section{„,Und in Göttingen}

Da schlägt man gute Klingen."

Weniger angenehm werden die beiden anderen Universitäten, an denen ich studierte, besungen:
,Und in Greifswald
Da weht der Wind so kalt,
Und nach Berlin
Ziehn nur Kamele hin."

Die drei besten Schläger waren damals der Erste der Westfalen, der Erste der Roten Hannoveraner und ein Teutone. Gleich die erste Mensur, die ich zu sehen bekam, war die am feinsten durchgeführte, 
die ich überhaupt gesehen habe: zwischen dem Senior der Westfalen und dem der Roten Hannoveraner. Die übliche Mensurzeit wurde durchgepaukt, aber beide Kämpen blieben unversehrt; es war geradezu ein Genuß, diesem geschickten Waffengange zuzusehen; der große Saal war auch mit Studenten voll besetzt. Nach der Paukerei reichten beide Gegner, sich augenscheinlich hochachtend, einander die Hand. Man legte es mir nahe, bei den Altbraunschweigern einzuspringen, wie der studentische Ausdruck lautet; ich lehnte es jedoch ab, weil mir mein Wechsel nicht genügend erschien. Aucỉ Conkneipant zu werden, lehnte ich ab nach meinem Grundsatze: Alles oder nichts!

In vollem Schwange stand noch der fast zwangsweise Frühschoppen für die Korpsstudenten auf der sogenannten ,Fink“. Die Burschen saßen da an den schweren Eichentischen, in die manche Namen eingeschnitten sind, die später einen guten Klang erhalten haben.

Außer meinem Freunde Koch wurden mir noch mehrere Hildesheimer bekannt, unter ihnen der bereits erwähnte Neuphilologe, bei dem ich englischen Unterricht nahm, denn ich sah bald ein, daß ich, außer Französisch, noch mindestens das Englische beherrschen müsse, wenn ich den Weg zum Hochschullehrer verfolgen wolle. Dazu kam noch ein Westfale, Albert Kayser, der bald einer meiner besten Freunde wurde, und dem zuliebe ich mit nach Greifswald ging. Koch starb vor wenigen Jahren als Geheimer Sanitätsrat und Bahnarzt in Hildesheim, Ka yser schon vor längerer Zeit in Frankfurt a. M., wohin er sich nach langen Jahren gut geführter ärztlicher Praxis in Wattenscheid zurückgezogen hatte, um seinem Sohne Heinrich, der dort als geachteter Frauenarzt lebt, nahe zu sein. Es war mir eine besondere Freude, den Sohn meines Freundes in Berlin zum Schüler zu haben und ihn dort als Dekan der medizinischen Fakultät im Beisein seines lieben Vaters zum Dr. med. promovieren zu können.

Der Kreis der Bekannten und Freunde, der sich um Albert Kayser, der sehr beliebt war, zusammengefunden hatte, verdankte ihm einst eine schöne sogenannte ,Spritzfahrt“, die wohl Alle, die sie mitgemacht haben, dauernd in angenehmer Erinnerung festgehalten haben werden. Sie sei hier kurz berichtet: In den Pfingstferien des Jahres I858 wollte Kayser einen Bekannten in Heiligenstadt, welcher Ort in einigen Stunden Fußwanderung von Göttingen aus zu erreichen ist, besuchen und wir, fünf oder sechs an der Zahl, gaben ihm bis zum 
nächsten Dorfe, so hatten wir vor, das Geleit. Es war ein herrlicher Frühlingsmorgen und unterwegs überkam uns die Wanderlust und es hieB, wir gehen mit bis Heiligenstadt! Ja, aber haben wir auch Geld? Die Taschen wurden umgekehrt. Kayser, der einen Bekannten besuchte, hatte nur ein paar Groschen Geld und wir übrigen hatten ungefähr drei Mark nach jetziger Münze zusammen. „Nun gehen wir erst recht mit," riefen Alle, ,,in Heiligenstadt wird der Wirt angepumpt." Wir konnten es ruhig wagen, denn in der Tat hatten damals die Göttinger Studenten auf Meilen weit im Umkreise Kredit. Als wir in Heiligenstadt ankamen, zog gerade eine Gänseherde vor uns her im richtigen Gänsemarsch; alsbald formierten wir uns in eine Reihe und zogen genau im Tempo hinter den Gänsen her in die Stadt zum großen Gaudium der sich ansammelnden Jugend. Im besten Wirtshause nahmen wir Quartier, ließen uns bei guter Speis' und gutem Trank wohl sein und nahmen abends an einer Kegelpartie mit den Bürgern der Stadt Teil. Am anderen Tage vergnügten wir uns in Heiligenstadt und Umgebung, wobei der Wirt sein Vertrauen auf die Göttinger Studenten bewies. Am dritten Tage zogen wir wieder gen Göttingen und nun hieß es, das Geld zusammenzubringen, um es dem Wirte zu schicken. Da traf es mich. Meine „Bude“, wie das Studentenheim heißt, lag am nächsten und so begleiteten mich Alle dahin. In der Haustür stand gerade der Postbote und fragte nach mir. Er hatte meinen Vierteljahrswechsel in Gestalt eines Geldbriefes für mich und reichte ihn mir hin. „Paßt ja ausgezeichnet, “ rief einer von meinen Begleitern, den wir den „Langen“ nannten, nahm mir den Brief aus der Hand, nahm so viel heraus, wie für Heiligenstadt nötig war und ich mußte mich mit dem Reste, so gut es ging, durchschlagen. Selbstverständlich bekam ich später den Betrag zurück.

Gern erwähne ich noch zweier Begegnungen, die zeigen, wie merkwürdig sich hin und wieder Bekanntschaften gestalten und erneuern. Als ich in das Kolleg Sterns über Analysis eintrat, hatte er bereits drei Vorlesungen gehalten. Ich nahm meinen Platz neben einem älteren Studenten, der in der vordersten Bank allein saB. Am Schlusse der Vorlesung stellte ich mich vor und bat ihn, mir mitzuteilen, worüber Stern in den voraufgegangenen Stunden gesprochen habe. Er gab mir Auskunft und nannte auch seinen Namen „Wagner“6. Er war. der Sohn Rudolf Wagners, des vielgenannten Göttinger Physio- 
logen; ich traf ihn später wieder als den berühmten Nationalökonomen Adolf Wagner, meinen Kollegen an der Universität Berlin und im Preußischen Herrenhause.

$\mathrm{Zu}$ der zweiten für mich bemerkenswerten Begegnung verhalf mir eine Einladung eines älteren Kommilitonen, der mit mir in demselben Hause wohnte, den Tee bei ihm einzunehmen. Außer mir war nur noch ein junger Student der Astronomie anwesend, mit dem ich später viele Jahre in der Berliner Akademie der Wissenschaften zusammenwirken sollte und den ich als einen der bedeutendsten Männer schätzen lernte, die mir im Leben begegnet sind, Arthur v. Auwers.

Physiologie hörte ich in Göttingen noch nicht, hospitierte aber einmal bei Rudolf Wagner. Da war ich Zeuge einer ergötzlichen Szene. Wagner hatte einen Frosch mit Curare, dem bekannten südamerikanischen Pfeilgift, behandelt, um seinem Auditorium die merkwürdige muskellähmende Wirkung dieses Stoffes zu zeigen. Das Tierchen war mit einer Glasglocke bedeckt, Wagner nahm die Glocke weg und sagte: „Ich kann jetzt den Frosch berühren, ihn mit der Pinzette kneifen, er wird sich nicht bewegen; damit faßte er mit der Pinzette ein Bein des Frosches und - siehe da - zur allgemeinen Überraschung der Zuhörer wie des Professors sprang der Frosch mit einem eleganten Satze vom Tische mitten unter die Studenten. "Staub, Staub, "rief Wagner dem schon betagten Diener des Laboratoriums zu, ,fangen Sie den Frosch!" Das war leichter gesagt als getan; die Partie war ungleich, denn Staub war Asthmatiker, der Frosch aber nicht. Man kann sich die Heiterkeit, die diese Froschjagd bei den Studenten erregte, denken. Schließlich kamen diese dem atemlosen Staub zu Hilfe; der Frosch, der augenscheinlich eine zu geringe Dosis Curare bekommen hatte, wurde eingefangen, aufs neue curarisiert und diesmal gelang das Experiment zu voller Befriedigung.

Bei den anatomischen Präparierübungen hielt es damals jeder Präparant für nötig, zu rauchen; der Prosektor Teichmann, später Ordinarius der Anatomie in Krakau, ging mit gutem Beispiele voran, aber modernisiert; er rauchte nur Zigarren und ich bewunderte seine Kunst, die Zigarre mit den Lippen zu halten, während seine beiden Hände anatomisch beschäftigt waren und er dabei sprach. Jetzt wird auf den Präpariersälen, obschon es wohl überall den Studierenden freisteht, dort zu rauchen, nur noch selten davon Gebrauch gemacht; 
Göttinger Wohnungen; Verkehr mit den Bürgern. Die Stiefelfüchse. 75

in den Hörsälen vor Beginn der Vorlesung zu rauchen, ist auch wohl seltener geworden. Wenn damals in Göttingen ein Dozent es nicht wünschte, da $B$ vor der Vorlesung in seinem Auditorium geraucht würde, so gab er dies durch Türanschlag bekannt. Ich entsinne mich, da B Lotze einen solchen Anschlag gemacht hatte.

Mit den Göttinger Bürgern, bei denen man Wohnung nahm, den "Philistern“, wie sie von den Studenten genannt wurden, stand man sich gut. Man zahlte die Wohnungsmiete nicht monatlich, sondern für das ganze Semester voraus. Diese Zahlweise hat ihr Gutes, denn dadurch wurde Mancher veranlaßt, bis zum Semesterschlusse auszuharren. Man bemerkte damals auch in Göttingen nicht die öde Leere, die sich meist in den Hörsälen bemerkbar zu machen pflegt, wenn der erste Tag des letzten Semestermonats herankommt. Da der offizielle Semesterschluß althergebrachter Weise für das Wintersemester am 15. März, für das Sommersemester am I5. August ist, die Wohnungen jetzt aber meist pränumerando monatlich am ersten jeden Monats bezahlt werden, so reisen viele Studierende bereits vor dem Monatsersten ab. Auf der anderen Seite ist es üblich geworden, da $B$ die Dozenten Ende Februar oder Juli mit ihrer Vorlesung fertig zu werden suchen, um die letzten Tage nicht vor leeren Bänken lesen zu müssen. Ebenso ist auch im Gefolge dieser Mietszahlungen der Anfang der Vorlesungen im neuen Semester im Sommer allmählich vom 15. April auf den Anfang des Mai und im Wintersemester vom 15. Oktober auf Anfang November hinausgeschoben worden. In Göttingen war das damals nicht so; meist wurde pünktlich mit den üblichen Terminen des I5. April und des 15. Oktober begonnen und am I5. März bzw. I5. August geschlossen. Mögen noch andere Ursachen bei den jetzigen bedeutenden Verkürzungen der Semester Einfluß geübt haben, jedenfalls hat die monatliche Mietszahlung dabei mitgewirkt.

Was man als Student brauchte, selbst an Tabak, Papier und anderen gewöhnlichen Bedarfsgegenständen, das nahm man auf Borg durch den Philister und zahlte, wenn der Wechsel kam. Ein wichtiges Faktotum war in Göttingen der "Stiefelfuchs", wie er hieß. Die Stiefelfüchse waren ursprünglich die Reiniger der Kleider und des Schuhwerks, hatten sich aber im Laufe der Zeit zu einer besonderen Zunft entwickelt, namentlich bei den studentischen Verbindungen, 
wo sie $\mathrm{zu}$ allen Diensten verwendet wurden. Ein gewandter Stiefelfuchs war eine sehr geschätzte Persönlichkeit. Durch den ständigen Umgang mit den Studenten hatten sie sich ein Stück studentischen Wesens angewöhnt, redeten in deren Sprache, kannten die Eigenarten der Dozenten, pumpten den Studenten, was meist nicht ihr Schade war und die älteren unter ihnen wußten vieles Ergötzliche und Bemerkenswerte zu erzählen, da sie mit vielen später bedeutend gewordenen Leuten in deren Studentenzeit bekannt geworden waren.

Von meinen Göttinger Lehrern gedenke ich als derer, die den bedeutendsten Einfluß auf mich gewonnen haben, Sterns, Friedrich Wöhlers, Wilhelm Webers und Jakob Henles.

Stern hatte einen ruhigen, musterhaft klaren Vortrag; es war geradezu eine angenehme Sache, ihm bei der Entwicklung auch schwieriger Dinge zu folgen und zu merken, wie er sie leicht und sicher darstellte, so da $\beta$ nicht der mindeste $Z$ weifel blieb. Ich erwähnte bereits, wie ich durch eine offene Aussprache mit ihm und, gefesselt durch Henles Vortrag, dazu kam, das Studium der Mathematik aufzugeben und zu dem der Anatomie überzugehen.

Dieselbe ruhige und klare Vortragsweise hatte Wöhler. Er las die gesamte Chemie sechstündig wöchentlich in einem Semester, wobei er von der Organischen Chemie jedoch nur einen kurzen Abriß gab und uns auf die ausführliche Vorlesung Beilsteins, seines Assistenten, verwies, die ich jedoch nicht mehr gehört habe. Wenn Wöhler ein Thema berühren mußte, bei dem er selbst als fördernder Forscher beteiligt war, so namentlich beim Aluminium, dann erwähnte er seinen Namen grundsätzlich nicht; wir quittierten ihm aber jedesmal mit dem üblichen Beifallsgetrampel, daß wir Bescheid wußten. Beim Kapitel „Kohlenstoff“ kam Wöhler auf die Diamanten zu sprechen und man merkte ihm an, wie ihn das Problem der künstlichen Herstellung von Diamanten lebhaft interessierte. Es schien ihm auch Spaß zu machen, wenn er seine Vorlesung mit einem Knalleffekt schließen konnte. Es war ja auch ganz richtig, daß er die Vorführung eines Explosivstoffes an das Ende der Vorlesung verlegte, wo die Explosion am wenigsten störend war. Wöhler stellte sich dann etwas beiseite und hielt sich beide Ohren zu. Den stärksten Knalleffekt, bei dem die Fenster klirrten, gab er uns mit Jodstickstoff zum besten. Vortrefflich für den damaligen Standpunkt der 
Chemie sind auch die Wöhlerschen kurzen Lehrbücher; ich habe aus ihnen und aus Wöhlers Kolleg eine, ich muß sagen, sehr gute Kenntnis der Chemie, wie sie damals war, erworben.

Ganz anders wie bei Stern und Wöhler war der lebhafte bewegliche Vortrag Wilhelm Webers. Er stand die ganze Zeit - zwei Stunden mit kurzer Unterbrechung - hinter dem großen Experimentiertische, ging von diesem zur Tafel, um dort mathematische Darlegungen, die er von Zeit zu Zeit dem Vortrage einflocht, anzuschreiben, dann wieder zum Tische zurück, um irgend etwas vorzuzeigen oder ein einfaches Experiment auszuführen, kurz, er war in fortwährender Bewegung. Beim Vortrage selbst sprach er rasch und mit lebhafter Gestikulation. Bei allem diesem war aber der Vortrag klar und übersichtlich. Das stets volle Auditorium, welches sich auch in den heißen sommerlichen Nachmittagsstunden so erhielt, zeigte, wie sehr Webers Vorlesung geschätzt wurde.

Von Henles meisterhafter Lehrweise habe ich bereits öfter erwähnt, daß sie mich zur Wahl meines späteren Berufes veranlaßte. Ich habe keinen Dozenten kennen gelernt, der in so ausgezeichneter Weise vortrug, wie Henle. Er sprach, vor der Tafel stehend, mit klarem, offenem Blick seine Zuhörer umfassend, völlig frei, gewandt und sicher mit einem angenehm klingenden Organ. Zuweilen strich er dabei mit einer charakteristischen, raschen Bewegung eine öfters vorfallende Haarlocke aus seiner Stirn. Das Hervorragendste war bei seinem Vortrage die meisterhafte Art, wie er das gesprochene Wort mit einer Tafelzeichnung zu verbinden wußte. So ließ er, während er irgendeinen Körperteil in Worten beschrieb, in derselben Zeit mit sicheren Strichen dessen Bild vor den Zuhörern auf der Tafel entstehen, so da $B$ gleichzeitig Ohr und Auge den Gegenstand aufnehmen konnten. Dabei entstanden die schwierigsten Formgebilde, wie etwa ein Schläfenbein, so korrekt und mit solcher Leichtigkeit, daß sie wie hingezaubert erschienen. Ich habe mich bemüht, es meinem großen Lehrer nachzutun, bin aber doch nur ein Stümper gegen ihn geblieben.

Diese Art der Unterweisung in naturwissenschaftlichen Dingen, wobei es zunächst einmal auf genaue Erfassung von äußeren Formen ankommt, ist meiner Meinung nach die beste und eindrucksvollste. Sie wird ja auch stets in den betreffenden Vorträgen von den Dozenten mit mehr oder weniger Geschick geübt. Man ist in neuerer Zeit 
vielfach mit der Demonstration großer, vom ganzen Hörsaale aus gut sichtbarer, vorher fertiggestellter Tafeln und besonders mit der Entwerfung von Lichtbildern vorgegangen; auch die Vorzeigung von Modellen, die jetzt in großer Vollendung angefertigt werden, ist sehr in Aufnahme gekommen. So empfehlenswert dieses alles ist, so kann es doch den Lehrwert, den die Verbindung eines guten, vor den $\mathrm{Zu}$ hörern entstehenden Bildes eines Gegenstandes mit dessen klarer Wortbeschreibung hat, nicht ersetzen. Ich werde später noch auf die Methoden des anatomischen Unterrichts, wie ich sie geübt habe, zurückkommen. Selbstverständlich fehlten beim Henleschen Kolleg die Demonstrationen der anatomischen Präparate nicht; wir konnten auch stets die Anatomische Sammlung besuchen und uns die dort aufgestellten Präparate ansehen.

Mikroskopische Demonstrationen gab es nur wenige; die Präparate wurden damals noch mit den einfachsten Mitteln hergestellt. Destilliertes und gewöhnliches Wasser, Kalilauge oder Natronlauge und Essigsäure waren fast die einzigen verwendeten Reagentien. Man kannte keine Färbungen, keine guten Härtungs- und Fixierungsflüssigkeiten, keine guten Dissoziierungsmittel, keine Einbettungen, keine Mikrotome und vor allen Dingen waren die zur Verfügung stehenden Mikroskope von Plössl und Schieck bei weitem nicht auf der Höhe, die man heute an diesen so hochwichtigen Instrumenten mit Recht bewundert. Ich erinnere mich, da $B$ Henle uns im Sommersemester $\quad$ $85^{8}$ einige Bindegewebspräparate mit einem großen Plösslschen Mikroskop zeigte und den sich herandrängenden Zuhörern sagte: ,Nehmen Sie sich in acht, meine Herren, da $B$ dies Instrument keinen Schaden leidet; es ist das Arbeitsmikroskop Johannes Müllers!“ Henle hatte es aus dem Nachlasse J. Müllers, der I 858 gestorben war, erhalten.

Für den anatomischen Präpariersaal standen damals nur wenige Leichen zur Verfügung; man wurde, sobald ein Übungspräparat vorhanden war, vom Anatomiediener bestellt und mußte oft wochenlang warten, bis man wieder an die Reihe kam. So präparierten gleichzeitig auf dem Übungssaale meist nur 4 bis 5 Studierende, und Prosektor Teichmann ebenso wie Henle hatten mit der Aufsicht und dem praktischen Unterrichte wenig Zeit und Mühe aufzuwenden. Doch war Teichmann in den festgesetzten Stunden stets 
zugegen und stets zur Unterweisung bereit. In den Zeiten, in denen er nicht in Anspruch genommen wurde, arbeitete er an seinen berühmten Lymphgefäßinjektionen. So sah ich manches dieser Präparate entstehen. Ich habe auch Teichmann stets ein dankbares und ehrendes Andenken bewahrt, habe ihn, als er Ordinarius der Anatomie in Krakau war, von Berlin aus dort besucht und bin mit ihm in dauernden freundschaftlichen Verkehr getreten. Teichmann gab in Göttingen auch praktischen Unterricht in der mikroskopischen Anatomie, woran jedoch nur wenige Studierende teilnahmen. Diese praktischen Übungen kamen damals gerade auf. Ich beteiligte mich daran erst in Greifswald.

Zur Zeit meiner Studien unter Henle erschien die erste Auflage seines mit Recht berühmten Lehrbuches. Ich kann heute noch sagen, $\mathrm{da} B$ dieses Werk seinen vollen wissenschaftlichen Wert behalten hat. Henles Lehrbuch liest sich nicht wie dieses oder jenes andere; sicher ist aber, daß der, welcher sich die Mühe gibt, es wirklich mit Ernst zu studieren, die darin enthaltene Anatomie wirklich lernt. Noch heute nehme ich, wenn ich etwas nachsehen will, das Henlesche Werk gern zur Hand und bin kaum jemals im Bereiche dessen, was damals Besitzstand der menschlichen Anatomie war, ohne die gewünschte Auskunft geblieben. Henles Werke veralten nicht.

Es gehört zu meinen liebsten und befriedigendsten Erinnerungen, da $B$ ich im Laufe der Zeiten zu meinem verehrten Lehrer Henle in freundschaftliche Beziehungen getreten bin. Von Königsberg aus schickte ich ihm für die von ihm und v. Pfeufer herausgegebene „Zeitschrift für rationelle Medizin“" meineErstlingsarbeit, der er freundliche Aufnahme schenkte. Von dieser Zeit an kam ich $\mathrm{zu}$ ihm in näheren Verkehr, der sich mehr und mehr freundschaftlich gestaltete. Mehrere Male besuchte ich ihn und es war mir immer eine Erfrischung und ein GenuB, mit ihm in Gedankenaustausch zu treten. Als die Feier seines 50 jährigen Doktorjubiläums herannahte, übernahm ich die Sorge für eine ihm zu widmende Festschrift und wohnte der schönen Feier in Göttingen bei. Am Tage darauf lud er mich zu einem Mahle im engeren Familienkreise ein und schenkte mir seine Büste. Sie schmückt von da ab meinen Schreibtisch und es vergeht kein Tag, ohne da $B$ ich mich in ihrer Betrachtung an meinen lieben Lehrer und Freund erinnere. 
Als die Straßburger Anatomenstelle 1872 besetzt werden sollte und Max Schultze und Lieberkühn abgelehnt hatten, wurde ich auf Henles Empfehlung gewählt und damit der Normalen Anatomie, dem Ziele meines Lebens, erst dauernd gegeben. Als dann 1883 der einstige Lehrstuhl Johannes Müllers, dessen Prosektor und Freund Henle gewesen war, durch Reicherts Rücktritt frei wurde, ist wiederum Henle für meine Berufung eingetreten; er schrieb mir damals, ich möge es nicht so machen wie er 1858 und ablehnen, sondern ich solle dem Rufe folgen. Ich fühlte mich damals in Straßburg sehr wohl in der nach meinen und meines Freundes v. Recklinghau sen Plänen neugebauten Anatomischen und Pathologisch-anatomischen Anstalt und wäre gern in Straßburg geblieben; aber Henles Rat bestimmte mich. In Straßburg erhielt ich den Besuch Henles und v. Köllikers, als das eben erwähnte Anatomische Institut eröffnet worden war. Ich fragte Henle, wie es ihm gefiele, er äußerte sich befriedigend, nur komme es ihm zu groß vor und, das Bildnis Johannes Müllers betrachtend, welches wir über der Eingangspforte hatten anbringen lassen, meinte er: ,Ganz gut, aber ich würde ihm die Locken scheren lassen." Unser Bildhauer hatte allerdings dem großen Biologen einen $\mathrm{zu}$ üppigen Haarschmuck gegeben.

Als Henle 1858 den Ruf, an Johannes Müllers Stelle zu treten, abgelehnt hatte, wurde ihm von der gesamten Göttinger Studentenschaft ein Fackelzug gebracht, dem ein Ehrenkommers folgte. Ich, ihm damals wohl noch kaum bekannt, trat mit meinem Glase auch an ihn heran und stieß mit ihm an. Wir beide ahnten sicher nicht, daß ich dereinst den Ruf annehmen sollte, für dessen Ablehnung Henle gefeiert wurde.

Aus seiner letzten Leidenszeit datiert, besitze ich noch Briefe von Henle, aus denen ich doch eine für ihn charakteristische Stelle mitteilen möchte. Er schrieb: ,Mich plagt jetzt manchmal eine sehr schmerzhafte Interkostal-Neuralgie, bei der mir aber besonders störend ist, da $B$ sie mit meiner Theorie nicht stimmen will." Henle dachte dabei an venöse Stauungen in den Gebieten der Venae azygos und hemiazygos. Die Obduktion seiner Leiche zeigte, weshalb das nicht stimmen wollte. Er erlag am I3. Mai I885 einer sarkomatösen Neubildung, die auf die Wirbelsäule übergegriffen hatte $\left({ }^{7}\right)$.

Außer mit meinen Lehrern machte ich in Göttingen noch die erste 
Ernst Ehlers. Otto Spiegelberg. In der Klinik bei Baum.

anknüpfende Bekanntschaft zweier mir später befreundet gewordener Kollegen, des Zoologen Ernst Ehlers und des Gynäkologen Ot to Spiegelberg. Ehlers, damals Assistent am Zoologischen Institut, arbeitete an einer besonderen Untersuchung auf dem Göttinger Präpariersaale und Spiegelberg, Assistent des Gynäkologen v. Siebold, habilitierte sich gerade in der Zeit meines medizinischen Studiums in Göttingen. Er war bei den Studenten beliebt und als er seine Antrittsvorlesung hielt, wurden alle Mediziner zusammengerufen, um dieser Vorlesung beizuwohnen. Ich kam auch hin. Als der junge Dozent eintrat und das dichtgefüllte Auditorium bemerkte, welches ihn mit einem frenetischen Getrampel begrüßte, war er sichtlich aufs angenehmste überrascht von diesem Beweise seiner Beliebtheit und konnte nur zögernd und öfter stockend seine Vorlesung beginnen; bald aber fand er sich zurecht und führte sie trefflich zu Ende. Die Göttinger medizinische Studentenschaft hat sich damals in der Bedeutung, die sie dem jungen Dozenten zumaß, nicht getäuscht.

In der Klinik bei Baum wohnte ich auch einige Male den Operationen bei, die Baum, obwohl Äther- und Chloroformnarkose schon fast allgemein geübt wurden, grundsätzlich, wegen der seiner Meinung nach damit $\mathrm{zu}$ sehr verbundenen Lebensgefahr, nicht anwendete. Aus historischem Interesse erwähne ich dies und berichte, da $B$ ich der Vornahme eines Steinschnittes beiwohnte, wobei dèr betreffende Patient in der für die Operation nötigen Stellung an Armen und Beinen gefesselt wurde, damit er keine störenden Bewegungen machen könne. Dabei bekam er eine Bleikugel in den Mund, um sich seinen Schmerz darauf zu verbeißen. Das leise Stöhnen des Mannes während der rasch und glücklich vollzogenen Operation war mir doch peinlich und ich konnte mich mit der Ansicht Baums nicht befreunden, wissend, da $B$ es Mittel gäbe, die Schmerzempfindung zu beseitigen. Welcher Fortschritt seitdem in der Chirurgie!

Ehe ich meine Göttinger Zeit verlasse, mögen noch ein paar andere Erinnerungen verschiedener Art hier verzeichnet sein. Die erste, eine heitere, die sich in Henles Hörsaale abspielte. Es war ein Bauchredner nach Göttingen gekommen und hatte um die Erlaubnis nachgesucht, sich in einem der Hörsäle der Universität mit seiner Kunst vorstellen und über diese vortragen zu dürfen. Er erhielt diese Erlaubnis und Henle erklärte sich bereit, seinen Hörsaal zur Verfügung 
82 Ein Bauchredner. Spiegelbergs Audienz beim König von Hannover.

zu stellen. Gegen ein geringes Entgelt für den Künstler konnte man der Sitzung beiwohnen. Der Saal war mit Dozenten und Studenten der Universität dicht gefüllt; ich nahm auch teil. Der Mann hielt erst einen guten Vortrag über die Bauchrednerei und gab dann eine Reihe Proben seiner Kunst, die in der Tat sehr gut ausfielen und viel Interesse erregten. Dann sagte er, daß es gar nicht schwer sei, die Kunst des Bauchredens zu erlernen; er sei bereit, sie Jedem, der sie lernen wolle, auf der Stelle in aller Kürze beizubringen und bat, es möge sich ihm hier einer der Anwesenden zur Verfügung stellen. Da sich Niemand meldete, wandte er sich direkt an einen der zunächst Sitzenden, einen alten Mediziner, einen der „ewigen Studenten“, wie sie früher auf fast allen Universitäten nicht allzu selten waren, der unter dem Namen ,der Arzt Schütte" stadtbekannt und eine etwas komische Persönlichkeit war. Die zufällige Wahl erregte schon eine gewisse Heiterkeit, die sich noch steigerte, als der Arzt Schütte sich erhob und sich auf das etwas erhöhte Podium begab, wo der Künstler seiner harrte. Dieser sagte ihm nun, wie er es machen müsse, tief einatmen usw. „Nun machen Sie es so, wie ich es Ihnen gesagt habe und es Ihnen noch einmal vormache." Gesagt, getan; der Arzt Schütte holte Luft mit aller Kraft seiner Lungen; Jedermann blickte gespannt auf ihn. „Nun, los,“ sagte der Künstler; was aber der Arzt Schütte zum besten gab, war kein Bauchreden, sondern ein fürchterliches Grunzen, welches im Zusammenhange mit der Persönlichkeit des Versuchsredners äußerst komisch wirkte; unter einem Ausbruch allgemeiner Heiterkeit schloß die Sitzung.

Die zweite Erinnerung betrifft ein Erlebnis Spiegelbergs, mir von ihm erzählt; es entbehrt wohl nicht eines gewissen historischen Interesses. Es war Brauch, da $B$ die für Göttingen neuernannten Professoren sich in Hannover beim Antritt ihres Lehramtes dem Könige persönlich vorstellen mußten. Spiegelberg wurde nicht lange nach seiner Habilitation zum außerordentlichen Professor ernannt. In Hannover regierte damals der letzte Welfenkönig, der erblindete Georg V. Als Spiegelberg dem Monarchen durch einen der persönlichen Adjutanten vorgestellt wurde, stand der König in dem Saale, den Vorzustellenden erwartend, in voller Uniform. Der Adjutant sagte zu Spiegelberg: „Treten Sie dicht an S. Majestät heran, nehmen Sie seine Hand, wenn er sie Ihnen entgegenstreckt und führen Sie 
diese zu Ihrem Gesicht und lassen Sie ruhig geschehen, was der König tut." So geschah es. Der König ließ, als er seine Hand an Spiegelbergs Gesicht fühlte, diese leicht einmal über das Gesicht gleiten, zog sie zurück und sprach dann den Vorgestellten freundlich an, sich nach dessen Studien, Lebensgang und Lehrfach erkundigend. Der Adjutant sagte nach der Vorstellung, daß der König durch diese kurze Befühlung des Gesichtes einer ihm bis dahin unbekannten Persönlichkeit sich eine gute Vorstellung von dessen Erscheinung mache, die er auch im Gedächtnis behalte.

In einer letzten ernsten Erinnerung sei einer öffentlichen Hinrichtung mit dem Schwerte gedacht, die im Jahre 1858 in Göttingen stattfand. Ich berichte darüber aus kulturhistorischem Interesse, da öffentliche Hinrichtungen, zumal mit dem Schwerte, seit langem nicht mehr stattfinden und wohl auch nie mehr stattfinden werden, glücklicherweise, setze ich nach den Erfahrungen, die ich in Göttingen machte, hinzu. Der zum Tode Verurteilte hatte an einem ihm vertrauenden Kameraden einen Raubmord begangen; die Strafe konnte also als eine gerechte angesehen werden und entsprach auch der allgemeinen Empfindung. Auf einem freien Platze in der Nähe der Stadt war ein weithin sichtbares Schaffott aufgeschlagen, auf welchem, außer dem Verurteilten, dem Scharfrichter und seinen Gehilfen und einigen Justizpersonen, auch noch mehrere Zuschauer Platz hatten. Ich befand mich unter diesen, konnte also den Vorgang gut beobachten. Ringsum auf der Richtstätte war eine nach vielen Hunderten zählende Menge versammelt. Der Verurteilte stand im weißen Gewande auf dem Schaffott neben dem Richtstuhle; der Scharfrichter im weiten Mantel, unter dem er das Richtschwert verborgen hielt, neben ihm. Von einem der Justizbeamten wurde das vom Könige bestätigte Urteil vorgelesen und dann nach alter Sitte der Stab über dem Verurteilten gebrochen. Darauf reichte der Scharfrichter ihm die Rechte, die dieser auch ergriff und schüttelte. Die Gehilfen führten ihn dann zum Richtstuhle, auf den er sich setzte, zogen ihm eine weiße Mütze über den Kopf und die Augen, banden ihm Arme und Beine am Stuhle fest und legten eine Lederschlinge unter das Kinn, mit der einer der Gehilfen ihm den Kopf straff in die Höhe hielt. Alles dieses wurde rasch und geschickt ausgeführt. Als dem Todeskandidaten die Mütze über die Augen gezogen war, zog der Scharfrichter das große, breite, 
scharfe, blitzblanke Richtschwert unter dem Mantel hervor, trat damit an die linke Seite des Verurteilten, holte aus und trennte im $\mathrm{Nu}$ den Kopf vom Rumpfe, indem er mehr mit einem glatten Zuge, als mit einem Schlage den Hals durchschnitt. Der Kopf blieb in der Lederschlinge, zwei Blutsäulen stiegen aus der Wundfläche fast bis zu einem halben Meter Höhe wie aus einem Springbrunnen hervor, um zurückzufallen und noch ein paarmal immer niedriger und schwächer mit den nächstfolgenden Herzschlägen wiederzukehren. Der Körper des Gerichteten blieb regungslos. Der ganze Leichnam wurde alsbald zur Anatomischen Anstalt gebracht, wo er zu Studierzwecken Verwendung fand.

Was ich besonders als kulturhistorisch bemerkenswert hervorheben möchte, sind einmal Äußerungen eines krassen Aberglaubens und dann das Verhalten der Menge nach dem ernsten Akte. Dicht am Schaffott hatten sich einige an epileptischen Krämpfen Leidende aufgestellt, die den Gehilfen Glasgefäße übergeben hatten. In diesen Gefäßen fingen die Gehilfen das hervorsprudelnde Blut auf und reichten es den Epileptikern, die es sofort tranken; es bestand die Meinung, daß das Blut Hingerichteter frisch getrunken die Fallsucht heilen könne. Es muß zugegeben werden, daß heftige Gefühlseindrücke, wie sie sicher doch durch das Trinken von frischem Menschenblut erzeugt werden, gewisse Fälle von nervösen Leiden zum Verschwinden bringen können; auch muß zugegeben werden, daß die Fallsucht für die damit Behafteten ein so qualvolles Übel darstellt, daß sie sich allem unterziehen, von dem sie Heilung erhoffen. Aber ein unfaßbarer Aberglaube spricht aus der Äußerung einer Bauersfrau, die sich auch etwas Blut in einem Fläschchen mitnahm, ,dat mott'en," sagte sie,

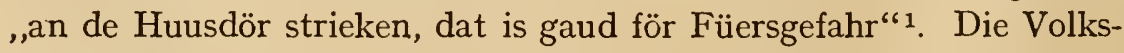
menge zerstreute sich; viele blieben aber noch in der Stadt und bevölkerten die Gastwirtschaften. Man konnte später eine Menge reichlich Angeheiterter durch die Straßen wanken sehen. Das war die Folge eines so ernsten öffentlichen Aktes!

Ich füge hier gleich die Schilderung einer zweiten Hinrichtung an, die zu Colmar im Elsaß stattfand und der ich von Straßburg aus beiwohnte, um von der frischen Leiche wichtige Präparate für mikroskopische Untersuchungen zu gewinnen. Für Leser dieser Zeilen, die

${ }^{1}$ Das muß man an die Haustür streichen, das ist gut für Feuersgefahr. 
mit den Aufgaben und Zielen der anatomischen Wissenschaften nicht vertraut sein sollten, bemerke ich, $\mathrm{da} B$ im Bau des menschlichen Körpers bis in die feinsten Einzelheiten hinein Unterschiede von denen auch der nächstverwandten Tiere bestehen. Namentlich gilt dies für die höheren Sinnesorgane, Ohr und Auge, sowie für das Zentralnervensystem. Alle diese Teile sind aber nach dem Tode sehr rasch, oft schon nach $I 5$ bis 20 Minuten eintretenden Veränderungen unterworfen. Je genauer wir aber von dem feineren Bau eines Körperteiles unterrichtet sind, desto besser vermögen wir seine Bedeutung für den Körper in gesunden und kranken Zuständen zu beurteilen. Es ist also sehr wichtig, jede Gelegenheit zu benutzen, völlig frische, unversehrte menschliche Körperteile zu bekommen, um sie für sofortige Untersuchung zu verwenden oder, gut konserviert, für später aufzubewahren.

In Colmar hatte man mir nahe dem Gefängnishofe, auf dem die Hinrichtung stattfand, ein Zimmer bereitgestellt, in welches der Leichnam sofort nach der Hinrichtung verbracht wurde. Die Hinrichtung fand mittels der Guillotine statt. Der Schuldige, der den Tod erlitt, weil er einen seiner Mitgefangenen aus Rache ermordet hatte, benahm sich sehr standhaft. Als ihm das Urteil vorgelesen worden war, in welchem es zum Schlusse hieB, daß S. Majestät der Kaiser auf sein Begnadigungsrecht verzichtet habe, sagte der Verurteilte mit fester, lauter Stimme: „Ich danke S. Majestät!“ Darauf schritt er ruhig die Treppe zur Guillotine hinan, stellte sich entschlossen vor dem Brette auf, auf das er nun festgeschnallt wurde. Darauf wurde das Brett rasch vorwärts geschoben, so da B der Nacken des Mannes gerade unter das hoch oben blinkende Fallbeil zu liegen kam; ein Druck auf einen Knopf, das Beil fuhr wie ein Blitz herab und ein dumpfer Schlag zeigte an, daß das Haupt vom Rumpfe getrennt war. Der Kopf fällt in ein Gefäß, in welches sich auch das Blut ergießt, so daß die Anwesenden davon nichts $z u$ sehen bekommen. Diese Hinrichtung fand im abgeschlossenen Gefängnishofe vor nur wenigen geladenen Zeugen statt. Fragt man, welche Art der Hinrichtung die humanere sei, so möchte ich der mit dem Schwerte am ehesten dieses Prädikat geben, denn das Aufschnallen an das Brett, das Umlegen und Vorwärtsschieben des Brettes schien mir für den zu Enthauptenden ein härterer Vorgang, als das Aufschnallen auf 
einen Stuhl und das Heben des Kopfes, wobei der Verurteilte nichts von dem Instrumente gewahr wird, welches ihm den Tod bringen soll. Der ganze Vorgang in Göttingen vom Niedersetzen des Schuldigen auf den Stuhl bis zur Enthauptung dauerte nicht länger, als der in Colmar vom Antreten vor das Brett bis zum Fallen des Beiles, welches der Verurteilte oben hängen sieht, jedenfalls dort hängen weiß, selbst wenn man es verhüllen würde. Man könnte die Art der Hinrichtung durch den elektrischen Schlag, wie sie in den Vereinigten Staaten von Nordamerika geübt wird, als die humanste bezeichnen; doch haben sich Stimmen gegen sie erhoben, da Fälle vorgekommen sein sollen, bei denen der erste Schlag den Tod nicht brachte. Freilich sind auch Fälle vorgekommen, wo der Scharfrichter den Kopf nicht mit dem ersten Hiebe gänzlich abtrennte. Das kann wohl bei der Guillotine nicht vorkommen und kaum auch bei der jetzigen Art der Hinrichtung in Deutschland durch das Beil auf dem Blocke.

Man möge dem Anatomen verzeihen, wenn er in kulturhistorischem Interesse diesen ernsten Gegenstand in seinen Erinnerungen zur Sprache brachte. Es mögen auch noch ein paar Erwägungen über die Todesstrafe als solche und ihre Berechtigung hier Platz finden. Niemand wird bezweifeln, daB Jedermann das Recht hat, sich eines Gegners, der ihn tödlich bedroht, dadurch zu erwehren, daß er ihn, falls er ihn nicht auf andere Weise unschädlich machen kann, tötet; das Recht der Notwehr selbst bis zur Tötung ist überall anerkannt. Der Staat hat nun die Verpflichtung, das Leben und das Eigentúm jedes seiner Bürger zu schützen; stellt sich heraus, daß andere Mittel, wie lebenslängliche Inhaftierung, nicht ausreichen, um diesen Schutz wirksam zu gestalten, so $\mathrm{muB}$ er $\mathrm{zu}$ strengeren Mitteln greifen, bis zur Todesstrafe. Man hat zwar gesagt, daß die Lehre von der Berechtigung einer Strafe wegen der durch sie $\mathrm{zu}$ erreichenden $\mathrm{Ab}$ schreckung nicht haltbar sei, aber die Erfahrung spricht dagegen. Wenn irgendwo, namentlich in Kriegszeiten, die Übeltaten irgend welcher Art so überhand nehmen, da $B$ man sich ihrer auf keine andere Weise mehr erwehren kann, dann wird das Standrecht verkündet oder es werden Strafen eingeführt, die als besonders peinlich empfunden werden, und das hilft allemal. Ich würde es für völlig berechtigt erklären, namentlich in jetziger Zeit, in der die Kriegsnot und die Kriegstrauer eher zur Abnahme von Untaten führen sollte, 
als leider $\mathrm{zu}$ so großer Zunahme, wenn jeder Einbrecher, bei dem man eine Waffe vorfände, mit lebenslänglicher Zuchthausstrafe belegt würde; und hätte er, wenn auch ohne Erfolg, Gebrauch von der Waffe gemacht, insbesondere gegen einen Polizeibeamten, der sein Leben zum Schutze seiner Mitbürger aufs Spiel setzt, so sollte er mit dem Tode bestraft werden. Die verwegensten Einbrüche unter Gebrauch von Waffen nehmen jetzt in so erschreckender Weise überhand, daß ein energisches Einschreiten dagegen dringend notwendig ist. Sicherlich würde dadurch auch binnen Kurzem Abhilfe geschaffen werden. Aber eines ist dabei die Hauptsache : ra scher Voll$z$ ug der Strafe. Soll eine Strafe überhaupt wirksam sein, dann muß sie möglichst rasch auf die Straftat folgen. Das lehrt schon die Erfahrung bei der Erziehung der Kinder in Haus und Schule, wenn Strafen verhängt werden müssen. Wollte man da längere Zeit warten, so würde der Vollzug der Strafe nur erbittern und unwirksam bleiben. Und bei den Strafen, die das Gericht über die Erwachsenen verhängt, ist das genau dasselbe, namentlich bei der Todesstrafe. Was nützt da der rote Zettel an der Litfaßsäule, wenn mitgeteilt wird, daß X. oder Z. heute enthauptet worden sei, wenn die Straftat, derentwegen er sein Leben lassen mußte, Monate; ja selbst über ein Jahr zurückliegt, so daB sie in unserem flutenden Leben längst aus dem Gedächtnisse geschwunden ist? Sie nützt gar nichts, weder im Sinne der rechten Vergeltungslehre, noch der Abschreckungslehre, ja, man wird fast versucht, Mitleid mit dem armen Menschen zu empfinden, der so lange in Todesangst um sein Geschick im Gefängnisse hat schmachten müssen. Gerne will ich zugeben, daß es Fälle gibt, wo die Aufhellung der Gründe für die Straftat, oder die Ermittlung von Mitschuldigen eine längere Untersuchungsfrist erheischt. Wenn aber der Tatbestand unzweifelhaft feststeht, mildernde Umstände, wie doch in vielen Fällen, klar auszuschließen sind, die Ermittlung von Mitschuldigen auch nicht dringlich ist, dann aber rascher Strafvollzug! 
2. Greifswald.

Abenteuer auf der Fahrt dorthin. - Greifswalder Studentenleben. - Beschäftigung mit Normaler und Pathologischer Anatomie. - EntschluB zum Verfolg einer akademischen Lehrtätigkeit. - Meine Lehrer: Budge, Sommer, Niemejer, v. Bardeleben, Pernice. - MiBgeschicke beim geburtshilflichen Unterricht.

Im Oktober 1858 begab ich mich zur alten pommerschen Universität am Ryck, wo ich mit meinem Freunde Albert Ka yser zusammentreffen wollte. Auf dem Wege dahin erlebte ich ein Reiseabenteuer, welches leicht sehr unangenehme Folgen für mich hätte haben können, jedoch noch glücklich ablief.

Meine beiden Brüder, die Landwirte werden wollten, hatten in Mecklenburg auf einem schönen Gute bei Schwerin, Gustävel, Stellung gefunden und ich wünschte meine Reise so einzurichten, da $B$ ich sie auf dem Wege besuchen konnte. Das Gut gehörte einem Herrn v. Arnswaldt, der mit der Familie v. Haxthausen verschwägert war. Ich reiste daher über Hannover, wo die Freifrau v. Arnswaldt, Mutter des Gutsbesitzers, wohnte, um etwaige Nachrichten für ihren Sohn mitzunehmen. Ich wurde in Hannover sehr gastfreundlich aufgenommen; als ich mich am anderen Morgen zur Weiterreise anschickte, fragte mich Frau v. Arnswaldt, ob ich nicht für ihren Sohn etwas bares Geld mitnehmen wollte? Auf meine bereitwillige $\mathrm{Zu}$ stimmung lieB sie mir in meine Reisetasche Iooo Silbertaler packen, wodurch die Tasche ein ansehnliches Gewicht bekam. Ich behielt die Tasche während der Bahnfahrt, die bis Boitzenburg reichte, natürlich bei mir. In Boitzenburg ging's über die Elbe und dann eine gewisse Strecke weiter in einem sogenannten Omnibus, bis man wieder zur Bahn kam. Ich stieg in den Omnibus, der stark besetzt war, ein und wollte die Tasche mit in den Wagen nehmen. Das verweigerte der Führer mit der Begründung, daß die Tasche zu groß sei, sie müsse auf dem Verdeck des Wagens befördert werden. Meine Beteuerungen, ich müsse die Tasche bei mir behalten, sie könne während der Fahrt vom Wagen fallen, halfen nichts; ich konnte auch die Iooo Taler nicht herausnehmen und in meinen Taschen unterbringen, durfte auch, um nicht auffällig zu werden, nicht $\mathrm{zu}$ sehr drängen, kurz, ich mußte nachgeben. Eine Leiter wurde an den Wagen gesetzt und meine Tasche nebst einigen anderen größeren 
Gepäckstücken hinaufgeschafft. Zwei Bedienstete der Omnibuslinie vollzogen das. Ich stand etwas von ferne, um genau zu beobachten, wohin die Tasche kam und wie sie da befestigt wurde. $\mathrm{Zu}$ meinem nicht geringen Schrecken sagte einer der Leute, der meine Tasche genommen hatte, zu dem Anderen: „Dunnerkiel! Jss dei schwar, da iss gewisse Geld inne" " Ich durfte mir nichts merken lassen, überzeugte mich, da $\beta$ die Tasche gut befestigt wurde, blieb so lange außer dem Wagen, wie es möglich war, um zu sehen, ob nicht Jemand sich auf das Wagendach begäbe und dort während der Fahrt bliebe. Als die Leiter weggenommen wurde und der Kutscher sich zur Abfahrt auf den Bock schwang, stieg ich dann auch ein. Ich wurde aber die Sorge nicht los, daß doch bei einem der Halteplätze Jemand auf den Wagen steigen und das Geld aus der Tasche nehmen möchte. Das wäre auch sehr leicht gewesen; er brauchte nur mit einem Taschenmesser einen Schlitz in die Tasche zu schneiden, da hätte er bequem alle harten Taler herausholen können. Doch ging alles gut. Wie froh war ich, als ich auf der Bahnstation die Tasche unversehrt und ebenso schwer, wie vordem wieder in meine Hände bekam! Ich lieferte das Geld in Gustävel richtig ab, verlebte dort mit meinen Brüdern einige angenehme Tage und fuhr über Rostock und Stralsund nach Greifswald. Von Rostock ab mußte ich Post benutzen und hatte bis Greifswald eine I8stündige Postfahrt hauptsächlich in der Nacht durchzumachen. Das dürfte heute in Deutschland auch nicht mehr vorkommen.

In Greifswald verbrachte ich fünf angenehme Semester, die mir besonders dadurch zugute kamen, da $B$ ich die Stelle eines Famulus oder Amanuensis, wie es auch heißt, am Anatomischen Institute bekam und Wohnung in diesem Institute selbst erhielt, wodurch ich so recht in das anatomische Studium einrückte. Ich habe dort den größten Teil meiner medizinischen Studien erledigt.

Das studentische Leben in Greifswald war ähnlich dem in Göttingen, nur hatte es einen schlichteren Anstrich, wozu wohl der Umstand beitrug, da $B$ viele unbemittelte junge Leute dort studierten. Es gab zwei Korps, die Preußen und Pommern, und eine Burschenschaft, die Rugia. Aus denselben Gründen wie in Göttingen trat ich keiner

' „Donnerkeil!“ (ein in Norddeutschland sehr übliches Wort zum Ausdruck von Verwunderung) „ist die schwer, da ist gewiB Geld darin." 
Verbindung bei, fand aber bald Ersatz in einem studentischen Gesangverein, der Greifswalder Studenten-Liedertafel, die Freunde von mir gründeten und die sich bald als ein durchaus geachteter Verein hervorhob. Wir kamen jede Woche einmal in einer Gastwirtschaft zusammen. Nach zweistündigen Gesangsübungen begann die Fidelitas, wobei ein Fäßchen Bier geleert und eine Bierzeitung verlesen wurde. Unser Dirigent war der Stud. theol. Bernhard Rothenberg, der im Jahre I9I7, hochbetagt, als Pfarrer in Treptow a. d. T. verstorben ist. Von Freunden waren darin Albert Kayser, dessen ich schon erwähnte, Gusta v Sch war ze, den als Arzt im Kriegsjahre 1866 in Gitschin die Cholera hinwegraffte, Leonhard Landois, der 1902 als Professor ordinarius der Physiologie in Greifswald verstarb, und Richard Hermes, der einer meiner besten Freunde wurde, Alter Herr der Bremenser in Göttingen, den ich später als Kommilitonen in Berlin abermals traf. Er ist vor drei Jahren als sehr angesehener Arzt in Erxleben bei Magdeburg gestorben. Ich bin mit ihm und seiner Familie in steter Verbindung geblieben.

An unser Zusammenleben in dieser Liedertafel knüpfen sich einige meiner angenehmsten Erinnerungen. So wurden wir einmal in ein benachbartes Dorf geladen, um durch unseren Gesang die Einweihung einer neuerbauten Kirche festlicher gestalten zu helfen. Nach Beendigung der kirchlichen Feier lud uns der Kirchenpatron, ein Gutsbesitzer, zu einem Festmahle ein, dem am Abend ein Tänzchen folgte. Unsere größte und zugleich verwegenste Leistung waren aber zwei Konzerte mit nachfolgendem Ball, die wir in Wolgast zwei Jahre hintereinander gaben. Einer von uns hatte Bekannte in Wolgast; er wurde ausgesandt, um zu hören, ob wir wohl auf Besuch rechnen könnten, wenn wir gegen ein Eintrittsgeld - denn das brauchten wir bei unseren dünnen Geldmitteln - in Wolgast ein Konzert mit nachfolgendem Ball geben würden? Den Wolgastern erschien die Sache so originell, da $B$ sie uns ermutigten. Die nötigen Verhandlungen mit dem Bürgermeister und dem ersten Gasthof zur Überlassung eines Saales brachten ein günstiges Ergebnis, ebenso die Einladungen, die wir an die benachbarten Gutsbesitzer erließen und unser Fest hatte einen guten Erfolg. Unsere gesanglichen Leistungen und ein Streichtrio, zu dem wir den Mut faßten, waren ja nicht hervorragend, aber alle Erschienenen amüsierten sich trefflich und die Hauptsache 
war ja der Ball. $\mathrm{Da} B$ die Veranstaltung gefallen hatte, bewies der Umstand, daß wir, als wir sie im folgenden Jahre wiederholten, einen fast doppelt so zahlreichen Besuch hatten.

Der edlen Frau Musica widmete ich mich in Greifswald noch weiter : ich trat in die Greifswalder städtische Liedertafel ein, die von dem damaligen Direktor der Landwirtschaftlichen Akademie in Eldena und Professor an der Universität Dr. Baumstark geleitet wurde. Die Zugehörigkeit zu diesem Verein vermittelte es, da $\beta$ ich aufgefordert wurde, an einem musikalischen Kränzchen teilzunehmen, in welchem sich einige Familien zusammenfanden, um Gesang zu pflegen. Die Zusammenkünfte fanden in den betreffenden Wohnungen statt. Der wohlbekannte medizinische Historiker Professor Haeser, der für einen Meister in der Musikkunst gelten konnte, leitete die Übungen. So hatte ich die Annehmlichkeit, Familienanschluß in Universitätskreisen zu finden und zugleich mich noch weiter in der Gesangskunst auszubilden, denn in diesem Kränzchen wurde nur beste Musik und zwar mit hohen Anforderungen gepflegt. Unter anderem lernte ich da die Meisterwerke von Palestrina und Orlando di Lasso kennen und schätzen.

Wegen der größeren Entfernungen reisten wir Westfalen nur zu den Herbstferien heim. In der Weihnachtszeit und in den Osterferien wurde gut gearbeitet, aber bei günstigem Wetter wurden Ausflüge gemacht. Zu Pfingsten war die schöne Insel Rügen das Ziel. In der Nähe bot das Seebad bei Wyk und der Elisenhain bei Eldena manches Angenehme. Einmal veranstalteten wir dort einen großen, bis tief in die Nacht hinein dauernden Kommers, zu dem die Veranlassung auf meine Kappe kam. Ich teile die Sache hier mit, um zu zeigen, wie frei und lustig das Studentenleben damals in Greifswald sich abspielte. Ich hatte als Amanuensis auf Veranlassung des Direktors der Anatomie, Professor Budge, eine kleine Mitteilung über die Art und Weise, wie in Greifswald die mikroskopischen Übungen, bei denen ich hauptsächlich tätig sein mußte, eingerichtet waren, in einer Berliner medizinischen Zeitung drucken lassen. Da sagten meine Liederfreunde: „Du bist unter die Schriftsteller gegangen, das ist ein Ereignis, das muß gefeiert werden.“ Gesagt, getan! Es wurde ein besserer Wagen gemietet, in diesem $s a B$ ich allein mit einer Feder hinter dem Ohr; in einem zweiten gewöhnlichen Leiterwagen folgten 
meine Sangesbrüder und ein ansehnliches $\mathrm{FaB}$ Bier. So fuhren wir langsam durch die gute Stadt Greifswald. Von Zeit zu Zeit wurde gehalten, einer oder der andere meiner Kommilitonen verließ mit einem Glase Bier den Leiterwagen und bot mir einen Trunk an. Dazwischen wurden frohe Studentenlieder gesungen. Im Elisenhain hielten wir dann im Freien einen regelrechten Kommers ab. Es wurde recht spät, bis wir heimkamen; aber das Ganze verlief in harmloser, echt studentischer Fröhlichkeit.

Das erste anatomische Präparat, welches ich in Greifswald anfertigte, waren die Brustmuskeln. Es fiel so gut aus, daß Budge es zur Demonstration in seiner Vorlesung bestimmte. Da ich fortfuhr, gut zu arbeiten, bekam ich bald den Auftrag, die Präparate für die anatomischen Vorlesungen herzustellen. Mit Freuden nahm ich das an, das war es ja, was ich wollte. Ich erwarb mir dadurch die Gunst Budges und insbesondere die des Prosektors Dr. Ferdinand Sommer, der dadurch entlastet wurde. Er war einer der tüchtigsten anatomischen Techniker, die ich kennen gelernt habe. Die Feder lag ihm nicht, wohl aber das Messer und die Injektionsapparate und es machte ihm große Freude, mich und meine Freunde: Landois, Siering, gestorben als Geheimer Sanitätsrat in Düsseldorf, und Bensberg, gestorben als Kreisphysikus in Demmin, die wir Alle großes Interesse an dem Studium der Anatomie zeigten, in allen den technischen Dingen, die für den Anatomen nötig sind und die er in seltener Weise beherrschte, zu unterweisen. Er zog uns zu seinen Privatarbeiten hinzu und trat nach und nach in ein mehr freundschaftliches Verhältnis zu uns, indem er uns öfters in seine Wohnung einlud und mit uns gemeinsame Spaziergänge machte. Dabei wurde dann auch nicht bloß über Anatomie gesprochen, sondern unsere Unterhaltungen trugen uns in alle Wissensgebiete hinein, selbst in politische Dinge. Ich entsinne mich noch, daß Sommer uns zuerst auf die Bedeutung Bismarcks aufmerksam machte; er sei der kommende und auch der rechteMann, wie er sich völlig zutreffend äußerte.

Ich gedenke meines Lehrers und werten Freundes Sommer, der später Budges Nachfolger in der Anatomie wurde, während Landois die Professur für Physiologie erhielt, stets mit größter Dankbarkeit.

Wir vier Freunde der Anatomie, Bensberg, Landois, Siering und ich, kamen fast täglich zusammen und unterrichteten uns gegen- 
seitig in anatomischen Dingen, debattierten über anatomische Streitfragen und Aufgaben und wurden nach und nach bekannt unter unseren Kommilitonen auf dem Präpariersaale als in diesen Dingen gut Bewanderte. Vielfach wurden wir auf dem Saale in Anspruch genommen, auszuhelfen und schwierigere Präparate zu erläutern; so wurden wir, ich möchte sagen, zu offiziösen Famulis, was uns ja nur förderlich war. Später, im letzten Jahre meiner Greifswalder Zeit, wurde ich, wie bereits erwähnt, offizieller Famulus in der Anatomie und hatte dort Dienstwohnung. Ich verrichtete als solcher völlig Assistentendienste auf dem Präpariersaale und beim mikroskopischen Kursus. Budge gab mir einen Arbeitsplatz in seinem Privatzimmer und speziell die Aufsicht über die Anstaltsbibliothek und die anatomische Sammlung. Auch zog er mich und meine drei genannten Freunde zur Assistenz bei seinen Privatarbeiten heran. Bensberg trat ebenfalls als Famulus beim Anatomischen Institut ein.

Es war dies die Zeit, in der an den deutschen Universitäten die Trennung der Professur der Physiologie von der der Anatomie sich allgemein durchzusetzen begann. Ordinariate für Pathologische Anatomie gab es nur an wenigen deutschen Universitäten. Nach Greifswald wurde damals Grohé, früherer Assistent R. Virchows, berufen. Er bekam für die Obduktionen und Laboratoriumsarbeiten einige Zimmer im Anatomischen Institut eingeräumt und so erlielt ich Gelegenheit, mit ihm näher bekannt zu werden. Dazu verhalf mir insbesondere die Feststellung von Trichinen an einer Leiche, die an das Anatomische Institut eingeliefert worden war. Ich hatte aus einer eingehenden Beschäftigung mit den menschlichen Parasiten, $\mathrm{zu}$ denen Landois und ich die Anregung von dem Zoologen und Botaniker Münter erhalten hatten, eine gute Vorstellung von dem Bilde einer trichinösen Invasion in die Muskulatur und erkannte an der Leiche sofort richtig die Lage der Sache. Ich meldete den Fall alsbald an Budge, Sommer und auch an Grohé, dem dann die Leiche für seine Demonstrationen überlassen wurde. So kam ich in nähere Beziehungen zu Grohé, sah auch bald ein, daß eine gute Kenntnis der Pathologischen Anatomie auch für den normalen Anatomen von großer Wichtigkeit ist und versäumte von da an keine Gelegenheit, die sich mir ja so leicht bot, um mich in der Pathologischen Anatomie möglichst gut zu unterrichten. Dies und der Umstand, daß um diese 
Zeit an manchen Universitäten besondere Professuren für Pathologische Anatomie erst geschaffen wurden, ist mir sehr $\mathrm{zu}$ Gute gekommen.

Mehr und mehr befestigte sich bei mir, als ich durch die eingehende Beschäftigung mit anatomischen und verwandten Disziplinen zur Überzeugung kam, daß ich diese Gebiete hinreichend beherrsche, um darin als Lehrer auftreten und mir eigene Aufgaben stellen zu können, der Plan, mich endgültig für den Beruf eines Universitätslehrers im Fache der normalen menschlichen Anatomie vorzubereiten. Dazu mußte ich suchen, eine besoldete Assistentenstelle $\mathrm{zu}$ erlangen, denn meine Eltern waren nicht in der Lage, mich dauernd weiter zu unterstützen. Auch fehlte mir noch eine gute Kenntnis der Entwicklungsgeschichte, deren durchschlagende Wichtigkeit für den gewählten Beruf ich einsah. Dieses Fach wurde damals in Greifswald nicht gelesen und es war in den dortigen Sammlungen auch kein Studienmaterial dafür vorhanden, ferner war dort keine Aussicht auf eine hinreichend dotierte Assistentenstelle. Als lebende und tätige deutsche Forscher auf dem Gebiete der Entwicklungsgeschichte waren damals bekannt Bisch off, Kölliker, Reichert und Robert Remak. Da ich wünschen mußte, in Preußen mein Staatsexamen zu machen, so entschloß ich mich, im Sommersemester I86I, in welchem Reichert Entwicklungsgeschichte las, nach Berlin zu gehen, dort zu promovieren und im Herbst gleich mit Beginn der medizinischen Staatsprüfungen diese $\mathrm{zu}$ erledigen. - Als ich Budge von meinem Vorhaben in Kenntnis setzte, betrübte ihn das sichtlich; er sagte mir, daß er gern gesehen hätte, wenn ich mich in Greifswald habilitiert hätte; er wäre bereit gewesen, das seiner Zeit bei der Fakultät zu unterstützen. Er verschloß sich jedoch nicht der Wichtigkeit der Gründe, die mich bewogen, Berlin aufzusuchen, und wir schieden in gutem Einvernehmen, das auch dauernd geblieben ist. Mich hat mein Weg noch öfters nach Greifswald geführt, wo ich Budge und Sommer noch als Berliner Anatom mit meinen Besuchen erfreuen konnte, wo, nach Budges Rücktritt, mein Jugendfreund Landois Professor der Physiologie wurde und später mein Schwiegersohn Tilmann; jetzt Professor der Chirurgie an der Universität Köln, einige Jahre Assistent der chirurgischen Klinik war. Hier geleitete ich in tiefer Trauer meinen Freund Landois zu Grabe und hielt ihm später in der Aula 
die Gedächtnisrede; auch nahm ich an der schönen Feier des 450 jährigen Bestehens der Alma mater gryphia teil. Ich hatte ferner noch die Freude, meinen ehemaligen Berliner Schüler Kallius, jetzigen Ordinarius der Anatomie in Breslau, als Professor der Anatomie für Greifswald ernannt zu sehen.

Einiges über meine Greifswalder Lehrer möge hier noch nachgetragen sein: Budges Vortrag war in der Form sehr einfach, ja, man kann sagen, nüchtern. Immerhin war er geeignet, gut belehrend zu wirken. Auf dem Präpariersaale gab sich Budge viele Mühe, die Arbeitenden auf das Wichtige an ihren Präparaten aufmerksam zu machen. Überhaupt mußte man anerkennen, da $B$ er, wo er nur konnte, bei seinen Schülern anregend und unterstützend eingriff. Er war aber mehr Physiolog als Anatom. Die Hauptarbeit leistete hier Sommer.

Felix Niemeyer, der damalige innere Kliniker, hatte einen glänzenden, lebendigen Vortrag, der namentlich in den klinischen Stunden fesselnd wirkte. Er war als praktischer Arzt auf Grund eines von ihm verfaßten, sehr beifällig aufgenommenen Lehrbuches, in welchem er es verstanden hatte, plastische Krankheitsbilder zu geben, als Kliniker nach Greifswald berufen worden. Ihm fehlte aber noch dieses und jenes, was man von einem Professor der inneren klinischen Medizin verlangen konnte. Das wuBte er auch selbst und machte kein Hehl daraus. Er suchte sich auch unverdrossen noch weiter in den Hilfswissenschaften: Botanik, Chemie und Physik, fortzubilden. Wir schätzten an ihm diese Offenheit und er erfreute sich allgemein der gröBten Beliebtheit unter den Studierenden. Von Zeit zu Zeit hielt er eine besondere klinische Stunde, in der er die Fälle kritisch besprach, bei denen seine Diagnose durch den pathologischanatomischen Befund nicht bestätigt worden war und schonte sich dabei nicht, wenn zuzugeben war, da $B$ die Fehldiagnose hätte vermieden werden können. Noch während meiner Studienzeit in Greifswald erhielt er einen Ruf nach Tübingen, den er annahm. Zu seiner Charakteristik mag hier folgendes erzählt sein: Niemeyer trug in dem letzten Semester seiner Greifswalder Zeit in seiner Vorlesung über spezielle Pathologie einen großen Teil desjenigen vor, welches in dem erst in Vorbereitung begriffenen zweiten Bande seines vorhin genannten Werkes über Pathologie und Therapie der inneren Krank- 
heiten erscheinen sollte. Man sah, da $\beta$ er sich für vieles Notizen gemacht hatte, denen er bei der Vorlesung folgte, da $B$ er aber dann wieder ganze Abschnitte frei vortrug. Ich hatte in keiner Stunde gefehlt, eifrig nachgeschrieben und mir zu Hause sofort das Nachgeschriebene ausgearbeitet, so da $B$ ich in den Besitz einer sehr vollständigen Niederschrift gekommen war. Eines schönen Morgens, in aller Frühe in der Zeit, als Niemeyer sich zur Abreise nach Tübingen rüstete, schickte er zu mir nach der Anatomie, wo ich damals bereits wohnte und ließ mich bitten, $\mathrm{zu}$ ihm $\mathrm{zu}$ kommen. Ich folgte sofort und traf ihn und seine Frau mitten zwischen Kisten und Kasten, mit Einpacken beschäftigt. Niemeyer empfing mich mit den Worten: „,Sagen Sie mal, Waldeyer, halten Sie mich für einen ehrlichen Kerl?“ Ich sagte, nachdem ich eine Weile sprachlos dagestanden hatte, da $B$ ich noch nie an ihm gezweifelt hätte. „Nun denn," sagte Niemeyer, „dann werden Sie mir auch vertrauen, daß ich Ihnen Ihr Heft, welches Sie, wie ich gesehen habe, bei meiner letzten Vorlesung nachgeschrieben haben, wiederschicke, wenn Sie es mir jetzt leihen." „Sicherlich," erwiderte ich. Niemeyer erklärte mir, weshalb er das Heft wünsche; er sei in der Ausarbeitung des zweiten Teiles seines Lehrbuches begriffen, habe vom Meisten genügende schriftliche Unterlagen, von Manchem jedoch nicht, habe aber über dieses im Kolleg frei vorgetragen. Es liege ihm daran, eine möglichst getreue Niederschrift dieses frei Vorgetragenen zur Hand zu haben; er traue mir zu, da $B$ ich gut gefolgt sei. Ich war natürlich hocherfreut über das Vertrauen, welches mir mein Lehrer schenkte, holte sofort mein Heft, welches ich bereits hatte einbinden lassen und übergab es Niemeyer. Ich habe es niemals wiederbekommen; dafür schickte mir aber Niemeyer von Tübingen den zweiten Band seines Werkes mit eigenhändiger Widmung; das war mir lieber als das Heft. Der Nachfolger Niemeyers war $\mathrm{R} u ̈ h l e$, der später nach Bonn berufen wurde. So sehr wir Niemeyer schätzten, mußten wir uns doch sagen, daß Rühle ihm, namentlich in der Diagnostik, überlegen war; in meinem letzten Greifswalder Semester habe ich noch Rühles Klinik als Praktikant beigewohnt.

Die bedeutendste und einflußreichste Persönlichkeit der Greifswalder Universität, in der damals die Mediziner die erste Rolle spielten, war neben Baumstark unstreitig der chirurgische Kliniker Adolf 
v. Bardeleben. Er hieß bei den Studenten einfach „Der Chef“. Sein theoretischer Vortrag wie sein klinischer Unterricht war anregend und klar, seine Diagnostik zuverlässig, seine operierende Hand, durch gründliche anatomische Kenntnisse geleitet, sicher und geschickt. Er liebte es, indem er, um uns die operative Technik zu zeigen, langsam vorging, während des Operierens den gerade Nahestehenden, die während einer Operation öfter wechseln mußten, die freigelegten Teile zu demonstrieren, wobei selbstverständlich auf das Wohl des Patienten stets strengste Rücksicht genommen wurde. Aus der Klinik Bardelebens mögen hier zwei Fälle mitgeteilt sein: Der elfjährige Sohn, einziges Kind eines Forstbeamten, wurde von seinem Vater der Klinik persönlich zugeführt. Der Vater hatte dem Knaben das Holzspalten beibringen wollen und dabei das Unglück gehabt, dessen linkes Kniegelenk durch einen Beilhieb zu verletzen. Flehentlich bat der besorgte Vater den Chirurgen Bardeleben, seinen Sohn zu retten, er wisse, wie gefährlich solche Wunden großer Gelenke seien. Bardeleben beruhigte den Mann; es werde sicherlich alles geschehen, was nötig sei, um die Wunde zum Heilen zu bringen. Das Bein wurde in ein Dauerwasserbad gelegt und die Wunde begann gut zu heilen. Schon nach einigen Tagen konnte dem Vater mitgeteilt werden, da $ß$ sein Kind außer Gefahr sei. Der kleine Patient verließ das Wasserbad und wartete die völlige Verheilung bei Bettlagerung ab. Bei einem der nächsten klinischen Besuchsgänge sah sich Bardeleben wieder die Kniewunde an und sagte zum Assistenten: ,, Geben Sie mir ein Messer, es ist da noch ein kleiner oberflächlicher AbszeB, den ich entleeren möchte." Der Knabe flehte und bat: „Nicht schneiden, nicht schneiden, Herr Professor!“ Bardeleben sagte: „Geben Sie ihm ein Paar Züge Chloroform" und wartete die beginnende Narkose ab. Mit einem Male setzte der Atem des Kindes aus; der den Puls überwachende Assistent meldete: ,Kaum fühlbarer Puls!“ Uns Alle befiel ein starrer Schreck. Bardeleben beugte sich über den Knaben, ich sah, wie sein Kopf hochrot wurde. Er sagte bestimmt, aber ruhig: ,Fenster öffnen! Chloroform weg!" Einer der Studierenden, ein Landsmann von mir, Niederleitner, der wegen seiner ungewöhnlichen Körperkraft bekannt war, öffnete das Fenster mit raschem Griff, ein frischer Luftstrom brach ein und siehe da, der kleine Patient tat wieder einen Atemzug, wir Alle aber mit ihm! Bardeleben machte schnell die kleine Ope- 
ration, alles ging gut. Als Bardeleben das Lager des Kleinen verließ, sah er etwas auf dem Boden liegen, hob es auf und sagte: „Nun, wer hat denn das fertig gebracht?" Niederleitner trat vor und sagte: „Ich." Es war der starke eiserne Griff des Fensters. Niederleitner hatte sich nicht erst die Zeit genommen, den Griff umzudrehen, sondern hatte das Fenster aufgerissen, wobei der Griff unter seiner herkulischen Kraft abgebrochen war. Bardeleben nickte ihm dankend $\mathrm{zu}$ und meinte lächelnd, das sei ein echt westfälischer Griff gewesen. - Der zweite Fall zeigte die ungeschwächte Lebenskraft eines alten pommerschen Recken, eines fast 9ojährigen Schiffers. Ihm mußte ein Oberschenkel amputiert werden. Nach Beendigung der Operation, die in der Klinik vorgenommen worden war, machte Bardeleben den üblichen Rundgang durch die Krankenzimmer und wir sahen den eben operierten Alten in fester Haltung in seinem Bette sitzen, seine Mahlzeit anscheinend mit bestem Appetit verzehrend. Bardeleben klopfte ihn auf die Schulter und fragte: „Na, Alterchen, schmeckt's denn schon wieder?" "Jo," erwiderte der, „Herr Professing, min Maag is jo nich krank!'،

Als Bardeleben in der Zeit meines Greifswalder Studiums Dekan war, wollten die Mediziner alle gern bei Promotionen als Opponenten hinzugezogen werden. Es war damals noch üblich, daß der Dekan dem Promovenden und den Opponenten vor dem Promotionsakte ein Frühstück geben mußte, und das Frühstück bei Bardeleben erfreute sich eines besonders guten Rufes. Zweimal kam ich in dieser Zeit dazu als Opponent gewählt zu werden; ich kann nur sagen, daß der gute Ruf berechtigt war.

In Pernice, der, ganz jung an Jahren, aus Halle, wo er klinischer Assistent und Privatdozent gewesen war, als Ordinarius nach Greifswald kam, war eine tüchtige frische Kraft und ein guter Lehrer gefunden. Gynäkologische Fälle wurden damals fast alle noch vom Chirurgen behandelt, falls sie operative Behandlung erheischten; es gab auch keine ,Frauenklinik“, sondern nur eine „Geburtshilfliche Klinik“. Die Erweiterung zu einer gynäkologischen oder Frauenklinik vollzog sich erst später, ganz allmählich; heute ist die chirurgische Behandlung der weiblichen Beckenorgane, zum Teil auch schon der Bauchorgane, größtenteils in die Hände der Frauenärzte übergegangen. Ich erwähne schon hier, daß Spiegelberg dazu bei- 
getragen hat, diese Erweiterung der Geburtshilfe zur gynäkologischen Chirurgie in Deutschland anzubahnen. Damals hatten wir in Greifswald nur geburtshilflichen Unterricht. Eine geburtshilfliche Operation habe ich aber dort auch nicht zu sehen bekommen. Nur durfte ich einmal einen Zangenlöffel anlegen, aber, wie Pernice ausdrücklich sagte, nur zur Belohnung dafür, da $B$ ich zwei Tage auf den Eintritt der Geburt hatte warten müssen. Die arme Patientin, die mir zur besonderen Beobachtung übergeben worden war, litt an Wehenschwäche und quälte sich schon zwei Tage damit herum, in Erwartung der Dinge, die da kommen sollten. Am dritten Tage verordnete Pernice ein warmes Bad und lauwarme Einspritzungen im Bade; da kamen die Wehen hinreichend stark, um die Geburt bei den ganz normalen Beckenverhältnissen, ohne jede Kunsthilfe, vor sich gehen zu lassen. Pernice legte dann den einen Löffel an und überließ mir den anderen, wie bemerkt, jedoch mit der ausdrücklichen Betonung, da $B$ hier die Anwendung der Zange nicht nötig sei.

Ein zweiter Fall, bei dem mir Pernice Teilnahme an einer geburtshilflichen Operation zugedacht hatte, war folgender: Ich wurde mitten in einer Nacht vom Diener der geburtshilflichen Klinik geweckt, ich möge schnell zu Professor Pernice kommen, ich solle mit ihm aufs Land zu einer von dort gemeldeten schweren Entbindung fahren. Rasch war ich zur Stelle in der Perniceschen Privatwohnung. Frau Pernice hatte für ihren Mann und mich schon eine Tasse Kaffee bereit, die nötigen Instrumente wurden in den vorgefahrenen Wagen verpackt und fort ging's in der Dunkelheit zu einem etwa zwei Wegstunden entfernten Dorfe. Wir kamen mit dem ersten Morgengrauen dort an. Voller Spannung, in der Erwartung eines Falles, bei der der Arzt und nicht die Hebamme einmal helfend und rettend eingreifen müsse, betrat ich das uns bezeichnete Bauernhaus. Wir fanden im Zimmer eine junge Person im Bett mit hochgerötetem Gesicht, offenbar schwer leidend, dabei die Mutter, einige Kinder und verschiedenes Federvieh. Pernice lie $B$ die Kinder und das Federvieh hinausschaffen und etwas Öl zur Vornahme der Untersuchung bringen, wăhrend ich die Instrumente bereit stellte. Pernice sagte mir, ich möge die erste Untersuchung vornehmen und ihm meinen Befund mitteilen. Ich tat, wie man bei der Annahme einer bevorstehenden Entbindung tun $\mathrm{muB}$, fand aber durchaus normale Verhältnisse, 
nichts, was auf eine bestehende Schwangerschaft oder gar bald zu erwartende Entbindung hinwies. Um mich nicht bloßzustellen, untersuchte ich so genau, wie ich konnte. Pernice, der sich über die Unentschlossenheit seines Schülers wunderte, trat hinter mich und fragte, ob ich nichts fände? Ich konnte nur erwidern, da $B$ ich in der Tat nichts fände. Peınice schritt dann sofort selbst zur Untersuchung, wandte sich aber gleich zur Mutter und sagte: "Ihre Tochter ist ja gar nicht in anderen Umständen." „Dat iss se ok nich,“ sagte ruhig die Mutter. Pernice wollte schon auffahren und sagen, weshalb schickt man denn zu mir?, faßte sich, aber schnell und sagte: "Ihre Tochter scheint sehr schwer krank," fragte die besorgte Mutter nach dem Nötigen, setzte sich dann ans Lager der Kranken, fragte sie, die nur mit Mühe antworten konnte, untersuchte sie genau und konstatierte einen Abdominaltyphus. Er gab die angezeigten Verordnungen und beruhigte die Mutter, indem er versprach, einen seiner Assistenten senden zu wollen. Kurz, er hinterließ bei beiden, Mutter wie Tochter, die Ansicht, da $B$ er der richtige Arzt sei, zu dem geschickt worden war, obwohl offenbar eine Verwechslung vorlag. Ich meldete den Fall in der inneren Klinik, von wo aus die weitere Behandlung geleitet wurde. Die Kranke genas glücklicherweise. Ich war wieder um einen operativen Fall gekommen, freute mich aber doch, daß ich mich nicht blamiert hatte.

Die erste geburtshilfliche Operation, wenn man von der überflüssigen halben Zange in Greifswald absieht, habe ich als Professor ordinarius in Breslau gesehen. Ich hatte im Obduktionsraume der dortigen Frauenklinik eine Autopsie vorgenommen und besprach in Spiegelbergs Arbeitszimmer mit ihm den Fall, als ihm gemeldet wurde, daß die diensttuende Hebamme eine Wendung bei einer Kreißenden für nötig halte. Spiegelberg bat mich, noch ein wenig zu verweilen, er werde gleich nach der Operation zurückkommen; darauf bat ich ihn, mich ins Kreißzimmer mitzunehmen, ich hätte noch nie eine Wendung gesehen. So kam ich denn dazu, einer regelrechten geburtshilflichen Operation beizuwohnen. Ich gestand mir dabei, daß, so geschickt ich auch diese Operation am Phantom auszuüben verstanden hatte, ich mich vielleicht an einer Lebenden das erste Mal etwas ungeschickt benommen haben würde. Ich halte noch immer einen möglichst eingehenden praktischen Unterricht in der 
Geburtshilfe, wo unter Umständen zwei Leben auf dem Spiele stehen, für eine der wichtigsten Aufgaben unserer ärztlichen Ausbildung. Es war nicht die Schuld von Pernice, wenn wir in Greifswald so wenig Gelegenheit gehabt hatten, geburtshilflichen Operationen beizuwohnen; das lag an der gesunden Landbevölkerung, aus der die in der Klinik Hilfesuchenden meist stammten.

Neben Niemeyer erteilten uns $Z i e m B e n$, der spätere berühmte Münchener Kliniker, und Liebermeister, der später in Tübingen weiter wirkte, Unterricht in der inneren Pathologie. Des vortrefflichen praktischen Kursus, den uns Liebermeister in den klinischen Untersuchungsverfahren gab, gedenke ich noch heute mit voller Anerkennung. Bei Bardeleben waren damals Schirmer, der Vater (für Augenheilkunde), und Heinecke tätig. Die Vorlesung über Augenheilkunde hielt Bardeleben selbst, nahm auch die augenärztlichen Operationen in der Klinik vor. Schirmer leitete die augenärztliche Poliklinik und gab die praktischen Übungskurse. Heinecke wurde später Ordinarius für Chirurgie in Erlangen. Es spricht für den guten Stand der damaligen medizinischen Fakultät in Greifswald, daß ihre jungen Kräfte so gern begehrt wurden, wobei es ein eigentümliches Zusammentreffen ist, da $B$ drei der genannten Lehrkräfte von der nordischen Universität sämtlich nach Süddeutschland gerufen wurden.

\section{Berlin.}

Berlin im Jahre 1861. - Im Hause meines Onkels. - Meine Lehrer: Reichert, Jüngken, v. Frerichs. - Doktorpromotion. - Medizinische Staatsprüfung. Medizinische Schlußprüfung. - Mein Examinator Ehrenberg. - Ernste Stimmung nach bestandener SchluBprüfung.

Zum Beginn des Sommersemesters I86I langte ich in Berlin an. Die jetzige Weltstadt hatte damals noch nicht ihren heutigen kosmopolitischen Anstrich, sie zählte rund 500000 Einwohner; jetzt das Vierfache. Für den inneren Verkehr dienten nur die jetzt verschwundenen Droschken zweiter Klasse; die Beleuchtung lie $B$ viel zu wünschen übrig Der Berliner Bürger lebte schlicht und recht, war sparsam und arbeitsam, wovon ich Gelegenheit hatte, mich in den zwei Wohnungen, die ich bezog, zu überzeugen. Ich wohnte zuerst in der Leipziger Straße bei einem Schneider, dann, um mit einem 
Freunde zusammen zu ziehen, in der Schumannstraße bei einem Tischler. Beide Männer arbeiteten tagsüber in größeren Werkstätten. Nach dem Abendessen gingen sie aber nicht aus, sondern arbeiteten zu Hause weiter. Ihre Frauen sorgten musterhaft für den Haushalt und auch für ihre Zimmermieter. Nur Sonntags am Nachmittag machte die Familie einen Ausflug ins Grüne dahin, wo „Familien Kaffee kochen konnten". Große Bierpaläste gab es noch nicht, die einfacheren Berliner Biere genügten allen Anforderungen, insbesondere die berühmte „Berliner Weiße“, die mit Recht ihren guten Ruf hat. Freilich, Gott sei's geklagt, sind sie in dieser Kriegszeit verwässert. Wir speisten damals zu Mittag recht gut für 60 Pfennige, dazu für Io Pfennige ein Glas Bier und Io Pfennige Trinkgeld; ebensoviel beanspruchte der Abend, wenn wir ausgingen, was aber nicht oft geschah. Blieben wir zu Hause, dann sorgte unsere Zimmerwirtin für uns, das kam dann viel billiger zu stehen. Ich habe die brave Frau, bei der ich in der Schumannstraße wohnte, später, als ich bereits Professor in Breslau war, bei einem Aufenthalte in Berlin noch einmal besucht und machte ihr damit eine große Freude.

Abends verkehrten wir, wenn wir ausgingen, gewöhnlich in einer Bierstube in der Nähe der Charité. Dort trafen wir häufig einen älteren Mediziner aus Schweden, der die Berliner Kliniken besuchte. Ziemlich regelmäßig entspann sich zwischen ihm und dem Kellner folgendes Gespräch: „Kellnär, Kellnär!‘“ Der Gerufene erschien. „Bringen Sie mir ein Beefsteak." Das Geforderte kam und wurde anscheinend mit großem Appetit verspeist. Nach einiger Zeit: „Kellnär, Kellnär !“ Der Mann im Frack kam: „Dieser Beefsteak war scheißlich, bringen Sie mir ein Omelett!" Das Omelett wurde gebracht und bis auf den letzten Rest verzehrt. Dann wieder: „Kellnär, Kellnär!“ Der Gerufene kam: „Dieser Omelett war scheißlich, bringen Sie mir der Dagblatt.“ Er las zu seinem Glase Bier ruhig die Zeitung, zahlte gut und ging, kam aber, trotz der Verurteilung, die er dem Beefsteak und dem Omelett hatte angedeihen lassen, immer wieder. Mehrere Male waren wir Zeuge einer ähnlichen Unterhaltung, so da $B$ wir schließlich, wenn uns etwas Unangenehmes widerfuhr, zu sagen pflegten: „Dieser Omelett war scheißlich.“"

Eine Annehmlichkeit für mich war, $\mathrm{da} B$ ich Sonntags fast regelmäßig in herzlichster Weise bei meinem Onkel Franz, von dem ich 
früher berichtete, da $B$ er ein so hohes Alter erreichte, als Gast aufgenommen war. Er bewohnte mit Frau und zwei Kindern, einem Sohne und einer Tochter, die etwas jünger waren als ich, eine Wohnung am Hafenplatz. Das Haus steht noch heute; ich kann nicht vorübergehen, ohne der Familie in Treue und Liebe zu gedenken. Der Sohn wurde Schauspieler, starb aber in jungen Jahren an Tuberkulose. Die Tochter, eine liebenswürdige, reizende Erscheinung, verheiratete sich mit einem gutgestellten Hamburger Kaufmann, Otto Kahlcke, in dem ich einen von uns Allen hochgeschätzten Verwandten und Freund gewann. Mein Onkel zog nach dem Tode seiner Frau zu ihm. Meine liebe Båse erkrankte in noch jungen Jahren an einem Unterleibskrebs. Ich besuchte sie noch auf ihrem Schmerzenslager in Hamburg, als ich IgoI meine erste Amerikareise antrat. Sie war gefaßt und lächelte leise, da ich ihr Trost und Mut zuzusprechen versuchte, als wollte sie sagen: „Du meinst es gut.“ Ich schied mit trüben Ahnungen. Ich sollte sie nicht wiedersehen. Ihr Gatte, mit dem ich in steter Verbindung blieb, überlebte sie nur wenige Jahre; er war einer der besten und edelsten Menschen, die mir im Leben begegnet sind.

Als ich mich in Berlin unter dem Rektorate des Theologen Twesten immatrikulieren ließ, fiel mir der etwas herrische, unangenehm berührende Ton auf, mit dem der damalige Universitätsrichter Lehnert, Bruder des Unterstaatssekretärs Lehnert im Kultusministerium, mit den Studierenden verkehrte. Das war ich weder von Göttingen noch von Greifswald her gewöhnt. Ich komme später auf diese Sache zurück.

Ich belegte Reicherts Vorlesungen über Entwicklungsgeschichte und allgemeine und vergleichende Anatomie, denen ich mich bauptsächlich widmete, dann noch die chirurgische Klinik bei Jüngken, die medizinische bei Frerichs und eine öffentliche Vorlesung über Diffusion bei du Bois-Reymond, um den berühmten Physiologen kennen zu lernen. Reicherts Vorlesungen machten mich zwar mit den mir bisher ziemlich fremden Gebieten der Zeugungs- und Entwicklungslehre sowie mit der vergleichenden Anatomie bekannt, befriedigten mich aber nicht, da ich die Kollegia Sterns, Wöhlers und vor allem Henles und Bardelebens gehört hatte. Reichert hatte eine wunderliche, oft zwar anregende, aber, ich möchte sagen, krause Art zu sprechen. Ich erinnere mich, da $\beta$ er eines Tages in der Vorlesung 
Meine Berliner Lehrer: Reichert.

über vergleichende Anatomie auf die chemische Beschaffenheit von Chitin und anderen tierischen Stoffen zu sprechen kam, bei denen zwischen den Chemikern Karl Schmidt in Dorpat und SchloBberger in Tübingen Meinungsverschiedenheiten bestanden, die Reichert erwähnte. Er fuhr dann fort in seinem ostpreußischen Dialekt, den er in unverfälschter Art sich bewahrt hatte, indem er ein recht großes Präparatenglas unter den vor ihm stehenden auswählte und in die Höhe hob: „Meine Herren, dies ist Karl Schmidt“; längere Zeit suchte er dann nach einem kleinen Glase und zeigte uns endlich eines der kleinsten: „Ich kann kein so kleines finden, wie ich wollte, dies ist Schloßberger !“ Mit ähnlichen Einfällen waren seine Vorträge gespickt; sie wirkten ja unterhaltend, aber nicht belehrend.

In der Entwicklungsgeschichte und vor allem in der allgemeinen Anatomie war er, der auf beiden Gebieten Arbeiten von hohem Werte aufzuweisen hat, seit seiner Dorpater Zeit nicht mehr vorwärts gekommen. Kölliker und Max Schultze waren ihm ein Dorn im Auge. Ich konnte mich nicht enthalten, als' er uns in seinem mikroskopischen Kursus, wobei aber nur fertige Präparate gezeigt wurden, einmal die Knötchen der Zungentonsille an einem Präparate von einer durch Kochen gehärteten Zunge sehen ließ und sie für Schleimdrüsen erklärte, zu bemerken, da $B$ ich sie für lymphatische Bildungen halte. Er verwies mich auf die eigentümlich glasige Beschaffenheit der betreffenden Bildungen, die auch an verschiedenen Stellen seitliche knospenförmige Vorwölbungen zeigten; das spräche doch für Schleimdrüsen. Ich erwiderte darauf, daß das doch auch auf das vorherige Kochen des Stückes zurückgeführt werden könne. Ich glaube nicht, daß mein Einwand Reicherts Meinung geändert hat. Ich kam auch mit ihm in wiederholte Disputationen über die morphologische Auffassung der tierischen Zellen, bei der Reichert hartnäckig an dem Schwannschen Schema festhielt. Einmal packte er mich, als wir in einem Flur des Anatomischen Institutes auf und ab wandelten und über diese Dinge sprachen, an beide Schultern, schob mich von sich ab und rief: „Ach, Sie sind auch so ein Ketzer wie der Schultze! Was kann man mit so einem Klümpchen Schleim, wie nach ihm eine Zelle sein soll, anfangen?" Ich meinte, man könne viel mehr damit anfangen, wenn dieses Klümpchen lebendiger Substanz frei sei, als 
wenn es eingesargt wäre in eine Membran. Reichert hat seine Meinung nicht aufgegeben. Wir blieben, trotz aller dieser Verschiedenheiten in unserer Auffassung vieler Dinge, im Ganzen guten Einvernehmens. Reichert gab mir einen Arbeitsplatz und Material für die Beendigung der Arbeiten an meiner Doktordissertation und bewies mir, wo er konnte, sein Wohlwollen. Es war überhaupt ein guter, anerkennenswerter Zug bei ihm, daß er sich seiner Schüler gern in freundlicher und fördernder Weise annahm. Wenn man Reichert beurteilen will, muß man auf seine frühere in Dorpat und Breslau verbrachte Zeit zurückgehen. Auch noch in den ersten Jahren seiner Berliner Tätigkeit hat er einige bedeutende Arbeiten geschaffen, so sein Werk über das menschliche Gehirn, über die Gehörschnecke und über eine junge menschliche Frucht im bläschenförmigen Zustande. Es war für ihn und seinen Ruf verhängnisvoll, da $\beta$ er $z u$ früh senilen geistigen Veränderungen unterlag, während er körperlich noch rüstig blieb und dadurch veranla $B t$ wurde, länger im Amte auszuharren, als für ihn gut war. Nur zu leicht bleibt dann in der Mit- und auch in der Nachwelt die Schattenseite des Lebens eines Mannes, der auf höherer Warte stand, in der Erinnerung erhalten und wirft ihr Dunkel auch auf die frühere lichte Zeit.

Gern hätte ich die chirurgische Klinik bei Langenbeck angenommen, sie lag aber für das Hauptziel, welches ich bei meiner Übersiedelung nach Berlin ins Auge gefaßt hatte, in der Zeit ungünstig, so daß ich, da mir noch ein chirurgisch-klinisches Semester fehlte, die Jüngkensche Klinik wählen mußte. Wie sie damals war, davon will ich lieber schweigen; es wäre auch viel besser für den alten Herrn gewesen, wenn er zehn Jahre vorher seinen Abschied genommen hätte. Gut wäre es für Manchen, wenn ihm ein treuer Freund zur Seite stände, der ihn darauf aufmerksam machte, daß es Zeit sei, aus dem Amte zu scheiden. Da mir in Reichert und Jüngken zwei Beispiele vor Augen standen, so habe ich in zwei Fällen, wo ich von dem Ministerialdirektor Alth off ersucht wurde, diesen Freundschaftsdienst zu übernehmen, eine so heikle Aufgabe dies auch ist, mich nicht geweigert, sie zu lösen. Althoff wünschte die Härte der Fälle nach Möglichkeit zu mildern und bat mich, dessen freundschaftliches Verhältnis zu den Betreffenden ihm bekannt war, diese zu veranlassen, selbst um ihre Versetzung in den Ruhestand einzukommen. Es gelang 
mir dies zu erreichen, ohne daß meine freundschaftlichen Beziehungen beeinträchtigt wurden. Ich bin sogar sicher, da $B$ beide Männer mir dankbar waren.

Frerichs hielt seine Klinik mehr in Vortragsform ab. Es war auch bei der großen Zuhörerzahl kaum anders möglich. Ich besuchte die Klinik als Praktikant und wurde zweimal in dem betreffenden Semester zur praktisch-klinischen Untersuchung aufgefordert. Um ein Bild von der Unterrichtsweise des großen Klinikers zu geben, versuche ich die eine dieser klinischen Stunden, in der ich tätig zu sein hatte, getreu zu schildern. Bevor Frerichs in den dichtgefüllten klinischen Saal eingetreten war, waren dort sechs oder sieben Betten mit Kranken aufgestellt, alles, wie sich bei der späteren Untersuchung herausstellte, Fälle von Pneumonie, aber jeder anders, in verschiedenen Stadien, mit verschiedenen Komplikationen und anderen Verschiedenheiten. Ich wurde nun aufgerufen, die einzelnen Kranken zu untersuchen, Frerichs trat mit mir an die Betten heran, ich mußte perkutieren, auskultieren, palpieren und ihm sagen, was ich fand. Meistens sagte es aber schon Frerichs selbst, der die Fälle ja kannte und nicht erst mehr zu untersuchen nötig hatte. Da nun begreiflicherweise dies alles für das übrige Auditorium, welches von den hinteren Reihen kaum die Kranken sehen konnte, äußerst langweilig war, so brach Frerichs bald damit $a b$, entlie $\beta$ mich auf meinen Platz und begann nun, auf einer Tischkante Platz nehmend, das Stethoskop in der Hand, mit dem er manchmal auf seine Oberschenkel schlug, seinen klinischen Vortrag über Pneumonie, an die gerade vorliegenden Krankheitsfälle anknüpfend. So kamen am folgenden Tage andere Krankheitsfälle heran, wenn möglich, stets mehrere Fälle derselben Art, was ja bei dem großen Material des Charitékrankenhauses meist geschehen konnte. Diese klinischen Vorträge von Frerichs waren Meisterstücke nach Form und Inhalt und gestützt durchweg auf eigenste reiche Erfahrung, wodurch sie besonders wirksam waren. Die Zuhörer lauschten denn auch mit gespanntester Aufmerksamkeit. Ich habe keine Stunde gefehlt, obwohl ich mir längst klar darüber war, daß ich niemals medizinische Praxis ausüben würde.

Die Möglichkeit sich gut auszubilden, diagnostisch wie therapeutisch, war, neben diesem großzügigen Unterricht in den klinischen Stunden, dadurch gegeben, daß die Assistenzärzte Unterrichtskurse 
gaben, daß unter ihrer Leitung und auch der des Klinikers selbst Untersuchungen der Kranken in den Krankensälen stattfanden und daß den Praktikanten einzelne Kranke überwiesen wurden, bei denen sie die Diagnose, Prognose und Behandlung festzustellen, tägliche Besuche zu machen und über den Verlauf der Krankheit öfters Bericht $\mathrm{zu}$ erstatten hatten. Solche Berichte dienten dann auch $\mathrm{zu}$ kritischen Besprechungen. Im Großen und Ganzen wird wohl so auch heute noch der klinische Unterricht an den deutschen Universitäten gehandhabt. Für die Schulung des angehenden Arztes zu seiner späteren praktischen Tätigkeit, namentlich bei minderbemittelten Patienten, halte ich eine gut geleitete Poliklinik mit reichlichem Krankenstand, wie größere Städte ihn bieten, für besonders wichtig. Und da haben tüchtige Assistenten, selbst gutgeschulte ältere Kommilitonen, deren Rat man als Jüngerer gern annimmt, oft mehr Einfluß auf die Ausbildung der Mediziner als die großen klinischen Lehrer selbst, denn denen ist es auch beim besten Willen unmöglich, selbst an kleineren Universitäten, sich um alles einzelne zu kümmern.

Von meinen Freunden traf ich nur den einen wieder in Berlin, den schon bei meiner Schilderung der Greifswalder Erlebnisse genannten Mediziner, Richard Hermes, gewann aber einen neuen fürs Leben, August Rheinstädter, einen Kölner, der später sich unter Spiegelbergs Leitung als Frauenarzt ausbildete und es in Köln zu einer geachteten Stellung brachte. Auch ihn deckt schon seit langem der grüne Rasen.

So kam nun die Zeit der medizinischen Endprüfungen heran; zunächst die Doktorprüfung, welche damals noch pflichtmäßig war und vor der letzten Prüfung, der medizinischen Staatsprüfung, abgelegt werden mußte. Ich hatte ein anatomisch-physiologisches Thema für meine Doktordissertation gewählt und völlig selbständig nach über ein Jahr lang fortgesetzten Untersuchungen bearbeitet: „,De Claviculae articulis et functione“, und hatte die Freude, mein bescheidenes Erstlingswerk im medizinischen Jahresbericht mit Anerkennung berüicksichtigt zu finden. Das mündliche Examen bestand ich mit zwei Kommilitonen im Hause des Dekans - es war der wohlbekannte Professor der gerichtlichen Medizin J. L. Casper - bei Torte und Wein, wie das damals üblich war. Außer dem Dekan selber prüften uns Reichert, Frerichs und Jüngken. Ich glaube gut geantwortet 
zu haben, während bei meinen beiden Prüfkollegen manche schlimme Lücke ihres Wissens zutage trat. So wußte der eine die Frage Reicherts, welche physiologischen Wirkungen der Speichel habe, nur sehr ungenügend zu beantworten, da ihm die Wirkung des Speichelferments auf Stärke gänzlich unbekannt war. Ich mußte aushelfen und nach einer ausgiebigen Antwort meinerseits schöpfte Reichert Mut und wagte die Frage an mich $2 u$ richten, wer denn diese Wirkung entdeckt habe? Auch das konnte ich beantworten. Noch schlimmer, wenn möglich, war die Lücke, die sich bei dem anderen meiner Mitprüflinge zeigte, der die Frage Jüngkens, was denn ein Abszeß sei, nicht $\mathrm{zu}$ beantworten wußte. Das war aber Jüngken doch $\mathrm{zu}$ arg; er sprang auf, stie $B$ seinen Stuhl auf den Boden und rief aus: „Das hätten Sie aber schon an den Kinderschuhen ablaufen müssen!“ Wir kamen alle drei durch; ich will auch nicht sagen, daß meine beiden Kommilitonen hätten durchfallen sollen, denn sie hatten eine ganze Reihe anderer Fragen richtig beantwortet; indessen war ich doch ein wenig verwundert, als ich am anderen Tage in der Universität unsere Diplome angeschlagen fand, jedes mit dem Prädikat „cum laude“. Das hat meinen Respekt vor dem Werte der Berliner Doktorprädikate, wie sie damals erteilt wurden, nicht erhöht.

Damals war es, wenigstens in Berlin, noch üblich, da $\beta$ man vor der Zulassung zur eigentlichen Doktorprüfung, dem Examen rigorosum, wie es ähnlich wie ,lucus a non lucendo" hieß, beim Dekan das sogenannte Tentamen medicum, eine Art Vorprüfung, zu bestehen hatte, wahrscheinlich, um Kandidaten mit zweifelhaftem Wissen nicht erst zur Hauptprüfung zuzulassen. Der Dekan stellte einige Fragen und gab jedem ein Thema, welches er auf der Stelle, im Hause des Dekans, schriftlich zu bearbeiten hatte. Es waren einige Stunden Zeit dazu gegeben, während der einige Erfrischungen in Gestalt belegter Brötchen mit einem Glase Wein gereicht wurden. Wir waren drei oder vier Kandidaten zum Tentamen; es ging auch alles glatt, nur bemängelten wir, da $B$ wir nicht noch ein paar von den leckeren Brötchen, die Casper uns mit gutem Wein hatte vorsetzen lassen, mehr bekommen hatten.

Da Casper gerade verhindert war, so kam es, daß ich zu meiner Freude den Doktorhut aus Reicherts Hand empfing. Dabei kam ein ergötzlicher Zwischenfall vor. Vor mir wurde als erster ein Lands- 
mann, der Doctorandus Venn, promoviert. Zufällig war die Tür, die durch eine kleine Schranke zum oberen Katheder führte, den man nach der Promotion zur Empfangnahme des Diploms besteigen mußte, nachdem sie Reichert durchschritten hatte, wieder verschlossen worden. Als Reichert nun Venn promoviert hatte und ihn mit den Worten: „Ascendas nunc in Cathedram majorem, quae est Doctorum" aufforderte, $\mathrm{zu}$ ihm auf den oberen Platz zu kommen, ließ sich die Türe nicht öffnen. Reichert winkte dem Pedellen, aber Dr. Venn, ein gewandter Turner, wartete nicht erst den Pedellen ab, sondern schwang sich, kurz entschlossen, über die Brüstung und erschien vor dem erstaunten Reichert, der inzwischen nach dem Pedellen ausgeschaut hatte, mit einer feierlichen Verbeugung. Selbst Reichert hatte Mühe, seiner Heiterkeit Herr zu werden.

Tags darauf reiste ich, mit neuen Besuchskarten als Dr. med. schon versehen, in die Heimat, um dort die Ferien vor der Staatsprüfung in ähnlich froher Stimmung zu vollbringen, wie damals, als ich vom Gymnasium zur Universität überging.

Als ich im Oktober I86I zur Ablegung der letzten Prüfung wieder in Berlin eintraf, war gerade König Wilhelm I. mit seiner Gemahlin, der Königin Augusta, von der Krönungsfeier in Königsberg nach dem Berliner alten Königsschloß zurückgekommen. Ich wohnte der Huldigung des Monarchen seitens der Berliner, die er vom Altan des Schlosses entgegennahm, bei. Es war ein erhebender Anblick, die Tausende und Abertausende vor dem Schlosse ihrem Herrscherpare begeistert zujubeln zu sehen. Mir und sicher vielen unter denen, die da standen, kam das Vorgefühl einer neuen Zeit, die über Preußen und Deutschland herankommen werde. Sie ist gekommen und jetzt standen wir seit vier Jahren in Waffen, um das, was sie uns gebracht, zu wahren, und haben es verloren!

Die Staatsprüfung umfaßte damals zunächst Anatomie und Physiologie, die aber, allerdings von zwei Examinatoren, an einem Tage mündlich geprüft wurden. Man ging zum festgesetzten Termine erst zu Reichert, demonstrierte das vorher angefertigte Präparat - nur ein Messerpräparat; mikroskopische Präparate wurden damals noch nicht gefordert - und wurde dabei mündlich geprüft; dann ging's zu du Bois-Reymond gleichfalls nur zur mündlichen Prüfung. Es gab eine bestimmte Anzahl Themata nach Nummern geordnet; das 
Thema für jeden Kandidaten wurde durch Losen ermittelt. Da die Themata gedruckt vorlagen, so war es natürlich, da $B$ man sich zur Vorbereitung für das Examen die einzelnen Themata gehörig, wie man sagt, ,einpaukte“. Freilich war es dem Examinator freigestellt, auch bei der Demonstration des Präparates Fragen zu stellen, ebenso nach dem Vortrage über das Thema, so da $B$ er sich doch überzeugen konnte, ob der Kandidat nur etwas auswendig gelernt habe oder etwas ,wisse“.

Nach bestandener Prüfung in diesen beiden Fächern war die Reihenfolge der übrigen: Innere Medizin, Chirurgie, Geburtshilfe frei. Dann kam noch das Schlußexamen. Es war also die damalige Prüfung viel einfacher als die jetzige, wo für mikroskopische und allgemeine Anatomie sowie für Physiologie ein besonderer Prüfungstermin besteht, wo außerdem noch in Pathologischer Anatomie, Kinderkrankheiten, Augenkrankheiten, Nervenkrankheiten, Pharmakologie und Hygiene besonders geprüft wird, während das Schlußexamen, das freilich mehr eine Komödie war, weggefallen ist.

Mir erging es in den meisten Fächern gut, nur in der inneren Medizin wäre ich, und ich muß gestehen mit Recht, aus Nachlässigkeit bei der Untersuchung eines der mir zugewiesenen Fälle, beinahe durchgefallen. Mich rettete damals die Pathologische Anatomie, deren Pflege meinerseits mir hier zum ersten Male fördernd wurde. Meine Examinatoren waren Frerichs und der ältere Quincke. Für Frerichs, der sich meistens vertreten ließ, prüfte der zur Charité kommandierte damalige Stabsarzt Dr. Kühne. Ich bekam von ihm einen Kranken zugeteilt, den ich am Abend bei mangelhafter Beleuchtung untersuchte. Ich brachte heraus, da $B$ er Alkoholiker war und deliriert hatte. Da war ich mit meiner Diagnose - ich weiß heute selbst noch nicht, wie ich dazu kam - ohne weitere physikalische Untersuchung, fertig. Am andern Morgen sollte ich meinen Fall dem Examinator vorstellen und weiter geprüft werden. Siegesgewiß kam ich mit meiner Diagnose: "Delirium tremens ex abusu alcoholis“" heraus. Dr. Kühne sagte nichts als: „,Wollen Sie einmal perkutieren!“ Ich tat das und konstatierte auf der einen Brusthälfte eine untere absolute Dämpfung. Ich bekam keinen geringen Schrecken, zumal ich gestehen mußte, da $B$ ich die Perkussion unterlassen hatte. Ich wurde nicht weiter geprüft, während in den nächsten Tagen die 
Prüfung der übrigen sechs Kandidaten, die mit mir im Termine waren, ihren Fortgang nahm. Am letzten Prüfungstage stellten wir uns Alle noch einmal zur Prüfung; ich stand, wie gewöhnlich nach meinem verunglückten Anfange, in der Überzeugung, da $B$ ich aufgegeben sei, am Ende der Reihe. Da fragte Dr. Kühne nach pathologisch-anatomischen Befunden bei verschiedenen Krankheitsprozessen, unter anderm auch bei der Pneumonie. Er fragte den ersten, den zweiten und dritten und so weiter, Niemand wußte etwas Ordentliches zu sagen. Nun kam mein Vormann an die Reihe, der gar nichts zu sagen fand. Ich reckte mich etwas, um mich bemerklich zu machen, indem ich dachte, jetzt darf er dich doch nicht übergehen, und richtig, ich wurde gefragt. Nun war ich in meinem Fahrwasser und entwickelte dem Examinator, meiner Meinung nach gut, die pathologischanatomischen Befunde bei den verschiedenen Formen der Pneumonie. Nach Schluß meiner Darlegungen sagte Dr.Kühne, indem er die Anderen entlie $B$, ich möge noch ein wenig zurückbleiben. Er lie $B$ mich dann noch in seiner Gegenwart drei Diagnosen an beliebig ausgewählten Fällen stellen, die mir alle drei gelangen, worauf er mir sagte, da $B$ ich meinen Fehler vom ersten Tage gut wett gemacht habe und er sich freue, mich als bestanden erklären zu können. Ich habe dem damaligen Stabsarzt Kühne, der sich bei dem ganzen Examen als ein strenger, aber gerechter und in der Form angenehmer Examinator erwies, stets ein hochachtendes Andenken bewahrt.

Bei der Prüfung durch Quincke ging es mir gut. Eine etwas komische Szene ist mir aus dieser Prüfung im Gedächtnis geblieben. An einem der Prüfungstage sagte Quincke, da $\beta$ er heute einmal in lateinischer Sprache prüfen wolle; es sei doch mitunter erwünscht, wenn die Ärzte sich bei einem Consilium in einer Sprache verständigen könnten, die man bei den meisten Patienten als unbekannt voraussetzen dürfe. Und er fing an ganz leidlich lateinisch zu reden. Wir schoben unvermerkt unseren Kommilitonen Dr. Veit aus Köln vor, von dem wir wußten, daß er ein guter Lateiner war. Quincke wendete sich auch an ihn mit einer Frage. Nequa quam! antwortete Dr. Veit, vortretend, mit fester Stimme und fuhr nun in einer lateinischen Rede fort, die die Quinckesche an Gewandtheit weit übertraf. Als Veit geendet hatte, dem Quincke erstaunt zuhörte, sagte dieser deutsch, er freue sich sehr, zu erfahren, da $B$ die edle lateinische Sprache 
bei der medizinischen Jugend noch gepflegt werde und fuhr fort 'zu examinieren, aber in deutscher Sprache! Dr. Veit und ich waren gute Bekannte geworden; wir hatten mit Freund Rheinstädter, dessen ich vorhin gedachte, viel zusammen gearbeitet. Veit wurde ein angesehener Arzt in Köln, wo er leider früh verstarb.

Im Anfang März I 862 unterzog ich mich mit etwa acht bis zehn Kandidaten der Schlußprüfung. Obwohl man bis dahin in allen Fächern bestanden hatte, wurde man nun noch einmal in allen kurz mündlich geprüft, und auch noch in einigen naturwissenschaftlichen Fächern; in diesen prüfte damals Ehrenberg. Man wußte ja, daß von einem Durchfallen nicht die Rede war und auch kaum sein konnte, da man doch schon vorher in diesen sämtlichen Fächern die Zensur „,bestanden“ erhalten hatte. Diese Prüfung war offenbar als ein alter Zopf aus früheren Zeiten, wo sie vielleicht einmal Bedeutung gehabt hatte, übrig geblieben. Es dauert gewöhnlich länger als gut ist, bis man solche veraltete Dinge in den Rumpelkammern verschwinden läßt. Es wäre auch vielleicht ganz angebracht, wenn von Staatswegen eine besondere Kommission eingesetzt würde, die von Zeit zu Zeit zu prüfen hätte, ob nicht eine Anzahl Gesetzesparagraphen oder Verwaltungs- und Polizeiverordnungen zu streichen wären.

Nun, bei dem Schlußexamen, welches ich abzulegen hatte, ging es zu, wie zu erwarten war. Die aus der Anatomie, Physiologie und aus den klinischen Fächern gestellten Fragen wurden leidlich beantwortet, aber bei dem alten würdigen Ehrenberg in der Botanik und Zoologie ging's sehr dürftig, so da $B$ man ihm bald anmerkte, da $B$ er nur mit einer gewissen Ängstlichkeit seine Fragen stellte. Nach einigen Mißerfolgen sagte er dann meinem Vormanne, er möge ihm irgendein Tier nennen, von dem er etwas wisse. Mein Nachbar antwortete: „Der Löwe.“ „Gut!“ sagte Ehrenberg, ,,was wissen Sie denn vom Löwen?" Kühn antwortete der Gefragte: „Der Löwe ist ein Raubtier" und schwieg. „Nun,“ fragte Ehrenberg weiter, „was wissen Sie denn sonst von ihm?" Mein Vormann dachte eine Weile nach und sagte: , Ja! er hat sehr große Zähne und das ist auch von medizinischem Interesse, denn er kann dem Menschen schwere Verwundungen beibringen." Auf weitere Fragen, nach zoologischen Merkmalen, reagierte mein Nachbar nicht mehr viel. Dann wandte sich Ehrenberg ganz verzweifelt an mich und ersuchte mich, ihm 
irgendein Tier zu nennen, von dem ich etwas wisse. Ich bat ihn darauf, er möge mir selbst ein Tier nennen oder eine Tiergruppe, über welche er Auskunft wünsche. Ehrenberg zögerte eine Weile, als ob er dem Gehörten nicht recht traue, dann sagte er: ,,Gut denn, bleiben wir bei den Raubtieren." Als ich ihm nun zufriedenstellende Auskunft geben konnte, erheiterte sich sein ganzes Wesen; er wurde kühn und fragte, ob ich auch etwas von wirbellosen Tieren wisse. Ich konnte dies bejahen und so stellte er mir nur noch einige Fragen aus diesem Gebiete, die ich glatt beantwortete. Ich hatte mich ja bei meinem Vorhaben, Anatom $\mathrm{zu}$ werden, schon seit Jahren eifrig mit Zoologie und vergleichender Anatomie beschäftigt und war daher meiner Sache sicher. Es machte Ehrenberg offenbar Vergnügen, auch einmal Antworten zu bekommen und nicht mit einem vollständigen Mißerfolge aus dieser Prüfung zu scheiden. Mich freute es, bei dieser Gelegenheit die Bekanntschaft des berühmten Mannes gemacht und ihn zufriedengestellt zu haben.

Wie war mir zu Mute, als ich damals nach beendigtem Examen an dem schon dunklen Märzabend auf die Straße trat? Nicht froh, ernst war meine Stimmung. Ich sagte mir, da $B$ nun die frisch-freifrohe Studentenzeit ihr Ende erreicht habe und der Ernst des Lebens beginne. Im Gespräch mit meinen Freunden verweilte ich noch eine kurze Zeit; früh ging ich heim und zur Ruhe. Am anderen Tage verließ ich Berlin, nicht ahnend, daß ich es dereinst, nach erreichtem Ziel, zu dauerndem Wohnsitz wiedersehen solite.

Für meine nächste Unterkunft hatte sich mir während der Prüfungsmonate in Berlin ein Platz gefunden. Dr Klebs, damals Assistent bei Rudolf Virchow, hatte von seinem früheren Lehrer Professor v. Wittich, Physiologen in Königsberg, Auftrag erhalten, ihm in Berlin einen Assistenten zu besorgen. Er hatte mich kennen gelernt und wußte, da $B$ ich nach einer Stellung suchte, die mir Gelegenheit bot, mich weiter in der Anatomie und Physiologie auszubilden, um dem Berufe eines Universitätslehrers zuzusteuern. So teilte er mir dann den Auftrag v. Wittichs mit und riet mir, die Assistentenstelle anzunehmen. Ich wäre zwar lieber Assistent an einer anatomischen Anstalt geworden; aber ich sagte mir, es sei wesentlich, nicht erst zur medizinischen Praxis überzugehen, sondern zu nehmen, was mich dem erstrebten Berufe näher brächte. v. Wittich v. Tralde yer-Hartz, Lebenscrinnerungen. 
hatte übrigens auch den Unterricht in der Histologie zu vertreten; außerdem befand sich die physiologische und die anatomische Anstalt Königsbergs in einem und demselben Gebäude, und so hoffte ich Gelegenheit $\mathrm{zu}$ finden, mich auch in allen Zweigen der menschlichen Anatomie weiterzubilden. Ich nahm also die Stelle an mit Bewilligung meiner Eltern, die ich um so mehr erbitten mußte, als mein festes Einkommen in Königsberg nur I50 Taler jährlich betrug, ich also auf weitere Zuschüsse angewiesen war.

\section{Kapitel.}

Universitäts-Dozentenjahre: Wanderjahre.

I. Königsberg.

Freundliche Aufnahme in der Universität. - Förderung durch die Pathologische Anatomie. - Assistententätigkeit bei Professor v. Wittich. - Erste anatomische Vorlesung. - Erlebnisse mit Papageien; etwas über Tierpsychologie. Eigene Erfahrungen mit Äther- und Chloroform-Narkose. - Der Anatom August Müller. - Meine Verlobung.

Anfang Mai 1862 traf ich in-der alten Preußenstadt am Pregel ein. Bei schönstem Frühlingswetter, mein Auge noch an den schön blühenden Rapsfeldern weidend, hatte ich Westfalen verlassen, auf der Fahrt durch die eintönige Landschaft Westpreußens begleitete mich Schneegestöber. Im Wittichschen Hause fand ich gleich die beste Aufnahme, die im Laufe der Zeiten zu herzlicher Freundschaft führte. Mein Dienst bestand in den Vorbereitungen für die Vorlesungen, in der Sorge für das Inventarium und die Laboratoriumsbestände, in der Hilfe bei den Arbeiten v. Wittichs und denen der Laboranten. Unter diesen befand sich damals ein älterer Student, Freund des Wittichschen Hauses, Max Cohn aus Elbing, mit dem ich bald Freundschaft schloß. Das wurde eine Freundschaft fürs Leben. Albert Kayser, Joseph Koch, Leonhard Landois, Richard Hermes und Max Cohn, der später in Wiesbaden unter dem Namen Conrady einer der angesehensten Ärzte war, sind meine treuesten und besten Freunde aus der Jugendzeit geblieben, und durch die Beziehungen zu mir auch selbst einander näher gekommen: die Katholiken, der Protestant und der Jude; oft haben religiöse 
Freundliche Aufnahme in Königsberg. Meine Verlobung.

Fragen den Gegenstand unserer ernsten Gespräche gebildet. Alle fünf sind schon seit Jahren verstorben, zuletzt der mir zuerst bekannt gewordene Hildesheimer Joseph Koch; aber ich unterhalte mit ihren Hinterbliebenen nach wie vor den freundschaftlichen Verkehr.

Ich wurde in Königsberg bald heimisch. Es ist einer der Vorzüge dieser Stadt, da $B$ man als neuer Ankömmling freundlich aufgenommen wird und $\mathrm{da} B$, wenn das Gefallen auf Gegenseitigkeit beruht, es in Treuen bestehen bleibt. Der Verkehr in den Familien, in denen ich bald Zutritt fand, war ein äußerst angenehmer, entwickelte sich frei und ungezwungen; man merkte und wußte, da $B$ man gern gesehen war. Besonders angenehm empfand ich es, da $B$ ich als noch nicht zum Lehrkörper der Universität gehöriger Assistent und junger Mann bald zu den Kreisen der Ordinarien der Universität Zutritt fand. So wurde ich in einen Kegelklub aufgenommen, in welchem mehrere Universitätsprofessoren Mitglieder waren, verkehrte im Hause des damaligen Chirurgen Albrecht Wagner, in den Familien Hirsch, des inneren Klinikers, wurde Mitglied der Gesellschaft des Börsengartens und kann noch heute sagen, da $B$ die zwei Jahre, die ich in Königsberg zubrachte, zu den angenehmsten meines Lebens gehört haben, wozu freilich das Meiste beitrug, daß ich dort glücklicher Bräutigam wurde. Dabei hat, freilich gänzlich unbeabsichtigt, mein Freund Cohn die Veranlassung gegeben. Das kam so: Wir Beide waren von der Gesellschaft junger Kaufleute in Königsberg zu einem Ball eingeladen worden, den diese Gesellschaft jeden Win: ter zu geben pflegte und der zu den besten Veranstaltungen dieser Art in Königsberg gerechnet wurde. Wir nahmen die Einladung an und gingen zusammen hin. Der Ball hatte schon begonnen und wir betraten einen der Nebensäle, wo sich die gerade am Tanze nicht Teilnehmenden und die älteren Familienmitglieder befanden. Da sagte Cohn, der die Gesellschaft überschaut hatte, zu mir: „Da sehe ich die Frau Geheimrat Dillenburger am Tische sitzen, sie hat mich schon gesehen; ich bin in ihrer Familie eingeführt, habe aber leider nach meiner letzten Einladung noch keinen Besuch gemacht und fühle mich in Schuld. Darf ich dich ihr vorstellen? Das lenkt ab." Gesagt, getan! Nichts ahnend nahm ich an der Seite meiner künftigen Schwiegermutter Platz; Cohn setzte sich zum Ge- 
heimrat Dillenburger, entschuldigte seine Versäumnis und bald war eine unbefangene Unterhaltung im Gange. Kurz darauf trat die Tochter des Hauses, von ihrem Tänzer geführt, strahlend in jugendlicher Frische und Schönheit, zu ihren Eltern und mein glückliches Geschick fürs Leben war besiegelt. Ein Tanz mit der Tochter war zwar nicht mehr zu erlangen; wenn sie auf den Bällen erschien, war in den nächsten Minuten die ganze Tanzkarte vergeben. Auch hielt ich mich mit der Bitte etwa um eine Extratour zurück, weil ich das für eine erste Begegnung nicht für passend hielt, außerdem mir bewußt war, daß zwar Euterpe meine Freundin, Terpsichore $\left(^{8}\right)$ aber mir ungnädig gesinnt war. Doch folgte ich dem guten Rate:

,Wer sich gut mit Muttern steht,

Dem die Tochter nicht entgeht",

und widmete meine Aufmerksamkeit vorzugsweise meiner Nachbarin. Die halbe Landsmannschaft, die zwischen den Rheinländern - Frau Dillenburger stammte aus Bonn - und Westfalen besteht, half und als ich mich empfahl, wußte ich, daß ich meine Besuchskarte mit dem Erfolg, in der Familie Zutritt $\mathrm{zu}$ finden, abgeben dürfte. So war es denn auch. Im Jahre darauf waren wir verlobt; aber erst zweieinhalb Jahre später hatte ich die Stellung errungen, die mir gestattete, meine Braut als Gattin in das neu zu gründende Heim einzuführen.

Unser Ehebeginn war ein schwerer, er fiel in das Kriegsjahr I866, wo wir in Breslau, nahe dem Kriegsschauplatze, unseren Wohnsitz hatten und, im Gefolge des Krieges, eine der furchtbarsten Choleraepidemien mitzuerleben hatten, bei der ich als Pathologischer Anatom durch mehrfache tägliche Obduktionen von Choleraleichen steter Gefahr ausgesetzt war. Aber alles ging gut, obwohl in dem Hause, wo wir wohnten, zahlreiche Choleraerkrankungen mit sieben Todesfällen vorkamen. Vierundvierzig Jahre war mir die Erwählte meines Herzens treueste Gattin und beste Mutter und Erzieherin unserer Kinder. Im Jahre I9Io bereitete ein Herzschlag ihrem Leben ein gänzlich unvorhergesehenes rasches Ende. -

Meine Verlobung griff auch bestimmend in mein weiteres Schicksal ein, ebenso wie meine in Greifswald erworbene Kenntnis der $\mathrm{Pa}$ thologischen Anatomie. Diese hatte mir auch bald in Königsberg 
eine gewisse Stellung verschafft. In Königsberg war noch keine Professur für Pathologische Anatomie vorhanden. Man hatte im Bedürfnisfalle zur Untersuchung pathologischer Objekte, wie Geschwülste und anderer bei klinischen Sektionen, welche von den Assistenten gemacht wurden, gefundener, zweifelhaft gebliebener Dinge sich an v. Wittich gewendet, dem die Sache, die von Jahr zu Jahr mehr Zeit in Anspruch nahm, lästig geworden war. Es war eine seiner ersten Fragen an mich, als ich sein Assistent geworden war, ob ich mich in der Pathologischen Anatomie hinreichend bewandert fühle, um ihm diese Untersuchungen abnehmen zu können. Ich glaubte das bejahen zu dürfen. Ich gab mir Mühe, erstattete den Klinikern und Ärzten stets genaue schriftliche Berichte, demonstrierte ihnen auf Wunsch Präparate und so verging nur kurze Zeit, bis ich vollauf damit zu tun hatte. Dann wurde ich auch ersucht, klinische Obduktionen zu machen und einer Anzahl Königsberger Ärzte praktische Kurse in Pathologischer Anatomie zu halten, wobei unter Anderen auch der Ordinarius der Chirurgie, Wagner, mein eifriger Hörer war. Damals kam auch die Trichinenschau auf, die mir übertragen wurde. Dieses alles brachte mir bald eine willkommene Ergänzung zu meinem bescheidenen Gehalte, so daß ich zu meiner größten Freude meinen Eltern schreiben konnte, ich sei in der Lage, ihrer Unterstützung nicht mehr zu bedürfen. Daneben förderte ich aber meine anatomischen Kenntnisse durch pflichtmäßige Beschäftigung mit der Gewebelehre und mikroskopischen Anatomie sowie mit der beschreibenden Anatomie durch die nachbarlichen Beziehungen, die sich mit Professor August Müller, dem damaligen Leiter der Anatomischen Anstalt und dessen Prosektor Friedrich Goltz, meinem späteren Kollegen in Straßburg, entwickelten. Goltz und ich hätten gern getauscht, denn Goltz zielte auf die Physiologie und ich auf die Anatomie. Es ließ sich das aber aus materiellen Gründen nicht machen, weil Goltz auf sein auskömmliches Prosektorgehalt angewiesen war. Ich komme auf Beide noch zurück. Auch die Beschäftigung mit der mikroskopischen Anatomie gab mir einige Mittel, indem ich Kurse für die Studierenden geben durfte. Meine erste Vorlesung in diesem Fache und erste akademische Vorlesung überhaupt, entsprach genau dem alten Satze: „Tres faciunt Collegium!“ 
Ich hatte drei Zuhörer; unter diesen befand sich Oskar Liebreich, mein späterer Berliner Kollege.

So ließ sich alles gut an in Königsberg, bis auf den Umstand, da B damals der streng protestantische Charakter der Universität noch aufrecht erhalten wurde, dem zufolge keine Dozenten anderer Bekenntnisse zugelassen werden durften. Ich, als Katholik, konnte dort also nicht weiterkommen. Da kam mir meine Verlobung zu Hilfe. Mein Schwiegervater, Provinzialschulrat für die katholischen höheren Lehranstalten Ost- und Westpreußens, hatte sich selbstverständlich auch um mein Vorwärtskommen gekümmert und bei seinem früheren Schüler, dem Professor theologiae Reinkens in Breslau, dem späteren ersten altkatholischen Bischofe, angefragt, ob ich etwa in Breslau eine Stellung finden könne. Da war mir wieder das Glück günstig. Reinkens sprach darüber mit dem ihm gut bekannten Physiologen Heidenhain, bei dem gerade eine Assistentenstelle frei geworden war. Dieser, dem ich dem Namen nach, da ich inzwischen einiges veröffentlicht hatte, nicht unbekannt war, war gern bereit, mich zu übernehmen und auch zu vermitteln, da $B$ mich die Fakultät zur Habilitation als Privatdozent zuließ. So kam ich denn im Frühjahr I864 nach Breslau.

Ehe ich von meinen dortigen Wanderjahren erzähle, mag noch einiges aus Königsberg hier Platz finden. Ich wohnte bei einer älteren Dame, Fräulein Kriele, einer Freundin des Wittichschen Hauses, die mütterlich für mich sorgte. So wohl ich bei ihr und ihrer Dienerin gelitten war, so verhaßt war ich bei dem Dritten im Bunde, einem Papagei, den sie seit vielen Jahren besaß. Zur Charakteristik dieser merkwürdigen Vögel mag hier das zwischen uns bestehende feindselige Verhältnis, das mich viel mit Versuchen, es zu begreifen, beschäftigt hat, kurz besprochen sein. Jedenfalls war es völlig einseitig, denn sowohl Fräulein Kriele, wie ich, bemühten uns, das Tier in freundlichere Gesinnung gegen mich zu bringen. Die Abneigung des Papageien gegen mich bestand vom ersten Augenblick an, als er mich sah. Oft habe ich versucht, ihn durch Darreichung seiner Lieblingsleckereien zu versöhnen, er nahm nichts von meiner Hand. Morgens pflegte ich das Frühstück im Zimmer der Dame mit ihr zusammen einzunehmen. Sie setzte dann den Vogel auf den Tisch und reichte ihm von den ihm angenehmen und zuträglichen Sachen, die 
er aus ihrer Hand nahm. Dabei hielt er sich stets in respektvoller Entfernung von mir. Versuchte ich ihm etwas zu reichen, so wich er zurück, hackte auch wohl nach meiner Hand oder schrie mich böse an. Fräulein Kriele zeigte ihm öfter ein Stück Zucker und wenn er sich näherte, um es zu nehmen, gab sie es mir, da $B$ ich es ihm reichen möchte; er nahm es aber niemals von mir an, selbst wenn ich es auf den Tisch legte, rührte er es nicht an. Da mußte Fräulein Kriele einmal auf vier Wochen verreisen; sie empfahl mir, für den Vogel zu sorgen, was ich auch sehr gern übernahm, neugierig, zu sehen, wie er sich nun benehmen würde. Am andern Morgen war der Frühstückstisch, wie gewöhnlich, hergerichtet. Ich stellte den Vogelkäfig, so wie es Fräulein Kriele machte, auf den Tisch und öffnete ihn. Der Papagei kam nicht heraus, solange ich in der Nähe blieb; erst als ich mich auf meinen gewohnten Platz setzte, kam er heraus, hielt sich aber möglichst von mir fern. Wenn ich ihm etwas reichen wollte, wich er zurück, hackte aber nicht nach mir und schrie mich auch nicht an. Wenn ich nun den Bissen in der Nähe des Käfigs auf den Tisch legte und mich wieder auf meinen Platz begeben hatte, nahm er ihn. Auf diese Weise versuchte ich es jeden Tag ein paarmal, ihn den Bissen aus meiner Hand nehmen zu lassen, in der Erwartung, da $B$ er endlich einsehen würde, ich wolle nur Gutes, aber vergebens. Das Tier nahm sein Futter entweder nur im Bauer oder vom Tische, wenn ich mich fern hielt. Er nahm es aber jetzt in Abwesenheit seiner Herrin, obwohl ich es in der Hand gehalten hatte, was er früher nicht tat. Fräulein Kriele kam an einem Abend von ihrer Reise zurück und ich begrüßte sie erst am anderen Morgen. Der Vogel befand sich in Freiheit auf dem Fußboden des Zimmers. Sobald ich eintrat, fuhr er schreiend auf mich los und biß wütend in meine Stiefel, so daß Fräulein Kriele ihn fortnehmen mußte. Ich konnte mir diese Wutäußerung nur so deuten, da $B$ das Tier mir zeigen wollte, es habe so lange zwangsweise sich mir, dem Verhaßten, fügen müssen, jetzt sei seine Schützerin wieder da, jetzt lasse er mich das büßen. Ob ich damit in das Papageienherz den richtigen Einblick getan habe? Immerhin scheint mir das bis zur äußersten Folgerichtigkeit gehende Verhalten des Tieres sehr bemerkenswert.

Noch ein anderer Papagei, den ich später in Berlin selbst besa $B$ und der mir keineswegs feindselig war, spielte mir dennoch einst 
sehr übel mit. Ich hatte eines Abends einige Herren bei mir zu Gast geladen und wir waren nach Tisch noch bei einem Glase Wein in dem Zimmer zusammen, in welchem der Papagei, ein vorzüglicher Sprecher, in seinem Bauer sich befand. Ich erzählte meinen Gästen eine längere Geschichte. Als ich geendet hatte, ertönte aus der Ecke, wo der Papagei in seinem Bauer saß, laut mit klarster Deutlichkeit das Wort "Quatschkopf"! Ich hatte meine Zensur weg und für allgemeinste Heiterkeit war gesorgt.

Ungeachtet dieser beiden üblen Erfahrungen sind mir die Papageien immer sehr gern gesehene, merkwürdige Geschöpfe gewesen. Ihr Zentralnervensystem ist ja mehrfach untersucht worden, verdiente aber noch weitere Erforschung, namentlich mit Rücksicht auf die Verbindung zwischen ihren Gehörnerven und der Innervation ihrer lautgebenden Organe. Es ist erstaunlich, wie genau sie verschiedene Laute nach ihrer Klangfärbung wiedergeben können. Der Papagei, den ich besaß, war ein grauer und war wie erwähnt, ein selten guter Sprecher. Ich erhielt ihn als junges Tier, welches damals, als es in meinen Besitz kam, noch kein Wort sprach. Wir gaben uns keine Mühe ihm Worte beizubringen, er ahmte alle Laute ohne weitere Anregung nach, bellte wie ein kleiner Hund, den wir hatten, so getreu, da $\beta$ dieser, als der Vogel es zum ersten Male tat. sich erstaunt aufrichtete und den Vogel wieder anbellte. Wir selbst wurden oft getäuscht und wußten im Augenblick nicht, ob es der Vogel oder der Hund war, der bellte. Wessen Sprache er in einem Wort nachahmte, war sofort-zu erkennen. Es war geradezu erstaunlich, wie vielerlei Klangfarben er in seinem Besitz hatte. Immerhin hat auch die Abneigung und $Z$ uneigung, die diese Tiere verschiedenen Personen gegenüber zeigen und meist dauernd behalten, ein hohes Interesse.

In der Nachbarschaft des Hauses in Königsberg, wo ich Unterkunft gefunden hatte, wurde es nach und nach bekannt, daß dort ein junger Doktor wohne und so wurde ich denn verschiedene Male zu Fällen, wo eilige Hilfe erforderlich schien, zu Kranken gerufen. Es handelte sich meist um Kinder ärmerer Familien. Ich habe mich stets verpflichtet gefühlt, in solchen Fällen zu folgen. Als einziges Honorar habe ich dafür aber nur eine Ansteckung mit der Krätze erhalten, wodurch natürlich meine ohnehin geringe Neigung, mich mit der ärztlichen Praxis zu beschäftigen, nicht gefördert wurde. 
Aus meiner Laboratoriumstätigkeit möchte ich noch einen Fall berichten, der mich in Bekanntschaft mit einem Ätherrausch brachte. Ich hatte an einer Katze zur Vornahme eines Versuches einen Nerv freizulegen, betäubte das Tier mit Äther und legte ihm, damit es während der Operation betäubt blieb, einen mit Äther getränkten Schwamm auf die Nase, beugte mich über den Kopf des Tieres und begann den Nerv freizupräparieren. Dabei atmete ich, ohne besonders darauf ziu achten, fortwährend die Ätherdämpfe aus dem Schwamm ein. Mit einem Male verlor ich, ohne vorher von beginnender Betäubung irgend etwas gemerkt zu haben, das Bewußtsein und als ich wieder zu mir kam, fand ich mich auf einer Fensterbank vor dem geöffneten Fenster liegen und v. Wittich, im Verein mit dem bekannten Ophthalmologen Julius Jacobson, bemüht, mich durch künstliche Atembewegungen wieder zum Erwachen zu bringen. v. Wittich berichtete mir, er habe im Nebenzimmer, wo er sich befand, plötzlich ein lautes Gepolter gehört, sei ins Laborantenzimmer geeilt und habe mich da, anscheinend leblos auf dem Boden liegend gefunden; er habe mich mit Hilfe des Laboratoriumsdieners zum geöffneten Fenster gebracht und Jacobson, den er gerade vor der Tür seiner gegenüberliegenden Klinik stehen sah, zur Hilfe herangerufen. Ich fühlte mich nach dem Erwachen völlig wohl, dankte den Herren und machte mich sofort daran, die Operation an der Katze zu beenden, den Schwamm nahm ich jedoch weg. Mir erscheint diese selbst erlebte Narkose bemerkenswert, weil sie so ohne jede Vorempfindung eintrat, wie es ein gesunder Schlaf tut und wie ich mir denke, da $B$ der Normaltod eintritt. Auch da $B$ nachher nicht die mindeste Störung in meinem Befinden sich zeigte, so da $B$ ich sofort die alle Aufmerksamkeit und sichere Messerführung erfordernde Freilegung des Nerven beenden konnte, ist bemerkenswert. Ich führe diesen Fall auch deshalb an, weil er mir die Verschiedenheit zeigt, die bei ein und derselben Persönlichkeit durch verschiedene Narkotika bewirkt wird. In Berlin fragte mich der Assistent der Jüngkenschen Klinik, an den ich mich wendete, um mir einen Zahn ziehen zu lassen, ob ich mich dazu chloroformieren lassen wolle. Ich bejahte, weil ich als angehender Mediziner selbst gern an mir erfahren wollte, wie eine Chloroformnarkose sich gestalte. Dabei merkte ich ganz deutlich vor dem Eintritt der Bewußtlosigkeit 
starkes Ohrensausen und allmählichen Rückgang des Sehvermögens, wovon beim Eintritt der Äthernarkose nicht das Geringste zu spüren war. Nach der Chloroformnarkose hatte ich mich mehrere Stunden mit Kopfschmerzen und sehr unbehaglichem Allgemeinbefinden herumzuplagen. Woran lag nun diese Verschiedenheit? War es der Umstand, daß ich den Äther ganz allmählich, mit viel Luft vermischt, eingeatmet hatte, während ich das Chloroform gleich mit vollen Zügen einsog? War es eine persönliche Note, die mich den Ätherrausch leichter ertragen lieB, als den Chloroformrausch? War vielleicht das Chloroform nicht rein? Das Letztere ist wohl auszuschließen, da es das in der Klinik gebrauchte und sicher erprobte Chloroform war. Ich meine, da $B$ die Mitteilung dieser eigenen Erfahrungen nicht wertlos sei, und habe sie deshalb hier angeführt.

Ich füllte in Königsberg auch noch eine Lücke meines Wissens oder vielmehr Könnens aus, indem ich bei Professor Werther an einem praktisch-chemischen Kursus teilnahm, sowie den berühmten anatomischen Paukkursus bei dem Anatomen August Müller hörte. Müller war in Berlin Privatdozent und Assistent am Anatomischen Institut gewesen und war dort durch seinen Repetitionskursus der Anatomie für Prüfungskandidaten, der den größten Beifall fand, unter dem Namen „Paukmüller" sehr bekannt geworden. Den Ruf nach Königsberg brachte ihm jedoch wohl seine mit Recht berühmte Entdeckung der Metamorphose der Neunaugen. Ich wollte doch, als angehender Anatom, nichts versäumen, was mich für diesen Beruf fördern konnte. Ich muß gestehen, daß Müller zwar seinen Kursus sehr gut gab, da $B$ ich jedoch nichts Besonderes darin finden konnte. Müller war ein origineller Mann, mit manchen Eigenheiten und witzigen, treffenden Einfällen. So hielt er in seinem Privatzimmer zwei Krokodile, die er sich als junge Tiere beschafft hatte und mit denen er sich täglich beschäftigte; er trug sie, auch als sie so gro $B$ geworden waren, da $B$ er sie kaum noch tragen konnte, in seinen Armen im Zimmer umher und hatte seinen SpaB daran, wenn Jemand ins Zimmer trat und von diesem Anblick erschreckt wurde. Einige andere Tierversuche, außer dieser Krokodilzähmung, machte er mit einem jungen Bären, um, wie er meinte, damit dessen Intelligenz zu prüfen. Einmal setzte er ihm der Reihe nach die Speisen eines üppigen Mahles vor, indem er annahm, wenn ein Tier daran, ebenso 
wie derMensch, Gefallen fände, so sei das für das Tier als ein Beweis von einer gewissen Kulturfähigkeit anzusehen. Petz bestand diese Probe glänzend, indem er nicht nur alle Delikatessen mit dem größten Appetite verzehrte, sondern auch die dargereichten Schnäpse nicht verschmähte. Dagegen fiel er bei einer zweiten Probe durch. Professor Müller ging von der richtigen Annahme aus, daß der Gebrauch irgendeines Gegenstandes als Werkzeug zur Erreichung eines Zieles auf eine Überlegung, also auf eine höhere Intelligenz desjenigen Geschöpfes, welches sich eines solchen Werkzeuges bediene, schließen lasse. Man erzählt solche Beispiele unter anderen von Elefanten. Sicher sind sie in überraschender Art festgestellt bei den auf der Anthropoiden-Station in Teneriffa ${ }^{1}$ (einer Gründung der Preußischen Akademie der Wissenschaften) beobachteten Schimpansen. Man richtet ja diese Tiere ab mit Messer und Gabel zu essen; das aber ist Dressur und kein Beweis von höherer Intelligenz. Als solchen kann man jedoch wohl folgende Beobachtung gelten lassen: Einem in einen Käfig eingeschlossenen Schimpansen wurde eine Banane in einer gewissen Entfernung vor den Käfig niedergelegt. In dem Käfig befand sich ein längerer und ein kürzerer Stab, der kürzere konnte auf den längeren gesteckt werden, so da $B$ dieser dadurch noch verlängert wurde. Diese beiden Stäbe befanden sich weit von einander entfernt an unauffälligen Stellen in dem Käfige, ehe der Schimpanse hineingebracht wurde. Als nun das Tier die Banane bemerkte, suchte es sie mit seinen Armen, die es durch die Gitterstäbe des Käfigs steckte, zu erreichen, und zwar in wiederholten Versuchen mit aller Anstrengung. Als das nicht glückte und das Tier mißmutig eine Zeitlang die Banane angestarrt hatte, fiel sein Auge auf den längeren Stab. Sofort bemächtigte es sich dieses Stabes, steckte ihn durch das Gitter und suchte so die Frucht zu erreichen. Auch das gelang nicht, die Banane lag zu weit ab. Nach mehreren vergeblichen Versuchen nahm der Schimpanse den Stab zurück und griff nach dem kleineren Stabe, hielt ihn an den größeren, wobei er offenbar bemerkte, daß der kleinere Stab auf den größeren aufgesteckt werden konnte. Er tat dies sofort und holte sich nun mit dem verlängerten Stabe die Banane heran. In diesem Verhalten liegt doch offenbar eine Überlegung.

iS. darüber Weiteres im Kapitel "Akademie der Wissenschaften“. 
124 August Müller. W. v. Wittich. Königsberger medizinische Fakultät.

Der Bär, den August Müller prüfte, zeigte eine solche Überlegung nicht. Er bemühte sich wieder und wieder, an einer Wand sich emporreckend und streckend, ein Stück Fleisch zu erreichen, welches für seine Reichweite zu hoch an der Wand aufgehängt war, vergebens. Den nahe dabei liegenden Holzklotz, der ihm leicht zum Ziele verholfen hätte, sah er wohl, schob ihn aber, was für ihn doch ein leichtes gewesen wäre, nicht heran. Nun bemerkte übrigens Professor Goltz, der dieser Prüfung beiwohnte, daß sie nicht entscheidend zu Gunsten der Intelligenz des Tieres hätte ausfallen können, selbst wenn es mit Hilfe des Klotzes das Fleischstück erreicht hätte. Da der Klotz absichtlich in größere Nähe der Stelle, wo er zur Erreichung des Stückes hätte hingeschafft werden müssen, gelegt worden war, so hätte er leicht bei den ungestümen Bewegungen des Bären unabsichtlich dorthin verschoben werden können, und man hätte bezüglich des Rückschlusses auf die Intelligenz des Tieres im Zweifel bleiben können. Der mitgeteilte Versuch beim Schimpansen scheint mir jedoch einwandsfrei.

Es sei hier noch eine originelle Äußerung August Müllers mitgeteilt, die ihn als in anatomischen Dingen lebend und webend charakterisiert. Bald nach seinem Eintreffen in Königsberg luden ihn die Königsberger Kollegen zu einem Ausfluge nach der Samländischen Küste ein, um ihm die landschaftlichen Schönheiten seiner neuen Heimat zu zeigen. Die Küste bietet in der Tat bei den Orten Rauschen, Neukuhren und Warnicken, wo eine bewaldete Hügellandschaft an das Meer in einfachen, felsfreien Formen herantritt, viel Hübsches und Anmutendes. Die Kollegen machten Müller auf die Schönheiten des landschaftlichen Bildes aufmerksam und fragten ihn, ob er das nicht schön finde? Er betrachtete längere Zeit das sich Bietende und sagte dann: ,Ja, alles schön, so weit das in Weichteilen geleistet werden kann."

Die medizinische Fakultät in Königsberg besa $\beta$ damals keine besonders hervorragende Kraft; das meiste Ansehen genossen Wagner, der Chirurg und v. Wittich, beides vornehme Naturen. Im physiologischen Laboratorium war v. Wittich sehr tätig und stets bemüht, zu Arbeiten anzuregen. Damals arbeiteten bei ihm der spätere Vertreter der Staatsarzneikunde in Berlin, Skrzeczka, der Pathologe Heinrich Jacobson, später angesehener Arzt und 
Professor an der Universität Berlin, der Physiologe Grünhagen und mehrere Studierende für ihre Dissertationen, darunter auch Freund Max Cohn. Es herrschte ein reger wissenschaftlicher Verkehr, der zugleich durch die Art, wie v. Wittich sich dabei gab, sich zu einem angenehmen gestaltete. Bald nach meinem Abgange kamen drei jüngere Kräfte ersten Ranges zur Königsberger Fakultät hinzu, der Pathologe Friedrich v. Recklinghausen, der Gynäkologe Otto Spiegelberg, dessen erste Bekanntschaft ich, wie erwähnt, in Göttingen gemacht hatte und der Kliniker Ernst Leyden, die ich bei meinen Besuchen von Breslau aus noch in Königsberg näher kennen lernte. Mit allen dreien sollte mich mein weiterer Lebensgang in dauernde mir förderliche und liebe Verbindung bringen.

\section{Breslau.}

Assistententätigkeit bei Rudolf Heidenhain. - Der Anatom K. L. Barkow. Weitere Förderung durch die Pathologische Anatomie; in drei Jahren rom Privatdozenten zum Professor ordinarius. - Tätigkeit als Pathologischer Anatom; bakteriologische Pläne. - Vergleichend anatomische Studien in Triest und Neapel. - Erste Bekanntschaft mit Rudolf Virchow; 4 Wochen im Berliner Pathologischen Institute; Julius Cohnheim, Willy Kühne. Berufung nach StraBburg.

Im Frühjahr I864 traf ich in Breslau ein, auf dem Wege von der Weser und Leine zum Meere, von da zur Spree und weiter gen Osten zum Pregel und wieder mehr westlich zur Oder. In der Familie meines neuen Amtshauptes Rudolf Heidenhain fand ich dieselbe freundliche Aufnahme, wie bei v. Wittich. Heidenhains junge Gattin, eine anmutige Erscheinung, war die Tochter des Physiologen Alfred Wilhelm Volkmann in Halle a. S., deren Bruder, den berühmten Chirurgen Richard Volkmann, ich bei seinen Besuchen in Breslau auch kennen lernte. Ich hatte für die Assistenz bei dem physikalischen und biologischen Teile der Vorlesungen und im Laboratorium zu sorgen, sowie bei den mikroskopischen Übungskursen mitzuwirken, während für die physiologisch-chemischen Teile des Unterrichts Lothar Meyer als Assistent angestellt war. Meyer war habilitiert und hielt auch die Vorlesungen über Physiologische Chemie.

Mein Arbeitsfeld sollte sich nun aber bald vergrößern und wieder durch die Pathologische Anatomie. Gerade wie in Königsberg war 
auch der Vertreter der Gewebelehre und mikroskopischen Anatomie in Breslau, Heidenhain, vielfach durch die mikroskopische Untersuchung pathologischer Produkte in Anspruch genommen. Er übertrug mir gleich diese Untersuchungen und binnen kurzem hatte ich, da ich mich, wie in Königsberg, der Sache annahm und den Ärzten eingehende Berichte lieferte, genug zu tun. Man forderte mich auch bald zur Vornahme von Obduktionen in mehreren Krankenhäusern auf, sowie zu pathologisch-anatomischen Kursen seitens der Breslauer Ärzte, von denen viele, ebenso wie in Königsberg, während ihrer Studienzeit keine Gelegenheit gehabt hatten, sich in der Pathologischen Anatomie auszubilden. So gewann ich nun auch selbst mehr und mehr Sicherheit in dieser Disziplin, so da $B$ ich es wagen durfte, darin ein Lehramt zu übernehmen. Immer blieb mir aber als Ziel die normale Anatomie unverrückt vor Augen und ich bewarb mich bald nach meiner Ankunft in Breslau um die Zulassung zur Habilitation für normale Anatomie und Physiologie. Die Physiologie fügte ich aus einem gewissen, ich möchte sagen, Anstandsgefühle hinzu, da ich doch Assistent an einem Physiologischen Institut war. Heidenhain hatte auch nichts dagegen, da er sich bei meiner Tätigkeit als Assistent überzeugt hatte, da $B$ ich auch in der Physiologie hinreichend bewandert und imstande war, Vorlesungen darüber $z u$ halten. Er war einmal durch Unpäßlichkeit einige Tage verhindert gewesen, seine Vorlesungen zu halten und beauftragte mich, da er die Stunden nicht gern ausfallen lassen mochte, ihn zu vertreten. Er hatte sein Privat-Arbeitszimmer dicht neben dem Hörsaal, durch eine Tür mit diesem verbunden und hatte sich seine Ruhestätte in dem Arbeitszimmer bereiten lassen, so da $B$ er meiner Vorlesung folgen konnte. Er war von dem Ausfalle derselben völlig befriedigt und sagte mir seine Zustimmung zur Habilitation auch für Physiologie zu. So konnte ich dann meine Habilitation noch im Laufe des Jahres 1864 bewerkstelligen. Da ich nun für Pathologische Anatomie bald mehr und mehr in Anspruch genommen wurde, so fragte ich bei der Fakultät an, ob man mir gestatten wolle, auch Kurse in der Pathologischen Anatomie für Studierende anzukündigen. Das wurde mir erlaubt, aber mit der Bemerkung, da $B$ ich daraus kein Recht auf Vertretung der Pathologischen Anatomie ableiten dürfe. Die Fakultät habe bereits Dr. Klebs in Berlin als Patho- 
logischen Anatomen für Breslau beim Ministerium in Vorschlag gebracht. Da kam denn Klebs zum zweiten Male, diesmal allerdings unfreiwillig, dazu, in mein Geschick einzugreifen. Ich hatte gar nicht die Absicht gehabt, mit der Bitte um die Erlaubnis pathologische Kurse geben zu dürfen, auf einem Schleichwege zu einer Professur für Pathologische Anatomie zu gelangen; es war mir nur darum zu tun, ein Kolleg zustande $z u$ bringen. Die Aussichten dazu waren in der Anatomie und Physiologie sehr gering. Der damalige Breslauer Anatom, der alte Hans Karl Leopold Barkow, hatte meine Habilitation nur ungern gesehen; er erblickte in mir, vollkommen unbegründet, einen Rivalen, der danach strebe, ihn von seinem Lehrstuhle zu verdrängen. Auf meine Bitte, mir für eine anatomische Vorlesung, die gar nicht in sein Gebiet hineinfiel, etwas Material, und zwar solches, welches bereits bearbeitet worden und zur Beerdigung bestimmt sei, zu überlassen, hatte er ablehnend mit der komisch klingenden Bemerkung geantwortet, er könne die Verhältnisse der Anatomie nicht verwirren. So gab ich es denn auf, so sehr ich dessen auch bedurfte, im Gebiete der deskriptiven Anatomie weiter zu arbeiten. $\mathrm{Da} B$ der Grund der ablehnenden Stellung, die Barkow mir gegenüber einnahm und dauernd festhielt, tatsächlich der war, den ich angegeben habe, geht klar daraus hervor, da $B$ er von dem Augenblick an, da ich den Ruf nach Straßburg als Anatom erhielt, wie umgewandelt war. Als ich ihm damals meinen Abschiedsbesuch machte, empfing er mich aufs freundlichste, sagte, da $B$ ich doch noch seine Sammlung kennen lernen müsse und führte mich hinein, zeigte mir die Präparate, die er gesammelt und zum Teil selbst hergestellt hatte, fragte mich um meine Meinung über diese und jene und schenkte mir beim Abschiede - wir waren mehrere Stunden zusammengewesen - seine Photographie mit eigenhändiger Unterschrift und bat um die meinige. Ich hatte dem alten Herrn, der als Sonderling bekannt war, seine früheren Unfreundlichkeiten nicht nachgetragen, nahm seine Führung im Museum gänzlich unbefangen als selbstverständlich an, schied von ihm mit freundlichem Händedruck und schickte ihm auch mein Bildnis, sowie später meine Veröffentlichungen, empfing auch noch die seinigen. Er lebte nur noch einige Jahre. Er hatte allerdings richtig vorgeahnt, als er in mir seinen Nachfolger erblickte, denn ich erhielt nach seinem Tode die 
offizielle Anfrage von der Breslauer Fakultät, ob ich einen Ruf nach Breslau als Anatom annehmen würde. Da ich erst so kurze Zeit in StraBburg war, antwortete ich ablehnend. Die Fakultät wollte mich in erster Stelle vorschlagen.

Wie nun Klebs dazu kam, unfreiwillig in mein Schicksal zum zweiter Male einzugreifen, sei jetzt erzählt. Ich hatte schon in Königsberg angefangen pathologisch-anatomische Veröffentlichungen herauszugeben und dies in Breslau fortgesetzt, hatte auch einige Dissertationen von Schülern angeregt und beeinfluBt. So war ich einigermaßen als Pathologe bekannt geworden. Da schrieb mir mein Greifswalder klinischer Lehrer Niemeyer aus Tübingen, die dortige medizinische Fakultät wünsche mich als Extraordinarius für pathologische Anatomie vorzuschlagen. Er wisse zwar, daß ich beabsichtige, in den Beruf eines Normalanatomen hineinzukommen, glaube aber aus meinen Veröffentlichungen schließen zu dürfen, da B mir die Pathologische Anatomie auch recht sein werde. Ich möge mich erklären; falls ich kommen wolle, wäre meine Berufung sicher. Ich ging mit dem Briefe zu Heidenhain als meinem Institutsleiter und bat um seinen Rat. Heidenhain sagte mir, wenn ich hinreichendes Interesse für Pathologische Anatomie habe, so wolle er mir nicht abraten, auch in dieser Disziplin das, was sich mir darböte, zu ergreifen; ich möge jedoch mit meiner Antwort an Niemeyer nicht zu eilig sein, denn, wenn man mich in Tübingen als Pathologischen Anatomen gebrauchen könne, gehe das vielleicht auch in Breslau. Gerade vor wenig Tagen sei eine Absage von Klebs eingelaufen. Dieser sei schon vor dem Breslauer Vorschlage von Bern vorgeschlagen gewesen und da man sich im preußischen Kultusministerium etwas lange besonnen habe, ihn zu berufen, habe er für Bern angenommen. So sei man in Breslau wieder frei. Er, Heidenhain, wolle sofort eine Fakultätssitzung beantragen und dort den Antrag stellen, daB die Fakultät mich, nachdem Klebs abgelehnt habe, als Extraordinarius für Pathologische Anatomie vorschlagen möge. Das geschah; am dritten Tage konnte mir Heidenhain die Mitteilung machen, daß die Fakultät mich einstimmig vorgeschlagen habe und in Berlin um schleunige Erledigung der Sache sofort nachsuchen werde. Ich entschied mich für Breslau. Ein Pathologisches Institut hatte ich weder in Breslau noch in Tübingen, das mußte erst geschaffen werden; 
Prof. extraord. d. Pathol. Anatomie. Begegn. mit v. Recklinghausen. 129

aber in Breslau wartete meiner ein ungleich größeres und mannigfaltigeres Material, als in Tübingen. Breslau hat nächst Berlin das reichste und vielseitigste pathologische Material in Deutschland. Dazu kam, da $B$ für die Pathologische Anatomie in Preußen überall Ordinariate in Aussicht standen, während das in Tübingen noch in weiterer Ferne zu liegen schien. Ich durfte somit hoffen, mir in Breslau bald ein eigenes Heim gründen zu können. Ich schrieb also meinem lieben Lehrer Niemeyer mit aufrichtigem Danke dafür, da $\beta$ er sich meiner in so treuer Weise erinnert habe und mit Angabe der Gründe, weshalb ich Breslau vorziehe, ab. Er erkannte in seinem Antwortschreiben meine Gründe vollauf an, beglückwünschte mich zu der günstigen Wendung meines Geschicks und ebenso sich, da $B$ er dazu habe beitragen können. Wir Beide blieben stets in bestem Einvernehmen; leider hat ihn der Tod früh hinweggerafft.

Durch Ministerialerla $B$ vom 23. September I865 erhielt ich meine Ernennung zum außerordentlichen Professor der Pathologischen Anatomie in Breslau und zum Direktor des zu begründenden Pathologischen Instituts. Mir wurde ein Gehalt bewilligt, wie es damals üblich war und welches gestattete, mit etwas Mut und Einschränkung eine Familie zu gründen. Ich erhielt ferner Mittel zu sachlichen Ausgaben und zur Anstellung eines Dieners. Im Herbst I865 begann ich meine Tätigkeit.

Die Herbstferien 1865 brachte ich als glücklicher Bräutigam mit der gesicherten Aussicht, die Braut bald heimführen zu können, bei meinen Schwiegereltern in Königsberg zu. Dorthin war inzwischen v. Recklingha usen berufen worden und hatte als Institut die frühere chirurgische Klinik, die ihrer Zeit von den Studierenden die ,Eiterbeule" benannt wurde, erhalten. Recklinghausen wollte die Ferien gern verreisen und übertrug mir während dieser Zeit die Verwaltung seines Instituts. So hatte ich denn, was mir sehr angenehm war, in dieser Zeit eine mir zusagende Tätigkeit an der Stätte meiner früheren Wirksamkeit und gewann Recklinghausens Freundschaft. Wir konnten damals nicht ahnen, da $B$ wir in wenigen Jahren einander so nahe kommen würden. Für meine Berufung nach Straßburg ist mir die in Königsberg damals eingeleitete freundschaftliche Beziehung zu Recklinghausen sehr förderlich gewesen.

Es galt nun in Breslau ein Pathologisches Institut zu gründen. 
Im großen Allerheiligen-Hospital hatte der spätere Göttinger Kliniker Ebstein die Obduktionen der städtischen Krankenabteilungen auszuführen. Die beiden dort untergebrachten Kliniken, die innere unter Lebert und die chirurgische unter Middeldorpf, hatten bisher ihre Obduktionen durch ihre Assistenten machen lassen. Ebstein, der in mir einen Rivalen sah, verhielt sich ablehnend gegen mich, so da $B$ ich keine Aussicht hatte, in dem großen AllerheiligenHospital unterzukommen. Da bot mir ein Breslauer praktischer Arzt, Dr. Long, der sich für Anatomie und Pathologische Anatomie interessierte, in seinem Hause in der Vorwerkstraße den ersten Stock mit sechs Zimmern als Instituts-Ersatz an. Manche rieten ihm ab; sie sagten, seine übrigen Mieter würden ihm kündigen, wenn sie erführen, da $B$ dort ein solches Institut mit Arbeiten an menschlichem Leichenmaterial untergebracht würde. Glücklicherweise ist das nicht eingetroffen. Selbstverständlich konnte ich keine Leichen dorthin verbringen und obduzieren lassen. Mein Diener Höhndorf, mit dessen Anstellung - er war mir von Dr. Long empfohlen worden ich großes Glück hatte, brachte in einem kleinen Blechkoffer die zur genaueren Untersuchung und für die Demonstrationskurse gewonnenen Leichenteile dorthin, und schaffte die, welche nicht als Sammlungsstücke aufbewahrt werden sollten, auf demselben Wege wieder fort. Das nötige Instrumentarium und das Mobiliar wurde beschafft und zu Anfang des Jahres 1866 konnte dort der Unterricht beginnen und ist dort bis $\mathrm{zu}$ meiner Berufung nach Straßburg fortgesetzt worden. Bevor dieses vielleicht eigentümlichste Pathologische Institut in einem Privathause aber eingerichtet war, mußte ich mich mit einer theoretischen Vorlesung und einigen Demonstrationen im Anschlusse an die Vorlesung begnügen. Dazu gewährte mir der Zoologe Grube in seinem Hörsaale im Universitätsgebäude Unterkunft. Höhndorf brachte in seinem Köfferchen die bei etwaigen Obduktionen als geeignet befundenen Leichenteile dorthin und nach der Vorlesung wieder an den Ort zurück, woher er sie genommen hatte, damit sie mit der zugehörigen Leiche beerdigt würden. Für meine Privatarbeiten hatte mir für dieses Interregnum Heidenhain einen Platz in seinem Institute belassen. Später fanden Vorlesungen, Demonstrationen, eigene und Laboranten- und Assistenten-Arbeiten im Longschen Hause statt. 
Selbstverständlich setzte ich in dieser Zeit meine Bemühungen eifrigst fort, ein geeignetes Haus entweder anzukaufen oder einen passenden Bauplatz zu finden, worauf ein Neubau errichtet werden könnte. Dabei wurde ich vom damaligen Oberpräsidenten v. Schleinitz bestens unterstützt; es gelang aber erst I87I, ein passendes Haus $\mathrm{zu}$ finden. Es ist mir aber nicht mehr zu Gute gekommen, sondern meinem Nachfolger Julius Cohnheim, da ich bereits 1872 nach Straßburg übersiedelte.

Auch in anderer Beziehung wurde es mir nicht leicht gemacht, den pathologischen Unterricht ganz in meine Hand zu bekommen. Die für diesen Unterricht wichtigsten Obduktionen, die der inneren Klinik, wurden mir nicht übertragen. Lebert sagte mir nach meiner Ernennung, er habe als früherer Pathologischer Anatom in Päris die Gepflogenheit beibehalten, die klinischen Sektionen selbst zu machen oder unter seiner Aufsicht von seinen Assistenten machen zu lassen. Davon möge er auch nach der Ernennung eines eigenen Pathologischen Anatomen nicht abgehen; ich möge das nicht als Inkollegialität oder Mangel an Vertrauen auffassen. Nun, ich hatte nur gute Miene dazu zu machen, beurteilte die Sache jedoch so wie sie lag: mein Kollege wollte sich nicht gern von einem ihm nicht genauer bekannten Dritten in seine klinischen Karten gucken lassen. Er wollte sich erst überzeugen, wie ich mein Amt als Obduzent auffaßte. Als er nach etwa 2 Jahren sich hinreichend überzeugt hatte, da $B$ ich mich nicht als Kritiker der behandelnden Ärzte zeigte, sondern als rein objektiver Feststeller des Tatbestandes, da $B$ ich auf Wunsch gern ihr Berater war und die von ihnen verlangten Untersuchungen stets bereitwilligst ausführte, da ließ er mich eines Tages bitten, die Obduktion eines in seiner Klinik Verstorbenen vorzunehmen mit der Begründung, es handle sich seiner Meinung nach um einen besonders schwierig zu beurteilenden Fall. Dies geschah und von da $\mathrm{ab}$ machte ich auch alle Obduktionen der inneren Klinik. Middeldorpf und Spiegelberg, der inzwischen nach Breslau berufen worden war, hatten mir von Anfang an ihre Obduktionen übertragen. Außerdem führte ich die Autopsien aus in dem großen Krankenhause der Barmherzigen Brüder, im Elisabeth-Krankenhause und im Diakonissen-Krankenhause, sowie auch bei den Fällen in der Stadt, wo auf Wunsch der behandelnden Ärzte oder der Angehörigen eine 
132 Lehrtätigkeit. Spital der „Barmherzigen Brüder“. O. Spiegelberg.

Obduktion vorzunehmen war, so $\mathrm{da} B$ ich in kurzem ein reiches Material für den Unterricht und für eigene Studien zur Verfügung hatte. Die erste Krankenanstalt, die meine Dienste erbat, war das Spital der Barmherzigen Brüder, wo der Chirurg Professor Paul Oberarzt war. Der Konvent ließ mir ein eigenes Sektionszimmer mit allem Nötigen herrichten und einige der dienenden Brüder wurden von mir im Nötigen unterrichtet, so daß sie mir später völlige Assistentendienste leisteten. Ich lernte dabei insbesondere während der Kriege I866 und I870 dieses Krankenhaus als eine wahre Musteranstalt kennen. Aber auch im Elisabeth-Krankenhause, wo als Ober arzt Dr. Lange und im Diakonissen-Krankenhause, wo in gleicher Stellung Dr. Methner tätig war, fand ich die bereitwilligste Unterstützung und die Schwestern unterzogen sich der nötigen Hilfe bei den Autopsien mit Interesse und Geschick.

Am förderlichsten gestalteten sich für mich die Obduktionen in der Frauenklinik bei Spiegelberg. Nicht nur, da $B$ mein Kollege stets mit der größten Aufmerksamkeit der Vornahme derselben folgte und dabei bald um diese bald um jene weitere Aufklärung ersuchte und sie den anwesenden Studierenden gab, sondern nach jeder Leichenschau besprachen wir in genauester Weise den betreffenden Fall und er gab mir auf meinen Wunsch gern Gelegenheit, Schwerkranke, deren Tod zu befürchten war, auf der Klinik zu sehen und besprach mit mir die Diagnose. Auch zog er mich öfters zu seinen Operationen hinzu, bei denen er meinen Rat in anatomischen Dingen wünschte. Dieses Zusammenarbeiten zwischen Kliniker und Anatom kann ja nur förderlich sein und vom besten EinfluB auf die Studierenden, welche einerseits dem klinischen Unterrichte, andererseits den klinischen Obduktionen und den Vorlesungen und Demonstrationen des Pathologischen Anatomen beiwohnen.

So angenehm und fruchtbringend sich nun auch meine Tätigkeit als Pathologischer Anatom in Breslau gestaltete, so gab ich doch meine stille Hoffnung, aus dem pathologischen Bereiche wieder zum normalen zurückkehren zu können, nicht auf. In der Entwicklungsgeschichte hatte ich mich in Berlin und durch eigene Arbeiten in Breslau hinreichend unterrichtet, nun fehlte mir eine vollgenügende Kenntnis der vergleichenden Anatomie, die ich gleichfalls in Berlin zu studieren begonnen hatte. Mir wurde bald klar, da $B$ da eigene 
Studien der Meeresfauna an Ort und Stelle am förderlichsten sein würden, und so begab ich mich in den Herbstferien 1868 nach Triest, bekam einen Platz in der dortigen zoologischen Arbeitsstätte im Museo civico und ging täglich auf den Fischmarkt, wo man, außer zahlreichen Arten von Fischen, allerlei andere Meertiere haben kann. Wenn die Fischer erst wissen, da $B$ man solche wünscht, so bringen sie gern alles, was sie fangen. Ich hatte das Glück, dort mit einem jungen Zoologen vom Fach, Dr. v. Marenzeller, - er ist vor kurzem als außerordentlicher Professor an der Technischen Hochschule in Wien verstorben - bekannt zu werden, mit dem ich öfter in die Bucht von Triest hinausfuhr, wo wir mit einem kundigen Fischer uns allerlei Getier, was wir nur fangen konnten, einholten. v. Marenzeller war mit der Fauna der Triester Bucht gut bekannt und war gèrn bereit, mir bei der Bestimmung der Tiere zur Hilfe zu sein. Ich präparierte dann die einzelnen Spezies im Museo civico oder auf meinem Zimmer sorgfältig durch und gewann so eine Grundlage aus eigener Anschauung und Bearbeitung. Später, von Straßburg aus, habe ich noch einmal derartige zoologische Studien getrieben und zwar in der eben von Anton Dohrn gegründeten Zoologischen Station zu Neapel, deren erster Besucher ich war. Michele, der vielen Zoologen bekannte Stationsfischer, fuhr mit mir fast jeden Morgen im Kahn mit allem Fischergerät hinaus ins Meer, öfters schon mit dem ersten Tagesgrauen. Unter Tags wurde dann die Beute verarbeitet. Mit Anton Dohrn, dem Maler Hans v. Marées und Meister Adolf Hildebrand, beide mit Dohrn befreundet, habe ich da manche genußreiche Stunde verlebt.

Mit Ebstein, der die nicht klinischen Obduktionen im Allerheiligenspital ausführte, hatte ich anfangs wenig Berührung. Wir Beide hatten Forschungsmaterial genug. Später, als Ebstein sich um die Habilitation bewarb und im Physiologischen Institut unter Heidenhain arbeitete, wurden wir näher bekannt und traten in gute Beziehungen zueinander, die sich dauernd erhalten haben; ich hatte Gelegenheit, noch öfter mit ihm, als er Ordinarius für innere Klinik in Göttingen wurde, zusammenzukommen.

Die Annahme, daß die Stellen für Pathologische Anatomie in Preußen bald sämtlich mit Ordinarien besetzt werden würden, verwirklichte sich in Breslau bald, denn am I3.Oktober I867 erfolgte meine 
Ernennung und mit Beginn meines 32. Lebensjahres trat ich als Ordinarius in die Fakultät ein. Im Jahre I872, als ich Breslau verlieB, hatte ich gerade das Dekanat zu verwalten.

Wie ich im Gebiete der normal anatomischen Disziplinen mich weiter fortzubilden suchte, so suchte ich es auch in der Pathologischen Anatomie. An den Universitäten der kleinen Städte Göttingen und Greifswald hatte ich wenig Gelegenheit gehabt, die so außerordentlich wichtigen und mannigfaltigen Produkte, welche die Syphilis im menschlichen Körper hervorbringt, genügend kennen zu lernen. In Königsberg war mir der Gedanke, daß ich einmal als Lehrer der Pathologischen Anatomie zu amtieren hätte, nicht in den Sinn gekommen, ebensowenig in meiner ersten Breslauer Zeit. Ich hatte freilich in Königsberg und Breslau keine Gelegenheit versäumt, meine Kenntnisse in diesem schwierigen Gebiete zu vertiefen, empfand aber, als ich mich zur Annahme der Professur entschlossen hatte, das pflichtgemäße Bedürfnis, mir diejenige Sicherheit $z u$ erwerben, die ein Dozent in seinem Fache haben soll. Im Anfang des Jahres I867 wendete ich mich brieflich an Rudolf Virchow, dessen Bekanntschaft ich bis dahin noch nicht gemacht hatte, aber als den berühmtesten Spezialkollegen nun auch gern persönlich näher kennen lernen wollte, mitderAnfrage, ob er mir gestatten wolle, während der bevorstehenden Osterferien den Obduktionen in seinem Institute beizuwohnen und die Präparate seiner Sammlung zu studieren, insbesondere die syphilitischen, deren ungenügende Kenntnis ich ihm offen eingestand. Virchow antwortete mir sofort in einem freundlichen Schreiben, ich sei ihm willkommen. So brachte ich dann vier Wochen in Berlin mit eifrigen Studien im Pathologischen Institut zu. Virchow empfing mich aufs Freundlichste, übergab mir die Schlüssel zur Sammlung, sagte mir, daß ich, ohne ihn weiter zu fragen, die Präparate, die ich näher untersuchen wollte, aus den Gläsern nehmen dürfe und gab mir einen Platz, an dem ich ungestört arbeiten konnte. Selbstverständlich versäumte ich es auch nicht, den Obduktionen beizuwohnen, um die Technik Virchows und seiner Assistenten kennen zu lernen, von denen damals Julius Cohnheim, mein Nachfolger in Breslau, die meisten ausführte. Die große Zuvorkommenheit Virchows, der mich auch in seine Familie einführte, berührte mich aufs angenehmste; ich habe es ihm in steter Dankbarkeit nie vergessen. 
Die Wochen in seiner Anstalt gingen bei ernster Arbeit schnell dahin, brachten mir aber viel Gewinn für meine Lehrtätigkeit und an werten Bekanntschaften fürs Leben. Außer mit Virchow und den Seinigen, trat ich mit Cohnheim und Willy Kühne, dem späteren Heidelberger Physiologen, der die chemische Abteilung des Pathologischen Instituts verwaltete, in näheren Verkehr. Auch Traube lernte ich damals kennen und wohnte einer Abendgesellschaft in seinem Hause bei, wo zwischen ihm, Virchow und du Bois-Reymond eine lebhafte Unterhaltung über verschiedene damals in Frage stehende Probleme entstand, die zu den interessantesten gehört, denen ich beigewohnt habe. Überhaupt herrschte damals ein sehr reges, weit seine Wellen schlagendes, geistiges Leben in der Berliner medizinischen Fakultät. Virchow, du Bois-Reymond, Frerichs, Traube, Langenbeck, Romberg, Eduard Martin standen auf ihrer Höhe. Unter den Assistenten der Institute und Kliniken gab es viele, die selbst schon in der Wissenschaft sich bewährt hatten und später ehrenvolle Rufe erhielten, wie Cohnheim und Kühne. Ich kann dieser Wochen noch heute nur mit größter Befriedigung gedenken, insbesondere deshalb, weil sie mir zu einer Freundschaft den Weg ebneten, die mir nebst der Henles die wertvollste meines Lebens gewesen ist, zu der mit Rudolf Virchow! Eine eigenartige Fügung, da $B$ ich mit beiden Männern, die sich in der wichtigen Bindegewebsfrage einst so arg befehdet hatten, in so nahe Beziehung trat. Ich hatte an dem Streit, in dem, wie gewöhnlich in solchen Dingen, Jeder ein Teil Recht auf seiner Seite behielt, lebhaften Anteil genommen und mußte in der wichtigsten Seite der Streitfrage Virchow Recht geben. Einige Jahre später - beide einander ebenbürtige Kämpen hatten die Waffen eingesteckt - war ich Zeuge einer für mich hochinteressanten Begegnung. Es war, irre ich nicht, auf der Naturforscherversammlung in Dresden. Ich stand an einer Treppe im Gespräch und sah Virchow hinaufgehen, gleichzeitig kam Henle von oben her$\mathrm{ab}$, Beide muBten aneinander vorbei; sie blieben einen Augenblick stehen, schauten sich an, reichten sich die Hände und gingen stumm ihres Weges. Sehr schätzenswert war mir auch die Bekanntschaft mit Cohnheim und Willy Kühne. Cohnheim arbeitete damals gerade an seiner so hochwichtigen Eiterbildungslehre. Er lieB mich gern Einsicht in seine Präparate und Untersuchungsweisen nehmen und wir 
besprachen oft dieses Thema. Mit Kühne verhandelte ich über Muskelnerven-Endigungen; außerdem sorgte er für mein leibliches Wohl. Er machte mir den Vorschlag, daß wir zusammen zu Mittag speisen wollten, wobei er sich ausbedingte, da $B$ er die Speisen auf der Karte für uns auswählen dürfe. Ohne Bedenken ging ich darauf ein; denn es war mir bekannt, daB Kühne, ein Meister in vielen wissenschaftlichen Dingen, auch in der Praxis der Nahrungsmittel-Physiologie ein Meister war; das bewies er damals auch. Als ich das letzte Mal in seinem Leben mit ihm zusammentraf, es war in Oxford, bereitete er mir in seiner freundlichen und liebenswürdigen Art noch einen hohen GenuB. Er fragte mich dort, ob ich Oxford näher kenne. Ich war zum ersten Male da und sagte ihm, daB ich noch nicht Zeit gehabt hätte, mich näher umzusehen. „Dann kommen Sie mit mir," sagte Kühne, ,wir machen einen Gang durch die Stadt.“ Da zeigte er mir alle die architektonischen Schönheiten, die Oxford reichlich bietet, und ich mußte mir gestehen, daß er auch darin ein Meisterkenner war. Ich sollte ihn nicht wiedersehen; kurze Zeit darauf starb er. Ich bewahre ihm, wie Cohnheim, dem leider auch nur eine kurze Lebensdauer vergönnt war, ein treues und hochachtendes Andenken.

Ich darf aber auch wohl einer für die Beteiligten charakteristischen Begebenheit, die sich bei der Obduktion einer Leiche von der Jüngken schen Klinik durch Cohnheim abspielte, gedenken. Jüngken hatte bei dem Verstorbenen, der einer unbedeutenden Kopfwunde wegen in die chirurgische Charitéklinik gekommen war, eine Meningitis als Todesursache diagnostiziert und erschien mit einem Teile seiner Hörer bei der Autopsie. Ich war gleichfalls zugegen. Cohnheim begann in üblicher Weise die Sektion mit den Brustorganen und es stellte sich eine umfangreiche doppelseitige Lungenentzündung heraus, die Jüngken ebensowenig, wie ich seinerzeit bei meinem Staatsexamen, diagnostiziert hatte. An den Unterleibsorganen fand sich nichts Bemerkenswertes. Der Befund an den Lungen erklärte auch vollkommen den eingetretenen Tod. Cohnheim diktierte zum Protokoll auch noch einige Worte über die in Heilung begriffene Kopfwunde und wollte, da keine Veranlassung vorlag, den Hirnschädel zu öffnen, das Protokoll damit schließen. Da trat Jüngken vor und sagte: „,Aber, mein lieber Herr Doktor, der Mann hatte noch eine Meningitis, 
ich bitte den Schädel zu öffnen." Cohnheim ließ den Schädel öffnen, nahm das Gehirn heraus, untersuchte es sowie die völlig unversehrten Hirnhäute und diktierte zu Protokoll: „An den Hirnhäuten sowie am Gehirn keine pathologischen Veränderungen." Jüngken machte ein erstauntes Gesicht, trat an die Leiche heran, hob deren Kopf hoch und sagte: ,Aber, mein lieber Herr Doktor, sehen Sie denn nicht die Rötung?" Cohnheim zuckte die Achseln und zog sich zurück. Jüngken aber in Eifer rief seinen Hörern zu : ,Sehen Sie, meine Herren, hier an der Schädelbasis die Rötung, der Mann hatte eine Meningitis, eine Meningitis, sage ich, sehen Sie diese Rötung!“ Ich hatte auch hingeschaut, aber nur eine leichte Rötung der harten Hirnhaut bemerkt, wie sie gewöhnlich an Leichen durch etwas ausgetretenen Blutfarbstoff bewirkt wird. Jüngken mit den Studenten verließ den Saal, ich blieb zurück, um mir einiges an den Leichenteilen anzusehen, während Virchows Institutsdiener F ischer, bekannt bei den Studenten unter dem Namen der "Leichen-Fischer", sich daran machte, die eben obduzierte Leiche für ihr Begräbnis herzurichten. Da fragte mich Fischer: „Herr Professor, haben Sie etwas von Meningitis gesehen ?" „Nein," gab ich zur Antwort. „Ich auch nicht, "sagte Fischer.

Meinen Unterricht gab ich in Breslau in einer theoretischen mit Demonstrationen verbundenen Vorlesung, die in zwei Semestern das ganze Gebiet der Pathologischen Anatomie umfaßte, dazu in jedem Semester eine öffentliche Vorlesung, im Winterhalbjahre über Mißbildungen, im Sommerhalbjahre über die Parasiten des Menschen. Ferner hielt ich einen demonstrativen und zugleich praktischen Übungskursus für Studierende, die bereits an den Vorlesungen teilgenommen hatten. Diesen richtete ich so ein, da $B$ je zwei Studierenden ein Präparat mit den nötigen Instrumenten, auch Mikroskop und Zubehör, übergeben wurde mit dem Auftrage, in der ẹrsten Kursstunde das Präparat genau zu untersuchen und über das Ergebnis ein Protokoll niederzuschreiben, welches der Eine dem Anderen zu diktieren hatte. In der sich gleich anschließenden zweiten Kursstunde wurden mir die einzelnen Präparate vorgelegt und ich ließ die dazugehörigen Protokolle verlesen und kritisierte sie. Dann gab ich, namentlich wenn die Protokolle der Studierenden Unrichtigkeiten enthielten oder Dinge übersehen waren, selbst ein Diktat zu Protokoll oder ließ dieses von den Studierenden aufs neue nieder- 
schreiben. Außerdem wurden die Studierenden zu den Obduktionen geladen und unterwiesen, wenn eine geeignete Leiche zur Verfügung stand, selbst die Sektion vorzunehmen. Endlich waren für Laboranten, die selbständige Arbeiten ausführen wollten, einige Plätze vorhanden.

Ich hatte das Glück, gleich in Karl Weigert, einem bei mir ausgebildeten Schüler, einen Assistenten ersten Ranges zu bekommen. Weigert nahm nachher die Stelle eines klinischen Assistenten bei Lebert an, ging aber später als Cohnheims Assistent nach Leipzig und dann als Leiter der Anatomischen Anstalt des Senckenbergianum nach Frankfurt a. M. zur Pathologischen Anatomie zurück, in der er sich ein dauerndes Andenken gesichert hat. Weigert war einer der edelsten Menschen, die ich kennen gelernt habe; wir wurden gute Freunde. Nachfolger Weigerts wurden bei mir in Breslau Kolaczek, späterer Professor extraordinarius für Chirurgie dort und Buchwald, später Extraordinarius in Breslau für innere Medizin. Alle drei Genannten sind seit langem ins Grab gesunken.

Außer Heidenhain war mir Spiegelberg von den Fakultätskollegen besonders nahe getreten, wie ich bereits erwähnte. In seinem Heim sowie bei Heidenhain war ich auch mit meiner Frau häufig zu Gast und ich setzte mit Spiegelberg meine musikalische Betätigung fort, indem wir häufig vierhändig spielten. Dann traf ich wieder dort meinen Freund Max Cohn, der Assistent bei dem Ophthalmologen Richard Förster geworden war und gewann neue Freunde in dem Historiker Karl Neumann, dem Mathematiker Schröter, dem Physiker Emil Meyer, Bruder Lothar Meyers und dem Mathematiker Paul Bachmann. In Bachmann, mit dem ich auch eifrig Musik trieb, lebte mir noch bis zur Niederschrift dieser Zeilen einer der Wenigen aus dieser Zeit, die, wie mich, der Tod bis jetzt verschont hat; inzwischen ist auch er heimgegangen. $\mathrm{Er}$ wurde später Ordinarius zu Münster in Westfalen und lebte dann in der Goethe-Schillerstadt Weimar. Wir sahen uns vor meiner Verheiratung fast jeden Tag beim gemeinsamen Mittagsmahle, an dem auch der Theologe Reinkens und Emil Meyer teilnahmen, und häufig in dem gastlichen Hause Schröters. Diese angenehmen Beziehungen setzten sich auch nach meiner Verheiratung fort und nachdem mir durch die Versetzung meines Schwiegervaters als Provinzialschulrat nach Breslau in dessen Hause eine wei- 
Bresl. Kollegen. Bakteriolog. Pläne mit F. Cohn. R. Heidenhain. 134

tere Heimstätte bereitet ward. Gern gedenke ich auch der beiden Juristen Otto Stobbe, der später Breslau mit Leipzig vertauschte und Schulze, der nach Heidelberg übersiedelte, des Zoologen Grube und des Geologen Ferdinand Römer, der als fanatisierter Junggeselle galt und zu sagen pflegte, in seiner Familie sei das Heiraten nie Mode gewesen. So kam es denn, da $B$ ich, als Römer sich doch noch zur Ehe entschloß und meine Frau, als ich vom Tagewerk nach Hause kam, mir sagte: ,Nun, rate einmal, wer sich heute verlobt hat ?" alle Junggesellen der Universität, zuletzt gar meinen alten Kollegen Barkow nannte, aber an Römer nicht dachte. Eine glückliche Ehe mit der Schwägerin Grubes belohnte seine Bekehrung. Vor allem muß ich aber hier noch der beiden Botaniker Breslaus, des alten Göppert, wie er genannt wurde, und Ferdinand Cohns gedenken, bei dem ich noch eine Vorlesung hörte. In meinen letzten Breslauer Jahren, angeregt durch Cohns Vorlesung, hatte sich bei mir die Vorstellung befestigt, da $B$ die Mikroorganismen: Kokken, Bakterien und Bazillen, sowie auch die parasitischen Protozoen in der menschlichen und tierischen Pathologie eine große Rolle spielen müßten, ebenso wie in der Pflanzenpathologie. Ich folgte hierin auch den Spuren meines Meisters Henle. Da faßte ich den Entschluß, ganz methodisch und systematisch diese Lebewesen in ihren pathologischen Beziehungen zu studieren und verband mich zu diesem Ende mit Cohn. Wir Beide hatten einen festen Plan bereits völlig verabredet bis in die Einzelheiten des Zusammenarbeitens hinein, da kam meine Berufung nach Straßburg und meine Anhänglichkeit an das alte Ziel trug den Sieg über die Bakterien davon. Es ist bekannt, daß Robert Koch gleichfalls bei Ferdinand Cohn in die Schule gegangen ist.

Heidenhain habe ich als ausgezeichneten Lehrer auf dem Katheder und im Laboratorium in allerbester Erinnerung. Ich habe von ihm viel gelernt, namentlich in der Art, wie er den mikroskopischen Kursus leitete. Es war mir ein besonderes Vergnügen, ihm bei seinen Arbeiten $\mathrm{zu}$ assistieren; man lernte immer dabei. Namentlich erwähne ich die Arbeiten über die Wärmeentwicklung bei der Muskelarbeit und über die Speichelsekretion, bei denen ich mithelfen konnte. Ich hatte die Empfindung, da $B$ ich von Heidenhain mehr als befreundeter Kollege, denn als Assistent angesehen wurde und so ge- 
staltete sich meine Arbeit bei ihm zu einer sehr förderlichen und angenehmen. Es war mir tief schmerzlich zu Mute, als ich ihn wenige Jahre nach meiner Übersiedelung von Straßburg nach Berlin bei einem Besuche in Breslau, körperlich sehr verändert, wieder sah und von ihm vernahm, daß er schwer und schmerzhaft leide. Sein $\mathrm{Zu}$ stand scheint nicht richtig erkannt zu sein; er erlag einem Duodenalgeschwür noch in der Kraft bester Jahre, ebenso, wie einige Zeit vorher, mein mir befreundeter Bonner Kollege Ma x Schultze. Neben Spiegelberg war der frühere Assistent von Spiegelbergs Vorgänger Betschler, Wilhelm Alexander Freund, Extraordinarius an der Universität, damals als Gynäkologe in Breslau angesehen. Freund schenkte mir auch sein Vertrauen und wir haben viel zusammengearbeitet. Mir war es leid, da B Spiegelberg und Freund, allerdings zwei ganz verschiedene Naturen, sich nicht verständigen konnten; gern hätte ich sie einander näher gebracht und ich machte auch verschiedene Versuche dazu, aber nur mit flüchtig vorübergehendem Erfolg. Freund sollte ich noch in Straßburg als Kollegen und in Berlin später wiedersehen.

In die Jahre meines Breslauer Aufenthaltes fiel die politisch große Zeit, die Oktavevon I864 bis I872, der Aufrichtung des neuen Deutschen Reiches, dem fast die ganze Welt jetzt, wo ich diese Zeilen niederschreibe, den Untergang bereiten will. Ich widme diesen großen Ereignissen ein besonderes Kapitel; erwähne sie nur hier, weil sie mich von Breslau nach Straßburg im ElsaB, von der Pathologischen Anatomie wieder zur Normalen, dem Endziele meines Lebens, führten. Breslau mit seiner Universität und mit der Schlesischen Gesellschaft für vaterländische Kultur bereitete mir ehrende Abschiedsfeste, die mir zeigten, da $B$ ich dort gern gesehen war und freundlichen Boden gefunden hatte. Etwas schwer wurde mir nur der Abschied von der Schlesischen Gesellschaft gemacht, indem man mir bei dem Festmahle den Platz zwischen Göppert und Ferdinand Cohn gegeben hatte, die beide schwerhörig waren. Der Abend war, so gern ich beide Männer hatte, nicht leicht. -

Eines Sonntags in der Frühe brachte mir der Postbote einen Brief, in dem zu meiner völligen Überraschung eine Anfrage des mit der Einrichtung der neuen deutschen Universität Straßburg betrauten Freiherrn v. Roggenbach an mich stand, ob ich einem Rufe als Ana- 
tom nach Straßburg im Elsaß folgen wolle. Mit meiner Frau ging ich zu meinen Schwiegereltern. Es war ja klar, da $B$ ihnen und meiner Frau der Abschied voneinander schmerzlich sein mußte; aber mein Schwiegervater, der meine Wünsche kannte, stimmte mir gleich freudig bei, den Ruf anzunehmen. Ich verdankte ihn, wie erwähnt dem Umstande, daB Max Schultze (Bonn) und Lieberkühn, dieser damals in Marburg, abgelehnt und Henle und v. Recklinghausen, der schon für Straßburg gewonnen war, für mich gewirkt hatten.

\section{Straßburg.}

Eröffnung der neuen Universität; der Zwischenfall v. AufseB-Binding. Freiherr v. Roggenbach. - Erste Einrichtungen; akademisches Lagerleben. Die medizinische Fakultät; mein Kollege und Freund G. Joessel. - Neubau des Anatomischen und Pathologischen Instituts. - Friedrich v. Recklinghausen. - Andere Straßburger Kollegen; Adolf Kussmaul. - Institutstätigkeit; meine Assistenten und Laboranten.-Das Straßburger Bürgerspital. Berufungen von Straßburg aus. - Vom Deutsch- und Französisch-Sprechen im Elsaß. - Politische Stellung Elsaß-Lothringens; v. Moeller, v. Manteuffel. - Gespräch mit französischen Kollegen über das Elsaß. - Unbeliebtheit der norddeutschen, namentlich der preußischen Beamten; der Zaberner Zwischenfall. - Die elsässische Bevölkerung. - Friedrich Alth off; meine Berufung nach Berlin; Einigung mit Reichert; Reicherts Tod.

Die Umzugsfahrt ging über Berlin zu meinen Eltern nach Bökerhof, wo meine Frau mit meinen beiden in Breslau geborenen Kindern noch einige Zeit blieb. Am I8. April 1872 hielt ich meinen Einzug in Straßburg und stieg im damaligen Englischen Hofe ab. Ich nahm Besitz von der mir durch den Universitätsquästor vorher gemieteten Wohnung am Alten Weinmarkt, machte die nötigen Besuche und richtete mich in dem damaligen Anatomischen Institute, so gut es eben gehen wollte, ein. Einige Tage darauf folgte mir meine Frau mit den Kindern nach; ich holte sie von Heidelberg ab. Auch kam mein Schwiegervater nach, um der Feier zur Eröffnung der Universität am I. Mai 1872 beizuwohnen.

Als erster Rektor war der Theologe Bruch, der bereits der französischen Universität angehört hatte, bestellt. Im Schlosse, welches als Festgebäude für die Universität eingerichtet war, wurde der Festakt vorgenommen und Bruch und Anton Springer hielten die 
142 Eröffnung der Universität Straßburg. Zwischenfall AufseB-Binding.

Festreden. Am Nachmittage ereignete sich der unliebsame Zwischenfall mit dem Freiherrn v. AufseB, der seiner Zeit soviel Aufsehen erregte. Wie mir berichtet wurde, ging es dabei in folgender Weise zu: Vor dem Schlosse hatten sich eine große Menge Einheimischer und Eingewanderte versammelt, um Festgesängen und Ansprachen zu lauschen. Nach einem der Gesänge oder nach einer Ansprache ertönten plötzlich vom Schlosse her einige schrille Pfiffe, die man im Augenblicke kaum anders als eine Verhöhnung deuten konnte. Der eben nach Straßburg berufene Rechtslehrer Karl Binding eilte ins Schloß und sah dort auf einer zum Hofe hinabführenden Treppe einen älteren Mann stehen, der mit einem kleinen Pfeifchen wieder pfiff. Er rief ihm von unten zu, daß er das Pfeifen unterlassen möge, der Mann hörte aber nicht darauf, sondern setzte wieder zum Pfeifen an. Da eilte Binding die Treppe hinauf, begreiflicherweise in der Meinung, da $B$ es sich tatsächlich um eine Verhöhnung handle und zog dem ihm Unbekannten heftig den Arm mit der Pfeife weg, ihm dabei seine vermeintliche Ungehörigkeit verweisend. Der im höheren Alter stehende, auf die unsanfte Berührung nicht gefaßte Mann, es war der Freiherr v. AufseB, der zur Teilnahme an dem Feste gekommen war, kam zu Fall. Weiter ist nichts geschehen. Von einer Mißhandlung seitens Bindings, wie verbreitet wurde, ist keine Rede. $v$. Aufse $B$ reiste auch am anderen Tage ohne irgend einen Schaden genommen zu haben $a b$, verstarb aber nach einigen Tagen an einer Lungenentzündung, die nun auch wieder ungerechter Weise mit dem Falle in Verbindung gebracht worden ist. Das Verhalten des Freiherrn v. Aufseß erklärte sich dadurch, daß der schwerhörige alte Herr durch das Pfeifen seinen Diener, der mit ihm im Schlosse Wohnung hatte, herbeiholen wollte. Wegen seines Gehörleidens hatte er auch den Warnungsruf Bindings nicht vernommen und so kam durch eine zufällige Verkettung von drei Dingen, die nichts miteinander zu tun hatten, der Gesänge und Reden, der Schwerhörigkeit des Freiherrn und dessen Erkrankung das Unglück zu Stande, infolgedessen Binding so hart beurteilt wurde.

Am anderen Tage fand der Ausflug nach dem Odilienberge statt, welcher den Glanzpunkt der Festlichkeiten darstellte. Wer diesen Tag miterlebt hat, wird ihn nicht vergessen. Die Begeisterung bei den Reden, die in das zu den Füßen der Redner und Hörer ausge- 
breitete blühende Land hinein von dieser hohen, geschichtlich berühmten Warte gehalten wurden, war hoch und echt. Die Beteiligung an dieser Bergfeier war eine unerwartet große, so daß wohl ein Viertel der Anwesenden bei der einfachen Mittagskost, welche die Klosterfrauen auf dem Odilienberge zu verabreichen übernommen hatten, übergangen werden mußten. Das führte $\mathrm{zu}$ manchen zum Teil komischen Szenen. Doch wurde zum Schluß noch so gut gesorgt, wie es eben möglich war. Ich habe den schönen Berg später noch öfter besucht.

Nun begann aber die Arbeit: Täglich fanden Beratungen von Seiten des Senates und der Fakultäten statt. Abends kam man dann meist in der Meisengasse im "Café de la Mésange" zusammen, wo oft wichtige Verabredungen getroffen wurden. Die ersten Sitzungen der medizinischen Fakultät fanden in dem Gebäude statt. in welchem das Physiologische Institut untergebracht war, wo Goltz uns ein passendes Zimmer zur Verfügung stellen konnte. Als die heiße Jahreszeit herankam, saßen wir öfters da in Hemdärmeln, rauchten Zigarren und nahmen auch wohl ein Glas Bier; Fakultätssitzungen wie diesc, sind gewiß sehr selten gehalten worden. Die ersten Einrichtungen in den Instituten mußten oft aus dem Stegreif gemacht werden; v. Recklinghausen und ich wanderten von Laden zu Laden, stiegen $\mathrm{zu}$ den Magazinen hinauf, um selbst alles auszusuchen und einzukaufen, was nötig war. Binding hatte völlig Recht, wenn er die damaligen Zustände in Straßburg als ein , akademisches Lagerleben" bezeichnete.

Trotz aller dieser Unvollkommenheiten und aller Mühen, die es machte, einen gewohnten und geordneten Betrieb einzurichten, kann ich sagen, da $B$ diese Zeit die schönste meines Lebens war. In dem erhebenden Gefühl, mitgewirkt zu haben an der Neuaufrichtung des Deutschen Reiches, an der Wiedergewinnung des echten deutschen Landes Elsaß und der Wiederaufrichtung einer alten, berühmten deutschen Universität, liegt etwas so Hohes und Befriedigendes, wie es durch nichts anderes gegeben werden kann. Wir Alle, die wir damals berufen wurden, mitzuhelfen und es in noch frischem, jugendlichem Alter mit voller Kraft tur konnten, sind $\mathrm{zu}$ beneiden.

Mit mir waren zur Medizinischen Falkultät berufen: Friedrich Goltz, mein ehemaliger Königsberger Kollege, als Physiologe, 
144 Die Straßb. medizin. Fakultät. Verhandl. mit Roggenbach u. G. Joessel.

Friedrich v. Recklinghausen als Pathologischer Anatom, Oswald Schmiedeberg als Pharmakologe, Ernst Leyden als innerer Kliniker, Albert Lücke als chirurgischer Kliniker, Adolf Gusserow als gynäkologischer Kliniker, Freiherr Richard v. Krafft-Ebing als Neurologe, Ludwig La que ur als Ophthalmologe. Dazu traten von der früheren französischen Universität Friedrich Wieger als Pathologe, Eduard Strohl als Pharmakologe, Adolf Aubenas als Gynäkologe, Abraham Ku h n als Otiater und Georg Joessel als Anatom. Sch üt zenberger behielt seine innere Klinik im Bürgerspital, trat aber nicht in die neue Fakultät ein. Er suchte längere Zeit für die Beibehaltung einer besonderen elsässischen medizinischen Fakultät neben der deutschen $\mathrm{zu}$ wirken und bereitete uns im Bürgerspitale manche Schwierigkeiten. Das taten auch noch andere Primarärzte, die aus der französischen Zeit am Bürgerspital verblieben waren. Wieger, Strohl, Aubenas, Kuhn und insbesondere Joessel dagegen schlossen sich aufrichtig der neuen deutschen Fakultät an.

Joessel war von Roggenbach, ohne da $B$ ich darüber befragt worden war, zum Ordinarius mit dem Lehrauftrage für topographische Anatomie ernannt worden. Er war aber völlig im Unklaren gelassen worden, wie seine Stellung zu mir abzugrenzen wäre, welche Rechte er am Leichenbezuge, am Präpariersaale, an der Sammlung, an den Räumen des vorhandenen Instituts haben sollte. Es mußte meine erste Sorge sein, zumal die vorhandenen Räume und das Material keine Teilung zuließ, hier Klarheit zu schaffen. Es lag da ein Fehler vor, wie sich deren Roggenbach mehrere hatte zu Schulden kommen lassen. Er war eine edle, hochzuschätzende Persönlichkeit, Idealist, aber kein Praktiker. Er hätte sich ja beraten lassen können; aber die Berater, die er zuzog, waren auch nicht in allem bewandert. So kam es denn auch, da $B$ Roggenbach, als wir erst Alle da waren, die Tätigkeiten beginnen sollten, und von allen Seiten die Anforderungen an ihn herantraten, gewahr wurde, da $B$ er der Sache nicht völlig gewachsen war und zurücktrat.

In der Angelegenheit meines Kollegen Joessel machte ich die Schwierigkeiten geltend, die sich aus der Doppelbesetzung des Faches der Anatomie gleich bei der Begründung der Universität ergeben mußten. Ich schlug vor, daß Joessel die Stelle eines Prosektors am Institute einnehmen solle; mir war ja dessen Direktion amtlich 
übertragen worden. Ihm, als Prosektor, würde ich einen Anteil an den Honoraren des Präpariersaales abtreten; ferner solle er die Vorlesungen über topographische Anatomie nebst topographisch-anatomischen Übungen an den Leichen allein übertragen bekommen, mir aber wieder im Sommer bei den mikroskopischen Übungskursen helfen. Ich bat Roggenbach, ihm die Annahme dieser Vorschläge zu empfehlen; ich würde auch selbst ihn dazu zu bestimmen suchen. Ich ging nun zunächst zu Joessel und stellte ihm vor, daß er mit Annahme meiner Vorschläge eine volle, ihn befriedigende Tätigkeit haben werde. Falls er nicht annehme, müßte ich mir einen anderen Prosektor suchen und dann wäre er in seinen Vorlesungen, wie in seinem Material, selbst bei meinem besten Willen, beschränkt. Wie ich vorausgesehen hatte, sagte mir Joessel, er wolle sich die Sache überlegen und mit Roggenbach Rücksprache nehmen. Am anderen Tage war die Angelegenheit nach meinen Vorschlägen erledigt und sie gedieh für Jeden von uns zum Besten. Joessel war ein aufrichtiger, vortrefflicher Mensch, der der Sache dienen wollte. Ebenso stand es mit seiner Familic. Seine junge Frau war eine Tochter aus dem altberühmten Glockengießerhause Edel, eine liebe, ihrem schönen Namen voll entsprechende Natur, mit der meine Frau bald volle Freundschaft schloß. Joessel nahm wahr, da $B$ er auf dem Präpariersaale den größten Einfluß gewann, der ihm als Prosektor auch zustand und den ich ihm gern überließ, zumal er sein Amt in bester Weise verwaltete. So konnte er auch für seine topographisch-anatomischen Vorlesungen und Übungen am besten sorgen, da ich ihm stets vorher sagte, welches Material ich für meine Vorlesungen gebrauchte und ihm die Bestimmung über das andere überließ. Seine Vorlesungen über Topographische Anatomie erwiesen sich, da er selbst ausübender. Chirurg gewesen war, als sehr geeignet und wirksam und wurden von den Studierenden sehr geschätzt. Von mikroskopischer Anatomie hatte er wenig Kenntnis; ich half ihm erst sich da einzubürgern, so daB er auch leidlich fertig wurde. Nachher, als ich in v. Brunn und v. Mihalkovics geübte Helfer fand und Joessel ohnehin genug Arbeit hatte, gab er die Teilnahme an diesen Übungen freiwillig ab. Zwischen Joessel und mir entstand bald eine aufrichtige Freundschaft, die sich auch auf die beiden Familien übertrug und bis heute bei den noch Überlebenden fortbesteht. Auch zwischen meinem 
Nachfolger Gustav Schwalbe und Joessel entwickelte sich ein gutes Verhältnis. Leider hat ein früher Tod (infolge eines Abdominaltyphus) den mir lieben und werten Kollegen vorzeitig hinweggerafft. Ich ließ es mir nicht nehmen, von Berlin nach Straßburg zu eilen, um ihm persönlich das letzte Geleit zu geben.

Von Kollegen anderer Fakultäten, die schon bei der Gründung der Universität zugegen waren, nenne ich die Theologen Bruch, Reuss und Cunitz, alle von der früheren französischen Universität übernommen, die Juristen Heinrich Brunner, Paul Laband, August Sigismund Schultze, Sohn meines früheren Greifswalder Lehrers Sigismund Schultze und Bruder Max Schultzes in Bonn und Bernhard Schultzes, des Jenenser Gynäkologen; von Mitgliedern der Philosophischen Fakultät den Chemiker Adolf Baeyer, den Physiker August Kundt, die Botaniker Anton de Bary und Graf Hermann v. Solms-La ubach, die Zoologen Oskar Schmidt und Alexander Götte, den Paläontologen Wilhelm Schimper, den Mineralogen Paul Groth, die Mathematiker Reye und Christ offel, den Geologen Wilhelm Benecke, den National-Ökonomen Gustav Schmoller, den Philologen Wilhelm Studemund und den Astronomen Friedrich Winnecke, von denen wir mit Oskar Schmidt, Götte, de Bary, Winnecke und Kundt auch in Familienumgang kamen.

Wie ich in Königsberg und Breslau das Kegelspiel gepflegt hatte, so auch in Straßburg, wo sich bald eine Kegelgesellschaft bildete, deren eifrigstes Mitglied der Graf Solms-Laubach war. Er zeigte das einst in belustigender Weise, indem er, als ich einen schön gezielten Wurf unserer Gegenpartei, der mit einem Schlage die Acht um den König niederwarf, mit einem „Das war ja eine prächtige Kugel", anerkannte, mir das leise verwies: „Das dürfe ich nicht sagen, das feuere unsere Gegner nur an."

Wie sich das naturgemäß entwickelte, herrschte damals im Verkehr mit den Kollegen eine angenehme Einigkeit. Jeder fühlte, daß er hier mit seinen Kollegen vor eine wichtige vaterländische und wissenschaftliche Aufgabe gestellt war, tat sein Bestes und suchte das $\mathrm{Zu}$ sammenwirken aller eingewanderten Deutschen und deutschfühlenden Einheimischen $\mathrm{zu}$ fördern, gegenüber der merkbaren Hinneigung vieler Elsässer zu Frankreich. Dieser Zusammenhalt, das sichtbare 
Aufblühen der Universität, die fast durchweg uns sympathische Bevölkerung des anheimelnden Landes, die Nähe des Schwarzwaldes und der Vogesen wie der Schweiz, die uns bequeme Gelegenheiten zu den lohnendsten kürzeren Ausflügen und zu längeren Ferienaufenthalten mit Familie bot, machten mir und den Meinigen die elf Jahre, die wir in Straßburg zubrachten, zu den angenehmsten, die es für uns gegeben hat.

In der medizinischen Fakultät trat bald ein Wechsel ein, indem Leyden und Gusserow nach Berlin, v. Krafft-E.bing nach Wien berufen wurden und den Ruf annahmen. An ihre Stelle traten Adolf Kussmaul von Freiburg kommend, Wilhelm A. Freund, nachdem Spiegelberg abgelehnt hatte, aus Breslau und Friedrich Jolly aus Würzburg. Mit allen dreien traten wir wieder in Familienverkehr angenehmster Art, der auch dauernd geblieben ist, wie überhaupt der mit sämtlichen Mitgliedern der medizinischen Fakultät, die Herren Wieger, Strohl und Aubenas ausgenommen, mit denen wir zwar in gutem Einvernehmen auf Fakultätsboden lebten, die jedoch keinen näheren Anschlu $B$ an die zugewanderten deutschen Kollegen suchten.

Insbesondere will ich hier noch, außer Joessels, der Kollegen und Freunde v. Recklinghausen, Kussmaul, W. A. Freund, de Bary, Kundt, Schmiedeberg, Oswald Kohts und Fr. Wilhelm $\mathrm{Zah} n$ gedenken, die mir im Leben besonders lieb und wert geworden sind, vor allem Recklinghausen. Ich erwähnte bereits von ihm, da $B$ ich die erste persönliche Beziehung in Königsberg hatte. Er kam von da nach Würzburg und war dann einer der ersten, die nach Straßburg berufen wurden. Er hat auch auf die Besetzung der medizinischen Fakultät in Straßburg Einfluß gehabt. Die erste Besprechung, die ich mit ihm in Straßburg hatte, betraf den Leichenbezug. In Straßburg bestand aus französischer Zeit die Gepflogenheit, da $B$ die Leichen derjenigen Personen, welche im Bürgerspital bis zu ihrem Tode unentgeltlich verpflegt und ärztlich behandelt worden waren, der Anatomie überwiesen wurden, wo sie eine Woche lang zum Unterricht der Studierenden verwendet werden durften. Nachher wurden. diese Leichen, nach sorgfältiger Herrichtung des früheren Zustandes, eingesargt, in die Spitalskapelle verbracht und von dort aus unter Zuziehung der Angehörigen und Freunde, die benachrichtigt wurden, in der üblichen feierlichen Weise beerdigt. Die Bevölkerung Straß- 
burgs war daran gewöhnt, so daß Niemand daran Anstoß nahm und da $B$ mit Ausnahme eines Falles, von dem ich bald berichten werde, solange ich in Straßburg war, keine Unzuträglichkeiten vorkamen. Für Recklinghausen war, da ein Pathologisches Institut bei der französischen Universität gefehlt hatte, eine Art Baracke an die Anatomische Anstalt angebaut worden und es handelte sich darum, festzustellen, wem die vom Spital zur Anatomie gelieferten Leichen überwiesen werden sollten, dem Pathologischen oder dem Normalen Anatomen. $\mathrm{Da}$ andere Bezugsquellen in Elsaß-Lothringen kaum vorhanden waren, so mußte diese Frage zwischen Recklinghausen und mir entschieden werden, denn der Spitalsverwaltung konnte die Überweisung unmöglich überlassen werden. Recklinghausen schlug vor, zunächst ihm die Leichen zu überweisen; ich möge das Bedürfnis der Anatomie ihm rechtzeitig anmelden; er werde sorgen, $\mathrm{da} B$ dem entsprochen werde. Als früherer Pathologischer Anatom mußte ich mir sagen, da $B$ Recklinghausens Vorschlag durchaus berechtigt war und so trafen wir die Einigung über diesen wichtigen Punkt. In der ganzen Zeit unseres Zusammenarbeitens in Straßburg ist nicht die geringste Mißhelligkeit zwischen uns vorgekommen.

Der Fall, dessen ich vorhin als einer Unzuträglichkeit bei der erwähnten Behandlung der Spitalsleichen in Straßburg gedachte, muB als ein tragikomischer bezeichnet werden. Es handelte sich um die Bestattung einer älteren Frau. Die Angehörigen und ein Teil der Bekannten der Verstorbenen waren in der Kapelle der Anatomie, die beim Neubau dieser Anstalt dort eingerichtet war, um den aufgebahrten Sarg bereits versammelt und warteten auf den Priester. Ich kam auf dem Wege zum Anatomischen Institute gerade an der offenstehenden Kapelle vorbei und als ich die Trauerversammlung dort gewahrte, stellte ich mich zu den Leuten vor den Sarg, in der bestimmten Absicht, ihnen zu zeigen, da B ich die Toten, die mir überwiesen waren, ehren wolle. Bei der Anatomie waren damals zwei Brüder, Toni Adam und Jean Adam, Elsässer, als Diener angestellt, die ich von der französischen Anatomieverwaltung her übernommen hatte, und mit denen ich auch sehr zufrieden war. Der Jüngere, Jean, war ein herkulisch gebauter Mann; er hatte gerade den Dienst bei der Beerdigung und ich hörte ihn, als ich hinzutrat, die Leidtragenden fragen, ob er den Sarg noch einmal öffnen solle. 
Einige schüttelten den Kopf, doch einer sagte: „Wir möchten doch die Mutter noch einmal sehen." Jean hob zuversichtlich den Deckel vom Sarge und man erblickte die Leiche eines bärtigen Mannes! Stumm schauten die Leute auf die Leiche, dann erhob sich ein Gemurmel des Unwillens; der Diener selbst war erschrocken. Ich dachte, es sei am besten, ihm als Elsässer die Lösung mit seinen Landsleuten zu überlassen und das war auch richtig. Jean, der bald seine Ruhe wiedergefunden hatte, sagte: „Wart' ein weng', ich hol' Euch die Mutter." Inzwischen war aber der Unwille der Leute gestiegen und aus dem Gemurmel brachen laute Vorwürfe heraus. Da verlor auch er seine Geduld, trat vor, faßte den Sarg und sagte festen Tones: „Meinen denn Ihr, ich könnt alli alte Wiwer von Stroßburi kennen?" Damit hob er den Sarg, wie wenn es eine kleine Kiste gewesen wäre und trug ihn hinaus, kam gleich darauf zurück mit einem anderen Sarge, stellte ihn auf die Bahre, hob den Deckel und zeigte auf die darin gebettete Leiche der Frau, um deren Bestattung es sich handelte. Alle blieben ruhig und ohne weitere Störung vollzog sich die Beerdigung in der hergebrachten Weise. Ich war froh, daB ich einen Elsässer als Anatomiewärter hatte; einem anderen Deutschen wäre die Sache wohl nicht so leicht geworden.

Toni Adam starb während meiner Amtsführung; Jean verheiratete sich, kündigte seine Stelle bei der Anatomie und eröffnete eine kleine Wirtschaft. Die dann von mir angenommenen beiden Diener, Sachsen von Geburt, hatten, obwohl sie sehr ruhige und gefällige Leute waren, doch viel mehr Schwierigkeiten mit der heimischen Bevölkerung.

Die von mir damals übernommene Anatomische Anstalt lag am Spitaltor, sie bestand aus einer ehemaligen Kirche, in der der Hörsaal und der Sammlungsraum untergebracht war, aus dem Präpariersaale und einigen kleinen Arbeitszimmern; das Ganze nur sehr bescheiden ausgestattet und in sehr dürftigem Zustande. Viel ungünstiger war Recklinghausen daran. Seine Baracke war in aller Eile hergerichtet worden. Die Fenster in dem Laboratoriumsraume schlossen sehr unvollkommen, so da $B$ man an kühlen Tagen beständig in Zugluft an den Tischen arbeiten mußte. Der Obduktionsraum lag nach der Sonnenseite; oft habe ich da im Sommer meinen Kollegen seines Amtes walten sehen, während ihm der Schweiß von der Stirne 
rann, und das ist, während die Hände mit der Leiche zu tun haben, wirklich keine Annehmlichkeit.

Uns Beiden war bei unserer Berufung ein neues Institut versprochen worden und wir hatten uns dahin geeinigt, da $B$ wir beide Anstalten in einem Gebäude unterbringen wollten, so daß die Leichenräume, die Hörsäle, die Zentralheizung, die Pförtnerwohnung für beide gemeinsam wären, alles übrige aber getrennt. Den Plan dazu hatten wir in den Grundzügen bald nach unserem Eintreffen in Straßburg entworfen in der sicheren Erwartung, da $B$ mit dem Neubau alsbald begonnen werden würde. Aber wir hatten unsere Rechnung ohne den Wirt, d. h. diesmal ohne die Regierung gemacht, die uns - und ich kann das nicht ohne Vorwurf sagen - noch mehrere Jahre warten ließ und, wer weiß, noch länger hätte warten lassen, wenn wir Beide nicht in die Lage gekommen wären, einen starken Druck auszuüben, namentlich Recklinghausen, der ja auch am übelsten daran war. Er erhielt, als Rokitansky, der berühmte Wiener Pathologische Anatom, in den Ruhestand getreten war, den Ruf, sein Nachfolger in Wien zu werden. Da brachte er, und mit Recht, das ihm gemachte Versprechen in Erinnerung, reiste nach Wien, um sich an Ort und Stelle von der Lage der Dinge zu überzeugen, denn so leicht schlug damals wohl kein Pathologischer Anatom einen Ruf nach Wien als Nachfolger Rokitanskys aus. Recklinghausen war es aber doch eine Ehrenpflicht, nicht gleich wieder Straßburg den Rücken zu kehren. Wir waren auch alle der Meinung, daß wir die Pflicht hätten, als erst berufene Lehrer einmal die Universität in vollen Betrieb bringen zu helfen, bevor wir, gegebenen Falles, einen weiteren selbst vorteilhafteren Ruf annähmen. Das war auch die Auffassung der Reichsregierung. Als Recklinghausen von Wien zurückkehrte, wurde ihm die bindendste Versprechung gegeben, da $B$ mit dem Neubau seines Institutes sofort begonnen werden solle. Er bestand darauf, da $B$, nach unserem vorhin mitgeteilten Planc, das Anatomische Institut gleichzeitig mit dem Pathologischen gebaut werden müsse. Zum Überfluß hätte auch ich dieser Forderung Nachdruck geben können; denn als nun Recklinghausen in Wien endgültig ablehnte, hatte man ihn vom Kreise der dortigen Kollegen aus ersucht, bei mir anzufragen, ob ich nicht etwa geneigt wäre, die Nachfolgerschaft Rokitanskys zu übernehmen. Ich lehnte, so ehrenvoll es für mich sein mußte, 
das Vertrauen der Wiener Kollegen zu besitzen, ab und bat Recklinghausen, dies nach Wien zu berichten. Die Aussicht, in Straßburg schöpferisch wirkend aufzutreten, dort mit Recklinghausen, den ich von Tag zu Tag mehr schätzen und als wahren Freund kennen lernte, zusammen unter einem Dache zu arbeiten, lie $B$ alles andere in den Hintergrund treten. Die nun kommenden Straßburger Jahre sind die schönsten meines Lebens geblieben. Recklinghausen und ich paßten gut zusammen: Beide von der roten Erde Westfalens, Beide mit den gleichen fachmännischen Interessen, denn Recklinghausen war ein ebenso guter Anatom wie Patholog und ich hatte ja die gleichen Arbeitsfelder. Wir vertrauten einander vollständig. Oft habe ich noch den Obduktionen Recklinghausens beigewohnt. Bei meinen Arbeiten zog ich sein reiches Wissen und sein mitunter auch wohl hyperkritisches Urteil zu Rate, ebenso wie er fast nichts arbeitete, ohne mir davon Mitteilung zu machen, mir seine Präparate zu zeigen und sich mit mir darüber zu besprechen. Unsere Sammlungen in einem Hause standen Jedem jeder Zeit zu Gebote. Ich hatte jeden Tag Gelegenheit, frisch gewonnene Präparate aus dem Pathologischen Institute zu erlangen, ebenso wie ich pathologische Befunde an den Leichen, die dem Anatomischen Institute überwiesen waren, alsbald Recklinghausen mitteilte und sie ihm auf Wunsch überlieB. Dies Zusammenarbeiten des Pathologischen mit dem Normalen Anatomen hat große Vorteile. Jedenfalls würde ich empfehlen, bei Neueinrichtungen von Universitäten, das Normal-Anatomische mit dem Pathologischen Institut dicht zusammenzulegen. Soll es unter einem Dache sein, dann müssen sich die beiden Anstaltsvorstände allerdings so gut verstehen, wie Recklinghausen und ich unserer Zeit, was nicht für Alle gesichert werden kann.

Wenn eines mir den Abschied von Straßburg schwer gemacht hat, so war es die Trennung von Recklinghausen. Ihm, das empfand ich, ging die Trennung von mir auch ans Herz. Recklinghausen war kein Mann vieler Worte, er hielt es mehr mit Taten. Ich vergesse ihm nie die Art, wie er Abschied von mir nahm, als ich StraBburg verließ. Den letzten Tag meines Aufenthaltes dort in meiner Stellung als Leiter der Anatomischen Anstalt brachte ich in dieser zu, um noch dies und jenes $\mathrm{zu}$ ordnen, mir noch einmal alle von mir der Sammlung einverleibten Präparate anzusehen und mich vom Per- 
sonal der Anstalt zu verabschieden. Als ich schweren Herzens das mir lieb und wert gewordene Haus verlieB, dunkelte es bereits. Ich sah auf der Straße einen Mann auf und ab gehen und als ich ihm näher kam, erkannte ich Recklinghausen. Stumm trat er an meine Seite und reichte mir die Hand. Wir gingen zusammen heim bis zu meiner Wohnung und wechselten nur wenige Worte; ich wußte auch so, was mir Recklinghausen sagen wollte. Noch ein fester Händedruck und wir schieden.

Wir schieden, aber nicht für immer. Mir war Straßburg so lieb und wert geworden, daß ich bis zum Ausbruch des jetzigen Weltkrieges kein Jahr vorübergehen ließ, ohne Straßburg für einige Tage besucht zu haben. In erster Linie galt mein Besuch Recklinghausen und seiner Familie und das war mir stets ein Festtag. Ihm, ich darf es wohl sagen, auch. Dann taute er auf, die Universitätsangelegenheiten, die Dinge im Elsaß, die eigenen Pläne und Arbeiten, die Familien und gemeinsamen Freunde gaben reichen Stoff zur Unterhaltung und man sprach sich offen aus, wie es unter wahren Freunden sein muß. Bei einem solchen Besuche war gerade auch Rudolf Virchow in Straßburg anwesend. Ich war mit Recklinghausen im Pathologischen Institut, wo er mir in seinem Zimmer einen Kinderschädel zeigte, den er auf einem Tische neben dem Eingang in sein Arbeitszimmer liegen hatte. "Sehen Sie sich den Schädel einmal an," sagte er zu mir, ,daran ist etwas Besonderes, worüber ich mir aber noch nicht völlig klar bin; ich habe ihn mir deshalb hier auf den Tisch gelegt, damit ich täglich öfters an ihn erinnert werde." Ich náhm den Schädel zur Hand, betrachtete ihn mir genau, sah auch wohl, daß er nicht normal war, vermochte aber auch keine bestimmte Diagnose abzugeben. Einige Zeit später kam Virchow. Wir Beide gingen ihm entgegen und Recklinghausen führte ihn in sein Zimmer; ich folgte. Virchow und Recklinghausen waren im Gespräch, als sie das Zimmer betraten, über andere Dinge, als über den Schädel, von dem Virchow nichts wußte. Als er mit Recklinghausen an dem Tische vorbeiging, streckte er mitten im Gespräch die Hand nach dem Schädel aus, nahm ihn im Weiterschreiten einen Augenblick vors Auge und sagte: „,Da haben Sie ja ein ausgezeichnetes Stück von“"... - leider kann ich mich nicht mehr entsinnen, um was es sich handelte. Der Schädel wurde wieder an seinen Platz gelegt; es war von ihm 
nicht weiter die Rede. Als Virchow sich später empfahl, geleiteten wir Beide ihn wieder zur Haustür und kehrten in Recklinghausens Zimmer zurück. Recklinghausen nahm den Schädel sinnend in die Hand, legte ihn wieder hin und sagte zu mir: „Der Alte sieht doch noch mehr, als wir Beide!" Darin gab ich ihm vollkommen recht. Ich habe in meinem Leben kaum einen Biologen kennen gelernt, der eine so scharfe und sichere Beobachtungsgabe hatte, wie Rudolf Virchow.

Meine Besuche in StraBburg galten, auBer der Familie Recklinghausen, insbesondere den Hinterbliebenen meines früheren Kollegen Joessel, dann meinem Nachfolger im Amte, Gustav Schwalbe, zu dem ich auch in ein freundschaftliches Verhältnis trat, dem Zoologen Alexander Goette, Nachfolger vor Oskar Schmidt, den beiden Ophthalmologen Laqueur und Jakob Stilling, Sohn von Benedikt Stilling in Kassel, dem deutschen Bahnbrecher in der Erforschung des feineren Baues des Zentralnervensystems. Jakob Stilling hatte das Interesse für die anatomisch-physiologische Untersuchung dieses Organs geerbt und hat mir manches schöne Präparat geschenkt. Besonders nahe traten die Meinigen mit mir zur Familie meines Hausarztes, Professors Oswald Kohts, der als Assistent Leydens von Königsberg nach Straßburg gekommen war und später dort die Professur für Kinderheilkunde erhielt. Mit Kohts befreundet war der Assistent v. Recklinghausens, Friedrich Wilhelm $\mathrm{Zah} \mathrm{n}$, der später Pathologischer Anatom in Genf wurde, dann Pa ul $Z$ weifel, Assistent Gusserows, der noch heute als Kliniker in Leipzig wirkt. Mit allen diesen jungen frischen Kräften, die sich sämtlich zu ehrenvollen Lebensstellungen durchgearbeitet haben, trat ich in gute Beziehungen, die sich $z u$ freundschaftlichen gestalteten. Zahn nahm sich später in Genf meiner beiden Töchter, die dort eine Pension zur Ausbildung im Französischen, Englischen und Italienischen besuchten, in bester Weise an und führte sie in seine Familie ein. So kam es, daß wir auch später noch in Verbindung blieben und ich ihn in Genf mehrere Male besuchte. Mit Freund Kohts habe ich manche Fußwanderung im Schwarzwalde und in den Vogesen, dem Wasgenwalde, gemacht. Auch über die alte St. Gotthardstraße bis nach Mailand hinunter sind wir einmal, manche Strecken zu $\mathrm{FuB}$, gewandert.

Nach und nach lichteten sich die Reihen der erstberufenen Straß- 
burger Kollegen und Freunde. Zuerst verließen, wie schon berichtet, Leyden und Gusserow die Argentina, um in Berlin ihre Laufbahn zu beschließen; dies war schon vor meinem Weggange von Straßburg. Dann starb Joessel; ihm folgten Lücke und Goltz. Später traf das Los Laqueur und Stilling, dann Recklinghausen und Kuhn, der in Anatomischen Institut jahrelang seinen ständigen Arbeitsplatz hatte. Zahn undZweifel verließen Straßburg. Oskar Schmidt, mit dem wir auch Familienverkehr pflegten, ging vorzeitig in den Tod. Sein Sohn Erich, später mein Kollege in Berlin und Rektor im Jahre der Ioo jährigen Jubelfeier der dortigen Universität, wo er seines Amtes meisterlich waltete - es war eine schöne Abendröte für sein bald endensollendes noch junges Leben - trat damals in Straßburg als "Aias“ in der danach genannten Tragödie des Sophokles auf, die aus einem festlichen AnlaB von Gymnasiasten gespielt wurde. Die Aufführung fand so viel Beifall, daß sie mit gleichem Erfolge wiederholt wurde. Der junge Erich Schmidt gab seine Rolle in vollendeter Weise, wie mir noch heute in lebhafter Erinnerung geblieben ist.

Lichtete sich so der Kreis der mit mir zur Gründung der Universität Berufenen, so kamen neue Männer hinzu; mit einigen von ihnen gewann ich wiederum treue Freundschaft. Besonders nahe trat ich Kussmaul. Seine mit Recht berühmt gewordenen , Jugenderinnerungen eines alten Arztes" haben mich angeregt, mit diesen Blättern $\mathrm{zu}$ versuchen, ob ich nicht, zunächst für meine Angehörigen und die wenigen mir noch lebenden alten Freunde und Bekannten etwas hinterlassen könnte, was ihnen liebe, aber vielleicht verblaßte Erinnerungen wieder belebte. Kussmaul pflegte, wenn er seine klinischen Verpflichtungen erledigt hatte, zu mir auf die Anatomie zu kommen, wo er wußte, daß ich zu dieser Zeit sicher zu treffen sei, sich mit mir über unsere eigenen Arbeiten und andere medizinische Dinge, aber auch in gemütlichem Plaudertone, der ihm in selten fesselnder Weise eigen war, über sonstige Erlebnisse und über die Tagesereignisse zu unterhalten. So verdanke ich ihm manche anregende und erquickliche Stunde. Eines von Kussmauls eigenen Erlebnissen mag hier mitgeteilt sein:

Der verstorbene Großherzog Friedrich von Baden, sicher einer der achtens- und liebenswertesten Fürsten seiner Zeit, war, als Kussmaul bereits von Freiburg nach Straßburg übersiedelt war, an einem 
schweren Typhus erkrankt. Der Leibarzt des Großherzogs, Dr. Tenner, war Kussmauls Freund, Studien- und Arbeitsgenosse; er veranlaßte, daß Kussmaul als ärztlicher Berater zugezogen wurde. Als dieser, der am Großherzoglichen Hofe gut bekannt und angesehen war, bei dem hohen Kranken erschien, fand er die Großherzogin am Bette ihres Gemahls, ihn besorgt überwachend und ihn öfter anredend. Kussmaul merkte, daß die um den Kranken, wie er bald erfuhr, fast ständig weilende besorgte Frau in ihrer Sorge des Guten $\mathrm{zu}$ viel tat und er bat, nachdem er einige Fragen an den Kranken gerichtet hatte, die Großherzogin, ihm in ein anstoßendes Zimmer zu folgen, um ihr, wie er vorwandte, einige Verhaltungsmaßregeln für die Besorgung des Kranken zu geben. Er sagte ihr da, daß vor allem bei solchen Fällen die größte Ruhe nötig sei und daß es sich deshalb empfehle, den Kranken möglichst viel allein unter der Obhut seines Arztes und eines Wärters zu lassen. Die Frau Großherzogin betonte darauf, daß es doch vorzugsweise ihre Sorge sein müsse, über ihren Gemahl $\mathrm{zu}$ wachen und seine Pflege zu übernehmen, sie möge sich das nicht nehmen lassen. Da sagte ihr Kussmaul, daß er das zwar vollkommen anerkenne, daß jedoch die Krankheit sich noch lange hinziehen könne und es deshalb Pflicht der hohen Frau sei, sich selbst frisch und leistungsfähig zu erhalten; namentlich möge sie sich die Nachtruhe gönnen. Auf Dr. Tenner und dessen Anordnungen könne sie sich unbedingt verlassen. Diese Nacht werde er selbst im Nebenzimmer des Kranken die Wache übernehmen. Es gelang Kussmaul, der in seinem ganzen Wesen als Arzt und als Mensch etwas so Beruhigendes und Vertrauen Einflößendes hatte, wie ich es bei keinem anderen Arzte in meinem Leben gesehen und selbst empfunden habe, die Großherzogin zu überzeugen. Er begab sich darauf allein in das Krankenzimmer zurück, ließ alle um den Kranken Anwesenden, außer Tenner und dem alten Leibdiener des Fürsten, das Zimmer verlassen, untersuchte den Kranken genau, bettete ihn dann selbst mit Hilfe Tenners und des Dieners und sagte dem Großherzog, er halte es für das Richtigste, wenn hauptsächlich der Leibdiener zur Pflege anwesend sei; die Großherzogin bedürfe der Ruhe, die er ihr dringend empfohlen habe. Darauf reichte der Kranke Kussmaul die Hand, sah ihn verständnisvoll an und sagte: „Ich danke Ihnen!“ 
156 A. Gusserow. W. A. Freund. Vereitelt. letzt. Besuch Straßburgs I9I4.

Ich erwähnte vorhin die so sehr überzeugende und beruhigende Art Kussmauls im Umgange mit Kranken oder deren Angehörigen. Ich möchte hinzufügend sagen, daß Kussmaul in seinem Auftreten als Arzt etwas so fast wunderbar Wirkendes hatte, daß seine Patienten, wenn sie ihn nur ansahen, sich halb genesen fühlen mußten. Wenn man von geborenen Ärzten spricht, so gehörte Kussmaul in erster Linie zu ihnen.

Ebenso wie mit Gusserow, trat ich mit W. A. Freund, der mir ja von Breslau her schon vertraut war, in lebhaften wissenschaftlichen und freundschaftlichen Verkehr. Im Hause Freunds, der ein großer Musikliebhaber und Kenner der Tonkunst war, wurde wieder eifrigst meiner Lieblingskunst gehuldigt, wie seiner Zeit in Breslau bei Freunds Rivalen Spiegelberg. - Gusserow hatte in Straßburg seine Glanzzeit; er war ein ausgezeichneter Lehrer und Kliniker. Von allen Seiten kamen die jungen angehenden Fachgenossen, um seine Lehrweise kennen zu lernen. Freund wie Gusserow sollte ich in Berlin später wieder treffen.

Ich setzte von Berlin aus meine jährlichen Besuche in Straßburg fort, bis ihnen der Ausbruch des Krieges am 4. August I9I4 ein Ziel setzte. Soll es mir vergönnt sein, die alte schöne Stadt nochmals zu betreten? - Ich darf es nach den über uns verhängten Friedensbedingungen und bei meinem hohen Alter nicht mehr hoffen. I9I4 war zum I. August mein Besuch dort schon geplant. Freund Schwalbe beging an diesem Tage seinen 70. Geburtstag und trat zugleich von seinem Lehramte zurück. Ich wollte der dazu geplanten Festveranstaltung beiwohnen, wobei ich zugleich meine Kollegen Goette und Schmiedeberg, sowie die hinterbliebenen Angehörigen Joessels, v. Recklinghausens und Stillings wiedersehen konnte. Von Straßburg wollte ich dann nach Lyon reisen, um an der zum 5. August aus gleichem Anlasse, wie für Schwalbe, geplanten Feier für meinen dortigen Kollegen Renaut, den ich sehr schätzte, teilzunehmen. Obwohl seit der Ermordung des Erzherzogspaares Franz Ferdinand von Österreich die Luft kriegsschwül war, glaubte ich immer noch nicht, daß der Krieg unvermeidlich sei und wollte am 3I. Juli noch abreisen; da kam die Erklärung der Kriegsbereitschaft und machte allen Friedensplänen ein jähes Ende. Ich bin seither wegen der durch den Krieg bedingten Reiseschwierigkeiten nicht 
wieder in Straßburg gewesen, traf aber mit Freund Schwalbe und dessen Frau I9I5 in Baden-Baden zusammen, wo wir zwei Wochen im selben Gasthofe weilten. Auch Kollegen Schmiedeberg sollte ich dort zu meiner großen Freude wiedersehen, den letzten aus den I872 nach Straßburg berufenen Mitgliedern der Medizinischen Fakultät, der noch in Straßburg im Amte war und nebst mir von allen damaligen Kollegen noch lebte. Schwalbe und dessen Gattin sind bald nach unserem letzten so angenehmen Badener Zusammensein aus dem Leben geschieden.

Im ersten Semester ihres neuerweckten deutschen Bestandes zählte die Straßburger Universität rund 250 Studierende. Ich hielt eine Vorlesung über die Anatomie des Zentralnervensystems vor I2 Zuhörern und gab einen mikroskopisch-anatomischen Kursus. Im darauffolgenden Winterhalbjahre fing dann der volle Betrieb an. Langsam, aber stetig wuchs die Zahl der Studierenden in allen Fakultäten; auch die jungen Elsässer, die sich anfangs noch zurückgehalten hatten, kamen heran und erwiesen sich vielfach als fleißige und tüchtige Leute. Mehrere von ihnen haben bei mir und meinen Kollegen gute eigene Laboratoriumsarbeiten $\mathrm{zu}$ Wege gebracht; ich nenne unter anderem die Dissertationen Dr. Paul Meyers über die Anatomie der Gehörschnecke, Dr. Sorgius' über die Lymphbahnen der Brustdrüse und Dr. Jaeger-Lüroths, der, wie auch Paul Meyer, Assistent am Anatomischen Institut wurde, über die Regio thyreoidea. Aber auch aus dem übrigen Deutschen Reiche kam uns guter Zuwachs, aus dem ich sechser hier gedenken will, des späteren Berliner Anatomen Hans Virchow, des Berliner Chirurgen Werner Körte, des Berliner Urologen Karl Posner, des Frankfurter Neurologen Ludwig Edinger und Paul Ehrlichs. Die beiden Letztgenannten zusammen mit Karl Weigert bildeten mein „Frankfurter

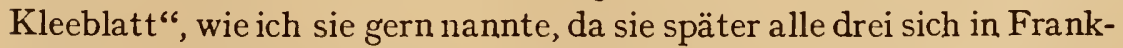
furt a. M. zusammenfanden. Als sechsten der Straßburger Schüler führe ich den späteren Hamburger Dermatologen Paul Unna hier an. Alle Genannten waren meine Schüler in Straßburg, außer Weigert, den ich schon in Breslau, wie berichtet, gewonnen hatte. Hans Virchow, Edinger und Unna arbeiteten auch in meinem Laboratorium. Paul Ehrlich aus Strehlen in Schlesien, ging, als Siebzehnjähriger schon mit dem Reifezeugnis vom Gymnasium entlassen, 
mit mir nach Straßburg. Sein Vater hatte ihn mir empfohlen und ich gab ihm gern Zutritt in mein Haus. Er nahm an meinen Vorlesungen und an meinem mikroskopischen Übungskursus teil. Jeder Teilnehmer bekam einen eigenen Arbeitstisch mit Mikroskop und den nötigsten Materialien. Viermal wöchentlich wurde in zwei aufeinanderfolgenden Stunden von mir und meinem Assistenten den Studierenden die nötige Anleitung gegeben; sie konnten dann täglich an ihrem Arbeitstische freihändig weiter arbeiten, so oft sie von morgens 9 bis abends $6 \mathrm{Uhr}$ wollten. Auch in dieser Zeit wurde von mir und vom Assistenten zu den Stunden, in denen von der freien Arbeit am meisten Gebrauch gemacht zu werden pflegte, noch Unterweisung erteilt. Ich bemerkte nun bald, da $B$ Ehrlich jeden Tag stundenlang an seinem Tische arbeitete, völlig in seine mikroskopischen Beobachtungen vertieft. Sein Tisch bedeckte sich dabei nach und nach mit Flecken in allen Farben. Als ich ihn eines Tages wieder so sitzen sah, ging ich auf ihn zu und fragte ihn, was er da. mache, da $B$ sein Tisch so in allen Regenbogenfarben schillere. Da sagte der junge Student des ersten Semesters, der in diesem Kursus seinen ersten akademischen Unterricht geno B: „Ich probiere." Ich sagte darauf, ihm freundlich zunickend: $\mathrm{Na}$, dann probieren Sie nur weiter!" Bei der Durchsicht der von ihm ohne besondere Unterweisung hergestellten Präparate sah ich bald, daß ich in Ehrlich einen außergewöhnlich begabten Schüler hatte. Er verlangte auch sehr selten einen Rat, sondern arbeitete gleich von Anfang an fast ganz selbständig. Solchen Schülern braucht man nur den Anfang des gebahnten Weges zu zeigen, sie durchlaufen ihn rasch, ohne weitere Führung und bahnen sich bald neue Wege. Auch H. Virchow, Weigert und Edinger gehörten zu diesen höchst schätzbaren und willkommenen Schülern, die man mit Freuden unterrichtet. Ihnen gesellte sich Unna zu, der in gleicher Weise bald selbständig weiter arbeitete. Ich freue mich, ihn noch in voller Frische unter den Lebenden zu wissen, während mein Frankfurter Kleeblatt entblättert ist. Weigerts Blatt fiel zuerst, dann folgte Ehrlich und jüngst Edinger.

Auch das Ausland lieferte mir nach Straßburg eine ansehnliche Zahl tüchtiger Schüler, von denen mehrere meine Assistenten wurden. Ich nenne v. Mihalkovics, Geza, später Ordinarius der Anatomie 
in Budapest, Pertik, Otto, später Ordinarius für Pathologische Anatomie in Budapest, beide treue Freunde meines Hauses. Pertik war zuerst Assistent bei mir, dann bei Recklinghausen, Mihalkovics Assistent nur bei mir. Aus den Vereinigten Staaten Nordamerikas arbeiteten bei mir Peabody, Longworth und Lanterman, der die nach ihm benannten kerbförmigen Bildungen der markhaltigen Nervenfasern im Straßburger anatomischen Laboratorium entdeckte, die gleichzeitig und völlig unabhängig von Schmidt in New-Orleans aufgefunden wurden. Aus Chile kam mir Vicente Izquierdo, später Ordinarius für Anatomie in Santiago de Chile, aus Belgien Renson, aus Italien Guglielmo Romiti, Ordinarius der Anatomic in Pisa, aus Rußland Georg v. Rein, später Ordinarius der Gynäkologie in Kiew, dann in St. Petersburg, wo er auch Präsident des Medizinalrats und Arzt am Hofe des Zaren Nikolaus II. wurde. Rein hat sich wissenschaftlich während seiner Straßburger Zeit ausgezeichnet durch anerkannte Arbeiten über die Befruchtung des Kaninchen-Eies und über die Entwicklung der Brustdrüse. Aus Japan kam Joschikijo Koganei, der dann mit mir nach Berlin übersiedelte, wo er mein Assistent wurde, um später den Lehrstuhl für Normale Anatomie in Tokyo einzunehmen. So gestaltete sich das wissenschaftliche Leben und Treiben in dem Straßburger Anatomischen Institute $\mathrm{zu}$ einem frischen und erfolgreichen. Hinzu kamen häufige Besuche von Kollegen aus dem Inlande und dem Auslande, die gern der neubelebten Universität ihren Besuch machten, wobei sie zugleich Deutschland und Frankreich berührten. Von der großen Zahl dieser Besucher nenne ich nur aus Deutschland Henle, Kölliker, Max Schultze und Ellenberger, jetzigen Direktor des Physiologischen Institutes der Tierärztlichen Hochschule in Dresden, aus der Schweiz His und Aeby, von Engländern John Struthers, Anatom in Aberdeen. Die fünf Letztgenannten erwähne ich, weil ich sie bei diesen Besuchen zuerst kennen lernte und sich hieraus dauernde nähere Beziehungen entwickelten, die insbesondere bei Max Schultze, His und Struthers eineI freundschaftlichen Charakter annahmen. Henles Urteil über das neugetaute Straßburger Anatomische Institut erwähnte ich bereits; ich füge hier noch hinzu, daß mein Nachfolger Schwalbe seinen Antrag, ein besonderes Anatomisches Institut erbaut $\mathrm{zu}$ sehen, unter anderem 
damit begründete, daß das bestehende zu klein sei. So erheblich waren die Bedürfnisse der Straßburger Universität gewachsen.

Max Schultz e gab zu dieser Zeit seine berühmten Untersuchungen über den Bau der Netzhaut heraus. Er pflegte fast jedes Jahr zum Besuche seines Bruders nach Straßburg zu kommen, wozu ihm die Fastnachtstage, die damals in Bonn noch "Dies academici“ waren, Gelegenheit gaben. Er brachte dann immer längere Zeit in der Anatomie bei mir zu, was mir die seit langem erwünschte Gelegenheit gab, dem berühmten Forscher und ausgezeichneten Manne näher zu treten. Ich erinnere mich noch lebhaft daran, mit welchem Interesse er die Präparate betrachtete, die ich von der Retina eines Chamäleon-Auges gefertigt hatte. Dr. Sachs aus Kairo hatte mir ein Chamäleon mitgebracht, welches ich längere Zeit in meinem Instituts-Arbeitszimmer lebend erhielt, schließlich jedoch tötete, um Präparate aus der ganz frischen Netzhaut zu gewinnen. Interessant. war es, das Tier im Leben zu beobachten. Es saß meist völlig regungslos in seinem großen Käfige, in welchen ich täglich einen frischen belaubten $Z$ weig einbrachte. Sein Körper nahm bald nach dem Einbringen des Zweiges die Laubfarbe an, so da $B$ man das Tier unter dem Laube nicht gut erkennen konnte. Das einzig Bewegliche an ihm waren dann die Augen, die fortwährend hin und her bewegt wurden bei regungslos bleibendem Kopfe und Rumpfe. Dabei machte es einen besonders merkwürdigen Eindruck, wenn das eine Auge nach vorwärts, das andere gleichzeitig nach rückwärts gerichtet war. Befand sich ein Insekt - meist wurden Fliegen eingesetzt - in dem Käfig und verhielt sich ruhig, so wurde es von dem Chamäleon anscheinend nicht beachtet. Rührte die Fliege aber nur eines ihrer Beinchen in kaum bemerkbarer Weise, so richteten sich beide Augen des Chamäleons auf sie und dann war sie verloren, falls sie in Schußweite war. Denn unmittelbar nachher schleuderte das Chamäleon seine lange Zunge auf die Fliege, die an ihr kleben blieb, und zog sie so in sein Maul. War die Fliege in richtiger Schußweite, und darüber schien sich das Chamäleon nicht zu täuschen, so habe ich niemals einen Fehlschuß gesehen. Es macht einen ganz eigentümlichen Eindruck, das regungslose Tier mit den fortwährend nach allen Seiten, und zwar links und rechts oft verschieden, umherrollenden Augen zu beobachten und dann die mit tötlicher Sicherheit hervorschnellende 
Zunge zu sehen, währenddem das Tier selbst regungslos blieb. Es mag vielleicht Diesen oder Jenen interessieren, meine Erfahrungen an diesem doch selten zur Beobachtung kommenden merkwürdigen Tiere kennen zu lernen, so habe ich sie denn hier mitgeteilt.

Ich gedenke als charakteristisch für die damaligen Straßburger Verhältnisse noch einiger Erlebnisse in der Anatomischen Anstalt und in dem alten ansehnlichen Straßburger Bürgerspitale.

Nach Übernahme der Verwaltung der Anatomie erkundigte ich mich bei dem ersten Diener der Anstalt, dem schon genannten Toni Adam, woher man den Spiritus für die Präparate bezogen habe. Mir wurde der Bescheid zu Teil, den habe seit Jahren eine Frau geliefert und man sei mit der Ware und dem Preise stets zufrieden gewesen. Also ließ ich es dabei; der Spiritus wurde weiter geliefert, war gut und preiswürdig und ich überließ alles dem Diener Toni, wie es bisher gewesen war, ohne mich weiter darum zu kümmern. Ich hielt die Frau für die Inhaberin oder Angestellte eines kaufmännischen Geschäfts in Straßburg. Da kam nach einigen Jahren Toni zu mir und sagte, es sei etwas für die Anatomie sehr Schlimmes vorgekommen, die Frau, die der Anstalt den Spiritus geliefert habe, sei gestorben. Nun, sagte ich, das tut mir zwar für die Frau und ihre Angehörigen leid, für die Anatomie habe das doch wohl keine besondere Bedeutung, man wende sich dann an ein anderes Geschäft, oder es bringe eben vom selben Geschäft ein anderer die Ware. Ja, meinte darauf, etwas zaghaft, der Toni, das mit der Frau habe aber eine eigene Bewandtnis gehabt, sie hätte den Spiritus von Kehl hereingebracht und zwar so, da $B$ er keine Steuer gekostet habe. Nun wurde ich doch neugierig und fragte nach, wie sie das denn angestellt habe? Von Kehl aus, hieß es da, hätte der Spiritus zweimal Steuer bringen müssen zur Zeit als Straßburg noch unter französischer Herrschaft stand, einmal die Landessteuer und dann die städtische Steuer beim Eingange in die Stadt, das sogenannte Octroi. Nachdem Straßburg wieder eine deutsche Stadt geworden war, blieb immer noch die nicht unbeträchtliche städtische Eingangssteuer. Ich erfuhr nun zu meinem nicht geringen Erstaunen, da $B$ die Frau sich aus dünnem Blech eine Art Küra $B$ hatte machen lassen, den sie unter ihrer Oberkleidung auf der Brust trug und der etwa 5 bis 6 Liter Spiritus faßte. Vorn in dem Küraß befand sich ein kleiner, leicht verdeckt $z u$ haltender 
Hahn, mittelst dessen sie den Spiritus auslaufen lassen konnte. Sie kam mit ihrem gefüllten Küraß fast täglich ein oder auch mehrere Male von Kehl nach Straßburg hinein und hatte so die Anatomie und wahrscheinlich auch noch andere Anstalten und Geschäfte versorgt. Die Sache war, da Jedermann geschwiegen hatte, unbemerkt geblieben. Toni meinte ganz unbefangen, man müsse doch sehen, ob man nicht wieder einen solchen Lieferanten finden könne und schien sich etwas zu wundern, als ich ihm erklärte, auf derartige Bezüge könne man sich nicht einlassen. Unser Spiritus wurde damit allerdings teurer.

Das altberühmte Straßburger Bürgerspital, in welchem die Kliniken untergebracht wurden wie zu französischer Zeit, war zugleich Altersversorgungs-Anstalt für die unbemittelte Bevölkerung. Das Spital verfügte über reiche Mittel und die materielle Verpflegung der Kranken und Hospitaliten war eine gute. Neben den Kliniken bestanden auch eine Reihe nicht klinischer Abteilungen für die verschiedenen Krankheiten, insbesondere für innere und chirurgische, wie das ja auch in anderen großen Krankenhäusern von Universitätsstädten in Deutschland der Fall ist. Eine gewisse Rivalität zwischen den Leitern der klinischen und nicht klinischen Abteilungen der gleichen Krankenarten bestand und besteht wohl überall; sie hatte auch im französischen Straßburg bestanden, wurde aber recht fühlbar, als die klinischen Abteilungen von den deutschen Universitätsprofessoren übernommen wurden, während die nichtklirischen unter der Leitung ihrer bisherigen Vorstände blieben. Die Gesamtleitung des Spitals lag in der Hand der ",Spitalskommission“, deren einflußreichste Mitglieder, die Herren Sengenwald und Klein, dieser Apothekenbesitzer, damals viel genannt wurden. Alle Verwaltungssachen der einzelnen Abteilungen mußten durch die Kommission gehen. So lag denn der medizinischen Fakultät viel daran, in dieser Kommission vertreten $\mathrm{zu}$ sein. Die Kommission wehrte sich anfangs und es bedurfte längerer Überlegung, bis die Regierung sich dazu entschloß, dem Wunsche der. Fakultät zu entsprechen und aus ihr ein weiteres Mitglied in die Spitalskommission hineinzubringen. Die Fakultät schlug mich vor und ich wurde auch ernannt. Von da ab nahm ich einige Jahre an den Sitzungen der Kommission als gleichberechtigtes Mitglied regelmäßig teil. 
Ich kann nur sagen, daß die Kommission in ihrer Verwaltungstätigkeit in durchaus anerkennenswerter Weise arbeitete, bei etwaigen Forderungen der Fakultät sich aber meist wenig entgegenkommend zeigte. Es gelang mir zwar in den meisten Fällen Wünsche zur Berücksichtigung $\mathrm{zu}$ bringen und Konflikte ausgleichen $\mathrm{zu}$ helfen; dennoch wurde ein solcher Fall, wo, ungeachtet meiner auf besonderen Wunsch der Fakultät vorgebrachten Einsprache, die Mehrheit der Kommission uns entgegentrat und die Regierung dem Mehrheitsbeschlusse beitrat, die Veranlassung, da $B$ ich aus der Kommission im Einverständnisse mit der Fakultät wieder ausschied. Zu persönlichen Schwierigkeiten ist es indessen zwischen den übrigen Mitgliedern der Kommission und mir nicht gekommen.

Die Verhandlungen bei den Sitzungen wurden von den von früher her in der Kommission gewesenen Mitgliedern in französischer Sprache weiter geführt. Ich sprach selbstverständlich deutsch und man antwortete mir, so lange ich in die Verhandlungen eingriff, auch deutsch, sprachen dabei aber die älteren Mitglieder miteinander, so kam wieder das Französische an die Reihe. Dies manchmal etwas komisch wirkende Durcheinander von Deutsch und Französisch war damals etwas ganz Charakteristisches, insbesondere für Straßburg und die unterelsässischen Städte. In den oberelsässischen Städten, insbesondere in Mülhausen, herrschte das Französische vor, auf dem Lande aber überall das Deutsche in der alamannischen Mundart. In den Städten konnte man es sehr häufig hören, wie die Bürger sich beim Glase Wein oder Bier, wobei es sonst ganz nach echt deutscher Art herging - es hieß auch immer zur Kellnerin: „Noch e Schoppe“ oder „Noch e Schöppele“ - unterhielten und einen Satz französisch anfingen und deutsch beendeten oder umgekehrt, etwa wie: ,Geschtern bin ich in Kolmar gewest et j'ai visité mon fils, vous savez, beim Herrn Meyer, le charcutier" und ähnliches. So ging es auch in der Spitalskommission zu, wenn mit Straßburger Bürgern verhandelt wurde. Kamen aber die Leute vom Lande, die meist weder französisch sprechen konnten, noch es verstanden, dann mußten sich wohl oder übel meine Herren Kollegen auch bequemen deutsch zu sprechen, selbstverständlich in elsässischer Mundart, die übrigens dasselbe anheimelnde hat, wie die alamannischen Sprechweisen überhaupt. Dasselbe gilt wohl auch ron der niederdeutschen Volkssprache, insbesondere 
wie sie in Neuvorpommern und Mecklenburg gesprochen wird und durch Fritz Reuter verewigt ist. Mir sind jetzt durch den Aufenthalt im Elsaß und durch meine westfälische Heimat beide Mundarten geläufig und ich befinde mich oft im Zweifel darüber, welche ich lieber habe.

Bei den Verhandlungen in der Spitalskommission fiel mir damals ein biederer unterelsässischer Bauersmann auf, der öfters von seinen ländlichen Erzeugnissen zum Verkauf brachte. Er bemühte sich auch, etwas französisch zu sprechen, brachte es aber nicht viel weiter, als „weu, weu“ zu sagen, womit er ,oui, oui“ zum Ausdruck bringen wollte. Ein derartiges Französisch konnte man damals im Elsaß vielfach radebrechen hören. Am liebsten war es den Leuten vom Lande, den Handwerkern und Gewerbetreibenden, wenn man mit ihnen in ihrer Mundart sprach. In den Kaufläden wurde man als Deutscher zunächst französisch angeredet, wenn man aber hartnäckig beim Deutschen blieb, so zeigte es sich, daß die Geschäftsinhaber oder deren Angestellte auch deutsch sprechen konnten. Manche der Eingewanderten verfielen in den Fehler, hier und da wohl aus einer gewissen Eitelkeit, um zu zeigen, daß sie französisch sprechen könnten, auf das Französische einzugehen. Ich nenne das einen Fehler, da doch die Elsässer alle deutsch konnten und zwar als ihre Stammessprache, es also nicht nötig war, ihnen mit dem Französischen entgegen $\mathrm{zu}$ kommen.

Übrigens muß ich hier einer Antwort gedenken, die ich von einer Elsässerin, der Frau des genannten Apothekers und Politikers Klein, erhielt, die gelegentlich einer Abendgesellschaft meine Tischnachbarin geworden war. Wir unterhielten uns gut und lebhaft, sic französisch, ich grundsätzlich deutsch sprechend. Im Eifer des Gesprächs kam es natürlich vor, daß meine Nachbarin das eine oder das andere Mal ins Deutsche fiel oder ich ins Französische und so nahm ich denn die Gelegenheit wahr, als Frau Klein einmal in deutscher Sprache längere Zeit die Unterhaltung fortgesetzt hatte, ihr zu sagen, wir möchten doch beim Deutschen bleiben. Sie erwiderte mir: „, Sehr gern, aber, wenn ich Sie sprechen höre, das reine Deutsch, wie wir es hier in den Büchern lesen und damit das Deutsch vergleiche, wie wir es im Elsaß zu sprechen gewohnt sind, dann empfinde ich von Ihrer Seite eine Überlegenheit; diese Empfindung fällt weg, sowie 
Das Französische in Deutschland. Elsässische Spracheigenheiten. 165

wir uns der französischen Sprache bedienen; diese ist unser Hochdeutsch." Man kann nicht bestreiten, daß darin etwas Richtiges liegt und $\mathrm{da} B$ das tatsächlich bei Vielen ein, wenn auch oft unbewußter Grund war, sobald wir unser Hochdeutsch sprachen, uns französisch zu antworten. Sprach man mit einem Elsässer in einer süddeutschen Mundart, so antwortete er sicher nicht französisch, sondern in seinen heimischen Lauten.

Das Elsaß war durch seine Einverleibung in Frankreich im größten Teile seiner Bevölkerung von der sprachlichen Entwickelung des übrigen Deutschland abgetrennt worden; es machte diese Entwickelung nicht in hinreichendem Maße mit und blieb auf der Stufe stehen, auf der sich damals das gesamte Deutschland befand. Die französische Sprache war der deutschen in ihrer Entwicklung zu einer Kultursprache weit voran; das haben wir erst viel später, seit Lessing, eingeholt. Zur Zeit Friedrichs des Großen - er selbst mag als erstes Beispiel genannt sein - war ja selbst an den deutschen Höfen und in den Kreisen der vornehmeren Gesellschaft in Deutschland das Französische zum guten Teil die Umgangssprache. Man staunt jetzt mit Recht über den schwerfälligen, weitschweifigen, kaum verständlichen Stil, in welchem damals die Erlasse der Behörden abgefaßt wurden, ja, noch heute klebt diesen Erlassen vielfach etwas von dieser Erbschaft an $\left(^{9}\right)$. Da war es nicht zu verwundern, daß in dem Königreiche Westfalen in der kurzen Zeit seines Bestehens so schnell die französische Sprache, namentlich in Kassel, der Residenz Jerome Napoleons, Verbreitung fand, wie ich aus den Erzählungen meines Vaters, dessen Jünglingsalter in diese Zeit fällt, weiß. Ich besitze heute noch die Grammatik, einen , Alten Meidinger“, aus der er damals französisch gelernt hat.

Einige andere sprachliche Erinnerungen aus dem Elsaß mögen hier noch Platz finden: So manche Worte, die im übrigen Deutschland einen ganz anderen Sinn bekommen haben, waren im Elsaß noch in ihrer ursprünglichen Bedeutung erhalten geblieben. So sagte man „Naslumpen“ für Nasentuch (Taschentuch), ,,Schmutz“ für, ,Schmalz“ oder auch für Fett und anderes dergleichen mehr. Komisch nahmen sich manche Aussprachen des Französischen aus, wie „S̈̈“ für das Geldstück ,Sous“, oder der „Herr Labbé“ als Übertragung von Monsieur l'Abbé. Bei der öffentlichen meistbietenden Versteigerung 
von Wirtschaftsabfällen des Bürgerspitals wurde eine kleine, etwa einer Räucherkerze an Größe gleichkommende Kerze angezündet und wenn das Bieten begonnen hatte, ausgerufen ,S'erscht Füer", dann Pause, in der weiter geboten wurde, dann , S'zweit' Füer" und bis zum ,Dritt' Füer" im Augenblicke, wo die Kerze erlosch; bis dahin konnte geboten werden.

Wenig beliebt war anfänglich unser Nickelgeld. Die Landleute und die Verkäufer auf den Marktplätzen waren die großen Sousstücke gewöhnt, man trug sie auf den Märkten offen in den Taschen und konnte sie mit den harten, arbeitsgewohnten Händen leicht fassen. Das war beim Nickelgeld unbequem. Mir sagte damals eine der Handelsfrauen: „Was soll' mer mit diese kleine Stückle anfange, das sind jo Lotto-Bätzle!"،

Jeder von uns Mitgliedern der Spitalskommission hatte eine besondere Abteilung zu verwalten. Man übertrug mir den Weinkeller. Ahnte man, daß ich mich hierfür besonders eigne? - Der große Weinkeller des Straßburger Bürgerspitals ist übrigens eine Sehenswürdigkeit. Da die Hospitaliten täglich Wein bekamen, so war der Bedarf ein sehr großer: es lagen mehrere Fässer in dem Keller, welche dem vielgenannten Heidelberger Fasse nicht viel nachgaben. Die älteren Fässer bis etwa zur Zeit der Juli-Revolution trugen deutsche Inschriften; erst von da an beginnen die französischen. Eins der Fässer zeigte den Spruch:

X. X. macht mich,

Dreitausend $\mathrm{MaB}$ faß ich;

Ein Schelm, der mehr verschluckt

Als er vertragen kann!

Des Namens des Küfers (X. X.) entsinne ich mich nicht mehr, auch weiß ich nicht mehr genau die Zahl der Maß anzugeben, die das ansehnliche Faß hielt; a ber die beiden Schlußzeilen sind richtig. In einer Säule des Kellers stand, in einem in diese Säule eingelassenen Raume, der mit einem Eisengitter verschlossen war, ein kleines FaB mit Wein aus einem weit zurückliegenden Jahrhundert. . Damals war das $F a ß$ gefüllt worden und man unterhielt die Füllung dadurch, daß alle paar Jahre genau von derselben Weinmarke wieder zugeführt wurde. Als eine Merkwürdigkeit des Kellers war dies stets unterhalten worden. Als behagendes Getränk kam dieser Wein nicht in 
Betracht; er hatte den Firngeschmack im höchsten Grade; dagegen gaben ein paar Tropfen davon auf ein Tuch gebracht, diesem für einige Tage einen angenehm würzigen Duft. Die sonstigen Weine des Kellers waren fast alle einfache Elsässer Landweine. Ich glaube, wenn man dem Weinbau im Elsaß noch mehr Sorgfalt widmete, könnte man noch viel bessere Ware erzeugen, als es heute der Fall ist. Da wäre, meines Erachtens, noch ein sehr beachtenswertes Feld für lohnende Verbesserungen.

Die Jahre, welche ich in Straßburg zubrachte, von 1872 bis 1883 , waren ruhige und glückliche $z u$ nennen und - ich glaube mich nicht zu irren - wir wären mit der inneren Angliederung wenigstens des Elsa $B$ an das alte deutsche Mutterland viel weiter gekommen, wenn wir das ruhige, feste, zielbewußte Regiment des ersten Oberpräsidenten der Reichslande, des Herrn v. Möller, ihm möglichst lange belassen, oder ganz in seinem Sinne weiter geführt hätten. Noch besser wäre es meiner Meinung nach gewesen, wenn man das Elsaß an Bayern und Baden verteilt und Preußen die Sorge für Lothringen zugewiesen hätte. Soweit ich erfahren habe, soll Bismarck s. Z. überhaupt nicht für die Annexion von Lothringen gewesen sein, der Ansicht v. Moltkes aber, wenn auch ungern, nachgegeben haben. Bei einer solchen Verteilung wären ja die anderen größeren deutschen Staaten, insbesondere Sachsen und Württemberg, freilich leer ausgegangen. Aber, kann man fragen, ist es denn immer ein Gewinn für das Glück eines Staates und seiner Bewohner, wenn er sich an Land und Leuten vergrößert? Ich meine, mit diesen Vorstellungen müssen wir einmal aufräumen, namentlich mit allen gegenseitigen Eifersüchteleien im Deutschen Reiche selbst. Da muß es heißen: Erst Deutschland, dann Baden, Mecklenburg, Sachsen, Preußen usw.! Leicht hätte man Württemberg mit den Hohenzollernschen Landen und Sachsen, da eine geographische Entschädigung nicht gut tunlich war, durch einen höheren Anteil an der Kriegsentschädigung zufriedenstellen können. Der Einwand, daß der König von Preußen als Hohenzoller nicht gut seine Hohenzollernschen Lande hätte abtreten können, wurde hinfällig, seit er nicht nur König von Preußen war, sondern auch die deutsche Kaiserkrone trug.

Was die Frage der Belassung Lothringens mit Metz an Frankreich anlangt, so entsinne ich mich einer mir sehr interessanten Unter- 
redung, welche ich bei einem meiner Besuche in Paris mit einer größeren Anzahl französischer Kollegen hatte. Das Gespräch war auf die Politik gekommen. Allgemein, von französischer, wie von deutscher Seite - es waren außer mir noch einige Deutsche anwesend - bedauerte man, daß unleugbar ein gespannter Zustand zwischen Deutschland und Frankreich bestehe. Ich bestritt, daB die Aktivität der Spannung auf deutscher Seite vorhanden sei. Man erwiderte mir, Deutschland halte aber das eine Ende des gespannten Kabels fest, das sei Metz mit Deutsch-Lothringen. Man möge das an Frankreich zurückgeben, das sei französisches Blut- und Sprachgebiet, dann würde die Spannung aufhören und zwischen Frankreich und Deutschland werde sich ein offenes, gutes Verhältnis herstellen lassen. Das Elsaß, das gebe man in Frankreich zu, sei deutsches Blut- und Sprachgebiet, dessen Verlust man verschmerzen werde. Wir haben lange über dieses nach Ort, Zeit und Teilnehmern heikle Thema gesprochen, auch mit voller Wärme, aber rein sachlich ${ }^{1}$. Ich kann nicht leugnen, daß ich eine Lösung der Spannung auf dieser Basis und dann ein Bündnis zwischen Frankreich und Deutschland gern gesehen hätte. Frankreich mit Deutschland im Bunde könnte der Welt die Ruhe bringen und gebieten! -

Möller verblieb leider nicht lange an der Spitze der Verwaltung Elsaß-Lothringens. Es hieß, daß er mit Bismarck in Mißhelligkeiten gekommen sei. Mir ist nichts Näheres darüber bekannt geworden. v. Möllers Nachfolger wurde der Feldmarschall v. Manteuffel, dem man als Alter Ego in Zivilverwaltungssachen den Staatssekretär Herzog zur Seite gab. Es war dies, wie sich bald herausstellte, eine ungünstige Lösung. v. Manteuffel war in den eigentlichen Verwaltungsgeschäften der Lage nicht gewachsen, mochte aber doch sich Herzog nicht in allen Dingen fügen, so da $B$ Einer den Anderen hemmte. Er suchte dann auf der anderen Seite sich bei den Elsärsern populär zu machen, griff aber mit seiner Art dabei doch fehl. Eine kleine Anekdote möge zur Beleuchtung dieser Dinge hier mitgeteilt

1 Es war mir sehr interessant, etwa ein Jahr nach der Niederschrift dieser Zeilen in dem Buche Otto Hammanns: „Um den Kaiser", Berlin rgr9, Verlag von Reimar Hobbing, S. 44, zu lesen, daß der Verfasser oft aus französischem Munde ähnliche Äußerungen gehört habe. Die hier mitgeteilte Meinung scheint demnach in Frankreich weitere Verbreitung gehabt $z u$ haben. 
sein. Der Feldmarschall pflegte öfters in einem Baumgange in der Nähe der Orangerie bei Straßburg zu spazieren. Der Gang führte zu einer kleinen, bürgerlichen Wirtschaft, bekannt unter dem Namen „Bäckehiesel“. Dort begegnete er eines Tages einem biederen Straßburger Handwerksmeister, redete ihn freundlich an und beide wandelten im Gespräch einige Male auf und ab. Als sie wieder in die Nähe des Bäckehiesels kommen, klopft der Straßburger mit einem Male dem Marschall zutraulich auf die Schulter und sagt: „Wie wärsch, wenn mer im Bäckehiesel noch 'en Schoppen trinke täten?" Was aber freundlichst abgelehnt wurde. - Gewiß, Manteuffel hatte die besten Absichten, aber die Art, wie er sie zu verwirklichen suchte, war nicht die richtige.

Nachher hat man oft mit dem Statthalter, der bald die Bezeichnung „Oberpräsident“ ersetzte, gewechselt. Der eine versuchte es mit der festen, der andere mit der milden Hand; aber Niemand kam dem Ziele, Elsaß-Lothringen sich als Glied des Deutschen Reiches fühlen zu lassen, näher, ja es muß zugestanden werden, wir waren diesem Ziele unter v. Möller näher als später unmittelbar vor Kriegsausbruch. Woran lag das? Ich will versuchen, darauf eine Antwort zu geben, soweit ich darüber etwas sagen kann.

Der Hauptgrund lag meines Erachtens in der Zwitterstellung des Landes, verbunden mit der Zusammenschweißung zweier so völlig verschiedener Volksstämme, wie der echt alamannisch-deutschen Elsässer und der frankogallischen Lothringer. Dadurch, daß ElsaßLothringen nicht als vollberechtigter Bundesstaat an Deutschland angegliedert wurde, blieb sowohl bei seinen Bewohnern, wie auch bei den Franzosen der Gedanke bestehen, da $B$ die ganze Sache doch nur ein Provisorium sei, daß schließlich doch einmal der Tag kommen werde, an welchem das Reichsland wieder mit Frankreich vereinigt werden würde. Anders wäre es gewesen, wenn man Elsaß-Lothringen in der vorhin angegebenen Weise verteilt hätte, oder es dem größten Bundesstaate von vornherein einverleibt hätte, oder endlich, als vollberechtigten Bundesstaat mit eigener Regierung an Deutschland alsbald angegliedert hätte; jedenfalls hätte man sich damit der Sympathien der elsässischen Bevölkerung für Deutschland am meisten versichert. So wie es tatsächlich eingerichtet wurde, schuf man sich für die Verwaltung die denkbar schwierigste Lage, der ein Mann 
170 Süddeutsches und Norddeutsches Wesen. Preußischer Kommandoton.

von Möllers Verwaltungskraft noch gewachsen war, die mit der Zeit jedoch immer schwieriger werden mußte. In der Beamtenschaft des Reichslandes befanden sich Männer aus allen Teilen Deutschlands, vorzugsweise jedoch aus Preußen, von denen ein Teil wenigstens dem elsässischen Wesen fremd blieb. Ich will gewiß nicht sagen, da $B$ die aus Preußen, selbst aus dem viel angefeindeten Ostelbien stammenden Beamten, weniger tüchtig und weniger guten Willens gewesen seien, als etwa die aus Süddeutschland stammenden. Der Brandenburger, Pommer, Schlesier, West- und Ostpreuße steht in Nichts dem Deutschen aus den übrigen Teilen des Reiches nach; er ist ebenso tüchtig, pflichtgetreu und wohlwollend wie die Westund Süddeutschen, er hat jedoch eine andere Art sich zu geben, die dem Süddeutschen und besonders auch dem Elsässer fremd bleibt, so daß Mißverständnisse leichter aufkommen und schwerer beseitigt werden. Durch die in Preußen seit langem eingeführte straffe militärische Durchbildung eines großen Teils des Volkes ist ein Ton in die Beamtenwelt, namentlich auch in die untere, die mit dem Volke am meisten in Berührung steht, gekommen, den ich als „Kommandoton" bezeichnen möchte, der sicherlich nicht verletzen will, leicht jedoch bei Allen, denen er völlig fremd ist, so wirken kann.

Es lie $B$ sich leicht feststellen, da $B$ die Süddeutschen im Elsa $B$ beliebter waren als die Norddeutschen, insbesondere die Preußen. In Straßburg lag damals auch ein württembergisches Regiment in Garnison; wenn dieses mit seiner Musik an der Spitze durch die Straßen marschierte, dann kamen gern die Bewohner an die Fenster und vor die Türen und man sah es ihren Mienen an, daB sie sich über das Regiment freuten; hier und da wurde auch ein freundlicher GruB zugewinkt. Anders, wenn das preußische Regiment entlang zog; da bemerkte man kaum etwas von einer Teilnahme. Die Süddeutschen hatten es eben mit den stammverwandten Elsässern leichter, schon der Sprache wegen; aber auch in ihrer ganzen Art sich zu geben und mit den Elsässern zu verkehren lag etwas Annäherndes an die elsässische Weise. Das hätte man beizeiten bedenken und namentlich alle Beamten, die unmittelbar mit dem Volke verkehren, indessen auch die Kreisdirektoren und die überwiegende Mehrzahl der höheren Beamten, den Statthalter an der Spitze, aus Süddeutschland wählen sollen. Ebenso die im Elsaß garnisonierenden Regimenter; dann 
wäre sicherlich die unliebsame Zaberner Affäre, die durch die verkehrte Art, wie sie militärischerseits behandelt wurde und wegen eines „Wackes“ die ganze Welt aufregte, wohl nicht so aufgebauscht worden. Grundsätzliche Behandlung der Dinge ist ja sicher gut; man muß aber $\mathrm{zu}$ unterscheiden wissen; das ist hier nicht geschehen. Nicht immer muß bei Zusammenstößen zwischen Bürgertum und Wehrmacht in Friedenszeiten die Militärpartei die Dinge nach dem Schema „F“ bis zum äußersten treiben. Das sei ihr in Kriegszeiten, bei ernster Sachlage, gern zugestanden; aber bei solchen Anlässen, wie seinerzeit in Zabern, hätte das militärische Ansehen nichts eingebüßt, wenn man den jungen Offizier - er ist inzwischen für sein Vaterland gefallen, Ehre seinem Andenken! - in der Stille für ein paar Wochen beurlaubt und nachher in eine andere Garnison versetzt hätte.

Was macht uns Preußen denn vielfach so unbeliebt bei anderen Volksstämmen, süddeutsche Reichsbrüder nicht ausgenommen? Es ist, wie vorhin erwähnt, ein gewisser befehlshaberischer Ton mit einer Färbung ,,von oben herab", der uns militärisch anerzogen ist und leicht in wenig angenehmer Weise hervortritt, wenn Jemand, der dazu befugt ist, eine Anordnung gibt. Bei uns betrachtet jeder Beamte von der untersten Stufe an, und auf dieser Stufe gewöhnlich åm ausgesprochensten, Alle, zu denen er als Anordner zu sprechen hat, als seine Untergebenen und dabei kommt dann, vielfach ihm selbst unbewußt, der Ton heraus. Er will ja damit auch gar nicht verletzen; aber er verletzt doch Jeden, der diesen Ton nicht gewohnt ist. Wir Preußen, namentlich die Ostelbier und Berliner, empfinden das nicht so; wir sind's gewohnt, wissen auch, daß der Anordnende nicht verletzen will; aber ein Süddeutscher und insbesondere ein Elsässer versteht das nicht. Ich erwähnte bereits, wie unangenehm mir die Art auffiel, mit der der damalige Universitätsrichter bei meiner Immatrikulation in Berlin verfuhr; sicherlich hat er dabei nicht gedacht, daß er damit anstoße. Wie oft hat es mich schon verdrossen, wenn ich hören mußte, in welchem Tone vielfach unsere Schutzleute ihre gewiß berechtigten Anordnungen trafen. Viel williger wären diese sicherlich befolgt worden, wenn eine andere Tonart angeschlagen worden wäre. Wer, wie ich, gesehen hat, in wie einfacher Weise durch Erheben und Signalisieren mit ihrem Stabe auf dem Broadway 
172 Süddeutsche und norddeutsche Art. Zukunft Elsaß-Lothringens.

in New-York die Polizeimannschaften die gewaltige Menschenflut leiten und alles ruhig und richtig vor sich geht, der lernt begreifen, $\mathrm{da} B$ es auch noch eine andere Weise gibt, die Menschen zu leiten als die oft bei uns beliebte.

Es ist merkwürdig, daß die Süddeutschen, selbst wenn sie einmal im Ärger harte Töne anschlagen, damit nicht so verletzend wirken. Ohne meinen bayerischen Reichsbrüdern $\mathrm{zu}$ nahe $\mathrm{zu}$ treten, glaube ich doch sagen $\mathrm{zu}$ dürfen, daß man dort in ,Dur" ebenso gut zu sprechen versteht, wie in „Moll“, vielleicht noch besser; aber das wirkt dort nicht so verletzend. Das liegt meines Erachtens darin, da $B$ dabei das Register ,von oben herab“ fehlt, was die preußischen Befehle so oft begleitet. Es wäre sicherlich zu wünschen, daß wir dieses Register außer Spiel setzten; unsere mit Recht vielgerühmte preuBische Ordnung würde dadurch nicht verlieren, unser Ansehen daheim und draußen nur gewinnen!

Die hier vertretene Ansicht, Elsaß-Lothringen wäre am besten an Deutschland geknüpft worden durch die Einverleibung teils in süddeutsche Staaten, teils (und zwar Lothringen), in Preußen, hatte ich mir während meines Straßburger Aufenthaltes gebildet und habe sie bis in den Weltkrieg hinein festgehalten. Sie wurde von vielen Straßburger Kollegen geteilt. Andere waren der Ansicht, daß man dem eroberten Gebiete gleich volle Selbstverwaltung, ja, die Autot nomie hätte geben sollen. Jetzt, nach dem unglücklichen Ausgange des Krieges, frage ich mich, ob nicht ein schon vor dem Kriege bestehendes autonomes Elsaß, selbst mit dem hinzugelegten Teile Lothringens, das beste gewesen wäre? Sicherlich war die Lage der Dinge, wie sie unmittelbar vor dem Kriege von IgI4 bestand, das Reichsland Elsaß-Lothringen, für uns die ungünstigste.

Auch während des Krieges ist unsererseits durch viele unnötige und hart empfundene Maßnahmen die Anhänglichkeit an Deutschland, die schon in manchen elsässischen Kreisen gewonnen war, wieder stark zurückgedämmt worden. Den Wünschen der Elsaß-Lothringer würde es auch jetzt noch, nachdem sie, wie die Franzosen und französisch gesinnte Elsässer euphemistisch sagen, dem „Mutterlande“ wieder gewonnen sind, am meisten entsprechen, wenn Elsaß-Lothringen, oder doch das Elsaß, einen besonderen Staat, vielleicht mit Anschluß an die Schweiz, bildete. Die Liebe zum galloromanischen 
„Mutterlande" hat sich, wie die neuesten Kundgebungen zeigen, merklich abgekühlt.

Ehe ich meine Erinnerungen an Straßburg und an das Elsaß abschließe, noch einige Zeilen über Land und Leute, die ich in mein Tagebuch niederschrieb, als ich 1883 von Straßburg Abschied nahm. Es hieB dort:

„Gut erinnere ich mich noch des Augenblicks, in dem ich 1872 bei meiner Einreise in das Elsa $B$ von fern das Straßburger Münster zum ersten Male erblickte; es war ein freundlicher, schöner Frühlingstag. Seither ist mir der hochragende Münsterturm immer als das Wahrzeichen einer neuen Heimat erschienen. - Seit ich selbst Angehöriger des Elsa $B$ war, begreife ich die Liebe der Elsässer für ihr Heimatland; ich habe Land und Leute hochschätzen und lieben gelernt. Lothringen ist mir weniger zusagend erschienen; es ist ein deutlicher Unterschied zwischen beiderlei Land und Leuten. Schlicht und bieder in dem vollen Sinn, wie der Norddeutsche in Hannover, Braunschweig, Westfalen, Mecklenburg, Schleswig-Holstein u. a. ist der Elsässer nicht. Es mischt sich in seinen sonst echt deutschen Charakter etwas mehr Berechnung und Wahrnehmung eigenen Vorteils, ich möchte sagen, etwas mehr von der DeutschSchweizerart. Das hat, meines Erachtens, nicht etwa die Berührung mit den Franzosen zuwege gebracht, es liegt in der ursprünglichen Natur des Volkes. Es tut dies aber dem Werte der Leute keinen Eintrag, da es nie in unangenehmer Weise hervortritt und ein Wort stets als Wort gehalten wird, so daß nirgends in deutschen Landen größere Ehrlichkeit in Handel und Wandel gehalten wird, als im ElsaB. Dabei sind Sinn und Sitte der Leute einfach, treu dem Angeerbten, von dem sie nur ungern lassen. Sie haben alle einen mehr oder minder glücklich sich äußernden derben Humor, der derselbe geblieben ist, wie zu den Zeiten der Fischart, Sebastian Brant und Murner; man vergleiche auch ,Arnolds Pfingstmontag“. Sie vertragen diesen satirischen Humor ebenso leicht, als sie ihn für Andere verwenden; jedoch muß man als Nicht-Elsässer schon ihr Vertrauen gewonnen haben, wenn sie ungescheut sich preisgeben und den gleichen Ton auch von anderer Seite annehmen sollen. Ich darf von mir wohl sagen, da $\beta$ ich mir dies Vertrauen erworben hatte. Der Sinn für Titulaturen, Zeremoniell und dergleichen, der namentlich im 
nordöstlichen Deutschland, aber auch in Deutsch-Österreich so stark hervortritt, ist im Elsa $B$ unbekannt; nirgends tritt die Überflüssigkeit eines „Geheimrat", eines Wohlgeboren, Hochwohlgeboren und Hochgeboren, so wie das Festkleben am "Leutnant", wenn man es zum Leutnant der Reserve gebracht hat, mehr hervor, als wenn man eine Zeitlang unter den Elsässern gelebt hat. Sie verfallen dabei nicht etwa in ein auffälliges Gegenteil; auch sie halten etwas auf Rang und Stand, nehmen eine Auszeichnung, wie etwa einen Orden, gern an, machen aber nicht bei jeder Gelegenheit für die Außenwelt Gebrauch davon. Sehr wohltuend berührte mich bei ihnen die Wertschätzung des Menschen als solchen und die Art des Verkehrs zwischen Hoch- und Niedriggestellten, zwischen Herren und Dienern; man kennt dort weder Herablassung noch Unterwürfigkeit, wobei Jeder doch zu seinem Recht kommt und sich seiner Stellung wohl bewußt ist. $\mathrm{Daß}$ man bei uns Jemandem die "Leutseligkeit" als besonderes Verdienst preist, das wird dort kaum verstanden. Angenehm berührt dort auch der Friede zwischen den verschiedenen Konfessionen, der übrigens zu meiner Jugendzeit, in Westfalen wenigstens, auch herrschte. Die Leute leben gern gut, verschwenden aber nicht. Sie haben es eben und knausern damit nicht. Ein angenehmer Wohlstand geht fast durchs ganze Land; so kommt es auch, da $B$ die Auswüchse des Sozialismus dort nicht Boden fassen. Körperlich finden wir bei beiden Geschlechtern im Durchschnitt einen schönen und kräftigen Schlag. Auffallend ist die große Zahl schöner und stattlicher Frauen in und um StraBburg."

Unter den jüngeren Professoren, die damals nach Straßburg berufen wurden, trat bald Friedrich Alth off hervor, nicht in seiner Eigenschaft als Universitätslehrer oder als Forscher auf dem von ihm vertretenen Gebiete (französisches Recht), sondern als Beamter. Althoff war damals Assessor und dem Oberpräsidium zugeteilt. Wir Professoren merkten bald die Hand Althoffs in allen Universitätsangelegenheiten, bei denen die Regierung in Frage kam, und es dauerte nicht lange, bis es klar wurde, da $B$ man seitens der Regierung vorzugsweise und gern seinen Ansichten folgte. Der bedeutende, zielbewußte und geschickte Verwaltungsbeamte, als der Althoff sich in seiner späteren Stellung als Ministerialdirektor der Unterrichtsabteilung des Preußischen Kultusministeriums erwies, trat 
schon in Straßburg in seinen Grundlinien hervor. Bei der medizinischen Fakultät in Straßburg erwarb sich allerdings Althoff damals keine Beliebtheit, da er bei den vielfachen Reibereien zwischen ihr und dem Bürgerspital mehr die Interessen des letzteren zu vertreten schien.

Während meiner Lehrtätigkeit in Straßburg bot sich mir, außer der vorhin schon erwähnten Möglichkeit, der Wiener Universität anzugehören, noch zweimal Gelegenheit, in den Lehrkörper einer anderen Universität einzutreten und zwar 1878 nach Bisch offs Emeritierung als dessen Nachfolger in München und bereits I874, nach meines Freundes Max Schultzes Tode, in Bonn. Ich kann nicht leugnen, daß beide Gelegenheiten mich sehr beschäftigten. Besonders verlockend war mir die Nachfolge Max Schultzes, und es schien auch der Preußischen Unterrichtsverwaltung daran gelegen zu sein, mich in Bonn anzustellen. Wenigstens wurde mir von dem damaligen Referenten in dem genannten Ministerium, Professor Göppert jun., eröffnet, da $B$ man mich bestimmt berufen werde, falls die Reichsregierung mich freigeben würde. Bei der zuständigen Reichsstelle sagte man mir, daß man mich zwar nicht freigeben könne, da $B$ ich mich jedoch als von Preußen aus berufen ansehen solle und meine Bedingungen für mein Verbleiben in Straßburg stellen möge. Diesem Entgegenkommen war nicht $\mathrm{zu}$ widerstehen; ich sprach den berechtigten Wunsch aus, daß man mich in meinem Gehalte mit den vor mir nach Straßburg berufenen Fakultätskollegen gleichstellen möge, was glatt bewilligt wurde; in fünf Minuten war die Sache entschieden; ich blieb in Straßburg.

Ich wäre, das merkte ich bald, je länger ich nun da war, gern für meine Lebenszeit dort geblieben, wenn es sich zum dritten Male nicht um Berlin gehandelt hätte, wo mir ein so viel höheres Einkommen aus meiner Lehrtätigkeit sicher war, daß ich im Interesse meiner Familie nicht anders handeln konnte, als die mir angetragene Stelle anzunehmen. Ich erhielt als erste Nachricht bald nach Pfingsten I883 einen Brief Henles, worin er mir mitteilte, daß Reichert zurücktreten werde und daß man plane, mich an dessen Stelle zu berufen; zugleich riet er mir, den Ruf anzunehmen. Einige Wochen später teilte mir Rudolf Virchow mit, daß die Berliner Fakultät mich einstimmig zum Nachfolger Reicherts vorgeschlagen habe. 
Am I4. Juli kam dann ein Telegramm Alth offs, der damals schon Referent für die Personal-Angelegenheiten im Kultusministerium war, in welchem er mich einlud, nach Baden-Baden zu kommen, um mit ihm über die Annahme der Berliner Stelle zu verhandeln. Am folgenden Tage, einem Sonntage, wurde unter Blitz und Donner eines ungewöhnlich heftigen Gewitters, im Bayerischen Hofe zu Baden-Baden die Angelegenheit erledigt und $\mathrm{zu}$ einem für beide Teile befriedigenden Ende geführt. Die Verhandlungen verliefen um so glatter, als beide Teile ja persönlich bereits seit Jahren einander bekannt waren. Ich hatte hinreichend Gelegenheit, mich von der Umsicht Althoffs und von seinem Geschick, wie er alles vorgesehen hatte und Schwierigkeiten zu ebnen wußte, vollauf zu überzeugen. Es tat mir wohl, zu erfahren, daß Althoff bemüht war, meinem alten Lehrer Reichert, den ich noch bei dessen Lebzeiten zu ersetzen berufen wurde, das Scheiden aus seinem Amte möglichst $\mathrm{zu}$ erleichtern. Er fragte mich um meine Ansicht, wie das wohl am besten zu erreichen sei. Da ich Reichert und dessen Neigungen genau kannte, so wurde mir die Antwort nicht schwer. Ich schlug vor, Reichert die Direktion des großen vergleichend-anatomischen $\mathrm{Mu}$ seums, welches wesentlich von Rudolphi und Johannes Müller begründet und im Universitätsgebäude untergebracht war, zu belassen und ihm dort den ihm vertrauten Präparator Wickersheimer und einen Diener beizugeben. Ich lege, sagte ich, vor der Hand keinen Wert darauf, diese Sammlung in Leitung zu übernehmen; mir möge das Anatomische Institut, welches unter Reicherts Leitung im Garten der Tierärztlichen Hochschule I868 erbaut worden war, übertragen werden; ich sei außerdem gern erbötig, falls Reichert Wert darauf lege, ihm dort einige Zimmer nebst der nötigen Dienerhilfe zur Verfügung zu stellen. Althoff dankte mir, noch mehr aber Reichert, dessen geheimsten Wünschen ich mit diesen Vorschlägen entgegengekommen war; ich wußte ja, wie sehr er an dem vergleichendanatomischen Museum hing und es war mir eine große Freude, auf diese Weise ihn ohne Bekümmernis aus seiner bisherigen Stellung scheiden zu sehen. Als wir uns im Oktober I883 in Berlin zum crsten Male wiedersahen, fiel er mir um den Hals und sagte in seinem unverfälschten ostpreußischen Dialekte: ,,WaIdeyer, Sie sind ein Ängel!“‘

So lange es uns beschieden war, noch zusammen zu bleiben, ver- 
kehrten wir in gegenseitigem freundschaftlichem Vertrauen. Reichert las im Wintersemester ein Kolleg über die Anatomie des Gehirns und gab einen mikroskopisch-anatomischen Übungskursus, wobei ihm Wickersheimer behilflich war, beides im Anatomischen Institut, so da $B$ wir uns täglich dort begrüßten. Er liebte es, nach diesem Kursus noch ein Plauderviertelstündchen auf dem Sofa in seinem Zimmer mit mir abzuhalten, während er behaglich eine Zigarre rauchte. Doch nicht lange mehr sollte es so bleiben. Im Dezember sagte eines Tages Reichert bei unserer Unterhaltung, er fühle sich heute so schwach, da $B$ er sich nicht getraue, allein die Treppe zu seiner Wohnung, die im benachbarten Verwaltungsgebäude der Tierärztlichen Hochschule gelegen war, hinaufzugehen; ich möge ihm den Anatomieinspektor Gellzuhn zu seiner Unterstützung mitgeben. Diese Schwäche mußte meinen alten Lehrer und Kollegen plötzlich überfallen haben, denn er hatte noch vorher seine Vorlesung gehalten. Wir sprachen noch eine Weile, dann reichte mir Reichert bewegt die Hand, es war unser letzter Händedruck. Der Inspektor berichtete mir, er habe Reichert fast mehr die Treppe hinauftragen müssen, als ihn führen. Zwei Tage darauf suchte ich Reichert in seiner Wohnung auf, um mich persönlich nach seinem Befinden zu erkundigen und ihn, wenn möglich, selbst zu sehen und zu sprechen; es wurde mir aber mitgeteilt, er sei zu schwach, um noch Jemanden empfangen zu können. Wenige Tage darauf, am 2r. Dezember 1883, erlöste ihn der Tod.

Ich übernahm nun auch die Verwaltung des Museums in der Universität, hatte aber nur die Aufgabe, dasselbe aufzulösen und auf die einzelnen Universitätsinstitute $\mathrm{zu}$ verteilen, die an den dort angesammelten Schätzen Interesse hatten, da die Universität die Museumsräume dringend zur Erweiterung ' ihrer Vorlesungssäle benötigte. Außer der Anatomischen Anstalt kamen in Betracht das Zoologische Museum und das Zoologische Institut, beide in erster Linie. Dann das Pathologische Institut und das Geologischpaläontologische Institut. Es war keine kleine Arbeit, die Verteilung gemäß den Wünschen der einzelnen Institutsleiter durchzuführen, und ich muß hier rühmend der Tätigkeit meines Kollegen und Prosektors am Anatomischen Institute, Robert Hart ma nn, gedenken, der mit Hilfe des sehr erfahrenen und zuverlässigen Präparators Wickersheimer in verhältnismäßig kurzer Zeit die Überführung erledigte. 
VI. K a p it el.

Universitäts-Dozentenjahre: Schlußjahre.

Berlin.

\section{Universität.}

Von Ordinarien und Extraordinarien. - Medizinische Akademien und ārztliche Fortbildung. - Medizinisches Prüfungswesen. - Universitätsreform. - Gründung neuer Universitäten. - Köln und Bonn.

So war ich denn am Schlusse meiner Dozentenwanderung, die mich so ziemlich im Kreise in Deutschland herumgeführt hatte, in dessen Mitte angelangt, wo ich nunmehr eine bleibende Stätte finden sollte. In Königsberg weilte ich 2 Jahre, in Breslau 8, in Straßburg II; in Berlin blieb ich $33 \frac{1}{2}$ Jahre im Amte. Am I. Oktober I883, 47 Jahre alt, hatte ich es angetreten; am I. April I9I7, nach Vollendung meines 8o. Lebensjahres (6.Oktober I9r6) ließ ich mich von der Verpflichtung Vorlesungen zu halten und von der Leitung des Anatomischen Institutes entbinden.

Die seit Gründung der Universität I8ro dort tätigen Ordinarien für menschliche Anatomie und Direktoren der Anatomischen Anstalt haben sämtlich lange Zeit ihres Amtes walten können: Karl Asmund Rudolphi, der von Greifswald her berufen wurde, 23 Jahre, von I8ro bis zu seinem Tode I833, Johannes Müller, von Bonn kommend, 25 Jahre, bis zu seinem Tode I858, Karl Bogislaus Reichert, von Breslau aus berufen, gleichfalls 25 Jahre, von 1858 bis 1883 . Mir ist also ein ansehnlicher Zuwachs an Jahren amtlicher Tätigkeit beschieden gewesen. Ich knüpfe an diese Jahresbetrachtungen die Besprechung der Frage, ob es geraten sei, den Universitätsprofessoren ein bestimmtes Endjahr ihres Lebens zu setzen, mit dessen Erreichung sie ihre amtliche Lehrtätigkeit aufgeben müßten, wie das u. a. in Österreich-Ungarn gesetzlich geregelt ist. Da ist, soviel ich weiß, das berühmte biblische 70. Jahr das festgesetzte Endjahr; in Straßburg hatte man das 65. Jahr gewählt. Es läßt sich manches dafür und dawider sagen. Man wird ohne weiteres zugestehen, da $B$ die beste produktivwissenschaftliche Tätigkeit des Gelehrten in die jüngeren Jahre fällt, etwa bis zum 6o. Jahre. Nur wenige Ausnahmen sind bekannt, in denen Forscher ihre beste Arbeit erst in späteren 
Jahren geleistet haben. Manches Gute und Anerkennungswerte bringen die meisten auch noch später zuwege; aber das Beste fällt in die Zeit des jugendlichen und vollkräftigen Mannesalters. Nun sind aber die Universitäten nicht nur Forschungsstätten, sondern, und zwar in erster Linie, wie ich besonders betonen möchte und später noch weiter zur Sprache bringe, Lehranstalten. Da vermag denn auch ein älterer Mann, falls er gesund und rüstig bleibt, seines Amtes noch voll $\mathrm{zu}$ walten, wobei ihm seine große Erfahrung zu Gute kommt. Nun kann man weiter sagen, da $B$ durch das längere Verbleiken im Amte den jüngeren Kräften das Tor zu lange verschlossen bliebe und sie meist erst zur vollen Ausnutzung ihrer Kräfte gelangten, wenn sie durch ermüdendes Warten schon mehr oder weniger verbraucht wären. Das hat gewiß etwas Richtiges. Ich selbst habe es wohl zu schätzen gewußt, da $B$ ich bereits mit 29 Jahren in eine Ordinariatsstellung hineinkam und mit 3I Jahren tatsächlich Ordinarius wurde. Das gibt Schaffenslust und stählt die Schaffenskraft. Jedoch sorgt schon Freund Hein meistenteils dafür, da $B$ die Universitätsprofessoren nicht zu lange im Amte bleiben. Wirklich fühlbare Nachteile sind an den deutschen Universitäten, wo ein Amtsschlußjahr nicht besteht, nicht entstanden und da $B$ die österreichischen Hochschulen daraus besondere Vorteile gezogen hätten, wird wohl nicht behauptet werden können; auch das Straßburger Experiment hat keine Beläge gebracht. Ich halte es für gleichgültig, ob man eine Altersgrenze setzt oder nicht.

In Berlin bezog ich mit meiner Familie eine Wohnung im Hause II3 der Potsdamer Straße. Diese Wahl brachte mir die sich angenehm gestaltende nähere Bekanntschaft mit meinem Kollegen der medizinischen Fakultät, August Hirsch, und mit dem Maler Anton v. Werner, welche Beide in demselben Hause wohnten. Ich kann nur beklagen, da $B$ der Tod Beider schon so früh unseren Beziehungen ein Ende machte.

Bald erwarb ich mir, auf Rat meines von Straßburg nach Berlin berufenen Kollegen, des Juristen H. Brunner, ein eigenes, dem seinigen angrenzendes Grundstück in Charlottenburg, Lutherstraße 35 , und erbaute mir darauf ein kleines Haus im Villenstil, welches ich von I886 bis I9I7, bis zur Niederlegung meines Amtes an der Universität, bewohnt habe. In diesem schönen Heim mit seinem hinreichend großen Garten, der durch unmittelbar angrenzende größere Garten- 
grundstücke ideell erheblich vergrößert wurde, so da $B$ man von da aus, wenn die Bäume belaubt waren, kaum Häuser sah und sich außerhalb der Großstadt versetzt zu sein glaubte, sind meine Kinder erwachsen und zum Teil noch meine Enkel. Alle konnten das schöne Gefühl eines eigenen Heimes haben. Ich kann meinem Kollegen Brunner, mit dem ich stets beste Nachbarschaft hielt, nicht genug danken, daß er mir den Rat gab, mich dort anzusiedeln. Sein im Jahre I9I6 erfolgter Tod und der Verkauf seiner Villa gab mir, dem seit Igro Verwitweten, auch den AnstoB, mein vereinsamtes Heim aufzugeben und eine kleinere Mietswohnung in der Uhlandstraße I84 in Charlottenburg zu beziehen. Dort wird man mich wohl dereinst, ohne daß ich es weiß, hinaustragen.

Als Rektor empfing mich bei meinem Eintritt in die Berliner Universität der Philologe Adolf Kirchhoff, mit dem ich später, I884, durch meine Aufnahme in die Akademie der Wissenschaften, näher bekannt werden sollte. In der medizinischen Fakultät traf ich als Dekan August Hirsch, den medizinischen Historiker und Pathologen, als Physiologen du Bois-Reymond, als Pathologischen Anatomen Rudolf Virchow, als Pharmakologen Oskar Liebreich, als Innere Kliniker v. Frerichs und v. Leyden, als Chirurgen v. Bergmann und v. Bardeleben, als Gynäkologen Karl Schröder und Adolf Gusserow, als Neurologen Karl Westphal, als Ophthalmologen Karl Schweigger. Reichert nahm, wie es in Berlin üblich ist, als Emeritus an den Sitzungen der Fakultät nicht mehr Teil. Niemand dieser meiner ersten Kollegen in Berlin weilt mehr unter den Lebenden. Mehrere von ihnen: du Bois-Reymond, Reichert, v. Frerichs und v. Bardeleben waren noch meine Lehrer gewesen, Liebreichs Lehrer war ich, wie bereits berichtet, in Königsberg gewesen, Rudolf Virchow hatte ich schon seit Jahren kennen und verehren gelernt, Leyden und Gusserow, insbesondere der Letztere, waren mir befreundete Kollegen aus Straßburg, Schröder, Schweigger und Westphal sollte ich erst hier kennen lernen, aber gerade mit ihnen gestaltete sich bald ein näherer Familienverkehr, da unsere Frauen einander näher traten, ebenso wie es mit der Familie August Hirsch der Fall war.

Wir waren also 1883 ein Kollegium von I3 aktiven Ordinarien. Man könnte in Versuchung kommen, hier auf den alten Aber- 
glauben zurückzugreifen, da $B$ von den 13 einer bald dem Tode anheim falle; hier bin ich, als der damalige dreizehnte, noch der einzige Überlebende!

Als ich nach 33 jähriger Tätigkeit aus der Fakultät schied, saßen mit mir darin: als Anatom und Embryolog Oskar Hertwig, als Physiologe Max Rubner, als Pathologischer Anatom Johannes Orth, als Pharmakologe Arthur Heffter, als Innere Kliniker Wilhelm $\mathrm{H}$ is und Friedrich Kraus, als Chirurgen August Bier und Otto Hildebrand, als Gynäkologen Ernst Bumm und Karl Franz, als Ophthalmologe Emil Krückmann, als Otorhinologe Adolf Passow, als Laryngorhinologe Gustav Killian, als Dermatologe Edmund Lesser, als Neurologe Karl Bonhoeffer, als Pädiatriker Adalbert Czerny, als Hygieniker Karl Flügge. Die Professur der Geschichte der Medizin war also nicht mehr vertreten, dagegen war ein zweiter Ordinarius für Anatomie und neue Ordinarien für Ohrenheilkunde, für Nasen- und Kehlkopfheilkunde, für Hygiene, für Kinderheilkunde und für Hautkrankheiten und Syphilis hinzugetreten, wodurch die Zahl der ordentlichen Fakultätsmitglieder auf 18 erhöht wurde.

Es mag mir hier im Anschluß an das Vorstehende gestattet sein, etwas näher auf die Frage nach der Schaffung medizinischer Professuren, insbesondere von Ordinariaten und damit auf den medizinischen Universitätsunterricht und die medizinischen Prüfungsordnungen einzugehen, über welche Dinge ich mir wohl eine gewisse Erfahrung zutrauen darf. Zuvor gehe ich noch weiter in der Besetzung der Berliner medizinischen Fakultät zurück, wie sie zu der Zeit bestand, als ich im Jahre 1856 meine Universitätsstudien begann. Damals vertrat Johannes Müller noch die Anatomie und Physiologie, eine besondere Professur für Pathologische Anatomie bestand noch nicht, sondern nur eine Prosektur für Obduktionen am CharitéKrankenhause, die Robert Froriep, der Lehrer Rudolf Virchows, innehatte. Es bestand ein Ordinariat für den klinischen Unterricht in der inneren Medizin unter Schönlein und eines für die medizinische Poliklinik unter Romberg. Zwei Ordinarien für Chirurgie, Jüngken und v. Langenbeck lehrten bereits, aber nur einer für Geburtshilfe und Frauenkrankheiten, D. W. H. Busch. Unter den damaligen Extraordinarien waren Männer von Weltruf, wie Albrecht 
v. Graefe, Robert Remak, Traube und Henoch. Ich habe bereits erwähnt, daß wir jungen Mediziner bei unserer Staatsprüfung nur geprüft wurden in Anatomie und Physiologie, von zwei Prüfern freilich, jedoch in einem Prüfungsabschnitt, dann in der Inneren Medizin, in der Chirurgie und in der Geburtshilfe - nicht noch besonders in Frauenkrankheiten, auch nicht besonders in der Arzneimittellehre, Hygiene und in der Pathologischen Anatomie. Zum Schlusse kam noch das von mir geschilderte, völlig unmaßgebliche Schlußexamen. Dagegen war damals die Doktorprüfung, das Examen rigorosum pflichtgemä $B$, ebenso wie am Ende des vierten Semesters oder am Anfange des fünften das Examen philosophicum.

Beim Vergleich des Einst und Jetzt sieht man, daß die Zahl der Ordinarien in der medizinischen Fakultät der Reichshauptstadt sich seitdem mehr als verdoppelt hat; ähnlich liegt die Sache auch bei den anderen deutschen Universitäten. Unzweifelhaft ist es nötig, bei Universitäten mit großer Hörerzahl, wie sie namentlich Berlin in den letzten Jahren vor dem Kriege aufwies, die Zahl der Ordinarien für dasselbe Fach zu verdoppeln, ja, wenn nötig, noch weiter zu vermehren, denn die Zahl von Zuhörern, die von einem Lehrer guten Unterricht in den praktischen Fächern, insbesondere aber in den klinischen erhalten können, hat ihre Grenze.

Noch besser, als an großen Universitäten viele Lehrer desselben Faches anzustellen, um der größeren Anzahl der Zuhörer gerecht zu werden, ist es unzweifelhaft, die Zahl der Universitäten zu vermehren, um jedem Studierenden Gelegenheit zu geben, sich möglichst gründlich auszubilden. Man hat auch davon gesprochen, eine Beschränkung der Zahl der Studierenden, die an einer Universität oder an einer Klinik zugelassen werden dürften, einzuführen. Dem kann ich nicht das Wort reden. Die Lehr- und Lernfreiheit, das kostbarste Gut der deutschen Universitäten, muß unbedingt aufrecht erhalten werden. Hat ein Student den Wunsch, bei einem Universitätslehrer von besonderem Rufe zu lernen, oder auch nur dessen Eigenart kennen zu lernen, so soll ihm da kein Hindernis im Wege stehen. Man zieht auch jetzt wieder in Erwägung, namentlich die Zahl der Ausländer zu beschränken; doch möchte ich dem widerraten. Es trägt zur Hebung der gesamten wissenschaftlichen Stellung und Bedeutung einer Universität bei, ja eines ganzen Landes, wenn diese Universität oder die 
Universitäten des betreffenden Landes Studierende vom Inland und Ausland zum Besuche anziehen. Sorge man nur für eine hinreichend große Zahl von Universitäten und namentlich, was den Unterricht in praktischen Fächern anlangt, für gut ausgestattete Institute mit ausreichender Zahl von Hilfskräften für den Lehrer und Leiter der Anstalt, dann läßt sich auch der freie Zuzug ertragen und jeder Student findet dann auch Gelegenheit, sich praktisch gut unterrichten zu lassen. Besonders beachtenswert ist eine möglichst große Anzahl von tüchtigen Assistenten und sogenannten Amanuensen oder Famulis aus dem Kreise der älteren Studierenden oder solcher, die eben ihre Staatsprüfung gut bestanden hatten. Man sollte aber auch diesen, obwohl sie ja schon durch ihre Stellung einen großen Vorteil haben, ein gewisses Gehalt gewähren; das gibt ihnen eine ganz andere Auffassung von der Bedeutung ihrer Stellung, die ihnen aber, um möglíchst viele heranziehen zu können, höchstens auf ein bis zwei Jahre verliehen werden dürfte.

Man hat wohl empfunden, da $\beta$ bei der fortschreitenden Entwicklung der medizinischen Wissenschaften und der Heilkunst die fünfjährige Studienzeit an der Universität nicht mehr ausreicht, um genügend geschulte Ärzte auszubilden und hat daher zwei weitere Einrichtungen getroffen: das sogenannte "Praktische Jahr" und die Schaffung von medizinischen Akademien in Verbindung mit einer Zentralstelle für das ärztliche Fortbildungswesen in Preußen, die ihrerseits in Verbindung steht mit ähnlichen Stellen im Deutschen Reiche. Seit dem Tode Ernst v. Bergmanns ist mir der Vorsitz bei den Verhandlungen dieser Zentralstelle übertragen worden, was mich wohl in die Lage versetzt, einiges zu diesen sicherlich gutgemeinten Einrichtungen zu äußern.

Während des sogenannten praktischen Jahres sollte der Kandidat der Medizin, nach abgelegter Endprüfung, an einer dazu berechtigten Krankenanstalt unter Leitung der dort angestellten Ärzte in die eigentliche praktische Tätigkeit des Arztes eingeführt werden. Es haben sich aber Schwierigkeiten herausgestellt mit bezug auf eine hinreichende Menge geeigneter Krankenhäuser und insbesondere in bezug auf Ärzte, die geeignet und geneigt waren, die weitere Ausbildung zu übernehmen. Und wie soll es da mit den verschiedenen Fächern gehalten werden? Alles in einem Jahre noch praktisch im 
Anschluß an den Universitätsunterricht durchzuarbeiten ist nicht gut möglich. Das ist aber, meines Erachtens, auch durchaus nicht erforderlich. Es müßte genügen und genügt auch, wenn die drei Hauptabschnitte der ärztlichen Ausbildung: Behandlung innerer Krankheiten, chirurgischer und geburtshilflicher Fälle besonders berücksichtigt würden. Dabei wäre in der Chirurgie vor allem Wert $\mathrm{zu}$ legen auf die sogenannte kleine operative Chirurgie, Verbandskunst, Behandlung von Wunden, Blutungen, Knochenbrüchen, Verrenkungen und Unterleibsbrüchen, sowie auf die gründliche Kenntnis der Asepsis und der Antisepsis. Fernere wichtige Gebiete sind die Kinder- und Säuglingspflege, die entweder im Anschlusse an die Geburtshilfe oder an die Innere Medizin praktisch zu betreiben"wären. Vor allem wäre wichtig, da $B$ der Kandidat möglichst oft zur Ausübung von operativer oder Hilfstätigkeit, z. B. zur Leitung der Narkose, Einführung von Sonden, speziell der Magensonde, Anlegung der Geburtszange, Ausführung von Wendungen u. a. dergl. herangezogen würde. Selbstverständlich würden ihm dabei Übungen in der selbständigen Stellung von Diagnosen, Indikationen und Heilplänen von größtem Nutzen sein.

Eines sollte jedoch vor allem anderen praktisch geübt werden: die Krankenpflege, wie sie von den Krankenwärtern und Krankenschwestern verrichtet wird. Ein bis zwei Monate sollte jeder angehende Arzt als Krankenwärter tätig sein mit aller Anspannung seiner Kräfte, dabei auch in Wohnungs- und Beköstigungsverhältnissen nicht anders gehalten werden, wie die übrigen Krankenwärter. Dann kann er später aus eigener Erfahrung seine Anordnungen treffen. Eigene Erfahrung bleibt immer der beste Lehrmeister.

Alles dieses wird er im Laufe des praktischen Jahres, wenn er an ein gutes, hinreichend belegtes Krankenhaus und in die Hände von Ärten kommt, die sich mit Interesse seiner annehmen, viel besser und fürs Leben fester lernen, als an der Universität, einmal, weil er gereifter dazu kommt und vor allem, weil er von der Examensorge frei ist. Diese Sorge ist eines der größten Hindernisse für das praktische Erlernen; denn zu den Prüfungen muß ja die größte Menge des Stoffes aus Büchern, d. h. rein theoretisch gelernt werden. 'Der Kandidat will gern erst einmal seine Examina überwunden haben und so richtet sich seine beste Kraft und Aufmerksamkeit auf das theore- 
Vom medizinischen Unterricht. Akademien für praktische Medizin. 185

tische Lernen. Dies kann ja auch bei einer schriftlichen oder mündlichen Prüfung nicht übergangen werden. Ganz von selbst ergibt sich für den Prüfling wie für den Prüfer die Schätzung der Prüfung größtenteils daraus, wieviele Fragen glatt und gut beantwortet wurden. Gewiß wird ja auch seit langem praktisch geprüft bei den Stellungen der Diagnosen, in der Anatomie durch Anfertigung und Erklärung von Präparaten, in der Chirurgie durch Vornahme von Operationen an der Leiche, Anlegung von Verbänden und anderem sich Darbietenden; aber von mündlichen Prüfungen kann sicherlich nicht abgesehen werden. Während des praktischen Jahres kann und soll aber der Kandidat alle seine Kraft und Aufmerksamkeit nicht auf das „Wissen“, sondern auf das „Können“ richten. So ließe sich, wenn die günstigen Bedingungen in bezug auf Krankenhäuser und Ärzte gegeben wären, das praktische Jahr zu einer höchst wirksamen Einrichtung gestaiten.

Die in bezug auf die Krankenhäuser und Ärzte bestehenden Schwierigkeiten, sowie das Bedürfnis nach einer Fortbildung der bereits ausübenden Ärzte, haben nun zur Errichtung einer zweiten Neuschöpfung, der Akademien für praktische Medizin geführt. Die erste Einrichtung dieser Art ist das Ka iserin-Friedrich-Ha us in Berlin, welches jetzt zur Zentralstelle für alle im Deutschen Reiche bestehenden ärztlichen Fortbildungseinrichtungen geworden ist. Da B Einrichtungen dieser Art von größtem Nutzen, ja notwendig sind, leuchtet bei einer so stetig fortschreitenden Wissenschaft und Kunst, wie es die ärztliche ist, ohne weiteres ein. Es sei hierzu bemerkt, da $B$ sich der Ministerialdirektor Alth off ein besonderes Verdienst durch die Förderung des Zustandekommens der beiden deutschen Akademien in Köln und Düsseldorf erworben hat. Meines Erachtens sollten diese Akademien sowohl der Aufnahme von Kandidaten für die ganze oder teilweise Ableistung des praktischen Jahres, als auch insbesondere der ärztlichen Fortbildung dienen. Sie müßten aber ihre Unterrichtsart ganz anders gestalten als die auf den Universitäten. Keine theoretischen Vorlesungen, die den gesamten Lehrstoff umfassen, wie sie für den Anfänger nötig sind und die Aufgabe der Universitäten bleiben müssen, sondern theoretische Behandlung einzelner Kapitel, in welchen besondere wissenschaftliche Fortschritte und Anderungen $\mathrm{zu}$ verzeichnen sind. 
Der Schwerpunkt des Unterrichts läge in den klinischen Fächern, und wäre hier auch so einzurichten, daß insbesondere wichtige und bewährte Fortschritte in Diagnose und Behandlung berücksichtigt würden, wie sie von den bereits ausübenden Ärzten zu der Zeit, als diese ihre erste ärztliche Ausbildung empfingen, entweder gar nicht, oder nur unvollkommen erlernt werden konnten. Es gibt da des Neuen und Wissenswerten in der Medizin so viel, daß alle paar Jahre ein neues Unterrichtsprogramm für die Fortbildung aufgestellt werden könnte.

An einer solchen Akademie müßten angestellt werden : 2 Professoren der Anatomie, davon einer für Beschreibende und Topographische Anatomie, einer für Allgemeine Anatomie, Histologie und Embryologie; ferner je ein Professor für Physiologie, für allgemeine Pathologie und Pathologische Anatomie, für sämtliche klinische Fächer mit Einschluß der Spezialitäten, endlich für Hygiene und soziale Medizin. Selbstverständlich würde ein klinischer Unterricht für die Kandidaten des praktischen Jahres gehalten werden müssen unter Berücksichtigung der für diese bestehenden besonderen Bedürfnisse, dann aber vor allem besondere Kurse für Ärzte, die dort ihre Fortbildung suchen. Solche Kurse werden von Dozenten der Berliner Universität, aber auch von Berliner praktischen Ärzten im Kaiserin-FriedrichHause gegeben und zwar mit gutem Erfolg.

Angesichts der jüngst eingetretenen Umwandlung der schon seit einem Jahrzehnt bestehenden Kölner Akademie für praktische Medizin in die medizinische Fakultät der in Köln wieder erstandenen alten Universität (10) kann man fragen, ob man eine neue Akademie in einer anderen Stadt, vielleicht im Osten, gründen solle? Soviel ich weiß, hat der Lehrkörper der Kölner Akademie sich in der weit überwiegenden Mehrzahl seiner Mitglieder für die Universität ausgesprochen. Andere Akademien, als die beiden dicht beieinander im universitätsreichen Westen gelegenen, sind bisher nicht gegründet worden, während doch in anderen deutschen Gauen Stettin und Hamburg, ferner Dresden, Erfurt, Stuttgart und Nürnberg - von Danzig muß leider jetzt abgesehen werden - geeignete Orte dafür gewesen wären. Haben etwa die medizinischen Akademien den auf sie gesetzten Hoffnungen nicht entsprochen?

Meines Erachtens könnten sie bei richtiger Führung Vortreffliches 
wirken. Sie müssen sich nur streng von der Art des Lehrens, wie es an den Universitäten betrieben wird, fernhalten und sich bewußt bleiben, daB sie eine höhere medizinische Lehrstufe, namentlich in den praktischen Fächern, zu vertreten haben. Ihre Lehrer müßten den Universitätslehrern vollständig gleichgestellt werden. Das ist ja auch bereits dadurch zum Ausdruck gekommen, da $\beta$ Universitätslehrer an die Akademien berufen wurden und umgekehrt.

Man versteht es indessen wohl, daB der Lehrkörper der Kölner Akademie sich der Bewegung, die alte Universität wieder aufleben zu lassen, anschloß. Es bleibt den Universitäten der besondere Reiz und Vorzug, der in der Vereinigung aller Wissenschaften liegt. Ungünstig ist, daß Köln und Bonn so nahe zusammen liegen. Wenn ich mich auch vorhin zugunsten der Vermehrung der Universitäten äußerte, so ist eine so nahe Zusammenlegung zweier Universitäten, wie Bonn und Köln, sicherlich nicht zu empfehlen. Die medizinische Fakultät Bonns wird unter dieser Nachbarschaft wohl am meisten leiden müssen. Hoffentlich lassen sich Mittel und Wege finden, der Bonner Fakultät Ersatz zu schaffen für den Ausfall, der ihr durch Errichtung einer gleichen Fakultät in Köln droht.

Wenn man nun so, wie ich glaubte vorschlagen $\mathrm{zu}$ sollen, einige Universitäten mehr gründete, wenn man in den medizinischen Fakultäten für reichliche Anstellung von auskömmlich besoldeten Assistenten sorgte und hinreichend Akademien mit angepaßtem Unterricht für die Kandidaten des praktischen Jahres und für die ärztliche Fortbildung einrichtete, dann wäre sicherlich für die Möglichkeit einer genügenden Ausbildung der Ärzte bestens gesorgt. Freilich, ohne Aufwendung bedeutend höherer Mittel, als sie bis jetzt zur Verfügung stehen, geht das nicht an.

Ich komme auf die Frage der anzustellenden Ordinarien, Extraordinarien und Privatdozenten an den Universitäten zurück. In den ersten Zeiten der Universitäten gab es nur eine Art von Professuren, die unsern heutigen ordentlichen entsprechen. Diese vertraten denn auch den Gesamtumfang des betreffenden Faches. Insbesondere auf die medizinische Fakultät angewendet, gab es nur Professoren für Fächer, die den ganzen Menschen umfaßten, nicht für Fächer, die sich auf ein einzelnes Organ oder einen bestimmten Organkomplex bezogen Ja, manche Professoren lehrten damals noch den gesamten Umfang 
der Medizin nebst Botanik und Zoologie. Später vertrat ein Professor meist noch mehrere Fächer, wie u. a. Johannes Müller noch die gesamte Anatomie, normale, vergleichende und pathologische, sowie die gesamte Physiologie und hat als Forscher und Lehrer in allen diesen Fächern Vorzügliches geleistet. Sein Schüler Henle erhielt noch im Jahre I834 einen Ruf als Nachfolger Heinrich Rat hkes nach Dorpat, wobei $\mathrm{ihm}$ als Lehrfächer, die Rathke auch tatsächlich vertreten hatte, genannt wurden: Physiologie, Pathologie, Pathologische Anatomie und Zoologie. An der medizinischen Schule in Berlin, welche dort schon vor Gründung der Universität bestand, war seiner Zeit der berühmte ältere Meckel zugleich Professor der Botanik, Anatomie und Geburtshilfe. Es seien hier nur diese wenigen Beispiele angeführt.

Ich kann es mir nicht versagen, hier wörtlich die Bemerkungen anzufügen, die der Biograph Henles, sein Schwiegersohn Fr. Merkel, der Mitteilung von Henles Berufung nach Dorpat hinzufügt: „Dieser Brief," sagt Merkel von dem Dorpater Berufungsschreiben, ,ist nicht allein im speziellen, sondern auch ganz allgemein dadurch interessant, daß er zeigt, wie wenig damals noch von einer Trennung der medizinischen Fächer die Rede war. Wie würde es heutzutage irgend Jemandem einfallen und einfallen können, einem Professor zuzumuten, menschliche und vergleichende Anatomie, Zoologie, Physiologie, allgemeine Pathologic und Pathologische Anatomie zu vertreten, ich sage gar nicht, zu beherrschen."

„Es wäre ein Glück zu nennen, daß die späteren Jahrzehnte mit dem alten Vielwissertum aufgeräumt haben und da $B$ sich die einzelnen Fächer durch immer größere Spezialisierung vertiefen konnten; doch muß da auch wieder einmal Halt geboten werden, damit die Gefahr, ins umgekehrte Extrem zu verfallen, beseitigt werde. Schon geht die Fühlung der Schwesterdisziplinen untereinander mehr und mehr verloren und wenn dem Anatomen aus der komparativen Schule die Physiologie ein böhmisches Dorf ist, wenn dem physiologischen Anatomen die embryologische Seite seiner Wissenschaft unbekannt bleiben kann, wenn der eine nur mit dem Skalpell, der andere mit dem Mikroskop unsere Kenntnisse $z u$ fördern vermag, so ist dies ein ungesunder Zustand, der ein Ende finden muB, wenn nicht schlimme Folgen entstehen sollen. Zum Glück für die Wissenschaft machen 
Medizin. Unterr.: Ordinarien, Extraordinarien. Spezialisierung. 189

sich in der Gelehrtenwelt mancherlei Anzeichen geltend, daß man an eine Umkehr denkt, und ist erst eine größere Reihe von allgemeinen und fundamentalen Tatsachen der Diskussion entrückt und zum Gemeingut geworden, dann werden sich die Forscher auch wieder auf eine höhere Warte schwingen, und es wird eine Zeit kommen, in welcher an den Hochschulen die ganze menschliche Biologie in einer Hand vereint oder doch nur an zwei Vertreter verteilt sein wird; dies Ziel zu erreichen wird die Aufgabe des 20. Jahrhunderts sein." (11)

Es war naturgemäß, daß, so wie die Kenntnisse vom Bau, von den Verrichtungen und Erkrankungen der einzelnen Körperteile, wie des Sehorgans, des Gehörorgans, des Nervensystems usw., sich mehrten und auch besondere Untersuchungsverfahren sich dabei herausbildeten, einzelne Ärzte sich besonders für die anatomische, physiologische und pathologische Kenntnis und damit für die Behandlung eines einzigen Organs interessierten. Solche Spezialisten aus der ältesten Zeit waren die Zahnärzte, die aber lange nicht als volle Ärzte angesehen wurden, bis erst in der Jetztzeit die Wandlung der Zahnheilkunde zu einem den übrigen medizinischen Spezialfächern gleichen Fache sich vollzieht. So kam es denn dazu, da $B$ besonders ausgezeichnete Vertreter solcher Spezialfächer auch zu Professoren ernannt wurden. Sie wurden jedoch noch nicht unter die Mitglieder der Fakultät, die deren allgemeine Geschäfte zu führen, zu examinieren und den Doktorgrad zu erteilen hatten, aufgenommen; so kam der Stand der außerordentlichen Professoren, der Professores extraordinarii, auf. In Österreich und in Frankreich ist man nun damit vorangegangen, auch die Vertreter von Sonderfächern zu Ordinarien zu ernennen. In Preußen und im übrigen Deutschland war wohl Albrecht v. Graefe, einer der hervorragendsten Mediziner aller Zeiten, einer der ersten, dem für das Fach der Augenheilkunde ein Ordinariat verliehen wurde (1866). Exempla trahunt, heißt es mit Recht. Freilich war schon ein Jahr früher Griesinger in Berlin zum Ordinarius für Ncrven- und Geisteskrankheiten ernannt worden, doch folgten erst nach meinem Eintritte in die Berliner Fakultät die Ordinariate für Kinderheilkunde, Ohrenkrankheiten, für Hals- und Nasenkrankheiten und für Hautkrankheiten und Syphilis. Schon regen sich Stimmen, welche ein Ordinariat für Orthopädie und für 
Nieren- und Blasenkrankheiten (für Urologie) haben möchten. Wie weit soll man da gehen? Die Chirurgie ist schon fast ganz zerpflückt in Einzelfächer: Die Otologen operieren am Ohr, die Ophthalmologen am Auge; der Nase und ihrer Nebenhöhlen, des Kehlkopfes bis zu den Lungen hinab haben sich operativ die Halsärzte, des Mundes die Zahnärzte bemächtigt; die Orthopäden beanspruchen die Chirurgie der Extremitäten. Die Gynäkologen nehmen die Bauchchirurgie beim Weibe, die Urologen die Chirurgie der Nieren und der Blase; so bleibt für den Chirurgen wenig mehr, wo er allein herrscht, übrig. Freilich wird er stets das alles auch beherrschen müssen, wenn er als Chirurg anerkannt bleiben will. Nur von den Augenoperationen scheinen sich die heutigen Chirurgen ganz zurückgezogen zu haben, während seiner Zeit v. Bardeleben in Greifswald auch noch sämtliche Augenoperationen, die damals bekannt waren, übernahm. Nun, in der Inneren Medizin geht es kaum anders. Seit die Geistes- und Nervenkrankheiten, die uns in Greifswald noch von dem Inneren Kliniker Niemeyer gelehrt wurden, und die Kinderkrankheiten abgezweigt sind, fängt man an, die Lungenkrankheiten, für welche in Berlin bereits eine eigene Poliklinik besteht, ferner die Herz- und Magenkrankheiten zu spezialisieren. Wenn es nun dahin kommen sollte, da $B$ auch für jedes dieser Organe oder Organkomplexe eine besondere Professur bestellt würde, dann kommt, wie die Erfahrung gelehrt hat, bald auch die Forderung der betreffenden Vertreter, da $B$ ihre Professur ein Ordinariat werden solle und da $\beta$ jedenfalls beim ärztlichen Staatsexamen die Kandidaten auch in diesem Fache besonders geprüft werden sollten. In diesem letztgenannten Punkte liegt nun meiner Meinung nach eine Gefahr für die Ausbildung unserer jungen Mediziner, die Gefahr, die mit dem altbekannten und gewürdigten Spruche: Non multa sed multum! gekennzeichnet ist. Wenn der angehende Mediziner gezwungen ist, der von ihm verlangten Prüfungen wegen, Vorlesungen und Übungen in nachstehenden Fächern zu hören: Chemie, Physik, Zoologie, Botanik, Beschreibende und Topographische Anatomie, Allgemeine Anatomie und Gewebelehre, Entwicklungsgeschichte, Physiologie, Pathologische Anatomie, Allgemeine Pathologie, Spezielle Pathologie und Therapie, Arzneimittellehre, Arzneiverordnungslehre, Allgemeine und spezielle Chirurgie, Geburtshilfe und Gynäkologie, Augenheilkunde, Ohrenheilkunde, Vorlesungen über Hals- und Nasenkrank- 
heiten, Hautkrankheiten und Geschlechtskrankheiten, ferner teilzunehmen an folgenden Übungen: Präparierübungen (2 Halbjahre), Mikroskopisch-anatomische Übungen (I Halbjahr), Entwicklungsgeschichtliche Übungen (I Halbjahr), Physiologische Übungen (I Halbjahr), Chemische Übungen (I Halbjahr), Physikalische Übungen (I Halbjahr), Pathologisch-anatomische Übungen (I Halbjahr), Medizinische, Chirurgische, Geburtshilfliche Klinik (je 2 Halbjahre), Psychiatrische und Nervenklinik, Augenklinik, Ohrenklinik, Hals- und Nasenklinik, Haut- und Syphilitische Klinik (je I Halbjahr), so sind das zusammen $2 I$ Vorlesungen und I4 Übungskurse. Wenn man ferner erwägt, da $B$ von diesen Vorlesungen die Chemischen, Physikalischen, Anatomischen, Physiologischen je 2 Halbjahre mit je 5 bis 6 Stunden wöchentlich in Anspruch nehmen, die übrigen meist auch 5 Stunden wöchentlich, die klinischen Übungen mindestens 6 Stunden wöchentlich in der Inneren Medizin, Chirurgie und Geburtshilfe, in den übrigen Kliniken noch 3 bis 4 Stunden, so kommen auf den Wochentag in allen 5 jetzt vorgeschriebenen Studienjahren je 8 Stunden Vorlesung oder praktische Übungen. Dabei sind besondere Übungen, wie in der Physikalischen Diagnostik, Spiegelkurse, klinische Untersuchung der Sekrete und Exkrete, Röntgen-Untersuchungen, Bakteriologische Kurse u. a., Dinge, die heute jedem praktischen Arzte unerläßlich sind, gar nicht gerechnet. Damit hat aber der junge Mediziner nur rein medizinische Dinge gelernt. Unsere Jugend soll sich aber, wenn sie sich zu den gelehrten Berufen der vier Fakultäten vorbereiten will, auch in ihrer allgemeinen Bildung vertiefen. Die Gymnasialbildung reicht dafür nicht aus. So würde ich für die Mediziner noch dringend empfehlen, Vorlesungen über Philosophie, namentlich Logik und Psychologie, Metaphysik und Geschichte der Philosophie, ferner über Kunstgeschichte und dann über Geologie, Paläontologie und insbesondere über Anthropologie zu hören. Ja, heute sollte Jeder sich einen Einblick in Sozialwissenschaften zu verschaffen suchen. $D a$ ergibt sich, da $B$ der Jünger der medizinischen Wissenschaft dazu gar nicht mehr kommen kann, wenn er noch jeden Tag das Gehörte durch Nachstudium in seinen Büchern, dieses aber mit der Feder in der Hand, sich klar und fest zu eigen machen will. Gewiß, die reichlich bemessenen Ferien geben ihm gute Zeit dazu und sollen auch dazu benutzt werden; es ist jedoch wichtig, da $B$ jedenfalls 
1 y2 Medizinisches Studium einst $\mathbf{u}$. jetzt. Gefahren der Spezialisierung.

das tagsüber Gehörte am Abend auch sofort durchgearbeitet wird, wenn es sich um ein ernstes, fruchtbringendes Studium handeln soll.

Vergleiche ich mit dem jetzigen Stande der Anforderungen diejenigen, welche $z u$ meiner Studienzeit gestellt wurden, so waren wir damals viel weniger belastet. Wir hatten freilich nur vier Jahre zur Verfügung, mußten auch noch Vorlesungen über Logik, Psychologie und Mineralogie hören; es fielen aber aus: Vorlesungen über Entwicklungsgeschichte und die Übungen darin, dann die Vorlesungen und Übungen in der Pathologischen Anatomie, die jetzt ein so besonders gründliches Studium erfordert, welches auch als ein schwieriges bezeichnet werden muB. Ferner fielen aus: alle Spezialvorlesungen über Augen-, Ohren-, Hals-, Nasenkrankheiten, Frauenkrankheiten, die chemischen, physikalischen und physiologischen Übungen, die Röntgenologie und Bakteriologie und manches andere, so daß wir mit täglich 4 bis 5 Stunden, später, in den klinischen Semestern, mit höchstens 6 Stunden Vorlesungen einschließlich der Übungen gut auskamen. Da behielten wir ausreichend Zeit zum privaten Studium in unseren Lehrbüchern, zum Wiederholen und $z u$ eigenen Ausarbeitungen, sowie zu Vorlesungen über außerhalb der Medizin liegende Gebiete von allgemein wissenschaftlichem Werte und schließlich, das soll nicht unterschätzt werden, zu dem frischfrei-frohen Studentenleben!

Es scheint mir angezeigt, in ernste Erwägung zu ziehen, ob wir die Zahl der Ordinariate in der medizinischen Fakultät noch vermehren sollen? Die Anforderungen dazu werden nicht ausbleiben. Ich wäre sogar dafür, grundsätzlich daran festzuhalten, daß medizinische Ordinariate nur für solche Teile der Medizin bestellt würden, die den ganzen Menschen umfassen, nicht aber für solche, die sich nur auf einzelne Organe und Apparate beziehen. Nach diesem Grundsatze würden als ordentliche Professuren verbleiben die Lehrfächer der Anatomie, Physiologie, der Pathologischen Anatomie mit Einschluß der allgemeinen Pathologie, die Pharmakologie, die Innere Medizin, die Chirurgie, die Geburtshilfe mit Einschluß der Gynäkologie, die Neurologie mit Einschluß der Psychiatrie, die Kinderheilkunde und die Hygiene mit Einschluß der sozialen Medizin. Ich wäre auch dafür, da $B$ die Lehre von den Haut- und Geschlechtskrankheiten als ordentliche Professur beibehalten würde wegen der außerordentlichen 
Wichtigkeit, die eine gründliche Kenntnis der betreffenden Krankheiten für jeden Arzt hat. Und ein Ordinariat für diese Fächer verstöBt auch nicht gegen den aufgestellten Grundsatz, denn die Syphilis trifft den ganzen Körper und geht durch Vererbung auf Generationen über in einer Weise, wie man es von keiner anderen Krankheit, selbst nicht von der Tuberkulose, sagen kann. Auch die Bestallung der Nervenkrankheitslehre mit Einschlu $B$ der Psychiatrie für ein Ordinariat ist mit dem Grundsatze nicht in Widerspruch, denn das Nervensystem beherrscht alle übrigen Apparate und Systeme des Körpers mehr als irgendein anderes und sein Feld, namentlich mit EinschluB der Psychiatrie, ist ein so ausgedehntes, da $B$ es in genügender Weise nicht mehr im Rahmen der Inneren Medizin behandelt werden kann. Auch hier ist die Wichtigkeit einer gründlichen Kenntnis für den Arzt so gro $B$, da $B$ ein besonderes Ordinariat gerechtfertigt erscheint.

In den vorhin angeführten Worten Fr. Merkels, denen ich durchaus beipflichten kann, ist als Gegengrund der zu weit getriebenen Spezialisierung angegeben, da $B$ damit die notwendige Fühlung der Schwesterdisziplinen miteinander verloren gehe. Ähnliche Betrachtungen findet man in dem jüngst erschienenen Werke des Referenten für das preußische Hochschulwesen im Ministerium für Wissenschaft, Kunst und Volksbildung, C. H. Becker ( $\left.{ }^{12}\right)$. Ich denke bei meiner Betrachtung über diese Dinge insbesondere an die Gefahren, welche die immer fortschreitende Spezialisierung im Unterrich te für die Lernenden, die Studierenden, mit sich bringt. Vorhin habe ich schon die Unmöglichkeit hervorgehoben, im Rahmen der fünf Studienjahre alles, was bei der weitgetriebenen Spezialisierung der Medizin gelernt werden soll, sich wirklich anzueignen und dabei auch noch für weitere Geistesbildung im Sinne einer Hochschule zu sorgen. Nun möchte ich noch auf eine andere Gefahr ausdrücklich hinweisen, die in der Überlastung der Studierenden mit Prüfungsfächern liegt. Die Vielprüferei ist entschieden ein Übel. Da möge Jeder sich fragen, mit wieviel mehr Interesse er das studiert, was er sich frei wählt und worüber er kein Examen abzulegen braucht. Gewiß, Prüfungen müssen sein und zwar recht ernste, aber nicht zu viele und nicht über zu viele Gegenstände auf einmal. So, wie die Dinge jetzt bei uns liegen, hält jeder medizinische Ordinarius darauf, da $B$ er in seinem Fache auch prüfe, wenigstens in der Hauptprüfung, im medizinischen Staatsexamen. Da

v. Waldeyer-Hartz, Iebenserinnerungen. 
kommt es bei der Vermehrung der Ordinariate für Einzelfächer notwendiger Weise zu einer üblen Vielexaminiererei. Das sollte vermieden. werden. Ich würde auch gar keine Bedenken tragen, in der medizinischen Fakultät die Extraordinariate überhaupt zu beseitigen und nur Ordinariate zu schaffen für alle Spezialfächer, welche sich soweit entwickelt haben, daß sie in vollem Umfange nicht mehr in Verbindung mit anderen Fächern gelehrt werden können; aber man müßte dann eine Prüfungsordnung schaffen, welche die Kandidaten nicht $z u$ sehr belastete. Man könnte daran denken, für diejenigen Kandidaten, welche sich als Spezialärzte niederlassen und als solche bezeichnen wollen, eine besondere Prüfung einzuführen, während man z. B. im Staatsexamen das, was jeder Arzt von der Augen- oder Ohrenheilkunde wissen und in ihr können muB, dem Chirurgen und die Prüfung in der Psychiatrie, in Nervenkrankheiten und Kinderkrankheiten dem Inneren Kliniker überließe. Wir stehen hier vor einer der wichtigsten Fragen der Ausbildung unserer Ärzte in Zukunft, aber auch vor einer der schwierigsten. Daß alle medizinischen Fächer hinreichend und in würdiger Weise vertreten sind, muß erste Sorge sein; aber auch ein richtiges und gründliches Lernen muß ermöglicht werden ohne Zersplitterung!

Was die Überlastung mit Prüfungen in vielen Fächern in ein und demselben Prüfungstermine angeht, so möchte ich da eine Änderung in Vorschlag bringen, die ich bereits eingehend während meiner aktiven Teilnahme an den Geschäften der Berliner medizinischen Fakultät begründet habe. Es handelt sich um die ärztliche Vorprüfung. Bei ihr wird in mehreren Abschnitten, jedoch kurz hintereinander geprüft in Botanik, Zoologie, Chemie, Physik, Anatomie und zwar in beschreibender und histologischer von zwei Examinatoren, in Entwicklungsgeschichte und in der Physiologie. Das sind alles jetzt weit ausgebaute Fächer und zum Teil sehr verschiedenen Inhalts; auch ist die Prüfung in den anatomischen und physiologischen Gegenständen bedeutend verschärft worden, seit sie im Staatsexamen weggefallen ist. Hier scheint mir nun eine Trennung in zwei Prüfungstermine angezeigt. Am Ende des ersten Studienjahres oder zu Beginn des zweiten sollte die Prüfung in der Botanik, Zoologie, Physik und Chemie abgelegt werden und für diese vier Fächer wären besondere, für Mediziner bestimmte kürzere Vorlesungen einzu- 
richten. Am Ende des zweiten Jahres oder in den ersten Wochen des dritten käme dann die Prüfung in den anatomischen, entwicklungsgeschichtlichen und physiologischen Fächern. Bei dieser Änderung könnten die Studierenden, wenn sie von der Examensorge um die naturwissenschaftlichen Fächer befreit wären, viel mehr Zeit auf die für sie so ungemein wichtigen anatomischen und physiologischen Studien verwenden; auch mit viel mehr Lust würden sie dann diesen Studien obliegen.

In den letzten Jahren und insbesondere seit der Revolution des Jahres I9I8 ist viel von Reformen unseres Hochschulunterrichts und insbesondere des Universitätsunterrichts die Rede. Ich verzichte darauf, hier auf diese wichtigen Dinge einzugehen. Nur auf eine Gefahr möchte ich aufmerksam machen. Meistens tritt bei den in der Presse und in Flugschriften behandelten Wünschen allzu sehr das Bestreben hervor, da $B$ alle Kategorien von Dozenten sowohl wie auch die Studenten mehr Rechte haben möchten, und alle möglichst viel in der Verwaltung der Hochschulen mitzureden und mitzutun hätten. Manche Wünsche mögen berechtigt sein, aber bedeutungsvolle Reform wird damit nicht geleistet. Diese liegt vielmehr in der möglichsten Verbesserung des Unterrichts. Darauf sollten vor allem die Reformbestrebungen gerichtet sein. Durch die Veränderungen in den Stellungen der Dozenten wird nicht viel genützt, ja, indem man die Hauptaufmerksamkeit dahin lenkt, wird sie vielleicht vom Wesentlichen abgezogen. Bis jetzt stehen unsere deutschen Universitäten noch obenan.

Die Universitäten sind in erster Linie Lehranstalten, indem sie für bestimmte Berufe, die ein größeres Wissen und Können nicht nur in Spezialgebieten, sondern auch im allgemeinen beanspruchen, die erforderliche Ausbildung zu geben haben. Aber in zweiter, der ersten parallel laufender Linie sind auch sie Forschungsanstalten, die dafür zu sorgen haben, da $B$ aus dem unerschöpflichen Born der Wissersschaft immer neue Schätze gehoben werden. Darin eben liegt einer der Hauptunterschiede zwischen den Hochschulen, insbesondere den Universitäten und den Mittelschulen. Vom Mittelschullehrer wird nicht verlangt, da $\beta$ er in den Fächern, die er vorzutragen hat, auch Forscher sei, der Hochschullehrer soll aber auch selbständiger Forscher auf dem von ihm zu lehrenden Gebiete sein, denn nur dadurch kann 
196 Universitäten und Akademien der Wissenscbaften. Frauenstudium.

er sich diejenige Lehrautorität verschaffen, die er seinen gereifteren Schülern gegenüber haben soll und muß. Er muB höchste Instanz in seinem Lehrgebiete sein, soweit man in den Wissenschaften überhaupt von Instanzen reden kann.

Diese Forschertätigkeit kommt aber auch der Lehrtätigkeit zugute; jeder Universitätslehrer wird an sich selbst die Erfahrung machen, da $B$ er diejenigen Stoffe am besten vorträgt und am eindringlichsten lehrt, mit denen er sich selbst als Forscher beschäftigt hat. Der akademische Lehrer soll „,Schule“6 bilden; das kann er nur, wenn er selbst ein angesehener Forscher ist, der für den Fortschritt in seiner Wissenschaft sorgt.

Neben den Universitäten, die zugleich Forschungs- und Lehranstalten sind, haben sich als reine Forschungsanstalten mit Recht die Akademien oder Gesellschaften der Wissenschaften entwickelt, über welche in einem besonderen Kapitel, im AnschluB an meine Erlebnisse in der Preußischen Akademie der Wissenschaften gehandelt werden wird.

\section{Frauenstudium und Frauenfrage.}

Als die Frage des Frauenhochschulstudiums in Deutschland aufzutauchen begann, habe ich mich verleiten lassen -- es war im Jahre 1888 bei der Deutschen Ärzte- und Naturforscherversammlung in Köln - darüber einen Vortrag zu halten, in welchem ich mich im ganzen ablehnend äußerte. Ich stach damit - die Damen mögen mir den Ausdruck verzeihen, er ist nicht bös gemeint - in ein Wespennest, denn in verschiedenen Zeitschriften, in anonymen und mit Namen versehenen Briefen wurde ich mehr oder minder heftig angegriffen, zumal ich auch den Frauen den Zutritt zu meinen Vorlesungen in der Anatomie und zu den Präparierübungen verweigerte. Später, als die Frauen offiziell immatrikuliert und mit allen studentischen Rechten ausgestattet wurden, mußte ich sie zulassen. Ich richtete jedoch einen besonderen Präpariersaal für Frauen ein, dessen Leitung ich meinem Kollegen und ersten Prosektor der Berliner Anatomie, Herrn Professor Hans Virchow, übergab. Anfangs sprachen sich manche der studierenden Frauen gegen diese Einrichtung aus; sie meinten vielleicht, daß sie nicht den gleichen Unterricht 
auf dem Präpariersaale erhielten wie ihre männlichen Kommilitonen. Diese Einsprachen ließen aber bald nach, als die Studentinnen einsahen, da $B$ sie genau denselben Unterricht und dieselbe Berücksichtigung erhielten und erfuhren wie die Studenten. Ich glaube nicht, $\mathrm{da} B$ sie jetzt eine andere Einrichtung wünschen würden. Sind nur wenige Studenten und Studentinnen auf einem Präpariersaale tätig, so geht alles glatt und gut ab und es herrscht Ruhe, wie sie für ungestörtes Arbeiten nötig ist. Handelt es sich aber um Hunderte, die gleichzeitig arbeiten, wie das zeitweise in Berlin der Fall war, dann wird viel $\mathrm{zu}$ viel geredet, selbst unter Studierenden desselben Geschlechts, und viel mehr, wenn beide Geschlechter vereinigt sind, so da $B$ dies auf die Dauer störend wirken muß. Ich habe diese Erfahrung auch in meiner theoretischen Vorlesung gemacht, bei der in den letzten Jahren oft über 400 Teilnehmer zugegen waren. Während der Vorlesung herrschte natürlich Ruhe. Nach der Vorlesung wurden nun meist noch Präparate demonstriert, zu denen ich stets nur eine beschränkte Anzahl, so viele als gerade noch gut sehen konnten, an den Demonstrationstisch herantreten lie $B$; die übrigen mußten auf ihren Sitzplätzen geduldig warten, bis sie an die Reihe kamen. Ich erlaubte ihnen dann zu rauchen; sie konnten auch durch Lesen oder durch eine leise geführte Unterhaltung, so weit sie meine Erklärungen am Demonstrationstische nicht störte, sich die Zeit vertreiben. So lange ich nur Studenten in meiner Vorlesung hatte, nahmen diese Unterhaltungen kaum jemals einen störenden Charakter an. Als aber auch die Frauen Zutritt zu meinen Vorlesungen erhalten hatten und in größerer Zahl erschienen, wurden die Unterhaltungen, wie das ja auch natürlich war, lebhafter, so da $B$ ich öfter um größere Ruhe bitten mußte.

Ich stehe auch noch heute auf dem Standpunkte, wie damals in Köln und meine, da $B$ es nicht erwünscht sei, da $B$ beide Geschlechter sich denselben Berufen in gleichem Maße zuwendeten. Alle Wege sollen den Frauen offen stehen, selbst die politischen, auch in der Familie habe die Frau die gleichen Rechte, natürlich dann auch die gleichen Pflichten wie der Mann; nur möge im Großen und Ganzen an der vernünftigen Arbeitsteilung, wie sie durch die natürlichen Verschiedenheiten der Geschlechter bedingt ist, möglichst festgehalten werden. 
Möge daher alles vermieden werden, was ein ungesundes Eindringen der Frauen in die bisher von Männern wahrgenommenen Lebensberufe fördert. Das, wogegen ich mich hier hauptsächlich wende, ist die gemeinschaftliche Erziehung mit dem männlichen Geschlecht und die dadurch veranlaßte Beeinflussung auf Lebensführung und Berufswahl, das, was man fremdwortlich als Coeducation bezeichnet. Wenn irgend möglich, sollte schon in den Elementarschulen, wenigstens bei den oberen Klassen, eine Trennung der Geschlechter stattfinden und die jungen Mädchen sollten durch Lehrerinnen unterrichtet werden, ferner besonders gerade in dem, was sie als künftige Hausfrauen, Erzieherinnen und Mütter verwerten können. Wenn die Gemeinden oder, wo diese die Mittel nicht hätten, der Staat in jeder Gemeinde eine Lehrerin anstellte und für eine besondere Mädchenschule sorgte, so würde das zwar erheblichere Kosten verursachen, aber die damit erreichten Vorteile wären nicht zu teuer erkauft und für viele Frauen wäre im Lehrerinnenberufe gesorgt. Den Lehrerinnen sollte auch das Eingehen einer Ehe freistehen; es ließen sich schon durch Vorsorge für Stellvertretung Wege finden, um die etwaigen Ausfälle von Schulstunden zu decken.

Was vom Elementarunterrichte gilt, finde auch durchweg seine Anwendung für den weiteren Unterricht in den Mittelschulen, den Oberschulen (Gymnasien, Realschulen) und vor allem an den Hochschulen (Universitäten, Technischen, Landwirtschaftlichen, Handels-, Zahnärztlichen und Tierärztlichen Hochschulen). Alle diese Schulen mögen den Frauen für ihre spätere Berufswahl offen stehen. Es sollen aber Frauen-Universitäten und Frauen-Hochschulen jeder Art nach Bedarf gegründet werden, an denen Frauen als Professorinnen unterrichten. Damit würde auch wieder vielen Frauen, welche die hinreichenden Fähigkeiten besitzen - und deren gibt es genug - ein zusagender Lebensberuf als Hochschullehrerinnen eröffnet. Man kann auch, meines Erachtens, es für die Hochschulen freigeben, ob an ihnen Männer und Frauen als Lehrer bzw. Lehrerinnen angestellt werden, das heißt, es könnte freigegeben werden, an eine Frauen-Universität Männer als Professoren zu berufen und umgekehrt, an eine MännerUniversität Frauen als Professorinnen. Damit würde der etwa entstehenden Meinung vorgebeugt, als ständen die verschiedenen Anstalten nicht auf gleicher Höhe. Die Lehrenden könnten aus beiden 
Geschlechtern genommen werden, nicht jedoch die Lernenden; hier möchte ich die von mir vorhin so entschieden betonte Lernfreiheit beschränkt wissen.

Frauenberufe gibt es genug, um den ledig bleibenden Frauen ihr Leben zu sichern, und dahin soll gewirkt werden, da $B$ unsere jungen Mädchen sich diesen Berufen zuwenden und nicht denen, die ihrer Art nach mehr dem männlichen Geschlechte liegen. Entschieden liegen die Berufe als Seelsorger, Rechtskundige in Verwaltung und Anwaltschaft — trotz Porzia - , als Ärzte, Zahnärzte, Architekten, Ingenieure u. a. der Art des Mannes näher als der der Frau, dieser wieder die Berufe der Haussorge, der Sorge für die Kinder und deren Erziehung, den wichtigsten und schönsten Beruf, den es gibt, der Wohlfahrtsund Krankenpflege und aller der Berufe, die weniger körperliche Anstrengung erfordern. Manche Berufe, namentlich auf den Gebieten der Kunst, liegen beiden Geschlechtern gleich gut und Ausnahmen gibt es auch zur Genüge.

Es ist nicht von ungefähr, oder allein durch die natürliche größere Körperkraft und Anstrengungsfähigkeit des Mannes entstanden, da B bei allen Völkern das männliche Geschlecht das führende, gebende, das weibliche das im öffentlichen Leben mehr zurücktretende, empfangende und für die zukünftige Generation sorgende geworden ist. Das liegt in der natürlichen Verschiedenheit der Geschlechter, die nicht nur auf körperlichem, sondern auch auf geistigem Gebiete besteht. Diese Verschiedenheit zu pflegen muß unser Bestreben sein, nicht, sie zu verwischen. Darin, in der sorglichen Pflege der Eigenart des Weibes und des Mannes bei der Erziehung liegt die Gewähr der Tüchtigkeit und der gesunden Fortentwicklung der einzelnen Menschen, wie der Staaten und Völker.

Je mehr wir durch Gemeinerziehung (Coeducation) und Übernahme männlicher Berufe und Lebensführung seitens der Frauen die von der Natur gegebenen Unterschiede zwischen den beiden Geschlechtern verschwinden lassen, desto gleichgültiger werden sie einander werden, desto seltener die Eheschließungen, desto kälter die Ehegemeinschaft. Die Steigerung der Übernahme männlicher Lebensberufe durch das Weib ist, meines Erachtens, ein Zeichen beginnender Überkultur und beginnenden Rückganges eines Volkes. Man könnte einwenden, daß doch in manchen Ländern und zwar in den frisch 
vorwärtskommenden Vereinigten Staaten Nordamerikas, ferner in den gewiß gesunden skandinavischen Ländern, sowie auch in Süddeutschland die Gemeinerziehung ohne bisher merkbaren Schaden eingeführt sei. Dazu bemerke ich, da $B$ die Verhältnisse in den Vereinigten Staaten Nordamerikas nicht ohne weiteres mit denen der älteren europäischen Staaten vergleichbar sind und daß die Erfahrungen, die wir mit der Gemeinerziehung in den Mittel- und Hochschulen gemacht haben, noch nicht ausreichen, um uns ein sicheres Urteil darüber zu bilden, was das Bessere sei: die Getrennterziehung oder die Gemeinerziehung. Es erscheint mir noch fraglich, ob die genannten Länder, zu denen neuerdings, wie berichtet wird, auch einzelne Teile Italiens getreten sind, dauernd bei der Gemeinerziehung verbleiben werden.

Je weiblicher in gutem Sinne das Weib, je männlicher der Mann, desto besser ist das Gesamtwohl des Menschengeschlechts bestellt. Aber, fragt man sich, tiefbesorgt, ist das heute noch möglich, diese Verschiedenheit in Erziehung, Lebensführung, kurz in allen Dingen und Beziehungen zu erhalten, wie das früher war? Hat nicht dieser Krieg gelehrt, daß wir die Frauen für die Berufe der Männer nötig haben und daß sie diese Aufgaben erfüllen? Gewiß ist das anzuerkennen; aber der Krieg hat eine abnorme Notlage geschaffen, die nicht als Stütze für die vielfach hervortretenden Bestrebungen, die Frauen in männliche Berufe einzuführen, dienen kann, und ich glaube, die meisten Frauen wünschen es selbst nicht, daß es nach dem Friedensschlusse so bleibe. Es wird auch wirtschaftlich unmöglich sein, da $\beta$ es so bleibt.

Kann man nun zu den Zeiten unsererVäter zurückkehren, oder ist es ein Verhängnis für jedes Volk, welches zu höherer Kultur kommt, da $B$ es dieser Kultur schließlich unterliegt? Fast scheint es so, wenn wir in die Geschichte zurückblicken. Möchten wir bei allen Fortschritten unserer Kultur nicht vergessen, daß wir in der Regelung der beiden elementarsten Bedingungen für ein gesundes Menschenund Völkerleben, das heißt in der Regelung der Erhaltungsbedingungen für den Einzelnen, wie in der Regelung des Geschlechtslebens uns den von der Natur gegebenen Einrichtungen anzupassen haben! 
Lehrtätigkeit in Berlin. .Mikroskopisch-anatomische Ubungskurse. 201

3. Einrichtung meiner Lehrtätigkeit in Berlin.

Vorlesungen. - Praktische Ubungen in der mikroskopischen Anatomie. Präparierübungen.

Wie ich in Breslau Pathologische Anatomie lehrte, habe ich bereits im Kapitel „Breslau“ kurz mitgeteilt. In Straßburg las ich die gesamte Beschreibende menschliche Anatomie, ferner die Allgemeine Anatomie, Entwicklungsgeschichte und abschnittsweise Vergleichende Anatomie, so in einem Semester vergleichende Knochen- und Gelenklehre, im folgenden vergleichende Muskellehre usw. Im Sommer wurden mikroskopisch-anatomische Übungen gehalten, im Winter Präparierübungen; bei beiden unterstützten mich wie erwähnt, mein Kollege Joessel und meine Assistenten.

In Berlin habe ich die ersten Jahre, bis zur Berufung O. Hertwigs, auch noch die Vorlesungen über Entwicklungsgeschichte und Allgemeine Anatomie im Sommersemester gehalten, dazu den Prak$\mathrm{t}$ isch-mikroskopischen Kursus im Verein mit meinen Assistenten. Nach der Zahl der Plätze konnten etwa Ioo Studierende an diesen Kursen teilnehmen. Sie wurden an drei Tagen in der Woche, jeweils zwei Stunden hintereinander ohne $Z$ wischenpause gegeben. Zuerst erläuterte ich kurz, unter Benutzung während des Vortrages selbst entworfener Tafelzeichnungen, die in den Arbeitsstunden anzufertigenden Präparate. Dann verteilten wir Dozenten uns an die einzelnen Gruppen, die aus je I5 Studierenden bestanden. Jede Gruppe behielt ihren Führer das Semester hindurch, nur ich selbst wechselte, damit ich einmal wenigstens jede Gruppe besorgen konnte. Es wurde nun zuerst von dem Dozenten das vorher durch Zeichnung und kurze Beschreibung erläuterte Präparat selbst angefertigt, so da $B$ alle Gruppenmitglieder den Vorgang gut sahen. Dieses Präparat wurde in der Gruppe demonstriert und dann mußten alle Studierenden in der betreffenden Gruppe das Präparat nachmachen. Es konnten hierbei natürlich nur einfache Prozeduren in Frage kommen: Ausstrich- und Schüttelpräparate,Zerzupfungspräparate, Schnitte und Schnellfärbungen. Ich hielt stets darauf, daß von allen Organen, bei denen es irgend möglich war, zuerst Schnitte vom frischen Material genommen wurden, dann erst vom gehärteten. Alle von den Studierenden selbst gefertigten Präparate wurden geprüft und darüber examiniert. Von 
schwierigen Objekten und seltenerem Material wurden Präparate, die vorher kunstgerecht angefertigt waren, verteilt; gegebenenfalls mußten aber die Studierenden sie selbst färben und als Dauerpräparate einschließen. Es wurde darauf gehalten, daß sich jeder eine Sammlung mikroskopisch-anatomischer Präparate anlegte.

Besonderes Gewicht wurde darauf gelegt, da $B$ jeder Schnitt zuerst mit freiem Auge genau durchgesehen wurde, dann mit Lupenvergrößerung und schließlich, nach und nach steigend, mit der stärksten Vergrößerung, die er vertrug, um so allmählich von der Betrachtung mit unbewaffnetem Auge zu Vergrößerungsbildern hinüberzuleiten, so daß die mikroskopische Anatomie an die makroskopische unmittelbar anschloß. Die Mikrotomtechnik wurde gezeigt und den Studierenden Mikrotome zur Verfügung gestellt. Jeder Student bekam einen eigenen kleinen Tisch mit einem Mikroskop und dem gebräuchlichsten technischen Material; für die kleineren Instrumente, die in besonderen Bestecken zusammengestellt waren, hatte er selbst zu sorgen. Ich empfahl den Studierenden, sich eigene Mikroskope anzuschaffen, bei deren Auswahl ich sie beriet und die angekauften Instrumente auch selbst prüfte, bevor sie die Studierenden übernahmen. Viele sind meiner Empfehlung gefolgt. Ein eigenes Instrument zu besitzen, ist für die Teilnehmer an solchen Kursen ein großer Vorteil; ich wenigstens habe die Erfahrung gemacht, daß die Besitzer eigener Mikroskope bald mit viel mehr Interesse arbeiteten, als diejenigen ihrer Kommilitonen, die nur die Institutsinstrumente benutzten. Gewöhnliche Kursinstrumente wurden gegen Leihscheine den Studierenden auch für die Ferienzeit überlassen. An den ihnen zugeschriebener Tischen konnten die Studierenden auch täglich von $8 \mathrm{Uhr}$ morgens bis $6 \mathrm{Uhr}$ abends zu beliebigen Stunden, außer der Kurszeit, arbeiten. Dieses freie Arbeiten, ohne besondere Aufsicht, hat große Vorteile und wurde auch vielfach geübt.

Bei der großen Zahl der Teilnehmer an den Präparierübungen an Leichen - im ersten Wintersemester in Berlin waren ihrer bereits über 500, und die Zahl stieg nach und nach mit einzelnen Schwankungen, bis sie im letzten Winterhalbjahre vor dem Kriege über rooo erreichte - hatte ich mit meinen Prosektoren und Assistenten reichlich zu tun. Leichen standen hinreichend zur Verfügung, so daß jeder Präparant während der zwei Halbjahre, die er an den Übungen 
teilzunehmen hatte, falls er es nicht am nötigen Fleiße fehlen ließ, alle Teile des menschlichen Körpers zu bearbeiten bekam. Im ersten Semester wurden Knochen, Gelenke, Muskeln und ein Teil der inneren Organe präpariert, im zweiten der übrige Teil der inneren Organe, die Gefäße, Nerven und Sinnesorgane. Die Eingeweide, Gefäße und Nerven erhielten die Präparierenden in größeren Körperabschnitten, wie z. B. obere Körperhälfte, welche Kopf, Hals, Brust und obere Extremität umfaßte, dann die untere Körperhälfte mit Bauch, Becken und unterer Extremität. Dann besonders noch das Gehirn und Rückenmark, Schläfenbeine und an frischen Leichen, an denen das Organ noch gut erhalten war, den Augapfel. Die Studierenden des II. Lehrganges erhielten Präparate, deren Blutgefäße injiziert waren. Die Verteilung der größeren Körperabschnitte geschah in dem Bestreben, die Teilnehmer des zweiten Kursus möglichst topographisch-anatomisch $\mathrm{zu}$ schulen. Um hierzu noch besondere Gelegenheit zu geben, veranlaßte ich den ersten Prosektor, Professor H. Virchow, im Sommersemester besondere topographisch-anatomische Präparierübungen abzuhalten.

Um bei der großen Zahl der Präparierenden hinreichende Lehrund Hilfskräfte zur Hand zu hạben, stellte ich aus älteren Studierenden, die ein besonders gutes Examen in der Anatomie abgelegt hatten, 6 bis 8 Demonstranten an, die von mir dafür remuneriert wurden. Diese Stellen waren natürlich sehr gesucht und ich hätte sie auch ohne Entgelt stets ausreichend besetzen können. Es schien mir aber richtig, durch Gewährung eines Honorars bei den jungen Leuten das Pflichtbewußtsein und zugleich eine bessere Vorstellung vom Ansehen ihrer Stellung zu wecken. Diese Einrichtung hat sich sehr bewährt, indem sie zugleich Manchen, die Interesse an einer gründlicheren Ausbildung in der Anatomie hatten, dazu die beste Gelegenheit gab. In den jährlich durch Druck veröffentlichten Berichten über die Tätigkeit der einzelnen Universitätsanstalten wurden diese Demonstratoren auch namentlich aufgeführt.

Die Verteilung der Präparate und die Kontrolle über deren vollständige und richtige Bearbeitung erforderte bei der großen Anzahl der Teilnehmer auch besondere Maßregeln, die bald nach meinem Antritt der Leitung der Anatomischen Anstalt in Berlin eingeführt wurden, wobei ich manche gute Vorschläge eines der Demonstratoren, 
des jetzigen Arztes Dr. Spandow in Berlin, benutzt habe. Jeder Präparant bekam danach bei der Meldung im Anatomischen Institute ein kleines Büchelchen von der Größe, da $B$ es bequem in der Westentasche Platz hatte. Er hatte auf dem Umschlage des Büchelchens Namen und Vornamen, Präpariersemesterzahl mit I bzw. II und, falls er Zahnheilkunde studierte, dies durch ein hinzugefügtes lateinisches $\mathrm{D}$ anzumerken. Um ein Präparat zu erhalten, mußte dies Büchelchen in einen von zwei Kästen gelegt werden, die am Eingange zum Institut sich befanden, der eine für die Präparanten des I. Präpariersemesters, der andere für die des II. bestimmt. So wurde gleich bei der Herausnahme der Büchelchen eine Sonderung in zwei Abteilungen für Mediziner und eine für die Studierenden der Zahnheilkunde, die besondere Präparate bekamen, erzielt. Die Verteilung von Präparaten fand jeden Montag und jeden Donnerstag im großen Hörsaale des Instituts statt. Diejenigen, welche zu Montag ein Präparat zu haben wünschten, mußten ihr Büchelchen bis zum Mittag des nächstvorhergehenden Sonnabends in den betreffenden Kasten einlegen, für den Donnerstag galt Frist bis zur gleichen Stunde des Tages zuvor. Hatte ein Praktikant schon ein Präparat bearbeitet, so erhielt er nur ein neues, wenn in dem Büchelchen durch einen der dazu berechtigten Unterrichtenden : Direktor, Prosektoren und Assistenten - nicht jedoch Demonstratoren - bescheinigt war, da $B$ er das zuletzt bearbeitete Präparat ordnungsmäßig zu Ende geführt habe. Die Verteilung der Präparate und deren Eintragung in die Präparierbüchelchen besorgte der I. Prosektor, der darüber auch Buch führte. Durch Anschlag an einer dazu bestimmten Stelle im Institut wurde bekannt gemacht, wer ein Präparat erhalten hatte, so daß Jeder sich Montags oder Donnerstags früh davon unterrichten konnte. Um nun die Präparate in Empfang zu nehmen, versammelten sich die Berücksichtigten um II Uhr vormittags an den genannten beiden Tagen im Hörsaale des Instituts; dort wurden ihre Namen verlesen und diejenigen, welche ein gleiches Objekt erhalten hatten, wurden angewiesen, sich sofort auf dem Präpariersaale bei einem der dort für den Unterricht schon Anwesenden, entweder dem Direktor, den Prosektoren oder Assistenten, einzufinden. Dort wurde an dem vorliegenden Teile gezeigt, in welcher Weise er zunächst zu bearbeiten sei; die erforderlichen Hautschnitte wurden an einem der Stücke 
ausgeführt und der ganze Präpariergang kurz erläutert. Dann erst bekamen die Präparanten ihre Büchelchen zurück; diese mußten sie dann einem der Anatomiewärter vorzeigen, der ihnen das verzeichnete Stück aushändigte.

Von früh 9 Uhr bis nachmittags 5 Uhr ohne Unterbrechung war immer einer der Unterrichtenden, meist auch zwei, nebst zwei Demonstratoren in den Präpariersälen anwesend. Hatte ein Präparant den ihm bei der Übernahme des Präparates vorgeschriebenen ersten Präparationsakt zu Ende geführt, so mußte er, ehe er weiter arbeiten durfte, sein Präparat demjenigen Unterrichtgebenden vorzeigen, der es ihm beim Empfange demonstriert hatte. Dabei wurde er über seine Befunde geprüft. War das Präparat richtig angefertigt und die Auskunft genügend, so.wurde mit Unterschrift des Abnehmenden ein Vermerk in das Büchelchen gemacht und dabei dem Präparanten die Auskunft über den folgenden Präparierakt gegeben. Dann konnte er weiter arbeiten und so ging es fort, bis das Präparat völlig fertig gestellt war. Dann durfte das Büchelchen zur Empfangnahme eines neuen Stückes wieder in den betreffenden Kasten gelegt werden. Diejenigen Studierenden, welche sämtliche Präparate des I. Kursus beendet hatten, konnten auch in ihrem I. Präpariersemester noch soviel Präparate des 2. Kursus bekommen, als sie gut zu bemeistern im Stande waren.

Um zu guter und sauberer Arbeit zu ermuntern, hatte ich bestimmt, daß denjenigen Studierenden, die tadellos bearbeitete Präparate hergestellt hatten und besonders gute Kenntnisse darüber zeigten, einzelne der von ihnen bearbeiteten Gegenstände, die sie leicht bei sich aufbewahren konnten, als ihr Eigentum übergeben wurden mit der Verpflichtung, diese, falls sie sie nicht länger benutzen wollten, an das Institut zurückzuliefern. Dazu zählten u. a. sämtliche Knochen und Gelenke, Präparate der Sinnesorgane, Kehlkopf, Herz u. a. Es war aber Bestimmung, da $B$ dazu meine besondere Erlaubnis unter Vorlegung der gewünschten Objekte eingeholt werden mußte. Ferner führte ich aus denselben Gründen einen 3. Präparierkursus ein für diejenigen Studierenden, die bereits die beiden ersten Kurse ordnungsmäßig erledigt hatten. Außer einer ermäßigten Honorarzahlung hatten die Präparanten des 3. Kursus die Vergünstigung, sich selbst die Präparate auswählen zu dürfen, 
die sie noch einmal bearbeiten wollten. Es wurde viel Gebrauch davon gemacht. Auch war stets Material genug vorhanden, um den Wünschen dieser Studierenden entsprechen zu können. Allerdings mußten stets zwei Herren an einem und demselben Präparate zusammen arbeiten, sonst hätte das Material nicht gereicht. Falls indessen Jemand allein zu arbeiten wünschte, so wurde ihm das gestattet. Nur selten jedoch wurde ein solcher Wunsch geäußert; weitaus die Meisten arbeiteten lieber zu zweien und baten, falls sie nicht selbst einen befreundeten Kommilitonen hatten, um Gestellung eines Konpräparanten. Unzuträglichkeiten sind aus diesem Zusammenarbeiten kaum entstanden, selbst nicht bei verschiedenen Nationalitäten, die ja auf dem Berliner Präpariersaale reichlich vertreten waren.

Am zahlreichsten waren unter den nicht deutschen Nationen die Russen vertreten, dann Angehörige der Balkanstaaten, Serben, Bulgaren, aber auch Griechen, Rumänen und Türken. Zahlreicher kamen auch Finnen. Vereinzelt Japaner und Chinesen, zahlreicher wieder Südamerikaner, insbesondere Chilenen, auch Mittel- und Nordamerikaner; wieder mehr vereinzelt Skandinavier, Engländer, Belgier, Holländer, Franzosen, Spanier, Portugiesen und Italiener. Die meisten Ausländer, vor allem die vereinzelt Erscheinenden, zeichneten sich durch Fleiß und Tüchtigkeit aus, was ja leicht erklärlich ist, da bei ihnen offenbar eine Auslese stattfand. Besonders empfahlen sich in dieser Hinsicht die Chilenen, Serben und Finnen. Ich habe auch bei den Ausländern keinen Unterschied in der Wahl zu Demonstratoren gemacht, wenn sie sich besonders tüchtig zeigten und gefunden, daß unsere deutschen Studenten, deren Tüchtigkeit anerkennend, sich ihnen willig fügten. Überhaupt muß ich meinen Berliner Studierenden das Zeugnis geben, da $B$, ungeachtet der starken Frequenz, die oft die Säle vollgepfropft zeigte und bei den verschiedenen Nationalitäten leicht hätte zu Reibungen Veranlassung geben können, kaum Unzuträglichkeiten vorgekommen sind. Jeder fügte sich der Lage der Dinge und unsere deutschen Studenten waren stets bereit, den Ausländern gefällig zu sein. Es ist in den letzten Jahren vor dem Kriege, als die Zahl der studierenden Ausländer, namentlich der Russen, in der medizinischen Fakultät bedeutend stieg, von Seiten der deutschen Studierenden darüber Klage geführt worden, 
da $B$ ihnen dadurch Beeinträchtigungen erwüchsen. Das bezog sich indessen hauptsächlich auf die Kliniken. Das Anatomische Institut war aber auch an der Grenze dessen angekommen, was es ohne Herabminderung des Unterrichts zu leisten im Stande war.

Ich hatte schon überlegt, wie dem etwa abzuhelfen gewesen wäre und kam zu dem Ergebnis, da B man bei weiterer Zunahme der Frequenz auch ein zweites Anatomisches Institut für Beschreibende und Topographische Anatomie gründen müsse, wie zwei innere, äußere und gynäkologische Kliniken bereits bestanden. Der Krieg hat diesen Erwägungen ein Ende gemacht. Zwar sind jetzt, unmittelbar nach dem Kriege, noch stärkere Beanspruchungen der Berliner medizinischen Anstalten hervorgetreten; doch sind diese nur vorübergehend und werden durch die Einrichtung von Zwischensemestern gut bewältigt. Inzwischen sind auch drei neue Universitäten entstanden: Frankfurt a. M., Köln und Hamburg, die einen guten Teil der Studierenden von den übrigen Universitäten und auch von Berlin abziehen werden. Ausländer werden wir wohl so bald nicht wieder an unseren Universitäten sehen.

Noch einer Maßregel muß ich bei der Handhabung der Präparierübungen, wie ich sie eingeführt hatte, gedenken. Ich erwähnte bereits, da $B$ ein Präparant, der von einem der Dozenten sein Präparat übermittelt und erklärt bekommen hatte, verpflichtet war, alle Abgaben des Präparates bis zur letzten, bei demselben Dozenten zu machen hatte. So lernte der Dozent den betreffenden Studierenden in dessen Art zu präparieren am besten kennen und konnte ihn leichter schulen. Dies hatte auch noch einen anderen Vorteil. Wenn der Dozent seine Pflichtstunden auf dem Präpariersaale begann, so war das erste eine Aufforderung an alle die Studierenden, die ein gleiches Präparat bei ihm abzugeben hatten, sich sämtlich an einem bestimmten Platze einzufinden, wo der betreffende Dozent dann mit der Abnahme der Präparate begann und zwar mit den Schlußabnahmen, dann zu den vorletzten usw. bis zu den ersten übergehend. Um ein bestimmtes Beispiel zu geben, handele es sich um ein Arm-Muskelpräparat. Bei einem solchen wurden fünf Abgaben gemacht: zuerst die der Schultermuskeln, dann der Oberarmmuskeln, der Vorderarmmuskeln und Handmuskeln, dann der sämtlichen Muskeln noch einmal, nach methodischer Durchschneidung der oberflächlich ge- 
legenen, zur Darstellung der tieferen, und zum SchluB die Abgabe der Knochen, Bänder und Gelenke. Zuerst wurden nun diese Schlußpräparate geprüft und nach Gutbefinden abgenommen, dann in umgekehrter Reihenfolge die übrigen, so da $B$ stets die Präparanten der vorhergehenden Präparationsakte sahen und erfuhren, was sie demnächst zu tun hatten. So konnte auch Jeder mindestens fünfmal und zwar an einer größeren Anzahl Armpräparate die Anatomie des Armes durch eigene Anschauung und Demonstration des Dozenten kennen lernen, dabei auch öfters die häufiger vorkommenden Varietäten. Auch wurde schon bei diesen Präparaten des r. Kursus gebührend Rücksicht auf die Lage der wichtigsten Gefäße und Nerven genommen. Im 2. Kursus erhielt dann der Schüler nochmals einen Arm, dessen Arterien injiziert waren, mit der Aufgabe, nunmehr die Arterien, Hauptvenen und Nerven unter Erhaltung der Muskeln zu präparieren, wobei wieder verschiedene Akte zur Abgabe in gleicher Weise gestellt wurden.

Bei der Bearbeitung der Präparate des 2. Kursus, durch die Studierenden des dritten oder vierten Semesters, die in dem dazwischen fallenden Sommersemester an den mikroskopischen Übungskursen teilgenommen hatten, ließ ich stets auch über den mikroskopischen Bau der einzelnen zur Präparation gelangenden Organe prüfen, sowie ich darauf hielt, da $B$ bei allen dazu geeigneten Organen im frischen Zustande dünne Messerschnitte angefertigt und genau mit freiem Auge studiert wurden, um so viel wie irgend möglich ohne Anwendung von Vergrößerungen von der Struktur dieser Teile erkennen $\mathrm{zu}$ lernen.

Ich bin nicht vollkommen einverstanden mit dem, was jüngst Kollege Hermann in Erlangen über Änderungen des anatomischen Studiums gesagt hat, namentlich nicht, wenn er meint, es würde zu viel Zeit auf die Herstellung anatomischer Präparate verwendet, es komme nicht darauf an, alles so eingehend zu präparieren, wie es vielfach verlangt werde. $\mathrm{Da}$ bin ich anderer Ansicht. Wie oft ist mir von meinen Präparanten, wenn ich ihnen ein nicht völlig sauberes Präparat, namentlich Gelenkpräparat, zurückgab, mit dem Bemerken, es noch sorgfältiger und sauberer auszuarbeiten, gesagt worden: ,Ja, Herr Professor, ich sehe ja doch alles an dem Präparate, habe ja auch alle Fragen richtig beantwortet." Ich ließ 
mich aber dadurch nicht rühren, denn ich wußte aus eigener Erfahrung als Schüler und Lehrer, wie viel besser sich ein tadellos sauber ausgearbeitetes Präparat mit allen Einzelheiten dem Gedächtnisse einprägt und wieder klar vorgestellt wird, gegenüber einem zwar ausgearbeiteten, so da $\beta$ alle Teile $z u$ sehen und $z u$ erkennen sind, aber weniger sauberen und weniger klar in allen Einzelheiten hergestellten.

Wozu in diesen „Lebenserinnerungen“ die lange Schilderung der Art, wie der Unterricht in der Anatomie von mir in der Berliner Anatomischen Anstalt geübt wurde? Gewiß wird das Diesen oder Jenen meiner etwaigen Leser kaum interessieren, doch schrieb ich auch für meine ehemaligen Schüler, deren Zahl mit 20000 nicht zu hoch benannt ist, und hatte ferner die Absicht, zu zeigen, wie ein anatomischer Präparierunterricht bei einer großen Zahl von Teilnehmern, meiner Meinung nach, mit gutem Erfolge geführt werden kann. Freilich muß für Hilfskräfte und für Unterrichtsmaterial genügend gesorgt sein, wie das in der Millionenstadt in der Tat der Fall war.

\section{Unterricht an den Militärärztlichen Bildungsanstalten.}

Für die besondere Ausbildung der Militärärzte bestand in Preußen seit langem, wie auch in den übrigen größeren Staaten, eine besondere Anstalt, in der die Zöglinge Wohnung, Verpflegung und besonderen Unterricht fanden, außerdem aber noch am Universitätsunterrichte teilnahmen. Sie wurden also in ihren ersten vier Semestern auch meine Schüler, so da $B$ bei meiner über 30 Jahre währenden Tätigkeit in Berlin es jetzt wohl nur wenige Armeeärzte in Preußen gibt, die nicht meine Schüler waren. Selbstverständlich entwickelten sich zwischen den Leitern dieser Anstalt, der früher in der Friedrichstraße gelegenen sogenaninten „Pépinière“ und der später an ihre Stelle getretenen „Kaiser Wilhelms-Akademie“ in der Invalidenstraße, und den Universitätslehrern, sowie zwischen diesen und den zur Dienstleistung bei der Anstalt befohlenen Stabs- und Assistenzärzten nähere Beziehungen, deren ich, was mich betrifft, nur mit erfreulichen Erinnerungen gedenken kann.

Die Zöglinge der Anstalt bildeten einen festgeschlossenen Stab unter meinen Zuhörern, der jedoch mit den übrigen Studierenden v. Waldeyer-Hartz Lebenserinnerungen. 
vollständig auf gleichem Fuße behandelt wurde. In jedem Halbjahre wurden je zwei Stabsärzte zu den anatomischen Vorlesungen und Präparierübungen entsendet, die eine gewisse Aufsicht über die Studierenden der Anstalt zu üben hatten, hauptsächlich aber an dem Unterrichte der militärärztlichen Zöglinge auf dem Präpariersaale teilnehmen sollten. Ich förderte deren Stellung zur Anatomischen Anstalt dadurch, daß ich sie bat, sich auch an dem Unterrichte der Zivil-Studierenden $\mathrm{zu}$ beteiligen, indem ich ihnen für diesen Fall die Stellung von vollberechtigten Assistenten zusicherte. Die Herren gingen alle gern auf diesen Vorschlag ein, erhöhten dadurch ihr Ansehen bei den Studierenden und gewannen einen viel bedeutenderen Wirkungskreis, was natürlich auch dem Gesamtunterrichte zugute kam. Manchen ausgezeichneten Mithelfer habe ich unter diesen Militärärzten gewonnen, ich nenne hier vor allen die späteren Generalärzte Dr. Rochs, Dr. Rudel off und Dr. Drüner, sowie den späteren Professor an der Berliner Universität, Dr. Renvers, einen der ausgezeichnetsten Ärzte Berlins. Ich pflegte im Sommer von meiner Wohnung in der Lutherstraße durch den Tiergarten zu meinem Institut zu wandern und da ich bereits um 7 Uhr früh meine Vorlesung begann, handelte es sich um einen erfrischenden Spaziergang in der Morgenfrühe. Renvers wohnte in der Nähe und so war er gewöhnlich mein sehr willkommener Begleiter in der Zeit seiner Tätigkeit am Anatomischen Institute.

Auch mit den Direktoren der Militärärztlichen Bildungs-Anstalten, den Herren Generalärzten Dr. Schubert, Dr. Grasnick, Dr. Kern und Dr. Keitel trat ich in guten Verkehr, sowie mit den obersten Leitern, den Generalstabsärzten der Armee Dr. v. Lauer, weiland Leibarzt Kaiser Wilhelms I., Dr. v. Coler, Dr. v. Leu thold und Dr. v. Sch jerning. Letzterer schuf bei der Kaiser Wilhelms-Akademie, deren ausgezeichnet ausgefallenen Neubau er leitete, eine Vereinigung, den wissenschaftlichen Senat, in dessen Sitzungen Referate, Vorträge und Besprechungen aus medizinischen Wissensgebieten gehalten wurden und zu dessen Mitgliedern ich gleichfalls zählte. Die Preußische Akademie der Wissenschaften ehrte die großen Verdienste v. Schjernings, die er sich im Weltkriege durch die musterhafte Organisation der Seuchenbekämpfung erworben hat, durch die Verleihung der goldenen Leibniz-Denkmünze. 
Noch eine nähere, ja, ich muß sagen, nächste Beziehung verknüpfte mich mit den Militärärztlichen Bildungsanstalten dadurch, daß mein lieber zweiter Schwiegersohn, der jetzige Generalarzt und Professor der Chirurgie an der Universität Köln, Gemahl meiner jüngeren Tochter Ilse, Dr. Otto Tilmann, einer ihrer Stabsärzte war.

\section{K a pit el.}

\section{Beziehungen zu Akademien der Wissenschaften und Gelehrten Gesellschaften.}

Association der Akademien. Deren Tagungen in Paris, London, Wien,

Rom, St. Petersburg. - Der Astronom Arthur v. Auwers.

Im Jahre I884 wurde ich zum ordentlichen Mitgliede der damaligen „Königlich Preußischen Akademie der Wissenschaften“, jetzigen seit I9I8 - „Preußischen Akademie der Wissenschaften“ gewählt und trat, da inzwischen mein Vorgänger C. B. Reichert gestorben war, gleich in die anatomische Fachstelle ein. I896, als Emil du Bois-Reymond seine Stelle als einer der beständigen Sekretare der Akademie niederlegte, wurde ich sein Nachfolger und habe dieses Amt bis I. September I9I9, bis zum fast vollendeten 83. Lebensjahre, mit welchem Datum ich es freiwillig niederlegte, getragen vom Wohlwollen und der kollegialen Gesinnung meiner Amtsgenossen im Sekretariate und vom Vertrauen der Mitglieder der Akademie, führen dürfen. Wenn irgend etwas in meinen verschiedenen Lebensstellungen mir Freude und hohe Befriedigung gewährt hat, so ist es diese meine Stellung als Mitglied und Sekretar der Preußischen Akademie gewesen. $\mathrm{Da}$ ich in ungeschwächter Gesundheit und Arbeitskraft dieses Amt bis zu so hohem Alter, ohne es als Last zu empfinden, verwalten konnte, dafür kann ich nur die größte Dankbarkeit im Herzen tragen und spreche sie auch offen aus.

Für diejenigen meiner Leser, die mit dem Wesen einer solchen Gesellschaft von Gelehrten, wie die Akademien der Wissenschaften oder „Gesellschaften der Wissenschaften“, wie einige heißen, weniger vertraut sind, mögen ein paar Angaben über deren Einrichtung und Bedeutung Platz finden, bevor ich meine Haupterlebnisse als Mitglied der Berliner Akademie erzähle. 
Zur Zeit besteht die Preußische Akademie, die sich seit ihrer Gründung am II. Juli I700 durch den Kurfürsten Friedrich III. von Brandenburg, späteren König Friedrich I. von Preußen, nach den Plänen des großen Philosophen und Mathematikers Leibniz, ihres ersten Präsidenten, vor allem aber seit ihrer Reorganisation durch Friedrich den Großen und später nach unseren Befreiungskriegen unter Friedrich Wilhelm III., wesentlich durch Wilhelm v. Hu mboldt, zu einer der bedeutendsten der Welt entwickelt hat, aus 60 Mitgliedern. Diese sind in 2 Klassen, die philosophisch-historische und die phyșikalisch-mathematische, verteilt. Die physikalisch-mathematische Klasse zählt zur Zeit 28 Mitglieder für folgende Fachwissenschaften: Mathematik, Physik, Chemie, Astronomie, Technische Wissenschaften, Geologie und Paläontologie, Mineralogie, Geodäsie, Geographie, Meteorologie, Botanik, Zoologie, Normale und Pathologische Anatomie, Physiologie und Allgemeine Biologie.

Die Mitglieder für die technischen Fächer sind erst unter Kaiser und König Wilhelm II. hinzugekommen.

In der philosophisch-historischen Klasse vertreten 32 Mitglieder folgende Fächer: Klassische Philologie, Deutsche, Romanische, Arabische, Indische, Keltische, Englische Sprachforschung und Archäologie, Ägyptologie, Sinologie, Mexikanische Archäologie, Vergleichende Sprachforschung, Philosophie, Geschichte, Prähistorie, Münzkunde, Kunstgeschichte, Nationalökonomie, Rechtswissenschaften und Religionswissenschaften.

Die Akademie ist in ihrer Verwaltung dem früheren Kultusministerium, jetzigen Ministerium für Wissenschaft, Kunst und Volksbildung, unterstellt. Die Verwaltung selbst wird durch vier ihrer Mitglieder, zwei für jede der beiden Klassen, die von den Klassen selbst gewählt, jedoch vom Ministerium bestätigt werden, geführt. Es sind dieses die beständigen Sekretare der Akademie, wie sie nach den gleichen Beamten der Pariser Akademien genannt worden sind. Sie werden auf Lebenszeit gewählt. Falls geeignet erscheinende Persönlichkeiten vorhanden sind, wählt man gewöhnlich die beiden Sekretare einer Klasse aus Vertretern verschiedener Fächer dieser Klasse. Als ich in die Akademie eintrat, waren Mommsen und Curtius die Sekretare der philosophisch-historischen Klasse, der Astronom A. Auwers und der Physiologe E. du Bois- 
Reymond Sekretare der physikalisch-mathematischen Klasse. Nach dem Tode von Mommsen und Curtius traten die Philologen Vahlen und Diels ein, nach Vahlens Tode an dessen Stelle der Germanist Roethe. An die Stelle von Auwers, der aus Gesundheitsrücksichten die seit 1878 bekleidete Sekretariatsstellung aufgab, wurde der Physiker Max Planck gewählt. Mein Nachfolger wurde seit I. September I9I9 der Physiologe Max Rubner, so da $B$ gegenwärtig die Sekretariatsstellen besetzt sind nach den Daten ihrer Wahl mit den Herren Diels, Roethe, Planck und Rubner.

In der Amtsführung wechseln die Sekretare von $4 \mathrm{zu} 4$ Monaten miteinander $a b$ und zwar so, daß einer von ihnen die Hauptgeschäftsleitung, den Vorsitz bei den Gesamtsitzungen und zugleich bei den Sitzungen seiner Klasse übernimmt, während ein zweiter Sekretar die zu seinem Fachbereiche gehörige andere Klasse leitet, die beiden übrigen Sekretare also frei sind. Jede Woche Donnerstags um 4 Uhr nachmittags finden die Sitzungen der Akademie statt, abwechselnd in einer Woche eine Gesamtsitzung beider Klassen zusammen, in der nächsten die Sitzungen beider Klassen getrennt.

Völlig frei von Geschäften ist jedoch keiner der Sekretare zu irgendeiner Zeit, denn jeder hat an den Verwaltungssitzungen teilzunehmen, die der jeweilige vorsitzende Sekretar anberaumt. Außerdem hat jeder einige Stiftungen, die bei der Akademie begründet sind, zu verwalten und noch an etwaigen Kommissionssitzungen teilzunehmen. Dazu kommt eine ausgiebige Korrespondenz in Angelegenheiten der Akademie. Ferien hat die Akademie, außer kurzen Unterbrechungen zur Weihnachts- und Pfingstzeit, 4 Wochen um Ostern und 8-ro Wochen im Herbst. Während dieser Zeit fallen nur die Sitzungen aus, die sonstigen Verwaltungsgeschäfte ruhen selbstverständlich nicht und derjenige Sekretar, dem in den betreffenden Wochen die Leitung der Gesamtakademie zufällt, ist auch für die Ferien verpflichtet. Bei der Führung der Geschäfte wird das Sekretariat durch ein Büro unterstuitzt, dem ein Archivar, der zugleich Bibliothekar ist, vorsteht.

Die Mitglieder der Akademie beziehen ein jährliches Gehalt von 900 Mark, wozu bei den Sekretaren noch I80o Mark treten. Dieser geringe Gehaltssatz bezieht sich aber nur auf diejenigen Mitglieder, welche bereits als Professoren an der Universität oder in anderen Stellungen eine höhere Besoldung beziehen. Falls Mitglieder berufen 
werden, die keine sonstigen Einkünfte haben, wird diesen ein höheres Gehalt nach Vereinbarung gezahlt, bisher meist Io 000 bis I2000 Mark. Zweimal im Jahre werden öffentliche Sitzungen abgehalten, im Januar die sogenannte Friedrichs-Sitzung als Erinnerung an den Geburtstag des zweiten Stifters der Akademie, Friedrichs des Großen, und Ende Juni oder Anfang Juli zur Erinnerung an Leibniz. In der Friedrichs-Sitzung erstattet die Akademie Bericht über ihre wissenschaftlichen Unternehmungen, gedenkt ihrer in dem verflossenen Jahre verstorbenen Mitglieder und einer der Akademiker hält eine Festrede über ein wissenschaftliches Thema. In der Leibniz-Sitzung halten die etwa neugewählten Mitglieder Antrittsreden, in denen sie ihren bisherigen wissenschaftlichen Werdegang darlegen und ein Programm derjenigen Tätigkeit aufstellen, welche sie in der Folge als Mitglieder der Akademie auszuüben gedenken. Einer der Sekretare, dessen wissenschaftliches Arbeitsfeld dem des Redners am nächsten steht, erwidert die Programmrede mit der Hervorhebung der wissenschaftlichen Leistungen, auf Grund deren die Wahl zum Mitgliede der Akademie erfolgte. Anschließend werden die Ergebnisse der Bewerbungen um die wissenschaftlichen Preise der Akademie verkündigt, sowie die Verleihung von Ehrendenkmünzen an Männer, die sich entweder durch litterarische Arbeiten oder in anderer Weise Verdienste um die Förderung der Wissenschaften erworben haben.

Außer ihren ordentlichen Mitgliedern, die ihren Wohnsitz in Berlin oder in dessen naher Umgebung haben müssen, so daß sie an den regelmäßigen Donnerstags-Sitzungen teilnehmen können, hat die Akademie Ehrenmitglieder, auswärtige ordentliche Mitglieder und korrespondierende Mitglieder. Ehrenmitglieder werden alle diejenigen bisherigen ordentlichen Mitglieder, die von Berlin so weit fortziehen, daß sie an den Sitzungen nicht mehr regelmäßig teilnehmen können, ferner Männer von besonderen Verdiensten um die Förderung der Wissenschaften auf irgendeinem anderen, als gerade einem gelehrten Arbeitswege. $\mathrm{Zu}$ auswärtigen Mitgliedern werden entfernter von Berlin wohnende Gelehrte von besonderer Bedeutung ernannt, die man hierdurch auszeichnen will; sie haben alle Rechte der in Berlin ansässigen ordentlichen Mitglieder in bezug auf Veröffentlichung ihrer Arbeiten in den akademischen Schriften, auf die Teilnahme an den Sitzungen, Abstimmungen der Akademie usw. 
Die zahlreichste Klasse der Mitglieder, außer den ordentlichen, sind die korrespondierenden Mitglieder. Sie haben das Recht, wissenschaftliçhe Arbeiten in den Veröffentlichungen der Akademie zum Abdruck zu bringen. Die Aka demien legen Wert darauf, da $B$ sie in der gelehrten Welt eine größere Anzahl korrespondierender Mitglieder haben, die ihr wissenschaftliche Arbeiten zum Druck zusenden, ihr baldmöglichst von ihren wissenschaftlichen Funden und Ausarbeitungen Kenntnis geben und die Interessen der Akademie gegebenen Falles vertreten. Mehr und mehr haben aber die Ernennungen zu korrespondierenden Mitgliedern den Charakter von ehrenden Anerkennungen angenommen. Die Zahl der korrespondierenden Mitglieder ist bei der Preußischen Akademie beschränkt. Die Berliner Akademie hat stets darauf gehalten, daß bei der Ernennung ihrer korrespondierenden Mitglieder mit sorgfältig überlegter Auswahl verfahren wurde; so sind kaum jemals alle Stellen besetzt.

Die meisten preußischen Könige haben es sich seit jeher angelegen sein lassen, der Akademie ihre Fürsorge und ihr Interesse zuzuwenden; insbesondere gilt dies von Friedrich dem Großen, der selbst eine Ehre darin fand, Mitglied seiner Akademie zu sein. Gebührend hebe ich auch hervor, daß Kaiser und König Wilhelm II. die Bedeutung der Preußischen Akademie der Wissenschaften stets voll gewürdigt hat, wie sich das durch die Schaffung neuer Mitgliedsstellen und durch die rege persönliche Anteilnahme kundgab, welche er für die Akademie bei dreien ihrer großen Feste, im Jahre Igoo bei ihrem 200jährigen Stiftungsjubiläum, im Jahre I9I2 bei der Feier des 200 jährigen Jahrestages der Geburt Friedrichs des Großen und I9I4 bei Übernahme ihres schönen Neubaues an den Tag legte. Es traf sich günstig für mich, daB ich als einer der Sekretare der Akademie - bei dem Feste I9I2, zu welchem der König den Weißen Saal seines Schlosses hergab, war ich vorsitzender Sekretar der Gesamtakademie - manche Gelegenheit hatte, mich persönlich davon $\mathrm{zu}$ überzeugen, wie sehr sich der Monarch um alle Einzelheiten, die diese Tage festlich gestalten konnten, kümmerte. Ich habe in meinem langen Leben vielfache Gelegenheit gehabt, an solchen Festlichkeiten teilzunehmen, habe aber den Eindruck erhalten und bewahrt, daß nur wenige Feiern dieser Art in allen Teilen so würdig und schön verlaufen sind wie die 200-Jahrfeier der PreuBischen Aka demie derWissenschaften. 
Vom äußeren Rahmen, in welchem sich die Tätigkeit der Akademie vollzieht, komme ich nun zu ihrer wissenschaftlichen Arbeit, zu dem, weshalb sie da ist, was ihr die Berechtigung zum Dasein und ihre Bedeutung gegenüber anderen wissenschaftlichen Anstalten, wie Universitäten und sonstigen Hochschulen, verleiht.

Die Akademien und Gelehrten Gesellschaften, die ihnen gleichstehen, haben ihre hohe Bedeutung in der planmäßigen Verfolgung zweier Aufgaben: einmal der eigenen Arbeit ihrer Mitglieder in rein wissenschaftlicher Forschung und deren Förderung in jeder Weise, und zweitens in der Herstellung und Unterhaltung der Verbindungen der Gelehrten aller Welt, also vor allem des wissenschaftlichen Verkehrs zwischen sämtlichen bestehenden Akademien und Gelehrten Gesellschaften zwecks Förderung der Wissenschaften.

Die erste Aufgabe hat ursprünglich zur Schaffung der Akademien geführt. Während die Universitäten und übrigen Hochschulen als ihre Hauptaufgabe den Unterricht zur Heranbildung von Leuten, deren späterer Beruf in der Gesellschaft oder im Staate eine wissenschaftliche Vorbildung erheischt, anzusehen haben, wobei selbstverständlich eigene wissenschaftliche Forschung, wie ich bereits hervorhob, unerläBlich ist, soll den Akademikern volle freie Zeit zu wissenschaftlicher Forschung gegeben werden, indem sie mit keinen anderen Verpflichtungen belastet werden, als mit denen, die sie sich selbst auferlegen. So ist es denjenigen Mitgliedern der Preußischen Akademie, die keinem anderen Berufe angehören, auch gestattet an der Universität Vorlesungen $\mathrm{zu}$ halten oder auch eine andere Gelehrtentätigkeit auszuüben, falls sie das mit ihren akademischen Verpflichtungen vereinigen können. Die Doppeltätigkeit der Universitäts- und Hochschulprofessoren, nicht nur als Lehrer, sondern auch als Forscher, und dies oft in erster Linie, tätig zu sein, bringt es mit sich, daß die Akademien die bei weitem größte Zahl ihrer Mitglieder dem bereitstehenden Universitätspersonal entnehmen. Sind doch jetzt auch alle deutschen Akademien und die meisten außerdeutschen an Orten eingerichtet, die Universitätsstädte sind: Berlin, München, Leipzig, Göttingen, Heidelberg, Wien, Budapest, Rom, Paris, London, Madrid, Petersburg, Kristiania usw. Bei der Gründung der Preußischen Akademie der Wissenschaften war dies allerdings nicht der Fall, sie hat über Ioo Jahre ohne den Rückhalt einer Universität be- 
standen und hat sich auch in dieser Zeit Ansehen und volle Anerkennung $\mathrm{zu}$ verschaffen und $\mathrm{zu}$ wahren gewußt. Freilich steigerte sich ihre Wirksamkeit seit Gründung der Universität um ein Bedeutendes. Der ideale Zustand wäre freilich der, daB bei der Akademie hinreichende Kräfte vorhanden wären, die ihr ihre ganze Arbeitsleistung, ohne noch durch Lehrtätigkeit und Teilnahme an den sonstigen Universitätsleistungen gehindert zu sein, widmen könnten. In dem Jahrhundert von I700-I8Io war, bis zu Friedrich II., für die Akademie eine schwere Zeit, namentlich unter Friedrich Wilhelm I., der für die Ziele der damaligen ,,Societät der Wissenschaften“" kein Interesse hatte. Es trat sogar die Frage der Auflösung heran. Immerhin hat sie ziemlich regelmäßig ihre wissenschaftlichen Mitteilungen herausgegeben und zählte unter ihren Berliner und auswärtigen Mitgliedern Männer von Ruf.

Mit Friedrichs II. Regierungsantritt änderte sich die Sachlage. Der König zeigte das größte Interesse für die Akademie, das jemals wohl ein Monarch für eine Gelehrte Gesellschaft gehabt hat; er muß als ihr zweiter Gründer bezeichnet werden.

Sichtlich ergibt sich aus der Liste ihrer Mitglieder, zu denen u. a. die Brüder v. Humboldt, Leopold v. Buch, Volta, Kant, Cuvier, Laplace, GauB, Lessing und Goethe gehörten, die steigende Bedeutung der Berliner Akademie, welche sie sich im folgenden Jahrhundert ihres Bestehens nicht nur zu wahren, sondern, gefördert durch die I8ro gegründete Universität, deren beste Kräfte in ihr Aufnahme fanden, noch zu erhöhen gewußt hat. Immerhin wäre es zu wünschen, wenn bei ihr die Zahl der reinen Akademiker - ich verstehe darunter Forscher und Gelehrte, die ihre ganze Kraft und Zeit der Akademie zu widmen hätten - noch vermehrt werden könnte.

Für die Berliner Akademie bot sich im Jahre Ig to eine vorzügliche Gelegenheit, ihre Wirksamkeit wesentlich zu erhöhen: es war die Gründung der Kaiser-Wilhelm-Gesellschaft. Die Mittel zur Gründung dieser Gesellschaft hätten meines Erachtens nicht für ein neues Unternehmen verwendet werden sollen mit unabhängiger Verwaltung, sondern die an sich höchst wertvolle Forschungsanstalt mußte der Akademie der Wissenschaften unterstellt und von ihr aus verwaltet werden; die Akademie mußte die Leiter der einzelnen In- 
stitute anstellen, die zugleich ihre Mitglieder wurden. Ich habe alsbald nach Gründung der Gesellschaft mich dafür ausgesprochen, daß diese innige Vereinigung mit der Akademie das Richtige wäre. Sie wurde nicht beliebt. Statt dessen wurde nur, ich möchte sagen, eine halbe Vereinigung getroffen. Die Gesellschaft blieb unabhängig, obwohl verschiedene der bei ihr in leitenden Stellungen tätigen Forscher zu Mitgliedern der Akademie gewählt wurden und auch der erste Präsident der Gesellschaft, Adolf v. Harnack, zu den Mitgliedern der Akademie zählte. Man wollte eben etwas Neues schaffen und es war auch begreiflich, daß diejenigen finanziellen Kräfte, die so reiche Mittel zur Gründung der Gesellschaft beigesteuert und deren Bestand gesichert hatten, Einfluß auf die Verwaltung behalten wollten. Aber es ist immerhin zu bedauern, daß bei der Gründung eines so bedeutenden Unternehmens eine Gelegenheit unbenutzt blieb, der Preußischen Akademie der Wissenschaften eine dritte Erneuerung zu verschaffen, die ihr unbedingt die erste Akademiestellung in der Welt gegeben haben würde.

Wie löst nun die Preußische Akademie ihre erste und Hauptaufgabe? Zunächst durch ihre wöchentlichen Sitzungen, in denen wissenschaftliche Vorträge, verbunden nach Bedarf mit Demonstrationen, gehalten werden. Jedes Mitglied ist verpflichtet, wenn es an die Reihe kommt, in einer solchen Sitzung einen Vortrag zu lialten, so da $B$ dafür gesorgt ist, in jeder Sitzung eine Mitteilung über eigene Forschungsergebnisse eines der Mitglieder zu hören. Es kommt aber auch öfters vor, daß Mitglieder noch außer ihrem Pflichtvortrage von ihren Arbeitsergebnissen Mitteilung machen. Bei den so verschiedenen Wissenschaften, die vertreten sind, kann nicht Jeder auf eine volle Würdigung dessen, was er vorträgt, bei seiner gelehrten Zuhörerschaft rechnen; auch wird nicht, wie man sagt, populär, sondern streng wissenschaftlich vorgetragen. Dabei kommen naturgemäß die Mathematiker am wenigsten gut weg, denn sie finden nur bei ihren wenigen Kollegen und bei den Physikern, und auch dort nicht einmal für alles, was sie vorzutragen haben, volles Verständnis. Immerhin muß man aber sagen, daß es einen großen wissenschaftlichen Wert hat und einen eigenen Reiz gewährt, durch diese Vorträge einen Überblick zu gewinnen von den großen Fortschritten, die eine Jahresleistung im Gesamtgebiete des menschlichen Wissens und Forschens darstellt. 
Nun sind aber diese Vorträge nicht nur für die Mitglieder der Akademie bestimmt, sondern für Jeden, der sich für den Fortschritt. der Wissenschaften und deren Förderung durch die Akademien interessiert. Sie werden in zwei periodisch erscheinenden Druckwerken veröffentlicht, die kürzeren Mitteilungen in den wöchentlich erscheinenden "Sitzungsberichten“, die umfangreicheren in den ,Abhandlungen". In beiden Druckwerken können auch Einsendungen von Nichtmitgliedern der Akademie erscheinen, falls sie von einem ordentlichen Mitgliede in einer der Sitzungen vorgelegt und zur Aufnahme empfohlen worden sind. Gegenwärtig sieht sich die Akademie leider gezwungen, da ihre Mittel nicht ausreichen, um die beispiellos gesteigerten Druckkosten zu bestreiten, auf die Aufnahme der Werke von Nichtmitgliedern in ihre "Abhandlungen" zu verzichten.

Ein anderer Weg zur Erfüllung der ersten Hauptaufgabe besteht in der Durchführung größerer wissenschaftlicher Unternehmungen aller Art, deren Dauer sich auf viele Jahre erstrecken kann und zu deren Lösung oft das Zusammenwirken vieler Sachverständiger nötig ist. Die Mittel hierzu sind teils aus den jährlichen Geldern zu bestreiten, die der preußische Staat gewährt, teils werden sie aus den Erträgnissen von Stiftungen gewonnen, die von der Akademie verwaltet werden. Ich führe einzelne dieser Unternehmungen an: Bei der philosophisch-historischen Klasse sind es die Monumenta Germaniae historica, das Corpus inscriptionum latinarum, das Corpus inscriptionum graecarum, eine neue Herausgabe der Schriften der Kirchenväter, der Werke Leibnizens, Wilhelm v. Humboldts und Kants, der Thesaurus linguae latinae, das Corpus medicorum u. a. Die drei erstgenannten Unternehmungen beschäftigen sich mit der Sammlung, Sichtung und Drucklegung aller der historischen Denkmäler jeder Art, die auf die Geschichte Deutschlands von den ältesten Zeiten an Bezug haben, ferner auf die Sammlung, Sichtung und Drucklegung der für die römische und griechische Geschichte so wichtigen uns erhaltenen Inschriften, von denen immer noch bisher unbekannte gefunden werden. Der Thesaurus linguae latinae ist das vollständigste lateinische Wörterbuch, welches bis jetzt vorliegt. Seit Jahren sind mehrere Gelehrte daran beschäftigt, in kritischer, mit Nachweisen versehener Bearbeitung jedes lateinischen Wortes, welches uns erhalten ist. Die Wichtigkeit dieses 
Unternehmens, das noch manches Jahr bis $2 u$ seiner Fertigstellung benötigt, leuchtet ein, wenn man bedenkt, welch' große wissenschaftliche und auch praktische Bedeutung die genaue Kenntnis der Sprache des Römervolkes hat, dem, als Erben und treuen Verwalter der griechischen Kultur, die Völker Europas und damit die Völker Amerikas und Australiens ihre Kultur verdanken.

Man könnte fragen, weshalb man noch die Werke Wilhelm v. Humboldts, die Werke Leibnizens und Kants, sowie die Werke der alten griechischen und lateinischen Ärzte, wie das im Corpus medicorum geplant ist, neu herausgebe? Daß uns und der Nachwelt die Werke der drei genannten deutschen Geistesheroen erhalten bleiben, wird Jeder, der wissenschaftliches Interesse hat, wünschen müssen; sind denn aber diese Werke nicht bereits verschiedene Male gedruckt worden und in den öffentlichen Bibliotheken Jedermann zugängig? Richtig! Aber ebenso richtig ist, da $B$ die vorhandenen Ausgaben noch nicht in allen Stücken zuverlässig sind und daß Werke, die der Nachwelt dauernd erhalten werden sollen, von Zeit zu Zeit neu herausgegeben werden müssen.

An das große lateinische Wörterbuch schließt sich als neuestes Unternehmen das Wörterbuch der ägyptischen Sprache an, welches auf viele Jahre die betreffenden Gelehrten der Akademie beschäftigen wird.

Ähnliche umfassende Arbeiten führt zur Zeit die physikalischmathematische Klasse aus. Sie liefert uns in einem riesengroßen Unternehmen die Geschichte des Fixsternhimmels, eine Darstellung aller bis jetzt beobachteten Fixsterne, ferner das „Pflanzenreich" und das "Tierreich", in welchen beiden Werken sämtliche bis jetzt beobachteten Pflanzen und Tiere, jede Abteilung von sachkundiger Seite bearbeitet, mit genauer Diagnostik, Abbildungen und richtiger Namensfeststellung aufgeführt werden. Solche Sammelwerke sind ja notwendig und auch schon früher geliefert worden; bei der fortschreitenden Kenntnis der schon bekannten Formen und bei dem steten Zuwachs an neuen müssen aber solche Katalogisierungen nach dem neuesten wissenschaftlichen Standpunkten wiederholt werden, wenn nicht bei der Fülle des Lebendigen alle Übersicht und sichere Grundlage für die Weiterarbeit verloren gehen soll. Auch an der Neuherausgabe wissenschaftlicher Werke beteiligt sich die Physikalisch- 
mathematische Klasse, so an der der Schriften des großen Mathematikers Euler.

Ein eigenartiges Unternehmen wird mit Mitteln der Stiftung des verstorbenen Berliner Bankherrn Albert Samson zur Zeit durchgeführt, außer anderen, die gleichfalls durch diese große Stiftung gefördert sind. Es gilt der Erforschung der Lebensweise und der Fähigkeiten der dem Menschen am nächsten stehenden Affen, der sogenannten Menschenaffen oder Anthropoiden, zu denen zwei afrikanische Arten, Schimpanse und Gorilla, und zwei ostindische Arten, der Orang und der Gibbon, gehören. Wir wissen von diesen interessantesten aller Tierformen noch sehr wenig. Nun ist es sicher, daß sie ebenso wie die großen Raubtiere mit dem Fortschreiten der Kultur in den von ihnen bewohnten Gegenden, wenn man dort nicht große Tierschutzparks einrichtet, zu Grunde gehen werden, denn sie vertragen sich mit dem Menschen nicht und zerstören dessen Kulturen. So mußte es von Interesse sein, bei Zeiten Vorkehrungen zu treffen, um diese Anthropoiden möglichst genau zu beobachten. Da kam nun der jüngst verstorbene Nervenarzt Dr. Rothmann in Berlin auf den Gedanken, in Teneriffa eine Beobachtungsstation einzurichten, wo die Tiere in Freiheit und Ungezwungenheit studiert werden könnten. Er besuchte selbst Teneriffa, prüfte die dortigen klimatischen Verhältnisse und seine dort gewonnenen Erfahrungen ließen ihn die Insel als günstigen Aufenthaltsort für die Tiere empfehlen. Er hat sich darin nicht getäuscht, denn seit 6 Jahren ist dort eine Beobachtungsstation zuerst unter Leitung des Cand. phil. Dr. Teuber und seit über 5 Jahren unter der des Privatdozenten an der Universität Frankfurt a. M., Dr. phil. W. Köhler, eingerichtet, die sich bestens bewährt. Es sind dort bereits eine ansehnliche Reihe von wertvollen Beobachtungen angestellt und von Dr. Teuber und Dr. Köhler in den Abhandlungen der Preußischen Akademie veröffentlicht worden.

Es lag auch von vornherein im Plane, auf Grund der in Teneriffa gewonnenen Erfahrungen, später in den deutschen Kolonien Togo und Kamerun an den natürlichen Wohnsitzen der Schimpansen und Gorillas Beobachtungsstationen einzurichten, um diese Tiere in ihren völlig natürlichen Verhältnissen zu studieren. Meine bereits vor dem Kriege bei dortigen deutschen Kolonisten eingezogenen Erkundigungen ließen dies als wohl möglich erscheinen. Jetzt müssen wir 
dies leider unseren Kriegsgegnern überlassen; es ist auch fraglich, ob wir bei dem niedrigen Stande unserer Geldwährung die TeneriffaStation werden bestehen lassen können. Mir wäre die Verzichtleistung auf die weitere Verfolgung dieser Aufgabe besonders schmerzlich, da mir der Vorsitz in der Kommission für die Samson-Stiftung übertragen worden war.

Ein dritter Weg zur Verfolgung ihrer wissenschaftlichen Tätigkeit steht der Akademie durch Ausschreibung wissenschaftlicher Preisaufgaben offen, deren mehrere ihr durch besondere Stiftungen möglich gemacht worden sind. Nach meinen Erfahrungen will es mich bedünken, als ob die Förderung der Wissenschaften auf diese Weise zur Zeit die wenigsten Erfolge aufzuweisen habe; die Preisstiftungen haben sich, wie man sagen kann, überlebt; wenigstens sollte bei einer Preisstiftung das Gebiet, welches zur Erlangung des Preises festgestellt wird, nicht zu eng bemessen sein und der Akademie sollte bei Festsetzung der Stiftungssatzungen möglichst freie Hand gegeben werden. Man darf einer Körperschaft, wie es eine Akademie der Wissenschaften ist, wohl das Vertrauen schenken, da $B$ sie die ihr anvertrauten Mittel gut verwenden wird. Ich kann aus mehr als zojähriger Erfahrung sagen, da $B$ in dieser Beziehung stets mit größter Sorgfalt verfahren worden ist. Anträge auf Bewilligung von Mitteln zu wissenschaftlichen Untersuchungen müssen vom Antragsteller eingehend begründet werden, gelangen dánn an den betreffenden Klassensekretar zur ersten Prüfung, dann an die zuständige Klasse, welche nach Befinden eine Kommission von Sachverständigen zu genauerer Prüfung ernennt. Ist diese Kommission mit der weiteren Behandlung des Falles einverstanden, so kommt er vor den bestehenden Geldverwendungsausschu $B$ der Klasse und von diesem entweder mit dem Vorschlage zur Annahme oder zur Ablehnung an die Klasse zurück, welche dann entscheidet. In gewissen Fällen findet auch noch eine Beratung im Sekretariate statt. Schließlich unterliegen die Geldbewilligungen noch der Genehmigung des vorgeordneten Ministeriums. Betreffs der wissenschaftlichen Tätigkeit der Akademie sei noch erwähnt, da $B$ sie auf Anforderung des genannten Ministeriums Gutachten in wissenschaftlichen Fragen zu erteilen hat.

Als zweite Hauptaufgabe der Akademien bezeichnete ich die Herstellung und Unterhaltung der Verbindungen der Gelehrten aller 
Welt. Der große Wert, den die Anknüpfung solcher Beziehungen hat, liegt auf der Hand und fand schon bei der Gründung der Akademie in der Einrichtung der Wahl korrespondierender Mitglieder, die sich nicht auf deutsche Wahlen beschränkten, sondern aus der ganzen wissenschaftlichen Welt herangezogen werden konnten, ihren Ausdruck. Man denke nur an die in den verschiedenen Bibliotheken der Welt lagernden handschriftlichen Schätze, die bei der Abfassung wissenschaftlicher Werke studiert werden müssen. Für zoologische, botanische, mineralogische, geologische und astronomische Untersuchungen, für die Ozeanographie, für die Erdmessungen muß die ganze Welt den einzelnen Forschern offen stehen. Um nur ein paar bestimmte Beispiele, die dem Aufgabenkreise der Preußischen Akademie entnommen sind, anzuführen, waren wir bei der begonnenen Neuherausgabe der Werke unseres eigenen Stifters, Leibniz; auf die volle Mitwirkung der Pariser Akademie der Wissenschaften angewiesen; bis zum Ausbruche des Weltkrieges haben wir auch einträchtig zusammen gearbeitet. Ferner benötigen wir bei der Herausgabe des Thesaurus linguae latinae und des Corpus medicorum die Benutzung vieler Bibliotheken und haben uns beim Corpus medicorum der Mitwirkung der Dänischen Akademie in Kopenhagen versichert. Für die Anthropoiden-Station auf Teneriffa brauchen wir zur Beschaffung der beiden Ostaffenarten, der Orangs und Gibbons, die Hilfe der Niederländischen Regierung, die uns auch bereitwilligst gewährt und weiterhin zugesagt worden ist. Bei allen diesen Verhandlungen sind die Gelehrten Gesellschaften der genannten Länder die gegebenen Vermittler.

Mit der erstaunlichen Entwicklung der Verkehrsmittel, zu denen jetzt der Funkspruch und dịe Flugzeuge gekommen sind, werden viele Aufgaben, die die Gelehrten sich jetzt stellen und stellen müssen, über die bisherigen Grenzen hinausgreifen. War schon immer die Arbeit der Gelehrten nicht in Zeit und Raum begrenzt, so wird sie in Zukunft mehr und mehr eine wissenschaftliche Weltwirtschaft werden. Da sind denn die Akademien die berufenen Vermittler.

In richtiger Würdigung dieser Sachlage haben gegen das Ende des vorigen Jahrhunderts auf besonderes Betreiben der Akademien von Wien, Paris und Berlin - ich nenne hier vor allem die Namen Hartel von der Wiener Akademie und Mommsen von der Preußi- 
schen - die genannten Akademien zusammen mit den übrigen deutschen Gelehrten Gesellschaften und den Akademien der skandinavischen Staaten, von Budapest, Amsterdam, Rom, Turin, St. Petersburg und Madrid, sowie der Royal Society of London u. a. sich zu einem Verbande geschlossen, der alle drei Jahre eine mehrtägige Sitzung abhalten sollte, auf der über das Zusammenwirken in gemeinsamen wissenschaftlichen Unternehmungen $\mathrm{zu}$ beraten und $\mathrm{zu}$ beschließen war. Diese Vereinigung wurde im Jahre 1899 inWiesbaden endgültig begründet, wobei seitens der Preußischen Akademie die Sekretare Mommsen und Auwers sowie Rudolf Virchow besonders mitwirkten. Es.wurde beschlossen, alle drei Jahre mit Wechsel der Orte eine Vorversammlung abzuhalten, zu der die einzelnen Akademien nur je einige Delegierte entsendeten, um die Tagesordnung für die im Jahre darauf an demselben Orte tagende Hauptversammlung vorzuberaten. Die erste Versammlung fand im Jahre I900 in Paris statt, der dort I90I die erste Hauptversammlung folgte. I903 und I904 tagte man in London, I906 und I907 in Wien, I909 und I9Io in Rom, I9I2 und I9I3 in St. Petersburg. Berlin sollte früher an die Reihe kommen; wir mußten jedoch die Fertigstellung unseres Neubaues abwarten, die erst IgI4 zu erwarten war. In Petersburg wurde für die Jahre I9I5 und I9I6 Berlin gewählt, aber vergebens!

$\mathrm{Ob}$ diese „Association der Akademien", wie die Vereinbarung genannt wurde, jemals wieder ins Leben treten wird? Sie hatte sich sehr bewährt; das zeigt sich schon jetzt (I9I9) darin, daß die Akademien unserer Kriegsgegner unter dem Namen „Union des Académies" eine ähnliche Vereinigung geschlossen haben, zu der jedoch Petersburg, Wien, Budapest und die deutschen Akademien nicht aufgefordert worden sind, wohl aber die Akademien der neutralen Länder. Diese sind auch der „Union“ beigetreten, haben aber erklärt, daß sie sich für den Verkehr mit den deutschen Akademien völlig freie Hand vorbehielten.

Von seiten der Berliner Akademie waren als ständige Delegierte zu diesen Versammlungen die beiden Sekretare Diels und ich bestimmt worden; wir hatten also den Vorversammlungen und den Hauptversammlungen beizuwohnen. Außerdem wurden zu jedem Kongreß diejenigen Mitglieder entsendet, welche für die zu behandelnden Fragen sachverständig waren. 
Da die Akademien der betreffenden Länder sowie deren Regierungen den als ihre Gäste angesehenen fremden Akademikern einen freundlichen Empfang zu geben wünschten, so boten diese Versammlungen willkommene Gelegenheit, abgesehen von der Anknüpfung persönlicher Bekanntschaften, auch manches Wertvolle in Stadt und Land, zu dessen Kenntnis man sonst kaum gekommen wäre, in Augenschein zu nehmen. So wurde ich Igoo und I90I in Paris mit den inneren und äußeren Einrichtungen des Institut de France genauer bekannt. Bei der Hauptversammlung Igor empfing der damalige Präsident, Emile Loubet, die Mitglieder zu persönlicher Vorstellung im Elysée. An diesen Empfang schloß sich ein Frühstück im Elysée, wobei man bei herrlichstem Wetter durch die weitgeöffneten Fenster den schönen Garten des Palastes stets im Auge hatte. Später wurden wir noch zu einem Diner geladen. Auch die Stadt Paris gab uns ein Abendfest. Ich hatte den Auftrag, in Vertretung von Gomperz (Wien), der früher abreisen mußte, bei diesem Feste den Trinkspruch auf die Stadt Paris auszubringen. Ich begann und schlo $B$ meinen Spruch französisch und gab den Hauptinhalt meiner Rede in deutscher Sprache. Ich möchte, da sich ein bezeichnender Zwischenfall daran knüpfte, hier etwas ausführlicher berichten: Ich begann meine Tischrede mit folgenden Worten: „D'abord, Messieurs, je remercie mes Collègues qui ont bien voulu me charger de l'honneur d'exprimer nos remercîments et nos meilleurs sentiments au Conseil municipal et à la Ville de Paris pour l'honorable et bienveillante invitation à cette fête splendide de ce soir! Si je ne me trompe on a dit que le langage est pour dissimuler la pensée, mais, si cela peut être vrai dans certaines limites, il est vrai toutefois que, si l'on veut exprimer les sentiments du cœur, il faut se servir de sa langue maternelle, et, comme je veux exprimer les sentiments de mon cœur qui sont dans ce moment solennel les mêmes que ceux de mes collègues, je demande la permission de parler en ma langue maternelle." Hierauf fuhr ich in deutscher Sprache fort und führte den Gedanken aus, daB durch die großen Ehrenbezeugungen, die man uns in Paris erweise, insbesondere aber durch die heutige Festlichkeit der Stadt Paris, die Aufmerksamkeit aller Welt auf die Gründung der Association des Académies gelenkt werde. Für uns folge hieraus, da $B$ wir Alles aufzubieten hätten, uns der Bedeutung, die man uns beilege, würdig zu erweisen. Es sei 
dies auch von Anfang an unser Bestreben gewesen und ich könne als Zeugnis dessen wohl anführen, daß man von den vielen Anträgen, die man uns bei dieser ersten Tagung in Paris vorgelegt habe, nur zwei nach ernstester Erwägung und Begründung angenommen habe. Daß gerade die Stadt Paris uns ehre, fuhr ich fort, müßten wir als eine besonders wertvolle Anerkennung ansehen, da ja Paris von jeher eine der ersten Pflegestätten für Kunst und Wissenschaft gewesen sei. „Alors, " so schloß ich kurz, ,,je lève mon verre et je vous prie, Messieurs, de vouloir bien faire autant, et je le vide avec mes meilleurs souhaits pour la Ville toujours jeune et renaissante, la Ville de Paris!"

Es fehlte nicht an Beifall; aber kurz darauf sprach sich der Nationalist und Antisemit Drumont in der von ihm beeinfluBten Presse sehr ärgerlich darüber aus, da $B$ man einem Deutschen den Toast auf die Stadt Paris übertragen habe, der ihn noch dazu in deutscher Sprache ausgebracht habe. Um zu beruhigen, erschien dann in einem anderen Blatte eine Notiz des Inhaltes, da $B$ ja beabsichtigt gewesen sei, Herrn Gomperz, der das Französische vollkommen beherrsche, den Trinkspruch zu übertragen, da dieser aber im letzten Augenblicke hätte abreisen müssen, so sei ich an seine Stelle getreten. Ich hätte ja auch in französischer Sprache begonnen, sei aber dann stecken geblieben (Sic)! Damit war aber nur Öl ins Feuer gegossen, denn nun schrieb Drumont: das sei ja noch ärger, da $B$ man einen „,sale juif“ (ipsissima verba) habe sprechen lassen wollen.

Im ganzen war unsere (der Deutschen) damalige Aufnahme in Paris eine, wie mir schien, angenehme und ich gab mich der Hoffnung hin, daß die Gründung der Association des Académies ein weiterer Schritt auf dem Wege einer endlichen Verständigung zwischen den Galliern und Germanen sein werde. Diese Verständigung ist immer, seit ich Frankreich und die Franzosen kenne, mein sehnlichster Wunsch gewesen; es scheint aber eine geschichtliche Notwendigkeit zu sein, da $B$ Nachbarvölker sich nicht vertragen. Ich führe den erwähnten Zwischenfall an als ein Zeichen, daß auch damals, I90I, selbst bei Anlässen, die keineswegs zu Äußerungen gegnerịscher Gesinnungen geeignet erschienen, solche hervortraten.

Einer äußerst angenehmen Erinnerung, im Gegensatze zu der eben erwähnten, sei hier aus der Reihe der uns bei der Hauptversammlung. 
gebotenen Gastlichkeiten gedacht, des Besuches des Schlosses und der Besitzung Chantilly, welche der Duc d'Aumale dem Institut de France geschenkt hat. Ein Extrazug brachte uns zur nächsten Haltestelle, von da führten uns Wagen nach Schloß Chantilly. Vor dem Schlosse erhebt sich auf einem großen freien Platze die Statue des Connetable de Montmorency. Der große Condé hat dort eine Zeitlang residiert und Ludwig XIV. prächtige Feste gegeben. Sehr sehenswert ist die Gemäldesammlung des Schlosses. Im "Santuario“, einem kleinen, zu ruhiger Betrachtung stimmenden Raume befinden sich zwei Raffaels, die "Madonna des Hauses Orleans" und die „Drei Grazien". Beide Gemälde schätze ich nicht so hoch als den dritten Schatz des Santuario, das Bild "Esther und Ahasverus" von Fra Filippino Lippi, nach meinem Dafürhalten eines der schönsten und reizendsten Gemälde, welche existieren. Interessant waren mir vom anthropologischen Standpunkte aus die vielen Familienbilder der Häuser Boùrbon und Orleans; unter den spanischen und neapolitanischen Bourbonenköpfen schienen mir mehrere Zeichen einer Degeneration an sich zu tragen. - Nach einem Spaziergange in dem prächtigen Parke und einem einfachen Abendessen im Hôtel de Cygne des Städtchens Chantilly brachte uns der Abendzug nach Paris zurück.

Das wissenschaftliche Ergebnis der Pariser Tagung war die Einigung über die Ausführung einer internationalen Gradmessung vom Kap der Guten Hoffnung bis zum nördlichsten RuBland, sowie über die Benutzung der Handschriften in den Bibliotheken der zu den vereinigten Akademien gehörigen Staaten.

Während der Vorversammlung rgoo fand in Paris gleichzeitig eine große internationale Weltausstellung statt und ein internationaler Medizinerkongre $B$, zu dem ich mit meinem Kollegen v. Bergmann als Delegierte Deutschlands entsendet worden war. Beide Aufträge, der für die Akademie und für den Kongreß, gaben mir Gelegenheit zu bemerkenswerten persönlichen Bekanntschaften. Ich nenne den berühmten Mathematiker Darboux, der die Sitzungen im Institut de France leitete, den Chirurgen Lannelongue, den Pathologen Bouchard und den damaligen Ministerpräsidenten WaldeckRousseau, bei dem ich zu einer Abendgesellschaft geladen war. Wissenschaftlich beteiligte ich mich am medizinischen Kongresse dưrch einen Vortrag über Gehirntopographie im Collège de France. 
Bei einer der Versammlungen in London wurden wir zum Empfang beim Königspaare nach Schloß Windsor eingeladen. Bei günstigem Wetter fuhren wir mit bereitgestellten Wagen durch den Park von Frogmore, hielten an den bemerkenswertesten Stellen, unter anderen auch an einem kleinen hübschen Gebäude, in welchem die für den Bedarf des Schlosses nötige Milch aufbewahrt wurde. Ein angenehm bläuliches Licht fiel von oben auf die weißen Marmortische, auf denen die hübschen, mit köstlichster Milch, teils frischer, teils Rahmmilch, gefüllten Gefäße standen; ein angenehmer, Appetit erregender Duft erfüllte den Raum, so da $\beta$ man versucht wurde, von der in reicher Fülle vorhandenen Gabe zu kosten. Ich gestehe, da $B$ mir während der jetzigen Kriegsjahre, bei der Knappheit der Nahrungsmittel, insbesondere reiner, guter Milch, oft der Gedanke an das Milchhäuschen im Park von Frogmore in den Sinn gekommen ist. -Als wir zum Schlosse zurückkehrten, fanden wir König Eduard VII. mit seiner Gemahlin vor der Freitreppe, in der Nähe konzertierte die Musikkapelle der Horse-Guards. Wir traten einzeln auf das Königspaar zu, dem wir von Sir Michael Foster vorgestellt wurden. Der König reichte Jedem die Hand, er wie auch die Königin richteten an Jeden einige Worte der Begrüßung, die auch bei Einzelnen zu längerem Gespräche führten. Mich fragte der König, was mir denn im Park am besten gefallen habe? Ich sagte, „das Milchhäuschen, das sei so reizend und appetitlich eingerichtet, da $B$ man versucht gewesen sei, von der Milch zu trinken." Darauf erwiderte der König, der fließend und korrekt deutsch sprach, ohne englischen Akzent: „Das hätten Sie nur tun sollen."

Reizend war das Bild einer kleinen, etwa vierjährigen Prinzessin, die neben der Königin stand und sich, etwas ängstlich vor den vielen so auf das Königspaar zutretenden Herren, in den Falten des Gewandes der Königin barg.

Nach Beendigung des Empfanges besichtigten wir noch Schloß Windsor im Inneren, wobei viele bemerkenswerte geschichtliche Erinnerungen auftauchten. Beim Durchschreiten der Zimmer und Säle befand ich mich wieder in Begleitung von Emile Boutroux, dessen Tischnachbar ich einige Jahre zuvor beim Dejeuner im Elysée gewesen war. Boutroux hatte mir damals schon sehr gefallen und gern erneuerte ich die stets interessante Unterhaltung mit ihm. Später, 
kurz vor Ausbruch des Krieges, besuchte Boutroux Berlin und wir gaben ihm in einem engeren Kreise von Akademikern bei einem zu seinen Ehren veranstalteten Mahle die erwünschte Gelegenheit zur Erneuerung gern gepflegter Bekanntschaft. Der Abend verlief auch, ich bin dessen sicher, für alle Teilnehmer in angenehmster Weise und mir war es wieder eine besondere Freude, mit dem mir vertraut gewordenen Gelehrten zusammen zu kommen. Um so schmerzlicher hat mich die völlig ungeahnte feindselige Stellung berührt, die Boutroux nach Ausbruch des Krieges eingenommen hat. Mein Kollege Diels hat dies in verdienter Weise gekennzeichnet ${ }^{(13)}$.

Bei dem Festmahle, welches uns der Lord Mayor von London in der Guildhall gab, hatte ich zwei mir interessante Tischnachbarn an Lord Bryce und Sir Charles Dilke; auch machte ich bei dieser Gelegenheit die Bekanntschaft Asquith's, des im Weltkriege so viel genannten Staatsmannes.

Wissenschaftlich war, insbesondere mir, die Tagung in London von großem Interesse, weil dort auf den Antrag von His (Leipzig) die Gründung einer Internationalen Vereinigung zur gemeinsamen Förderung der Erforschung des Gehirns geschah. Ich führte bei den betreffenden Verhandlungen den Vorsitz und die Statuten der Vereinigung, die wir kurz die „Brain Commission" - Br. C. - nannten, wurden nach meinen Vorschlägen angenommen. Mir wurde später der Vorsitz in dieser Kommission übertragen und es gelang, eine Anzahl von Instituten, die als „Interakademische HirnforschungsInstitute" bezeichnet wurden, zu Arbeiten mit gemeinsamem Ziel zusammenzuschließen. Die Vertreter dieser Anstalten kamen zu einer gemeinsamen Tagung meist im Anschlusse an die Versammlungen der Association der Akademien zusammen, wo Arbeitsberichte ausgetauscht, Vorträge gehalten und Arbeitspläne besprochen wurden. Besonders nahmen sich der Sache an die bereits bestehenden Neurologischen Institute in Wien unter der rühmlichen Leitung H. Obersteiners und in Frankfurt a. M., wo L. Edinger unermüdlich tätig war. In Budapest wurde unter K. Schaffers Leitung ein neues Institut eingerichtet und im Auslande traten wir mit Golgi (Pavia) und mit Ramón y Cajál (Madrid) in Verbindung, ebenso mit englischen Anstalten. Die Vereinigung versprach eine fruchtbare Entwicklung, der der Krieg - wie so vielen internationalen wissenschaft- 
lichen Unternehmungen - ein Ende bereitete. Ich will hoffen, da $B$ es nur ein vorläufiges ist. Das immer größer werdende Arbeitsfeld der einzelnen Wissenschaften fordert solche Vereinigungen zu gemeinsamer Tätigkeit und zum Austausch von Präparaten und Untersuchungsmaterial; man wird darauf zurückkommen müssen.

Eines kleinen Reiseabenteuers von der Reise nach London, welches zeigte, wie vorteilhaft es ist, wenn man sich um die Seekrankheit nicht zu kümmern braucht, sei noch erzählt. Ich hatte auch in Paris zu tun gehabt und fuhr von da über Calais nach London. Das Schiff lag zur Überfahrt im Hafen bereit. Ich hatte mich etwas verspätet und sah, an der Laufplanke angelangt, die vom Ufer zum Schiffe führte, da $\boldsymbol{B}$ an Bord schon eine große Anzahl Reisender eifrig beschäftigt waren, der reichbesetzten Frühstückstafel zuzusprechen. Ich dachte schon schlecht wegzukommen, aber es kam anders: Als ich eben den Dampfer betreten hatte, wurden die Befestigungen gelöst und das Schiff setzte sich in Bewegung. Alsbald spürten wir den starken Seegang und nach wenigen Minuten waren fast alle Plätze vor den immer noch gut versehenen Frühstückstischen leer. Behaglich lie $B$ ich mich nieder und begann mir gütlich zu tun, denn meinetwegen kann das Meer so hoch Wellen schlagen, wie es will, mich stört das nicht. Mit neidischen Blicken verfolgten viele der Abgeschreckten meinen gesunden Appetit.

Bei den beiden nächsten Versammlungen in Wien 1906 und $x 907$ übernahm der hochgeschätzte und liebenswürdige Erzherzog Rainer unseren Empfang. In besonders angenehmer Erinnerung aus diesen Tagungen ist mir die Einladung des Grafen Hans Wilczek nach seiner Burg Kreuzelstein an der Donau geblieben. Die Burg ist in bester Weise ganz in ihrer mittelalterlichen Art, sowohl in den Außenteilen wie in ihrer inneren Einrichtung, hergestellt worden, so da $B$ man ein getreues Bild der Wohnsitze der Ritter jener Zeit erhält. Nach eingehender Besichtigung fanden wir uns im Speiseraum der Burg zusammen, wo erste Sänger der Wiener Hofoper uns durch ihre vollendete Kunst erfreuten. Alle Teilnehmer dieser Burgfahrt werden sich sicher daran stets in angenehmstem Empfinden erinnern.

Die Jahre 1909 und IgIo sahen uns in Rom. Auf der ersten Fahrt dorthin traf ich von Berlin ab mit Professor Dr. Axel Johannessen, Generalsekretär der Norwegischen Gesellschaft der Wissenschaften, dessen Reiseziel dasselbe war, zusammen. Diese mir sehr willkommene. 
Begegnung führte $\mathrm{zu}$ einem freundschaftlichen Verhältnis, welches ein dauerndes geblieben ist. Oft noch regt sich in mir der Wunsch, noch einmal mit meinem norwegischen Freunde auf einem akademischen Kongresse oder wo sonst zusammen zu sein. - Rom war mir von öfteren Besuchen gut bekannt; nur die Räume der Accademia dei Lincei waren mir neu. Auch persönliche Bekanntschaften wurden erneuert und angeknüpft, unter denen ich den Physiker Blaserna besonders erwähne, zumal ich die Freude hatte, ihn im Oktober desselben Jahres, I9ro, bei Gelegenheit der Hundertjahrfeier der Berliner Universität, als Gast bei mir empfangen zu können. Erwähnen will ich auch den Empfang der Mitglieder unserer Versammlung durch das italienische Königspaar im Quirinal, sowie den Besuch der Villa Malta, wozu Fürst Bülow die deutschen Delegierten freundlichst eingeladen hatte. $\mathrm{Da}$ ich dem Fürsten von einer Begegnung in Neapel her bekannt war, so fiel es mir zu, ihm und der Fürstin meine Kollegen vorzustellen. Der Fürst zeigte uns in liebenswürdigster Weise alle die Merkwürdigkeiten seines schönen Heims, worunter mir besonders die im Garten der Villa von Goethe gepflanzte Palme im Gedächtnisse geblieben ist.

Der Besuch Italiens anläßlich der Hauptversammlung der Akademien im Jahre IgIo hinterläßt mir noch eine schöne, aber wehmütige Erinnerung. Damals schon im 74. Lebensjahre stehend, hatte ich das Vorgefühl, zum letzten Male in meinem Leben die ewige Stadt und wohl auch Italien zu sehen. Dies Gefühl hat sich als richtig erwiesen, denn der Weltkrieg und zehn Lebensjahre mehr ließen und lassen eine weitere Romfahrt nicht mehr zu. Am Tage vor meiner Abreise aus Rom nahm ich mir bei schönem Wetter eines der öffentlichen Fuhrwerke und ließ mich um ganz Rom herumfahren. An allen Stellen, von denen aus man einen guten Ausblick auf die Stadt oder auf deren Umgebung hatte, stieg ich aus und nahm in aller Ruhe das Bild zur Erinnerung in mich auf. Ich brachte damit zur Zufriedenheit des Vetturino, der sein Rößlein nicht anzustrengen hatte und mehrere Male durch eine von mir angebotene Erfrischung erquickt wurde, den ganzen Nachmittag zu. Als die Sonne im Scheiden war, langten wir, das hatte ich so ausgemacht, bei der Kirche San Pietro in Montorio in der Nähe des Garibaldi-Denkmals an. Von da aus hat mir das Bild der ewigen Stadt immer einen besonders schönen 
Eindruck gemacht. Ich stieg aus, lohnte meinen Kutscher ab, nahm dort Platz, von wo aus sich mir der beste Blick bot und ließ in aller Ruhe noch einmal meine Augen mit Entzücken auf dem schönen Bilde ruhen. Als die Sonne versunken war, stand ich auf, entblößte mein Haupt und rief Rom den Abschiedsgruß zu. Still, freudig und wehmütig zugleich bewegt ging ich zu FuB in mein Quartier, das Albergo di Milano an der Piazza di Monte-Cittorio, wo ich bei jedem Besuche Roms gewohnt hatte.

Von Rom aus begab ich mich am anderen Tage nach Siena, wo ich eine Zusammenkunft mit meinem schon erwähnten Laboranten aus der Straßburger Zeit und Freunde Guglielmo Romiti, Professor der Anatomie in Pisa, hatte. Am Morgen nach meiner Ankunft besichtigten wir das Anatomische Institut; ich besuchte meinen früheren Schüler in Berlin, Professor der Chirurgie D. Biondi, den Anatomen und Histologen auch bekannt durch das nach ihm benannte färbetechnische Gemisch. Dann begaben wir, Romiti, Biondi und die beiden Sienenser Anatomen Bianchi und Angelo Ruffini, der mir vorher eine ganze Reihe seiner schönen mikroskopischen Präparate demonstriert hatte, uns nach einer vor den Toren Sienas gelegenen Osteria, wo wir im Freien unser Mittagsmahl einnahmen. Wir hatten da auf einer Anhöhe einen herrlichen Platz mit dem Ausblicke auf die wundervolle Landschaft um Siena. Selten habe ich so angenehme, frohe Stunden verlebt, wie damals im Kreise zweier lieber Schüler und Freunde, Romiti und Biondi, und zweier sympathischer Kollegen. Leider ist Biondi einige Jahre darauf aus dem Leben geschieden; ich bewahre dem mir treu ergeben gewesenen prächtigen Manne ein treues Andenken. Der Krieg hat Romiti nicht von mir geschieden; er war der Erste, der nach Einstellung der Feindseligkeiten des Weltkrieges den brieflichen Verkehr mit mir wieder aufnahm.

Nach unserem Mittagsmahle wanderten wir noch zu dem nahegelegenen Kloster Osservanza, wo sich ausgezeichnete glasierte Terrakotten aus der Schule Luca della Robbias befinden: in der Tat ganz hervorragende Kunstwerke. Am Abend fuhr ich mit Romiti nach Pisa und begab mich anderen Tags auf den Heimweg. Das war mein Abschied von Italien für immer!

Drei Jahre später, I9r3, fand die nächste Hauptversammlung der vereinigten Akademien in St. Petersburg statt. Aus dem Süden 
nach dem Norden! Abgesehen von den wissenschaftlichen Verhandlungen, die in sehr eingehender Weise stattfanden, wurde uns auch hier bei günstigem Wetter viel Schönes und Interessantes geboten. Der Zar Nikolaus II., dem wenige Jahre später mit seiner Familie ein so grauenhaftes Lebensende beschieden sein sollte, empfing uns in Zarskoje-Selo, wohin wir in kaiserlichen Wagen befördert wurden. Bevor wir in den Schloßhof einfuhren, wurden die Insassen jedes Wagens noch genau rekognosziert. Im großen Empfangssaale ordneten wir uns in einer Reihe in alphabetischer Ordnung nach den Anfangsbuchstaben der Städte, in denen die verschiedenen Akademien ihren Sitz hatten. So waren die Mitglieder der Amsterdamer Akademie die ersten und darauf kamen die der Berliner Akademie. Der Zar, in Begleitung eines Adjutanten, der ihm die Namen der Anwesenden nannte, begrüßte Jeden einzeln, mit einigen sich länger unterhaltend. Ich folgte auf Diels, den der Zar fragte, ob er bereits in Rußland gewesen sei. Diels verneinte dies, wies aber auf mich, der ich bereits mehrere Male in Rußland gewesen sei. Darauf wandte sich Nikolaus II. zu mir und fragte, wo ich gewesen sei? Ich nannte ihm Petersburg, Moskau, Kiew, Odessa und schlo $B$ mit der Angabe, da $B$ ich auch in Podolien 8 Tage auf dem Gute meines Freundes und früheren Schülers, Exzellenz v. Rein, zugebracht hätte. v. Rein war als Leibarzt der Zarin dem Kaiser gut bekannt und dieser sagte mir darauf: $O$, den liebe ich sehr! Nikolaus II. sprach das Deutsche geläufig und ohne fremden Akzent. Ebenso geläufig hörte ich ihn englisch und französisch sprechen. Es wurde mir gesagt, da $B$ er mit den Kopenhagener Herren dänisch gesprochen habe. Die äuBere Erscheinung des Zaren war mir sympathisch; keineswegs erweckte er mir den Eindruck von geistiger Minderheit, was man wohl von ihm behauptet hat. Sein Verhalten gegenüber den großen weltgeschichtlichen Ereignissen, vor die er gestellt worden ist, zeigt allerdings, da $ß$ er ihnen nicht gewachsen war; jedenfalls fehlte es ihm an Willensstärke. Sein tragisches Ende muß, wie das Ludwigs XVI., an den er erinnert, als ein unverdientes bezeichnet werden.

Ich will nicht unerwähnt lassen, daß uns der Winterpalast in allen seinen Räumen, der Kronschatz und vor allem die großen Kunstschätze der Eremitage in zuvorkommendster Weise zu eingehender Besichtigung zugängig gemacht wurden. Zweimal waren wir Gäste des Zaren, 
im Winterpalaste und im Schlosse der Kaiserin Katharina II., nach dem Empfange in Zarskoje-Selo. In diesem Palaste fiel mir besonders das fast ganz mit Bernsteinmobilien ausgestattete Zimmer auf. Einen eindrucksvollen Abendempfang bereitete uns Herr Nobél, Bruder des bekannten schwedischen Preisstifters, indem er uns zu einem Konzert einlud, welches von russischen Künstlern in russischen Kompositionen jeder Art und mit russischen Instrumenten gegeben wurde. Diese Vorführungen waren für jeden Musikfreund äuBerst interessant.

Was ich sonst an freier Zeit übrig hatte, brachte ich in der Familie meines Freundes v. Rein $7 \mathrm{u}$. Es mag hier gleich angeführt werden, daß ich auch während des Krieges durch Vermittlung des Roten Kreuzes mit ihm in Verbindung geblieben bin. Ich habe ihn wiederholt um Auskunft über verwundet in russische Gefangenschaft geratene Bekannte gebeten und umgekehrt hat er mir das gleiche Ansuchen gestellt. Nach Ausbruch der russischen Revolution verlor v. Rein seine hohe Stellung in St. Petersburg und ging mit seiner Familie nach Kiew, wo er früher Professor der Gynäkologie an der dortigen Universität gewesen war. Als die bolschewistische Herrschaft auch dort ausbrach und er sein Leben bedroht sah, begab er sich nach Nizza und verweilte auf dem Wege dahin einige Zeit in Berlin. Es war mir eine große Freude, ihn wiederzusehen und in meine Familie einführen zu können. Wir waren die alten treuen Freunde geblieben, trotz allem, was dazwischen lag. Wieder und wieder kamen unsere Gedanken und Aussprachen auf den Unterschied zwischen unserer letzten Begegnung in St. Petersburg I9I3 und unsere jetzige in Berlin zurück. Selten konnte das, was ein so großer Völkerkrieg zerstören kann, an einem Beispiele von so erschreckender Klarheit dargelegt werden, wie an diesem. Aber mein Freund blieb ungebrochen! -

Die Zusammenkunft der Weltakademien in St. Petersburg war die letzte, die ich erleben werde; sie wird auch wohl die letzte sein für lange Zeit überhaupt. Wie wird sich aber die Zukunft der deutschen Akademien gestalten? Da ist es schwer, etwas Sicheres zu sagen. Wenn Deutschland in kleinere Einzelrepubliken aufgelöst wird, können sich da die verhältnismäßig zahlreichen Akademien, die es besitzt, so wie sie sind, halten? Nehmen wir an, da B Preußen als besonderer Staat aufhört und in einen Preußischen, Pommerschen, 
Brandenburgischen, Sächsischen, Westfälischen, Hannoverschen, Schleswig-Holsteinischen und Rhein-Gau zerlegt wird, die sich nicht zu einem preußischen Bundesstaate vereinigen, sondern unmittelbare Glieder Deutschlands werden, wer übernimmt die Preußische Akademie der Wissenschaften, wer die Münchener, wenn eine ähnliche Zerlegung des jetzigen Bayernstaates stattfinden sollte?

Bis jetzt bestand ein bereits vor dem Inslebentreten der großen Association gegründeter Kartellverband der einzelnen deutschen Akademien mit Einschlu $\beta$ der Wiener Akademie; wird diese dem Kartell weiter angehören können? Zur Zeit ist erfreulicherweise die Verbindung nicht gelöst worden.

Bei dem Ausdrucke von $\mathrm{Ha} B$ und Verachtung, welcher bei vielen Mitgliedern der Akademien unserer Feinde bis zur Stunde sich noch zeigt, angesichts der Tatsache, da $B$ manche Mitglieder deutscher Akademien - ich selbst bin davon betroffen worden -- von der Liste der korrespondierenden Mitglieder der Académie des Sciences in Paris und der Royal Society in London gestrichen worden sind, liegt es wohl noch in weiter Ferne, daß sich die Akademien von Frankreich und England wieder zur Zusammenarbeit mit deutschen Akademien geneigt finden werden. Es ist auch noch nicht abzusehen, wie sich die Akademien in Turin, Rom und Washington verhalten werden. Mit den Akademien der Neutralen und vielleicht mit der Petersburger Akademie dürfen wir hoffen, bald wieder in Verbindung zu treten.

Als Grund der Ausstoßung mancher deutscher Akademiker aus den Pariser und Londoner Akademien ist angegeben worden, da $B$ diese Mitglieder die bekannte Erklärung der „Dreiundneunzig“ unterzeichnet hätten. Diese Erklärung, unterzeichnet von 93 deutschen Gelehrten, Schriftstellern und Künstlern, war allerdings in einem sehr entschiedenen Tone gehalten. Dies ist aber vollkommen begreiflich angesichts der Schmähungen und Verleumdungen, mit denen unsere Gegner gleich zu Beginn des Krieges die Deutschen überhäuften. Man vergleiche nur einmal die französische und englische Tagespresse jeder Art von I9I4 mit der deutschen und man wird sehen, auf welcher Seite die meisten und schwereren Verleumdungen und Schmähungen waren und auch bis zum Ende des Krieges geblieben sind. Die deutsche Presse hat sich in ihrer Mehrheit davon frei gehalten. $\mathrm{Da}$ ist es doch begreiflich, da $B$ in der Erregung, die in 
den ersten Monaten des Krieges alle Völker ergriff, auch einmal ein entschiedenes Wort von deutscher Seite gesprochen wurde. Und, man bemerke wohl: die Erklärung der Dreiundneunzig war kein Angriff, sondern lediglich eine Verteidigung. Zur Zeit dieser Niederschrift hat der französische Ministerpräsident $\mathrm{Clémenceau}$ die Unterzeichner des Manifestes als „dreiste Lügner" und das Manifest selbst als ein ,schamloses Verbrechen" bezeichnet. Wenn man die einzelnen Sätze des Protestes richtig Wort für Wort erwägt, so wird es klar, daß von „Lügen" keine Rede sein kann. Der beständige Sekretar der Preußischen Akademie, Professor Dr. Max Planck, hat in einem veröffentlichten Schreiben an Professor Lorentz in Holland die Sachlage klar auseinandergesetzt; ich habe mich dieser Erklärung angeschlossen.

Wir haben in der Preußischen Akademie erwogen, was wir angesichts der feindseligen Schritte der Akademien unserer Gegner tun sollten. Es überwog die Ansicht, da $B$ es einer wissenschaftlichen Körperschaft nicht gezieme, in Feindseligkeiten einzutreten. Es wurde beschlossen, nichts auf die Maßnahmen der gegnerischen Akademien zu erklären oder ins Werk zu setzen, sondern die Ruhe zu bewahren und die Zurückhaltung, die, so glauben wir, das einzig Richtige und Würdige ist, was gelehrten Gesellschaften im Falle politischen Streites und selbst harten Waffenganges zwischen den Nationen wohl ansteht. Freilich werden wir - das ist nach dem, was vorgegangen ist selbstverständlich - nicht die Ersten sein können, die die frühere Verbindung wieder suchen.

Unter den vielen bedeutenden Persönlichkeiten, mit denen mich meine Mitgliedschaft in der Preußischen Akademie der Wissenschaften in nähere Berührung brachte, will ich nur eines Mannes gedenken, dem ich eine besondere Hochachtung und Zuneigung bewahre, des Astronomen Arthur v. Auwers. Schon als Student in Göttingen war ich, wie erwähnt, einmal zufällig mit ihm bei einem gemeinsamen Bekannten zusammengetroffen; erst als ich $\mathrm{I} 884$ in die Berliner Akademie eintrat, also fast 30 Jahre später, sah ich ihn als den berühmten Astronomen und beständigen Sekretar der Akademie wieder. Mein Eintritt in das Sekretariat brachte mich ihm näher. Ich habe selten einen Mann kennen gelernt, der als hochbedeutender Gelehrter und Forscher ein solches sicheres Gedächtnis, solchen Sinn für Recht 
A. v. Auwers. Mein sonstiges Vereinsleben. Breslau. Die Fabier. 237

und Ordnung und einen so bestimmten Charakter besa B, wie v. Auwers. Die Akademie wird nicht leicht wieder einen Sekretar bekommen, der ihre Interessen so gut wahrnimmt, wie es v. Auwers bei seinem eminenten Verwaltungstalent zu tun imstande war. Er konnte sich freilich, da er als Astronom der Akademie keine weiteren Verpflichtungen hatte, ganz unserer Körperschaft widmen, was er denn auch tat. Auwers war bekannt durch seine Wortkargheit; er wußte aber in knapper Form viel zu sagen. Es gereichte mir zu hoher Befriedigung, da $B$ ich das Vertrauen und, ich darf auch sagen, die Zuneigung dieses Mannes genoB. Viel zu früh hat der Tod ihn hingenommen; es vergeht kaum ein Tag, ohne daß ich seiner gedenke. -

\section{K a p it el.}

Mitgliedschaft in wissenschaftlichen, gemeinnützlichen und geselligen Vereinen. Außeramtliche Tätigkeit. KongreBreisen.

Insbesondere: Deutsche Anthropologische Gesellschaft, Anatomische Gesellschaft und Internationale medizinische Kongresse.

In Königsberg trat ich der seit langem bestehenden Gesellschaft für Heilkunde und der Physikalisch-ökonomischen Gesellschaft bei und bin auch deren Mitglied geblieben. In Breslau wurde ich Mitglied der Schlesischen Gesellschaft für vaterländische Kultur und dreier geselliger Vereinigungen, einer turnerischen, die sich „Alte Herren-Riege“ nannte, einer Kegler-Gesellschaft und dem Verein der „Fabier". In der Alten Herren-Riege waren sehr eifrige Mitglieder der schon bejahrte Philologe Haase und der Mathematiker Schröter, mit dem ein freundschaftliches Verhältnis zustande kam. Die Fabier waren eine Ärzte-Gesellschaft; sie hatten sich ihren Namen gewählt von der Sitte, daß der alljährlich neu zu wählende Präsident, der den Namen Fabius I., II. usw. führte, durch eine in einen Kuchen eingebackene Bohne bestimmt wurde. Am Stiftungsfeste wurde dieser Kuchen in so viele Stücke zerteilt, als Mitglieder anwesend waren; dasjenige Mitglied, in dessen Stück sich die Bohne fand, wurde der neue Fabius. Viel Heiterkeit erregte uns öfters eines der Mitglieder, ein älterer Herr, der, nachdem er eine Flasche Wein ge- 
leert hatte, nun anfing, sich halbe Flaschen zu bestellen; wenn man ihn aber aufforderte, sich doch noch eine volle Flasche zu gönnen, dies stets ablehnte mit der Begründung, das sei zuviel; dabei trank er aber meist noch drei bis vier halbe Flaschen. Wir waren nur eine mäßige Zahl Mitglieder, etwa ein Dutzend, kamen aber sehr regelmäßig monatlich zweimal zusammen und lernten uns dadurch recht gut kennen. Der bekannte schlesische Dichter Holtei war uns gut befreundet und hat einige Male in unserem Kreise aus seinen Werken vorgelesen.

In StraBburg gründeten wir bald den Naturwissenschaftlichmedizinischen Verein, der eine rege wissenschaftliche Tätigkeit entfaltete. Zwei der Sitzungen dieses Vereins sind mir besonders bemerkenswert geblieben. In der einen wurde der Phonograph und das Telephon zum ersten Male gezeigt. Ich wurde ausgewählt, um mich in dem Phonographen zu verewigen; ich sang das Volkslied: "Sah' ein Knab' ein Röslein stehn“ hinein. Nach Vorstellung des Telephons, durch welches wir ein Zimmer des Oberstockes mit unserem Sitzungszimmer verbunden hatten, sagte ich, ganz erfüllt von dieser Leistung, das sei ja ein großartiger Fortschritt, dessen Tragweite man kaum ermessen könne. Darauf bemerkte der Physiker Kundt, das sei wohl von mir überschätzt, ich sei ja aber als Sanguiniker bekannt. - Als die Mitteilungen über die karyokinetischen Kernteilungen ( $I_{4}$ ) bekannt wurden, hielt ich darüber im Vereine einen Vortrag, in welchem ich gleichfalls auf die hohe Bedeutung dieser Entdeckungen hinwies. Da war es der berühmte Botaniker de Bary, der etwas Wasser in meinen Wein goß. Die weitere Entwicklung beider Dinge hat aber meiner Auffassung Recht gegeben.

Als gesellige Vereinigung diente uns ein aus Universitätskreisen begründeter Kegelklub, von dem bereits beim Kapitel „Straßburg“ die Rede war.

In Berlin gaben die Größe der Stadt, die vielen dort bestehenden wissenschaftlichen Anstalten und die mannigfachen Beziehungen, in die man, ohne da $B$ man gerade darnach strebte, hineingezogen wurde, ausgiebige Gelegenheit $\mathrm{zu}$ einem wissenschaftlichen und geselligen Vereinsleben. Leider blieb keine Zeit übrig, das von mir sehr gern betriebene Kegelspiel fortzusetzen, welches ich bereits seit Königsberg, I862, also 2I Jahre lang, eifrig betrieben hatte. 
Von wissenschaftlichen Gesellschaften wählten mich die Große Berliner Medizinische Gesellschaft, der Verein für Innere Medizin, die Freie Vereinigung der Chirurgen Berlins, die Geburtshilflich-gynäkologische Gesellschaft, die Laryngologische Gesellschaft, die Zahnärztliche Gesellschaft, die Gesellschaft für Erdkunde, die Physiologische Gesellschaft und die Gesellschaft für Anthropologie, Ethnologie und Urgeschichte zum Mitgliede. Ferner wurde ich Mitglied der Militärärztlichen Gesellschaft; und, wie schon angegeben, des bei der Kaiser Wilhelm-Akademie begründeten Wissenschaftlichen Senates. In fast allen diesen Vereinigungen habe ich Vorträge gehalten; am meisten in der Gesellschaft für Anthropologie, Ethnologie und Urgeschichte, in deren Vorstand ich auch hineingewählt wurde. Sie war und ist eines der bedeutendsten Glieder der großen Deutschen Anthropologischen Gesellschaft. Die Jahresversammlungen und die internationalen Versammlungen dieser äußerst tätigen und namentlich unter Rudolf Virchows Leitung sich rasch entwickelnden Vereinigung gehören mit $\mathrm{zu}$ den interessantesten und belehrendsten Erlebnissen, die mir geboten worden sind. Gern lasse ich bei dieser Niederschrift die einzelnen Jahresversammlungen in meinem Erinnerungsfelde vorüberziehen. Falls diese Zeilen dem einen oder dem anderen der damaligen Teilnehmer unter die Augen kommen, mögen und werden sie ihm gleichfalls angenehme Erinnerungen wecken. Verdient um die Gründung der Berliner Anthropologischen Gesellschaft, wie sie kurz bezeichnet sein mag, ist der Weltreisende und Ethnograph Adolf Bastian, aber als Hauptgründer ist Rudolf Virchow zu bezeichnen.

Auf der Ärzte- und Naturforscher-Versammlung in Innsbruck, im Jahre I869, wurde von Karl Vogt und R. Virchow eine besondere Sektion für die gesamte Anthropologie eingerichtet und durch einen Aufruf die Gründung von anthropologischen Ortsvereinen in ganz Deutschland angeregt, der auch - es war tatsächlich ein Bedürfnis - vollen Erfolg hatte. Virchow brachte noch im selben Jahre die genannte Berliner Gesellschaft zustande; sie hielt am II. Dezember I869 ihre erste Sitzung ab, feierte also in den Jahrestagen, an welchen ich diese Zeilen niederschreibe, Anfang Dezember I9I9, ihr 50. Jahresfest. Ich wohnte der Feier bei; sie war recht geeignet, die großen Störungen, welche der Weltkrieg im wissenschaft- 
lichen Verkehr angerichtet hat, zu zeigen. Die Festsitzung fand in dem gewöhnlichen Versammlungsorte der Gesellschaft, im Museum für Völkerkunde, statt. Die bekränzte Büste Adolf Bastians und das bekränzte Bildnis Rudolf Virchows schauten auf uns herab. Die drei noch lebenden Mitglieder aus dem Gründungsjahr I869, Professor Dr. Gustav Fritsch, Geh. Sanitätsrat Dr. Kroner und Professor Dr. Schütz, wohnten auf Ehrenplätzen der Sitzung bei. Professor Schuchhardt, derzeitiger erster Vorsitzender, hielt die Festansprache und darauf einen wissenschaftlichen Vortrag über die Ergebnisse seiner Untersuchungen an Ringwällen. Dann folgte die Verlesung der Glückwunsch-Kundgebungen und die Bekanntmachung der Ehrenerweisungen. Damit schloß die in schlichter, aber würdigster Weise verlaufene Feier. Ich will nicht beklagen, da $B$ kein Festmahl, wie es bei solchen Gelegenheiten üblich ist, folgte. Unter anderer politischer Lage unseres Vaterlandes hätte es nicht gefehlt und hätte auch nicht fehlen dürfen. Aber ein wehmütiges Empfinden konnten wir doch nicht unterdrücken darüber, daß kaum ein Mitglied einer der anderen zur Deutschen Anthropologischen Gesellschaft gehörigen Vereine anwesend war wegen der Verkehrsschwierigkeiten und der enormen Teuerung aller Lebensmittel, die jetzt schwer auf uns lastet. Die Festsitzung war reichlich besucht, aber fast nur von Berlinern und aus Berlins nächster Umgebung. Und eben so traurig stimmte, daß unter den von außen angelangten Glückwünschen zwar eine reiche Zahl aus Deutschland und die der befreundeten Wiener Anthropologischen Gesellschaft sich befanden, aber aus dem übrigen Auslande nur zwei aus Schweden. Die Gesellschaft begrüßte warm diese Kundgebungen unserer nordländischen Freunde. Wie ganz anders wäre der Besuch von Gästen aus ganz Deutschland und aus dem Auslande gewesen und wieviele Glückwünsche und Grüße wären uns unter anderen Verhältnissen aus dem Auslande zugekommen!

Die große deutsche Anthropologische Gesellschaft, der ich seit ihrer Gründung angehörte, beging im Jahre I894 im Verein mit der österreichischen Schwestergesellschaft das Fest ihres 25 jährigen Bestehens in Innsbruck, an demselben Orte, wo sie I869 entstanden war. Ich wohnte dieser Festversammlung bei, wie ich denn seit I883, dem Jahre meiner Übersiedelung nach Berlin, fast allen Jahres- 
versammlungen dieser deutschen Anthropologen-Gesellschaft beigewohnt hatte. An den Sitzungen der Berliner Gesellschaft habe ich bis zu meinem höheren Alter gleichfalls ziemlich regelmäßig teilgenommen. I883 tagte die deutsche Gesellschaft in Trier, I884 in Breslau, I885 in Karlsruhe, I887 in Nürnberg, I888 in Bonn, I889 in Wien und in Budapest, I890 zu Münster in Westfalen, I89I in Danzig und Königsberg i. Pr., I892 in Ulm, I893 in Hannover, I894 wie bemerkt, in Innsbruck, I895 in Kassel, I896 in Speier, I897 in Lübeck, I898 in Braunschweig, I899 in Lindau, I900 in Halle a. S., Ig0I in Metz, I902 in Dortmund, I903 in Worms, I904 in Greifswald, I906 in Görlitz, I907 in StraBburg i. Els., Ig08 in Frankfurt a. M., I909 in Posen; auch nahm ich in demselben Jahre an der Anthropologen-Versammlung in Paris teil; IgIo tagten wir in Köln und IgII in Heilbronn. Aus den Jahren I896, I9I2 und I9I3 besitze ich keine Aufzeichnungen; seitdem sind die Versammlungen durch den Weltkrieg unterbrochen. In den hier nicht aufgeführten Jahren nahm ich an den Versammlungen nicht teil.

Man ersieht aus dieser Aufzählung, da $B$ man tunlichst bemüht war, einen planmäßigen Wechsel der Örtlichkeiten zwischen Ostund West-, Nord- und Süddeutschland eintreten zu lassen und da $B$ Österreich-Ungarn mit eingerechnet wurde. Man ersieht ferner daraus, da $B$ es kein besseres Mittel gab, Deutschland, das Heimatland, kennen zu lernen, als die Teilnahme an diesen Versammlungen, die gewöhnlich drei Tage dauerten und bei denen nicht nur die Sehenswürdigkeiten der Tagungsorte selbst, sondern auch die der näheren und entfernteren Umgebung unter sachkundiger und ortskundiger Führung in Augenschein genommen wurden. Wenn auch das anthropologische, ethnologische und prähistorische Interesse dabei im Vordergrunde stand, so wurden doch die anderen wichtigen Sehenswürdigkeiten in nationalökonomischer, geographischer und kunsthistorischer Beziehung nicht vernachlässigt; auch angenehme Geselligkeit kam zu ihrem Recht, viele mir wert gebliebene persönliche Bekanntschaften habe ich dabei anknüpfen können.

Rudolf Virchow war sozusagen die Seele dieser Versammlungen; sah man ihn mit dem Generalsekretär Johannes Ranke und dem Schatzmeister, dem Papa Weismann, wie wir ihn gern nannten, 
am Vorstandstische sitzen, so waren alle zufrieden und überzeugt, daß die Tagung gut verlaufen werde. Später kam noch die sympathische Erscheinung des österreichischen Freiherrn v. AndrianWerburg hinzu. Virchow war es vergönnt, über ein Menschenalter der Spiritus rector der Anthropologischen Gesellschaft und ihrer Versammlungen zu sein und man mußte sich sagen, er war nirgends lieber als in seiner Schöpfung, der Anthropologischen Gesellschaft. Und wer Rudolf Virchow als Menschen kennen lernen wollte, der mußte ihn bei den Tagungen der Deutschen Anthropologischen Gesellschaft begleiten. Die anregendsten und schönsten Stunden sind es für mich gewesen, abends, nach getaner Arbeit nebst einigen wenigen Kollegen, die Virchow sich aussuchte, bei einem Glase Wein mit ihm zusammen zu sein. Da ging er aus sich heraus und zeigte sich auch als der gemütliche, aber stets geistreiche und anregende Plauderer, dem zuzuhören man nicht müde wurde, obwohl diese Nachsitzungen meist zu Nachtsitzungen wurden.

Vormittags fanden bei den Versammlungen die Vorträge und Demonstrationen statt, nachmittags die Besichtigungen, vor allem der einschlägigen Sammlungen, und Ausflüge in die Umgebung, je nach Lage der Dinge verbunden mit Ausgrabungen. Ein gemeinsames Mahl pflegte an einem der Tage alle Teilnehmer zu vereinigen, auch war für die Abende, jedoch zwanglos, ein Treffpunkt bestimmt, so da $B$ bei dem nötigen Zusammenhalt doch der Freiheit des Einzelnen hinreichend Raum gelassen wurde.

Über die wissenschaftlichen Ergebnisse dieser Tagungen $\mathrm{zu}$ berichten, ist hier nicht der Platz; sie sind in der ,Zeitschrift für Ethnologie" niedergelegt. Dagegen mögen einige persönliche Erlebnisse angenehmer und bemerkenswerter Art, die sich meinem Gedächtnisse eingeprägt haben, hier erwähnt sein.

I883 in Trier gab uns an einem Nachmittage die Stadt ein Gartenfest auf einer der Anhöhen an der Mosel, von wo man einen schönen Überblick über die Stadt und das Moseltal genoß. Man hatte auf einer kleinen Erhöhung ein ansehnliches $\mathrm{FaB}$ aufgestellt, in welchem angesichts der Teilnehmer eine Weinbowle kunstgerecht. gemischt wurde. Dabei mußte der Küfer auf einer Trittleiter stehen, um über den Rand des Fasses hinauslangen zu können; man hatte es absichtlich so hoch gestellt, damit alle, auch die entfernter Sitzenden, sich 
an dem Schankgeschäft erfreuen könnten. Ich kann nur sagen, da $B$ der Küfer seine Aufgabe vorzüglich löste, gibt ja doch auch die Umgegend von Trier genug des köstlichen Rebensaftes her, wie er zu einer solchen erquickenden Mischung besonders geeignet ist. Ein kleines Gewitter konnte die frohe Stimmung nicht beeinträchtigen, und für das bißchen Wasser, welches es in unseren Wein träufelte, wurden wir reichlich entschädigt durch das wundervolle Schaustück eines herrlichen Regenbogens, der sich über die Mosel hinwegwölbte, meiner Erinnerung nach des schönsten, den ich gesehen habe.

Das wichtigste und dauernd beste Ergebnis der Trierer Tagung für mich war, daB ich in dem Sohne Rudolf Virchows, Dr. Hans Virchow, einen treuen, zuverlässigen wissenschaftlichen Gehilfen für meine in Berlin bevorstehende umfängliche Arbeit gewann, indem er auf meinen Vorschlag die Stelle eines zweiten Prosektors an der Berliner Anatomischen Anstalt übernahm. Ich hatte Hans Virchow in Straßburg, wo er in dem von mir geleiteten Institute mit einer anatomischen Arbeit sich beschäftigte, kennen und schätzen gelernt. Er ging dann als Assistent Köllikers nach Würzburg, von wo er, gemäß unsęren Abmachungen in Trier, nach Berlin übersiedelte und mir 34 Jahre hindurch, bis zur Niederlegung meines Amtes, erst als zweiter, dann, nach Robert Hartmanns Tode, als erster Prosektor und als mein Stellvertreter im Direktorium der Anatomischen Anstalt der treueste und beste Helfer und Mitarbeiter war, ja, mehr als das! Auch unsere Familien traten in freundschaftliche Beziehungen.

Bei der Tagung in Bresla u I884 konnte ich dort alte, liebgewordene Erinnerungen wieder auffrischen, und in Karlsruhe I885 hatte ich die Freude, mit meinem hochgeschätzten ehemaligen Breslauer Kollegen Ferdinand Römer und zweien meiner früheren Schüler, Militärärzten, einen Abend im „Krokodil“" in höchst angeregter Unterhaltung, die besonders Römer zu beleben wußte, zu verbringen; es war leider das letzte Zusammensein mit ihm.

Die Zusammenkunft in Nürnberg verschaffte mir und meiner Familie die Bekanntschaft mit diesem hohen Schatze unter den deutschen Städten. Ich trat von da aus meine Orientreise an, über die ich an anderer Stelle zu berichten haben werde. Bonn, I888, stand unter der Führung Schaaffhausens und im Zeichen der 
Neanderthaler-Funde, die ich dort zum ersten Male sah. Gern gedenke ich dabei auch einer abendlichen Rückfahrt von einem Ausfluge auf dem Rhein, wobei in allen Orten, die unser Dampfer berührte, Feuerwerke zu unseren Ehren abgebrannt wurden, von wunderbarer Wirkung an dem schönen ruhigen Abend in ihrer Wiederspiegelung in dem dunkeln Rheinstrome.

Viel Belehrendes und Angenehmes brachte die nächste Tagung in Wien und Budapest mit dem Besuch der prähistorisch wichtigen Stätten von Deutsch-Altenberg, mit der eingehenden Besichtigung von Schloß und Park Schönbrunn und der Dampferfahrt auf der Donau von Wien nach Budapest. In sehr angenehmer Erinnerung ist mir ein Mittagsmahl geblieben, zu welchem mich Rudolf Virchow hinzugezogen hatte, im Garten des bekannten Gasthofsbesitzers Sacher unter einem Prachtbaume im Freien; außer uns Beiden nahmen nur noch teil Graf Hans Wilczek, Graf Wurmbrand, Baron Mundy und der Admiral Sternecker. Gern erinnert man sich an ein Symposion, wie dieses es war, wo der geistige Genuß den leiblichen, den ich keineswegs unterschätzen will, noch weit überragte. Auf meinen Vorschlag tagten wir $1890 \mathrm{zu}$ Münster in Westfalen. Dort traf ich mit alten Freunden zusammen, mit Albert Kayser, meinem Göttinger und Greifswalder Studiengenossen, nunmehr wohlgesetztem Arzt in Wattenscheid an der Ruhr. Kayser lehrte mich das Münstersche Altbier schätzen, namentlich, 'wenn es mit einer Zugabe köstlichen westfälischen Schinkens in der blitzblanken Küche eines münsterländischen Altbierhauses am Herdfeuer genossen wird - auch ein Stück Ethnologie, vielleicht auch Prähistorie. Ich wohnte dort bei meinem Freunde aus der Breslauer Zeit, dem Professor der Mathematik an der Theologisch-philosophischen Lehranstalt zu Münster, Paul Bachmann, von dem ich bereits berichtete. Gern erinnere ich mich auch an den Professor der Geologie und Mineralogie Hosius dort, der bei der Organisation der Versammlung besonders tätig gewesen war, sowie des Zoologen Professor Hermann Landois, Bruder meines Freundes, Professors der Physiologie, Leonhard Landois in Greifswald, beides höchst originelle Köpfe. Im zoologischen Garten zu Münster fand eine gesellige Abend-Zusammenkunft statt, bei der ich in dem mir stets lieb und geläufig gebliebenen westfälischen Plattdeutsch einen Trinkspruch auf Hosius ausbrachte. 
Ein sehr belehrender Ausflug führte uns in die Umgegend von Osnabrück, wo auch alte westfälische Bauernhöfe besichtigt wurden. Verfehlt wurde der Zweck dieses Besuches bei einem der am meisten charakteristischen Gehöfte dadurch, da $B$ der Besitzer, als man ihm den Besuch der Anthropologen schon einige Monate vorher angekündigt hatte, glaubte, er müsse sein Haus zum würdigen Empfange möglichst modernisieren und damit manches von dem, was wir gerade sehen wollten, weggeschafft hatte.

Das folgende Jahr I8gI brachte uns eine der abwechslungsreichsten und interessantesten Versammlungen; für mich war sie besonders angenehm, als sie mir wieder Gelegenheit gab, zusammen mit meiner Frau und meinen Töchtern Ostpreußen und vor allem Königsberg $\mathrm{zu}$ besuchen, wo wir vor 25 Jahren unseren Lebensbund geschlossen hatten. Die Fahrt dahin ging über Danzig und Elbing, mit Besuch des mit Recht hochberühmten Deutsch-Ordensritterschlosses in Marienburg. In Königsberg nahm die Besichtigung der großen, schön geordneten Bernsteinsammlung, insbesondere der Bernstein-Einschlüsse, unter Führung des Dr. Klebs mein volles Interesse in Anspruch, ebenso wie die großen Bernsteinwerke der rühmlichst bekannten Firma Stantien \& Becker in Palmnicken an der Ostsee. Nicht minder bemerkenswert ist mir ein Besuch der Stadt RuB mit dem benachbarten Ibenhorster Forstbezirk in Erinnerung geblieben, wo uns Gelegenheit geboten wurde, die einzigen noch in Deutschland vorhandenen Elche zu sehen. Am Abend vereinte uns ein fröhlich in den ortsüblichen „Wasserpunsch" auslaufendes Mahl mit den Herren des zu unserem Empfange gebildeten Ortsausschusses. Als man mir nach Tische, wo wir bereits dem Weine gut zugesprochen hatten, anbot, noch einen Wasserpunsch als Schlaftrunk zu nehmen und ich erfuhr, da $B$ der Name dieses Punsches daher komme, da $B$ er kein Tröpfchen Wasser enthalte, sondern nur aus schwerem Burgunder, Cognac und Zucker bestehe, welche man zusammen erhitze, lehnte ich zunächst $\mathrm{ab}$, da ich meinte, einer solchen Mischung nicht gewachsen zu sein. Der angenehme Duft, den die inzwischen kredenzten Gläser verbreiteten und gutes Zureden der Einheimischen, ließ mich indessen den Versuch wagen und es hat mich nicht gereut. Ich hatte eine vortreffliche Nachtruhe und befand mich, rechtzeitig zur Weiterfahrt bereit, am anderen Morgen frisch und wohl. 
Die Ostpreußen dort sind ein kräftiger gesunder Schlag Menschen; sie können nicht nur den wasserfreien heißen Punsch, sondern auch Eiswasser vertragen, wie das im folgenden berichtete Erlebnis eines der ärztlichen Kollegen in RuB, der es mir an dem Abende mitteilte, beweist. Der Kollege wurde in einer Winternacht zu einer Bauersfrau gerufen, um ihr in Kindesnöten beizustehen. Im Schlitten ging es über eines der dort zahlreichen Wasserbecken, welches eine tragfähige Eisdecke zu haben schien; doch das Eis brach und der Insasse mußte ein unfreiwilliges Eiswasserbad nehmen. Da jedoch an der Stelle das Wasser nicht tief war, kam er mit dem Bade davon, aber in völlig starrem Eisgewande im Hause des Bauern an. In diesem Gewande der Bauersfrau beizustehen war unmöglich. Die schnell herbeigeschafften Kleider des Bauern erwiesen sich aber als viel $\mathrm{zu}$ klein für den kräftigen, hochgewachsenen Jünger Aeskulaps. Es blieb nichts anderes übrig, als ihn mit Kleidern der Bäuerin, der er beizustehen gerufen worden war, notdürftig zu drapieren und in diesem Kostüm, äußerlich in eine Hebamme verwandelt, waltete er mit bestem Erfolge seines Amtes. Mit bestem Erfolge auch für ihn, denn er hat nicht einmal einen Schnupfen davongetragen; doch meinte er, er müsse eine höchst komische Figur abgegeben haben, die Röcke der Bäuerin seien viel zu kurz gewesen.

Zur Charakteristik Rudolf Virchows, der mit seiner Familie und seinem künftigen Schwiegersohne, dem jüngst verstorbenen Leipziger Anatomen Karl Rabl, auch an der in Rede stehenden Jahresversammlung teilnahm, sei hier noch eines $Z$ wischenfalles gedacht, der sich bei einer Fußwanderung zur Besichtigung von Dünenbildungen abspielte. Unten am Fuße der Dünen gingen Virchow und ich ziemlich beschwerlich in dem dort recht lockeren Sande. $\mathrm{Da}$ hörten wir von oben uns anrufen, wir sollten doch nach oben kommen, dort gehe es sich viel bequemer. Wir sahen da die weiblichen Mitglieder unserer Gesellschaft unter Führung der Frau Pastorin des Ortes zwischen dem dort angepflanzten Dünenhafer, der dem Dünenboden Halt geben soll, unserem Ziele zuwandern, obwohl ein am Zugange des Ortes befindlicher Anschlag diesen Weg als verboten bezeichnete. Virchow rief hinauf, das gehe nicht an, der Weg sei ja verboten, die Damen möchten herunter kommen. Die Frau Pastorin entgegnete, man könne bei einer solchen Gelegenheit, 
wie der heutigen, auch wohl einmal eine Ausnahme machen, das sei nicht so schlimm. Virchow wurde ganz erregt und entgegnete ärgerlich, gegen Maßnahmen wie dieses Verbot, das gesetzlich zum Schutz der Düne erlassen sei, gäbe es keine willkürliche Ausnahme, da habe sich Jeder zu fügen, wandte sich ab und wanderte mit mir den beschwerlichen Weg weiter. Unterwegs äußerte er sich über die Schwierigkeiten, die es manchmal bereite, dem weiblichen Geschlecht volle Achtung vor dem Gesetz auch bei anscheinenden Kleinigkeiten beizubringen. Ich habe wiederholt bei Virchow erfahren, da $B$ ihm jede bequeme, willkürlich erscheinende Auslegung einer gesetzlichen Verordnung zuwider war; er hatte eine strenge Auffassung von Recht und Gesetz.

Von der Weichsel, die uns nunmehr genommen werden soll, gingen im nächsten Jahre I892 zur Donau, nach Ulm, und weiter hinein ins schöne Schwabenland, nach Schussenried, nach Stuttgart, wo uns Fraas Führer war und in die Hohenzollernschen Lande; da gab es viel Interessantes und Wichtiges in Ethnographie und Prähistorie zu beachten. Aber auch die freundliche Aufnahme, die wir überall fanden, ist mir in angenehmster Erinnerung geblieben, so in Ulm, wo ich mit Johannes Ranke zusammen beim Apotheker Dr. Leube, Bruder des berühmten Würzburger Klinikers, wohnte. Das Schönste und Eindrucksvollste dieser Tagung bereitete mir aber wieder Frau Musica durch ein wundervolles Orgelkonzert im Ulmer Münster, dessen Orgel ja eine der ausgezeichnetsten ist, die wir in Deutschland besitzen, und wobei uns eine der ersten Sängerinnen des Stuttgarter Hoftheaters durch echt künstlerische Wiedergabe der besten Sachen von Händel und Bach tief ergriff und entzückte. Ich kann wohl gestehen, da B keine Musikdarbietung mich jemals so - ich muB sagen aus der Welt entrückt und so nachhaltig auf mich eingewirkt hat wie diese. Rudolf Virchow saß neben mir; wir wechselten kein Wort; aber wenn ich ihn ansah, wußte ich, daß es ihm ging wie mir. Stumm reichten wir uns, als der letzte Ton verklungen war, die Hand.

Am anderen Abend erfreute uns wieder das Reich der Töne; in einer geselligen Zusammenkunft trug uns eine andere begnadete Sängerin deutsche Volkslieder, insbesondere schwäbische, vor. Das war, wenn auch in ganz anderer Art, wundervoll und entzüickend. Wie sie das rührende und tiefsinnige Liedchen sang: , Jetzt gang I 
Von der Macht der Töne.

an's Brünnele, trink aber nit", das klingt mir noch heute in den Ohren und im Gemüte. -

Welche wunderbare Macht liegt doch in den Luftschwingungen, wenn sie sich mit dem kunstvollen Apparate des Ohrlabyrinths in der Gehörschnecke verbinden und durch diesen den Weg zum Schläfenteile des menschlichen Gehirns finden! Vom.Donner des Gewitters und des Felsen- und Lawinensturzes, vom Donner der schweren Kriegsgeschütze bis zum leisen Geräusche eines herabfallenden Blattes, vom Heulen des Sturmwindes bis zum Säuseln des linden Abendlüftchens, das kaum die Blätter bewegt, vom Brausen der Meereswogen und dem Donner eines Katarakts, wie des Niagarafalles, bis zum leisen Plätschern und Rieseln eines Bächleins über den Kieseln, vom Gebrüll eines Löwen, dem wütenden Gebell eines Hundes, zum Lockruf einer Henne an ihre Küchlein, zum Gesang einer Nachtigall und zum Zirpen einer Grille, vom Schmerzensschrei und Angstruf eines gequälten Menschen oder Tieres zum fröhlichen Jauchzen und Lachen und den vielerlei Äußerungen des Behagens und nun von dem unfaßbar großen Reiche der Töne, welche uns durch unsere musikalischen Instrumente geboten werden, zur schier unendlichen Mannigfaltigkeit der Stimmen und Sprachen der Menschen, von denen nicht zwei unter den Milliarden, die auf Erden gelebt haben, einander völlig gleich waren und sind! Die Erinnerung an die beiden Eindrücke, die mir durch die Tonwelt in Ulm geboten wurden, bringt mich noch einmal auf die Gedanken zurück, welch' hohen Wert die Gehörsempfindung für uns vor allen anderen hat. Nun kann man ja leicht dartun, da $B$ die Gesichtsempfindungen ebenso mannigfaltig sind und wohl auch die Berührungsempfindungen; aber mir scheint, da $B$ die Gesichtsempfindungen nicht so unmittelbar auf das Gefühl und die Stimmung des Menschen wirken wie die Gehörsempfindungen. Oder sollte das bei mir daran liegen, daB ich kurzsichtig und zugleich grünblind bin? Dabei hatte ich aber stets ein gutes, scharfes Auge, konnte stundenlang bis, in mein hohes Alter mit dem Mikroskop arbeiten und lese heute in meinem 84. Jahre noch feine Druckschrift ohne irgendein optisches Hilfsmittel; freilich brauche ich gute $\mathrm{Be}-$ leuchtung.

I894 in Innsbruck wurde die Erinnerung an die vor 25 Jahren dort erfolgte Gründung der Deutschen Anthropologischen Gesellschaft er- 
neuert. I895 bot sich uns in Treysa ein Volksfest, zu welchem die Umwohner uns zu Gefallen in ihrer alten Schwälmer Tracht erschienen und ihre ortsüblichen Tänze aufführten. Damit verband sich ein Ausflug in meine engere westfälische Heimat, wo bei Bad Driburg eine Ausgrabung vorgenommen wurde.

I896 sah uns in der Pfalz, wo ja prähistorisch und althistorisch vieles Bemerkenswerte zu finden ist. Die alte Kaiserstadt Speier mit ihrem herrlichen Dome, einem Musterstück romanischer Kirchenbaukunst, der uns in künstlicher Beleuchtung vorgeführt wurde, ein Besuch der Limburg und Dürkheims, wo ich die Mitglieder der alten Pfälzer Gesellschaft „Pollichia“, die mich schon während meiner Straßburger Zeit zum Mitgliede gewählt hatte, begrüßte, bot viel des Fesselnden und Erinnerungswerten. In Dürkheim lernte ich auch die Vorzüge des Pfälzer Weines kennen und das kam so: Wir nahmen dort nach dem Besuche der Limburg unser Mittagsmahl ein. Einer der Weingutsbesitzer aus der Gemarkung Deidesheim hatte sich uns angeschlossen und war mit seinem Wagen zur Limburg hinaufgefahren. Ich stand mit einigen mir bekannten jungen Leuten zufällig neben dem Wagen, als sein Besitzer sich anschickte, ihn zur Rückfahrt $\mathrm{zu}$ besteigen. Er forderte uns freundlich auf, mit ihm zu fahren, was wir dankend annahmen. So kam es, da $B$ wir auch bei Tisch zusammenblieben. Ich' bestellte zusammen mit meinen erwähnten jungen Reisegefährten eine Flasche von dem auf der Weinkarte verzeichneten billigen Tischweine, einer Pfälzer Marke, und sagte, da er mir, dem von dem Ausfluge durstig Gewordenen, trefflich mundete, „ist das ein ausgezeichneter Wein! Ich kenne die Pfälzer Weine nicht genug, wenn sie aber so sind, dann alle Achtung." Da wandte sich der Herr, der uns auf seinem Wagen zurückgefahren hatte, an mich und sagte: „,Gefällt Ihnen der Pfälzer so gut? Nun, das freut mich; ich bin Weingutsbesitzer und da erlauben Sie, da $B$ ich Ihnen einmal zeige, was die Pfalz in Weinen leisten kann." Er winkte seinem Diener, der sich in der Nähe befand, und gab ihm einen Auftrag. Der fuhr davon und noch vor Schluß unseres Mahles kam er mit einigen Flaschen Wein zurück, die uns freundlichst kredenzt wurden. In deutschem Rebensafte habe ich, obwohl ich manche Probe gemacht habe, nie etwas Besseres genossen, als diese köstliche Gabe. Der gütige Spender sagte, daß er diesen Wein nicht zum Verkaufe bringe, sondern ihn nur 
für gute Freunde und bei besonderen Gelegenheiten hergebe. Ihm habe der gute Zug, mit dem ich mein erstes Glas geleert und mein offenes Lob, welches ich dem allerdings guten, aber schlichten Tischwein gespendet hätte, so wohl getan, daß er dies für eine der Gelegenheiten erachtet habe, von seinem Besten eine Probe aufzutischen. Nun, die Probe war nicht karg und brachte uns alle in eine so fröhliche Stimmung, da $B$ der freundliche Geber dadurch sich selbst eine angenehme heitere Stunde bereitete, wie wir sie ihm von Herzen wünschten.

Die nächsten beiden Jahre führten uns zum Norden nach Lübeck und Braunschweig, wo, wie in Nürnberg, wahre Schätze deutscher Baukunst in seltener Blüte zu finden sind. Dann kam I899 Lindau am Bodensee, wo wir in überaus angenehmer Weise, Dank herrlichen Wetters, reizvoller Umgebung und freundlicher Aufnahme, tagten. Prinzessin Therese von Bayern, die gelehrte Tochter des Prinzregenten Luitpold, lud uns zu einem sehr angenehm verlaufenden Mittagsmahl in ihre Villa Amsee ein und mit Freund Andrian fuhr ich noch nach Zürich, wo Dr. Jakob Nüesch selbst die im dortigen Museum aufgestellten, von ihm, in der berühmten prähistorischen Siedelung Schweizersbild gehobenen Funde uns zeigte und erklärte. I9oo nahm uns Halle am Saalestrande auf und Igor Metz. Wir besichtigten hier die merkwürdige Briquetage und machten einen Ausflug nach Vic, nahe der französischen Grenze. Dort kamen wir mit den Mitgliedern der französischen Anthropologischen Gesellschaft aus Nancy zusammen, hielten eine gemeinsame Sitzung ab und blieben auch beim Mittagsmahle beieinander, während dessen von beiden Seiten freundliche Trinksprüche gewechselt wurden. Es ist bezeichnend, da $\beta$ eine derartige friedliche Zusammenarbeit damals noch möglich war.

Bemerkenswert ist die Metzer Versammlung auch dadurch, daß es die letzte war, der Rudolf Virchow beiwohnte. Ich bewunderte die Rüstigkeit, mit der unser Altmeister, damals nahe der Vollendung seines 80. Lebensjahres stehend, an allen Ausflügen als Fußwanderer teilnahm; es kam mir vor, als ob Virchow selbst beschwerlichere Strecken, die mir bei empfindlicher Hitze des Augustmonats ermüdend waren, leichter nehme als ich, der I5 Jahre Jüngere. Aber bei unserer nächsten Versammlung in Dortmund, an die sich ein Besuch Leidens und Amsterdams zu gemeinsamer Tagung mit 
den niederländischen Kollegen schloß, sollten wir ihn nicht mehr unter uns sehen. Ich schließe hier eine kurze Schilderung der Todesursache Virchows, seiner letzten Lebenszeit und seines Begräbnisses an und gedenke dabei der übrigen Abgeschiedenen aus meinem Familien-, Freundes- und Bekanntenkreise, die das Jahr I902 in auffallend großer Zahl abforderte.

Im Frühsommer I902 brach Virchow infolge eines Falles den Oberschenkelknochen an der bekannten Stelle, wo ein Knochenbruch so häufig bei älteren Leuten einzutreten pflegt. Während der notwendigen Bettruhe blieb Virchow von weiteren üblen Folgen verschont und der Bruch heilte. Er beschloß zu einer Nachkur nach Teplitz zu gehen; kurz vor seiner Abreise ließ er von der Bruchstelle noch eine Röntgenaufnahme machen und unterzog sich der beschwerlichen Lagerung mit Entschlossenheit und Humor; er wolle wissen, sagte er, ob der Bruch genau von der Art wäre, wie er ihn sich vorgestellt hatte. Wenige Tage vor seiner Abreise besuchte ich ihn. Ich fand ihn vollkommen frisch und wohlgemut. Als ich mich verabschiedete, forderte er mich auf, noch einen Augenblick zu verweilen, er wolle mir zeigen, da $B$ der Bruch gut geheilt sei; damit stand er auf und ging, auf eine Gehbank gestützt, sicheren und verhältnismäßig raschen Schrittes in das anstoßende Zimmer. Ich verließ ihn in der festen Überzeugung, da $B$ wir Virchow im Herbst als völlig Genesenen und Leistungsfähigen wieder unter uns sehen würden.

In Teplitz machte die Wiederherstellung weitere gute Fortschritte. Virchow beschäftigte sich wieder mit wissenschaftlichen Plänen und schrieb auch über solche an die Berliner Anthropologische Gesellschaft. Von Teplitz begab er sich dann im August nach Harzburg, um noch die erfrischende Luft des schönen deutschen Waldgebirges auf sich wirken zu lassen. Auch da ging es anfangs weiter gut. Aber dann stellte sich eine nicht zu überwindende Appetitlosigkeit ein, deren ernste Bedeutung dem großen Pathologen bald klar wurde. Er verlangte nach Berlin zurückgebracht zu werden, um, wie er sagte, in seinem Heim zu sterben. Er hatte richtig vorausgesehen; am 5. September I902 nahm ihn ohne weiteres Leiden ein sanfter Tod hinweg aus dem Kreise der Lebenden.

Rudolf Virchows Bestattung auf dem alten Matthäikirchhofe im Westen Berlins gestaltete sich zu einer nationalen Kundgebung. Der 
Sarg war im Großen Saale des Berliner Rathauses aufgebahrt; aus ganz Deutschland hatten sich Kollegen, Schüler, Freunde und Verehrer Virchows zahlreich eingefunden; ich durfte ihm dort auch ein paar Abschiedsworte widmen. Auf allen Straßen, durch die der Leichenzug sich zum Friedhof bewegte, standen dichtgeschaart, zu beiden Seiten ein dunkles Spalier bildend, in stiller würdiger Haltung die Volksreihen. Man sah es den Männern und Frauen an, da $B$ nicht Neugier, sondern Teilnahme und das Gefühl, ihrem Mitbürger die letzte Ehre erweisen zu sollen, sie hergeführt hatte. -

Ich erwähnte, daß in diesem Jahre der Tod in auffallend großer Zahl seine Opfer aus den mir nahestehenden Kreisen genommen habe. Ich nenne als Verwandten den Vater meines lieben Schwiegersohnes Julius v. Bonin, Generalmajor v. Bonin in Detmold, dann den früheren Staatssekretär für Elsaß-Lothringen und Mitglied der später zu besprechenden Mittwochs-Gesellschaft Herzog und den früheren Kultusminister Gustav v. Goßler, den ich bereits kennen gelernt hatte, als er noch junger Assessor in Königsberg war. Unter der ansehnlichen Zahl von Ministern des Kultus und Unterrichts, die ich seit I865, dem Jahre meiner Ernennung zum Professor extraordinarius, erlebt habe - es sind ihrer I2 - war er meines Erachtens einer der hervorragendsten. Von mir nahestehenden und befreundeten Kollegen starben der Ophthalmologe Richard Förster in Breslau, die Kliniker Karl Gerhardt in Berlin und Karl Ewald Hasse, 92 Jahre alt, in Barsinghausen bei Hannover, wohin er sich von der letzten Stätte seiner Wirksamkeit, Göttingen, zurückgezogen hatte, einer der angesehensten Kliniker und Pathologen seiner Zeit. Ferner mein Freund und Kollege von Königsberg und Straßburg im Elsaß, der Physiologe Friedrich Goltz, mein gleichfalls Straßburger Kollege, der Kliniker Adolf KuBmaul, der Physiologe Leonhard Landois in Greifswald, der mir von Königsberg her gutbekannte Professor der Staatsarzneikunde und gerichtlichen Medizin in Berlin, Karl Skrzeczka und mein ehemaliger Lehrer und Freund, der Anatom Ferdinand Sommer in Greifswald. Von den meisten der hier Genannten ist in diesem Buche bereits die Rede gewesen.

Das Jahr I903 führte die deutschen Anthropologen nach Worms, wo wir unter der trefflich durchgeführten Leitung des dortigen Arztes Dr. Köhl die prähistorischen und althistorischen Schätze des Museums 
Tagungen in Worms, Greifswald, Bornholm, Wisby, Stockholm. 253

in der ehemaligen Pauluskirche studierten und über 30 sehr lehrreiche Ausgrabungen machten, denen der Großherzog von Hessen mit großem Interesse beiwohnte. An einem der Abende hatte uns der Fürst in das jetzt dem Freiherrn Heyl v. Herrnsheim gehörige ehemalige Dalbergsche Schloß, wo er Wohnung genommen hatte, geladen. Ein zweites Mal traf ich mit ihm dort bei einem vom Freiherrn gegebenen Frühstück zusammen. Der junge Fürst zeigte sich als ein in vielen wissenschaftlichen und Tagesfragen gut unterrichteter Mann, mit dem. wir in anregender Unterhaltung mehrere Stunden verkehrten. Sehr angenehm war mir auch das Wiedersehen mit Professor Dr. Lothar Heidenhain, Chirurgen am Wormser Krankenhause, ältestem Sohne meines Freundes in Breslau. Das alte, von der deutschen Heldensage verklärte Worms ist mir auch in treuer Erinnerung durch seinen prachtvollen, in stolzer Kraft, so möchte ich sagen, dastehenden Dom geblieben. Auch wollte es sich in seinen Rebengaben von den benachbarten Pfälzerstädten Deidesheim und Dürkheim nicht ausstechen lassen, sondern bescherte uns die köstliche Liebfrauenmilch, von der man sagt, da $B$ die echte und beste nur auf dem Gelände wachse, das bei sinkender Abendsonne die Liebfrauenkirche mit ihrem Schatten bedecke. Glücklicherweise nimmt es aber Gott Bacchus nicht so genau und läßt seine edle Gabe doch noch auf einer größeren Fläche wachsen.

Eine sehr lehrreiche und wechselvolle Fahrt brachte uns das Jahr 1904 mit der Tagung in Greifswald, Bornholm, Wisby auf Gotland und Stockholm, an die ich mit meinen schon genannten Schwiegersöhnen, dem damaligen Hauptmann v. Bonin und dem Professor chirurgiae Tilmann, damals in Greifswald, und meinem Vetter, Professor der Psychiatrie und Direktor des städtischen Krankenhauses in Königsberg i. Pr., Dr. F. Meschede, eine Rückreise über Norwegen und Kopenhagen anschloß.

Wir begannen in Greifswald mit den wissenschaftlichen Sitzungen, besuchten Stralsund und Rügen, von da Bornholm. Die Fahrt dorthin gestaltete sich bei stark bewegter See für den nicht seefesten Teil der Teilnehmer ungünstig; die See ging so hoch, daß wir an der geplanten Stelle in Rönne nicht anlegen konnten, sondern mit einer Abteilung in Nexö und mit einer zweiten, bei der ich mich befand, in Allinge ausbooten mußten. Am anderen Tage war wieder schönes 
Wetter und wir konnten ungestört die bemerkenswertesten Teile der Insel besuchen. Ich erwähne hier nur Aakirkeby, die trutzig dastehende Ruine Hammerhuus, die interessanten Rundkirchen und die Klippen von Hellingdommen, Almendingen u. a. In Wisby übernahm der wohlbekannte schwedische Reichsantiquar Hildebrand die Führung; die Besichtigung der altberühmten Stadt gestaltete sich zu einem der interessantesten Erlebnisse dieser Reise. Bei prächtigem Wetter durchfuhren wir dann die Schären von Stockholm. In Stockholm besichtigten wir unter Hildebrands und Montelius' Führung die reichen Schätze des Museums, namentlich in der prähistorischen Abteilung und hielten gemeinsame Sitzungen mit den schwedischen Anthropologen ab. Ich machte dabei auch die Bekanntschaft Sven Hedins und des Klinikers Henschen. Montelius war mir bereits von einer früheren Begegnung bekannt.

Auf der erwähnten Rückfahrt über Norwegen besuchten wir die sehr sehenswerten Trollhätta-Fälle und Christiania, dessen wundervolles Stadtbild wir vom Holmenkollen überblickten. Kopenhagen, so oft ich auch dort geweilt hatte, sah ich in der Begleitung meiner Verwandten gern wieder; die dänische Hauptstadt ist mir stets als einer der angenehmsten Plätze erschienen unter den vielen, die ich auf meinen Wanderungen kennen gelernt habe; das Thorwaldsen-Museum ist mir immer wieder neu. Auch in anthropologischer, ethnographischer wie prähistorischer Beziehung bieten die dortigen Sammlungen ungewöhnlich viel Gutes.

Die folgenden Jahresversammlungen in Görlitz, in Straßburg im Elsaß, in Frankfurt am Main, in Köln und Heilbronn gaben uns an jedem Orte die gesuchte Anregung und Belehrung sowie die Gelegenheit, manches von Stadt und Umgebung zu sehen und genauer kennen zu lernen, was den meisten Besuchern $\mathrm{zu}$ entgehen pflegt. Insbesondere ist mir Heilbronn und die schön gelegenen Nachbarstädte, Schwäbisch-Hall und das durch seine Frauen berühmt gewordene Weinsberg in Erinnerung geblieben. Igog nahm ich an der französischen Anthropologen-Versammlung in Paris teil und benutzte diese willkommene Gelegenheit, die reichen Schätze, welche die französische Hauptstadt dem Anthropologen, Ethnologen und Prähistoriker bietet, soweit es die drei Tage meiner Anwesenheit erlaubten, zu besichtigen. 
Tagung in Posen. Vom Ungarwein. Anatomische Gesellschaft. 255

In demselben Jahre tagte auch die Deutsche Antlropologische Gesellschaft und zwar in Posen. Es wird mir schwer, dies im Jahre I9I9 niederzuschreiben. Doch gedenke ich gern dieser Tagung, indem sie mir Gelegenheit bot, Stadt und Land kennen zu lernen, eine ungewöhnliche Anzahl sehr belehrender Vorträge zu hören und - last not least - die Vorzüge eines echten alten Ungarweines kennen zu lernen, den uns der Posener Magistrat zu einem Abendimbiß im schönen Posener Rathause darbot. Ich darf wohl sagen, daß dieser Wein die Krone aller Weine war, die ich genossen habe; seither erscheint mir das Sprichwort: , Nullum vinum nisi hungaricum" voll berechtigt. - An den beiden Jahresversammlungen IgI2 (Weimar) und I9I3 konnte ich leider nicht teilnehmen. Der Weltkrieg hat dann unsere Tagungen bis jetzt unterbrochen.

Diejenigen meiner etwaigen Leser, welche die Geduld hatten, der Beschreibung unserer anthropologischen Wanderfahrten $\mathrm{zu}$ folgen, werden mir wohl zugestehen, daß diese geeignet waren, vor allem unser Vaterland gerade in dem, was es uns lieb und wert macht, in seiner historischen Vergangenheit, in seinen Kunstschätzen und in seinen Siedelungen mit Land und Leuten kennen zu lernen, aber nicht unser deutsches Land allein, sondern auch unsere Nachbarländer. Ich wünsche sehnlichst, daß nach der langen Unterbrechung durch die fünf Kriegsjahre die Deutsche Anthropologische Gesellschaft ihre Wanderfahrten wieder in alter Weise werde aufnehmen können.

Ähnlich wie die.Deutsche Anthropologische Gesellschaft war die Anatomische Gesellschaft eingerichtet, die jedoch, obwohl in Deutschland und zwar in Berlin 1886 gelegentlich der dort tagenden Ärzte- und Naturforscherversammlung gegründet, sich nicht als besondere deutsche Gesellschaft bezeichnen wollte, sondern von vornherein auf den Beitritt der Anatomen der ganzen Erde rechnete. Sie war die erste Gesellschaft dieser Art; bald folgten ihr aber gleiche Gründungen in England, Frankreich, Italien und in den Vereinigten Staaten Nordamerikas nach. Die skandinavischen Anatomen blieben einstweilen bei der in Deutschland gegründeten Gesellschaft, ebenso die niederländischen und deutschschweizerischen. Der französischen Gesellschaft traten die Spanier, Portugiesen und Belgier näher; alle Gesellschaften aber, ohne Ausnahme, hielten Verbindung untereinander. Zweifellos hat bis zur letzten Tagung in Innsbruck I9I4 
die 1886 in $^{\circ}$ Berlin gegründete Gesellschaft einen gewissen Altersvorrang behauptet, ohne ihn jedoch ihrerseits gesucht und betont zu haben. Die beiden Anatomen, welche die Hauptanregung zur Schaffung der Gesellschaft gegeben haben, waren Wilhelm His senior (Leipzig) und Julius Kollmann (Basel), der erstere aus der Schweiz nach Deutschland gekommen, der andere aus Deutschland (Bayern) nach der Schweiz. Als litterarisches Organ der Gesellschaft wurde der "Anatomische Anzeiger" geschaffen, welcher unter der Leitung Karl v. Bardelebens (Jena) zu einem anatomischen Weltblatte geworden ist. Der Anzeiger hat den Weltkrieg glücklich überstanden und wird heute, nach dem im Jahre IgI8 erfolgten Tode v. Bardelebens, von Professor v. Eggeling (Jena) herausgegeben. Die jährlichen Versammlungen mußten jedoch aufgegeben werden; die letzte fand wenige Monate vor Ausbruch des Krieges in Innsbruck statt. Bis dahin waren regelmäßige Jahresversammlungen abgehalten worden mit stets bestem Erfolge bezüglich des durch Vorträge, Besprechungen und Demonstration Gebotenen. Selbstverständlich mußten die Tagungen in Städten mit anatomischen Anstalten, also in Universitätsstädten, stattfinden. Von Zeit zu Zeit tagte die Anatomische Gesellschaft aber auch bei unseren Nachbarn, in Brüssel, in Pavia und in Genf; außerdem wurden unsere Mitglieder auch Mitglieder der sonstigen anatomischen Gesellschaften; so war ich Mitglied der italienischen, französischen und englischen Gesellschaften und habe auch mehrere Versammlungen dieser Vereine besucht. Außer der steten Anregung und Erfrischung, die unser Wissen auf diesen Kongressen empfing, waren besonders angenehm die zahlreichen persönlichen Bekanntschaften, die man mit den Fachgenossen anknüpfen und auch öfter erneuern konnte. Da ich wohl einer der regelmäßigsten Besucher der Versammlungen war und auch, wie bemerkt, an denen des Auslandes öfters teilnahm, so gab es nur wenige Fachgenossen, die ich nicht persönlich kannte. Auf die Erlebnisse bei den Fahrten zu den einzelnen Versammlungen näher einzugehen, ist hier nicht der Ort; es liegt da mehr ein rein fachmännisches Interesse vor. Es sei nur erwähnt, da $B$ mir die Versammlung in Pavia den Genuß $B$ bot, die Certosa kennen zu lernen. Besonders hebe ich hervor, $\mathrm{da} B$ der internationale Verkehr sich stets in völlig zwangloser Weise vollzog, sowohl bei den Tagungen, denen ich in Deutschland bei- 
wohnte, wie bei denen in Frankreich - dort war ich in Nancy, später noch in Montpellier, Toulouse und Bordeaux. Bei der Tagung in Berlin führte A. Nicolas (Paris) den Vorsitz, wie er denn auch noch mit seiner Gemahlin, die ich damals die Ehre hatte zu Tisch zu führen, I9I4 an der Versammlung in Innsbruck teilnahm. Ich kann zu meiner Freude hier noch berichten, daß während des Druckes dieser Zeilen die Tagungen der Anatomischen Gesellschaft wieder aufgenommen worden sind. Vom 23.-25. April d. J. fand in Jena, wohin uns Kollege Maurer freundlichst eingeladen hatte, die erste Versammlung nach dem Weltkriege mit bestem Erfolge statt. Wir hatten uns dabei des Besuches mehrerer Kollegen aus Schweden und Finland zu erfreuen.

Einer der treuesten Besucher der Versammlungen der Anatomischen Gesellschaft war mein schon öfter erwähnter lieber Freund Romiti. Mit großem Genuß lauschten wir stets seinen Worten, wenn er in seiner schönen und melodischen Muttersprache, die er inhaltlich wie lautlich meisterhaft beherrschte, an unserer gemeinsamen Tafel die Haupttischrede hielt. Wir waren nicht eher zufrieden, als bis Romiti das Wort genommen hatte.

Unter den anatomischen Versammlungen im Auslande erwähne ich außer der in Pavia abgehaltenen noch derer in Nancy, Montpellier und Toulouse-Bordeaux, ferner der Brüsseler und Genfer Versammlung. Sie alle verliefen in bester Weise und boten viel des Wissenswerten und manche Gelegenheit zu erwünschten persönlichen Bekanntschaften. In Montpellier fesselte mich Armand Sabatier, auch traf ich wieder mit dem berühmten spanischen Anatomen S. Ramón y Cajál zusammen. In Toulouse lernte ich Adrien Charpy kennen, ferner den Lyoner Histologen Renaut, zu dem ich mich besonders hingezogen fühlte, während es sich nicht fügen wollte, da $\beta$ ich seinen Kollegen Léon Testut, mit dem ich schon lange in brieflichem und Schriftenaustauschverkehr stand, persönlich kennen lernte. In Nancy traf ich außer Nicolas und Prenant von jüngeren Kollegen die Herren Ancel und Bouin.

In Bordeaux wurden wir auch von der Municipalität als willkommene Gäste angesehen. Im Stadtheater wurde uns zu Ehren R. Wagners Lohengrin aufgeführt und an einem zweiten Abend waren wir $\mathrm{zu}$ einem Essen geladen. Beides in seiner Art war ausgezeichnet: Wagners 
Oper wurde sehr gut gegeben und Speis' und Trank beim Festmahle ließen nichts zu wünschen übrig. Die Stadt Bordeaux zeigte, da B der: nach ihr benannte Wein mit Recht einen Weltruf hat; wir konnten et wa sechs Jahrgänge in verschiedenen „Chateaux" prüfen, den folgenden immer noch besser als den vorhergehenden, bis ein "Grand Cru" erster Klasse den Schluß machte. Das Beste bei der Sache aber war, daß uns allen die edle Gabe nicht nur gut mundete, sondern auch gut bekam.

Außer an den Spezialkongressen der Anthropologischen und Anatomischen Gesellschaft, von denen ich kaum einen versäumte, nahm ich auch an vielen der größeren Versammlungen der alljährlich tagenden Deutschen Ärzte- und Naturforscherversammlung und an den alle 3 bis 4 Jahre stattfindenden Internationalen Medizinerkongressen teil, mehrfach als Delegierter des Deutschen Reiches, wodurch mir zwar manche Arbeit erwuchs, aber auch manche Annehmlichkeiten geboten wurden. Von den internationalen Kongressen nenne ich die Versammlungen.in Moskau, in Kopenhagen, in Madrid, in Lissabon, in Budapest, in Paris, von der schon die Rede war, in Rom, in Berlin und in London. Ich beschränke mich auf einige Einzelheiten: Der Kongre B in Moskau gab mir Gelegenheit, der Einladung meines Freundes Rein folgend, ihn auf seinem Gute Gulewtzi unweit Kiew zu besuchen und dabei das schöne, am Dniepr gelegene Kiew kennen zu lernen, sowie ein Stück Landlebens in Südrußland. Ich begab mich von da nach Odessa, weiter über das Schwarze Meer nach Konstanza, und kehrte über Bukarest, Budapest und Wien heim. Dabei machte ich die Erfahrung, da B man damals leichter in RuBland hinein- als herauskam. Ich reiste über Thorn und Alexandrowo ein. Es war angeordnet worden, da $B$ man die Kongreßteilnehmer möglichst wenig mit Grenzmaßnahmen behelligen solle. Als wir an der Grenzwacht ankamen, unsere Pässe vorzeigten und unser Gepäck herbeibrachten, hie $B$ es seitens der Zollbeamten, indem sie öfters mit der Hand auf das Gepäck schlugen: „Kongre $B$ ! Kongre $B$ !“ und man lie $B$ uns sofort durch. So wurde Mann und Gepäck schnell befördert. Anders erging es mir bei der Einschiffung in Odessa. Ich hatte mich in meinem Gasthofe rechtzeitig gemeldet und dem Pförtner meinen $\mathrm{Pa} B$ übergeben zur Unterschrift durch den Polizeipräsidenten. Unser Schiff sollte am späten Nachmittag abfahren. Als ich am Morgen vom Pförtner meinen $\mathrm{Pa} B$ einforderte, stellte es sich heraus, da $B$ er ver- 
gessen hatte, die Unterschrift einzuholen. Es war gerade irgendein größerer russischer Feiertag, an dem Empfang bei dem höchsten Beamten stattfand. Mein Pförtner gestand mir unter vielen Entschuldigungen, $d a B$ des hohen Feiertages wegen der Polizeipräsident nicht verpflichtet sei, seine Unterschrift zu geben. Nun war guter Rat teuer. Ich begab mich zum deutschen Konsul, um dessen Ansicht zu hören. Er gab mir einen seiner Unterbeamten mit, von dem er sagte, da $B$ dieser auf dem Polizeipräsidium gut bekannt sei, vielleicht gelinge es ihm, den Präsidenten noch zur Unterschrift zu veranlassen. Wir gingen zur Polizei und mein Begleiter machte mich darauf aufmerksam, da $B$ ich 5 Rubel in meiner Tasche etwas lockern müsse. Er stellte mich einem der anwesenden Polizeibeamten vor unter Darlegung der Sachlage, meine Rubel glitten unbeachtet in die Hände des Russen und dieser sagte, er wolle dem Präsidenten, der nach dem Empfange noch in sein Amt kommen werde, meinen $\mathrm{Pa} B$ zur Unterschrift vorlegen. Er hoffe, da $B$ er noch unterzeichnen werde, wenn er guter Stimmung sei, versprechen könne er es jedoch nicht. Mit diesem Troste ging ich mit meinem Begleiter in ein benachbartes Weinhaus, wo wir uns mit einem guten Frühstück und einer Flasche Wein aus der Krim die Zeit vertrieben. Wir konnten von da aus sehen, wann der Präsident kam, gingen dann zum Präsidialgebäude, wo uns schon unser russischer Freund mit dem unterschriebenen Passe entgegenkam. Der Präsident, sagte er, sei sehr guter Laune gewesen. Das alles lockerte noch einen Rubel in meiner Tasche.

Soweit war alles noch gut gegangen. Ich begab mich auf den Dampfer und wartete der Abfahrt. Eine Stunde vorher erschienen nun die Polizeibeamten zur Durchsicht der Pässe; das nahm beinahe eine halbe Stunde in Anspruch. Als sie sich entfernt hatten, sollten die Anker gelichtet werden. Aber kaum hatte man damit begonnen, so erschienen die Beamten wieder; es hie $B$, man habe eine Revision versäumt, oder was es nun für ein Grund oder Vorwand war, kurz, die ganze Pässedurchsicht ging noch einmal los und wir konnten erst mit einer halben Stunde Verspätung abfahren. - Ich schimpfte damals weidlich in mich hinein über alle diese Umständlichkeiten, mußte aber die Erfahrung machen, da $B$ im Jahre I9I9, als ich zu einer Badekur von Berlin nach dem von den Franzosen besetzten Bade Ems mich begeben wollte, ebenso IgI6 und IgI7 nach Bad Gastein im Lande 
unseres Verbündeten Österreich-Ungarn, die formellen Schwierigkeiten zur Ein- und Ausreise ebenso groß waren. Wann wird sich die Welt einmal von diesem Kram befreien! In Konstanza interessierte mich die Statue, die man dort dem alten Ovidius Naso zu Ehren errichtet hat und später die Fahrt über die große Brücke und durch die Dobrudscha mit ihrer mannigfaltigen Tier- und Pflanzenwelt; auch die Fahrt durch die Karpathen bot manches eindrucksvolle Bild.

In Rom wurden wir vom Könige Umberto I., den bald darauf der Mordstahl traf, empfangen. Ähnlich war es in Lissabon, wo wir auch vom Könige empfangen wurden, der bald darauf der Revolution zum Opfer fiel. Nimmt man das tragische Ende des Zaren Alexander II., des Königs Alexander von Serbien und seiner Gemahlin Draga, sowie die Ermordung des Präsidenten Carnot von Frankreich und der Präsidenten Lincoln, Garfield und Mac Kinley von Nordamerika, welche Übeltaten zum Teil nicht weit voneinander liegen, so sieht man, daß, je höher die Spitze ist, sie desto eher zum Ziel genommen wird und daß die Republiken in dieser Beziehung sich von den Monarchien kaum unterscheiden.

Aus Madrid habe ich mir eine angenehme Erinnerung an unseren damaligen Botschafter, Herrn von Radowitz, bewahrt. Er hatte die deutschen Kongreßteilnehmer zur Abendtafel geladen und ließ dazu ein Glas Ioojährigen Portweins reichen, ein edler Trank! Ich bemerkte dies leise zu meinem Tischnachbar; aber der Botschafter, der uns schräg gegenüber saß, hatte es doch gehört und nickte mir mit erhobenem Glase freundlich zu. Am anderen Morgen erschien sein Diener und überbrachte mir mit dem Wunsche des Botschafters „Wohl bekomm's" eine Flasche des köstlichen Weines. - Unvergeßlich ist mir die Erinnerung an die unvergleichlichen Kunstschätze der Madrider Gemäldesammlung im Prado, deren Glanzpunkte Murillo und Velasquez sind; namentlich der Letztere erscheint mir als einer der größten Maler aller Zeiten. Übrigens findet sich dort auch von Goya manches Wackere. In Spanien besuchte ich ferner Burgos, Sevilla, Cadiz und Granada, sowie auf der Rückfahrt Zaragoza und San Sebastian.

Die Gasthöfe und die Verkehrsmittel ließen derzeit in Spanien noch vieles $\mathrm{zu}$ wünschen übrig, namentlich in bezug auf gewisse Örtlichkeiten, die als Gegenstücke zu den Speisewagen zu bezeichnen sind. 
Soll der körperliche Haushalt des Menschen in Ordnung bleiben, so müssen Einnahmen und Ausgaben in ein von der Natur vorgesehenes und eingerichtetes Gleichgewicht gebracht werden, wobei man viel leichter mit den Einnahmen einmal im Rückstande bleiben kann als mit den Ausgaben. Man kann also leichter den Speisewagen in einem Zuge entbehren, als die Ausgaberäume. Diese aber waren damals in Spanien nirgends in den Zügen vorgesehen und die Ersatzräume auf den Halteplätzen waren meist in einem entsetzlichen Zustande, so da $B$ man erschreckt zurückfuhr, wenn man es gewagt hatte, die Tür zu öffnen. Aber die Eingeborenen wußten Rat. Als ich von Cadiz nach Granada fuhr, kam ich in einem Abteil mit einer spanischen Familie zusammen: Vater, Mutter und drei Kinder. Die Mutter hatte sorglich eine Flasche Wasser sowie ein gewisses Geschirr mit, welches als ein wahrhaft internationales Objekt $\mathrm{zu}$ bezeichnen ist, da es, soweit meine nicht geringe Erfahrung reicht, in allen Ländern dieselbe charakteristische Form besitzt. Mit Hilfe dieses Geschirres konnte denn auch den Kindern die nötige Erleichterung geboten werden, wovon sie öfters Gebrauch machten. Die Flasche Wasser und die Möglichkeit, die Fenster zu öffnen, erwiesen sich dabei als höchst nützlich. Ich dachte an meinen bereits bei der Schilderung des westfälischen Landlebens zitierten Spruch: „naturalia non sunt turpia“ und belästigte meine Reisegesellschaft nicht durch übel angebrachte Neugier, sondern wendete, sobald ich die Vorbereitungen merkte, meine völlige Aufmerksamkeit der zu durchfahrenden Gegend zu. Ein Glück nur, da $B$ wir Erwachsenen unsere Ausgaben vorher in Ordnung gebracht hatten.

Eine ähnliche Erfahrung machte ich in Madrid. Mir, wie vielen anderen der Teilnehmer am KongreB, war auf meinen Wunsch von einer dazu bestimmten Kommission eine Wohnung besorgt worden; wir nahmen in derselben Wohnung auch unsere Mahlzeiten ein. Da war nun die anscheinend sehr praktische Einrichtung getroffen, da $B$ Einnahme- und Ausgaberaum dicht zusammenlagen und man nur vom Speisezimmer aus in den Ausgaberaum gelangen konnte. Es ließ sich auch nicht immer vermeiden, daß, während wir unsere Mahlzeiten einnahmen, Andere den Ausgaberaum benutzten. Mein Zimmerchen lag drei Treppen höher im Hause und dort befand sich in dessen Nähe glücklicherweise noch ein besonderer kleiner Ausgabe- 
raum. Als ich ihn vorsichtigerweise sofort nach Besitzergreifung meines Zimmers mir ansah, schreckte ich über den Zustand, in welchem er sich befand, zurück. Ich ließ die diensttuende Sennora kommen und machte ihr unter Demonstrationen am Objekte in meinem besten Spanisch klar, daß die sonst so wohltätige Anstalt in ihrer jetzigen Verfassung unbenutzbar sei, was ihr auch einleuchtete. Nach einiger Zeit rief sie mich aus meinem Zimmer und zeigte mir mit Stolz, daß sie einen gewissen Rand reichlich mit Zeitungen drapiert hatte, das sei doch nun wunderschön. Sie war sehr enttäuscht, als ich ihr nun klar machte, daß dies nicht genüge. Endlich einigten wir uns und ich durfte mit ihrer Sorge für mein Wohl zufrieden sein.

Für die Kongreßmitglieder wurde auch ein großes Stiergefecht veranstaltet, an welchem ich als Delegierter von einem bevorzugten Platze aus hätte teilnehmen können. Ich vermochte mich jedoch nicht dazu zu entschließen, denn die Tötung eines Tieres, nur um den Menschen ein aufregendes Schauspiel zu verschaffen, vermag ich nicht zu billigen. Schon genug, daß wir die Tiere töten müssen, um uns die nötige Nahrung zu verschaffen und uns und unsere Habe zu schützen; weiter jedoch sollte man nicht gehen.

Noch eines Vorkommnisses möchte ich Erwähnung tun, um zu zeigen, da $\beta$ damals die Organisation des Kongresses manches zu wünschen übrig ließ. Bei unserer Ankunft mußten wir für unsere Wohnung und Verpflegung und allgemeine Kongreßunkosten gleich den Betrag von 200 Francs hinterlegen; falls wir früher abreisten, würde uns, so war uns mitgeteilt worden, ein bestimmter Betrag für die Tage, die wir nicht mehr am Kongresse teilnahmen, zurückgezahlt werden. Ich mußte zwei Tage früher abreisen und hätte etwa 40 Francs zurückerhalten müssen. Ich meldete mich auf dem betreffenden Büro, da hieß es, es sei heute geschlossen; ich mußte aber am Abend des „Heute“ abreisen und hatte das Nachsehen. So wie mir ging es Manchem. Klar war doch, daß ein derartiges Büro für die Dauer der betreffenden Veranstaltung stets zugängig sein muß. Auf dem einige Jahre später in Lissabon stattfindenden Internationalen Kongresse herrschte eine weit bessere Ordnung. Vielleicht hatte man in Madrid gelernt. Soweit mir berichtet worden ist, sind jetzt auch die Zustände in den Gasthöfen und auf den Verkehrswegen in Spanien durchweg weit bessere geworden. 
Es hat auch bei uns in Deutschland längere Zeit gedauert, bis man sich darüber klar geworden ist, da $B$ man den Ausgaberäumen dieselbe. Sorgfalt in bezug auf Reinlichkeit und Einrichtung zu widmen hat, wie den Einnahmeräumen. England ist uns hier mit gutem Beispiele. voraufgegangen, obwohl man selbst in den großen Städten London, Edinburg und Dublin - ich habe reichliche Erfahrungen darüber sobald man sich von den großen Hauptstraßen entfernt, einer Unsauberkeit begegnet, wie sie in Deutschland nirgends besteht. In Irland konnte man in den Jahren, in denen ich es bereiste, Zustände finden, die man nicht für möglich halten sollte; die vielgerühmte englische Reinlichkeit bestand wenigstens in der Zeit, als ich Großbritannien wiederholt besuchte, nur bei den Familien der wohlhabenderen und gebildeteren Klassen, während man in Deutschland auch bei den unbemittelten und einfacher gebildeten Leuten fast durchweg einem wohltuenden Sinn für Sauberkeit und häuslichen Schmuck, soweit es die Mittel erlauben, begegnet.

Mit der Einrichtung der Ausgaberäume in unseren Eisenbahnzügen bin ich auch jetzt noch nicht völlig zufrieden. Abgesehen davon, daß sie während des Krieges arg verwahrlost sind, sind sie meist zu eng. Man hat Mühe, wenn man sie verlassen will, $z u$ verhüten, da $B$ man mit seinen Kleidungsstücken die darin befindlichen notwendigen Vorrichtungen berührt. Die Räume ließen sich leicht so weit vergrößern, da $B$ dies vermieden werden könnte. Ich wiederhole, da $B$ eine besondere Sorge für diesen Teil der menschlichen Lebensnotwendigkeiten zu den dringendsten Aufgaben der öffentlichen Gesundheitspflege gehört; er scheint mir leider immer noch nicht genug beachtet zu werden.

Wozu ich das in meinen Lebenserinnerungen niederschreibe? Ich wünschte ein getreues Bild der Zeit, in der ich lebte, zu geben und in dessen Rahmen gehört auch, in einer Ecke wenigstens, das Besprochene.

Eine eingehendere Schilderung möchte ich dem X. großen Internationalen Medizinerkongreß widmen, der im Jahre I89o in Berlin stattfand, da ich dabei an leitender Stelle vielfach beteiligt war. Der vorhergehende Kongre $B$ dieser Art hatte I887 in Washington getagt; man hatte dort für die nächste Versammlung Berlin gewählt und auf Vorschlag des damaligen Berliner Privatdozenten, späteren Ordinarius für Gynäkologie in Greifswald, A. Martin, der der Tagung in 
Washington beigewohnt hatte, Rudolf Virchow, v. Bergmann und mich als diejenigen bezeichnet, welche die Vorarbeiten für den Berliner Kongre $\mathrm{I} 890$ in die Hand nehmen möchten. Wir nahmen den Auftrag an. Virchow hatte den guten Gedanken, uns dies Mandat durch die I888 in Heidelberg tagende Deutsche Ärzte- und Naturforscherversammlung bestätigen zu lassen. Wir sendeten eine Einladung zur Beschickung der genannten Versammlung durch Delegierte, die die Wahl der Kongreßleiter für Berlin vornehmen sollten, an die ärztlichen Vereine, größeren Krankenhäuser, militärärztlichen Stellen und medizinischen Fakultäten Deutschlands. In Heidelberg fand dann I888 auch die Wahl statt. Wir drei in Washington Vorgeschlagenen wurden bestätigt und außerdem der innere Kliniker Berlins, v. Leyden, hinzugewählt. Da schon drei Universitätsprofessoren den leitenden Ausschuß bildeten, so schien mir die Wahl eines vierten nicht als eine richtige. v. Leyden erhielt auch nur eine Stimme Mehrheit über seinen Gegenkandidaten, den Praktiker Dr. Graf, Vorsitzenden des Deutschen Ärztevereins-Bundes, dessen Wahl vorzuziehen gewesen wäre. Die praktischen Ärzte, die nun keine Vertretung im Vorstande hatten, waren großenteils mit dem Ausfall der Wahl, obwohl v. Leyden in ihren Kreisen das höchste Ansehen genoB, nicht zufrieden und das, wie ich sagen muB, mit Recht.

Im November I888 begannen wir im Vorstande regelmäßig zu arbeiten. Die Kollegen Dr. Max Bartels, Dr. Pistor und Dr. A. Martin, die wir als außerordentliche Mitglieder uns angegliedert hatten, halfen uns getreulich, ebenso Kollege Dr. Lassar, der das Amt eines Generalsekretärs übernommen hatte. Virchow war unser erklärtes Haupt, er entfaltete, trotz seiner zum biblischen Alter neigenden Jahre, eine seltene Frische und Rüstigkeit; alles ging durch seine Hand, er dachte an alles, sorgte für alles und war stets zur Stelle. Unsere Sitzungen fanden in den Büroräumen des Generalsekretärs statt, meist Freitags am Abend von 8-II Uhr, in der letzten Zeit zogen sie sich öfters bis I2 Uhr, ja bis I Uhr hin. Kollege Bartels waltete seines Amtes als Schatzmeister des Kongresses in musterhafter Weise. Für gewisse technische Fragen, betreffend die Versammlungsräume, die Bereitstellung von Erfrischungen bei den Sitzungen, das Festmahl und ein geplantes Gartenfest hat uns der sehr tüchtige und gewandte Wirt der Ausstellungshalle am Lehrter 
Bahnhof, Herr Zweig, die besten Dienste geleistet. Schwierig war die Beschaffung von geeigneten Räumlichkeiten für die Sitzungen des großen Kongresses. Wenn man die bei ihm eingerichteten verschiedenen Sektionen hätte getrennt tagen lassen wollen, so wären mit Leichtigkeit hinreichend gute Räume zu beschaffen gewesen; aber es schien doch besonders wünschenswert, daß alle Sitzungen in möglichst nahe zusammengelegenen Räumen stattfänden und daß man auch Erfrischungsräume in der Nähe zu Gebote hätte. Da einigten wir uns denn auf meinen undLa ssar s Vorschlag auf die ebengenannte GemäldeAusstellungshalle am Lehrter Bahnhof, mit der Restaurationsräume und eine große parkartige Anlage verbunden waren. In den zahlreichen getrennten Räumen der Halle sollte zwar zur Zeit des Kongresses die große Berliner Kunstausstellung stattfinden, aber die Bedenken, daß wir dann mit den Gemälden dort zusammen tagten, wurden durch meinen, vom damaligen Kultusminister v. Goßler unterstützten Vorschlag, uns für die Zeit vom 4. bis ro. August von früh $8 \mathrm{Uhr}$ bis abends 6 Uhr die Räume zu überlassen, während von da ab in den Abendstunden das Publikum wieder Eintritt haben sollte, überwunden. v. Goßler übernahm es, den Präsidenten der Akademie der Künste, Herrn Becker, für die Sache zu gewinnen, während er Virchow und mir die Verhandlungen mit dem Maler Anton v. Werner, dem Vorsitzenden der Ausstellungskommission, übertrug. Anton v. Werner war mir, da ich mit ihm 3 Jahre in demselben Hause gewohnt hatte, persönlich gut bekannt geworden; er kam meinen Wünschen in zuvorkommendster Weise entgegen. Die Ausstellungskommission gab nun ihre Zustimmung und es verlief alles gut. Nur einen Übelstand mußten wir in den Kauf nehmen: die Störung durch die Züge der Stadtbahn, die in rascher Folge in der Nähe des Ausstellungsparkes verkehrten und von Manchem unangenehm empfunden wurden; aber die Vorteile, welche andererseits durch die Verlegung aller Sektionen auf einen großen, bequem zu erreichenden Platz geboten wurden, überwogen doch, meines Erachtens, bei weitem die erwähnte Unzuträglichkeit.

Für alle erforderlichen Einrichtungen hatten wir den Regierungsbaumeister Jaffé gewonnen, dessen in angenehmster Art geübte unermüdliche Tätigkeit und Umsicht ich sehr schätzen lernte. - Auf meinen Vorschlag wurden schließlich noch die Herren v. Coler, Generalstabsarzt der Armee, Dr. Graf, Vorsitzender des Deutschen 
Årztevereins-Bundes und Professor Adolf v. Bardeleben, zeitiger Dekan der Berliner medizinischen Fakultät, in unseren leitenden Ausschuß aufgenommen, was allgemein mit Befriedigung begrüßt: wurde.

Wissenschaftlich bot die Versammlung viel des Besten und Anregenden; indem ich mich auf mein Fach beschränke, erwähne ich nur den ausgezeichneten Vortrag Sir William Turners über die vergleichende Anatomie des Gehirns.

Virch ow regte an, daß wir, die leitenden Mitglieder des Ausschusses, den beteiligten Mitgliedern der deutschen Behörden, den Delegierten der fremden Staaten und den Herren, welche die allgemeinen Vorträge übernommen hatten, ein Ehrenmahl geben sollten; wir stimmten gern zu und ich übernahm die Sorge für diese Veranstaltung, die im Kaiserhof zu Berlin stattfand und gut verlief. Das Mahl fand gleich zu Anfang des Kongresses statt und sollte wesentlich dazu dienen, die genannten Persönlichkeiten mit dem Organisationsausschusse der Versammlung bekannt zu machen. Virchow hatte den Herzog Karl Theodor in Bayern und den amerikanischen Botschafter, Herrn Phelps, zu Tischnachbarn, v. Bergmann die Minister v. Bötticher und v. Goßler, neben Herrn v. Bötticher hatte der französische Botschafter Herbette seinen Platz, meine Nachbarn waren der Anatom v. Kölliker und der Pariser Physiologe Richet, von dem noch die Rede sein wird. Unsere Mitglieder v. Bergmann und v. Leyden brachten Trinksprüche in deutscher Sprache aus, Virchow in französischer, ich in englischer. Mir scheint es nicht ohne ein gewisses Interesse zu sein, diese Dinge hier zu erzählen: sie geben ein Bild des internationalen Verkehrs, wie er vor 30 Jahren war; wann werden wir ihn wieder haben? So schwer es uns werden mag, mit unseren gegenwärtigen Feinden die Beziehungen, wie sie damals bestanden, wieder aufzunehmen, diese Schwierigkeiten müssen überwunden werden. Die wissenschaftliche Isolierung geht nicht an, das werden unsere jetzigen Gegner ebenso empfinden wie wir.

Eine Hauptarbeit, die mir der Kongreß brachte, war die Übernahme eines großen Teiles der Druckkorrekturen. Wir hatten zwar Übersetzer für Deutsch-Französisch und Deutsch-Englisch gewonnen, aber diese erwiesen sich bezüglich der medizinischen Ausdrücke als ihrer Aufgabe nicht gewachsen und es kamen die merkwürdigsten, 
oft sehr komisch wirkenden Dinge heraus; ich hatte viele Mühe, sie zurechtzurücken, wage aber nicht zu behaupten, da B es mir überall gelungen sei.

Bedauerlich war der nervöse Zusammenbruch unseres bisher so tätigen Generalsekretärs Lassar. In der Schlußsitzung am 9. August erbat er sich das Wort und erklärte zum allgemeinen Erstaunen, daß der Kultusminister die Verlängerung der mit dem Kongresse verbundenen Ausstellung bis zum $3 \mathrm{r}$. August genehmigt habe und da $\beta$ in Berlin ein Internationales Trachten-Museum begründet werden solle. Uns, im Organisationsausschusse, war von beiden Sachen nichts bekannt. Wir hielten gleich nach Schluß der Versammlung eine Sitzung ab, zu der jedoch Lassar, obwohl er besonders eingeladen war, nicht erschien. Am Abend desselben Tages reiste er, vieles ungeordnet zurücklassend, nach Amerika $a b$, von wo er erst nach längerer Zeit, glücklicherweise vollkommen hergestellt, zurückkehrte. Es gelang, mit Hilfe Dr. Posners, damaligen Assistenten Lassars, und des Geheimen Rechnungsrates Kleinschmidt die Ordnung der Dinge herzustellen, wobei auch Virchow und v. Bergmann manche Sorge zufiel, denn v. Leyden war alsbald nach SchluB des Kongresses nach der Schweiz abgereist und ich mußte am Tage nach Schluß mich zur Anthropologen-Versammlung nach Münster begeben, wo ich im Vorstande tätig zu sein und einen Vortrag zu halten hatte. Ich erwähne hier gern, daß der jetzige Geheime Medizinalrat Professor Dr. Posner in Angelegenheiten internationaler und anderer ärztlicher Kongresse und Veranstaltungen sich bald als einer unserer besten Organisatoren erwies, wie auch im Auslande anerkannt wurde. So unter anderem beim Internationalen medizinischen Kongresse in Rom, bei dem ich gleichfalls zugegen war. Als der Kongre $B$ begann, zeigte es sich, da $B$ das italienische Geschäftsbüro nicht genügend vorbereitet war; man wendete sich an Professor Posner, der die dortigen deutschen geschäftlichen Kongreßangelegenheiten besorgte, und binnen kurzem war auch der geschäftliche Apparat des Gesamtkongresses in Ordnung gebracht.

Das Jahr I89o war für mich in bezug auf Vereinstätigkeiten und Reisen eines der ereignisreichsten. Ende des März und Anfang April reiste ich mit meiner älteren Tochter Hedwig und meiner Nichte Gertrud Dillenburger nach Paris und von da über Dijon und Pontarlier nach Genf zum Besuch meiner jüngeren Tochter Ilse, die sich 
dort in Pension befand. Ich wollte den beiden jungen Mädchen die Sehenswürdigkeiten von Paris und seiner Umgebung, insbesondere auch von Versailles, zeigen. Auch wohnten wir mehreren Vorstellungen in der Großen Oper und in der Comédie française bei. Die Reise war vom besten Wetter begünstigt und verlief in allen ihren Teilen höchst erfreulich. Es sei in Hinsicht auf den Stand unserer Valuta von heute und vor 30 Jahren eines Zwischenfalles erwähnt. Ich hatte verabsäumt, mir in Paris hinreichend französisches Geld einzuwechseln; in Dijon fuhren wir spät am Abend $a b$ und als ich kurz vorher im Gasthofe meine Rechnung begleichen wollte, mußte ich einen preußischen Hundertmarkschein zur Zahlung vorlegen. Dem Kellner war ein solcher Schein unbekannt, die Banken bereits geschlossen. Was tun? Da meinte der Kellner, in der Nähe des Gasthofes wohne ein Uhrmacher, der sei in Deutschland gewesen, der werde den Schein wohl kennen. Dem Manne wurde der Schein vorgelegt und er erklärte zu meiner nicht geringen Befriedigung, solche Scheine seien die sichersten der Welt, sie seien so gut wie Gold. Das half.

Im August folgte dann der Internationale Medizinerkongre $B$ in Berlin und unmittelbar anschließend die Jahresversammlung der deutschen Anthropologen in Münster, von welchen beiden Veranstaltungen ich bereits berichtete. Von Münster nach Berlin zurückgekehrt, nahm ich noch an einer nachträglichen Geschäftssitzung des Medizinerkongresses teil und trat dann am I8. August mit meiner Frau und meinen beiden Töchtern eine längere Reise durch ÖsterreichUngarn, Italien, Tunis und Frankreich an, von der wir erstam 28. Oktober nach Berlin zurückkehrten. Ich werde hiervon noch mehreres berichten.

Der letzte Internationale Medizinerkongre $B$, dem ich, gleichfalls als Delegierter der deutschen Reichsregierung, beiwohnte, fand I9r3 in London statt. Inzwischen war ein Internationales Komitee für medizinische Fortbildung begründet worden, zu dessen Vorsitzenden man mich gewählt hatte; wir hatten in London mehrere Sitzungen abzuhalten. Auch nahm ich regelmäßig an den Sitzungen der Anatomischen Sektion teil. Ferner wurde ich zum Vorsitzenden des Permanenten Komitees für die Internationalen medizinischen Kongresse ernannt und hatte als solcher in der Albert Hall eine Ansprache zu halten, die ich französisch eröffnete, englisch fortsetzte und deutsch schloß. Von Sir Thomas Barlow, innerem Kliniker in London, dem Vorsitzenden 
des Londoner Kongreßkomitees, wurde ich sehr freundlich empfangen. Wir hatten eine längere Unterredung über Friedrich den Großen und als ich dabei erwähnte, da $B$ ich mich mit den Bildnissen dieses Fürsten beschäftigt habe, verabredete Sir Thomas mit mir eine Besichtigung eines Bildes Friedrichs des Großen, welches sich im Londoner Athenäum-Klub befindet. Er holte mich mit seinem Wagen vom Hotel $\mathrm{ab}$ und wir besichtigten zusammen sehr eingehend das Porträt, welches mir als das beste Bild des Königs erschien von allen, die ich gesehen hatte. Später war ich noch zum Dinner bei Barlow geladen und hatte dort meinen Platz zwischen dem damaligen Staatssekretär des Innern Sir McKenna und dem Dean of St. Pauls, einem der höchsten Würdenträger der Englischen Kirche. Nach dem Essen fuhr ich zum Empfang beim deutschen Botschafter, Fürsten Lichnowsky. Ich komme auf unseren damaligen Vertreter in London gelegentlich der Darstellung meiner Erlebnisse im Preußischen Herrenhause zurück. Außer Sir Barlow nahm sich Professor Lauder Brunton meiner besonders freundlich an. Ich war bei ihm einmal $\mathrm{zu}$ einer größeren Festlichkeit im British Empire Club geladen, wo ich meinen Tischplatz zwischen Lady Barlow und Frau Professor Ehrlich, Gattin meines ehemaligen Schülers, späteren Kollegen in Frankfurt am Main, hatte. Das zweite Mal nahm ich Teil an einer kleineren Gesellschaft in seinem Hause, wo ich die Ehre und die Freude hatte, seine liebenswürdige Tochter Mrs. Henry zu Tisch zu führen. Mrs. Henry erwies sich als eine Freundin Irlands; sie sprach sich offen gegen manches aus, was England über Irland verhängt hatte und gab mir auch ein Buch mit, in welchem die englische Politik gegen Irland in vielen Punkten verurteilt wird. Auch trug sie mir Grüße auf an unser, leider jüngst verstorbenes Mitglied in der Akademie der Wissenschaften, Professor Kuno Me yer, den ausgezeichneten Kenner Irlands und der keltischen Sprache. Ich erinnere mich mit großem Interesse an die damalige sehr angeregte Unterhaltung und es würde mich sehr interessieren zu erfahren, ob die schweren politischen Ereignisse, die zwischen I9I3 und I920 liegen, das Urteil von Mrs. Henry gewandelt haben. Ich kann nur sagen, da $B$ ich, trotz allem dem, was dazwischen liegt, stets gern und dankbar der mir aufrichtig und herzlich erwiesenen Freundlichkeiten seitens der britischen Kollegen Sir Thomas Barlow und Sir Lauder Brunton gedenke. 
270 Berliner Vereine: Natur forschende Freunde. Natur- und Heilkunde.

Bei der Schlußsitzung des sehr zahlreich besuchten Kongresses hatte ich für Deutschland die Abschieds- und Dankesworte zu sprechen. Als nächster Versammlungsort wurde in London München gewählt und Professor Friedrich Müller, innerer Kliniker daselbst, mit der Übernahme der Organisationsarbeiten betraut. Damit war mein Mandat als Präsident des Dauerkomitees für die Internationalen medizinischen Kongresse erloschen. Als aber der Münchener KongreB hätte stattfinden sollen, da sprachen die Kanonen, und seit diese schweigen, schließt die gegenseitige Verbitterung den Mund der Völker für friedliche Aussprache im Gebiete der Wissenschaften. Die Zeit der Internationalen Kongresse ist wohl für lange vorbei.

Als eine dritte wissenschaftliche Gesellschaft, deren Mitglied ich sẹit meiner Übersiedelung nach Berlin war, nenne ich die „Gesellschaft naturforschender Freunde". In ihr werden hauptsächlich die biologischen Naturwissenschaften, insbesondere die Zoologie, gepflegt. Die Gesellschaft besaß früher ein eigenes Haus in der Französischen Straße, welches ihr vom König Friedrich Wilhelm II. geschenkt worden war. Auf Anregung insbesondere des Zoologen Möbius verkaufte sie das sehr wertvolle Grundstück, um durch die Zinserträge des Erlöses in den Stand gesetzt zu werden, das von ihr herausgegebene "Archiv für Biontologie" besser als bisher auszustatten. Da für die anderweitige Unterkunft der Gesellschaft gut gesorgt werden konnte, ging man auf den Verkauf ein, der dem genannten wissenschaftlichen Organ auch vollkommen zugute gekommen ist.

Außer in der Anthropologischen und Anatomischen Gesellschaft war ich am meisten tätig in der Gesellschaft für Natur- und Heilkunde, deren Vorsitz ich noch heute führe. Diese Gesellschaft besteht seit I8Io. Bei ihrer Gründung beteiligten sich u. a. der Chemiker Klapproth, der ihr erster Präsident wurde und der Anatom Rudolphi, ihr zweiter Sekretär. Als Präsidenten gehörten ihr später an: Heim I8I7-I834, Link I834-I85I, Ehrenberg I85I-I875, Wolff I875-I878, Reichert I879-I883, Robert Hartmann I884-I893. Als Nachfolger Hartmanns wurde ich gewählt, der vierte Anatom, der dieser Gesellschaft vorsteht und unter den bisherigen Präsidenten derjenige, der am längsten seines Amtes gewaltet hat, 27 Jahre, demnächst Ehrenberg, den ich auch zu den Anatomen 
rechnen darf, 24 Jahre. Früher entsprach die Gesellschaft durchaus. ihrem Namen, da fast ebensoviele Naturforscher wie Ärzte unter ihren Mitgliedern waren. Später wurden nun besondere Gesellschaften für die einzelnen naturwissenschaftlichen. Fächer gegründet, so daß die dafür interessierten Personen sich diesen Gesellschaften zuwendeten; zur Zeit ist die Gesellschaft eine gänzlich medizinische geworden, obschon auch jetzt noch naturwissenschaftliche Vorträge nicht völlig fehlen. Die Sitzungen finden monatlich einmal und zwar am ersten Dienstag im Monate statt. Jedes Mitglied ist verpflichtet, einen wissenschaftlichen Vortrag zu halten, wenn die Reihe es trifft; daran knüpft sich eine Besprechung; ein einfaches Mahl beschließt den Abend. Die Zahl der Mitglieder geht selten über 80 hinaus; so daB sich im Laufe der Jahre die Einzelnen gut kennen lernen. Der Verkehr in dieser Gesellschaft bildet eine der angenehmsten Erinnerungen meines Lebens. Der in ihr herrschende Geist wird am besten gekennzeichnet durch die Worte Rudolphis, die er am zweiten Stiftungsfeste, I8II, sprach und die bei jedem Stiftungsfeste durch den Präsidenten verlesen werden; sie lauten: „Die Gesellschaft für Natur- und Heilkunde feiert heute ihr Stiftungsfest. In Liebe und Einigkeit sind ihre Mitglieder in jeder Sitzung zusammengekommen und mit einem freundlichen Händedruck jedesmal auseinander gegangen. Ihr Zweck war nicht bloß, durch wechselseitige Belehrung den Kreis ihres Wissens zu erweitern. Was kann dem praktischen Arzte, was kann dem Lehrer willkommener sein, als nach einem treu durchgearbeiteten Tage mit gebildeten Männern desselben Faches zusammenzutreten. Hier empfängt er Belohnung für seine Mühe und Aufmunterung zur Arbeit des nächsten Tages. Der Mensch darf in dem Gelehrten nie untergehen. Er muß rein menschlich mit seinen Mitbrüdern zusammenkommen, um sich näher an sie anzuschließen. Wer das Buch eines Mannes gelesen, wer eine Vorlesung von ihm gehört, eine Operation oder eine Kur von ihm in Erfahrung gebracht hat, der weiB sehr wenig von ihm. Wer nach einem arbeitsvollen Tage denselben. Mann am Abend sein Herz der Freude öffnen sieht, ihn unter Freunden im traulichen Kreise ohne Amtsmiene wiedersieht, der nur mag ihn menschlich beurteilen. Dessen haben wir Alle Not."

„Jenen doppelten Zweck haben wir vor Augen gehabt. Wir haben unser Wissen bereichert, wir haben uns vor Einseitigkeit, Pedanterei 
und Kälte zu bewahren gesucht. Jeder ist dem Anderen mit Liebe entgegengetreten. Unsere gelehrten Ansichten und Meinungen müssen häufig verschieden sein, oder wir wären nicht wert, einen solchen Verein zu bilden; aber diese Verschiedenheit muB, statt zu trennen, näher anziehend wirken."

„Wir gehen neuen Arbeiten entgegen. Mögen sie für die Wissenschaft ersprießlich sein! Mögen die Mitglieder der Gesellschaft noch viele Jahre in Freude und Friede zusammen bleiben!"

Goldene Worte! Wenn die Gesellschaft an diesen Grundsätzen festhält, wird der Wunsch Rudolphis sich fernerhin dauernd erfüllen.

Halb wissenschaftlich, halb gesellig wie die eben besprochene, ist die Berliner Mittwochs-Gesellschaft, der ich seit I884 angehöre. Der Psychiater West phal führte mich dort ein. Die Gesellschaft wurde gegründet vom Minister v. Bethmann-Hollweg, dem Vater des Reichskanzlers. So lange wir in Frieden lebten, bis zum Winter Igr4/I5, kamen die Mitglieder regelmäßig alle I4 Tage an einem Mittwoch Abend abwechselnd in ihren Wohnungen zusammen, gewöhnlich um 8 Uhr abends. Es wurde zunächst von einem der Mittwochsfreunde, wie wir uns zu nennen pflegten, ein wissenschaftlicher Vortrag gehalten; daran schloß sich ein Mahl im häuslichen Stil, bei dem aber am Schlusse die Torte nicht fehlen durfte. Bei einem Glase Wein und guter Zigarre blieb man dann noch in anregender zwangloser Unterhaltung bis gegen II Uhr zusammen. Eines der Mitglieder, das älteste der Zugehörigkeit nach, führte den Namen "Kanzler" und ordnete alle geschäftlichen Angelegenheiten, so die Reihenfolge der zur Bewirtung Verpflichteten und der Vortragenden, die zu Anfang des November schon für den ganzen Winter festgesetzt wurde; die letzte Versammlung fiel gewöhnlich in den Anfang des Mai. Bis zum nächsten November fanden dann meist keine Versammlungen statt, außer einem Landausfluge in die Umgebung Berlins, an welchem auch die weiblichen Angehörigen der Gesellschaft teilnahmen. Als ich eintrat, war der Historiker Duncker Kanzler. Ihm folgte der Astronom Wilhelm Förster. Von Mitgliedern nenne ich die Theologen von der Goltz und Kleinert, den Philologen Hermann Diels, die HistorikerWaitz, Weizsäcker und Meinecke, die Romanisten Tobler und Morf, den Architekten Fr. Adler, die Juristen Beseler und Seckel, den Kunsthistoriker Weisbach, den 
Zoologen Mübius, die Generale Perthes und Rothe, dən Direktor der Deutschen Bank v. Gwinner, den Geographen Penck, den Physiker Kurlbaum, den Botaniker Correns und den Verlagsbuchhändler Dr. Vollert. Ich führe diese Namen an, um zu zeigen, da $B$ für möglichste Vielseitigkeit in der Vertretung der einzelnen Gebiete Sorge gatragen wurde.

Der jedesmalige Vortragende ist verpflichtet, den Inhalt seines Vortrages in einer genügend ausführlichen, auch für etwaigen Druck geeigneten Form niederzuschreiben; diese Niederschrift wird dann zu Anfang der tolgenden Sitzung verlesen. So ist das ganze Vortragsmaterial seit Gründung der Gesellschaft in den Protokollbüchern aufbewahrt und bildet einen wertvollen Archivbestand.

Der Weltkrieg hat auch bei dieser friedfertigen Vereinigung störend eingegriffen, zwar nicht in ihre wissenschaftlich belehrende Tätigkeit, wohl aber empfindlich in ihre Geselligkeit. Bei der steigenden Teuerung der Lebensmittel und des Weines war es den meisten Mitgliedern, ungeachtet der einfachen Form des Abendessens und der bescheidenen Ansprüche, die an des Weingottes Gabe gemacht wurden, nicht möglich, die Bewirtung im Hause zu übernehmen. So kamen wir denn eine Zeitlang in einer der kleineren Wirtschaften Berlins zusammen und begnügten uns mit einem Glase Bier, an das man aber in der Kriegszeì auch nur sehr geringe Ansprüche stellen durfte. Wir empfanden alle schmerzlich den großen Unterschied in der Behaglichkeit und Annehmlichkeit der Zusammenkunft in unseren Wohnungen unter der Sorge der Hausleitung einerseits und der unpersönlichen Kellnerwirtschaft in der Gaststube. Hoffentlich wird die Berliner Mittwochs-Gesellschaft, der ich einen dauernden blühenden Bestand wünsche, nicht wieder in eine solche Lage versetzt werden!

Auch nach einem Wochentage, als „Montags-Klub“, benennt sich eine zweite gesellige Vereinigung, deren Mitglied ich seit dem Jahre I902 bin. Sie besteht seit 1749 , also bereits I70 Jahre unverändert fort und ist rein dem geselligen Verkehr gewidmet. Ihre Leute sucht sie hauptsächlich in Regierungskreisen. Aktive und inaktive Staatsminister, sowie höhere Ministerialbeamte bilden den Grundstock, an den sich Angehörige aus den Kreisen der Kunst und Wissenschaft, Seelsorge, des Militärs u. a. anschließen. Man kommt von Oktober bis Anfang Juli jeden Montag von 9-II Uhr zusammen; früher, seit v. Waldeyer-Hartz, Lebenserinnerungen. 
vielen Jahren, in dem wohlbekannten „Englischen Hause“ in der Mohrenstraße, seit dessen Eingehen im Gasthof zum „Prinzen Albrecht". Punkt 9 Uhr beginnt das einfache Mahl, an welches eine meist sehr anregende Aussprache anschließt; Punkt $x \mathrm{I}$ Uhr ist SchluB. Zum Beginn und Schluß der Versammlung gibt dasjenige Mitglied, welches die längste Zeit dem Klub angehört, der Senior, das Zeichen. Außer dem Senior sind bei der Verwaltung tätig dessen Stellvertreter, der Subsenior, der Schriftführer und der Kassenverwalter. Man zahlt an diesen vierteljährlich einen bestimmten Betrag, dafür wird das jedesmalige Abendessen frei gewährt; nur das dazu bestellte Getränk - das übliche ist eine halbe Flasche Wein - ist besonders zu bezahlen; doch besteht kein Weinzwang, man kann auch ohne jedes Getränk am Mahle teilnehmen. Als ich eintrat, betrug der vierteljährliche Beitrag I8 Mark. Dafür wurden außer der Suppe zwei Gänge geliefert. Während der Kriegszeit mußte für ein viel bescheideneres Essen der Betrag auf 30 Mark erhöht werden.

Am ersten Montage im neu angefangenen Vierteljahre gestaltete sich als sogenanntes ,, Quartal“ der Abend festlicher. Es wurde besser gegessen und als Getränk eine Weinbowle gereicht, bei der auch der Sekt nicht fehlte; auch blieb man länger beisammen. Den Mitgliedern kostete der Quartalsabend nichts; auch die Bowle war frei. $\mathrm{DaB}$ dies in der Friedenszeit für den Vierteljahrespreis von I8 Marl möglich war, erklärt sich daraus, daß jeden Montag Abend, mochten auch nur sehr wenige Teilnehmer erschienen sein, dem Wirt für jedes der Gesellschaft angehörige Mitglied die auf dasselbe fallende Quote gezahlt wurde. So sammelte sich ein Überschuß, aus dem die Quartalskosten gedeckt werden konnten. Merkwürdigerweise, am Quartalsmontag waren die Mitglieder fast sämtlich da; ich gestehe, daß ich bei einem Quartalsabend selten gefehlt habe. - Während der letzten Kriegsjahre gestaltete sich dieser Tag viel einfacher und die Bowle fiel fort.

Bei der Wahl neuer Mitglieder wurde darauf gesehen, da B möglichst viele Lebensberufe vertreten waren; man wünschte in der Unterhaltung auch Belehrung zu finden. Die gegenseitige Aussprache - und das gab den Versammlungen ihren besonderen Reiz und Wert -, war eine freie, auf das gegenseitige volle Vertrauen gegründet. Die Gesellschaft hat sich seit I749 auf voller Höhe erhalten; die Mitglieder 
sind in dem Archiv der Gesellschaft durch biographische Angaben und Bildnisse vertreten; Namen besten Klanges finden sich reichlich. Als ihr Begründer wird der Theologe Johann Georg Schulthess, später Pfarrer zu Münchaltdorf bei Zürich, genannt, der u. a. den Professor der Philosophie bei der Académie militaire und Mitglied der Akademie der Wissenschaften Johann Georg Sulzer, den Polizeiregistrator und Ratmann Lukas Friedrich Langemak, den Porträtmaler Wilhelm Hempel, den Konrektor am Cöllnischen Gymnasium, späteren Oberdomprediger in Magdeburg, Johann Georg Sucro, den Professor am Kadettenkorps und Oberdirektor des Nationaltheaters Karl Wilhelm Ramler und den Hofrat Johann Wilhelm Bergius als Mitbegründer gewann. Unter den späteren Mitgliedern findet man Gotthold Ephraim Lessing, Christoph Friedrich Nicolai, den Mathematiker Johann Bernoulli, den Staatsminister v. Wöllner, die Botaniker Gleditsch, Willdenow, Link und Alexander Braun, den Grafen v. Carmer, den Anatomen Rudolphi, den Zoologen Lichtenstein, den Geologen Leopold v. Buch, den Architekien Schadow, den Staatsminister Eichhorn, den Astronomen Encke, den Generaldirektor der Museen v. Olfers, die Physiker Magnus und Dove, den Philologen Lach mann, den Juristen Homeyer, den Oberbibliothekar Pertz, den Theologen Twesten, den Baurat Stüler, den Legationsrat Abeken, den Unterstaatssekretär Lehnert, die Juristen Rudorff und Heffter, den Geheimen Regierungsrat im Kultusministerium Justus Olshausen, den Theologen Dorner, den Bankpräsidenten v. Dechend, den Chemiker Aug. Wilh. Hofmann, den Professor der Landwirtschaft Dr. Thaer, den Professor Fr. Reuleaux, den Physiker v. Helmholtz, den Bildhauer Drake, den Generalpostmeister v. Stephan, den Polizeipräsidenten v. Madai, den Baurat Adler und den Reichskanzler Grafen v. Caprivi. Noch mancher Name gleichen Klanges ließe sich den etwa 300 Mitgliedern, die seit der Gründung verzeichnet sind, hinzufügen.

Eine weitere Vereinigung zur Pflege der Geselligkeit war eine ausschließึlich ärztliche, zur Erinnerung an den seiner Zeit berühmten und originellen Arzt Dr. Heim - öfters als der ,alte Heim" bezeichnet - vor vielen Jahren ins Leben gerufen. Ihre aus den angesehensten Kreisen der Berliner Ärzteschaft in beschränkter Zah 
gewählten Mitglieder wurden jeden 22. Monatsdatum zur Erinnerung an das Geburtsdatum ihres Namengebers von dem jeweiligen Vorsitzer zur Versammlung eingeladen. Punkt 7 Uhr mußte man sich einfinden. Wer zugesagt hatte und ohne Entschuldigung fortblieb, hatte den auf ihn fallenden Betrag des Abends zu zahlen. Wer zu spät kam, das heißt nach dem Augenblicke, in welchem der Vorsitzer seinen ersten Löffel Suppe genommen hatte, zahlte eine Mark Strafgeld. Auch hier war das Mahl einfach, außer der Suppe die üblichen zwei Gänge; der Tischwein wurde von allen Anwesenden zu gleichen Teilen bezahlt; jeder hatte zu sehen, wie er auf seine Kosten kam. Auch in diesem gut gewählten und gut gehaltenen Kreise, den der Weltkrieg nicht gesprengt hat, habe ich manche angenehme Stunde verlebt.

Zur Charakteristik des alten Heim seien zwei Anckdoten mitgeteilt, die man in Berlin von ihm erzählte. So habe er einen Teil seiner Praxis in den entlegeneren Teilen Berlins häufig zu Pferde abgemacht; damals gab es in diesen Teilen noch viele niedrige nur aus einem Erdgeschoß bestehende Häuser. Wenn Heim vorbeiritt, riefen ihm die seine Hilfe in Anspruch Nehmenden von den Fenstern aus zu, er ritt heran und konsultierte die Leute vom Pferde aus, fühlte den Puls, lie $B$ sich die Zunge zeigen und gab dann seine Verordnungen, wenn dies in dieser einfachen Weise geschehen konnte. Ein anderes Stück wird von ihm mit folgendem berichtet: Eines Tages wàr der bekannte Chirurg Rust bei ihm zum Besuche, als ein Bauersmann gemeldet wird, den Heim schon seit einiger Zeit ohne Erfolg mit der Diagnose "Schulterrheumatismus" behandelt hatte. Heim läßt den Mann eintreten, dieser klagt, daß die letzte Einreibung nichts geholfen habe, die Schmerzen hätten sich nur vermehrt. Da sagt Heim zu Rust: ,,Sieh' dir doch mal den Patienten an." Rust tritt heran, hilft dem Manne den Rock ablegen, untersucht, sagt: „Dem kann geholfen werden" und mit einem Ruck war der verrenkte Oberarm wieder an seinem Platze; der Mann trollt vergnügt ab. Da sagt Heim: „Warum kommt der Esel denn auch zu mir ?!“ -

Auch einem studentischen Vereine, dem Akademischen Verein für Medizin und Naturwissenschaften in Berlin, bin ich durch die Wahl zum Ehrenmitgliede beigetreten. Es hat mir Freude gemacht, noch als 82 jähriger in der Verbindung einen Vortrag halten nud nachher dem Kommers beiwohnen zu können. Dis deutschen 
studentischen Formen und Gepflogenheiten gehören in ihrer Eigenart, so ganz aus dem deutschen Wesen hervorgegangen, zum deutschen Volke; sie sind volkstümlich geworden. Die studentischen Lieder mit dem "Gaudeamus" an der Spitze sind ein Schatz, wie kein anderes Volk ihn hat. Möchte das deutsche Studententum sich seine echte Art und seine Weisen auch unter den neuen Verhältnissen, in die wir eingetreten sind, bewahren! Es drängt mich, diesen Wunsch, dem ich bereits bei der Schilderung meiner Fahrt nach Göttingen, um in das Studentenleben einzutreten, warmen Ausdruck gab, hier zu wiederholen.

Ich bin absichtlich etwas näher auf die Darstellung des Vereinslebens in Berlin, soweit ich es kennen gelernt habe, eingegangen. Manchem mag dies nicht der Mühe wert erscheinen. Ich meine aber, $\mathrm{da} B$ es in diese Erinnerungen, deren Untergrund es ist, ein Bild vergangener Zeiten und Lebensverhältnisse möglichst treu zu entwerfen, hineingehört. Die besprochenen Vereine bewahren zum Teil hundertjährige Formen, die sich bewährt haben. Wir sind jetzt in eine neue Zeit, sozusagen kopfüber, eingetreten. Wir wollen hoffen, da $B$ der Spruch vom neuen Leben, das aus den Ruinen sprosse, sich bewahr- heite. Aber gerade jetzt gilt es, die Erinnerungen an das, was war, festzuhalten und auch das scheinbar Kleine und Unbedeutende sollte für die Geschichte der Kulturentwicklung eines Volkes nicht vernachlässigt werden. Das Interesse wächst mit dem Voranschritt der Zeit, wie uns die Geschichte der alten Völker lehrt. Wer kann, mag sein Scherflein dazu beitragen, da $B$ unsere Nachfahren wissen, wie ihre Vorfahren gelebt und gedacht haben. Ich maße mir nicht an zu glauben, da $B$ diese einfache Darstellung meiner Erlebnisse irgendeinen Wert für die Zukunft behalten werde; sie ist, wie gesagt, zunächst für meine Angehörigen bestimmt und für diejenigen meiner Freunde und Schüler, die sich meiner erinnern. Sie werden, so denke ich, vielleicht gern einmal nachlesen, wie es einstmals war.

Allen den auswärtigen Vereinen, Akademien und gelehrten Gesellschaften, die mir die Ehre erwiesen haben, mich zu ihrem Mitgliede zu erremnen, sage ich an dieser Stelle meinen aufrichtigen Dank! Daß ich derjenigen Gesellschaften dabei besonders gedenke, die an den Orten, wo ich meine erste Bildung erhielt und als akademischer Lehrer tätig war, Göttingen, Greifswald, Königsberg in Pr., Berlin und 
278 Volkstüml. Hochschulkurse. Ärztl. Fortbild. Litt. Sachverst.-Kammer.

Straßburg im Elsaß, ihren Sitz haben und hatten, brauche ich nicht noch eigens hervorzuheben. Doch nenne ich besonders noch den pfälzischen Verein „Pollichia" mit dem Sitze in Dürkheim an der Hardt, der einer der ersten auswärtigen war, die mich unter die Zahl ihrer Mitglieder aufgenommen haben. „Fröhlich Pfalz, Gott erhalts“ - bei Deutschland - !

Kurz sei meiner Tätigkeit in gemeinnützlichen Vereinen und in außeramtlicher Beschäftigung gedacht. Viele Jahre, bis zur Auflösung des Vereins im Jahre I9I9, war ich Mitglied und zugleich Vorsitzender des Vereins für volkstümliche Kurse von Berliner Hochschullehrern; ich habe auch in diesem Vereine eine Reihe von Vorträgen aus dem Gebiete der Biologie, insbesondere der Anatomie, gehalten, die stets von weit über hundert Zuhörern besucht waren. Dieser Verein, dem Berliner Hochschullehrer aus allen Wissensgebieten angehörten, hat eine rege Tätigkeit entfaltet. Die Vorträge, die in einem Winter- und Sommerkursus gehalten wurden, waren stets gut besucht; die einzelnen Vortragenden wechselten in den verschiedenen Stadtteilen; auch die Vororte Berlins wurden cinbezogen. Im Jahre IgI9 nahmen die Berliner Hochschulen auf Anregung des in Rede stehenden Vereins selbst und unter Mitwirkung des Ministeriums für Wissenschaft, Kunst und Volksbildung die Sache in die Hand und der bisherige Verein ging in der neuen Organisation auf. Bis dahin war er der "Zentralstelle für Volkswohlfahrt" eingegliedert gewesen.

Ein weiterer Verein mit verwandten Bestrebungen, dem ich angehörte und in dessen Vorstande ich tätig war, ist der Verein für Volkshygiene. Ferner gehörte ich zu den beratenden Mitgliedern der Kaiser Wilhelm-Gesellschaft, von der bereits die Rede war. Nach v. Bergmanns Tode übernahm ich das Präsidium der Zentralstelle für die ärztliche Fortbildung in Preußen, die mit dem Kaiserin-Friedrich-Hause in Berlin verbunden ist. Auch gehörte ich seit ihrer Gründung der Litterarischen Sachverständigen-Ka mmer an. Diese amtliche Stelle ist dazu berufen, sich gutachtlich zu Rechtsfragen in wissenschaftlichen und künstlerischen Publikationt $n$, insbesondere iiber Nachdruck, auf Erfordern der Gerichte zu äußern. Es sind mir dabei manche sehr schwierig $\mathrm{zu}$ entscheidende und interessante Fälle bekannt geworden. Schließlich erwähne ich gern meine 
Mitgliedschaft in dem von $\mathrm{H}$. Riegel gegründeten Deutschen Sprachverein. Dieser Verein ist namentlich in letzter Zeit vielfach angegriffen worden, als leiste er einem übertriebenen Purismus Vorschub. Im Großen und Ganzen kann man jedoch sagen, da $B$ seine Wirksamkeit eine sehr beachtenswerte und segensreiche ist. Manche Verdeutschung eines seit langem eingebürgerten Fremdwortes erscheint zunächst unbequem und, ich will sagen, fremdartiger als das bisherige Fremdwort - als Beispiele nenne ich „Fahrschein" oder ,Fahrkarte“ für „Billet“, „Bahnsteig“ für „Perron“. Heute gebraucht fast: Niemand mehr diese Fremdworte. Ich könnte leicht noch viele Beispiele dieser Art anführen. Es ist hauptsächlich dem Deutschen Sprachverein zu verdanken, wenn hier Wandel geschafft ist. Aber es gibt immer noch viel zu tun. Warum noch immer "Hôtel", wo wir das viel schöner klingende deutsche Wort "Gasthof" haben? Warum ,Restaurant", ,Restauration" statt ,Wirtschaft", ,Weinwirtschaft", "Bierwirtschaft", "Speisehaus"? Warum "Chauffeur", "Garage“, „Automobil" statt „Führer", „Kraftwagenschuppen“, "Kraftwagen"? Ich hoffe in diesen meinen Lebenserinnerungen gezeigt zu haben, da $B$ man der Fremdworte recht gut entbehren kann. Gern gebe ich $z u, d a B$ es noch eine Anzahl von Fällen gibt, in denen man sie beibehalten sollte. Hierher gehört u. a. das Wort "Interesse“. Es ist auch weniger abzulehnen, wenn wir fremde Worte aus dem Lateinischen oder Griechischen übernehmen, als wenn wir sie einer jetzt lebenden Fremdsprache entlehnen. Auch die Termini technici in den einzelnen Wissenschaften sollen und müssen des internationalen Verkehrs wegen bleiben. Nur sei man mit ihrer Bildung vorsichtig, denn was uns jetzt in der Bezeichnung neuer chemischer Produkte, im besonderen der vielen neuen, wie Pilze aus der Erde schießenden Arzneimittel oder Schmuckmittel geboten wird, ist vielfach geradezu fürchterlich. 


\section{Ka p it el.}

\section{Von einigen Berliner und Leipziger Kollegen.}

Theodor v. Frerichs, Ernst v. Leyden, Karl Gerhardt, August Kundt, Robert Koch, Wilhelm His senior, Karl Ludwig.

Manche Erinnerungen an bekannte Berliner Persönlithkeiten, vor allen an Kollegen von der Universität und von der Akademie der Wissenschaften, sind der vorhergehenden Darstellung bereits eingeflochten worden, andere werden folgen.

Besondere Erinnerungen an einige Mitglieder der Berliner Universität und einer der nächsten Nachbaruniversitäten, Leipzig, sollen hier niedergelegt werden.

Unter den Berliner Kollegen nahm, als ich in die Fakultät eintrat, Theodor Frerichs unbestritten einen hervorragenden Platz ein. Es mögen von ihm noch einige Züge, die ihn charakterisieren, nachgetragen werden: Frerichs machte mir nach meinem Eintritt in die Berliner Fakultät seinen Gegenbesuch im Anatomischen Institut. Er erschien mit seinen beiden damaligen Assistenten Paul Ehrlich und Ludwig Brieger. Wir trafen einander auf dem Flur im Erdgeschoß, wo ich mich gerade befand, als die Herren eintraten. Nach den ersten Begrüßungsworten fragte mich Frerichs, wie es mir gefalle und ob ich mit meinem Institut zufrieden sei? Als ich er widerte, da $ß$ ich hoffe, mich hier gut einzuleben, daß jedoch vorerst noch vieles zu ändern und zu ergänzen sei, sagte er : „Lieber Kollege, eins rate ich Ihnen, packen Sie sich gleich zu Anfang nicht zu viel auf, überhasten Sie sich nicht; Berlin ist ein eigenes Pflaster, da kommt Einem, ehe man sich dessen versieht, so viel auf den Hals, daß man es kaum bewältigen kann; schonen Sie Ihre Kräfte." Frerichs hatte ganz recht und meinte es gut mit mir. Ein anderes Mal trafen wir uns Beide Ende des Monats Februar auf einer Abendgesellschaft beim damailigen Kultusminister v. Goßler. Frerichs fragte mich, ob ich meine Vorlesungen geschlossen habe? „O, nein,“ entgegnete ich, ,ich lese bis zum Semesterschlusse am I5. März." „Da haben Sie ganz recht," sagte Frerichs, „,die jungen Leute müssen was lernen; ich habe heute geschlossen." Echt charakteristisch für Frerichs! Bei sich zu Hause war er recht behaglich und gemütlich in kleinem Kreise, wenn er nach 
der Abendmahlzeit sich mit der langen Pfeife, die ihm seine Frau reichte, in seinem großen Lehnstuhle setzte und mit seinen um ihn versammelten Gästen sich unterhielt. Dabei sorgte er auch für einen guten Tropfen, den er mit wohlangebrachter Empfehlung zu würzen verstand, obwohl es einer solchen gar nicht bedurft hätte.

Ein Gegenstück zu Frerichs war Leyden, mit dem ich, nach unserem Zusammensein in Königsberg und Straßburg, in Berlin wieder zusammentraf. Leyden war, ich möchte sagen, die Aktivität selbst; er gründete in Berlin alsbald den Verein für Innere Medizin und wußte selbst Frerichs zur Teilnahme zu bewegen. Unermüdlicher Arbeiter, regte er auch seine Assistenten stets zur Arbeit an. Man hat ihm oft persönliche Eitelkeit vorgeworfen. Gewiß war er für Ehrungen empfänglich und freute sich an Erfolgen; aber ich glaube ihn von dem, was man in üblem Sinne unter Eitelkeit versteht, freisprechen zu sollen. Er hatte etwas Gütiges und Liebenswürdiges in seinem Wesen, insbesondere seinen Kranken gegenüber, die ihn liebten und verehrten. Bezeichnend dafür ist, daß Zar Alexander III., an dessen letztes Krankenlager Leyden gerufen wurde, den Wunsch aussprach, Leyden möge bis zu seinem, des Zaren, Tode bei ihm bleiben, ein Wunsch, der auch erfüllt werden konnte. Übrigens spielte in der gewinnenden Weise, wie Leyden sich seinen Kranken gegenüber gab, Rang und Stand bei ihm keine Rolle. Traurig war es für mich, ihn vor seinem Ende in geistiger Umnachtung zu wissen. Ich habe ihn in dieser letzten Zeit seines Lebens noch mehrere Male aufgesucht und da er mich noch erkannte und ich auf seine Ideen einging oder sie unbeachtet ließ und ablenkte, so beunruhigten ihn diese Besuche nicht; sie waren ihm, wie ich annehmen darf, angenehm. Körperlich frei von Schmerzen und Beschwerden, sah man den sonst so gesunden und tätigen Mann lángsam dahinsiechen und immer stiller und stiller werden. Bei meinem letzten Besuche sagte mir der Diener - Frau v. Leyden war nicht zu Hause - , als ich nach dem Kranken fragte, er sei im Garten; ich möge aber nicht zu ihm gehen; er erkenne mich vielleicht jetzt nicht mehr und es rege ihn auf, wenn Jemand zu ihm komme, den er nicht alle Tage sehe. Ich blieb von ferne stehen und betrachtete lange meinen alten lieben Kollegen, wie er regungslos in sich zusammengesunken in seinem Stuhle saß. Bald darauf löschte ein sanfter Tod den verglimmenden Lebensfunken aus. 
Auf Ernst v. Bergmann und Karl Gerhardt, die ich beide gleichfalls aus dem Leben scheiden sah, komme ich bei der Schilderung der Erkrankung Kaiser Friedrichs III. zurück. Gerhardt war eine gerade, offene Natur, ein fester Charakter; in mehreren Fällen hat er mir guten Rat gegeben und ich gedenke seiner in größter Hochschätzung. Hier möchte ich von seinem Lebensende sprechen. Gerhardt hatte sich mit zunehmendem Alter auf seinen kleinen Landsitz, in der Nähe von Würzburg, zurückgezogen. In Vertretung des Dekans unserer Fakultät war ich bei seiner Bestattung zugegen, die sich in der kleinen Dorfgemeinde so würdig und, ich muß sagen, so ergreifend schön gestaltete, wie ich es kaum wieder bei gleichem Anlasse erlebt habe. Die ganze Dorfgemeinde folgte der Bahre zum Kirchhof; der Pfarrer, ein Schwiegersohn des Verstorbenen, hielt dort eine ergreifende, den Abgeschiedenen treu schildernde Grabrede und unter dem Gesange der Schuljugend sank der Sarg in die Tiefe hinab. Allen, die da standen, sah man es an, daß sie mit dem Herzen dabei waren, wenn sie diesem Manne, den sie Alle persönlich kannten, liebten und ehrten, das letzte Geleit gaben. Rudolf Virchows letztes Geleit gestaltete sich ja auch durch die aufrichtig gemeinte Teilnahme der Berliner Bevölkerung zu einer ergreifenden Kundgebung, wie ich sie S. 252 geschildert habe; aber das Bild der großen Stadt und ihr unermüdlich pulsierendes Leben stimmt nicht zu einer Totenfeier, mag sie sonst noch so würdig und in voller, aufrichtiger Teilnahme der Anwesenden erfolgen.

Das am tiefsten Ergreifende und Schönste, was ich in einer Großstadt von einer Totenehrung erlebt habe, war die Feier im Berliner Dome zur Bestattung Adolf Menzels, um deren würdige Gestaltung sich auch Kaiser Wilhelm II. persönlich gekümmert hatte. Nach der Leichenrede Dryanders wurde unter Joseph Joachims persönlicher Leitung ein wunderbar schönes passendes Musikstück vorgetragen, bei dem Meister Joachim mit seiner Geige sein Bestes gab. Und während dieser erhabenen, zum Herzen dringenden Sprache der Töne wurden still die Kränze am Sarge niedergelegt. -

Noch von einem mir lieb und wert gewordenen Straßburger und Berliner Kollegen, von dem Physiker August Kundt, möchte ich etwas erzählen und auch von dessen Lebensende; es charakterisiert ihn. In Berlin empfand Kundt nach mehrjähriger reichgestalteter 
Tätigkeit Beschwerden, die ihn sehr quälten; wir erkannten sie bald als vom Herzen ausgehend, Kundt wollte jedoch nicht recht daran glauben. Er nahm mir das Versprechen ab, seinen Leichnam zu obduzieren und hatte dies auch testamentarisch festgelegt. Als er nach einem Ferienaufenthalte auf seiner Besitzung in Israelsdorf bei Lübeck nach Berlin zurückkehrte und ich ihn besuchte, rief er mir lachend entgegen: „Nun, Sie kommen wohl, mich zu sezieren?“ Ich darauf: „Nein, ich komme, mich zu überzeugen, daß ich das noch lange nicht nötig habe." So scherzten wir plaudernd weiter. Ich sollte ihn zum letzten Male lebend gesehen haben. Bald darauf ging er wieder auf kurze Zeit, wie er meinte, nach Israelsdorf. Dort hatte er mit den Seinigen einen Spaziergang verabredet und erwartete, anscheinend völlig guter Dinge, in seinem Lehnstuhle sitzend, die Bereitschaft seiner Frau zum Ausgange, wollte sich erheben, sank lautlos zurück und war tot. Die Leiche wurde nach Berlin überführt und ich wurde benachrichtigt. Bei der Obduktion fand sich ein Herz von solcher Größe, wie ich bis dahin noch keines gesehen hatte; sonstige Veränderungen keine. Ich habe die Meinung, da $B$ mein Kollege sich diese Herzhypertrophie durch seine Leidenschaft für den Bergsport zugezogen hat. So erzählte er mir einmal in Straßburg, daß er in einer Woche die Jungfrau, das Schreckhorn und das Finsteraarhorn bestiegen habe. Ähnliches pflegte er in jeden Ferien auszuführen, so lange er das konnte. Kundt war einer der bedeutendsten Physiker seiner Zeit und einer der vorzüglichsten Lehrer in seinem Fache, die ich kennen gelernt habe. Er war Mecklenburger von Geburt, frisch und lebensfroh, mit dem Humor seines Landsmannes Fritz Reuter.

Als eines der bedeutendsten Förderer der medizinischen Wissenschaft habe ich noch Robert Kochs zu gedenken, dem ich in Berlin gleichfalls näher trat und stets in gutem Einvernehmen mit ihm blieb. Ihm ist einer der ehrenvollsten Plätze in der Geschichte der Medizin gesichert; aber die Erlebnisse, die sich an seine vollberechtigten Bemühungen zur wirksamen Bekämpfung der Tuberkulose knüpften, mahnen auf das Entschiedenste zur größten Vorsicht bei der Beurteilung und Verwendung solcher als Grundheilmittel gegen bestimmte Krankheitsprozesse oft voreilig angesehenen Präparate, wie des Tuberkulins. So viel ich von dieser Angelegenheit weiß, trifft Koch bei der Überschätzung dieses Mittels keine Schuld. Es ist vielmehr 
anzuerkennen, daß er sich nicht nur mit der Entdeckung des Tuberkelbazillus begnügte, sondern auf deren praktische Verwertung sann. Auch ist die Darstellung des Tuberkulins an sich eine Leistung von hohem Werte. Ich begegnete während des Internationalen medizinischen Kongresses I89o Robert Koch in der Karlstraße in Berlin; wir gingen eine Strecke weit zusammen und Koch sprach sein Bedenken darüber aus, daß er bei scinem angekündigten Vortrage über Tuberkulose auch über das von ihm vor kurzem hergestellte Tuberkulin sprechen solle. Er möchte das vermeiden, da er über dessen Wert für die Bekämpfung der Tuberkulose mit sich noch nicht im Reinen sei. Aber er werde von allen Seiten gedrängt, insbesondere lasse ihm der Kultusminister v. Goßler keine Ruhe. Alle Kongreßmitglieder erwarteten, so sagte ihm v. Goßler, daß er, wenn er überhaupt über Tuberkulose spreche, auch von seinen Versuchen mit dem Tuberkulin, von denen einiges bekannt geworden war, etwas mitteile. Koch sagte mir damals noch, er möchte am liebsten auf seinen Vortrag überhaupt verzichten.

Einige Tage später war die große Halle des Zirkus Busch, in welchem der Vortrag Kochs stattfand, bis auf den letzten Platz gefüllt; ich befand mich unmittelbar neben der Rcdnerbühne, so daß ich kein Wort des Vortrags verlor. Während der ersten Auseinandersetzungen Kochs, die sich in die Länge zogen, kam es nach und nach, obwohl sich die Zuhörer größte Zurückhaltung auferlegten, doch zu dem leisen Allgemeingeräusch, welches auf die Dauer bei einer tausendköpfigen Menge unvermeidlich ist. Da sagte nun Koch gegen Ende seines Vortrages ungefähr wörtlich: „Sie werden erwarten, meine Herren, da $B$ ich auch Versuche mit dem Tuberkulin angestellt habe, um zu prüfen, ob man damit Heilwirkungen bei der Tuberkulose erzielen kann." Koch hatte kaum diesen Satz beendet, so entstand in dem großen Raume eine Totenstille. Alles lauschte gespannt auf die folgenden Worte, von denen man keins verlieren mochte; es war geradezu ein dramatischer Augenblick. Koch berichtete dann ganz schlicht und kurz, da $B$ er durch Tuberkulin bei Impftuberkulose von Meerschweinchen Besserung erzielt habe, da $B$ er aber keineswegs ein bestimmtes Urteil über den Wert des Tuberkulins abgeben könne, sondern nur die Hoffnung aussprechen wolle, da $B$ es sich als Heilmittel auch bei der Menschentuberkulose bewähre. Damit brach der 
Redner $\mathrm{ab}$ und man merkte, daß viele der Anwesenden enttäuscht waren. Ich fand, daß Koch vollkommen Maß gehalten hatte.

Nun brach aber das von Koch selbst gefürchtete Verhängnis los. Von allen Seiten wurde sein Laboratorium mit Ansuchen von Ärzten um Verabfolgung von Tuberkulin überschüttet. Ich erhielt fast von allen mir bekannten Ärzten aus den Provinzen Briefe mit der Bitte, ihnen durch meine Vermittlung bei Koch Tuberkulin zu besorgen. Ich lehnte $a b$, weil ich wußte, daß unmöglich alle diese Wünsche befriedigt werden konnten, bedachte aber einige meiner besten Freunde aus der Jugendzeit, die sich gerade nicht an mich gewandt hatten, um mir nicht lästig zu werden. Ich schrieb an Koch, daß ich mit solchen Gesuchen überfallen würde, aber alle abgelehnt habe und in Zukunft ablehnen werde; ich bäte ihn jedoch, wenn es möglich sei, mir sechs Fläschchen für einige bewährte Freunde, die in bescheidener Zurüickhaltung sich nicht an mich gewendet hätten, zu überlassen. Wenige Tage darauf schickte mir Koch mit einem freundlichen Schreiben das Gewünschte. Ich habe aber auch mein Wort gehalten.

Bekannt ist, da $B$ in dieser Zeit fast ein Wallfahrten von Tuberkulösen nach Berlin stattfand, die alle von dem neuen Mittel Heilung erhofften, zumal sich auf Anwendung desselben bestimmte Reizerscheinungen geltend machten, die als Anfänge von Heilungsprozessen gedeutet werden konnten. So wurde denn in der ersten Zeit nach Einführung des Tuberkulins von vielen Seiten Koch als einer der größten Wohltäter der Menschheit gefeiert, dem es gelungen sei, einen der größten Feinde des Menschengeschlechtes, den Tuberkelbazillus zu bannen. Selbst ein sonst so klarer, überlegener und erfahrener ärztlicher Meister, wie unser damaliger Chirurg Ernst v. Bergmann, wurde von der Tuberkulinbegeisterung ergriffen. Ich war bei dem Vortrag zugegen, den er damals vor einer Gesellschaft von Ärzten in seiner Klinik hielt und wobei Fälle von Hauttuberkulose, bei denen die erwähnten Reaktionen eingetreten waren, vorgestellt wurden. v. Bergmann schlo $\beta$ mit den Worten, da $B$ wir uns glücklich schätzen könnten, einen Mann unter uns zu haben, dessen Ruhm in künftigen Zeiten dem des Hippokrates gleich geschätzt werden würde. Und das ganze Auditorium brach in brausenden Beifall aus. Bezüglich des Tuberkulins hätte Koch sagen können: „, Gott sclıütze miclı vor meinen Freunden!" 
Beinahe wäre es meinem lieben Schüler und Freunde, Paul Ehrlich, mit seinem Salvarsan ähnlich gegangen; aber etwas kritischer war man doch geworden. Und jetzt mit dem viel besprochenen Friedmannschen Mittel, welches ja aus dem Kochschen Tuberkulin hervorgegangen ist, hat man doch viel mehr Zurückhaltung geübt, wiewohl man auch hier mit der Reklame nicht gespart hat. Immerhin muß man jedoch sagen, da $B$, angesichts einer so verheerenden Volkskrankheit, wie die Tuberkulose es ist, die gerade die Jugend bedroht, jedes Mittel, das einige Aussicht auf Erfolg zeigt, ernstlich geprüft werden sollte. $\mathrm{Zu}$ vermeiden ist nur die vorzeitige Besprechung solcher Dinge in den Tageszeitungen; dies sollte man den Ärzten in den medizinischen Fachblättern überlassen, bis feststehende Ergebnisse mitzuteilen sind. Überhaupt stiften die Besprechungen medizinischer Fragen in der Tagespresse oft mehr Schaden als Nutzen und, falls sie nicht von Schaden sind, bringen sie meist auch keinen Nutzen und blieben daher besser weg. Es ließe sich im Großen und Ganzen über das Kapitel „Presse“ mancherlei sagen, was in unserer reformfrohen Zeit am Platze wäre.

Die bereits über 500 Jahre bestehende Universität Leipzig ist die nächste außerpreußische Nachbarin der Berliner Universität; so bieten sich manche Gelegenheiten zur Anknüpfung wissenschaftlichen und persönlichen Verkehrs zwischen Lehrern und Studierenden der beiden Hochschulen, die auch an Bedeutung gleichstehen. Ich gedenke hier besonders zweier Männer, die zu den besten Kräften der sächsischen Universität gehörten und mit denen ich in freundschaftlichen Verkehr trat, Wilhelm His' und Karl Ludwigs, des Anatomen und des Physiologen.

His war von Basel, wo er seinen Ruf begründet hatte, nach Leipzig berufen worden. Arbeit an denselben Aufgaben hatte uns bereits früher einander näher gebracht, persönlich lernte ich His jedoch erst später auf der Naturforscherversammlung in Dresden kennen. Ich erinnere mich noch lebhaft daran, da $B$ wir dort nach unserer ersten Begegnung fast stets zusammen blieben und uns über unsere Arbeiten besprachen. Wir merkten bald, daß wir zueinander paßten. Als ich dann nach Berlin kam, war His einer der Ersten, die mich dort besuchten; dabei sagte er mir, da wir nun so nahe Nachbarn geworden seien, müßten wir auch stete gute Nachbarschaft halten und uns in 
unseren Arbeiten gegenseitig unterstützen und fördern. Nichts entsprach meinen eigenen Wünschen mehr als das, zumal einem Manne gegenüber wie Wilhelm $\mathrm{His}$, in dem ich alsbald einen der zuverlässigsten und edelsten Männer erkannte, die mir je im Leben näher getreten sind. Wir suchten einander öfter auf, besprachen unsere wissenschaftlichen Arbeiten und halfen einander mit Material, wo dies gewünscht wurde und möglich war, aus. Auf Kongressen trafen wir uns öfter und traten dann immer als Verbündete auf. Tiefschmerzlich berührte es mich, als mein lieber Kollege an einem unheilbaren Magenleiden erkrankte. Er sah dem unabwendbaren Verhängnis fest ins Auge, bat mich um meinen Besuch und übertrug mir die Sorge für die Anatomische Abteilung des Archivs für Anatomie und Physiologie und für die von ihm geplanten Hirnforschungsinstitute, welchen Aufträgen ich auch getreulich entsprochen habe. Nachdem alles dieses erledigt war, nahmen wir noch Platz vor einem Fenster, von dem aus man auf einen in vollster schönster Blüte stehenden Apfelbaum sah; zu uns gesellte sich der ältere Sohn meines Freundes, der dessen vollen Namen trägt: mein jetziger Kollege in der Berliner Fakultät, der innere Kliniker Wilhelm His. Wir blieben noch länger im Gespräch beisammen. Ich sah, wie mein Freund seinen Blick oft in den schönen blühenden Baum versenkte, als wollte er vor seinem Scheiden aus dieser Welt noch einmal ein schönes Bild in sich aufnehmen. Als ich His wiedersah, lag er auf der Totenbahre; ich hatte ihm im Namen der Preußischen Akademie der Wissenschaften den letzten Nachruf zu bringen.

Unter den Physiologen aus meiner Lebenszeit steht Karl Ludwig mit in erster Reihe. Mein erstes Interesse für ihn datiert aus meiner Berliner Studentenzeit, in der ich mich nach seinem Lehrbuche für das Examen vorbereitete und merkte, mit welch hervorragendem Geiste ich mich dabei unterhielt. Das Ludwigsche Werk ist keine leichte Ware, es will ähnlich wie die Henleschen, nicht gelesen, sondern studiert sein; aber man hat dann auch den Gewinn davon. Ludwig trat zuerst zu mir in persönlichen Verkehr durch einen Besuch, den er mir kurz nach Antritt meines Lehramtes in Straßburg machte. Als ich dann in Berlin Nachbar von Leipzig wurde, setzte sich der Verkehr in angenehmster Weise fort. Ludwig lud mich in seine Familie ein, und wir machten gemeinsame Ausflüge, so erinnere ich mich be- 
sonders an einen Besuch Altenburgs. Ludwig besaß in hohem Grade die Gabe angenehmer und fesselnder Unterhaltung, wobei Leben und Wissenschaft, Ernst und Frohsinn in gleicher Weise zu ihrem Rechte kamen; seine Gäste waren die Gewinner dabei. Mit großer Befriedigung erfüllt es mich, diesem hochbedeutenden Manne und Forscher näher getreten zu sein.

Im Anschluß an die vorhin erwähnten Berliner und auswärtigen Kollegen gedenke ich noch meiner Mitarbeiter, die mir als Assistenten zur Seite standen oder als Laboranten in den von mir gcleiteten Anstalten in Breslau, Straßburg und Berlin tätig waren. Auch die Laboranten darf ich als „Mitarbeiter“ bezeichnen, denn im Verkehr mit ihnen bei der Lösung der gestellten Aufgaben wird gemeinsame Arbeit geleistet, die ebenso dem Leiter der Arbeitsstätte wie den Laboranten zugute kommt. In der Laboratoriumstätigkeit liegt die schönste und fruchtbarste Aufgabe des akademischen Lehrers, die Aufgabe, die ihn selbst am meisten fördert. Ich führe hier, sofern ihrer nicht bereits gedacht wurde, vor allen die Namen derjenigen an, welche in den anatomischen Disziplinen weiter gearbeitet haben, sich verwandten akademischen Lehrfächern zuwendeten oder in diesen litterarisch tätig blieben. Einige von ihnen sind bereits genannt worden.

In Breslau war, wie erwähnt, mein erster Assistent Karl Weigert, später Assistent J. Cohnheims in Leipzig und zuletzt Anatom des Senckenbergischen Instituts in Frankfurt am Main. Dann hatte ich die nachherigen Extraordinarien für Innere Medizin Dr. Buchwald und für Chirurgie Dr. Kolaczek zu Gehilfen. Als Laboranten nenne ich den späteren Professor der Laryngologic Gottstein, in Breslau, dessen Habilitationsschrift über die Anatomie der Gehörschnecke nicht unbekannt geblieben sein dürfte, ferner Ferdinand v. Brunn, der ïber Bau und Entwicklung der Nebennieren in meinem Laboratorium arbeitete und Neigung zeigte, sich der Anatomie zu widmen. Ich veranlaßte ihn, als mein Assistent mit mir nach Straßburg zu gehen, wo wir bald in ein freundschaftliches Verhältnis traten. Als dann Henle mich fragtc, ob ich ihm nicht einen Assistenten empfehlen könnte, nannte ich ihm v. Brunn, obwohl es mir schwer wurde mich von ihm zu trennen; aber es war mir eine Freude, mich meinem Lehrer Henle gefällig erwcisen zu können, und bei Henle Assistent 
zu werden, konnte auch v. Brunn nur förderlich sein. Darin hatte ich richtig vorausgesehen, denn auf diesem Wege ist v. Brunn, der allerdings einer der tüchtigsten Assistenten war, die ich gehabt habe, Ordinarius für Anatomie in Rostock geworden. Wir Beide blieben bis $\mathrm{zu}$ seinem leider früh erfolgten Tode in treuer Freundschaft verbunden.

Später hatte ich in Dr. Lor ent aus Bremen, Dr. J. Disse aus Höxter und in Wilhelm Nahmmacher aus Rostock sowie in Paul Schiefferdecker aus Königsberg treue und tüchtige Gehülfen. Die drei Erstgenannten sind gleichfalls früh aus dem Leben geschieden. Schiefferdecker kam später auch als Assistent zu Henle und ist z. Z. Professor extraordinarius für Anthropologie in Bonn. In meinem Straßburger Laboratorium arbeiteten außer den bereits S. 158 Genannten noch der jetzige Berliner Gynäkologe Karl Abel, mit dem ich in Berlin in steter Verbindung geblieben bin, und der jetzige Ordinarius für Anatomie an der Tschechischen Universität in Prag Jan Janošik.

In Berlin traf ich als ersten Prosektor Professor Robert Hartmann, der mir noch mehrere Jahre treu zur Seite stand. Als zweiter Prosektor trat, wie erwähnt, Dr. Hans Virchow ein, als Assistenten fand ich die Dr. Dr. G. Jablonowski und G. Brösike vor, zu denen noch, wie bemerkt, Dr. J. Koganei hinzutrat. Nach Hartmanns Tode rückte Professor Hans Virchow in dessen Stelle ein und Dr. Brösike wurde zweiter Prosektor. Professor Wilhelm Krause aus Göttingen übernahm als Abteilungsvorsteher die Stelle eines Laboratoriumsleiters, half beim Unterricht auf dem Präpariersaale und verwaltete den anthropologischen Teil der Sammlungen. Ich hatte Kollegen Krause, der sich nach einem größeren Wirkungskreise sehnte, als er ihn in Göttingen haben konnte, veranlaßt, am Berliner Institut die genannte Stellung, welche ich für ihn eingerichtet hatte, $\mathrm{zu}$ übernehmen. Er war mir ein lieber und treuer Kollege, stets zu jeder Mithilfe bereit; ich freute mich, dem verdienten Anatomen eine Stellung verschaffen zu können, die ihın voll befriedigte.

Später traten als Assistenten des Berliner Instituts norh ein die Dr. Dr. Zimmermann, gegenwärtig Professor extraordinarius der Anatomie in Bern, Paul Bartels, vor einigen Jahren als erster Assistent des Anatomischen Instituts in Königsberg verstorben, Verfasser der Anatomie des Lymphgefäßsystems in dem von Professor v. Waldeyer-Hartz, Lebenserinnerungen. 
K. v. Bardeleben herausgegebenen Handbuche, J. Sobotta, Ordinarius für Anatomie in Bonn, H. Klaatsch, später Professor extraordinarius der Anatomie und Anthropologie in Breslau, daselbst vor einigen Jahren verstorben, Fritz Frohse und Ferdinand Hein, beide gleichfalls als junge Männer aus dem Leben geschieden, und Professor Fr. Kopsch, z. Zt. zweiter Prosektor am Berliner Anatomischen Institut.

Von den zahlreichen Laboranten des Berliner Instituts führe ich nur diejenigen an, welche sich der Anatomie gewidmet haben. Ich darf unter ihnen auch wohl Professor Franz Keibel, später in Freiburg und Straßburg, jetzt in Königsberg i. Pr. nennen, obwohl er nur noch ein Semester auf dem Präpariersaale während meiner Vorstandschaft in Berlin tätig war. Von Inländern nenne ich die Professoren Kallius, Ordinarius in Breslau, und Lubosch, Extraordinarius in Würzburg, dann Dr. Grafen Haller, z. Zt. Assistenten des Berliner Instituts. Aus Amerika kamen Professor Dr. Geo Piersol, Anatom in Philadelphia, Professor Karl Huber, Anatom in Ann Arbor (Michigan), Professor Corning, Ordinarius der Anatomie in Basel; aus RuBland: Kultschitzky in Charkow, Smirnow in Tomsk, und Argutinsky in Kasan; aus Japan: Taguchi, Ordinarius für Anatomie in Tokyo, Buntaro Suzúki und Keïtaro Kamon, Beide aus Kyoto; aus Polen: K. v. Kostanecki, Ordinarius für Anatomie in Krakau; aus Rumänien: Professor Gerota, topographischer Anatom und Chirurg in Bukarest, bestens bekannt durch seine Untersuchungen über das Lymphgefäßsystem; aus Griechenland: Dr. Cilimbaris, Dozent der Anatomie, jetzt der Chirurgie in Athen, Verfasser eines Lehrbuches der topographischen Anatomie, für welches er die Vorarbeiten im Berliner Anatomischen Institut ausführte.

Fast die Hälfte der hier Genannten weilt nicht mehr unter den Lebenden. Ihnen ein ehrendes Gedächtnis und allen meinen Mitarbeitern treuen Dank in Erinnerung an gemeinsame Arbeit! 
X. Ka pitel.

\section{Von meinen Reisen und Wanderungen.}

Schwarzwald und Vogesen, Frankreich, Italien, Orientreisen, Vereinigte Staaten von Nordamerika, Mexiko. - Die Todesfahrt der Russischen Flotte I 904. - Die Kämpfe um die Weltmeere.

Die Nähe des Schwarzwaldes und der Vogesen, des alten Wasgenwaldes, sowie der Schweiz legte es den nach Straßburg Berufenen nahe, ihren Erholungsaufenthalt in den Ferien an einem oder dem anderen dieser drei, seit jeher für solchen $Z$ weck besonders beliebten Plätzen zu wählen. Für Straßburg, welches in dieser Beziehung besonders günstig gelegen ist, kommt ja auch noch das Rhein- und Moselgebiet in Betracht. Am beliebtesten war den Straßburgern auch schon $\mathrm{zu}$ ehemaliger französischer Zeit der Schwarzwald, insbesondere Baden-Baden gewesen, welches ja sozusagen vor den Toren Straßburgs liegt. Weniger besucht waren noch damals die Vogesen; uns neuen Elsässern waren sie gänzlich fremd. Ich habe es mir angelegen sein lassen, durch öftere Fußwanderungen, die mich auch in französisches Gebiet führten, bis Remiremont, Epinal und Belfort, über die sogenannte "Schlucht" nach Gerardmer und nach anderen Orten, mir Kenntnis dieses Waldgebirges anzueignen. Ein besonders hübscher Ort sind die „Drei Ähren“, die auch am meisten von den Altelsässern besucht wurden. Auf einer dieser Fußwanderungen, die ich in Begleitung meiner Kollegen Lücke und v. Recklinghausen unternahm, war der Vogesenkamm noch reich mit Schnee bedeckt. Beim Aufstieg kamen wir an einem ländlichen Wirtshause vorbei und fragten, ob wir später bei der Rückkehr dort zu Mittag speisen könnten? Die Wirtin meinte, daß es sehr schwer sei, in dieser Jahreszeit etwas $z u$ beschaffen, ein paar Butterbrote könne sie uns allenfalls geben, kurz, wir merkten, daß sie uns mit einem gewissen Mißtrauen, wie es damals von manchen Seiten den eingewanderten Deutschen, als welche sie uns natürlich sofort erkannte, entgegengebracht wurde, betrachtete. Als wir von unserer etwas beschwerlichen Wanderung zurückkamen und einkehrten, trat uns die Frau mit ihrem Säugling auf dem Arme entgegen, einem netten frischen Bübchen. Lücke trat auf sie zu, kniff dem Kleinen in die roten Pausbacken und sagte der 
Frau ein artiges Kompliment über ihren Sprößling und damit hatten wir ihr Zutrauen gewonnen. Sie meinte, sie hätte noch etwas gefunden, wir möchten nur ein wenig Geduld haben. Es dauerte nicht lange, da erschien sie mit einem schmackhaft zubereiteten, reichlich bemessenen Eierkuchen, Butter, Brot und gutem Käse und fragte, ob die Herren auch ein Glas Wein wünschten, was wir gerne bejahten, und siehe da, sie brachte ein paar Flaschen vorzüglichen französischen Rotweins heran. Recht erquickt und unter voller Zufriedenheit beider Parteien traten wir den Heimweg an. Ich habe oft an dics kleine Erlebnis denken müssen, wenn die Frage der Einigung des Elsa $B$ mit der alten deutschen Stammheimat zur Erwägung kam.

So lange, wie ich in Straßburg war, habe ich mich beim Besuche französischen Bodens auf die erwähnten Vogesenwanderungen beschränkt. Später, von Berlin aus, habe ich im Laufe der Zeit ganz Frankreich wiederholt besucht und lernte Paris fast so gut kennen wie Berlin. Die Normandie, die Bretagne, die Provence, die Pyrenäen, Westfrankreich am Atlantischen Ozean wie das Loiregebiet sind mir nicht fremd; einiges darüber ist schon zur Sprache gekommen, anderes mag hier angefügt werden: Zunächst hebe ich hervor, daß mir bei allen diesen Reisen, die mich in vielfache Berührung mit allen Volksschichten brachten, niemals auch nur die geringste Unannehmlichkeit im Verkehr mit den Bewohnern vorgekommen ist, obwohl ich stets darauf hielt, mich nicht nur als Deutschen, sondern auch als „Prussien“" aus Berlin bekannt zu geben. Im Gegenteil kann ich sagen, daß man mich überall entgegenkommend, ja freundlich behandelt hat. Mögen ein paar Beispiele erzählt sein. Eine meiner Fahrten führte mich nach St. Malo, wo ich Seebäder nahm und von da die Insel Jersey besuchte. In dem Gasthofe, wo ich Unterkunft nahm, bekam ich bei Tisch meinen Platz neben einem alten französischen Schiffskapitän, einem derben, echten Seebären. Das Gespräch schwenkte oft ins Politische ein und mein Nachbar hielt mit seinem Zorn auf Bismarck nicht zurück, den ich nun ebenso entschieden verteidigte. Die übrige Tischgesellschaft ergötzte sich augenscheinlich an unserem Wortgefecht. Aber wenn es auch noch so hitzig gewesen war, beim Aufstehen reichten wir uns stets die Hand; es kam nie zu einer Störung. Bei Tische speisten meist einige Offiziere der Garnison von St. Malo. Ich wurde auch mit ihnen bekannt. Von meinem Fenster aus konnte 
ich täglich die Übungen eines der Bataillone aus der Ferne sehen. Es interessierte mich, die französische Art des Exerzitiums näher kennen zu lernen und ich fragte einen der Offiziere, ob ich wohl die Erlaubnis dazu erhalten könne? Sie wurde mir ohne weiteres gewährt. Man wies mir einen bequemen Sitz auf dem Übungsplatze an, von wo aus ich ein paar Stunden lang den Übungen gut folgen konnte.

Ich erwähnte bereits, da $B$ ich bei Gelegenheit meines Aufenthaltes in St. Malo kennen lernte, wie man mit der Kunkel spinnt. Ich komme noch einmal auf diese interessante bretagnische Stadt und auf die Insel Jersey zurück.

Ein anderes Mal fuhr ich - es war gerade in der Zeit, in der die sogenannte „,Schnäbeli-Affäre“ eine gewisse Erregung in der Presse hüben und drüben erzeugt hatte - mit der Bahn auf der Strecke Marseille-Toulon-Nizza. Mit mir im selben Abteil saßen einige französische Offiziere, die von einem gerade beendeten Manöver in ihre Garnisonen zurückreisten. Ich sa $B$ in der einen Wagenecke, zog eine Karte der Strecke hervor und begann mit ihrer Hilfe die Gegend, die wir durchfuhren, mir zurechtzulegen. Da sagte mir einer der Offiziere, wenn ich mich gut zurechtfinden wolle, möge ich seinen Platz einnehmen, stand zugleich auf und bot ihn mir an. Ich erhob mich und stellte mich als den Professor W. aus Berlin vor, der auf dem Wege nach Nizza zum ersten Male diese Strecke fahre. Auf dem mir angebotenen Platze konnte ich mich viel besser über die Gegend belehren, wobei mir die Offiziere außerdem freundlich behilflich waren.

Von allen meinen Reisen und meinem Verkehr in Frankreich habe ich, abgesehen von dem erzählten Zwischenfalle in Paris Igor, nur angenehme Eindrücke mitgebracht und ich $\mathrm{mu} B$ sagen, da $B$ mir nichts so leid' tut, als da $\beta$ wir Deutsche mit unseren französischen Nachbarn stets auf dem Kriegsfuße leben. Geeint könnten wir die Welt beherrschen, wenigstens dem von der einen Seite anschwellenden Angelsachsentum sowie dem von der anderen Seite drohenden Slawismus einen sicheren Damm entgegensetzen, der Europa die ihm gebührende Weltstellung bewahrte. Gern komme ich hier noch einmal auf den gleichen, schon S. I68 ausgesprochenen Gedanken zurück.

Bleiben wir noch eine Weile bei Frankreich. Ich erzählte schon von einer Reise mit meiner älteren Tochter und einer meiner Nichten nach Paris und von da über Dijon nach Genf. Eine zweite Reise 
machte ich mit derselben Tochter und einer meiner Schwiegertöchter, Frau meines älteren Sohnes, über Annecy, Lyon, Montpellier, Carcassonne, Lourdes, Bagnères de Luchon, Biarritz und Paris, dann von da nach Salzburg, wo die Anthropologenversammlung tagte, von da nach Linz und weiter auf der Donau bis Wien. In Annecy bin ich mehrmals gewesen; eine Fahrt auf dem dortigen See gehört mit zu den schönsten Reisegenüssen, die man sich bieten kann. Hat man günstiges Wetter und kann in Talloires unter den Bäumen am Seegestade ein paar Stunden verweilen und sein Mittagsmahl im Freien einnehmen, so hat man sich einige der angenehmsten Eindrücke verschafft, die man haben kann und, je schlichter das Mahl, desto besser! Es schadet auch nichts, wenn der Wein nur dem "vile Sabinum“ entspricht, den Horaz seinem Gönner Maecenas vorzusetzen in der Lage war.

Eine der bemerkenswertesten Erinnerungen bot uns auf dieser Reise das malerisch auf der Höhe gelegene alte Carcassonne mit seinen Jahrhunderte alten Mauern. In der neueren unteren Stadt wohnten wir recht angenehm in einem einfachen Gasthofe, dessen freundliche Wirtin meinen beiden Begleiterinnen, die eine von ihr bereitete Brioche gelobt hatten, mit echt südfranzösischer Lebhaftigkeit zeigte, wie man eine solche Brioche mache.

Von Bagnères de Luchon, einem reizend gelegenen Orte, machten wir einen Ausflug nach dem so berühmt gewordenen Wallfahrtsort Lourdes. Ich habe mir dort Alles genau angesehen - wir waren einen vollen Tag dort - und kann nur sagen, da $B$ ich an solchen Dingen, wie sie da vorliegen und geübt werden, keinerlei Erbauung finden konnte. Wundererscheinungen, wie sie zur Annahme, daß Lourdes ein besonderer Gnadenort sei, geführt haben, begegnen heutzutage berechtigten Zweifeln. Meiner Meinung nach hat auch sonst die Kirche in ihrem schönen Gottesdienste und in der Abwechslung der religiösen Feste im Kirchenjahre Mittel genug an der Hand, um das kirchliche Leben bei allen Ständen und Bildungsgraden ihrer Gläubigen wach zu erhalten.

In St. Malo interessierte die dort immer auffallend starke Ebbeund Flutbewegung des Meeres. Ein Hauptvergnügen der Meerbadegäste bestand darin, daß man nachmittags, wenn die Flut zu steigen begann, vor einem in der Nähe des Strandes, der dort langsam an- 
stieg, gelegenen Kaffeehause Platz nahm. Während man nun seinen Kaffee trank und plauderte, stieg die Flut heran und spülte bis an die Stühle, dann galt es, sich beizeiten auf einen höher gelegenen Platz zurückzuziehen. Dieser oder Jener, Männlein oder Weiblein, ließ sich wohl in der Unterhaltung vom andringenden Wasser überraschen und mußte dann unter allerlei Heiterkeit seinen Stuhl durchs Wasser tragen. Ebenso ergötzlich gestaltete sich das Flutvergnügen auf den hohen alten Festungswällen von St. Malo in den Tagen der Springflut, die ich dort miterlebte. Die Wasser stiegen so hoch, daß sie ab und zu selbst die hohen Mauern überschlugen, hinter denen die Leute, um sich das wirklich großartige Schauspiel anzusehen, dicht gedrängt standen. Wenn nun so ein tüchtiger Spritzer oder wie ich lieber sagen möchte ,Klatscher“ die Mauer überschlug, so bekamen die gerade dahinter Stehenden mitunter ein gehöriges Seebad zum großen Jubel der Menge. Das geschah aber bald an dieser, bald an jener Stelle der dem Meere zugewandten Mauerstrecke, so da $B$ Niemand sicher war, ob es nicht in der nächsten Minute ihn treffen werde. Gerade in diesem Schwankenden und Ungewissen lag ein besonderer Reiz dieses Naturschauspiels.

Die rasch eintretende starke Flut stellt bei St. Malo den Leuten noch eine andere Falle. Auf einer Landzunge, die mit niedrigem Rücken beginnt und ansehnlich erhöht im Meere endigt, liegt auf dieser höheren Endstelle das Grab Chateaubriands. Die Grabstätte wird viel besucht; auch hat man von da einen Ausblick auf das Meer von großer Wirkung. Zur Zeit der Ebbe liegt der niedrige Teil der Landzunge unbedeckt und man kann einige Zeit nach Ablauf des Wassers gut zur Anhöhe hinüber gehen. Bei voller Flut geht die See meterhoch über den Rücken hinweg und diejenigen, welche die rasch einsetzende Flut nicht beachtet haben, werden auf mehrere Stunden vom Lande abgesperrt, falls nicht gerade ein Boot zur Stelle ist. Um die Besucher der Anhöhe aufmerksam zu machen, wird kurz vor dem Einsetzen der Flut ein Kanonenschuß gelöst. Das Anbooten dort ist bei der Flut auch nicht leicht. Ich war einmal Zeuge, daß mehrere Besucher der Anhöhe auf diese Weise abgesperrt wurden.

Viel Schönes bietet auch die Insel Jersey, zwischen der und St. Malo eine regelmäßige Dampferverbindung besteht. Sehr lohnend ist da ein Besuch der Markthalle von St. Helier, der Hauptstadt der 
In Italien. Der Soracte. Perugia.

Insel, mit der Fülle der dort feilgebotenen Früchte und Blumen. Ich wanderte durch die ganze Insel, besuchte das alte Schloß Mont Orgeuil und fand in dem kleinen, am Meere um eine aus Feldsteinen erbaute epheuumrankte Kapelle gelegenen Friedhofe von St. Brelade eine Totenstätte von solcher, nur vom Meeresrauschen beherrschten Ruhe und Friedensstimmung, da $B$ in mir der Wunsch sich regte, dort einst in Ewigkeit zu ruhen. Es gibt solche stillen Orte, die in vielen Menschen diesen Wunsch entstehen lassen, dort vom Leben auszuruhen. St. Brelade hat bei mir einen Mitbewerber gefunden, den kleinen Domhof zu Hildesheim mit dem als tausendjährigen angesprochenen Rosenstocke. Sicherlich hat der Stock mit seinen mehr als 300 Jahren ein respektables Alter.

Meine crste Italien-Reise war die bereits kurz im Kapitel „Breslau" erwähnte, die mich auch zur Zoologischen Station nach Neapel führte. Meiner Arbeit dort ist bereits gedacht worden; mögen hier noch ein paar Reiseeindrücke Platz finden. Besonderen Eindruck machten auf mich die Stätten, die mir aus der Zeit meiner Gymnasialstudien bekannt waren, so unter anderen die Fahrt am Trasimenischen See entlang im Gedenken an den berühmten Zug Hannibals, und der Anblick des Soracte, der mir das Horazische „Vides ut alta stet nive candidum Soracte“ ins Gedächtnis rief, obwohl bei meiner Vorüberfahrt der Soracte kein Schneehaupt trug. Dann das Forum Romanum und so vieles andere, was man als Schüler eines humanistischen Gymnasiums kennen gelernt und gern einmal zu sehen gewünscht hat. Ich glaube nicht zu irren, wenn ich annehme, da $B$ man mit humanistischer Vorbildung einen viel höheren Genuß hat, wenn man diese Dinge später zu sehen bekommt, als ohne eine solche Vorbildung. Gewiß will ich den Leuten, die dieser Vorbildung entbehrten, einen ästhetischen Kunstgenuß, einen Genuß an den Landschaften usw. nicht absprechen; viele von ihnen mögen einen höheren Genuß daran haben, als ehemalige Gymnasialschüler; aber ich meine, daß in den Fällen, wo die ästhetische Genußfähigkeit auf beiden Seiten gleich ist, der Gymnasialschüler im Vorteil ist; bei ihm kommt, so möchte ich sagen, ein gewisser Schmelz hinzu, der dem nicht klassisch Vorgebildeten fehlt und durch nichts ersetzt werden kann.

Auf dieser Fahrt brachte ich auch zwei Tage in Perugia zu, um die Stadt Pietro Peruginos und Raffaello-Sanzios sowie die in der Nähe 
befindlichen etruskischen Altertümer kennen zu lernen. Von dem hochgelegenen Orte hat man einen herrlichen Blick auf dic umbrische Landschaft. Ich besuchte dort auch meinen anatomischen Spezialkollegen, Professor Morta ra, der zugleich ein klinisches Fach vertrat. Ich ging mit ihm in das Anatomische Institut, dort öffnete Mortara ein Fenster, ließ mich hinausschauen und sagte: „Sehen Sie, das ist das Beste am Anatomischen Institut." Und er hatte Recht!

Auf der Fahrt von Rom nach Neapel, die ich in der Nacht unternahm, so da $B$ ich mit vollem Tagesanbruch in Neapel ankam, schaute ich beim beginnenden Tagesgrauen nach dem Vesuv aus, begreiflich für Jeden, der noch keinen Vulkan gesehen hat. Und der alte Feuerspeier tat mir den Gefallen, sich als Vulkan zu dokumentieren, indem er ständig eine hohe Rauchsäule emporsteigen ließ. Ich habe denn auch seinem Krater den selbstverständlichen Besuch abgestattet. Zweifellos gehören die vulkanischen Erscheinungen mit zu den merkwürdigsten und, falls sie mit voller Kraft auftreten, großartigsten Erscheinungen des inneren Erdenlebens. Ein wenig davon bekam ich auf einer zweiten Reise nach Neapel, die ich mit meiner Frau und meinen Töchtern unternahm, zu sehen. Kurz vor unserer Ankunft war ein ansehnlicher Ausbruch des Berges gewesen; der frische Lavastrom war kaum erkaltet. Während der Dunkelheit sah man von Neapel aus noch eine Feuersäule aus dem Krater aufsteigen und beim Besuche des Berges konnten wir uns dem Krater nur bis zu einer gewissen Strecke nähern, denn in kurzen $Z$ wischenräumen warf der Berg unter starkem Getöse mit einer dichten Rauchwolke eine Menge Asche und Schlacken aus.

Während meines Aufenthaltes an der Neapeler Zoologischen Station machte ich zusammen mit dem leider so früh verstorbenen Anatomen Dr. Langerhans, damals in Freiburg i. B., Sohn des bekannten Berliner Stadtrats Langerhans, Freund Rudolf Virchows, und mit dem späteren Leipziger Kliniker Albin Hoffmann einen Ausflug nach Salerno, Amalfi und Paestum, der sich äußerst angenehm gestaltete. Wir drei, jung an Jahren - ich als ältester mit 36 - lebensund wanderlustig, Wetter wundervoll, das, was wir besichtigten, geschichtlich wie landschaftlich hochinteressant, als Drei gerade in der richtigen Zahl und einander gut verstehend: da muB eine solche Wanderschaft wohl gut ausfallen. Gern denke ich stets noch daran 
zurück. Etwas Ländlich-Sittliches sei aus unseren damaligen Erlebnissen erzählt. Einer unserer Wandertage war ein Sonntag; wir kamen an einer kleinen Kirche vorbei, die unter einer hübschen Baumgruppe am Wege lag. In der Kirche wurde gerade der Hauptgottesdienst gehalten, die Eingangstür war weit geöffnet, so da $B$ man den Priester am Altar sehen und so von draußen am Gottesdienste teilnehmen konnte; es standen auch außen einige Leute, die in der Kirche nicht mehr Platz gefunden hatten; das war nun weiter nichts Besonderes. Auffällig aber für uns Nordländer war, da $\beta$ ein Fleischer dicht neben der geöffneten Kirchentür beschäftigt war, ein an einem Gestell, welches an die Kirchenmauer gelehnt war, aufgehängtes Schwein kunstgerecht auszuweiden. Dabei nahm er an dem Gottesdienst insofern teil, als er bei den Glockenzeichen, welche die Hauptabschnitte des Meßopfers anzeigen, so beim Offertorium, bei der Wandlung, bei der Kommunion des Priesters, in der üblichen Weise niederkniete und sich bekreuzigte, dann aber sofort wieder in seiner Arbeit fortfuhr. Wir, begreiflicherweise neugierig, weshalb das Geschäft gerade hier während des Gottesdienstes dicht an der Kirche verrichtet wurde, warteten das Ende der Messe ab und erhielten des Rätsels Lösung. Der Fleischer hatte mittlerweile das Schwein in einzelne Stücke zerlegt und diese auf seinem Karren zur Schau ausgestellt. Die Kirchgänger sammelten sich um den Karren und in kurzer Zeit war alles Fleisch verkauft. Die Kirche bildete offenbar einen Mittelpunkt für die in der Umgegend zerstreut wohnenden Landleute, die sich sicher zum sonntäglichen Gottesdienste dort zusammen fanden. Diese Gelegenheit wurde dann gleich benutzt, um sie mit Fleisch zu versorgen. Es spielte sich alles so ruhig ab, da $B$ auch wir schließlich uns nicht weiter wunderten; befremdlich blieb uns aber doch, weshalb der Fleischer das Herrichten des Tieres nicht schon vor dem Gottesdienste erledigt hatte. $\mathrm{DaB}$ er sein Gestell dicht an die geöffnete Kirchentür gestellt hatte, war verständlich, denn auf diese Weise konnte er dem Kirchengebote, Sonntags eine Messe zu hören, genügen.

Noch drei größere Fahrten nach Italien, abgesehen von mehreren kürzeren, habe ich unternommen, die größte I89o mit meiner Frau und meinen beiden Töchtern, von der ich vorhin kurz den zweiten Besuch des Vesuv erwähnte. Die Reise ging über Dresden, Prag, 
Wien, Budapest, Agram, Fiume zunächst nach Abbazia, wo ein mehrtägiger Aufenthalt genommen wurde. In Dresden und Wien wurden hauptsächlich die Kunstschätze, an denen beide Städte so reich sind, in Augenschein genommen. In Budapest besuchten wir meine früheren Assistenten v. Mihalkovics und Pertik, die inzwischen dort Professoren an der Universität geworden waren. Die Fahrt von Wien nach Budapest hatten wir auf der Donau zurückgelegt. Abbazia war angenehmer Ruhepunkt und Station für kleinere Wanderungen in der hübschen Umgebung. Von dort mit dem Dampfer nach Pola, wo uns das Tegetthoff-Denkmal und das alte Amphitheater interessierten, dann längs durch Istrien nach Triest, von da nach Venedig, Bologna, Florenz und Rom. In Bologna verbrachten wir einen angenehmen Abend zusammen mit meinem früheren Laboranten Biondi, dessen ich bereits gedachte und in Pisa und Siena, wohin unsere Weiterfahrt von Bologna zunächst führte, kamen wir mit Freund Romiti und seiner Familie zusammen. In Rom verweilten wir beinahe zwei Wochen. Wir nahmen uns hier vor, wie überall auf unserer ganzen Reise, nicht alles zu sehen, was unser Reisehandbuch anführte, sondern widmeten den Museen und Baudenkmälern nur wenige Stunden am Vormittage und verwendeten die Nachmittage zu Ausflügen in die Landschaften, immer darauf bedacht, am Abend zeitig zurück zu sein, in aller Behaglichkeit die Abendmahlzeiten einzunehmen und nachher noch in gemütlicher Unterhaltung über das Gesehene und Erlebte in einem Kaffeehause ein Stündchen zu verbringen, dann bei guter Zeit zur Ruhe! Theater, Konzerte, kurz, dergleichen Abendvorstellungen haben wir nur selten besucht, um uns nicht zu übermüden. So blieben wir die ganze Zeit hindurch frisch und empfänglich für neue Kunstgenüsse. Als wir am Ende unserer Reise in Köln anlangten, haben wir uns dort das Museum Wallraf-Richartz mehrere Stunden lang mit demselben Genusse und Interesse angesehen, wie wenn es das erste auf unserer Reise gewesen wäre. Was wir uns ansahen, haben wir uns gründlich angeeignet; gefiel uns etwas besonders, so sahen wir es uns an einem anderen Tage lieber noch einmal an, als etwas Neues. Ich bringe hier keine Beschreibung alles des Gesehenen, darüber findet man in unseren guten Reisehandbüchern und in den kunstgeschichtlichen Werken viel Besseres, als ich zu geben vermag. Lieber ein paar kleine Reiseanekdoten: Von Rom aus 
machten wir eine Seitenfahrt nach dem Albaner See und dem NemiSee. Besonders dieser See mit seiner stillen, abgeschlossenen Umgebung ist mit das Eindrucksvollste von dem, was ich an Landschaftsbildern gesehen habe; ich habe ihn auf allen meinen Romreisen aufgesucht. Wir kebrten uiber Ariccia, Genzano und Albano nach Rom zurück. In Genzano war eine Art Jahrmarkt. Ein Mann stand auf einem Tische und pries mit helltönender Stimme allerlei Bekleidungsstücke zum Verkaufe an, unter anderen Frauenhemden; er konnte nicht genug Worte zum Anpreisen gerade dieses Artikels finden. Als immer noch keine der anwesenden Frauen Miene machte, zu kaufen, zog er sich plötzlich eines dieser Frauenhemden über den Kopf, strich es glatt, stellte sich in Positur und rief: „Ecco, Signore e Signori, gentile! ammirabile!“

Nach Rom kam Neapel mit Capri an die Reihe, dann Messina und Taormina, wolll einer der schönsten Punkte der Welt, in seiner glänzenden, weit umfassenden Art ein Gegenstück zum ernsten, düsteren, abgeschlossenen Nemi-See. Dann Syrakus. Hier wieder ein kleines, echt italienisches Reiseerlebnis. Wir hatten uns an die Casa Politi gewendet, deren Besitzer als Fremdenführer empfohlen war. Zu unserer Überraschung empfing uns Signora Politi mit unverfälschtem ostpreußischem Dialekt, den wir in Syrakus am wenigsten zu hören erwartet hatten. Frau Politi stammte aus Königsberg in Preußen und das gab nun allerlei Gesprächsstoff zwischen ihr und meiner Frau. Signor Politi, ein echter Sizilianer, spannte dann sein Rößlein an und führte uns $z u$ den Sehenswürdigkeiten, insbesondere zu den Latomien, den Katakomben, zum römischen Amphitheater und zum altgriechischen Theater. Mittlerweile war die Mittagszeit näher gerückt, Signor Politi nahm seinen Hut ab und wir bemerkten auf seinem etwas durchwärmten Schädel ein kleines Päckchen, welches sauber eingewickelte Butterbrote enthielt. Unbefangen bot er uns davon an, aber ebenso unbefangen lehnten wir ab, die Nähe des Mittagessens vorschützend.

Von Syrakus fuhr uns die Bahn durch die Mitte der Insel über Castrogiovanni nach Palermo, einer mit ihrer näheren und ferneren Umgebung sehenswertesten Stadt, die ich kennen gelernt habe; vor allem denke ich dabei an Monreale! Ich besuchte auch den wohlerhaltenen giiechischen Tempel von Segesta. In Marsala schifften wir 
uns dann nach Tunis ein. Auch da ein kleines Reiseabenteuer. Man hatte uns empfohlen, doch eines der jüdischen Wohnhäuser, welches Fremden gezeigt zu werden pflege, zu besuchen. Gesagt, getan. Wir traten ein, da fanden wir in einem Zimmer zwei Frauen beschäftigt, den Fußboden mit nassen Tüchern zu reinigen. Wir blieben einen Augenblick stehen, um abzuwarten, bis sie ihr Geschäft beendet hätten. Da erhob sich zwischen den beiden Frauen ein Wortstreit und ehe wir uns dessen versahen, sprang die eine auf die andere zu und versetzte ihr mit dem nassen Wischtuche einen Schlag ins Gesicht. Die Geschlagene trat nun auf meine Frau zu, heftig gestikulierend und in uns unverständlicher Sprache auf sie einredend; meine Frau wandte sich an den Führer, der ihr erklärte, die Geschlagene rufe sie zur Zeugin an und verlange, da $\mathrm{B}$ sie vor Gericht Zeugnis ablegen solle. Wir zogen vor, die Bekanntschaft mit dem Kadi nicht zu machen und verließen rasch diesen ungastlichen Ort.

Vor der Abfahrt besuchten wir noch die Ruinenstätte des alten Karthago. Auf der Fahrt nach Marseille erging es uns übel; wir erlebten einen gehörigen Meeressturm derart, daß die Wellen über dem Oberdeck zusammenschlugen. Meine Frau und meine ältere Tochter litten arg unter der Seekrankheit, während meine jüngere Tochter und ich völlig frei blieben. Bei Tisch waren wir Beiden die einzigen Teilnehmer; auch ein Teil der Schiffsoffiziere hatte vor Neptuns Zorn kapitulieren müssen. Schüsseln und Teller mußten auf dem Tische befestigt werden und das Schiff schwankte so sehr, daß einer der Diener, als er mit einem neuen Gericht in die Kajüte trat, der Länge nach mit seiner Schüssel zu Boden fiel. Einen ähnlichen Sturm habe ich auf der Überfahrt von der Insel Jersey nach Granville erlebt, doch war der Mittelmeersturm schon wegen seiner längeren Dauer der schlimmere. In Marseille angekommen, erholten sich meine seekranken Reisegefährtinnen bald. Über Paris, wo wir einige Tage verweilten und unter anderem Madame Sarah Bernhardt auftreten sahen, dann als letzten Reisehalt über Köln ging es der Heimat zu. Es war, selbst den Seesturm eingerechnet, denn es hat sein Interesse weniger freilich für die armen Seekranken - auch so etwas zu erleben, die schönste und lohnendste Reise, die ich gemacht habe, insbesondere dadurch, daß ich sie in Begleitung meiner Frau und Töchter, die im blühenden Alter von I9 und I7 Jahren standen, machen konnte. 
Eine weitere Italien-Reise unternahm ich mit meinem älteren Sohne, meiner jüngeren Tochter und meiner jüngeren Nichte, Agathe Dillenburger, deren ältere Schwester Gertrud ich, wie berichtet, zusammen mit meiner älteren Tochter auf eine Reise Paris, Dijon, Genf, Salzburg, Wien zur Begleitung gehabt hatte. Wir beschränkten uns bei dieser Italienfahrt auf Nord- und Mittelitalien bis Rom einschließlich. Unvergeßlich ist mir von dieser Reise ein Abend in Frascati. Nach Tische setzten wir uns bei herrlichem Mondschein ins Freie und ließen uns vom besten Chianti in den großen strohumflochtenen Flaschen kommen. Es war ein köstlicher Wein; ehe wir uns dessen versahen, war der Fiasco leer; wie viele wir noch nachkommen ließen, weiß ich nicht mehr, aber es war längst Mitternacht vorüber, als wir unser Nachtlager aufsuchten. Doch in aller Morgenfrühe waren wir munter und wohlgemut wieder zur Stelle, wanderten zu Fuß nach Rocca di Papa und von da hinab zum Nemi-See. Unterwegs überfiel uns eines der stärksten Gewitter, die ich erlebt habe; man konnte ein unheimliches Gefühl bei dem fast ohne Pausen erfolgenden Blitzen und Kra chen nicht ganz verbannen. Dies Gefühl hatte offenbar auch der junge Bursche, den wir als Träger unseres Gepäcks mitgenommen hatten; er kniete, des strömenden Regens nicht achtend, vor einem in der Nähe befindlichen Steinbildnisse der Mutter Gottes nieder in den schlammigen Boden, bekreuzigte sich und rief den Schutz der Madonna an. Das Gewitter hörte, wie fast alle heftigen Explosionen dieser Art, bald auf und wir kamen, freilich etwas durchnäßt, aber wohlbehalten in Nemi an. Der Bursche schabte sich mit einem Holzspan den Schlamm von seinen Hosen und vertilgte nachher, da ihm offenbar der Schreck guten Appetit gemacht hatte, eine Schüssel Maccaroni, die ich, als sie hereingebracht wurde, als ausreichend für uns fünf insgesamt erachtet hatte.

Ein drittes Mal führte mich im Frühjahre I897 die Feier des 25 jährigen Bestehens der Stazione zoologica nach Italien bis Neapel. Ich reiste in Begleitung meiner Frau und meines älteren Sohnes. Bei der Feier fiel mir als ältestem Laboranten der Station eine der Begrüßungsreden zu. Ich lernte dort den derzeitigen Botschafter in Rom, v. Bülow, kennen. Anton Dohrn sagte mir damals voraus, v. Bülow sei der kommende Mann; er hatte richtig geurteilt: Zwei Monate später wurde v. Bülow 
Staatssekretär des Auswärtigen und drei Jahre später, im Oktober I900, Reichskanzler.

Zweimal noch habe ich auf einer schönen Mittelmeerfahrt einen Teil Italiens besucht. Das erste Mal mit dem Dampfer „Karlsruhe“ von Bremen aus entlang der Südküste Englands, der Westküste Frankreichs, Spaniens, Portugals, dann durch die Meerenge von Gibraltar, weiter Spanien, Frankreich und Italien entlang bis Neapel. Dieselbe Fahrt machte. ich später noch einmal mit dem Dampfer ",Prinz Heinrich", diesmal in Begleitung meiner beiden Schwiegersöhne, des Hauptmanns v. Bonin und des Professors Tilmann und dessen Frau, meiner jüngeren Tochter Ilse. Auf demselben Schiffe machten gleichzeitig die gleiche Reise der Herzog Johann Albrecht von Mecklenburg mit seiner Gemahlin. Wir brachten gewöhnlich die Abende zusammen in angenehmer und anregender Unterhaltung zu. Diese Mittelmeerküstenfahrten sind wohl die angenehmsten Reisen, die man machen kann, vorausgesetzt, da $B$ man seefest ist.

Auf der zweiten Reise verließen wir in Neapel das Schiff und besuchten noch in Sizilien Messina, Taormina und Syrakus, fuhren von Catania $a b$ nach Genua und von da heim. Der Glanzpunkt dieser Reise war Taormina. Wir standen in der Osterzeit. Ganz Sizilien war schon ein Blütengarten, der Koloß des Ätna aber noch bis tief hinab in blendend weißem Schneekleide, ebenso noch die Spitzen der Berge auf dem gegenüberliegenden italienischen Stiefelfuße, dazwischen das tiefblaue Meer; alles dieses umfaßte bei herrlichstem Sonnenschein von Taormina aus der Blick. Der Reiz wurde noch erhöht dadurch, daß der Ätna ständig seine Rauchwölkchen sehen ließ. Erst dieses Mal empfand ich die wunderbare Schönheit der TaorminaLandschaft vollständig; man muß Taormina im Frühjahre besuchen.

In Syrakus machte mein Schwiegersohn Bonin - er ist protestantischer Konfession - , eine unfreiwillige Bekanntschaft mit Ostergebräuchen der katholischen Kirche. Er hatte sich nach der Mittagsmahlzeit auf sein Zimmer zurückgezogen, um ein wenig der Ruhe zu pflegen und lag noch wach auf seinem Ruhebette, als sich die Tür öffnete, ein Priester mit der Alba bekleidet und gefolgt von einem Chorknaben, der das Weihwasser trug, in der Türöffnung erschien und unter einigen Ritualworten meinen Schwiegersohn mit Weihwasser besprengte. Es geschah mir in meinem Zimmer nebenan ebenso; mir 
Orientreise.

als Katholiken war ja die Sache bekannt, während mein Schwiegersohn höchst verwundert diesen frommen Brauch über sich hatte ergehen lassen müssen.

Weit über Italien hinaus führte mich eine Orientreise, die ich vom Anthropologenkongresse in Nürnberg I887 aus antrat. Ich reiste über Wien, durch Ungarn und Rumänien nach Varna, wo ich mich für Konstantinopel einschiffte. Beim Morgengrauen fuhren wir in den Bosporus ein und die Fahrt durch diese enge Meeresstraße und von da aus der Blick auf Konstantinopel ist überaus lohnend. In Stambul verweilte ich acht Tage, besuchte den Palast Dolmabagdsche, wohnte einer FreitagsMoscheefahrt des Sultans Abdul-Hamid bei, der in einem Wagen mit dem Sieger von Plewna, Osman Pascha, sa $B$, konnte die prächtige Haltung des türkischen Militärs, welches das Gefolge des Sultans bildete, bewundern, sah die tanzenden Derwische und vieles andere, was noch das echt alttürkische Leben charakterisierte. Jetzt wird man in Konstantinopel einen ganz anderen Eindruck haben. Damals waren noch die Hunde, man konnte sagen, die Herren der Straße, scheußlich aussehende, räudige Tiere, die Niemandem auswichen und es als selbstverständlich anzunehmen schienen, da $B$ Wagen und Menschen ihnen ausbogen, wenn sie auf der Straße lagen. Jeder Hund hatte aber seinen Bereich und duldete es nicht, da $\mathrm{B}$ ihm ein anderer da hineinkam. - Öfters nahm ich meine Mahlzeiten in türkischen Speisehäusern und versuchte auch das Nargileh, die Wasserpfeife, zu rauchen, ohne jedoch dieser Art des Tabaksgenusses besonderen Geschmack abgewinnen zu können. Das Sehenswürdigste in Konstantinopel ist die Sophienkirche, die Hagia Sophia, ein Wunder der Baukunst, von außen leider durch Um- und Anbauten verunziert, vielfach auch im Inneren durch die Anbringung allerlei türkischer Inschriften, welche die Wände verdecken, großartig aber in ihrem Inneren durch die Gesamtwirkung des hochragenden Baues. Um einen Überblick von Konstantinopel zu erlangen, machte ich mit einem Führer auch noch einen Ritt um die alten Stadtmauern.

Ich besuchte auch die Prinzeninseln und Brussa, in schöner Lage am Bithynischen Olymp gelegen, und dort die Gräber der ersten osmanischen Sultane. Ferner führte mich mein Weg nach Smyrna und von da in mehreren Ausflügen landeinwärts. Ich besuchte die Insel Syra und fuhr weiter durch das Ägäische Meer zum Piräus und 
Athen. Da empfand ich wieder dasselbe dankbare Gefühl über meine Ausbildung auf einem humanistischen Gymnasium, wie ich es von meinem ersten Besuche Italiens erwähnt habe.

Ich hatte in Athen die Freude und den Vorteil, mit einem mir gut bekannten belgischen Kollegen, dem Professor der Anatomic in Lüttich, Dr. Swaen, zusammenzutreffen. Dieser vermittelte mir die Bekanntschaft mit dem belgischen Gesandten in Athen, der ein guter Kunstkenner und trefflicher Führer in den dortigen Sammlungen war. Bei einer der Führungen ereignete sich ein ergötzlicher Zwischenfall. Ich bemerke vorher, daß ich am Tage meiner Ankunft in Athen, bei warmem Wetter vom Durst geplagt, im Gasthofe mich erkundigt hatte, ob man nicht in Athen ein Glas trinkbaren Bieres bekommen könne; man hatte mir eine kleine, ganz bescheidene Bierstube genannt, die unfern meines Gasthofes lag und ich fand dort auch ein leidliches bierähnliches Getränk, sogar angenchm gekühlt. Also, nach einer der Museumsbesichtigungen sagte der Gesandte zu mir: „Nun will ich Ihnen auch ein Extravergnügen machen, bitte, folgen Sie mir." Anfangs war ich im Zweifel, was das sein möchte, als aber der Weg sich mehr und mehr der Gegend näherte, wo mein Bierhäuschen stand, merkte ich, um was es sich handelte. Und richtig, triumphierend wies mein Führer auf das Schild und sagte: ,,Treten Sie ein, das haben Sie doch in Athen nicht erwartet." Ich verneigte mich, lüftete den Hut und sagte, er habe den Deutschen richtig eingeschätzt, daß er ihn gleich zu einer Bierstube als zu einem besonderen Vergnügen führe, er habe ihn aber doch nicht völlig richtig erkannt, denn ich sei bereits am Tage meiner Ankunft hier gewesen. Darob natürlich große Heiterkeit.

Von Athen fuhr ich noch nach Alexandrien und Kairo und machte von da einen Ausflug nach den Pyramiden von Gizeh. Die große Pyramide des Cheops bestieg ich, von den dort die Fremden bedienenden Beduinen unterstützt, denn allein kann man die hohen Stufen nicht nehmen. Dabei war es komisch, zu hören, da $B$ die Beduinen, wenn sie einen Deutschen, den sie sofort erkannten, führten, von Zeit zu Zeit ausriefen: Bismarck! Bismarck! Kolossal! Kolossal! Offenbar hatten sie das letztere Wort, welches in Deutschland so oft und vielfach ganz unangebrachter Weise, ausgerufen wird, häufig von den deutschen Reisenden gehört. Und wenn sie, um zu zeigen, 
da $B$ sie in dem betreffenden Fremden einen Deutschen erkannt, den Namen unseres größten Staatsmannes gleichsam als Repräsentanten von ganz Deutschland ausriefen, so erwies das, wie weit der Ruhm dieses Giganten die Welt erfüllt hatte. Leider konnte ich, da der Beginn meiner Wintervorlesungen bevorstand, nicht noch nach Assuan und weiter nach Oberägypten gelangen. Ich fuhr nach Genua zurück und reiste von da durch die Schweiz zunächst nach Bad n-Baden, wo ich einige Tage blieb. Und ich muß gestehen, nach allem dem Schönen, was ich landschaftlich geschen hatte, fühlte ich mich in dem Waldes- und Wiesengrün von Baden-Baden erst wieder recht heimisch und wohltuend erquickt.

Noch einer Reise nach dem Osten gedenke ich, der nach Jassy, wohin ich als Delegierter der Berliner Universität anläßlich der Halbhundertjahrfeier der Moldauischen Universität entsendet worden war. Die Feier hätte bereits IgIo stattfinden sollen, da jedoch in dieses Jahr die Hundertjahrfeier der Berliner Universität fiel, so war Jassy zurückgetreten; um so mehr hatte Berlin Anla B, sich in Jassy durch einen besonderen Abgesandten vertreten zu lassen. Auch die österreichischen Universitäten und andere deutsche Universitäten nahmen durch Abgesandte an der Feier teil, während Rußland, dessen Universität Odessa doch nahe lag, durch Nichtbeteiligung auffiel. In Rücksicht auf die Haltung Rumäniens im Weltkricge verdient dies besonders bemerkt $\mathrm{zu}$ werden: Freundlichkeiten auf anderen Gebieten gelten in der Politik Nichts! Ich hatte in Jassy Gelegenheit, mit König Carol I.von Rumänien und seiner Gemahlin, die unter dem Namen "Carmen Sylva“ als Dichterin bekannt ist, oft zusammen zu kommen. Bei einem vom Könige gegebenen Frühstück saß ich an seiner Seite, ebenso später auf besonders an mich gerichtete Einladung des Königs bei einem von der Stadt gegebenen Feste, wo die Plätze nicht vorher bestimmt waren. Unsere Unterhaltung war lebhaft und für mich sehr interessant, da ich in dem Fürsten einen auf vielen Wissensgebieten gut bewanderten, philosophisch durchgebildeten Mann kennen lernte. Die ganze Art des auch als hervorragender Politiker und weiser Regent hochangesehenen Monarchen hatte etwas sehr Gewinnendes. Daß er seinem Geburtslande treu gesinnt war und in Kriege treu blieb, hat er bewiesen. Doch war er von seiner Pflicht für Rumänien tief durchdrungen und es fragt 
sich, ob er, als unser Stern im Sinken war, das Steuer Rumäniens in der bisherigen Richtung weiter hätte festhalten können. Sicherlich wäre er in einen schweren Konflikt gekommen. Auch mit der Königin habe ich mich wiederholt längere Zeit unterhalten, wobei sich Gelegenheit ergab, daß sie mir einige ihrer Gedichte vortrug. Es war zu merken, daß Beide, der König wie die Königin, im Lande sehr angesehen und beliebt waren; sie verdienten es auch in vollem Maße.

Gern gedenke ich an die wohlgelungene Feier in Jassy und an die in bester Weise mir erwiesene Gastfreundschaft im Hause meines Kollegen, des Professors der Physiologie Dr. Socor zurück. Sehr lieb war mir auch ein Wiedersehen mit meinem früheren Laboranten, jetzigem Professor der Chirurgie in Bukarest, Dr. Gerota, dessen ich bereits gedachte.

Nicht nur nach dem Süden und Osten, sondern auch nach dem Westen wendeten sich meine Fahrten: England, Schottland und Irland habe ich wicderholt besucht und mehrere dieser Besuche bereits erwähnt. Besonders möchte ich noch einer Reise nach Dublin gedenken zur Teilnahme an der Dreihundertjahrfeier des dortigen Trinity College, weil sie mir Gelegenheit gab, meinen dortigen Kollegen, den Anatomen D. J. Cunningham und seine Familie, kennen zu lernen. Ich war Gast seines Hauses und es wurde aus dieser Begegnung eine wahre Freundschaft fürs Leben. Cunningham kam später als Anatom nach Edinburg, wo ich ihn abermals besuchte; wiederholt trafen wir uns noch in England. Seine Tochter Lizzie, jetzige Mrs. Bramwell in Edinburg, war längere Zeit in Deutschland und verkehrte bei uns, wie zur Familie gehörig; eine meiner Enkelinnen brachte ich dann zu ihr zu längerem Aufenthalte in Edinburg. Professor Cunningham gehört zu denjenigen meiner Freunde, die ich am meisten schätzen lernte; ich vergleiche ihn am liebsten in seinem ganzen Wesen als Forscher und als Menschen mit Wilhelm His, meinem Leipziger Freunde. Beide haben bemerkenswerter Weise wiederholt auf gleichem Felde gearbeitet, nur überwog bei His die Entwicklungsgeschichte. Cunningham starb, wie His, leider früh, noch in den Jahren voller Schaffenskraft. Der Krieg hat das Band, welches mich mit seiner Familie verknüpfte, nicht durchtrennt. Sobald die Postverbindung mit England wieder eröffnet war, schrieb mir Mrs. Bramwell und wir haben unseren brieflichen Verkehr wieder 
aufgenommen. Die Politik darf an die echten Freundschaften nicht rühren, sie $\mathrm{zu}$ stören!

Bei dem Besuche der Feier des Trinity College lernte ich auch etwas von der Stimmung der Irländer gegen England kennen. Bei dem Festzuge durch die Stadt zur englischen Kirche, wo der Festgottesdienst gehalten wurde, fehlte jede Beteiligung der Einwohnerschaft; der glänzende Festzug ging fast gänzlich unbeachtet durch die Straßen, die schmucklos dalagen. Beim Abendfeste, welches der Lordmayor von Dublin zu geben hatte, war auch nur englische Gesellschaft zugegen und seitens des Gastgebers fehlte jeder wärmere Ton. Es ist eigenartig, daß England, welches die Schotten für sich gewonnen hat, das zweifellos von allen Völkern, welche Kolonien erwerben, die glücklichste Hand hat, sie in sein Interesse zu ziehen, in dem bereits seit Jahrhunderten angegliederten Irland versagt. Da braucht man sich nicht zu wundern, wenn es Deutschland nicht gelungen ist, in 50 Jahren die Elsässer oder Nordschleswiger zu gewinnen. Und für uns war diese Gewinnung noch schwieriger, da die genannten Nationen in steter Verbindung mit ihren anderen Nachbarn blieben, während Irland isoliert liegt und die nächste und ausgiebigste Verbindung mit England hat. Die von Preußen in Besitz genommenen polnischen Gebiete sind erst die Hälfte der Zeit in deutscher Verwaltung gewesen, wie Irland unter englischer. Es wäre besser, wenn die englische Presse sich in der Beurteilung unserer Angliederungsund Kolonisationsfähigkeit etwas mehr Zurückhaltung auferlegte. Alle Völker, welche Kolonien anlegen, müssen erst Erfahrungen machen und ohne Streitigkeiten, die von Zeit zu Zeit wieder aufflackern, ging und geht es bei keinem Volke, weder im Altertum noch in der Neuzeit, ab.

Meine größten Westreisen führten mich nach den Vereinigten Staaten von Nordamerika und nach Mexiko. Im Jahre Igor durchquerte ich von Bremen aus zum ersten Male den Atlantischen Ozean, um als Abgeordneter der Berliner Universität an der Zweihundertjahrfeier der Yale-University in Newhaven teilzunehmen. Ich wohnte dort sehr angenehm bei meinem früheren Schüler in Straßburg, zeitigem Professor der Chirurgie an der Universität Newhaven, Dr. Carmalt, und hatte Gelegenheit, mit dem damaligen Präsidenten der Vereinigten Staaten, Theodor Roosevelt, mit dem 
zusammen ich zum Ehrendoktor of Law promoviert wurde, persönlich bekannt zu werden. Von Newhaven begab ich mich nach Washington, wo ich mit Professor Wardell Stiles, den ich in Berlin kennen gelernt hatte, zusammentraf. Durch dessen Vermittlung konnte ich in angenehmster Weise alle Sehenswürdigkeiten Washingtons kennen lernen. Auch vermittelte er mir eine Unterredung mit dem Präsidenten Roosevelt, die nicht in meinem Programm war. Als ich mit Stiles das Kapitol besucht hatte und wir das Gebäude verlassen wollten, kamen wir an einem Zimmer vorbei, durch dessen nur angelehnte Tür man Jemanden sprechen hörte. Stiles erkannte Roosevelts Stimme und fragte mich, ob ich den Präsidenten vielleicht sprechen wolle - ich hatte ihm erzählt, daß ich mit ihm in Newhaven zusammen gewesen sei. Ich meinte, wenn das ohne weitere Störung geschehen könne, so wäre es mir angenehm. Stiles trat in das Zimmer und brachte mir sofort die Nachricht, der Präsident lasse bitten. Roosevelt bewillkommnete mich als Doktorkollegen recht freundlich und ein Gespräch war bald im Gange. Der Präsident fragte mich, ob ich das Buch meines Berliner Kollegen Hans Delbrück über die Geschichte der Kriegskunst kenne. Das Buch habe ihn sehr interessiert; er habe nie an die großen Zahlen, die über die Stärke der Armeen des Altertums mitgeteilt würden, glauben können und es freue ihn, daß Delbrück sich in gleicher Weise äußere. Nun hatte ich Delbrücks Werk, von dem die erste Lieferung erschienen war, mit an Bord genommen und es auf der Überfahrt gelesen, so daß wir sehr willkommenen Gesprächsstoff fanden. Dazu kam ein zweiter. Bei meinem Kollegen Carmalt hatte ich ein Werk Roosevelts in die Hände bekommen: „Big game hunting“", welches mich wegen der ausgezeichneten Abbildungen und lebendigen Schilderungen der in den Felsengebirgen lebenden Hochwildarten gefesselt hatte; daran knüpfte sich eine weitere mir interessante Unterhaltung. So schied ich mit einem guten Eindruck von einem Manne, der damals in der politischen Welt eine bedeutende Stellung einnahm und in welchem ich einen Freund Deutschlands zu erblicken vermeinte.

Von Washington brachte mich die Bahn zunächst nach Baltimore, wo ich Franklin P. Mall von der John Hopkins University kennen lernte, dann nach Philadelphia, wo ich Professor Geo Piersol, der mich in Berlin besucht hatte, wieder traf. Es war mir besonders 
wertvoll, die Einrichtungen der Anatomischen Institute an diesen beiden hochangesehenen nordamerikanischen Universitäten näher kennen zu lernen. Später fand ich noch Muße, auch die Anatomischen Anstalten der Columbia-University unter Huntingtons Führung in New York, sowie am Schlusse meiner damaligen Reise in Cambridge Massachusetts unter Th. Dwight und das Histologische Institut dort unter Ch. Sedgwick Minot eingehend $\mathrm{zu}$ besichtigen. Ich glaube mit diesen und der Yale University zusammen wohl die angesehensten und besten nordamerikanischen Universitäten, insbesondere in ihren Anatomischen Instituten, kennen gelern t zu haben; ich habe den Eindruck behalten, als ob die deutschen Anatomischen Anstalten den Vergleich nicht zu scheuen hätten. In Yale ist insbesondere die vergleichend-anatomische Sammlung bemerkenswert.

In Philadelphia machte ich Bekanntschaft mit den Temperenzeinrichtungen in den Vereinigten Staaten. Ich kam abends in meinem Gasthofe an und bestellte mir eine halbe Flasche Wein im Gastzimmer. Der Kellner erklärte mir, da $ß$ ich kein alkoholisches Getränk haben könne, es war an einem Sonntag Abend. Als ich ihm meine Verwunderung darüber ausdrückte, sagte er, ich möge nur auf mein Zimmer gehen, da könne ich so viel Wein trinken, wie ich wolle. Ich trank also dann meinen Schoppen einsam in meinem Zimmer. Ich gestehe, daß ich den Nutzen dieser Verordnung nicht recht einsehe, oder soll sie sich auf eine Heiligung des Sonntags beziehen? Mir gefallen da die deutschen Sitten besser; jedenfalls ist die öffentliche Moral in Deutschland nicht schlechter als in den Vereinigten Staaten. Oder müssen vielleicht die Bürger der Vereinigten Staaten besser im Zaume gehalten werden wie wir Barbaren? Ein Seitenstück zu dieser Erfahrung erlebte ich in Aberdeen in Schottland. Ich kam dort gegen Mittag an und nahm am Bahnhofe einen Wagen, dem ich einen in meinem Baedeker ohne weitere Bemerkung verzeichneten Gasthof als Ziel angab. Der Kutscher erwiderte etwas in seinem mir unverständlichen Dialekt und machte zunächst keine Miene, seinen Wagen in Bewegung $\mathrm{zu}$ setzen. Ich dachte, er habe mich nicht verstanden und zeigte ihm den Namen des Gasthofes in meinem Reisehandbuche, worauf er dann, noch etwas in den Bart murmelnd, mit mir losfuhr. Im Gasthof bestellte ich mir ein Frühstück und dazu Porter. Der Kellner sagte: „No Porter.“ Darauf ich: „,Some Ale.“ Darauf der 
Kellner: ,No Ale“! Dann, ich war in der Meinung, es gebe hier nur Wein: "Some Claret“. Darauf der Kellner: „No Porter, no Ale, no Claret, only Water or Tee or Coffee!" Ich war in ein TemperenzHotel geraten und der Kutscher, dessen erste Äußerung ich nun verstand, hatte es gut mit mir gemeint. Ich verließ den Gasthof sofort. Von Philadelphia führte mich die Bahn in dem Susquehannagebiete zum Teil in lieblichen Tälern aufwärts nach Buffalo. Auf dieser Fahrt kamen mir Erinnerungen an James Fenimore Coopers Indianergeschichten, welche die Jugend meiner Zeit so gern las; sie spielen ja zum großen Teile in dieser Gegend. Buffalo wähite ich als Standplatz für die Niagarafälle, denen ich zwei Tage widmete. Als ich den mit Recht berühmten, großartigen Wasserfall zuerst sah, ging es mir wie dem preußischen Gardeleutnant, von dem man erzählt, er habe, als er den Montblanc zum ersten Male erblickte, sein Monokel eingeklemmt, den Bergriesen eine Zeitlang fixiert und dann wegwerfend gesagt: ,Nicht hoch genug'“! Ich hatte mir auf Grund von Schilderungen und Abbildungen ein Phantasiegebilde von den Fällen entworfen, welches erheblich über die Wirklichkeit hinausging und war etwas enttäuscht, als ich dem Tatsächlichen gegenüber stand. Ich besah mir den Fall von allen Seiten, ging mit der Öljacke bekleidet unter dem Falle auf der nordamerikanischen Seite bei betäubendem Donnergetöse her, fuhr mit der Maid of Mist an die Fälle heran und nach und nach ging mir die staunenswerte Größe dieses Naturschauspieles auf. Als ich an dem anderen Tage, einem schönen warmen Novembertage, nochmals den Fall besuchte, kam er mir immer großartiger vor. Lange stand ich in der Beleuchtung der sinkenden Sonne auf der Brücke vor dem Falle; ich konnte mich kaum von ihm trennen. Über Boston und New York trat ich die Heimfahrt an.

Meine zweite Fahrt über den Atlantischen Ozean führte mich im September und Oktober des Jahres I904 zur Weltausstellung nach St. Lou is im Staate Missouri und von da nach Mexiko. Ich war von unserer Regierung beauftragt worden, in der deutschen Unterrichtsabteilung die medizinische Ausstellung zu überwachen und $\mathrm{zu}$ gleich in der Jury für die Verteilung der Preise mitzuwirken. Mit Hilfe des Präparators am Berliner Anatomischen Institute, meines tüchtigen, geschickten und treuen Gehilfen, Seifert, wurden hier in Berlin die aus Deutschland eingesendeten Ausstellungsstücke sorg- 
lich verpackt und unter dessen Aufsicht nach St. Louis überführt, dort aufgestellt und später zurückbefördert.

Das Jahr I904 war für mich ein Hauptreisejahr. In den Mai fiel meine Reise nach London zur Teilnahme an der Sitzung der Vereinigung der Akademien, von der die Rede war. Ebenso berichtete ich schon über meine Fahrt nach Greifswald, Bornholm, Schweden, Norwegen und Kopenhagen zum Besuche der Deutschen Anthropologenversammlung. Nach Schluß dieser Reise schiffte ich mich alsbald nach England ein, um in Southampton an Bord des Lloyddampfers „,Kaiser Wilhelm der Große" zu gehen zur Überfahrt nach New York. In St. Louis fand ich Seifert bereits vor; er empfing mich am Bahnhofe und ebendort traf ich Mr. Frederick Lehmann, Rechtsanwalt in St. Louis, einen geborenen Berliner, der den Wunsch geäußert hatte, einen von den Berliner Besuchern der Ausstellung als Gast bei sich aufzunehmen. Während der ganzen Zeit meines Aufenthaltes in St. Louis habe ich bei ihm und seiner Gemahlin in seinem hübschen, Benton place Io gelegenen Hause eine Heimstätte gefunden, wie man sie sich nicht besser denken kann; es war mir, als gehöre ich zur Familie. Frau Lehmann war eine geborene Amerikanerin aus Des Moines im Staate Jowa; ich fand selten eine Frau, die in so guter Lebenslage, wie ihr Gatte ihr bieten konnte, sich so persönlich um ihren Haushalt kümmerte und so schlicht und einfach, wenn auch in völlig ihrem Stande angemessener Form, lebte, wie ich es Frau Lehmann gerne nachrühme. Rechtsanwalt Lehmann war gänzlich vermögenslos aus Berlin nach den Vereinigten Staaten gekommen und hatte sich zunächst als Cow-Boy seinen Lebensunterhalt verschafft. Durch seine Tüchtigkeit kam er zu einem Aufseherposten und in Besitz von Mitteln, sich Bücher anzuschaffen, um sich zur Aufnahme in eine höhere Schule vorzubereiten. Er wurde aufgenommen, ging dann zur Universität und war nun einer der angesehensten Rechtsanwälte in St. Louis. Er besa B eine ausgewählte Bibliothek, namentlich an Werken der schönen Litteratur, Kunst und Geschichte, die er mir in liberalster Weise zur Verfügung stellte. Er besa $B$ aber diese Werke nicht nur, sondern er kannte auch ihren Inhalt. Shakespeare kannte er fast auswendig, wie ich mich mehrfach zu überzeugen Gelegenheit hatte. Als Redner suchte er Seinesgleichen. Dabei ein Mann festen Charakters, politisch überzeugter Anhänger der 
Vereinigten Staaten, aber auch seinem Geburtslande treu gesinnt. Er war Mitglied eines deutschen Klubs in St. Louis und führte mich auch dort ein. Gern widme ich diese Worte ehrender und lieber Erinnerung meinen freundlichen und hochachtbaren Gastfreunden in St. Louis.

In St. Louis fand ich ferner mehrere Ärzte, die meine Schüler gewesen waren, unter anderen Dr. Ludwig Bremer, der mehrere anatomische Arbeiten, Früchte seiner Tätigkeit in meinem Laboratorium, im „Archiv für mikroskopische Anatomie“ veröffentlichte, und Dr. Goldstein. Alle diese Kollegen vereinigten sich zu einer Abendfestlichkeit für mich auf dem Dache des Deutschen Hauses im Ausstellungsparke. Im Deutschen Hause waltete der deutsche Reichskommissar, Geheimrat Dr. Lewald, in bester Weise seines Amtes; ich bin ihm für die große Freundlichkeit, die er mir zur Förderung meiner amtlichen Tätigkeit in der Ausstellung sowie außeramtlich erwies, stets dankbar geblieben.

$\mathrm{Zu}$ Preisrichtern (Juroren) in der Unterrichtsabteilung - es ist nicht ohne Interesse, die Zusammensetzung kennen $\mathrm{zu}$ lernen waren bestimmt: ein Nordamerikaner als Präsident, - mir ist der Name entfallen -, ferner Mr. Wood aus Washington als Sekretär, Reverend father Conway, S. J. Professor of political Oeconomy, und Dr. Loe b, Professor für Hals- und Nasenkrankheiten an der von den Jesuiten ge ründeten Universität in St. Louis, ferner Miss Temple vom Board der Lady Managers aus Knoxville (Tennessee), die ich als unser ,Spinster" bezeichnete, dann der Chemiker Professor Gautier aus Paris, der Astronom Lecointe aus Brüssel, Graf LimburgStirum als Kommissar der deutschen Regierung, Professor Dr. Otto Cohnheim, Sohn meines Kollegen, des berühmten Pathologen J. Cohnheim in Leipzig, und ich. Der Präsident der Kommission verlie $B$ bereits nach einigen Tagen St. Louis und ich wurde an seine Stelle gewählt. Die meiste Arbeit leisteten die Herren Wood und Lecointe, die ich beide sehr schätzen lernte. Überhaupt darf ich sagen, da B wir alles sehr gewissenhaft prüften und auch die Arbeit für diejenigen Staaten, welche zwar in der Unterrichtsabteilung ausgestellt, aber keine Vertreter in die Jury gesendet hatten, mit übernahmen. England hatte auf Preise verzichtet. Unsere Vorschläge wurden dann einer Oberkommission unterbreitet, wo ich sie $\mathrm{zu}$ begründen hatte; dort wurde dann entschieden. 
Die ganze Ausstellung war sowohl in ihrer Lage, in ihren Baulichkeiten und in ihrem Inhalte als musterhaft zu bezeichnen; leider konnte ich wegen meiner Tätigkeit als Preisrichter außer den Gegenständen meiner Aufgabe von all dem übrigen nur verhältnismäßig wenig in genügender Weise sehen; auch wünschte ich an einer von den anwesenden Geographen veranstalteten Reise durch Mexiko teilzunehmen und verlieB daher bald nach Abschlu $B$ meiner Preisrichtertätigkeit St. Louis.

Die Mexiko-Fahrt traten wir in einem Sonderzuge an, in welchem wir auch übernachteten. Von guten Bekannten beteiligten sich an der Fahrt Frau Professor Selenka aus München und mein Berliner Kollege, der Geograph A. Penck. Im ganzen brachten wir I7 Tage in den Eisenbahnwagen $z u$, wovon I Tag am Cañon von Arizona und 2 Tage in der Stadt Mexiko abgehen, während welcher wir in Gasthöfen Unterkunft hatten. An bemerkenswerten Punkten hielt der Zug; Karten wurden an die Wagen geheftet und von Sachverständigen, insbesondere von dem nordamerikanischen Geographen und Geologen Da vis, Vorträge gehalten. Die Mittags- und Abendmahlzeiten nahmen wir auf den dafür vorgesehenen Stationen ein. So lange wir auf nordamerikanischem Boden waren, hatten wir dort Bedienung von sauber in Weiß gekleideten, zum Teil hübschen jungen Mädchen; als wir bei El Paso über den Rio grande in Mexiko anlangten, bedienten uns bezopfte Chinesen! Der Unterschied war deutlich. -

Die bemerkenswertesten Daten dieser Fahrt sind die Besichtigung des großen Cañon des Coloradoflusses, eine stellenweise bis 2000 Meter tiefe Schlucht, oben von der Breite etwa des Rheinstromes unterhalb Kölns, nach unten sich allmählich verschmälernd zum Coloradoflusse hin, der in der Tiefe sich hinwindet. Die Länge dieser Schlucht dürfte der Entfernung zwischen Berlin und Hamburg gleichen. Ein Blick in diese Schlucht hinein, namentlich bei heller Mondbeleuchtung, wirkt zauberhaft. Man kann zweifelhaft sein, was packender wirkt, der Niagarafall oder dieser Cañon. Man sieht nämlich nicht in eine Schlucht mit steil abfallenden kahlen Wänden, sondern die Wände sind vielfach gegliedert mit Berg- und Talbildungen, die reich mit Bäumen, Sträuchern und sonstigem Pflanzenwuchs bedeckt sind. An gewissen Stellen sieht man dann in der Tiefe das Silberband des Flusses aufleuchten. Am besten macht man sich eine Vorstellung 
von der Gestaltung des Cañon - ich spreche natürlich nur von der Stelle, wo ich ihn sah - , wenn man ihn sich dadurch entstanden denkt, da $B$ ein längsverlaufender Gebirgszug mit niedrigeren und höheren Bergspitzen und dazwischen liegenden Einsattelungen, der an seiner Basis die Breite des Cañon an dessen Eingange an der Erdoberfläche hat, in eine weiche Masse so tief hineingedrückt sei, da $\beta$ seine Basis bis an die Oberfläche des Erdbodens kommt. Nun denke man sich diesen Gebirgszug wieder aus der Masse - sagen wir dem Erdreich herausgehoben, die schluchtartige Höhlung, welche bleibt, gibt das treue Bild des Canon. Man schaut also wie in ein tiefes schmales Tal, dessen beide Wände mit Bergspitzen und talähnlichen Seiteneinschnitten besetzt sind, und an dessen Grunde ein ansehnlicher Fluß strömt, von oben hinein.

Ehe wir nach Mexiko einliefen, mußte unser Zug und anschließend noch ein anderer fahrplanmäßiger Zug mitten in einer Wüstengegend, wo nur einige spärlich besetzte Niederlassungen der dortigen Indianer sind, über 24 Stunden halten, weil eine Brücke baufällig geworden war. Daß dies zu den Annehmlichkeiten unserer Fahrt gehörte, will ich nicht behaupten, zumal unsere Lebensmittel knapp wurden. Eine kleine Abwechslung brachte am Abend des ersten Tages unseres Haltes eine niedliche Mexikanerin, die sich aus einer Indianerniederlassung die erforderlichen Materialien besorgt hatte und kleine flache Kuchen aus Mehl bereitete, die bei uns guten Absatz fanden. Wenn ich zu ihr herantrat, sagte sie: „Mein Schatz, mein Schatz!“, irrte sich aber sicherlich bei meinen 68 Jahren über die Bedeutung dieses Wortes, welches sie irgendwo einmal aufgeschnappt haben mochte. Aber es gab doch Anlaß zur Heiterkeit bei uns und eine kleine Abwechslung bei unserem unfreiwilligen Warten.

Nordmexiko bietet auf dem Bahnwege von El Paso aus wenig bemerkenswerte Landschaftsbilder; erst von Querétăro an, wo wir bei schöner Morgenbeleuchtung nahe an der Kapelle vorbeifuhren, die an der Stelle errichtet ist, wo I867 Kaiser Maximilian erschossen wurde, kommen schöne und zum Teil großartige Landschaftsbilder. Von den berühmten Schneebergen dieser Gegend zeigte aber nur der Pic von Orizaba, der Citlaltepetl, auf kurze Zeit sein glänzend weißes Haupt; der Popocatepetl und Iztaccihuatl blieben leider im Nebel verhüllt $Z$ wei Tage Aufenthalt in der Stadt Mexiko nützten wir noch 
nach Kräften aus, insbesondere durch den Besuch des ungemein interessanten Museums der alten Aztekenkultur. Wir hatten dabei das Glück, daß gerade Professor Seler, mein Kollege von der Akademie der Wissenschaften in Berlin, einer der besten Kenner der mexikanischen Altertumskunde, in Mexiko anwesend war und uns in der liebenswürdigsten Weise die dortigen Schätze zeigte und erklärte. Ich erwähne noch den Empfang beim Präsidenten Porfirio Diaz, der das durch Erdrevolutionen wie durch Menschenrevolutionen vielerschütterte Land damals mit starkem Arm zusammenhielt, ferner den Besuch des Schlosses Chapultepcc, in dessen Park prächtige alte Bäume, viele von Riesengröße, alle Beachtung verdienen; endlich eine Fahrt nach Orizaba. In der Stadt Mexiko hatte ich noch die Freude, einen mir lieben Verwandten, Bruder meiner Frau, der dort als Kaufmann lebte, wiederzusehen und begrüßen zu können. Durch seine Kenntnis von Land und Leuten hatte ich manchen Vorteil. Als ich den Wunsch aussprach, das Nationalgetränk des Volkes, die Pulque, kennen zu lernen, riet er mir ab. Ich folgte seinem Rate nicht, mußte aber zugeben, daß er gut gemeint war, denn ich hatte an dem einen Versuche genug.

Die Rückfahrt traten wir auf der mehr östlich gelegenen Bahnstrecke über San Luis Potosi an, die bei Laredo den Rio Grande überschreitet. In Saltillo, dem Hauptorte der mexikanischen Grenzprovinz Cohahuila, wo wir die letzte Verpflegung auf mexikanischem Boden einzunehmen hatten, wurden wir vom Gouverneur freundlich begrüßt und auf Staatskosten bestens bewirtet.

Ich schied von dem schönen und reich gesegneten Lande damals mit der Überzeugung, daß es sich in wohlgeordnetem Zustande befinde und einer guten Zukunft entgegensehe. In dieser Ansicht wurde ich auch durch meinen Schwager bestärkt, der bereits mehrere Jahre in Mexiko unter dem straffen Regimente von Porfirio Diaz ansässig war. Wie bald sind wir in dieser guten Meinung enttäuscht worden! Liegt nun die Schuld bei den Parteien in Mexiko selbst oder ist es der mächtige Nachbar im Norden, der gar zu gern die großen Schätze des Landes durch dessen Angliederung für sich nutzbar machen möchte und daher die Unordnungen im alten Aztekenlande nicht zum Ausgleich kommen läßt, damit es ihm selbst als reife Frucht in den Schoß falle? Können die Mexikaner sich nicht selbst ein geordnetes Regi- 
Zukunft Mexikos. Dankbare Neger. Die russische Kriegsflotte. 317

ment schaffen, welches von Dauer ist und dem Lande eine friedliche und gesunde Entwicklung sichert, dann muß man zu dessen eigenem Besten wünschen, daß es der nordamerikanischen Union zufalle, die damit freilich auf kaum abschätzbare Zeit zum weitaus mächtigsten Staate der Welt werden würde.

Auf der Rückfahrt hatte ich Gelegenheit, die guten Eigenschaften der nordamerikanischen Neger kennen zu lernen. Ich vermißte eines Morgens beim Ankleiden den Mann, der mir bis dahin die kleinen Morgendienste geleistet hatte. Sein Ersatzmann sagte mir auf Befragen, da B Tommy erkrankt sei. Ich ging sofort zu ihm, kümmerte mich um ihn und konnte ihm einen guten Rat geben, durch dessen Befolgung er bis zum anderen Morgen wieder zu Wohlbefinden kam. Seit dieser Zeit waren alle Neger in unserem Zuge bemüht, mir ihre Dankbarkeit zu beweisen; wo sie mir einen Wunsch sozusagen an den Augen ablesen konnten, waren sie gleich alle bereit, ihn nach Möglichkeit zu erfüllen. Als unser Zug in St. Louis sein Endziel erreichte und wir uns trennten, kamen alle Neger zu mir und dankten mir in rührender Weise, daß ich so gut zu einem ihrer Kameraden gewesen sei; dieser selbst wußte gar nicht, was er tun sollte, um mir seine Dankbarkeit zu beweisen.

Ich blieb noch einige $Z$ eit in St. Louis, verabschiedete mich von dem Reichskommissar, von meinem getreuen Seifert, von Dr. Bremer, vom deutschen Konsul und von meinen mir lieb gewordenen Gastfreunden, von diesen, leider, auf Nimmerwiedersehen, und fuhr nach New York, wo ich mich zur Heimkehr auf dem Dampfer „Kronprinz Wilhelm", einem der neuesten Bremer Schnelldampfer, einschiffte. Ich landete in Cherbourg an, um von dort aus einer meiner Enkelinnen, Irmgard v. Bonin, die sich auf einer kleinen ländlichen Besitzung ihrer französischen Sprachlehrerin in Pension befand, einen Besuch abzustatten. Auf dem Wege zwischen Southampton und Cherbourg hatten wir eine unerwartete, höchst bemerkenswerte Begegnung mit der russischen Flotte unter Admiral Rosdjeschtwensky, die, man darf wohl annehmen, ahnungslos ihrer Vernichtung entgegenlief. In aller Morgenfrühe fuhren die Kriegsschiffe in Kiellinie so dicht an uns vorbei, daß wir ihre Namen bequem lesen konnten. Sie hatten, wie wir später erfuhren, in der Nacht ihr Don Quixote-Gefecht mit den britischen Fischerfahrzeugen an der Doggerbank gehabt, ein Signum 
pessimi ominis, wie ich mir sagte, als ich in Cherbourg davon erfuhr. Ich stand auf unserem Dampfer zusammen mit mehreren Offizieren vom Schiff in stummer Betrachtung der vorüberfahrenden Flotte. Ich weiß nicht, woher mir die Vorahnung kam, aber ich konnte den Gedanken nicht unterdrücken, daß von diesen Schiffen kaum eines wieder zurückkehren werde. Derselbe Gedanke wurde auch von Anderen laut; wenigstens sagte einer von den Offizieren, als das letzte russische Schiff an unserem Heck vorbeigefahren war, sein Glas absetzend: Wie viele davon werden wohl wiederkehren?

Mit dem russisch-japanischen Kricge I904/O5 ist der, dritte Abschnitt der Weltgeschichte, soweit wir sie gut kennen, eröffnet worden. Die einzelnen Abschnitte charakterisieren sich als Kämpfe um die Weltmeere und nehmen nach deren Größe an Bedeutung für unsere Erdkugel zu. Zuerst der Kampf um das Mittelmeer; diesen gewannen die Römer. Dann der Kampf um den Atlantischen Ozean bis hinein in die Westsphäre des Indischen Ozeans; den gewannen die Engländer und haben jetzt das Siegel darauf gedrückt, indem sie ihren letzten Mitbewerber, Deutschland, mit Hilfe fast der ganzen Welt zu Boden gezwungen haben. Jetzt geht es um den Großen Ozean, und die Ouvertüre dazu spielten die Kanonen im russisch-japanischen Kriege, vor allem in der Seeschlacht des Tsushima-Kanals. Indem Amerika, dessen Ufer von beiden Ozeanen bespült werden, auch an dem Atlantis-Drama teilnahm, hat es, wie ein junger Recke, seine Kräfte erprobt. Man wird sehen, daß es jetzt vom „Militarismus" nicht mehr loskommt. Wer wird siegen, das alte Asien oder das junge Amerika?Und wird dann die Weltgeschichte so weiter rollen, von Ost nach West, wie bisher?

$\mathrm{Zu} \mathrm{kurz}$ war mein Aufenthalt in dem Lande der unbegrenzten Möglichkeiten, wie man die Nordamerikanische Union genannt hat, um mir ein sicheres Urteil erlauben zu können. Doch Eines habe ich als Eindruck von drüben mitgebracht, daß es sich um ein großartig organisiertes Staatswesen handelt, welches die Keime höchster Blüte und Machtentfaltung in sich trägt. Freilich sind die natürlichen Hilfsquellen des Bodens und der Lage an den zwei größten Weltmeeren, die dem Lande geboten werden, auch so bedeutend, daß es sich leichter, wie viele andere, durchsetzen kann. Immerhin haben die Männer, welche dem jungen Lande seine erste Organisation gaben, 
ein hochbedeutendes Werk vollbracht, was sich bis jetzt wenigstens bewährt hat. Ist es nicht eine Riesenaufgabe, ein Völkergemisch, wie das der Vereinigten Staaten, eine Vielheit von Religionen und mitgebrachten Anschauungen, wie sie dort zusammenkommen, unter einen politischen Hut zu bringen! Diese Aufgabe hat die Union gelöst, wie sich im abgelaufenen Weltkriege gezeigt hat. Die nordamerikanische Staatsidee hat sich als so mächtig erwiesen, daß abweichende Meinungen, mochten sie auch im Herzen Vieler bestehen, nicht durchdringen konnten. Es ist tief schmerzlich für uns Deutsche, da $B$ in diesem Kriege eine so weitverbreitete Abneigung gegen Deutschland, ja, klar ausgesprochener $\mathrm{Ha} B$ hervorgetreten ist, während die Union doch einen großen Teil ihrer besten Bürger aus Deutschland erhalten hat, die gerade in der am meisten kritischen Lage, in der sich die Vereinigten Staaten jemals befunden haben, in den großen Sezessionskämpfen vor nahezu 50 Jahren, sich als die treuesten Anhänger des Unionsgedankens erwiesen haben. Und wie sehr hat Kaiser Wilhelm II. sich bemüht, gute Beziehungen zwischen den U. S. A. und Deutschland zu erhalten und zu schaffen! Mir ist es immer noch unerklärlich, wie die Nordamerikanische Union im Weltkriege dazu kam, sich aktiv auf die Seite unserer Gegner zu stellen und nach dem einzig und allein durch ihre Mitwirkung erzielten Niederbruche Deutschlands mit verschränkten Armen zuzusehen, wie England und Frankreich den niedergesunkenen Kämpen vollends erdrosseln.

Ich möchte die Berichte über meine Reisen, die mich in Verbindung mit vielen Persönlichkeiten brachten, deren ich mich gern erinnere, nicht schließen, ohne noch des berühmten schwedischen Anatomen Gustaf Retzius und seiner Gattin, Anna v. HiertaRetzius, zu gedenken. Lange schon hatte ich den Wunsch nach persönlicher Bekanntschaft gehegt; da trafen wir uns das erste $\mathrm{Mal}$ in dem wohlbekannten fränkischen Orte Rothenburg ob der Tauber. In der kleinen stillen Stadt mit so vielen Sehenswürdigkeiten aus dem deutschen Mittelalter, die wir gemeinschaftlich besichtigten, bot sich die beste Gelegenheit, einander näher zu treten. Später trafen wir uns noch öfter, so bei der Zweihundertjahrfeier der Preußischen Akademie der Wissenschaften, deren korrespondierendes Mitglied G. Retzius war. Wir blieben in stetem Briefwechsel und Schriftentausch, wobei ich der Bevorzugte war. Tief 
betrauere ich den vor Kurzem erfolgten Tod des großen Gelehrten und edlen Mannes, den ich zu meinen besten Freunden zählen durfte. Ich habe ihm im Anatomischen Anzeiger einen Nachruf gewidmet.

\section{K a pitel. \\ Beziehungen zum Preußischen Königshause.}

Kaiser und König Wilhelm I., Kaiser und König Friedrich III., Kaiser und König Wilhelm II.

Als ich geboren wurde, regierte König Friedrich Wilhelm III.; I840 folgte ihm sein Sohn Friedrich Wilhelm IV., dessen festlichem Einzuge in Paderborn ich beiwohnte; ich erinnere mich dieses Monarchen noch sehr gut. Als er I857 schwer erkrankte, folgte ihm sein Bruder Wilhelm zunächst als Stellvertreter, dann, I858, als Regent und, I86I, nach Friedrich Wilhelms IV. Tode, unter dem Namen Wilhelm I. als König von Preußen, seit I87 I Deutscher Kaiser! Es war mir vergönnt, mit diesem hervorragenden Herrscher wiederholt in Bezielıung zu treten, und da $B$ meine Rechte einst in der seinen geruht hat, ist mir eine der wertesten Erinnerungen meines Lebens. Die Gestalt des ersten deutschen Kaisers seit der Neugründung des Deutschen Reiches wird in der Geschichte dereinst sich immer höher hervorheben. Welch ein tragisches Geschick in dem Hohenzollernhause, welches so viele bedeutende, ja große Herrscher aufzuweisen hat, daß der Sohn Wilhelms I. als ein dem Tode verfallener Mann den deutschen Kaiserthron nur für Ioo Tage besteigen konnte und daß der Enkel WilheIms I., des Begründers des neuen deutschen Reiches, nach 30 jähriger glanzvoller Regierung Thron und Reich in Trümmern verlassen und in der Fremde ein Asyl suchen mußte! Wessen Lebensschicksal ist härter, kann man fragen, oder vielmehr nicht fragen, das des Vaters, Friedrichs III., oder des Sohnes, Wilhelms II. ?! -

Aus meinen Begegnungen mit Kaiser und König Wilhelm I., seien einige Erlebnisse, die den charaktervollen, ruhigen und gütigen Mann kennzeichnen, erwähnt. Es war in Straßburg I877; der Kaiser hatte dem Reichslande einen Besuch gemacht und empfing auch die Professoren der Universität. Im Schlosse, in welchem damals die Amts- 
räume der Universität untergebracht waren, war bei dieser Gelegenheit in einem der Säle das Buch aufgelegt, in welches der Kaiser seine Namensschrift zum Andenken an diesen Besuch eintragen sollte. Als der Monarch bereits ins Schloß eingetreten war und die Begrüßung durch den Rektor eben begonnen hatte, begab ich mich noch einmal in das Zimmer, wo die Eintragung erfolgen sollte, um nachzusehen, ob alles in Ordnung sei. Das Buch lag da, aufgeschlagen, für Tinte war gesorgt, aber es fehlte eine Feder. Ich machte einen der Pedellen darauf aufmerksam und in aller Eile wurde die erste beste Feder herbeigeholt; sie zu prüfen war keine Zeit mehr, der Kaiser mit seinem Gefolge erschien schon im Zimmer und wurde vom Rektor gebeten, sich in das Buch einzutragen. Ich war an dem Tische stehen géblieben und befand mich in unmittelbarer Nachbarschaft des Fürsten, als dieser die Feder ergriff, eintauchte und nun mit kräftigem Ansatz seinen Namenszug zu schreiben begann; aber siehe da, es ging nicht, die Feder ließ keine Tinte aus. Der Kaiser tauchte abermals sorgfältig die Feder in das Tintenfa $\beta$, prüfte, ob sie Tinte gefaßt hatte, setzte wiederum an, es ging wieder nicht, die $\mathrm{zu}$ spitze Feder war dem kräftigen Zuge, mit dem der Kaiser zu schreiben gewohnt war, nicht gewachsen. Es war, namentlich für mich, eine etwas peinliche Szene. Der Kaiser aber blieb ganz ruhig, besah sich die Feder, drückte sie auf seinem Fingernagel etwas zurecht, tauchte wieder ein und begann etwas vorsichtiger zu schreiben und da ging es! Lächelnd reichte er die Feder dem Nächststehenden aus seinem Gefolge, der auch einschreiben sollte und von da ab gingen die Unterschriften glatt $a b$. Der Monarch ging weiter und ich schloß mich dem Gefolge an, kehrte aber sofort, nachdem der Kaiser das SchloB verlassen hatte, in das Zimmer, in welchem die Eintragungen vorgenommen waren, zurück, um mir die Feder als Andenken mitzunehmen. Das Buch lag noch aufgeschlagen da, aber die Feder war weg! Ich gestehe, da $B$ ich sie gern aufbewahrt hätte und ärgerte mich nicht wenig darüber, da $B$ sie in andere Hände gekommen war, während ich das größere Anrecht darauf zu haben vermeinte. Dem Inventarium der Universität hätte ich gern ein Dutzend anderer Federn dafür gestiftet.

Am Abend erschien der Kaiser $z u$ einem festlichen Empfang im Stadthause, bei dem auch die Damen zugegen waren. Der Kaiser lieB sich die Erschienenen vorstellen und man bewegte sich, da alles ohne 
großes Zeremoniell gehalten wurde, frei und ungezwungen. In einem der Säle hatten sich eine Anzahl Damen und Herren aufgestellt; der Kaiser trat heran und unterhielt sich mit einzelnen, die er freundlich ansprach, so auch meine Frau. Neben dieser stand eine junge Offiziersgattin und hinter dieser ihr Gemahl, ein Hauptmann. Der Kaiser redete die junge Frau an und fragte, als er erfahren hatte, sie sei die Gattin eines aktiven Offiziers: „Nun, wo steht denn Ihr Mann?"“ Sie wendete sich prompt um, schob ihren Mann vor und sagte: „Hier, Majestät!“ Man kann sich ihre und des Hauptmanns Verlegenheit ob dieser Antwort denken. Der Kaiser aber ließ nichts merken, redete den Offizier freundlich an und unterhielt sich auch noch weiter längere Zeit gänzlich unbefangen mit der jungen Frau, so daß er Beiden bald die ganze Verlegenheit nahm. Jeder der Umstehenden hatte die wohltuende Empfindung der Herzensgüte und des ritterlichen Sinnes des hohen Fürsten. Es war dies auch, wie ich noch bei manchen anderen Gelegenheiten feststellen konnte, ein ungemein gewinnender Zug seines Charakters.

Mit Kaiser Friedrich III. brachte mich dessen Erkrankung in nahe Verbindung, wenn auch ohne persönliche Begegnung. Was ich dabei erlebte und zu tun hatte, sei hier getreu berichtet:

Ich habe Kaiser Friedrich III. viermal in meinem Leben gesehen, das erste Mal in Königsberg, wo er als geborener Rektor der dortigen Universität im Jahre 1863 der Eröffnungsfeier ihres Neubaues beiwohnte, dann viele Jahre später ein zweites Mal ganz kurz in Berlin, als ich einmal vom Anatomischen Institut her den Park der Tierärztlichen Hochschule an dem Ausgange nach der Friedrichstraße verließ. Gerade im Ausgange begegneten mir drei Offiziere; ich schaute auf und erkannte in der hochragenden, stattlichen Erscheinung des mittleren, dessen strahlendes Auge mir einen Blick zuwarf, den damaligen Kronprinzen Friedrich von Preußen. Etwa ein Jahr später erfolgte die Eröffnungsfeier des neuen Museums für Völkerkunde in Berlin. Als Mitglied des Vorstandes der Berliner Anthropologischen Gesellschaft hatte ich meinen Platz in einer der vordersten Sitzreihen. Im Auftrage König Wilhelms I. eröffnete Kronprinz Friedrich die Feier mit einer Ansprache. Er erschien in der blauen Uniform seines Dragonerregiments, noch die schöne, stattliche Erscheinung, die Allen angenehm auffiel, und in ungebeugter Haltung 
stand er dicht vor mir. Er ließ sich von einem Adjutanten die Niederschrift der Ansprache vorhalten, die er verlas. Da fiel es mir auf, mit welch sichtlicher Anstrengung und eigentümlichem Stimmklange er sprach. Ich dachte natürlich damals nicht an das furchtbare Leiden, welches offenbar schon sein Leben bedrohte, sondern an eine gewöhnliche vorübergehende Affektion seines Stimmorganes, wie man sie als eine Erkältung zu bezeichnen pflegt. Bald aber sollte die Erklärung kommen und ich den Kronprinzen als Kaiser wiedersehen - aber auf dem Totenbette.

Wenige Monate nach der Museumseröffnung wurde durch den Leibarzt des Kronprinzen, Generalarzt Dr. Wegner, der damalige Leiter der zweiten Berliner medizinischen Klinik, Professor Dr. K. Gerhardt, dessen ich bereits S. 282 gedachte, gebeten, eine Untersuchung der Halsorgane des Kronprinzen vorzunehmen, da sich bei diesem seit Anfang des Jahres I 887 eine Heiserkeit eingestellt hatte, die den üblichen Erkältungsbehandlungen nicht weichen wollte. Gerhardt, einer der ausgezeichnetsten Ärzte und klinischen Universitätslehrer, die mir im Leben begegnet sind, und gleich hervorragend als charaktervoller Mann, war bekannt als auf dem Gebiete der Kehlkopfkrankheiten besonders bewandert. Er nahm die Untersuchung am 6. März r887 vor; er schöpfte bereits damals, nach den ersten Untersuchungen, den Verdacht, daß es sich um die Anfänge eines Krebsleidens handle. Am linken Stimmbande des Kronprinzen fand sich eine kleine flache Geschwulst. Gerhardt zerstörte sie mit der galvanokaustischen Glühschlinge, worauf die Heiserkeit schwand. Das Allgemeinbefinden des Kronprinzen war damals ein durchaus gutes. Um die Diagnose zu sichern, wurde nach dem schon früher ins Auge gefaßten Plane Wegners eine Kur in Bad Ems vorgeschlagen und ausgeführt. War die durch den Glühdraht beseitigte Geschwulst eine gutartige, so mußte unter den günstigen Verhältnissen von Ems die kleine, durch die Operation gesetzte Wundfläche schnell heilen und durfte die Geschwulst nicht wieder anwachsen. War diese nach der Emser Kur aber wieder erschienen und mit ihr die Heiserkeit, dann mußte auf eine bösartige Geschwulst geschlossen und sofort radikal eingegriffen werden.

Als Mitte Mai r887 Kronprinz Friedrich Wilhelm von Ems zurückkam, bestätigte die Untersuchung die schlimmen Befürchtungen 
Gerhardts. Die Geschwulst war größer als zuvor und die Heiserkeit der Stimme war wiedergekehrt. In einer Konsultation, an der noch der berühmte Berliner Chirurg v. Berg ma nn und der Laryngologe Tobold nebst dem Leibarzt Kaiser Wilhelms I., v. Lauer, und Oberstabsarzt Schrader teilnahmen, wurde nach eingehendster Untersuchung des Kranken die Ansicht Gerhardts von der krebsigen Art der Kehlkopfgeschwulst als die richtige festgestellt und als der einzig mögliche, aber auch aussichtsvolle Weg zur Erhaltung des Lebens die Entfernung der Neubildung durch Spaltung des Kehlkopfes von außen her erkannt und in Vorschlag gebracht. Freilich war mit dem Verlust der tönenden Stimme zu rechnen; doch war Aussicht auf Erhaltung einer hinreichend lauten, wenn auch heiseren Stimme vorhanden.

Schon während des Aufenthaltes des Kronprinzen in Ems war angeregt worden, noch einen allgemein anerkannten Laryngologen hinzuzuziehen; unter den verschiedenen Genannten erhielt der von Generalarzt Wegner vorgeschlagene Sir Morell Mackenzie aus London die Zustimmung der deutschen Ärzte. Die Operation sollte, falls auch Mackenzie sich dafür ausspreche, ungesäumt vorgenommen werden. Es wurde daher am 20. Mai, an welchem Tage Mackenzie zur Untersuchung erwartet wurde, auf Anordnung der Frau Kronprinzessin alles zur Operation für den Vormittag des 2I. Mai vorbereitet. Auch der Kronprinz gab seine Zustimmung zu dem äußeren Eingriffe.

Zur größten Verwunderung der deutschen Ärzte erklärte Mackenzie nach der im Beisein Gerhardts und v. Bergmanns am 20. Mai von ihm vorgenommenen Untersuchung, daß es sich nicht um Krebs handle; ihm seien solche Veränderungen bekannt und er werde den Kronprinzen heilen. Keinesfalls könne er in die vorgeschlagene Operation der Wegnahme der Geschwulst nach Spaltung des Kehlkopfes willigen, bevor nicht durch die mikroskopische Untersuchung eines von der Neubildung entnommenen Stückes deren krebsige Natur erwiesen sei. Die deutschen Ärzte stimmten zu und Sir Morell führte die dazu nötige Operation aus. Gerhardt, der bald darauf den Kehlkopf des Patienten untersuchte, sagte gleich zu dem englischen Arzte, daß nach seiner Meinung das Stückchen nicht genau von der affizierten Stelle entnommen sei, wogegen Mackenzie bestimmt behauptete, er habe es richtig entnommen. Alles dieses hat 
mir kurze Zeit nachher Gerhardt persönlich genau so, wie ich es hier niederschreibe, erzählt. Das entfernte Stückchen wurde Rudolf Virchow übergeben, der, da Gerhardt richtig gesehen hatte, natürlich keine krebsigen Veränderungen finden konnte. Gerhardt und v. Bergmann waren und blieben von der Richtigkeit ihrer Diagnose überzeugt, waren aber fürs erste zu Schweigen verurteilt.

Man weiß, was folgte. Der Kronprinz wurde unter Begleitung Wegners, des Stabsarztes Dr. Landgraf, Assistenten Gerhardts, und eines Assistenten Sir Morells zunächst nach England geschickt, um, wie Mackenzie meinte, dem günstigen Einflusse der Insel Wight und später Schottlands ausgesetzt zu werden. Dann folgte die Übersiedelung nach San Remo. Aber die in Aussicht gestellte Heilung blieb aus; mehr und mehr stellte sich heraus, daß die Diagnose der deutschen Chirurgen die richtige sei. Es entspann sich nun in der medizinischen und politischen Tagespresse eine höchst bemerkenswerte und unerquickliche Fehde zwischen den Anhängern der deutschen Ärzte und denen Sir Mackenzies, zu dem die Frau Kronprinzessin Viktoria hielt. Die Angelegenheit nahm auch eine politische Färbung an; die liberale Presse begünstigte offensichtlich das englische Lager, wie ich mich kurz ausdrücken will, und die Partei der Kronprinzessin, der es begreiflicherweise darum zu tun war, den Kronprinzen zu retten oder wenigstens, im Falle, daß eine Rettung nicht mehr möglich war, ihn so lange am Leben zu erhalten, wie irgend angängig. Vielleicht widersetzte man sich deshalb am kronprinzlichen Hofe, der durchaus von der Kronprinzessin geleitet wurde, der Vornahme einer radikalen Operation, weil man fürchtete, der hohe Patient würde sie nicht überstehen, denn damals war das Operationsverfahren bei totaler Kehlkopfwegnahme, die bei dem weiteren Fortschreiten der Krankheit nötig gewesen wäre, um das Leben zu erhalten, noch nicht so ausgebildet und Erfolg versprechend, wie es heute ist. Und bei dem anfangs langsamen Fortschreiten des Übels schien die Hoffnung nicht ausgeschlossen, dem kranken Kronprinzen bei leidlichem Befinden noch längere Zeit das Leben $\mathrm{zu}$ fristen, so daB Aussicht bestand, er werde bei dem sehr hohen Alter seines Vaters, der das 90. Lebensjahr überschritten hatte, noch in regierungsfähigem Zustande auf den Thron gelangen. Diese Erwägungen falls, sie bestanden und das Verhalten der Kronprinzessin geleitet haben, 
haben sich als falsch erwiesen, während, wenn man den beiden deutschen Klinikern gefolgt wäre, Kronprinz Friedrich höchstwahrscheinlich als Kaiser Friedrich III. in voller Manneskraft der Lenker der Geschicke des Deutschen Reiches hätte sein können; denn am 2I. Mai I887, als alles zur Operation vorbereitet war, handelte es sich nur um die Spaltung des Kehlkopfes. Der Hand eines Ernst v. Bergmann hätte man sie ruhig anvertrauen können; er hatte sie bereits mehrere Male mit stets gutem Erfolg ausgeführt.

Als sich nach und nach in San Remo herausstellte, daß weder Sir Morell Mackenzies Wissen und Können, noch das Klima der Riviera dem unerbittlichen Übel des Kronprinzen Einhalt zu tun vermöchten und die Gefahr einer Erstickung näher und näher rückte, mußte die Tracheotomie ins Auge gefaßt werden. Es wurde beschlossen, daß entweder Professor v. Bergmann oder in dessen Vertretung sein damaliger Assistent Dr. Bramann, später Professor der Chirurgie an der Universität Halle, ständig anwesend sein sollten, um, wenn erforderlich, die für den Augenblick lebensrettende Operation sofort vornehmen zu können. Wie gewissenhaft v. Bergmann diese ihm bevorstehende Aufgabe nahm, geht daraus hervor, daß er mich ersuchte, ihm die Leiche eines Mannes zur Verfügung zu stellen, dessen Kehlkopf und Luftröhre sowie die ganze Ausbildung des Halses der des Kronprinzen Friedrich Wilhelm möglichst nahe käme, wie das v. Bergmann ja leicht feststellen konnte. An einer solchen Leiche führte dann der berühmte Chirurg, dem ja die Vornahme einer Tracheotomie ein leichtes war, die Operation aus, um, wie er sagte, sie möglichst sicher und tadellos beim Kronprinzen machen zu können. v. Bergmann wünschte auch die Operation nicht erst im Augenblicke der eintretenden Erstickungsgefahr, die vielleicht ein überstürztes Handeln erfordert hätte, vorzunehmen, sondern bereits vorher, sobald festzustellen war, daß Lebensgefahr durch Behinderung der Atmung drohend wurde. Ungeachtet des Drängens von seiten des Dr. Bramann, daß man v. Bergmann zur Vornahme des Luftröhrenschnittes nach San Remo kommen lassen möge, verschob Mackenzie seine Zustimmung von Tag zu Tage, bis die Atemnot des Kronprinzen so groß wurde, daß keine Zeit mehr war, Professor v. Bergmann kommen $\mathrm{zu}$ lassen und Bramann die Operation in der Notlage, wie er gefürchtet hatte, vornehmen mußte. Bramann hat 
übrigens die Operation tadellos ausgeführt; zu Unrecht hat ihm später Mackenzie den Vorwurf gemacht, er habe den Schnitt nicht genau in die Mittellinie verlegt. Es ist kaum verständlich, daß Mackenzie so zögerte. Vielleicht besorgte er, daß, sobald die Ausführung der Tracheotomie bekannt würde, sein Kartenhaus, das er dem Publikum gegenüber bezüglich der Krankheit des Kronprinzen aufgebaut hatte, zusammenstürzen würde.

Da nun immer wieder, trotz der Tracheotomie, in der dem englischen Lager geneigten Presse, sobald von einer Verschlimmerung des Leidens Nachricht kam, dem widersprochen wurde, ja, noch Heilung in Aussicht gestellt wurde, so lag es v. Bergmann daran, noch einmal die Art des Leidens feststellen zu lassen. Ich erhielt auf Befehl Kaiser Wilhelms I. durch dessen Leibarzt, Herrn v. Leut hold, den Auftrag, mich nach San Remo zu begeben, um eine anatomische Untersuchung vorzunehmen. Diese konnte damals ohne jede Belästigung des Kranken geschehen, da sich seit einiger Zeit feste Stückchen in dem durch Husten Entleerten befanden, die zweifellos Teile des in Zerstörung befindlichen Kehlkopfes waren. Handelte es sich in der Tat um Krebs, was schon nach diesen Entleerungen und nach dem stetigen Fortschritt des Leidens nicht mehr zu bezweifeln war, so war mit Sicherheit vorauszusehen, daß eine mikroskopische Untersuchung dieser Stückchen ein bestimmtes Ergebnis liefern werde, dem nicht mehr zu widersprechen war. Ich stellte alsbald mein Instrumentarium zusammen und reiste am I. März I888, am Tage nach dem erhaltenen Befehl, ab. Kurz vor meiner Fahrt zum Bahnhof erschien in meiner Wohnung noch der Berichterstatter einer amerikanischen Zeitung, um mich zu ,,interviewen". Da er mich nicht zu Hause fand, ließ er sich bei meiner Frau melden, und suchte allerlei zu erfahren. Woher er von der Sache Wind bekommen hatte, ist mir unbekannt; aber diese Herren hören ja das Gras wachsen. Meine Frau sagte ihm, da B sie ihm nichts mitteilen könne, darauf fragte er, mit welchem Zuge ich dann abfahren werde und ob er mich zum Bahnhof begleiten könne, worauf ihm meine Frau kurz erwiderte: „Zum Bahnhof werde nur sie mich begleiten." Das war nicht mißzuverstehen und der Aushorcher empfahl sich.

Auf der Reise hatte ich einen bis dahin noch nicht genossenen Anblick: die ganze lombardische Ebene in tiefem Schnee - am 
2. März I888! Erst kurz vor Sampierdarena, wo die Bahn sich zur Riviera hinabsenkt, wurde der Boden schneefrei. In San Remo wurde ich von v. Bergmann begrüßt und nahm das von ihm vorher bestellte Zimmer im Gasthofe - Hotel Méditerranée - ein. Der kronprinzliche Hofhalt befand sich in der gegenüberliegenden Villa Zirio.

Schon am anderen Tage erhielt ich eine bei einem Hustenanfall aufgesammelte Entleerung und konnte sofort die Anwesenheit der für den sogenannten Plattenepithelkrebs charakteristischen Bildungen nebst kleinen Stückchen von den Kehlkopfsknorpeln feststellen. Ich erhielt noch mehrere solcher Entleerungen, die alle dieselben Befunde ergaben. Dasselbe sah ich an mikroskopischen Präparaten, die vor meiner Ankunft schon von den Kollegen v. Bergmann und Bramann angefertigt und mir zur Verfügung gestellt worden waren. Ich demonstrierte die Präparate den deutschen Ärzten und erhielt auch den Besuch Sir Morell Mackenzies, der ebenfalls meine Ansicht zu hören wünschte. Ich gab ihm Auskunft, daß unzweifelhaft ein Krebsleiden vorliege und forderte ihn auf, sich eines der bestgelungenen Präparate, welches ich gerade unter das Mikroskop gelegt hatte, anzusehen. Sir Morell näherte sich dem Instrument und schaute von oben auf das Okular, jedoch sein Auge etwa einen Fuß weit oberhalb des Okulars haltend. Ich trat hinzu und sagte: „Bitte, Herr Kollege, das Auge dicht an das Okular zu legen und mit der Mikrometerschraube einstellen," zugleich zeigte ich ihm die richtige Stellung. Mackenzie machte keinen weiteren Versuch und sagte: ,Ich verstehe nichts von diesen mikroskopischen Dingen; ich glaube Ihnen auch so. Wenn Sie bestimmt aussagen können, daß es Krebs sei, so nehme ich an, daß es richtig ist." Wir verabschiedeten uns in aller Höflichkeit. Einige Tage darauf war jedoch in den Parteiblättern Mackenzies zu lesen, da $B$ ich zwar die krebsige Natur des Leidens festgestellt zu haben glaubte; man müsse aber abwarten, ob sich das bestätige; eine Heilung sei nicht ausgeschlossen. Und ähnliches.

In San Remo sah ich auch zum ersten Male, damals als Prinzen Wilhelm von Preußen den Mann, der ein Vierteljahr später als Kaiser und König Wilhelm II. seinem Vater Friedrich III. auf dem Throne folgen sollte in dem für immer denkwürdigen Drei-Kaiser-Jahr I888. Kurz nachdem Sir Morell mich verlassen hatte, trat Prinz Wilhelm 
in Begleitung v. Bergmanns bei mir ein und erkundigte sich nach meinen Befunden. Ich gab Auskunft und bat den Prinzen, das Präparat, welches ich Mackenzie demonstrieren wollte, in Augenschein zu nehmen. Der Prinz schritt auf das Mikroskop zu, erfaßte gleich die Mikrometerschraube, schaute in vollkommen korrekter Weise hinein und sagte dann: „Also diese kleinen Körperchen, die ich da sehe, sind das, worauf es ankommt?" Prinz Wilhelm hatte Alles richtig gesehen. und ich brauchte hier keine weiteren Erläuterungen zu geben.

Tags darauf reiste ich nach Berlin zurück. Es war mir aufgegeben worden, mich gleich bei meiner Rückkehr zu melden, da ich Kaiser Wilhelm I. Immediatvortrag halten sollte. Es war am 9. März, etwa 7 Uhr morgens, als ich ankam. Die Straßen zeigten das gewöhnliche Bild, nur fiel es mir auf, daß auf den öffentlichen Gebäuden Flaggen Halbmast standen. $\mathrm{Zu}$ Hause angelangt, fragte ich meine Frau, was denn das bedeute; unterwegs hatte ich nichts erfahren. Meine Frau konnte mir auch keine Auskunft geben. Als ich dann sofort zu Generalarzt v. Leuthold fuhr, um meine Rückkehr zu melden, trat er mir mit den Worten entgegen: ,Heute Nacht ist unser lieber alter Kaiserlicher Herr gestorben!“

Die kurze Iootägige Regierung Kaiser Friedrichs III. war für ihn nur eine schwere Leidenszeit. Der Eindruck, den es auf mich machte, als er, der todkranke Mann, am Ir. März, zu Beginn der dunklen Nacht, unter Schneegestöber, von einer Ulaneneskorte geleitet, als zweiter deutscher Kaiser und achter König von Preußen in das Charlottenburger Schloß einzog, kann schwer in Worte gefaßt werden. Am I3. März, bei starker Winterkälte, erfolgte die Bestattung Wilhelms I., ein trauriger Zug! Vieles wäre noch über das Verhalten der nunmehrigen Kaiserin Friedrich während der kurzen Lebenszeit Regierungszeit kann man kaum sagen - Friedrichs III. zu erwähnen, doch beschränke ich mich auf persönliche Erlebnisse.

Am I5. Juni 1888 wurde Friedrich III. von seinen Leiden erlöst. Die deutschen Kliniker v. Bergmann und Gerhardt mußte n darauf bedacht sein, da $B$ den immer noch vertretenen falschen Auffassungen der Anhänger Mackenzies, die das Bestehen eines Krebsleidens als Todesursache nicht zugeben wollten, ein für allemal ein Ende gemacht würde. Das konnte nur durch Vornahme einer regelrechten Obduktion der kaiserlichen Leiche geschehen und zwar im Beisein des 
ärztlichen Personals, welches während der Krankheit Friedrichs III. in Anspruch genommen worden war, und von Hofbeamten. v. Bergmann stellte dies dem jungen Kaiser Wilhelm II. vor, und überzeugte ihn von der Notwendigkeit dieser Maßnahme. Die Obduktion wurde für den Nachmittag des I6. Juni bestimmt; ich wurde aufgefordert, teilzunehmen. Ich besprach mich mit Rudolf Virchow und übernahm die Sorge für die Obduktionsinstrumente und für ein Mikroskop mit den nötigen Hilfsmitteln zur sofortigen Anfertigung mikroskopischer Präparate. v. Bergmann, v. Bardeleben, Mackenzie, dessen Assistent Dr. Hovell und einige Andere der genannten Kreise waren gleichfalls erschienen. Virchow sollte die Obduktion vornehmen, ich die mikroskopische Untersuchung. Als wir in einem Zimmer des Neuen Palais versammelt waren, mit uns der Oberhofmarschall Graf Stolberg-Wernigerode, erschien der bisherige Leibarzt des verstorbenen Kaisers, Dr. v. Wegner, und eröffnete uns, er habe im Auftrage der Kaiserin Friedrich mitzuteilen, daß sie, die Kaiserin, die Vornahme der Sektion nicht wünsche. Erstaunt sahen wir einander an, Virchow trat vor und fragte den Grafen Stolberg, was zu tun sei? Der Oberhofmarschall erwiderte, er werde zum Kaiser gehen und dessen Befehle einholen. Wenige Minuten später erschien er wieder mit der in fester Stimme vorgetragenen Botschaft: „Seine Majestät der Kaiser befiehlt, daß die Sektion unverzüglich vorgenommen werde!'“ Wir begaben uns darauf in das Zimmer, in welchem die Leiche Kaiser Friedrichs aufgebahrt lag. In richtiger Voraussicht, daß bei einer Obduktion geschultes Dienerpersonal nötig ist, hatte ich den Präparator Wickersheimer des Anatomischen Instituts und den ersten Anatomiewärter, Drößler, mitgenommen; Virchow hatte außerdem den Inspektor des Pathologischen Instituts, Hübner, mitgebracht. Da ich sah, wie die anwesenden Hofdiener nicht recht wußten, wie sie die Leiche des Kaisers auf dem dazu herzurichtenden Tische betten sollten, winkte ich die von mir mitgenommenen erfahrenen Leute heran. Schnell hatten diese einen passenden Tisch hergerichtet, die Instrumente und das sonst Nötige geordnet und Beide trugen nun die Leiche auf den Tisch und lagerten sie ordnungsgemäß; das alles war ein Werk weniger Minuten, ohne jede Stockung und Unzuträglichkeit. Ich war froh, daran gedacht $z u$ haben, die beiden Männer mitzubringen. Virchow vollzog kunst- 
gerecht die Obduktion der Hals- und Brustorgane, wobei ich ihm assistierte. Die weitgehende krebsige Zerstörung des Kehlkopfes, Metastasen in den zugehörigen Lymphdrüsen sowie zahlreiche bronchopneumonische Herde waren das Ergebnis der Obduktion, wie auch durch sofort von mir angefertigte mikroskopische Präparate sichergestellt und zu Protokoll gegeben wurde. Damit war nun der Legendenbildung ein Ende gemacht. Die Art und Weise, wie Mackenzie seine Aufgabe erfaßt und durchgeführt hat, wurde in der Folge selbst von den britischen Ärzten streng verurteilt.

Das Verhalten Gerhardts und v. Bergmanns muß als ein durchaus würdiges und richtiges anerkannt werden; nur mit größter Hochachtung kann ich dieser beiden Männer gedenken. Mit v. Bergmann verband mich seit dieser Zeit ein freundschaftliches Verhältnis. Zur Charakteristik dieses bedeutenden Mannes schalte ich hier einen Bericht über die letzte Begegnung, die ich mit ihm hatte, ein. Wir hatten geplant, nach einer Sitzung der Medizinischen Gesellschaft noch in einer Weinwirtschaft zusammenzukommen. Ich wurde verhindert, gleich mit den übrigen zusammen hinzugehen und kam spät nach, als man dort schon an den Aufbruch dachte. Als ich in den Saal trat, rief v. Bergmann: „Ah, da kommt noch Waldeyer, nun trinken wir noch ein Glas Sekt zusammen!"6 Gesagt, getan; wir blieben noch eine Weile und v. Bergmann sagte uns, er habe die Absicht, mit dem Ende des Semesters sein Lehramt niederzulegen. Wir Alle waren bestürzt und ich besonders drang auf ihn ein, daran doch noch nicht $\mathrm{zu}$ denken. Er erwiderte, daß er merke, wie seine Augen und die Sicherheit seiner Hände nachließen, worauf ich bemerkte, daß er doch schwierige Operationen seinen erprobten Assistenten überlassen könne; es komme doch auch nicht nur auf die Operationen an, sondern auf die ganze, von Allen als meisterlich anerkannte Art, wie er den klinischen Unterricht halte. v. Bergmann reichte mir die Hand und sagte: „Alles oder Nichts!" Er begab sich nach Wiesbaden, ich auf meine zweite Mittelmeerreise. Wir sollten einander nicht wiedersehen.

Rudolf Virchow zeigte mir die mikroskopischen Präparate, die er von den ihm übergebenen Stückchen aus dem Kehlkopfe des Kronprinzen gewonnen hatte, so wie ich ihm die meinigen vorlegte. Aus den Befunden an dem von Mackenzie im Mai und später im Juni (ohne Beisein von Gerhardt) entnommenen Stückchen war 
die Diagnose „Krebs“ nicht zu stellen und Virchow hatte mit dem Urteil, welches er seiner Zeit abgab, Recht.

Er sagte in seinem Gutachten vom 9. Juni I887 über zwei von Mackenzie aus dem Kehlkopf des Kronprinzen Friedrich Wilhelm entnommene Stücke folgendes: „Die mikroskopische Untersuchung bestätigt die bei der groben Betrachtung gewonnene Diagnose: I. Die Oberfläche besteht überall aus einer sehr starken und dichten Decke von vielschichtigem Plattenepithel. In vielen Zellen zeigten sich größere Gallertkörner. Hier und da lag ein Nest konzentrisch geschichteter Zellen. Nach innen folgte eine gleichfalls mehrschichtige Lage zylindrischer Zellen (ohne Cilien), welche direkt auf dem Bindegewebe aufsaßen. 2. Die Bindegewebsschicht der Schleimhaut war an ihrer Oberfläche mit langen papillären Auswüchsen besetzt, welche außer den Elementen des Bindegewebes größere Gefäßschlingen enthielten. In jedes Korn der Oberfläche trat eine derartige Papille ein. Im übrigen zeigte die Schleimhaut keine Veränderungen, selbst Kernund Zellwucherungen waren nur spärlich wahrzunehmen. Beide Schnitte haben in ausgiebiger Weise in die Schleimhaut und in die Submucosa eingegriffen" (Virchow beschreibt hier noch den Befund von Nervenfasern, elastischen Fasern und Drüsenläppchen). Es heißt dann weiter: „Obwohl dadurch bewiesen wird, daß der operative Eingriff tiefe, unterhalb der Schleimhaut gelegene Teile erreicht hat, so ist doch, trotz genauester Durchmusterung dieser tieferen Teile, insbesondere an der Schnittfläche keine einzige, in nennenswerter Weise veränderte Stelle aufgefunden worden. Alle wesentlichen Veränderungen gehören der Oberfläche an. Sie charakterisieren das Übel als eine mit papillären Auswüchsen (mißbräuchlich Papillom genannt) verbundene Epithelwucherung: $\mathrm{Pa}$ ch ydermia verrucosa. Irgendein Hineinwuchern dieser Epithelgebilde in die Schleimhaut konnte nicht entdeckt werden."

„Der vorliegende Befund geht erheblich über den Befund vom 2I. Mai hinaus. In dem damaligen Objekt waren nur sehr schwache, höchstens annäherungsweise mit den jetzigen in Vergleich zu stellende irritative Veränderungen nachzuweisen. Allem Anschein nach gehörten sie nur der Peripherie des Krankheitsherdes an. Gegenwärtig ist eine offenbar mehr zentrale Stelle gefaßt worden. Obwohl diese Stelle eine sehr ausgeprägte Erkrankung erlitten hat, so ergibt doch 
die gesunde Beschaffenheit der Gewebe an der Schnittfläche ein prognostisch sehr günstiges Urteil."

„,Ob ein solches Urteil in bezug auf die gesamte Erkrankung berechtigt wäre, läßt sich aus den beiden exstirpierten Stücken mit Sicherheit nicht ersehen. Jedenfalls ist an denselben nichts vorhanden, was den Verdacht einer weiteren ernsteren Erkrankung hervorzurufen geeignet wäre."

Man hat diese Fassung bemängelt, obwohl sie die Möglichkeit durchblicken ließ, es könne an einer anderen Stelle des Kehlkopfes doch eine ,weitere ernstere" Veränderung - Virchow vermeidet das Wort „Krebs" — vorhanden sein, während in der Nachbarschaft nur die von Virchow richtig festgestellte Epithelverdickung nachgewiesen wurde. Angesichts der bestimmten Diagnose Gerhardts und v. Bergmanns und der festgestellten Epithelverdickung, also eines nicht normalen Befundes, wäre es meines Erachtens richtiger gewesen, kurz nur zu sagen, daß an den vorgelegten Stückchen eine Epithelverdickung mit vergrößerten Papillen, jedoch keine krebsige Veränderung zu finden gewesen sei. Indem Virchow aber weiter ging und eine bestimmte Diagnose, die einer „Pachydermia verrucosa“ aufstellte, sowie mehrere Male besonders betonte, daß die Schnittfläche unverdächtig sei und daß der Befund ein prognostisch sehr günstiges Urteil gestatte, leistete er Mackenzies Angaben Vorschub, wie es ja in der Tat der Fall war, denn das Gutachten Virchows wurde von der Presse des englischen Lagers in diesem Sinne verwertet. Virchow selbst hatte später Mühe, Mackenzie von sich abzuschütteln. Siehe hierüber die Anmerkung Nr. I5.

Von San Remo aus erhielt Virchow noch ein von dem Kranken ausgehustetes Gewebsstück. Er fand an einer ,harten Stelle desselben fast in jedem Schnitte Nester von zwiebelschalig angeordneten epidermoidalen Zellen. Sie lagen vorzugsweise in der Deckschicht oder in deren nächster Nähe. In den tieferen Teilen waren sie nicht $z u$ finden". Deutlich isolierte Alveolen, nach denen er anhaltend suchte, hatte er nicht gefunden. Virchow zog aus diesem Befunde zwar noch nicht den Schluß, daß es sich um Krebs handle, schrieb aber doch an den Laryngologen Professor Krause, der sich unter den beim Kronprinzen tätigen Ärzten befand, er möge in der Deutung des beschriebenen Befundes vorsichtig sein. Ich bekenne, daß ich nach dem 
von Virchow beschriebenen Befunde an der Diagnose „Krebs“, und zwar in der Form des sogenannten Cancroids, nicht mehr gezweifelt und diese anatomische Diagnose auch bestimmt ausgesprochen hätte. $\mathrm{DaB}$ Virchow nicht so weit ging, kann ich mir nur daraus erklären, daß er damals über die anatomische Charakteristik derjenigen Neubildungen, die man klinisch als Krebs (Carcinoma) bezeichnet, noch nicht mit sich einig geworden war. Ihm schien das Vorhandensein von rundlich geformten, mit Zellen gefüllten Räumen, "Alveolen", das Wesentliche. Bezeichnend für meine Annahme ist, da $B$ Virchow in seinem meisterhaften großen Werke über die krankhaften Geschwülste gerade die wichtigsten, die Krebsgeschwülste, nicht behandelt hat; er hat den dritten Teil dieses bereits in den Jahren 1863 bis I867 erschienenen Werkes, der die krebsigen Neoplasmen hätte enthalten müssen und der von allen beteiligten Seiten mit dem größten Interesse erwartet wurde, nicht mehr herausgegeben.

Es sei ausdrücklich hervorgehoben, daß Mackenzies Ansehen als Laryngologe zur Zeit der Übernahme der Behandlung des deutschen Kronprinzen unbestritten feststand. Daß er den krebsigen Charakter des Kehlkopfleidens seines Patienten nicht von Anfang an schon richtig erkannt haben sollte, ist bei der Erfahrung, die er in seinem Fache besa B, wohl auszuschließen. Er hat meiner Meinung nach von Anfang an wider besseres Wissen gehandelt. Ich unterlasse es, hier auf die Vermutungen über die Motive zu seinem Verhalten weiter einzugehen. Die überaus traurige Tragödie des Leidens Kaiser Friedrichs III. hat durch dessen frühen Tod ihren erschütternden AbschluB gefunden; denjenigen, die dabei gefehlt haben mögen, ist schweres Leid nicht erspart geblieben.

In den glücklichen ersten 25 Jahren der Regierung Kaiser Wilhelms II. habe ich oft Gelegenheit gehabt, mit ihm zusammenzutreffen. Mehrere Male wurde ich zur Kaiserlichen Tafel gezogen, sowie $z u$ anderen Hoffestlichkeiten. Ich erwähnte bereits der Teilnahme, welche der König als Protektor der Preußischen Akademie der Wissenschaften dieser Körperschaft zu ihrer Zweihundertjahrfeier gab, sowie bei der Feier, welche die Akademie zu Ehren der zweihundertsten Wiederkehr des Geburtstages Friedrichs des Großen veranstaltete. Dreier Begegnungen mit Wilhelm II. möchte ich noch besonders ge- 
denken. Der einen im Stadtschlosse zu Potsdam, wo ich als neugewählter Rektor der Berliner Universität I 898 empfangen wurde. Der Monarch lenkte das Gespräch auf den kurz vorher verstorbenen Fürsten Bismarck. Er, der Kaiser, habe seiner Zeit nicht anders handeln können, als sich vom Altreichskanzler zu trennen: entweder sei Er der Regent oder der Fürst Bismarck, das sei die Lage der Dinge gewesen. Niemand könne den Fürsten höher schätzen und achten, als er und er bedaure es sehr, daß es so habe kommen müssen. Ein zweites Mal - es war nach einer Abendtafel im Königlichen Schlosse zu Berlin - folgte ein Teil der Geladenen dem Monarchen in die sogenannten Prinz-Heinrich-Zimmer, wo sich bei Zigarren und einem Glase Bier eine gänzlich ungezwungene Unterhaltung entwickelte und der Kaiser nur der freundliche Wirt seiner Gäste war. Unter anderem kam das Gespräch mit mir auf eine bevorstehende Reise nach Paris, die ich als Sekretar der Akademie anzutreten hatte. Ich erwähnte, daß wir Akademiker dort auch zum Grafen de Franqueville eingeladen seien, worauf mir der Kaiser Grüße an den Grafen auftrug und mir später, als ich mich verabschiedete, noch unter der Tür nachrief: „Vergessen Sie mir die Grüße an den Grafen nicht!“ Ich habe sie getreulich, so wie sie gegeben waren, ausgerichtet und der Comte de Franqueville, damaliger Präsident des Institut de France, war sichtlich von der Aufmerksamkeit des Deutschen Kaisers erfreut. Das waren andere Zeiten! - Als dritter Begegnung, die mir erwähnenswert erscheint, gedenke ich eines Empfanges wegen des Denkmals 'für Rudolf Virchow, desjenigen, welches auf dem Karlsplatz in Berlin errichtet ist. Es ist ein Vorrecht der preußischen Könige gewesen, daß sie bei Errichtung eines Denkmals in ihrer Residenzstadt die Erlaubnis dazu zu geben hatten. Als man sich nach manchem Für und Wider endlich auf die Ausführung des vom Bildhauer Klimsch vorgelegten Entwurfes geeinigt hatte, lag es mir, als dem Vorsitzer des Denkmalausschusses, ob, die Genehmigung Sr. Majestät einzuholen. Ich erhielt Audienz im Marinesaale des Berliner Königlichen Schlosses, wo ich den Kaiser erwartete, der bald darauf, von einem Spaziergange heimkehrend, erschien und mich freundlich begrüßte. Ich legte ihm die betreffenden Zeichnungen vor und gab dazu kurze Erläuterungen; besonders gefiel dem Monarchen das Reliefporträt Virchows, welches am Denkmal in Marmor angebracht ist 
und dessen Photographie ich vorlegte. Er nahm diese, hielt sie ins passende Licht und sagte: „Famos! Das lassen Sie nur so ausführen." Wir sprachen dann noch mehreres über das Denkmal, wobei die Hochschätzung des Kaisers für Rudolf Virchow zum vollen Ausdruck kam.

In allen Begegnungen, die ich mit Kaiser und König Wilhelm II. hatte, habe ich nur den Eindruck gewonnen, daß man einer offenen, freimütigen, vom besten Wollen beseelten Persönlichkeit gegenüberstand, die herzgewinnend wirkte. Doch die Fürsten dieser Erde haben einen schweren Stand. - Ich komme auf Kaiser Wilhelm II. noch bei Darstellung meiner Eindrücke vom Weltkriege zurück.

\section{K a p it el.}

\section{Politische und Kriegs-Erlebnisse.}

Das Jahr 1848. - Der kurhessische Verfassungsstreit. - Olmütz. - Der Krimkrieg. - Der österreichisch-französische Krieg. - Die Kämpfe um Deutschlands Einigung: 1864, 1866, 1870/71. - Bemerkungen über die späteren Kriege: PeruChile, Vereinigte Staaten-Spanien, Russisch-türkischer Krieg, Boxerkrieg in China, Russisch-japanischer Krieg, Balkankriege I9I2/I3.

Meine ersten Eindrücke von politischen Dingen, Unruhen und Veränderungen, die sich daraus entwickelten, sowie von kriegerischen Geschehnissen reichen in das Jahr I 848 zurück. Es erscheint mir noch heute merkwürdig, wie damals, als in Paris das sogenannte Bürgerkönigtum durch die Februarrevolution gestürzt wurde, die politische Bewegung wie eine Welle sich so rasch über fast ganz Mitteleuropa verbreiten konnte, besonders aber von Deutschland und Österreich aufgenommen wurde. Ich verfolgte als I2jähriger Knabe schon mit regem Interesse die Vorgänge, die auch bald den stillen Erdenwinkel, in welchem ich lebte, in Unruhe versetzten.

Ich nahm derzeit Partei für das preußische Königshaus und freute mich des Sieges, den der damalige Prinz von Preußen, später Kaiser Wilhelm I. über die süddeutschen Revolutionäre erfocht. Der Erhebung Schleswig-Holsteins gegen die willkürliche Regelung der Erbfolge in den Elbherzogtümern durch den dänischen König Christian VIII., die sein Sohn und Nachfolger Friedrich VII, zu Anfang des Jahres 1848 durchsetzen wollte, brachte ich mit der ganzen 
deutschen Jugend volle Sympathie entgegen und sang mit voller Begeisterung das damals aufgekommene Lied:

„,Schleswig-Holstein meerumschlungen,

Deutscher Sitte hohe Wacht" usw.

Die Kämpfe in Schleswig-Holstein, die dem alten Wrangel zu Namen und Ehren verhalfen, vor allem die Zerstörung des dänischen Linienschiffes Christian VIII. und die Eroberung der Fregatte Gefion in der Bucht von Eckernförde begeisterten in Deutschland Jung und Alt. Mir schweben diese Tage noch heute sozusagen lebendig vor. Aber wie bald folgten ihnen die Tage tiefster Erniedrigung für Preußen! England und Rußland traten für Dänemark ein, Preußen schloß darauf Frieden mit Dänemark und überließ die Herzogtümer ihrem Schicksal (2. Juli I850). In dieser Zeit waren auch Spannungen zwischen Österreich und Preußen aufgetreten, die Preußen wohl zum Frieden gedrängt haben mögen. König Friedrich Wilhelm IV. hatte, wie mir scheint, in richtiger Erkenntnis der Lage der Dinge in Deutschland, die ihm von der Frankfurter Nationalversammlung angebotene deutsche Kaiserkrone abgelehnt, suchte aber doch gegenüber Österreich Einfluß in Deutschland zu gewinnen, zumal Österreich durch den Aufstand in Ungarn mit sich selbst beschäftigt und allen Einflusses in Deutschland bar war. Er knüpfte mit Sachsen und Hannover die sogenannte Union, die aber, sobald Österreich nach der Besiegung Ungarns wieder frei wurde und nun auf die Wiederherstellung der alten Bundesverfassung drang, durch den Abfall Sachsens und Hannovers wieder in die Brüche ging. Es bildete sich durch den ZusammenschluB Bayerns und Württembergs mit Sachsen und Hannover ein Vierkönigsbund, der sich zu Österreich hielt, so da $B$ Preußen isoliert dastand. Dieses alles in dem denkwürdigen Jahre I850. Dazu kam in demselben Jahre noch der kurhessische Verfassungsstreit. Seit I83I bestand in Kurhessen eine verhältnismäßig liberale Verfassung, die dem damaligen Kurfürsten abgerungen worden war. Dessen Sohn suchte mit Unterstützung des Ministers Hassenpflug ( $\left.{ }^{16}\right)$, dem der Beiname „Hessenfluch" gegeben wurde, diese Verfassung $\mathrm{zu}$ beseitigen und $\mathrm{zu}$ dem früheren autokratischen Regiment zurückzukehren. Österreich und die mit ihm verbündeten Vierkönige begünstigten dies und als die Hessen sich nicht fügen wollten, rückten 25000 Mann österreichisch-bayerische Truppen von 
Süden her in Kurhessen ein; man nannte diese Truppe damals die „Strafbayern“. Preußen, in dessen Machtbereich Kurhessen zunächst lag, erhob Einspruch gegen diese Bundesexekution und ließ von Norden her zwei Divisionen einmarschieren. In der Nähe des kleinen Dorfes Bronnzell bei Fulda stießen die beiderlei Vortruppen aufeinander und es kam zu einer kleinen Schießerei, wobei einige österreichische Jäger und auf preußischer Seite ein Trompeterpferd, der bekannte „Schimmel von Bronnzell“" verwundet wurden. Österreich, damals von Rußland und dem größten Teile Deutschlands unterstützt, erreichte sein Ziel, die Wiederherstellung der alten Bundesverfassung und seine Vorherrschaft; Preußen zog sich zurück. Es war ein Tag bitterer Schmach für Preußen, an dem dies geschah, der Tag von Olmütz, 29. November r850!

Damit waren die zwei ersten Revolutions- und Kriegsjahre, die ich erlebte, beendet. Sie hatten, von Frankreich her angefacht, doch einen frischen Luftzug durch ganz Deutschland wehen lassen, dessen Spuren durch den hauptsächlich von RuBland und Österreich beeinflußten und von Preußen begünstigten Gegenstrom nicht mehr völlig verweht werden konnten. Ich habe damals schon, im I4. Lebensjahre stehend, alle diese Ereignisse mit reger Anteilnahme verfolgt, zumal die durch den kurhessischen Verfassungsstreit hervorgerufenen Maßnahmen sich in der Nähe meiner Heimat vollzogen und die durchziehenden Truppen zum Teil auf dem Rittergute Abbenburg Quartier bekamen. Wir Jungen dachten damals an eine große Schlacht und waren enttäuscht, als uns nur der Schimmel von Bronnzell gemeldet wurde. Die Preisgabe Schleswig-Holsteins und die Kapitulation vor Österreich in Olmütz habe ich schmerzlich empfunden. Später hatte ich auch Gelegenheit, den damals vielgenannten Minister Hassenpflug persönlich kennen zu lernen. Er war mit der Familie v. Haxthausen gut bekannt und ich traf ihn bei einem Besuche, den er der Familie machte, in deren Kreise, zu dem ich auch geladen war; ich fand bei ihm eine freundliche und ungezwungene Art geselliger Ünterhaltung und ich gewann von ihm den Eindruck eines bedeutenden und gewandten Mannes.

Wenn auch der nächste große Krieg, der Krimkrieg, dahinten in der Türkei die Völker aufeinander platzen ließ, so wurde er doch von mir, dem damaligen Paderborner Gymnasiasten, mit großem Inter- 
esse an der Hand der Zeitungsberichte verfolgt. Meine Sympathien sowie die der ganzen Kreise, in denen ich mich damals bewegte, waren auf Seiten der Franzosen und Engländer; namentlich der Marschall Pellissier erschien uns als der große Held des Tages. Die Franzosen stellten wir weit über die Engländer und die Operationen der englischen Flotte, geführt von Lord Charles Napier, der als ,the fighting Charlie" bezeichnet wurde, bei Bomarsund, wo er, wie es hieß, einige Teertonnen in die Luft gesprengt hätte, wurden bespöttelt. Als nachher die Franzosen kamen, wurde Bomarsund erobert.

Allgemein fiel es auf und erregte auch mein Nachdenken über Krieg und Kriegsziele, daß das damalige kleine Königreich Sardinien sich den beiden großen Westmächten anschloß und sich mit einem Hilfsheere von I5000 Mann an dem Unternehmen gegen Rußland beteiligte. Wozu, fragte ich mich, müssen sich diese Italiener in der Krim totschlagen lassen? Was geht der Streit zwischen Rußland und der Türkei das Königreich Sardinien an? Die Antwort sollte bald auf den Schlachtfeldern der Lombardei gegeben werden.

Napoleon III., der bei der Wiederaufrichtung des Kaisertums in Frankreich gesagt hatte, ,l'Empire c'est la paix", fuhr bald fort, seine Worte Lügen zu strafen. Dem Krimkriege, der ihm die Augen der ganzen Welt zugewendet hatte, ließ er drei Jahre später den Krieg mit Österreich um Lombardo-Venetien folgen, der uns in Deutschland schon viel näher anging, Preußen auch auf den Plan rief und in meine Familie eingriff. Ich bekenne, daB ich anfangs auch Sympathien mit den französischen Waffenerfolgen hatte, denn ich sah es für eine gerechte Sache an, daß den Italienern die echt italienische Lombardei und das echt italienische Venetien zurückgegeben werde. Als sich jedoch Napoleon mit Zustimmung des französischen Volkes dafür Savoyen und Nizza, die Geburtsstadt Garibaldis, als Honorar aushändigen ließ, da war es mit meiner guten Stimmung für Frankreich vorbei.

Damals, wie jetzt beim Weltkriege, wollte Preußen Österreich nicht im Stiche lassen und ordnete nach der Schlacht von Solferino die Mobilmachung an. Die darin liegende Drohung war es wohl hauptsächlich, die Napoleon veranlaßte, Halt zu machen und von der Einlösung seines Wortes: „Italien frei bis zur Adria“ Abstand zu nehmen. 
Die preußische Mobilmachung traf auch meinen zweiten Bruder, der damit eine gute Stellung als Landwirt in Mecklenburg verlor.

Nicht lange darauf, I860, befand sich England im Kriegszustande mit China, und Frankreich nahm daran teil; mir ist aus diesem Kriege die Plünderung des Kaiserlichen Winterpalastes in China durch die Franzosen in Erinnerung geblieben.

Schon ein Jahr später hatte Na poleon bereits wieder einen Krieg entfacht, den mexikanischen. Mit dem größten Interesse verfolgte ich den Gang des Geschickes des unglücklichen Erzherzogs Maximilian, Kaisers von Mexiko von Napoleons Gnaden. Alles das, was er erlebte, sein Kämpfen, sein Leiden, sein tragischer Tod trat mir wieder lebhaft vor die Seele, als ich später sein Schloß Miramare bei Triest, sein Denkmal in Pola, sein lebensgroßes Bildnis im Schlosse Chapultepek bei Mexiko-Stadt und die zum Andenken an seinen tragischen Tod erbaute Sühnekapelle auf der Höhe bei Querétăro sah. Kaum 35 Jahre alt, wurde er dort, nachdem er erst am I2. Juni I864 von der mexikanischen Kaiserkrone durch seinen feierlichen Einzug in die Stadt Mexiko Besitz ergriffen hatte, jedoch nie recht Herr des Landes gewesen war, am I9. Juni I867 kriegsrechtlich erschossen. Wie die neueren Ereignisse zu lehren scheinen, haben die Begründungen von Dynastien durch fremdländische fürstliche Persönlichkeiten in jetziger Zeit ihre Schwierigkeiten; ich erinnere an die Ereignisse in Bulgarien und insbesondere an Albanien; ob auch die Hohenzollerndynastie in Rumänien noch lange Bestand haben wird, oder die dänische in Griechenland, kann bezweifelt werden.

Das Abenteuer Napoleons III. in Mexiko stützte sich auf den großen Bürgerkrieg der Nordamerikanischen Union I86I-I864, dem Deutschland durchgehends mit Wünschen für den Sieg der Nordstaaten in größter Spannung folgte. Dieser Krieg ist aber auch, das empfand ich damals schon lebhaft, ein welthistorisches Ereignis von der größten Bedeutung, denn durch den entscheidenden Sieg der Nordstaaten wurde die Gesamtunion erhalten und zu jener Macht erhoben, die von da an aktiv und bestimmend in die Geschicke der Welt eingreifen konnte, wie das jetzt der Verlauf des Weltkrieges klar gezeigt hat.

Gleichzeitig brachen nun neue, für das Geschick Deutschlands entscheidende Kriegswetter in Europa aus,.an denen ich persönlichen 
Anteil nehmen sollte. Seit der Preußenthron auf den Bruder Friedrich Wilhelms IV., den späteren deutschen Kaiser Wilhelm I. übergegangen war, der den bisherigen Bundestagsgesandten v. Bis ma rckSchönhausen an die Spitze der Regierung berief, war es unverkennbar, da $B$ Preußen sich von der in Olmütz eingegangenen Nachgiebigkeit gegenüber Österreich freimachen und wieder selbständige Politik treiben wollte. Das zeigte sich zuerst klar I863 bei Berufung des Fürstentages nach Frankfurt am Main durch Kaiser Franz Josef I. König Wilhelm folgte der an ihn ergangenen Aufforderung nicht und der mit so vielem Pomp in Szene gesetzte Fürstentag verlief crgebnislos. Es mußte dies naturgemäß eine Spannung zwischen Preußen und Österreich, dem der größte Teil der deutschen Bundesstaaten folgte, erzeugen und unterhalten, die über kurz oder lang - es sollte nur drei Jahre dauern - zúr Entladung führte.

In demselben Jahre 1863 hatte Dänemark nach dem Tode König Fredericks VII. eine neue Verfassung angenommen, durch welche Schleswig zu einem integrierenden Teile des dänischen Staates erklärt wurde. Dies mußte notwendig, falls keine Zurücknahme erzielt werden konnte, zum Kriege mit Deutschland führen, der am I. Februar I864 tatsächliçh mit dem Übergange österreichischpreußischer Truppen über die Eider eröffnet wurde. Ich war diesmal persönlich insofern dabei interessiert, als meine Einziehung zum aktiven Heeresdienste bei der mobilen Truppe mir als demnächst bevorstehend angekündigt worden war; der Friede wurde indessen eher geschlossen, als meine Einziehung nötig wurde.

Die kriegerischen Ereignisse, insbesondere die Eroberung der Düppeler Schanzen, das Zusammenwirken Österreichs und Preußens, welches aber schon den Keim der Entzweiung in sich trug, das oberflächliche Pflaster des Gasteiner Vertrages vom I4. August 1865, welches den Riß wohl für eine Zeitlang verdecken, aber nicht heilen konnte, sind bekannt. Man kann sich kaum vorstellen, mit welcher Spannung in allen Kreisen diese Vorgänge, die sichtbarlich dem Kriege zwischen Österreich und dessen Anhängern im Deutschen Bunde einerseits und Preußen mit seinem geringen Anhange andererseits zutrieben, damals in Breslau, wo ich eben durch meine Verheiratung am 5. April 1866 meinen eigenen Hausstand gegründet hatte, 
verfolgt wurden. Kam es zum Kriege, so waren wir ja in Schlesien zunächst dessen möglichen Wechselfällen ausgesetzt. Am II. Juni I866 wurde der Krieg erklärt und schon am 4. Juli I866 war er durch die Schlacht bei Königgrätz für Preußen entschieden!

Verschiedene Erlebnisse dieser Zeit sind im Kapitel „Breslau“ berichtet worden. Vor allem muB ich hier noch der schweren Kriegsgeißel gedenken, die uns unmittelbar nach Beendigung des Waffenganges schwer traf und die Freude am Siege sehr herabminderte, der Cholera. In Breslau wütete diese Seuche schrankenlos; in den Augusttagen 1866 zählte man während einiger Wochen täglich über roo Tote, an einzelnen Tagen bis 300. In dem Hause, wo ich als junger Ehemann im April I866 mein Heim gegründet hatte, kamen 7 Todesfälle vor. Ich hatte täglich mehrere Obduktionen an Choleraleichen auszuführen und somit Gelegenheit, die Pathologie der Cholera gründlich kennen zu lernen. Es hat mich nicht nach einer zweiten Bekanntschaft verlangt.

Gern erzähle ich hier ein kleines Erlebnis aus meiner Tätigkeit im Spital der Barmherzigen Brüder, wo ich mich an der ärztlichen Pflege der Verwundeten beteiligte. Ein ungarischer Soldat - Andrea hieB er - war mit einer Splitterschußfraktur des linken Oberarmes eingeliefert worden. Der tägliche Verbandwechsel war für den Mann sehr schmerzhaft. Er bat dann eines Tages, man möge ihm doch, während der Arm verbunden werde, erlauben, zu rauchen; dann könne er den Schmerz leichter ertragen. Gern wurde ihm die Erlaubnis erteilt. Glücklich steckte er sich eine Zigarre an, hielt den Arm hin, rauchte vergnügt und verzog keine Miene trotz großer Schmerzen, die er zweifellos hatte. Oberarzt Professor Paul, der den Verband selbst machte, merkte sich das zufriedene Gesicht Andreas und brachte ihm nun jedesmal zum Verbande eine echte Habana mit, die der Mann glückstrahlend in Empfang nahm und sofort, nachdem er sie angesteckt, seinen verwundeten Arm ohne Zaudern hinhielt. Nach Erledigung des Verbandes ging er mit seiner Zigarre im Zimmer auf und $\mathrm{ab}$ und es wurde Jedem, der zusah, wie Andrea mit großem Behagen rauchte, selbst behaglich zumute; alle Verwundeten warteten mit Vergnügen täglich auf die Stunde, in der Andrea seine Zigarre rauchte; ich habe niemals Jemand so virtuos rauchen sehen wie diesen Ungarn. Sein Arm blieb ihm erhalten. Der Fall ist ein gutes Beispiel von 
der beruhigenden Wirkung des Tabakrauchens, die dies offenbar für manche Menschen hat.

Nach diesem Kriege, den man wohl als einen ritterlichen, gesunden Kampf bezeichnen kann, denn er führte zur offenen klaren Versöhnung, zu einem dauernden Bündnisse der beiden streitenden Parteien und zu einem unter Preußens Führung starken Deutschland, durfte man auf eine längere Friedensdauer, wenigstens in Europa, hoffen. Doch diejenigen, welche diese Hoffnung hegten, hatten mit dem ewigen Unruhestifter Europas, mit Frankreich und dessen Kaiser, der seit dem Mißlingen des mexikanischen Abenteuers in eine mißliche Lage geraten war, nicht gerechnet. Napoleon III. glaubte seinen wankenden Thron auf jeden Fall durch einen äußeren Erfolg stützen zu müssen. Die glänzende Pariser Weltausstellung 1867 , zu der auch König Wilhelm von Preußen kam, war etwas, reichte aber nicht aus. Äußerungen, wie „Revanche pour Sadowa“ und andere Zeichen ließen erkennen, daß es in Frankreich eine starke Partei gab, die in dem Emporkommen Preußens und der damit verbundenen engeren Einigung Deutschlands eine Gefahr für Frankreich sah. Kaiser Napoleon glaubte nun, da $\beta$ er beì einem Kriege mit Preußen sofort Österreich-Ungarn und den größten Teil Deutschlands auf seiner Seite haben würde und das um so sicherer, je eher er den Krieg beginne, bevor also die Wunden von Königgrätz und von Langensalza vernarbt seien. In dieser Hinsicht verloren offenbar er selbst wie auch seine Minister die kluge Einsicht in die wahre Sachlage. Auch das neue Gewehr, von dessen Wirkung in dem Treffen bei Mentana gegen die Garibaldianer der General Failly gesagt hatte: „Les Chassepots ont fait merveille" und die Äußerung des damaligen Kriegsministers Le Boeuf, da $B$ die Armee ,archiprêt" sei, mögen mitgewirkt haben, da $B$ der Kaiser einen so törichten Vorwand zur Kriegserklärung nahm, wie es die Wahl eines Hohenzollern zum König von Spanien und die bekannte Ablehnung König Wilhelms in Bad Ems am I3. Juli I870 war. $\mathrm{Da} B$ Bismarck in seiner Kürzung der von Geheimrat Abeken verfaßten Emser Depesche(17), die so gern als Fälschung bezeichnet wird, den Text so gab, wie er dann zur Veröffentlichung kommen sollte, war die richtige Antwort auf das beleidigende Ansinnen, welches an Preußen und seinen König mit der von der französischen Regierung durch den Mund ihres Gesandten Benedetti 
vorgetragenen Forderung gestellt worden war. Die Erregung in Frankreich war aber schon so gro $B$, daß nun die Form der Veröffentlichung der Emser Depesche, durch welche die Ablehnung der Forderung Benedettis seitens König Wilhelms den Mächten mitgeteilt wurde, alsbald als Grund zur Kriegserklärung dienen mußte; diese wurde bereits am I9. Juli I870 durch den Herzog von Gramont abgegeben.

Wie der Krieg verlief und was im Frankfurter Frieden erreicht wurde, braucht hier nicht geschildert zu werden; nur die persönlichen Eindrücke, die der Krieg bei mir selbst und in den Kreisen, mit denen ich verkehrte, hervorrief, seien noch kurz angeführt. Gegenüber der großen Erregung, die in Paris herrschte, wenigstens bei einem großen Teile der Bevölkerung, war man, soweit meine persönlichen Erfahrungen und die mir zugekommenen Nachrichten reichten, wohl überall in Deutschland ruhiger und gefaßt. Den Ernst der Lage verkannte man nicht, hatte jedoch volles Vertrauen $\mathrm{zu}$ unserer I866 so sicher erprobten Heeresführung. Gestärkt wurde unsere Haltung durch die feste Überzeugung, daß wir den Krieg mit Frankreich nicht gesucht hatten, sondern daß er uns unter gänzlich haltlosen Vorwänden aufgezwungen worden war. Wir unterschätzten aber auch nicht unseren Gegner, dem gleichfalls glänzend bewährte Heerführer zur Verfügung standen. Als am 2. August I870 das Gefecht bei Saarbrücken in Paris als groBer Sieg verkündet wurde, hat vielleicht den Einen oder den Anderen Besorgnis ergriffen, ob wir die Sache gut bestehen würden; die Ungleichheit der Kräfte, die tapfere Haltung des beteiligten deutschen Regiments und der geringe Erfolg der französischen Waffen ließ jedoch keine Befürchtung aufkommen. Und nun folgte Schlag auf Schlag: Weißenburg, Wörth, Straßburg, die Schlachten um Metz, Sedan; in vier Wochen war das kaiserliche Frankreich besiegt und erledigt. $\mathrm{Da} B$ sich da in Deutschland eine volle Begeisterung zeigte, wie sie selten so rein und hehr - so kann man sagen - gefunden werden dürfte, ist selbstverständlich. Das Erhebendste bei der Sache war das erstmalige Hervortreten des gesamten deutschen Volkes zu einheitlichem Tun und das unter der Führung von Männern, wie König Wilhelm I., Bismarck und Moltke: Männern echt deutscher Art, ohne Furcht und Tadel, zu denen man nicht nur volles Vertrauen haben durfte, sondern die auch als sittliche Größen vor aller Augen bestehen 
konnten. Uns allen und auch der staunenden Welt wurde klar, was das geeinte deutsche Volk vermochte!

Das Kaisertum in Frankreich war besiegt, aber Frankreich war noch nicht besiegt. Die schwerere Aufgabe stand uns noch bevor. Man muß den Franzosen das ehrenvolle Zeugnis geben; daß sie sich, ungeachtet der schweren Niederlagen, die der größte Teil ihrer Armee erlitten hatte, unverzagt und tapfer bis zum letzten Mann aufrecht erhalten haben. Gambettas Ruhm wird stets in der Geschichte als ein glänzendes Bild bestehen bleiben; aber auch der Ruhm Frankreichs selbst. Frankreich hatte, nach dem Verluste seiner ganzen Armee, eine Million feindlicher Krieger im Lande, hatte den Übergang von einer Monarchie durch das Fegefeuer der Commune zur Republik durchzumachen und Frieden zu schließen. Es hat diese Aufgabe glänzend gelöst. Es drängt sich die Frage auf, ob wir uns jetzt, da dieselbe Aufgabe für uns zu lösen war, gleich gut gehalten haben. Das müssen wir leider verneinen. Wenn man nach dem Grunde fragt, so liegt der meines Erachtens klar zu Tage. Frankreich war damals in seinem Unglück einig; einig bis zum letzten Mann scharte es sich um die Fahne Gambettas und der Republik; die bestehenden anderen politischen Ansichten und deren Vertreter wurden schnell beseitigt. In Deutschland trat sofort nach dem Zusammenbruche des alten Regiments die alte Uneinigkeit wieder zu Tage; statt sich um die Mittelparteigruppe fest zu schließen und sie zur Wiedergeburt und Rettung des Vaterlandes zunächst einmal fest zu unterstützen, bereiteten ihr die extremen Parteien sowohl von rechts wie namentlich von links die größten Schwierigkeiten und ließen die Regierung nicht zu ruhigem Werke kommen. Dazu kam aber auch ein zweites, die bis zum äußersten übelwollende Haltung unserer Feinde, das heißt fast der ganzen Erdenwelt, und die fortbestehenden steten Unruhen an unserer großen östlichen Grenze. I87I, als die Armee Bourbakis über die Schweizer Grenze gedrängt und der Waffenstillstand geschlossen war, hörte bei uns jede feindselige Stimmung gegen Frankreich auf. Aus meinem eigenen Empfinden und aus dem, was ich von anderer Seite erfuhr, kann ich das bestimmt behaupten. Schwer verwundet konnten sich die Franzosen nur durch den Verlust von Metz mit dem anliegenden lothringischen Gelände fühlen; das war aber auch nur ein geringer Verlust gegen das, was jetzt uns genommen wird. Und dann bei uns: 
Fahrt zum Kriegsschauplatze I87o.

Feinde ringsum! Selbst bei den meisten Neutralen kaum eine Spur von Wohlwollen, während dies I870/7I Frankreich von allen Seiten entgegengebracht wurde. Uns brachte man während des Waffenstillstandes täglich Schwierigkeiten und die Friedensbedingungen sind so abgefa $B t, d a ß$ wir noch auf Menschenalter hinaus unter einer übelwollenden Kontrolle stehen und nicht Herren im eigenen Hause sind. Nimmt man dies alles zusammen: unsere innere Uneinigkeit und die äußeren Schwierigkeiten, dann muß man sich doch noch wundern, da $B$ wir so durch diese Krisis hindurchgekommen sind, wie bisher. Möchten wir aber vor allem Eines aus diesem Vergleich zwischen Frankreich I870/7I und Deutschland I9I8/I9 lernen: Einigkeit! Einigkeit!

Von meinen persönlichen Erlebnissen im Kriege $1870 / 7 \mathrm{I}$ berichte ich noch folgendes: Als es klar wurde, daß der Krieg unvermeidlich sein würde, bereitete man sich auch überall auf die genügende Pflege der Verwundeten und Kranken vor. Der Breslauer Professor der Chirurgie, Dr. Hermann Fischer, ein durch sein Werk über Kriegschirurgie vorteilhaft bekannter Fachmann, setzte sich mit dem Johanniter-Orden in Verbindung, der geplant hatte, alsbald nach Ausbruch des Krieges eine Expedition von Ärzten und Pflegepersonal auszurüsten, nach dem Kriegsschauplatze zu entsenden und dort zu unterhalten. Fischer forderte eine Anzahl von Ärzten, darunter auch mich und Spiegelberg, auf, ihn zu begleiten und unter seiner Oberleitung an den von den Johannitern zu errichtenden Lazaretten tätig zu sein. Freudig sagten wir zu, übten uns unter Fischers Leitung in dem Anlegen von Verbänden und in der Vornahme leichterer und lebensrettender Operationen ein und fuhren, als die Nachricht von dem Scharmützel bei Saarbrücken und der Schlacht bei Weißenburg eingetroffen waren, am Abend des 6 . August $1870 \mathrm{ab}$. Wir passierten in der Nacht Liegnitz, da war gerade die Depesche von Wörth eingetroffen. Während der Zug hielt, trat ein Schaffner an die Wagen und verlas das Telegramm mit folgenden Worten: „Der General Max Mohan ist bei Wörth angegriffen und geschlagen worden." Den Max Mohan an Stelle Mac Mahons kann ich noch nicht vergessen. Hatte die französische Siegesnachricht von Saarbrücken uns stutzig gemacht, so war durch die bald darauf erfolgte Nachricht von Weißenburg und jetzt durch die Nachricht von Wörth unsere Stimmung 
hochgehoben, und froh, mit guter Zuversicht, fuhren wir in die Nacht hinein. Und das erste, was uns am Morgen auf dem Schlesischen Bahnhofe in Berlin empfing, war die Nachricht vom Siege in der Schlacht am Spicherer Berge! Nach kurzem Aufenthalte in Berlin fuhren wir weiter, mußten aber die nächste Nacht im Zuge auf der Kölner Rheinbrücke zubringen. In Rüdesheim schlossen wir uns einem pommerschen Grenadierregiment an, dessen Kommandeur, Oberst v. Zitzewit $z$, freundlichst für uns sorgte. Das Regiment war zunächst nach Saarbrücken bestimmt und auf die in Berlin erhaltene Nachricht von der Schlacht am Spicherer Berge schloß Professor Fischer mit Recht, daB in der Nähe von Saarbrücken für uns Verwendung $\mathrm{zu}$ erwarten sei und darin hatte er sich glücklicherweise nicht getäuscht.

Auf der Fahrt dorthin erlebte ich zwei ergötzliche Szenen. In dem Abteil, in welchem ich mich befand, waren auch einige junge, lebensfrohe Leutnants; auf einem der Bahnhöfe, wo wir einige Zeit hielten, standen eine Anzahl Kisten, von denen eine geöffnet war. Man sah in dieser eine Anzahl Flaschen von charakteristischer Form, deren Hälse mit Silberpapier umklebt waren. Einer der jungen Offiziere erblickte aus dem Fenster die Kisten und fragte einen in der Nähe befindlichen Bahnbeamten, was das für Kisten seien und wohin diese geliefert werden sollten? Der Mann sagte, die Kisten seien hier vor ein paar Tagen ausgeladen und man wisse nicht, wohin damit. „Nun,““ sagte der Offizier, ,,dann geben Sie einmal ein paar von den Flaschen aus der offenen Kiste her," drehte sich zu uns um in den Wagen und rief: „Kinder, Sekt, Sekt!“, hob dann gleich einige Flaschen hinein und, ohne erst das Etikett näher anzusehen, entkorkte er mit kundiger Hand eine Flasche, die auch sprudelnd ihren schäumenden Inhalt ergoß, füllte schnell ein bereitgehaltenes Glas, dann zu uns gewendet: „Prosit, Kameraden!“ Getrunken und — „Pfui Deubel! Limonade gazeuse!" Wir lachten ihn weidlich aus, behielten aber doch die Flaschen, deren Inhalt uns nachher noch sehr angenehm war.

Bei der Weiterfahrt setzte bald darauf ein starkes Gewitter ein, so $\mathrm{da} B$ an einer Stelle der Bahnkörper überschwemmt wurde und der Zug halten mußte. Diesen Umstand benutzten die braven pommerschen Grenadiere, um sich zu erleichtern und, zum Wagenfenster hinausschauend, erblickte ich eine ganze Anzahl der stämmigen Leute 
in Positur auf der Böschung sitzend und ihre ansehnlichen Kehrseiten unserem Zuge zuwendend. Dann hörte ich aus dem Nebenabteil in unserem Wagen eine weibliche Stimme - es saßen eine Anzahl Frauen darin, die Erlaubnis erhalten hatten, ihre Angehörigen bis Saarbrücken zu begleiten - : „Was halten wir denn hier so lange? Sieh' doch mal hinaus!“ Gleich darauf ertönte ein unterdrückter Schrei: „Hu!“ „Na, was ist denn los?" sagte die erste Stimme. "Ja, sieh selbst,“ sagte die zweite und abermals ein „Hu!“ und ein unterdrücktes Kichern und Lachen. Bald brachte uns dann der Zug aus dieser gefahrvollen Lage hinaus. Ich sage nochmals: Naturalia non sunt turpia! Was sollten die armen Grenadiere auch machen?

Gegen Abend kamen wir in Neunkirchen an; da wurden die Truppen ausgeladen. Es regnete noch immer leise weiter. Wir von der Expedition Fischer begaben uns in den Wartesaal, aber die Grenadiere konnten keine andere Unterkunft finden, als auf einer nassen Wiese. Dort stellten sie sich in kleinen Gruppen auf, jeder die beiden Hände auf die Schultern eines Kameraden gelegt, und versuchten so $\mathrm{zu}$ schlafen. Da gedenke ich des braven Oberst v. Zitzewitz. Er kam als der Letzte seiner Offiziere völlig durchnäßt zu uns in den Wartesaal. Ich hatte gesehen, wie er auf der Wiese von Trupp zu Trupp ging und alles musterte. Wir sagten ihm, er hätte doch auch für sich sorgen sollen, aber er meinte, erst kämen seine Leute, dann er. Ich habe ihn später in Straßburg noch einmal wieder getroffen. Ich sagte mir, wenn man mit solchen Führern in den Krieg zieht, dann kann der Sieg nicht ausbleiben! -

In Saarbrücken war einer der leitenden Persönlichkeiten des Johanniter-Ordens anwesend; Lazarette waren inzwischen in der Umgegend eingerichtet, es fehlte aber an Ärzten, da die einstweilen zurückgebliebenen Truppenärzte ihren Heereskörpern nacheilen mußten; wir waren also sehr willkommen. Professor Fischer schlug sein Hauptquartier in Forbach auf in demselben Hause, in welchem einige Tage vorher noch Marschall Frossard gewohnt hatte; mir wurde ein Lazarett in der Kohlengrube Heinit $\mathrm{z}$ angewiesen, welches notdürftig eingerichtet, aber noch nicht belegt war; ich war dort mit einigen jüngeren Ärzten und Studenten der klinischen Semester zusammen. Am späten Abend fuhr ich noch auf einer Lokomotive dorthin. In dem Direktor der Grube, Herrn Geheimen Bergrat v. Roenne, Sohn 
des berühmten Staatsrechtslehrers, fand ich einen äußerst umsichtigen und tätigen Mann, der uns bei der am anderen Tage vorgenommenen Endeinrichtung des Lazaretts mit bestem Rat und bereitwilligster Tat zur Seite stand, und weiter so während der ganzen Zeit meiner Tätigkeit dort. In der Nacht darauf kamen dann etwa 60 zum Teil schwer Verwundete an, die alle verbunden, erquickt und gebettet werden mußten; bis zum Tagesanbruch hatten wir damit zu tun. Ich war etwa vier Wochen dort beschäftigt, dann muBte ich das bisher von französischen Militärärzten besorgte Lazarett in StieringenWendel, wo der Kampf während der Spicherer Schlacht auch gewütet hatte, übernehmen, da die französischen Ärzte wieder nach Frankreich zurückkehren wollten. Die Herren übergaben mir ihre Pflegebefohlenen, etwa 70 an der Zahl; wir nahmen ein gemeinsames Mahl ein, wie es die Kriegszeit bieten konnte, tauschten unsere Adressen aus und schieden mit kräftigen Händedrücken voneinander, uns gegenseitig das Beste wünschend.

$\mathrm{Da}$ ich französisch sprach, verständigte ich mich bald mit den Verwundeten und Kranken, mit den beiden französischen Pflegerinnen, den Sœurs Jeanne de la Croix und Jeanne de Dieu, die ihren schweren Dienst in ausgezeichneter Weise versahen, sowie mit einem Jesuitenpater, der die Seelsorge dort übte. Auch mit meinem Quartiergeber, einem Beamten der großen Eisenwerke des Baron de Wendel, die in Friedenszeiten viele Hundert Arbeiter beschäftigten, war ich bald einig, ebenso mit dem Maire des Ortes Monsieur Aweng, dessen Haus von Kugeln völlig siebartig durchlöchert war.

Außer den Franzosen lag ein deutscher Wachtmeister der reitenden Artillerie dort, dem ein Oberschenkel gebrochen war. Ich untersuchte den Bruch, fand ihn gut geheilt und sagte dem Manne, er könne jederzeit, wenn er wolle, nach Deutschland überführt werden; er brauche nur noch einige Wochen Schonung, der Bruch sei geheilt. Die in der Nähe liegenden Franzosen, die etwas Deutsch gelernt hatten, verstanden, um was es sich handelte und sagten einmütig, der Wachtmeister dürfe nicht fort, der sei ein viel zu braver Kerl, den möchten sie nicht missen und, siehe da, der Wachtmeister bat auch, da $B$ er seine Schonwochen an Ort und Stelle verbringen dürfe, mit den Franzosen habe er sich nun schon angefreundet und möchte nicht gerne noch vor seiner völligen Wiederherstellung mit anderen zu- 
sammen sein. Natürlich gewährte ich seinen Wunsch und darob großer Jubel auf beiden Seiten.

Das Schlimmste, was ich dort zu sehen bekam, waren vier pockenkranke Franzosen, die man in eine Scheune verlegt hatte; sie hatten die sogenannten schwarzen Pocken und waren schon am Sterben, als ich sie von den französischen Kollegen übernahm. Glücklicherweise wurden sie am anderen Tage von ihren Leiden erlöst. Wer einmal solche Pockenkranke gesehen hat, wie diese armen, elenden Menschen, der begreift nicht, wie man gegen die Schutzpockenimpfung auftreten kann. Jenner ist einer der größten Wohltäter der Menschheit gewesen.

Zweier Verwundeter, die ihren Wunden erlagen, will ich hier besonders gedenken, eines Deutschen aus der Provinz Brandenburg, der bald nach der Übernahme des Lazaretts Grube Heinitz dort eingeliefert wurde, und eines Franzosen in Stieringen. Der Brandenburger war ein kräftiger, schöner Mann, ein junger Müller in guten Verhältnissen; er war verlobt und hoffte, seine Braut bald heiraten zu können. Er hatte in den ersten Kämpfen vor Metz einen Schuß mit Eingang der Kugel dicht unter dem Kniegelenk erhalten; die Kugel war auf das Schienbein aufgeschlagen, es bestand aber keine Ausgangsöffnung. Es waren seit der Verwundung mehrere Tage vergangen, ehe er in unser Lazarett kam. Der Mann hatte leichte Schmerzen dem Schienbein entlang und geringes Fieber. Das Kniegelenk war frei beweglich und ohne Schmerz. Ich ließ das Bein gerade halten und suchte behutsam nach der Kugel, die nach Aussage des Verletzten bisher nicht gefunden worden war. Vorsichtig betastete ich den Unterschenkel, da sagte plötzlich einer unserer Studenten, der den FuB hielt: „Ich fühle hier etwas Hartes auf dem Fußrücken." Ich überzeugte mich sofort, daß es die Kugel war, machte unter aller antiseptischen Vorsorge den Schnitt durch die Haut und beförderte die Kugel, welche unmittelbar unter der Haut lag, leicht zu Tage. Die kleine Wunde wurde sauber vernäht, die Kugel übergab ich dem Verwundeten, der überglücklich war in der festen Überzeugung, daß nun alles gut sei und er in kurzer Zeit vollkommen gesund, nur mit zwei kleinen Narben am Bein, nach Hause entlassen werden könne. Ich teilte diese Stimmung nicht; im deutsch-österreichischen Kriege hatte ich zuviele Erfahrungen mit Eiterfieber und septischem Fieber gemacht, 
um nicht gemerkt zu haben, daß der Arme in größter Gefahr war. Doch wollte ich ihm an dem Tage die frohe Stimmung, auf deren Erhaltung auch so viel ankommt, nicht verderben. Ich ordnete alles an, was geschehen konnte, um das Schlimmste zu verhüten, mußte aber am anderen Morgen mich entschließen, dem Manne zu eröffnen, da $B$ nur noch in einer Amputation des Oberschenkels eine Möglichkeit der Lebensrettung für ihn bestehe. Man kann sich die Bestürzung des Verwundeten denken. Mit aller Entschiedenheit lehnte er die Operation $\mathrm{ab}$, mit einem Stelzfuß wollte er seiner Braut nicht unter die Augen kommen; die Kugel sei ja auch gefunden und es bestehe ja eigentlich keine Verletzung. Ich suchte ihm seine Lage und die Gefahr, in der er schwebte, klarzumachen, verhehlte ihm auch nicht, da $B$ jede Stunde der Zögerung sein Leben in die größte Gefahr bringe; er blieb fest und man kann sein Verhalten auch verstehen, denn er fühlte sich noch kräftig, hatte auch noch keinen ausgesprochenen Schüttelfrost gehabt. Aber in der kommenden Nacht stellten sich die Schüttelfröste ein, das Allgemeinbefinden verschlechterte sich zusehends und als ich am anderen Morgen zu ihm trat, bat er mich mit festem Entschlusse, die Amputation vorzunehmen. Es war mir klar, daß ich kaum Aussicht hatte, ihn jetzt noch durch die Amputation zu retten, versagen konnte ich sie ihm aber auch nicht. Ich nahm die Operation sofort vor, aber, wie ich vorausgesehen hatte, ohne den gewünschten Erfolg; am anderen Tage starb der Ärmste infolge des Eiterfiebers. Hätte er gleich eingewilligt, sich amputieren zu lassen, so wäre er vielleicht noch gerettet worden; mehr als ein „Vielleicht" kann ich jedoch auch nicht sagen. Solche Fälle sind die schmerzlichsten, die man als Arzt im Kriege erlebt; ich könnte von mehreren berichten. Vielfach fallen die Verwundeten zum Opfer, die nicht alsbald nach ihrer Verwundung in sachgemäße Behandlung kommen. Wie viele derartige Opfer mag der jetzige Weltkrieg gefordert haben!

Der zweite Fall, von dem ich berichten möchte, betraf, wie bemerkt, einen französischen Soldaten, den ich in Stieringen übernahm. Die französischen Ärzte hatten ihn mir bereits als hoffnungslos bezeichnet. Es handelte sich um eine SchuBfraktur des Oberschenkels, bei der der Knochen bis zum Hüftgelenk hinauf in mehrere Stücke zersprengt war. Ob durch eine Exartikulation des Beines im Hüftgelenk alsbald nach der Verwundung der Mann zu retten gewesen wäre, entzieht sich 
meiner Beurteilung; als er in meine Behandlung kam, war sein verwundeter Oberschenkel bereits in einen Eitersack verwandelt und Eiterfieber hatte sich eingestellt; ein lebensrettender Eingriff war unmöglich; ich mußte mich damit begnügen, durch sorgfältigen Verband mit gründlicher Entleerung des Eiters und Verabreichung von Schlafmitteln für die Nacht die Leiden des Verwundeten möglichst herabzumindern. Die beiden vorhin genannten Krankenschwestern erkannten gleichfalls die große Gefahr, in welcher der Kranke sich befand und baten mich, ich möge ihm doch Mitteilung davon machen und ihn veranlassen, den Besuch des Priesters anzunehmen. Ich sagte, da $B$ ich es für meine Pflicht halte, dem Kranken das Bedenkliche seines Zustandes nicht zu verschweigen mit Rücksicht darauf, daB er noch Anordnungen für seine Verwandten treffen könne; was jedoch den Empfang des Priesters anlange, so müsse ich das zu bestimmen ihm selbst überlassen. Beim nächsten Besuche, nachdem der Verwundete auf meine Frage, wie es ihm ginge, erwidert hatte, er fühle sich von Tag zu Tag schlechter und sehe sein Ende voraus, sagte ich ihm, ich und die Schwestern würden alles aufbieten, ihn zu retten, ich könne aber nicht leugnen, daß er in Gefahr sei. Falls er etwa den Seinigen noch Nachrichten zukommen lassen wolle, sei ich bereit, ihm dabei behilflich $\mathrm{zu}$ sein. Er ergriff meine Hand und dankte mir vollkommen ruhig und gefaßt. Er habe, sagte er, von nahen Angehörigen nur eine Schwester am Leben, der er die kleinen Gegenstände, die er bei sich habe, vermachen wolle, sowie das kleine Habe daheim. Er bat um Schreibmaterial und gab mir später einen Brief an seine Schwester, sowie ein kleines Paket für sie mit der Bitte, ich möge dafür sorgen, da $B$ sie es bekomme. Das versprach ich ihm und habe auch mein Versprechen gehalten. Ich unterhielt mich dann noch eine Weile mit ihm, wobei ich ihn vollkommen ruhig fand; herzlich dankte er mir wiederholt und bat, da $B$ ich doch noch öfters zu ihm kommen möge, was ich denn auch gern tat. Als ich nach einigen Stunden wiederkam, beklagte er sich, $\mathrm{da} B$ der Priester bei ihm gewesen sei und ihm ins Gewissen geredet habe; er habe es abgelehnt, dessen Wunsch zu erfüllen; er sei Freidenker und halte von dem, was die Kirche verlange, nichts; ich möge dafür sorgen, daß der Priester nicht mehr zu ihm komme. Ich sprach mit dem Pater darüber und mit den Schwestern, die unglücklich darüber waren. Der Pater sagte, er habe es für 
seine Pflicht gehalten, den Versuch zu machen, wolle aber dem Kranken nicht weiter lästig fallen. Ich konnte sein Verhalten nur billigen. Ich ging noch mehrere Male zu dem Leidenden, der immer erfreut war, miclı zu sehen, fand ihn aber zusehends schwächer werden. Gegen Abend, als ich ihn nach einem Besuche wieder verlassen wollte, legte er sich zurecht und sagte, ich möge ihm die weiße Nachtmütze, die er trug, über die Augen ziehen. Ich tat das, dann suchte er meine Hand, drückte sie und dankte mir. Ich crwiderte seinen Händedruck, legte dann leise meine Hand auf seinen Kopf und verließ das Zimmer. Als ich nach einer Stunde wieder eintrat, fand ich ihn genau in derselben Lage, wic ich ihn verlassen hatte, entschlafen. Ich habe selten einen Menschen so ruhig und gefaßt seinem Ende entgegengehen sehen, wie diesen in der Blüte des Lebens stehenden schlichten Mann.

Nicht um mich zu rühmen, sondern weil es mir wohltat, und noch heute wohltut, selbst nach der Stellung, in die der Weltkrieg uns zu Frankreich gebracht hat, berichte ich, da $B$ ich mir bald das vollste Vertrauen der mir übergebenen französischen Verwundeten und Kranken, sowie der beiden Pflegeschwestern erwarb. Ich sah es ihnen an, wie sich Alle frcuten, wenn ich in die Krankenzimmer trat, und als ich im Oktober scheiden muBte, um in Breslau meine Vorlesungen an der Universität wieder aufzunehmen, umklammerten Alle meine Hände, wollten mich nicht ziehen lassen und sprachen in rührendster Weise mir ihren Dank aus. Mit Tränen in den Augen schied ich. Ein schwerer Beruf, der des Arztes, aber ein schöner Beruf!

Noch eine ganze Reihe von Kriegen in der Alten und Neuen Welt habe ich als Zuschauer miterlebt, über die ich nur mit kurzer Erwähnung hinweggleiten will. Da war es in Südamerika der Krieg zwischen Chile einerseits und Peru nebst Bolivia andererseits. Da ich eine ganze Reihe von Chilenen zu meinen Schülern zählte, die ich alle als sehr tüchtige Studierende kennen gelernt hatte und da einer meiner früheren Laboranten, Dr. Vicente Jzquierdo, mit dem ich brieflichen Verkehr unterhielt, Professor der Anatomie in Santiago geworden war, so gewann ich ein größeres Interesse für diesen fernliegenden Kriegsschauplatz. Meine Sympathien waren auf Seiten Chiles, doch zollte ich dem klugen und tapferen Verhalten des peruanischen Admirals Grau mit seinem Schiffe „Huascar" vollste Anerkennung. $\left({ }^{\mathbf{8}}\right)$ 
Hatten sich bis dahin die kriegerischen Ereignisse, von denen ich $\mathrm{zu}$ berichten habe, vorzugsweise im Westen abgespielt, so werden sie seit 1870 in auffälliger Weise nach dem nahen und fernen Osten verlegt und dieser beginnt an den Welthändeln in bemerkenswerter Weise teilzunehmen. Selbst der kurze Spanisch-amerikanische Krieg, in welchem wohl die Sympathien der ganzen Welt auf seiten des unrühmlich vergewaltigten Spaniens waren, griff mit der Einverleibung der Philippinen durch die nordamerikanische Union auf den Osten über. Widerlich erschienen mir die Ruhmredigkeiten, in denen sich damals die Unionspresse gefiel; es war wahrlich kein Ruhm, weder für Herrn Roosevelt mit seinen Rough Riders, noch für die nordamerikanischen Admirale Sampson und Schley, die Spanier zu besiegen, deren Admiral Cervera alle Anerkennung verdient, während der Streit, der zwischen den Anhängern Sampsons und Schleys über deren Verdienste ausbrach, einen sehr unerquicklichen Eindruck machte.

Die Kriege im Osten wurden eröffnet durch den großen Russischtürkischen Krieg der Jahre I877/78, der durch den für Rußland günstigen Frieden von San Stefano (3. März I878) beendet wurde, aber erst durch den von England beantragten, von Österreich und Preußen unterstützten Berliner Kongre $B$ am I3. Juli I 878 seinen endgültigen AbschluB fand; hier wurde der Friede von San Stefano zum merklichen Nachteile Rußlands abgeändert. Unzweifelhaft hat diese Aktion einen Stachel in den Herzen der maßgebenden russischen Kreise hinterlassen, dessen Wirkung sich vorzugsweise gegen Österreich und Deutschland kehrte. Merkwürdig, da B England bei solchen Aktionen fast stets unbescholten bleibt! Man wird in dem Berliner Kongre $B$ auch eine der weiter zurückliegenden Ursachen des Weltkrieges von I9I4 $\mathrm{zu}$ suchen haben.

Nun kam I90o der chinesische Boxerkrieg, wo wir zwar kriegerisch uns in gutes Licht setzten, jedoch in den folgenden Verhandlungen und in unserem Verhalten beim Frieden von Shimonoseki uns die Freundschaft Japans verscherzten, während das kluge Albion wiederum seinen Vorteil wahrzunehmen verstand.

Am 5. Februar I904 brach dann einer der folgenschwersten Kriege der Neuzeit, der Russisch-ja pa nische Krieg aus. Sein großer Erfolg für Japan in der Einnahme von Port Arthur am 2. Januar I905 und der glänzend durchgeführten Vernichtung der russischen Flotte 
durch den Admiral Togo in der Seeschlacht bei Tsushima am 27. und 28. Mai I905 brachte diese ostasiatische, der englischen vergleichbare Seemacht in das Konzert der großen Mächte. Zugleich liegt in dem Ausgange dieses Krieges wieder eine entferntere Wurzel für I9I4. Er brachte Rußland an den Rand einer Revolution und gab der Partei, welche durch einen klaren Erfolg auf dem Balkan das Ansehen Rußlands und des Zarismus gegen die drohende Revolution wieder herzustellen vermeinte, das Heft in die Hand, damit dann die Gegnerschaft gegen Österreich und Deutschland.

Meine Sympathien in diesem großen Kampfe waren auf seiten Japans. An einer anderen Stelle habe ich über meine Begegnung mit der russischen Flotte, als sie zu ihrer Vernichtungsfahrt auszog, berichtet.

Ein kleiner, jedoch auch - im Zusammenhange betrachtet -, nicht $\mathrm{zu}$ vernachlässigender Krieg war inzwischen rasch erledigt worden, der Krieg zwischen der Türkei und Griechenland im Jahre I897. Die Türken, deren Sache mir die gerechte schien, blieben Sieger. Dieser kurze Krieg war nur ein Vorläufer der großen Balkankriege I9I2/I3, die mit der Liquidation der europäischen Türkei endeten, aber auch fast direkt in den Weltkrieg von I9I4 hinüberführten. Ich gestehe, meine Sympathien den Türken in diesen Kämpfen nicht haben versagen zu können; als es sich aber später um die Bulgaren, Serben und Griechen handelte, wendete sich mein Interesse den letzteren zu. Das neugeborene Fürstentum Albanien habe ich von Anfang an als eine nicht lebensfähige Mißgeburt angesehen. Wenn man sich nicht klar einigen kann und jedem Kontrahenten bei einer Neuschöpfung nachgeben will, dann kommen solche unhaltbaren Dinge zustande.

\section{Ka pitel.}

\section{Der Weltkrieg und die Revolution.}

Es war mir beschieden, auch noch das Schlimmste zu erleben, was kommen konnte, den Weltkrieg von I9I4-I920 ${ }^{1}$ und seinen für Deutschland so tieftraurigen und schmachvollen Ausgang. Die poli-

${ }_{1}^{1}$ Obwohl die Waffen gegen Deutschland seit Ende des Jahres I9I8 ruhten, kann doch als Endjahr des Krieges erst 1920 bezeichnet werden, da im Januar dieses Jahres der Friede unterzeichnet wurde. 
tische Spannung, die etwa seit dem Jahre I9Io immer fühlbarer wurde, war mir nicht entgangen. Es war auffallend, da $B$ jeder geringfügige $Z$ wischenfall bei unseren westlichen Nachbaren sofort die größte Empfindlichkeit auslöste, obgleich ich persönlich bei meiner wiederholten Anwesenheit in Frankreich, wie ich in meinen Reiseerlebnissen bereits mitgeteilt habe, darunter nicht gelitten habe. Wir deutschen Mitglieder der Internationalen Assoziation der Akademien bemerkten auch sehr wohl bei unseren Zusammenkünften in Paris, London und St. Petersburg die größere Annäherung der Franzosen, Russen und Engländer untereinander, während mit uns der Verkehr über den Rahmen der Höflichkeit kaum hinausging. Im Jahre I909, als Graf Aehrenthal die Einverleibung Bosniens und der Herzegowina in Österreich-Ungarn aussprach, war offenbar Rußland noch nicht genügend vorbereitet, sonst wäre es damals schon zum Kriege gekommen. Der feste Wille Deutschlands, Österreich die Bündnistreue zu halten, konnte noch den Weltkrieg verhüten, während er I9I4 ihn entfachte; da war Rußland gerüstet!

Als am 28. Juni IgI4 die Entsetzen erregende Kunde von dem Doppelmorde in Serajewo nach Berlin kam, hatte ich das bestimmte Vorgefühl, daß diese grausige Tat zum Kriege führen werde, wenigstens zum Kriege zwischen Rußland, Serbien und Frankreich einerseits und Österreich-Ungarn im Bunde mit Deutschland andererseits. Ich sagte mir, Österreich-Ungarn müsse diesen Mord von Serbien schwer sühnen lassen, da werde Rußland, von dessen Rüstungen der „Krieg in Sicht-Artikel“ der Kölnischen Zeitung schon Kunde gebracht hatte, Einspruch erheben, Österreich werde bei seinen Forderungen beharren müssen, wir würden ihm Bündnistreue halten, Frankreich sei durch sein Bündnis mit Rußland verpflichtet, das Schwert zu ziehen, halte auch den günstigen Augenblick für gekommen, Elsaß-Lothringen wiederzugewinnen, da wir nun den Zweifrontenkrieg führen müßten und werde deshalb keinen Augenblick zögern, loszuschlagen. Ich dachte damals nicht daran, da $B$ England aktiv eingreifen und dadurch den Krieg zu einem Weltkriege machen würde, wie er es eben durch Englands Eingreifen und nur durch dieses geworden ist. Ich komme hierauf zurück, wenn ich am Schlusse noch einmal die Ursachen dieses Krieges, so wie sie sich mir darstellen, bespreche. 
Während der zunächst folgenden Verhandlungen wurde die Spannung immer größer und als Kaiser Wilhelm II. am I. August I9I4 die Kriegserklärung an Rußland aussprach, empfand man ein Gefühl der Befreiung, wie es der erste Donnerschlag nach lange drückender Gewitterschwüle auslöst. Ich glaube nicht, daß irgend Jemand in Deutschland, am wenigsten Kaiser Wilhelm II. selbst, den Krieg gewünscht hat; eine Ankündigung der definitiven Beilegung der Streitfrage würde, neben dem befreienden Gefühl der Lösung, auch noch eine freudige Stimmung gebracht haben. Wir Alle in Deutschland waren damals auch sicherlich der Meinung des Kaisers, es handle sich nur um einen Verteidigungskrieg zur Erhaltung des Bestandes unseres österreichisch-ungarischen Bundesbruders und unserer Interessen im nahen Orient, sowie um die Erhaltung dessen, was wir zur Schaffung des Deutschen Reiches seit I864 gewonnen hatten. Kaiser Wilhelm hatte es bei seiner Kriegserklärung ohne Hintcrgedanken ausgesprochen, daß wir keinen Eroberungskrieg führen wollten und würden; ganz Deutschland stimmte ihm bei. So war denn die Stimmung bei uns im Gefühl einer gerechten Sache, ungeachtet des anfänglichen Vordringens der Russen in Ostpreußen, eine gehobene und zuversichtliche, die auch nicht schwand, als die Engländer, Portugiesen und Japaner uns den Krieg erklärten und Montenegro zu den Waffen griff. Fast jede Woche konnten wir die Fahnen als Verkünder eines Erfolges in den Straßen Berlins begrüßen. Das war so IgI4 und auch noch I9I5.

Obwohl in der Vorahnung stehend, daß nach den Ereignissen in Serajewo der Krieg unvermeidliclı sei, glaubte ich ihn doch nicht so nahe bevorstehend und plante noch, wie S. I56 erwähnt, eine Reise nach Straßburg im Elsaß, um dort meinen Freund, den Anatomen Schwalbe, zum 70. Geburtstage zu beglückwünschen, und von ' da nach Lyon zur gleichen Beglückwünschung des dortigen Professors Renaut. Von da wollte ich durch die Schweiz und Tirol nach Badgastein zur Wiederholung der von mir seit einigen Jahren mit bestem Erfolge unternommenen Badekuren. Da sagte mir am 3I. Juli mein Schwiegersohn, Oberstleutnant v. Bonin, es sei Kriegsbereitschaft befohlen, dem folge dann alsbald die Mobilisierung des Heeres, eine Reise nach Straßburg und Lyon verbiete sich damit. Vielleicht wäre ich ohne diese rechtzeitige Warnung in Frankreich interniert worden. Wir hatten uns I9I4 von Deutschland aus in Lyon noch an 
einer Ausstellung beteiligt, ich gehörte dem Ausstellungskomitee an und wir hatten mehrere Sitzungen in der französischen Botschaft unter Beteiligung des Botschafters Herrn Cambon abgehalten; gern waren wir der von der Stadt Lyon an uns ergangenen Aufforderung gefolgt. So war ich auch zu dem Plane gekommen, Lyon aufzusuchen und wählte absichtlich die Zeit, die es mir möglich machte, zugleich meine mir lieben und werten Kollegen Schwalbe und Renaut zu deren Festen begrüßen zu können.

Was das Treiben der Bevölkerung Berlins und dessen Straßenbild anlangt, so hielt es sich von allen lärmenden und übertriebenen Kundgebungen fern. Gewöhnlich sah man größere Ansammlungen von Leuten mit lebhafterer Unterhaltung auf dem Potsdamer Platz und Unter den Linden. Die an mehreren Stellen öffentlich angeschlagenen Verlustlisten sorgten schon dafür, daß, ungeachtet der anfänglichen Erfolge, die Stimmung eine ernste blieb. Unsere politische Presse wie unsere Witzblätter hielten sich von beleidigenden und unflätigen ÄuBerungen über unsere Gegner fern, was bei diesen in bezug auf Deutschland nicht der Fall war. Mögen ein Gedicht ernsten und ein Verschen launigen Inhalts hier zur Erinnerung Platz finden, die mir besonders gefallen haben. Sie zeigen, daß sowohl der Ernst des Krieges zum Bewußtsein kam mit voller Opferbereitschaft, daß aber auch der Frohmut nicht verloren ging. Beide Gedichte, so will ich auch die heiteren Zeilen bezeichnen, mögen als Stimmungsbild der ersten Kriegstage dienen. Das schöne Gedicht ernsten Inhalts gilt dem Abschied eines jungen Offiziers von seiner Gattin. Ein einfaches Bild, das in dem Druckblatt dazu gegeben war, veranschaulicht die Szene. Man blickt auf dem Bilde in einen Hof, vor dem Tor hält der Offiziersbursche das Pferd, der Offizier steht im Hofe und blickt zu seiner Frau auf der Freitreppe des Hauses hin, ihr folgende Abschiedsworte zurufend:

Der Morgen küßt die Erde,

Im Grase blitzt der Tau;

Es scharren unsre Pferde:

Ade, geliebte Frau!

Wohl gibts ein heißes Wandern;

Zeig' mir ein stolz Gesicht:

Und weinen alle Andern -

Du nicht! 
Dein Bild soll durch die Schlachten

Begleiten meinen Ritt,

Ich will mir's noch betrachten,

Wenn ich vom Sattel glitt.

Noch in den Schlaf ein Treuer

In seinen Traum es nimmt,

Wenn schon das Lagerfeuer

Verglimmt.

Und deckt mich wo der Rasen,

Wo nimmer geht dein FuB,

Die schweren Reiter blasen

Heimkehrend meinen GruB.

Hat mich die Schlacht genommen,

So denk: ihn rief die Pflicht.

Als Sieger will ich kommen,

Sonst nicht!

Die heiteren Wortreime beziehen sich auf den Fall von Lüttich, welches bekanntlich von dem General v. Emmich genommen wurde:
Der Kaiser sprach zu Emmich
Du, Emmich, nimm mich Lüttich!
Da sagt der Herr v. Emmich:
Das nemm ich!

Leider habe ich es versäumt, mir die Quellen zu merken, aus denen beide Gedichte entnommen sind.

Nach dem gewaltigen Erfolge Hindenburgs bei Tannenberg und nach unserem raschen Siegeslaufe durch Belgien und der Besitzergreifung Nordfrankreichs änderte sich, ungeachtet des Stillstandes in unseren Operationen nach der Marneschlacht, bei Manchen, namentlich in den Kreisen der alldeutschen Parteien und beim Militär, die Stimmung und ließ Wünsche nach Erweiterung unseres Kolonialbesitzes und vor allem nach Erwerb von Teilen Belgiens und Nordfrankreichs aufkommen. Insbesondere waren es die flandrische Küste mit Antwerpen sowie die Erzlager von Briey und Longwy in Französisch-Lothringen, auf die man Anspruch erheben zu sollen meinte. In der Presse der alldeutschen Parteien und in Flugschriften wurden 
bald die Stimmen laut, die dafür eintraten. Und als die Russen mehr und mehr zurückgewiesen wurden, kamen auch die Gelüste nach Erwerbungen an der russischen Ostseeküste auf. Selbst, wie bemerkt, der Verlust des Marnegebietes in den Septembertagen I9I4, ferner der Abfall Italiens und Rumäniens, die vergeblichen Anstrengungen vor Verdun, dic uns so viele Opfer kosteten, ließen diese Annexionsbestrebungen nicht zur Ruhe kommen. Hatten wir doch bis zuletzt immer noch wieder erfreuliche Erfolge zu verzeichnen, so den $\mathrm{Zu}$ sammenbruch Rußlands, die schnelle und gründliche Erledigung Rumäniens, als es uns den Krieg erklärt hatte, den raschen Siegeslauf an der Piave in Italien und noch im Frühjahre I9I8 den Vorstoß bis zur Eroberung des Kemmelberges, allerdings die letzte erfreuliche Nachricht, die uns wurde.

Ich habe mich niemals mit diesen Annexionsbestrebungen befreunden können. $\mathrm{Zu}$ deutlich haben wir es selbst erfahren, wie schwierig es ist, sich fremde Völkerschaften zu assimilieren, wenn diese bereits geordnete staatliche Einrichtungen und eine Kultur hatten, die der des in Besitz nehmenden Volkes ganz oder nahezu gleich war. Ich brauche nur an unsere polnischen Erwerbungen, an Nordschleswig, soweit es von Dänen bewohnt ist und an Elsaß-Lothringen zu erinnern. Selbst bei weniger kultivierten Stämmen ist es jetzt, wo der Weltverkehr immer mehr zunimmt, schwierig, zu kolonisieren. Hätten wir selbst entschieden gesiegt und einen Teil Belgiens in Besitz genommen, wir hätten uns damit einen neuen unversöhnlichen Feind im eigenen Grenzgebiet geschaffen, den schlimmsten von allen. Ich kenne die Belgier; das Urteil Caesars besteht, wie die Ereignisse dieses Krieges erwiesen haben, noch heute zu Recht.

Meine Meinung über unsere Kriegsziele und die Annexionen habe ich im Herbst I9I5 auf Wunsch der Frau Selenka, Witwe des Münchener Zoologen Emil Selenka, ihr in einem ausführlichen Briefe mitgeteilt. Frau Selenka war im Begriffe, sich über Holland nach den Vereinigten Staaten zu begeben nnd wünschte meinen Brief dort in den ihr bekannten Kreisen mitzuteilen. Es werde, wie sie meinte, in beiden Ländern vielleicht von guter Wirkung sein, auch einmal eine gegen Annexionen gerichtete Stimme zur Kenntnis zu bringen. Sie schrieb mir von Holland und von New York, da $B$ der Brief dort in ihren Bekanntenkreisen gut aufgenommen sei und man ihr es nahe- 
gelegt habe, ihı zu veröffentlichen. Ich schrieb zurück, daß ich meinerseits die Veröffentlichung gestatte, zuvor jedoch die Genehmigung unseres Auswärtigen Amtes einholen müsse. Ich legte dort Abschrift des Briefes vor; man teilte mir jedoch am anderen Tage mit, da $B$ man die Veröffentlichung, zumal in einer ausländischen Zeitung, zur Zeit nicht für tunlich erachte. Meine Abschrift wurde im Amte zurückbehalten, die Veröffentlichung unterblieb. Zur Kennzeichnung meiner Auffassung der Sachlage mögen die Stellen des Briefes, auf die es ankommt, hier mitgeteilt werden. Ich bin noch heute der Meinung, damit im wesentlichen das Richtige getroffen $\mathrm{zu}$ haben und zugleich dargetan zu haben, daß Deutschlañd für eine gerechte Sache kämpfte und den Kampf nicht vermeiden konnte. Hatten England und Frankreich, hatte noch jüngst Italien ihrer Zeit sich aus den einzelnen Staaten gleicher oder verwandter Nationen zu einem Einheitsstaate zusammengeschmiedet, warum sollte dies von Deutschland nicht geduldet werden? Hatte Frankreich, die Zeiten unserer tiefsten Ohnmacht benutzend, das deutsche Elsa $ß$ genommen, war es dann Unrecht, es wieder zu nehmen, nachdem wir in einem von Frankreich provozierten Kriege Sieger geblieben waren? Sollten wir nicht unsere Marine, unseren Handel und unsere Industrie nach Kräften sich frei entwickeln lassen, wie es England getan hatte und wie es jedem Volke frei steht? Das waren die Empfindungen, die jedes Deutschen Brust beseelten, als am I. August I9I4 die Würfel fielen. - Aus diesem Empfinden heraus schrieb ich damals:

,,Sie fragen mich, geehrte Frau, in Ihrem letzten Briefe nach meiner Ansicht über Deutschlands Kriegsziele, eine sehr naheliegende Frage, die heuer wohl Jedermann, bei Freund wie bei Feind, sich vorlegt. Ich habe diesen furchtbaren Krieg seit seinem Beginn im August I9I4 durchaus mit dem Siebenjährigen Kriege verglichen. Noch vor 4 Wochen in der Festsitzung unserer Akademie der Wissenschaften zum Gedächtnisse Leibnizens habe ich in einer einleitenden Ansprache diese Ansicht öffentlich kundgegeben.

„Im Siebenjährigen Kriege mußte Friedrich der Große gegen eine sehr bedeutende feindliche Übermacht - es ist damals ungefähr dasselbe Verhältnis der beiden streitenden Parteien gewesen, wie im gegenwärtigen Kriege - dasjenige behaupten, was er in den schlesischen Kriegen errungen hatte. 
„,Das Kriegsziel seiner Gegner war, das ihnen zu mächtig gewordene Preußen wieder auf den Stand seiner Markgrafschaft Brandenburg herabzudrücken. Ein hartes siebenjähriges Ringen zeigte, daß der König von Preußen stark genug war, das zu behaupten, was er vor dem Kriege besaß. Der Friede wurde geschlossen; es gab keinen Sieger und keinen Besiegten. Aber Friedrich der Große ging mit Ehren aus dem Kampfe hervor und es folgte ein langer Friede, dem nur ein von Frankreich erfolgender AnstoB, die französische Revolution, ein Ende machte. Besser wäre es gewesen, Frankreich sich damals selbst $\mathrm{zu}$ überlassen.

„Mir erscheint der jetzige Krieg als ein vollkommener Parallelfall zum Siebenjährigen Kriege. Seit dem Jahre I864 haben Deutschland und Preußen gewonnen: I. ihre Einigkeit zum geschlossenen Deutschen Reiche mit einem Deutschen Kaiser an der Spitze; das ist eine für Deutschlands Weltstellung kaum hoch genug zu schätzende Tatsache, 2. den vollen Besitz von Schleswig-Holstein, 3. den Besitz von Elsaß-Lothringen, 4. die Stärkung Preußens durch die Einverleibung von Hannover, Schleswig-Holstein, Kurhessen, Nassau und Frankfurt am Main; dadurch konnte Preußen seine Vormachtstellung im neuen Deutschen Reiche halten und dadurch das Reich selbst stärken, 5. einen beträchtlichen Kolonialbesitz, 6. eine ansehnliche Seemacht. Dies alles zusammen ist sicherlich etwas Großes und Hochbedeutendes. ,Wie vor hundertfünfzig Jahren die mit Österreich-Ungarn verbündeten Staaten gegen Friedrich II., so vereinigten sich seit etwa ro Jahren als „Entente“ die alten europäischen Großmächte: England, Frankreich und RuBland, gegen das emporgewachsene neue Deutschland und das mit ihm verbündete Österreich-Ungarn. Das gemeinsame Hauptziel der Entente-Mächte ist, wie es von deren leitenden Staatsmännern ja unverblümt ausgesprochen wird, die Zurückdrückung des Deutschen Reiches auf den Stand vor I866 und, wenn möglich, noch weiter, namentlich die Schwächung seiner militärischen Kräfte. Dabei hat freilich noch jede der drei genannten Entente-Mächte ihr besonderes Ziel. Rußland: die Dardanellen, Konstantinopel und Türkisch-Armenien; Frankreich: ElsaB-Lothringen (als bescheidenste Forderung); England: die deutschen Kolonien und die Zurückdrängung der deutschen Marine- und Handelsstellung. Ich habe hier von Serbien, Montenegro und Italien abge- 
sehen, wie ich auch die Berechtigungsfrage nicht diskutiere. Nur so viel möchte ich sagen, da $B$, meiner Meinung nach, den Forderungen Englands nicht ein Schatten von Berechtigung innewohnt, denn jedem Lande muB das uneingeschränkte Recht zugesprochen werden, Kolonialbesitz zu erwerben, seine militärischen, Industrie- und Handelskräfte zu entwickeln, so weit es ihm gut erscheint. Hat sich England jemals darin einen Einspruch gefallen lassen?

„,Bei dieser, wie ich glaube, richtig dargestellten Lage der Dinge war mir bei Beginn des Krieges klar, daß, wenn wir aus diesem Kriege hervorgingen mit der völligen Behauptung alles dessen, was wir vor dem Kriege hatten, einschlieBlich insbesondere unserer gesamten Kolonien und unserer Seestellung, auch ohne irgendeinen $\mathrm{Zu}$ wachs an Land und Geld, daB wir dann unser Kriegsziel erreicht hätten. Denn wir hatten ja zu Beginn des Krieges, wie es auch unser Kaiser klar ausgesprochen hat, nichts anderes im Auge, als uns völlig intakt zu behaupten. Schließen wir also einen Frieden genau so wie Friedrich der Große, dann gehen wir ebenso ehrenvoll aus diesem gigantischen Streite hervor, wie dieser große Fürst aus dem seinigen."

So schrieb und dachte ich ein Jahr nach Beginn des Krieges im Herbst Igr5; ich habe meine Meinung nicht geändert.

Ich gedenke hier noch weiter der vorhin schon gestreiften Tatsache, da $B$ unsere Gegner in ihrer Presse und durch Flugblätter nicht nur, sondern auch in ihren Parlamenten und selbst von den Ministertischen aus sich in Schmähungen Deutschlands, seines Kaisers und seines Volkes ergingen, die in den Witzblättern sich bis zum unflätigsten Schmutz steigerten. Wir sind im Besitze einer ganzen Sammlung dieser Dinge; es wird am Verhalten unserer bisherigen Gegner liegen, sie uns vergessen und vernichten zu lassen. Dazu kam die unglaubliche und heuchlerische Anmaßung, die namentlich von den Ministertischen, insbesondere Englands, aus der Welt ständig vorgepredigt wurde, da $B$ sie, unsere Feinde, den Krieg nur im Interesse der Gerechtigkeit, der Freiheit der Völker und der Zivilisation unternommen hätten und führten. Welche Völker haben wir denn in Fesseln geschlagen, ungerechter behandelt, als andere Staaten die ihrigen, und bedroht? Wenn man uns die polnischen Besitzungen nennt, so frage ich, weshalb man diese denn Rußland so weit verzieh, daß man sogar mit 
ihm ein Bündnis einging und da $B$, hätten wir im Kriege nicht Rußland besiegt und hätte dieses, wie man hoffte, gleich IgI4 seine Dampfwalze über Berlin rollen lassen können, dieses Land noch hente nicht nur im Besitze Kongreßpolens, sondern wahrsclieinlich des ganzen ehemaligen Königreichs Polen sein würde, und kein englischer Minister würde von Vergewaltigung gesprochen haben. Und England? Was sagt es, um nur wenige Dinge zu nennen, zu Irland, was zı Ägypten, was zum Burenlande? Und Frankreich? Was sagt es zu Marokko und Madagaskar, doch ihrer Zeit selbständige und ordnungsmäßig regierte Staaten? Und Italien? Da brauche ich nur an die Kolonie Erythräa und Tripolis zu erinnern. Jedenfalls, so viel kann mit Sicherheit behanptet werden, haben unsere Gegner nicht weniger auf dem Kerbholze als wir. Es liegt mir fern, alle Maßnahmen zu verteidigen, die wir, um unsere polnischen Provinzen zu germanisieren, ergriffen haben; insbesondere das Enteignungsgesetz muß auf das schärfste verurteilt werden; aber in dem Verfahren, welches unter anderem England in Irland und bis in die neueste Zeit hinein in Ägypten eingeschlagen hat, lassen sich ganz ähnlich harte Maßnahmen nachweisen.

Kurz, diese immer wiederholten ungerechten Anklagen und Beschimpfungen unserer Gegner brachten als natürliche Folge eine Erbitterung auf unserer Seite zu Wege. In Frankreich namentlich, wie auch in Rußland, tat mit wenigen Ausnahmen die Presse das ihrige, nicht nur zu verleumden und zu schmähen, sondern auch geradezu den $\mathrm{HaB}$ der heimischen Bevölkerung gegen die Deutschen zu schüren. Dazu kam, daß in Belgien nach unserem Einrücken die bürgerliche und ländliche Bevölkerung sich manchen blutigen Racheakt, selbst von seiten der Frauen, gegen unsere Soldaten zu Schulden kommen ließ. Da natürlich harte Strafen von unserer Seite nicht ausblieben, aber doch wieder nur Strafakte, wie sie in jedem Kriege von allen Völkern gegen hinterrücks verübte Angriffe auf ihre einrückenden Truppen stets verhängt worden sind, so wurde der $\mathrm{HaB}$ bei der gegnerischen Landbevölkerung noch verschärft und bei unseren Truppen naturgemä $ß$ auch entfacht. Und so steigerte sich die gegenseitige feindselige Erregung von Tag zu Tag. Ich habe, wie in dem vorhergehenden Kapitel beschrieben ist, den Verlauf vieler. Kriege, teils als persönlich Beteiligter, teils als zwar ferner stehender, aber 
doch sorgfältiger Beobachter erlebt, in keinem aber ist eine solche Fülle von $\mathrm{HaB}$ zwischen den einander bekämpfenden Völkern zu Tage getreten, wie in dem eben ausgetragenen Weltkriege. Der $\mathrm{HaB}$ erzeugte nun seinerseits auch Verleumdungen bezüglich begangener Grausamkeiten aller Art, die sowohl wir als von seiten unserer Feinde sicher begangen ohne weiteres annahmen, wie diese noch viel mehr von uns. Und nicht nur die weniger Gebildeten glaubten solche Kriegsmärchen, wie ich sie nennen will, sondern selbst Leute, von denen man annehmen durfte, daß sie sich ein klareres und ruhigeres Urteil bewahrt hätten. Es war fast über die ganze Welt das gekommen, was man als "Kriegspsychose“ bezeichnet hat.

Um nur einige selbsterlebte Beispiele zu berichten, erzähle ich von liriegspsychotischen Verirrungen auf deutscher Seite. So las ich selbst den Brief einer Pastorenfrau aus Ostpreußen, die einer Frcundin von ihren Kriegserlebnissen während der Besetzung eines Teiles der Provinz durch die Russen berichtete. Darin hieß es, ihr Mann, der Pastor, habe, als die Russen sich näherten, beschlossen, obwohl man ihm dringend geraten hatte, sich und die Seinigen in Sicherheit $\mathrm{zu}$ bringen, in seiner Gemeinde auszuharren. Da sei ihm aber dic Nachricht zugekommen, die Russen hätten in einem Nachbardorfe nicht nur aufs ärgste geplündert, sondern auch den Pfarrer des Orts mit gebundenen Händen an einem Baume aufgehängt und unter seinen über dem Boden schwebenden Füßen ein Feuer angezündet. Da sei denn ihr Mann mit seiner Familie geflohen. Ich habe mich genauer erkundigt; an dieser feurigen Bastonnade ist kein wahres Wort. Viele Fälle von Verwüstungen und unnötigen Härten, die die Russen in Ostpreußen verübt haben, sind ja sicher konstatiert, der erzählte Fall war aber ein Produkt der Kriegspsychose. Wahr ist aber ein anderer Fall unnötiger, oder, ich will licber sagen, übereilter Kriegsjustiz: Glockenzeichen zu geben, war begreiflicherweise von den Russen verboten worde11. Da stirbt in einem Dorfe, welches hart an der russischerseits besetzten Zone lag, die Frau eines Landmannes. Es ist üblich, durch ein Sterbegeläut dem Verstorbenen die letzte Elhre zu erweisen und zugleich der Gemeinde den Tod cines Insassen anzuzeigen. Der Mann der Verstorbenen geht zum Pfarrer, zeigt den Tod an und bittet um das Geläut. Der Pfarrer macht ihn darauf aufmerksam, daß dies falsch beurteilt werden könne, da die Russen in der Nähe seien, fügt 
sich aber schließlich den inständigen Bitten des Mannes und ordnet ein kurzes Geläut an. Bald erscheint eine russische Patrouille aus der Nachbarschaft, der Pfarrer wird festgenommen und, ungeachtet der von ihm gegebenen Aufklärung, der man nicht glaubt, kriegsrechtlich erschossen.

Viel geglaubt wurden Erzählungen von abgeschnittenen Nasen und Ohren sowie von ausgestochenen Augen, denen man mehrfach in der Presse begegnen konnte, oder die von Mund zu Mund weitergegeben wurden. So berichtete man mir eines Tages, der ich immer Zweifel bei solchen Erzählungen geäußert hatte, daß ganz sicher in einem belgischen Kloster mehrere deutsche Verwundete lägen - es wurde sogar eine bestimmte Zahl genannt - , denen man die Augen ausgestochen habe. Ich schrieb sofort an die Oberin des Klosters und bat um Auskunft. Sie wurde mir umgehend gewährt: im Kloster war bisher kein einziger Fall der Art eingeliefert worden! Noch ein selbsterlebter Fall von Nasenabschneiden sei erwähnt, der eines gewissen Humors nicht entbehrt. Ich ging eines Abends im Spätherbst I9I4 durch die Lützowstraße in Berlin am Elisabethkrankenhause vorbei. Da hörte ich, wie eine aus dem Krankenhause kommende Frau zu einer anderen sagte: „Die Leute wollen's nicht glauben, aber da im Krankenhause liegt ein Verwundeter, dem sie die Nase abgeschnitten haben." Sie meinte natürlich, unsere Feinde hätten das getan, das ging deutlich aus ihrer Entrüstung und aus dem, was sie noch weiter sagte, hervor. Ich trat sofort in das Krankenhaus ein, fragte nach dem behandelnden Arzt, der mich kannte und alsbald zur Stelle war. Ich fragte, ob das wahr sei, daß ein Verwundeter mit abgeschnittener Nase im Krankenhause sei? „Jawohl,“ sagte er, ,,aber ich selbst habe sie ihm abgeschnitten!" -

Nun glaube man nicht, daß nur bei uns legendarische Kriegsgreuel entstanden und geglaubt worden sind; ich habe mir eine französische Broschüre gekauft, die eigens herausgegeben worden war und eine ganze Menge von Grausamkeiten der Art enthielt, die von deutschen Soldaten in Frankreich verübt sein sollten. Bei sehr vielen war für jeden Unbefangenen und kritisch Denkenden ohne weiteres klar, daß es sich um Erzeugnisse der Kriegspsychose oder wenigstens um Übertreibungen an sich unbedeutender oder doch durch vollkommen berechtigte Kriegsmaßregeln erklärte Vorkommnisse handelte, wie sie 
jede Truppe, sei es eine englische, französische oder irgendeine andere, in Feindesland für zulässig, ja notwendig erachtet hätte. Angesichts aller dieser Erfahrungen und der Steigerungen des Völkerhasses, die durch die Verbreitung ungeprüfter Erzählungen seitens der Presse oder von Mund $\mathrm{zu}$ Mund hervorgerufen werden mußten, entschloß ich mich bereits in der ersten Zeit des Krieges zu einer Veröffentlichung in der Zeitschrift „,Nord und Süd ${ }^{1 \text { “ }}$ unter der Bezeichnung ,Frieden im Kriege“, worin ich diesen Dingen, warnend vor der unnötigen Steigerung des Völkerhasses, entgegentrat.

Als die von mir beabsichtigte Fahrt nach Straßburg im Elsa B, Lyon und Badgastein durch den frühen Ausbruch des Krieges vereitelt wurde, begab ich mich in Begleitung meiner älteren Tochter nach Bad Nenndorf am Deister bei Hannover. Dort nahmen wir Abschied von meinem jüngeren Sohne, der als Marineoffizier zur Übernahme einer Matrosenabteilung nach Flandern kommandiert war und auf der Reise dorthin die Bahnstrecke Hannover-Hameln benutzte. Er nahm in Flandern an der Eroberung Antwerpens teil und wurde darauf bei Lombartzyde schwer verwundet. So sah ich ihn dann in der Heimat wieder. Geheilt ging er auf den flandrischen Kriegsschauplatz zurück zum Stabe des Admirals v. Schröder und wurde später im ReichsMarineamt, wo er bereits früher im Dienst gewesen war, bis fast zur Beendigung des Krieges verwendet. Kurz vor Ausbruch der Revolution wurde er zum Kommandanten des Linienschiffes „Schlesien“ ernannt. Die in dieser Stellung erlebten Ereignisse, die ein klares Bild von dem Verlaufe der revolutionären Vorgänge bei unserer Marine geben, hat er selbst jüngst in einer kurzen Schrift ${ }^{2}$ dargestellt.

Während meines Aufenthaltes in Bad Nenndorf gelangte die Aufforderung an die deutschen Ärzte, sich in den Sanitätsdienst zu stellen. Ich verließ sofort Nenndorf und stellte mich in Berlin zur Verfügung, insbesondere zur Führung von Lazarettzügen. Da aber jüngere Kräfte genügend vorhanden waren, blieb es bei meinem guten Willen. Ich fand jedoch bald erwünschte Tätigkeit durch topographisch-anatomische Lehrkurse für Ärzte mit besonderer Berück-

1 Nord und Süd. Deutsche Monatsschrift, herausgegeben von Ludwig Stein. 39. Jahrgang, Novemberheft I9I4.

2 von Waldeyer-Hartz, Fregattenkapitän: „An Bord des Kriegsschiffes Schlesien bei Ausbruch der Revolution." Berlin 1918, Verlag von Zillessen. 
sichtigung der Kriegschirurgie, sowie derartige Übungskurse für ältere Studierende, die zum baldigen Ausrücken in den Feldsanitätsdienst bestimmt waren.

In meine Familie griff der Krieg, da meine beiden Söhne und beide Schwiegersöhne im Militärdienste standen, sehr fühlbar ein. Ich erwähnte bereits die Kriegstätigkeit meines jüngeren Solınes. Mein älterer Sohn war bei Ausbruch des Krieges als Oberstleutnant Kommandeur eines in Danzig garnisonierenden Feldartillerie-Regiments, machte unter Hindenburg den Feldzug gegen die Russen in Ostpreußen mit und blieb auch später in Rußland bis zu dessen $\mathrm{Zu}$ sammenbruch. Dann fand er dienstliche Verwendung in Frankreich mit dem besonderen Auftrage, eine feste Stellıng vor Verdun auszubauen. Infolge einer Erkrankung trat er im letzten Kriegsjahre in eine Dispositionsstelle in seiner früheren Garnisonstadt zurück. Der Gatte meiner älteren Tochter, Oberstleutnant v. Bonin, zu Beginn des Krieges im 5. Garderegiment in Spandau, rückte als Bataillonskommandeur mit in Belgien ein und besetzte Namur. Von dort wurde er noch im ersten Kriegsjahre in gleicher Eigenschaft nach RuBland versetzt; dort wurde er zweimal schwer verwundet, beide Male aber vollkommen wieder hergestellt, so daß er, unter Ernennung zum Regimentskommandeur, im aktiven Dienst verbleiben konnte. Nach Beendigung des Krieges mit RuBland kam er nach Frankreich und fiel dort am 2I. März I9I8 beim Beginn der letzten für unser Heer so ruhmvoll verlaufenen großen Offensive bei St. Quentin; er ruht in französischer Erde. - Der Gatte meiner jüngeren Tochter, Dr. O. Tilma nn, war zu Beginn des Krieges ordentlicher Professor der Chirurgie und Direktor der chirurgischen Abteilung des Krankenhauses „Zur Lindenburg“" in Köln. Er kam von da als Generalarzt und beratender Armeechirurg zuerst nach Metz, dann bald darauf zur Armee des Generals v. Woyrsch nach RuBland, wo er bis zur Auflösung dieses Armeeverbandes verblieb. Dann übernahm er die Behandlung der zahlreich im „Lindenburg-Krankenhause“ untergebrachten Verwundeten. Auch meine Neffen, Söhne meiner beiden Brüder, standen sämtlich im Felde, teils als Ärzte, teils als Offiziere, teils als Musketiere. Einer der letzteren, Friedrich Waldeyer, Sohn meines jüngeren Bruders, verheiratet und Vater zweier Kinder, ein mir besonders lieber Verwandter, fand auch den Tod vor dem Feinde. So habe ich, weun 
Die deutsche Revolution I918. Plünderungen im Akademiegebäude. 369

zwar in diesem Kriege nicht mehr im Felde tätig, doch in Sorge und Trauer ihm, wie fast alle meine deutschen Landsleute, meinen Tribut reichlich zollen müssen. Und wie Vielen hat er noch weit Schwereres auferlegt! -

In den beiden ersten Kriegsjahren verspürte man in der deutschen Heimat noch keinen Mangel; es war noch reichlich alles Gewohnte vorhanden, wenn auch die Preise nach und nach, jedoch nur langsam, sich hoben. Im Winter I9I6/I 7 begann aber die Zeit der Entbehrungen an allem, was zum Leben notwendig war: Feuerungsmaterial, Bekleidungsstoffe, Lebensmittel stiegen erheblich im Preise und die Zwangswirtschaft setzte ein.

Mit dem Weltkriege hängen die Revolutionen zusammen; sie sind überall bei den besiegten Nationen gekommen. Hätten wir gesiegt oder auch nur einen von der bisherigen monarchischen Regierung eingeleiteten, einigermaßen annehmbaren Frieden errungen, so wäre sie sicherlich in Deutschland nicht gekommen.

Eines der bemerkenswertesten Ereignisse der Nacht vom 8. zum 9. November I9I8 war die gewaltsame Besitznahme der Königlichen Bibliothek nebst dem damit zusammenhängenden Gebäude der Akademie der Wissenschaften Unter den Linden. In der hier angesammelten Menge entstand plötzlich der Ruf, es sei aus den Fenstern des Bibliotheks- und Akademiegebäudes auf das unten angesammelte Volk geschossen worden. Gleich hieß es weiter, es seien Offiziere darin versteckt, die eine Gegenrevolution einleiten wollten. Die Menge, meist aus Mobgesellen und rauflustigen jungen Burschen bestehend, zerschlug unter Anwendung rohester Gewalt die schöne bronzene Eingangstür zur Akademie und drang ein. Alle Zimmer wurden durchsucht, Schränke erbrochen, Türen eingeschlagen, Möbel beschädigt und verschiedene Sachen mitgenommen. Man suchte nach den angeblich in den Gebäuden versteckten Militärpersonen, natürlich ohne irgendeine solche zu finden, denn die Dienerschaft, welche in den Gebäuden wohnte, hatte diese vorschriftsmäßig sorgfältig verschlossen. Ich befand mich noch spät am Nachmittage des 8 . November in dem Gebäude der Akademie und mußte mir von einem der Diener die Türen wieder öffnen lassen; es befand sich außer der Dienerschaft Niemand in dem Gebäude. Es ist auf das Bestimmteste erwiesen, daß keine Militärperson in den beiden Gebäuden anwesend 
war und ebenso ist erwiesen, daß kein Schuß aus den betreffenden Fenstern oder sonstigen Straßenöffnungen des Bibliotheks- und Akademiegebäudes abgegeben worden ist. Wahrscheinlich hat Jemand aus der vor den Gebäuden angesammelten Menge leichtsinnig oder in provokatorischer Absicht, um eine Gelegenheit zum Plündern herbeizuführen, oder auch nur aus Unvorsichtigkeit einen Schuß abgegeben, der dann bei der erregten Menge zu den unsinnigsten und übelsten Folgen führte. Ich kam dabei am schlechtesten weg. Auf die Nachricht von den berichteten Vorfällen begaben wir vier Sekretare der Akademie uns an Ort und Stelle. Im Pförtnerzimmer befanden sich einige uns unbekannte junge Leute nebst einigen Soldaten und Matrosen, offensichtlich zum Schutze des Gebäudes, denn wir mußten uns ihnen als zum Eintritt Berechtigte ausweisen. Mir wurde ein junger Matrose als Begleitmannschaft zum Besuche meines Amtszimmers mitgegeben. Ein seltsames Gefühl hatte ich, der bis dahin zum Betreten dieses Zimmers vor allen'Anderen Berechtigte, es nunmehr, nach den Vorgängen einer Nacht, nur mit Erlaubnis bis dahin mir völlig unbekannter junger Leute und in Begleitung eines Bewaffneten, der mir zur Beaufsichtigung gestellt war, besuchen zu dürfen! Ich fand auf dem Arbeitstisch ein Manuskript mit dazu gehörigen, etwa 6o Zeichnungen, mit dessen Durchsicht ich am Tage vorher noch beschäftigt gewesen war, nicht mehr vor. Es war mir von einem holländischen Anatomen zur Veröffentlichung in einem der von mir herausgegebenen Archive übersendet worden; statt dessen fand ich eine geleerte Bierflasche und Zigarettenreste. In der Schublade des Tisches waren alle dort lagernden Papiere, die Bruchstücke und Aufzeichnungen zu einer von mir selbst seit zwei Jahren in Bearbeitung genommenen wissenschaftlichen Untersuchung enthielten, durcheinander gewühlt und sämtliche zu dieser Arbeit gehörigen, vorzüglich ausgeführten Zeichnungen, die einen Wert von mindestens Iooo Mark hatten, verschwunden! Das entwendete Manuskript des holländischen Autors nebst den dazu gehörigen Zeichnungen sowie die zu meiner Arbeit gehörigen Zeichnungen haben sich nicht wieder gefunden, ungeachtet der öffentlichen Aufforderungen unter Zusicherung einer Belohnung, sowie durch sorgfältigste, von mir in Begleitung eines Angestellten der Akademie vorgenommenen Untersuchung des ganzen $\mathrm{Ge}-$ bäudes, womit wohl alles geschah, was in diesem Falle vorgenommen 
werden konnte, um wieder in Besitz der verschwundenen Sachen zu kommen. Es fehlte noch in meinem Zimmer ein Sofakissen, und man kann begreifen, daß Jemand, dem es auf die Unterscheidung von Mein und Dein nicht ankam, sich dieses in der Plünderungsnacht angeeignet hatte. Wem von der Qualität der dort Eingedrungenen konnte aber an Zeichnungen über die Entwicklung von Reptilienzähnen, die der Holländer bearbeitet hatte, oder an Zeichnungen von MikrocephalenSchädeln und -Gehirnen gelegen sein, die zu meiner Arbeit gehörten? Ich kann mir nur denken, da B Jemand sie aus Neugier, um sie näher zu betrachten, zunächst in Eile aus dem Zimmer entnommen hat und dann, als er an einem anderen Orte, wo er sie in Ruhe betrachtete, fand, daß sie für ihn kein Interesse hatten, sie einfach fortwarf.

Ich fragte noch den mich beaufsichtigenden Matrosen, weshalb man denn das Gebäude der Akademie und der Bibliothek gestürmt habe? „, Ja," meinte er, ,es seien doch Offiziere darin versteckt gewesen, die aus den Fenstern geschossen hätten." „Hat man denn," fragte ich weiter, „Offiziere oder Soldaten darin gefunden ?" „Nein,“ lautete die Antwort, ,aber einen Säbel hat man gefunden." Darauf ich: „Nun, der Säbel konnte auch einmal von einem Offizier, deren mehrere die Bibliothek besuchen, um darin $\mathrm{zu}$ arbeiten, versehentlich vergessen sein, oder einem der Angestellten, die doch meist beim Militär gedient hätten, gehören.“ Darauf meinte der Mann : „Das sei auch möglich.“Ich teile diese Vorkommnisse deshalb ausführlicher mit, weil sie charakteristisch sind für viele Revolutionen. Da gesellt sich zu den anständigeren Elementen der Mob und die unreife, zu allen Zerstörungen leicht geneigte Jugend. Denen, die noch Ordnung halten möchten, gleitet in der ersten Aufregung dann das Heft aus der Hand. Wohl bei keiner bisherigen Revolution, außer der ersten französischen, sind aber so viele Plünderungen, unsinnige Zerstörungen und Morde vorgekommen, wie bei denen der Jahre I9I8 und I9I9 in Rußland, Österreich-Ungarn und Deutschland. Kein Wunder auch, wenn die Träger dieser Revolutionen damit beginnen, die Gefängnisse zu öffnen und auch die schlimmsten Verbrecher loszulassen. Dieser Vorwurf eines so törichten, ja verbrecherischen Tuns kann unseren Revolutionären nicht erspart werden. Verbrecherisch muB auch das Treiben der Kommunisten und Spartakisten in Deutschland genannt werden. Die Wahlen zur Nationalversammlung waren einwandfregi und in aller 
Ordnung vor sich gegangen. Das deutsche Volk hatte in überwiegender Mehrheit sich für die zur Zeit bestehende Regierung und für die Parteien der Demokraten, Mehrheitssozialisten und des Zentrums entschieden; die beiden Extreme, sowohl nach rechts wie nach links, waren in bedeutender Minderheit geblieben. Man durfte auf eine ruhige Weiterentwicklung hoffen. Aber die Spartakisten waren damit nicht zufrieden. Noch lange nachher organisierten sie stets Aufläufe mit Schießereien auf den Straßen und von den Dächern, die manches Opfer forderten. Nun war ja bei der großen Minderheit, in der sie sich tatsächlich befanden, vorauszusehen, daß alle diese Blut fordernden Demonstrationen vergeblich sein würden und man muß doch sagen, wenn eine notorische Minderheit einer überwiegenden Mehrheit ihren Willen durch Blutvergießen und Zerstörungen von Nationalwerten aufzwingen will, so ist das ein Verbrechen. Verbrecherisch nenne ich daher auch die Streiks, die in dieser jetzigen schweren Zeit, wo wir alles daran setzen müssen, unsere Nationalwerte $\mathrm{zu}$ erhalten und zu mehren, uns daran in der schwersten Weise hindern.

Ebenso wie ich die Versuche, die von der ordnungsmäßig gewählten Nationalversammlung bestätigte Regierung von links her zu stürzen, verurteile, würde ich auch solche Versuche von rechts her verurteilen. ${ }^{1}$ Da der Reichspräsident und sein Ministerium nur auf bestimmte Zeit gewählt wird, so kann ja jede Partei oder Parteiengruppe zu ihrem Rechte auf ordnungsmäßigem Wege kommen, sobald sie die Mehrheit der Wähler für sich hat. Möchte Deutschland und sein Volk bald zur Einsicht kommen, da $B$ hierin der einzige Weg gegeben ist, um unserem Vaterlande wieder aufzuhelfen!

Ich möchte meine letzten Lebenserinnerungen aus der Zeit unseres Weltkrieges und unseres Zusammenbruches nicht schließen, ohne meinen Ansichten über die Ursachen dieses gigantischen Kampfes

1 Diese Zeilen waren bereits vor dem sogenannten Kapp-Putsche niedergeschrieben; ich stehe heute auf demselben Standpunkte in der unbedingten Verurteilung aller solcher Unternehmungen. Es gibt nur eine Möglichkeit, Deutschland wieder aufzurichten: Völlige Unterwerfung Aller unter die jeweilige Regierung, die auf Grund der verfassungsmäßig vollzogenen Volkswahlen zu Stande gekommen ist. Da die Wahlen in regelmäßigen Zwischenräumen wiederholt werden, können ja diejenigen politischen Anschauungen, welche im Volke die Majorität gewinnen, alle ihrer Zeit zu ihrem Rechte kommen. 
und unserer Niederlage Ausdruck gegeben zu haben. Ich füge dazu einiges weitere über unsere diplomatische und militärische Führung während des Krieges selbst, sowie über die Ergebnisse des Kampfes, soweit diese sich jetzt schon beurteilen lassen.

Über die letzten Ursachen dieses Krieges habe ich meine Mcinung in dem, was ich S. 36I aus meinem Briefe an Frau Selenka mitteilte, bereits angeführt. Es waren die stets wachsende Macht Deutschlands auf der einen Seite und das von Rußland als Lebensaufgabe erfaßte Ziel, den freien Weg zum Mittelmeer clurch die Meerengen und durch die Beherrschung der Balkanländer zu gewinnen, zusammen mit dem gleichfalls als Lebensziel von Frankreich erfaßten, nie aus dem Auge gelassenen Verlangen, Elsaß-Lothringen wieder zu gewinnen und die schwere Niederlage von I870/7I auszuwetzen, auf der anderen Seite. Den Zielen Rußlands und Frankreichs stand als einziger Gegner das mit Österreich-Ungarn verbündete und mit der Türkei befreundete Deutschland entgegen. „Der Weg nach Konstantinopel führt über Berlin" schrieb ein russischer Politiker. In Frankreich lebte man nicht nur nach dem Rezepte Gambettas: „Stets daran denken, aber nicht davon sprechen," sondern hielt auch in der Öffentlichkeit mit dem genannten Ziele nicht zurück. Ich bin freilich, wie bereits mitgeteilt, in Frankreich auch gemäßigteren Anschauungen begegnet.

Man empfand nun sowohl in RuBland wie in Frankreich klar, daB mit jedem Jahre, falls die Machtsteigerung Deutschlands zu Wasser und zu Lande weiter fortschreite, es schwieriger sein würde, die gesteckten Ziele zu erreichen. So wuchs naturgemäß die Spannung von Tag zu Tage. Das Bündnis zwischen Frankreich und Rußland wurde geschlossen.

Von Italien war nichts anderes zu erwarten, als daß es, sobald Österreich in einen Krieg verwickelt sein würde, der es in eine schwierige Lage brächte, sofort aus dem Dreibund austreten und Österreich den Krieg erklären würde, wie das ja auch tatsächlich geschehen ist. Hätte Österreich nur mit Serbien Krieg zu führen gehabt, es würde Italien nicht eingefallen sein, Österreich den Krieg zu erklären. Unter keinen Umständen trat Italien auf unsere Seite; es konnte dies auch nicht, sobald England an dem Kriege teilnahm.

Und England? England zeigte wieder seine Meisterschaft in der Diplomatie und blieb mit glänzendstem Erfolge seinem alten, ihm zur 
Weltmacht verholfen habenden Grundsatz getreu, jede Macht, die ihm zur See gleich zu werden drohte, unter kluger Berechnung der allgemeinen politischen Weltlage, niederzuzwingen. Waren es früher Holland, Spanien und Frankreich, so kam jetzt Deutschland an die Reihe. Wie bei diesen früheren Kriegen hat England es wieder in bewundernswerter Weise verstanden, sich Bundesgenossen zu verschaffen und den richtigen Augenblick zu wählen, um sich mit seiner Kriegserklärung ins Recht zu setzen. Es wartete ab, bis da ß der Augenblick des Losschlagens seitens Österreichs-Deutschlands nicht mehr zu vermeiden war und trat dann noch als Vermittler mit seinem Konferenzprojekte auf, dessen Annahme in diesem Augenblick von seiten Österreichs und Deutschlands ausgeschlossen war, denn sie hätte nur dazu gedient, den Aufmarsch der russischen und französischen Truppen gegen unsere Grenzen zu vervollständigen. Ich glaube nicht, daß man Deutschland einen Vorwurf daraus machen kann, daß es, als Rußland und Frankreich ihre Rüstungen auf unsere Vorschläge nicht einstellten, beiden Mächten den Krieg erklärte, dazu war die Lage, in die wir durç den Zweifrontenkrieg kamen, zu ernst. Ich irre sicher nicht in der Annahme, daß England der Ausbruch des Krieges gelegen kam; seine vorherigen Verständigungen mit Rußland und Frankreich beweisen dies. Ich gehe nicht so weit, zu behaupten, daß England den Krieg mit uns gesucht habe und daß es im Unrecht war, uns den Krieg zu erklären, als wir in Belgien einrückten. Ich habe stets unseren Einmarsch in Belgien als einen schweren Fehler beurteilt, ungeachtet der später enthüllten Abmachungen zwischen England und Frankreich mit Belgien für den Fall eines Einmarsches deutscher Heere in Belgien. Nur wäre es von Belgien, wenn es seine Neutralität richtig wahren wollte, zu verlangen gewesen, da $B$ es Deutschland von dem Bestehen solcher Abmachungen Kenntnis gegeben und mit Deutschland gleiche Vereinbarungen für den Fall eines Einmarsches französischer oder englischer Truppen getroffen hätte. England sah durch die Vermehrung unserer Flotte, deren Tüchtigkeit es von vornherein richtig einschätzte, von der es denn auch an der südamerikanischen Küste und bei Skagerrak sowie durch unsere U-Boote genugsam überzeugt wurde, sich stark bedroht und durch Deutschlands steigende Handelskraft und Industrie seinen Weltmarkt beengt. So ist es erklärlich, da $B$ es, statt beim Löschen des drohenden Weltbrandes aufrichtig zu 
helfen, wie es das wohl gekonnt hätte, ihn entstehen ließ und die erste Gelegenheit benützte, ihn zu unterhalten, bis die deutschen Scheiter verzehrt waren.

In der geschilderten Gesamtlage der großen europäischen Mächte lag der Grund zum Weltkriege; sie drängte förmlich dazu und wenn der Krieg nicht I9I4 zum Ausbruch gekommen wäre, so wäre es doch vielleicht I9I5 oder IgI6 gewesen. Kommen mußte er einmal, so lange Rußland und Frankreich nicht auf ihre Ziele verzichteten und Deutschland fortfuhr, seinen Handel und seine Industrie sowie seine Marine weiterzuentwickeln.

Hat nun Deutschland oder ein anderer der kriegführenden Staaten, wie sie zu Beginn des Kampfes einander gegenüberstanden, einzig und allein Schuld am Weltkriege? Unsere Gegner suchen die Schuld allein auf Deutschland abzuwälzen. Aus dem vorstehend Angeführten, von dem Nichts geleugnet werden kann, geht aber unzweifelhaft hervor, daß Deutschland allein die Verschuldung des Weltkrieges nicht trifft. Alle zu Anfang des Krieges in den Kampf eingetretenen Mächte trifft ein Verschulden in goleicher Weise; auch Deutschland und Österreich-Ungarn können nicht freigesprochen werden. Österreich-Ungarns Ultimatum an Serbien war zu scharf; ob Deutschland Einfluß haben konnte, es zu mildern, bleibt nach dem bisher bekannt Gewordenen noch zweifelhaft. Aber Deutschland hat noch andere Fehler gemacht. Die offene Teilnahme für Marokko, die mit dem Besuche Kaiser Wilhelms in Tanger etwas theatralisch in Szene gesetzt wurde, der „Panthersprung" nach Agadir waren Dinge, die besser unterblieben wären. Sie führten nur dazu, Deutschland als den Unruhestifter im Weltkonzert, als den „Hecht im Karpfenteiche“ hinzustellen, wie das Verhalten der Mächte auf der Algeciras-Konferenz klar erwies. Wir hatten da nur Gegner und zweifelhafte Freunde. Gewiß hatten wir wichtige Interessen in Marokko, aber Marokko lag ganz und gar in der Interessensphäre Frankreichs und Spaniens; wir konnten unsere Interessen geltend machen, mußten aber, als wir sahen, da $\beta$ Frankreich auf unsere Wünsche nicht eingehen wollte, zurücktreten, wie Frankreich es bei der Faschoda-Sache vor England tat. Unglaublich wollte mir die Nachricht erscheinen, und ich kann sie auch heute noch nicht glauben, daß wir Frankreich, um uns seiner Neutralität zu versichern, 
angeboten hätten, einige französische Festungen $\mathrm{zu}$ besetzen. Was würden wir geantwortet haben, wenn uns von Frankreich zugemutet worden wäre, daß es, um Deutschlands Neutralität zu sichern, Metz und Köln besetzen wolle? Diese beiden Dinge, Marokko und die Frage der Festungsbesetzung sind zwar nicht die direkte Ursache zum Kriege gewesen, sie haben aber jedenfalls die bestehende Spannung bis zum Äußersten vergrößern helfen. Deutschland hat ferner eine direkte Schuld am Ausbruche des Krieges mit England durch den Einmarsch in Belgien. Dieser war und bleibt ein Unrecht. Militärisch brachte er uns zwar Vorteile, völkerrechtlich war er nicht zu rechtfertigen, und in einer Notlage, die ihn hätte rechtfertigen können, befanden wir uns damals nicht. Hatten wir I870, ohne Belgiens Neutralität zu verletzen und ohne den Besitz von Metz und Straßburg, über Frankreich gesiegt, so konnte das auch I9I4 möglich sein, jedenfalls konnten wir mit den verfügbaren Truppen im Westen in der Defensive uns halten, während dieselben Heere, die wir damals gegen Rußland ins Feld führten, uns für den Krieg im Osten frei blieben. Daß wir zuerst den Krieg an Rußland und Frankreich erklärten, war gleichfalls ein Fehler, der besser vermieden worden wäre. Alles dieses gibt Deutschland eine gewisse Schuld am Weltkriege; aber ihm allein die Schuld aufzubürden, ist im höchsten Grade ungerecht. Ich wiederhole: Alle kriegführenden Mächte haben Schuld am Weltkriege und Deutschland wohl die geringste, denn alle anderen Mächte führten den Krieg mit der bestimmten Absicht, etwas an Land-und Machtbesitz zu erlangen oder die Machtmittel Deutschlands einzuschränken, Deutschland allein nahmden Krieg auf, um sich dagegen zu verteidigen. Deutschlands Kriegserklärung trug einen defensiven Charakter; sie wurde ihm aufgenötigt durch seine zentrale Lage, nach allen Seiten von Nationen umgeben, die seine Entwicklung mit mißgünstigem Auge betrachteten und ihm etwas nehmen wollten. Auch Italien kann zu diesen Nationen gerechnet werden, indem es Ansprüche auf Gebiete machte, die für das Wirtschaftsleben Deutschlands ein hohes Interesse hatten: das Gebiet von Triest. Triest in der Hand Österreich-Ungarns hatte für Deutschland eine ungemein wichtige Bedeutung, die es in der Hand Italiens verloren hat. Wenn man die ungemein günstige maritime Lage bedenkt, die alle unsere Gegner - außer Rußland - haben, gegenüber 
der Lage Deutschlands, so begreift man, wie schwer der Verlust eines österreichisch-ungarischen Hafens an der Adria auch für Deutschland ist. Es ist vollkommen begreiflich und kann ihm nicht als Schuld am Kriege angerechnet werden, wenn es, von allen Seiten gedrückt, zur Kriegserklärung schritt, als es sah, da $B$ dem Kriege nicht mehr auszuweichen war.

Unsere Gegner vereinigen nun ihre Anklagen auf das damalige Haupt Deutschlands, Kaiser Wilhelm II. Etwas Törichteres als dieses kann kaum erdacht werden. Wilhelm II. hat sich persönlich vielfach bemüht, mit England, Rußland, Frankreich und Italien gute Beziehungen zu unterhalten. Seine Bemühungen in Österreich-Ungarn und in Rußland beim Zaren Nikolaus II sprechen deutlich genug dafür, daß er, weit entfernt zum Kriege $\mathrm{zu}$ treiben, vielmehr alles, was möglich war, aufgeboten hat, um ihn zu verhindern. Seine Proklamation bei der Kriegserklärung sprach es zudem mit voller Klarheit aus, daß er nicht an Eroberung, sondern nur an Erhaltung des Bestandes Deutschlands denke, wie er ihm beim Antritt seiner Regierung zugekommen war. Und das war seine Pflicht! Ebenso unerhört ist die Forderung unserer Feinde auf die Herbeiführung eines richterlichen Urteils über eine Anzahl deutscher Heerführer und dies dazu noch durch einen Gerichtshof, der nur aus Mitgliedern der uns feindlichen Länder zusammengesetzt ist ${ }^{21}$ ). Aber der Grund aller dieser Dinge : des ständigen, fast lächerlich gewordenen Betonens, daß sie, unsere Gegner, nur für die Sache der Freiheit der Völker und für die Zivilisation kämpften, der Anklage, daß Deutschland und sein Kaiser die alleinige Schuld am Weltkriege hätten und der Forderung, deutsche Heerführer zur Verantwortung zu ziehen, ist sonnenklar: im Bewußtsein, daß die Hauptschuld bei ihnen selbst liegt und daß dereinst das Urteil der Geschichte gegen sie ausfallen wird, wollen sie beizeiten durch einen richterlichen Spruch Deutschlands und seines Kaisers angebliche Schuld feststellen und von sich abnehmen lassen. Es gibt ein französisches Sprichwort, welches hier ausgezeichnet paßt: Qui s'excuse s'accuse!

Man hat uns vorgeworfen, daß wir durch die Angriffe unserer Zeppeline und durch den U-Bootkrieg das völkerrechtlich $\mathrm{Zu}$ lässige überschritten hätten. Dieser Vorwurf ist nicht gerechtfertigt, da unsere Gegner im Luftschiffkriege sich genau so verhalten haben 
wie wir. Ich verurteile aber dennoch das Bombardieren offener und selbst befestigter Städte zwecks Abschreckung und Einschüchterung durch Flugzeuge oder weittragende Geschütze, wie wir das letztere mit Paris versucht haben: Der Erfolg ist bisher nur der gewesen, da $B$ eine Anzahl von Zivilpersonen, darunter Frauen und Kinder, getötet wurden, ohne daß dadurch das Mindeste zur Entscheidung des Krieges erreicht wurde; nur der $\mathrm{Ha} B$ wurde auf beiden Seiten gesteigert. Selbst die Zerstörung von kriegswichtigen Anlagen, wie Brücken, Bahnhöfen und anderen derartigen Bauten in Städten durch Fliegerbomben möchte ich nicht ausnehmen. Bis jetzt ist es noch nicht gelungen, da $B$ Flieger ihre Bomben mit Sicherheit auf solche, selbst große Ziele abwerfen können, wenn für gute Abwehr gesorgt wird. Köln hat während des Krieges mehrfach unter Luftfeuer gestanden. Die feindlichen Flieger hatten sicher nicht die Absicht, friedliche Einwohner zu töten, wie auch wir nicht, wenn wir London beschossen. In Köln hatten sie es stets auf den Bahnhof oder die Rheinbrücken abgesehen. Es ist ihnen nicht gelungen, diese in nennenswerter Weise zu beschädigen, wohl aber bei einem Angriffe, den ich selbst in Köln miterlebt habe, 33 Menschen, darunter mehrere Frauen und Kinder, zu töten, über 60 mehr oder minder schwer $z u$ verwunden und einige Privathäuser zu beschädigen. So, meine ich, sollte man von dem Luftbombardement auf Ortschaften, das trotz unserer Zeppeline in England keinen entscheidenden Effekt gemacht hat, gänzlich absehen, bis die Luftfahrtechnik sich so weit entwickelt hat, da $B$ man bestimmte Ziele mit Sicherheit erreichen kann.

Am besten aber sähe man nach den furchtbaren Lehren dieses Weltkrieges vom Kriege selbst ab. Wozu mußten Millionen junger kräftiger Menschen auf den Schlachtfeldern getötet werden, wozu ebensoviele zu Krüppeln werden, wozu reiche und fruchtbare Gegenden, wie in Ostpreußen, Rußland, Serbien, Italien, Österreich-Ungarn und Nordfrankreich verwüstet werden, Hunderttausende von Nichtkämpfern in Not und Elend geraten und sterben? War nicht Rußland groß und mächtig genug, auch ohne die Meerengen? Blieb nicht England reich und mächtig auch bei zunehmender Konkurrenz Deutschlands, nicht Frankreich, welches nach dem Kriege I870/7I einen herrlichen Kolonialbesitz erworben hatte, ohne Elsaß-Lothringen? Nicht Deutschland ohne Erwerbung nordfranzösischer und belgischer Ge- 
bietsteile? Der Krieg ist zwar von Deutschland nicht mit diesem Ziele begonnen worden; aber man hat auch seitens der Regierung diesen Erwartungen, die von alldeutschen und industriellen Kreisen in der zugehörigen Presse und in Flugschriften immer wieder gefordert wurden, niemals klar widersprochen, was, meines Erachtens, jedenfalls zu einer Abkürzung des Krieges und zu einem besseren Frieden für uns geführt hätte, wenn es sofort geschehen wäre, als diese Wünsche der genannten Parteien zuerst auftauchten.

Es war das überhaupt eine Schwäche der Stellung Deutschlands während des Krieges, daß es, abgesehen von der ersten Erklärung des Kaisers, die nur einen Verteidigungs-, keinen Eroberungskrieg verkündete, in allen späteren Äußerungen und in dem kaiserlichen Friedensangebote vom Jahre I9I6 an der Aufstellung bestimmter Kriegsziele gefehlt hat. Wie oft ist das uns von unseren Gegnern vorgehalten worden, da $B$ wir bei diesen Angeboten nicht sagten, was wir eigentlich wollten! Es steht wohl ohne Zweifel fest, daß an dem Tage unserer Kriegserklärung kein Deutscher, selbst der äußersten alldeutschen Richtung, gedacht hat, daß wir diesen Krieg als einen Eroberungskrieg mit dem Ziele Belgien oder Kurland oder dem Erzbecken von Longwy und Briey führen würden. Sicherlich hat Jeder empfunden, daß wir ihn führen mußten, und zwar bis zum äußersten, um ElsaßLothringen, um unsere Kolonien, um unseren Bundesgenossen Österreich-Ungarn, um unsere Wege nach Kleinasien und um die Freiheit der Meere auch für uns. Das verstand man im ganzen deutschen Volke bis zur ärmsten Hütte hinab. Wäre dieses Programm stets von unserer Regierung unverrückt festgehalten und bei jedem Anlaß öffentlich kundgegeben worden, so würde im Heere und in der Heimat der Wille zum Durchhalten und der gute Mut niemals gebrochen worden sein. Man hätte dieses Friedens- oder Kriegsprogramm, wie man es nun nennen will, stets betonen und vor aller Welt bei dem Auftauchen weiterer Gelüste klar verkünden müssen. Als man aber an maßgebender Stelle $\mathrm{zu}$ den weitgehenden Forderungen gewisser Kreise schwieg, mußte im Volke wie im Auslande, bei Gegnern wie bei Neutralen, die Meinung Boden fassen, als sei die Regierung im Grunde einverstanden. Und so wurde das Friedensangebot rgI6 vielfach als nicht ehrlich gemeint im Auslande angesehen, ebenso wie später die Friedensresolution des Reichstages nur als Zeichen der 
Schwäche. Hätte die deutsche Regierung unentwegt ihr bei der Kaiserproklamation aufgestelltes Programm des reinen Verteidigungskrieges festgehalten und bei allen ihren Kundgebungen klar und entschieden betont, dann wären keine Friedensangebote und Reichstagsresolutionen nötig gewesen. Höchstwahrscheinlich wäre es auch nicht zur Revolution gekommen und wir hätten schlimmstenfalls, wenn vielleicht auch mit einigen Opfern, einen besseren Frieden erlangt.

Die Ansichten und Forderungen der alldeutschen Partei und vieler Industrieller, die auch von dem deutschen Heere und von der Marine geteilt wurden, sind aber durchaus erklärlich und verständlich, nach den immer wieder zu verzeichnenden Erfolgen unserer Waffen, worauf schon eingangs dieses Kapitels hingewiesen wurde. Da konnte wohl der Wunsch aufkommen, für die schweren Opfer, die uns der Krieg auferlegt hatte, auch noch eine Entschädigung $\mathrm{zu}$ erhalten, die uns gestattet hätte, unsere Macht so weit zu entfalten, daß wir Behinderungen und neuen Angriffen von seiten unserer dermaligen Feinde nicht mehr ausgesetzt worden wären. Solche Sicherungen wünschen selbstverständlich alle kriegführenden Mächte. Man denke an Rom und Karthago, an den Limes romanus, an die Besitzergreifung von Metz im Jahre I87I, die uns eine Sicherung gegen erneute Angriffe Frankreichs geben sollte. Im Friedensschlusse des eben beendeten Krieges haben unsere Feinde es verstanden, sich so weit zu sichern, daB für absehbare Zeit Deutschland zur politischen Ohnmacht verurteilt ist. Jetzt kommen andere Mächtekombinationen an die Reihe, aus denen sich, so hoffen wir, auch für uns die Befreiung von der Knechtschaft, in die wir versetzt sind, dereinst ergeben wird. Wir können, wollen und werden dann auch mit unseren Nachbarn in Frieden leben, wenn wir wieder ein freies Volk mit voller Selbstbestimmung geworden sind. Niemand bei Freund und Feind wird einen zweiten Weltkrieg, wie es der letzte war, herbeizuführen bestrebt sein.

Welches waren nun die Ursachen unseres militärischen Versagens in diesem Kriege nach den so vielversprechenden Erfolgen bis fast in die letzte Zeit hinein, und welches waren die Ursachen unseres $\mathrm{Zu}$ sammenbruches? Man muß meiner Meinung nach diese beiden Punkte trennen.

Militärisch mußten wir unterliegen durch den Eintritt Nordamerikas in den Krieg. Frankreich und England hätten uns, nachdem wir 
RuBland und Rumänien erledigt hatten, allein nicht besiegt, denn Österreich-Ungarn konnte Italien im Schach halten und wir hätten unserem Bundesgenossen, wenn Amerika nicht eingetreten wäre, noch Hilfe gewähren können. ' In den vier Jahren harten Kampfes waren unsere tapferen Heere freilich hart mitgenommen; der Hauptbestand unserer Berufsoffiziere war gefallen oder durch Erkrankungen und Verwundungen ausgeschaltet, unsere Kriegswaffen und Kriegsmaschinen vielfach abgenutzt, immer schwieriger wurde die Beschaffung der Munition; aber das meiste von diesen Verlusten und Schwierigkeiten bestand ebenso bei unseren Gegnern. Da traten die Nordamerikaner mit I $1 / 2$ Millionen frischer Truppen und einer Füille von neuen Waffen und Kriegsmaschinen, wie Flugzeugen und Panzerwagen, sowie großen Mengen von Munition auf den Kriegsschauplatz. Jeder Soldat bei uns mußte bald selbst gewahr werden, daß er nicht mehr im Besitze der gleichen Waffen war, wie der neu auftretende Gegner; er mußte sich so fühlen wie ein Kämpfer mit hölzernem Schwert gegen einen solchen mit dem Stahlschwerte. Da hilft die größte persönliche Tapferkeit und die beste Führung nichts. Zu diesem kam nun noch die immer mehr sich steigernde Schwierigkeit der Ernährung auch des Feldheeres. Da zeigte es sich, ein wie großes Machtmittel ein Staat in den Händen hat, der das Meer beherrscht, denn die Hauptschwierigkeit unserer Ernährung wurde durch die englische Blockade geschaffen.

Alles dieses kam zusammen, um uns einen Sieg, wie wir ihn nach unseren anfänglichen Erfolgen erhoffen durften, über unsere verbliebenen Feinde unmöglich zu machen. Immerhin war aber die moralische und physische Widerstandskraft unseres Heeres noch fest genug: úm den Krieg von unseren Grenzen fernzuhalten und uns einen besseren Frieden zu sichern, als wir ihn jetzt abschließen mußten. Die uns auferlegten, in der Geschichte beispiellosen schweren Friedensbedingungen sind eine Folge des Zusammenbruches in der Heimat. Die Vorbedingungen dazu liegen weiter zurück. Sie wurzeln in der sich von Jahr zu Jahr steigernden Unzufriedenheit der handarbeitenden, an Zahl die übrige Menschheit weit überragenden Klassen mit ihrer sozialen Lage. Das Deutsche Reich hatte sicherlich viel getan, um diese Lage zu verbessern. Das genügte aber nicht; die Arbeiter wollten kein Gnadenbrot, sondern volle Rechtstitel in poli- 
tischer und Erwerbsbeziehung. Während wir im Reiche das allgemeine Wahlrecht besaßen, blieb es uns in Preußen, ungeachtet des Kaiserlichen Versprechens, versagt. Ich habe es stets als einen der größten politischen Fehler der Mehrheitsparteien im preußischen Abgeordnetenhause und im Herrenhause, dessen Mitglied ich war, angesehen, daß man zögerte und immer wieder zögerte, das Kaiserwort einzulösen. Als man schließlich unter dem Druck der Kriegslage dazu schritt, war es zu spät, um damit eine versöhnende Wirkung auf die unzufriedenen Massen zu erzielen. Erzwungene Gaben wirken in dieser Beziehung nicht. Nun kam hinzu die immer schwieriger werdende Ernährungsfrage mit der langen Dauer des Krieges. Alles dieses machte die Gemüter der breiten handarbeitenden Volksklassen empfänglich für die revolutionären Ideen, die ihnen reichlich genug von den verschiedensten Seiten als Heilmittel für alles sie Bedrückende vorgeführt wurden. Dazu kam die gewaltige Einwirkung, die unstreitig der Sieg der Revolution in dem großen Rußland auf die Nachbarländer Österreich-Ungarn und Deutschland gehabt hat. Die monarchische Regierungsform hatte nach und nach an Ansehen und Vertrauen verloren. Es ist ja doch nichts Zufälliges, da $B$ in den neu zur Kultur gelangten Weltteilen Amerika und Australien keine Monarchie mehr besteht, denn die englische Herrschaft über den australischen Kontinent und über Kanada kann man keine monarchische nennen. Selbst China hat die Monarchie fallen gelassen. Und ist es nicht bezeichnend genug, daß gerade die großen entschieden monarchischen Staatengebilde Europas in diesem Kriege und durch diesen Krieg zu Grunde gegangen sind und bei ihrer Neuordnung zur republikanischen Regierungsform übergingen?!

Die revolutionären Ideen wurden nun planmäßig sowohl wie auch vielfach unbeabsichtigt von der Heimat in das Heer und in die Marine getragen; einzelne Symptome traten gerade bei der Flotte schon geraume Zeit vor Ausbruch der Revolution hervor. Mir sind von vielen Offizieren und Ärzten zuverlässige Angaben darüber zugegangen, daß in den ihnen bekannten Armeekörpern auf die Zuverlässigkeit der Truppen nicht mehr mit Sicherheit gerechnet werden konnte. Die Heimatsluft, anstatt das Heer zu stärken, schwächte es ab. Da war es verhängnisvoll und hat uns zu dem Abgrunde geführt, in den Deutschland jetzt versunken ist, daß die Führer der Volksmassen die 
Gelegenheit, welche die schwierige Kriegslage bot, benutzten, um ihre Ziele zu erreichen. Vielleicht waren sie der Meinung, uns gerade durch die Revolution einen rascheren und auch besseren Frieden zu verschaffen. Hätte man Ruhe gehalten und wäre die bisherige Regierung mit dem Ka,iser an der Spitze bestehen geblieben, dann hätten auch die Armee und die Flotte, so schwer sie auch zu leiden und zu kämpfen hatten, so viel Widerstandskraft bewahrt, um uns einen glimpflichen Frieden $\mathrm{zu}$ sichern. Ich glaube in dieser Überzeugung nicht fehl $\mathrm{zu}$ gehen. Volle Klärung in diesen ungemein verwickelten und schwierigen Dingen wird erst später kommen.

Noch ein Wort über den Unterseebootkrieg. Diese Kriegführung als völkerrechtswidrig zu bezeichnen, ist verfehlt. Ein feindliches Kriegsschiff oder ein bewaffnetes Handelsschiff durch ein U-Boot $\mathrm{zu}$ versenken, verstößt sicherlich nicht gegen die Kriegsregeln und da wir der Schiffahrt der Neutralen eine freie Zone ließen, so war für sie noch ungefährdete Bewegungsfreiheit genug. Auch würde sich ohne allen Zweifel jeder unserer Feinde derselben submarinen Waffe bedient haben, wenn er in die gleiche Lage gebracht worden wäre, wie Deutschland. Leider hat uns aber der U-Bootkrieg mehr geschadet als genützt. Wir hatten, als wir den rücksichtslosen U-Bootkrieg erklärten, viel $\mathrm{zu}$ wenig U-Boote; die doppelte Zahl hätten wir haben müssen, um England wirkungsvoll einzukreisen. Wir verloren aber stets ungefähr so viel dieser Boote, wie wir neu herstellen konnten und so blieb dieser Grundfehler bestehen. Alsbald lernte man auch der U-Bootgefahr zu begegnen. Darin, wo die U-Boote am wirksamsten gewesen wären, in der Hinderung des Transportes von Truppen und Kriegsmaterial aus Amerika, wie wir sie wohl Alle erwarteten, haben sie fast gänzlich versagt. Und wenn man ein Truppentransportschiff so sichern kann, daß ihm ein U-Boot aus dem Wege gehen muB, dann kann man auch ein Lebensmittelschiff in derselben Weise sichern. Unsere Marine- und Heeresleitung haben durch ihre Zuversicht und, man muB sagen, unzulängliche Abschätzung der enormen Leistungsfähigkeit der Vereinigten Staaten Nordamerikas uns auf einen falschen Weg geführt. Mir ist von glaubwürdiger Seite berichtet worden, daß einer unserer Admirale, als man ihm von der Gefahr, die uns von den U. S. A. drohe, - dem Sinne nach, für den Wortlaut kann ich nicht einstehen - gesagt haben solle: ,Mögen sie 
nur lrommen, das ist etwas für unsere U-Boote!" Nun, sie sind gekommen, in einer Zahl und in so verhältnismäßig kurzer Zeit, wie es wohl keiner von uns Allen für möglich gehalten hat - gestehen wir es nur offen ein - und unsere U-Boote haben sie nicht daran hindern können.

Eine weitverbreitete Meinung ist, da $B$ die Erklärung des uneingeschränkten U-Bootkrieges die Veranlassung zur Kriegserklärung Nordamerikas gegen uns gewesen sei. Darüber habe ich mir keine feste Ansicht bilden können. Es wird die Zeit kommen, da dieses und andere noch unbekannte Dinge aufgehellt werden. Ich glaube indessen, da $B$ Deutschland bei diesen Aufklärungen nichts zu befürchten hat. Daß uns die Volksstimmung und die Politik in den Vereinigten Staaten von Anfang des Krieges an nicht günstig, ja im Gegenteil ungünstig war, steht fest. Wir haben es allerdings auch im Verlaufe des Krieges an Unvorsichtigkeiten, um kein stärkeres Wort zu gebrauchen, seitens unserer Diplomaten nicht fehlen lassen. Ich erinnere nur an das Angebot eines Bündnisses mit Mexiko und Japan und an den drastischen Ausspruch des Grafen Luxburg in Argentinien, die beide von der nordamerikanischen Durchgangsstelle aufgefangen wurden, wie man sich leicht hätte vorhersagen können.

Das traurige, ja furchtbare Endergebnis des Krieges für Deutschland steht fest. Es bedurfte des Zusammenwirkens fast der ganzen Welt und, halten wir das fest, auch unserer eigenen inneren Zerrissenheit, um uns niederzuzwingen. Niemand unserer ursprünglichen Gegner, weder Frankreich noch England, kann sich des Sieges über uns rühmen. Auch Nordamerika nicht. Erst ihren vereinten Anstrengungen ist es nach mehr als vierjährigem Ringen gelungen, ein durch Hunger und Entbehrungen ermattetes, der gleichen Kampfmittel bares Volk zum Niederlegen der abgestumpften Waffen zu zwingen. Ein -Sieg unserer Feinde war es nicht, so sehr auch ihre Presse von einem solchen spricht. Wenn unsere Gegner über den erreichten Erfolg nachdenken, recht freuen können sie sich darüber nicht in dem Bewußtsein, daß sie um den Beistand der ganzen Welt werben mußten, um ihr Ziel zu erreichen. Fast 900 Millionen gegen I50 Millionen, wobei China und Brasilien, weil sie für den Entscheid des Krieges nicht in Betracht kommen, nicht mitgerechnet sind! Das, was unser deutsches 
Volk in diesen Kriegsjahren geleistet und ertragen hat, gereicht ihm zu hohem Ruhm. Stolz können wir auf unsere gesunkenen Fahnen schauen: dies bleibt unser Trost in unserem Elend und unsere Hoffnung für die Zukunft!

\section{Ka pitel.}

\section{Das Bild Deutschlands vor und nach dem Weltkriege.}

Als treuer Chronist, der gern ein klares Bild des Lebens und Treibens seiner Zeit geben möchte, kann ich mir die schmerzliche Aufgabe nicht ersparen, den Zustand Deutschlands, wie er sich bald nach dem Kriege und nach der politischen Umwälzung darstellte, zu schildern und 'mit dem Eindruck, den man von unserem Vaterlande vor dem Kriege bekam, zu vergleichen.

Vor dem Kriege boten alle deutschen Städte, besonders Berlin, ein Bild größter Ordnung und Sauberkeit. Vielfach habe ich dies von Ausländern bestätigen gehört. Ich selbst konnte ja viele Vergleiche anstellen, da ich in Amerika New York, Philadelphia, St. Louis Mo., Boston, Baltimore und Mexiko, in England London, Glasgow, Edinburg, Oxford, Cambrigde, Aberdeen und Dublin, in Frankreich Nancy, Paris, Lyon, Dijon, Bordeaux und Marseille, in Holland und Belgien Amsterdam, Leiden, Utrecht, Haarlem, s'Gravenhage, Lüttich, Löwen, Antwerpen und Brüssel, auf der Pyrenäischen Halbinsel Barcelona, Burgos, San Sebastian, Zaragoza, Madrid, Granada, Sevilla, Cadiz und Lissabon, in Italien Venedig, Mailand, Turin, Bologna, Florenz, Rom, Palermo und Neapel, in den Skandinavischen Reichen Kopenhagen, Kristiania und Stockholm, in RuBland St. Petersburg, Moskau, Kiew und Odessa, in Rumänien Jassy und Bukarest, in Österreich Wien, Prag, Graz, Krakau und Innsbruck, in Ungarn Preßburg und Budapest, in der Türkei und Ägypten Konstantinopel, Brussa, Smyrna und Kairo, in Afrika noch Tunis und in Griechenland Athen kennen gelernt hatte. Ich habe hier nur die Hauptorte genannt. Diese Vergleiche ließen klar erkennen, daß Deutschland in seinen Städtebildern, was Ordnung und Sauberkeit anlangte, in der vordersten Reihe stand. Straßenbilder, wie ich sie namentlich in London, Edinburg und besonders in Dublin gesehen habe, waren in Deutschland nicht zu finden. 
Denselben guten Eindruck, und hier kann ich wohl sagen, einen besseren als überall sonstwo, gewann man von unserem Verkehrswesen, Landstraßen, Eisenbahnen, Postwesen. Unsere Gasthöfe, früher in mancher Beziehung den englischen nachstehend, waren ihnen in der letzten Zeit völlig gleich geworden und den meisten Gasthöfen der übrigen Länder überlegen. Namentlich konnte man auch in vielen kleineren Städten Deutschlands auf gute Unterkunft rechnen. Und wie gut war es mit unserem Münzwesen bestellt, wo wir Papiergeld nur in größeren Stücken kannten und wir darin den übrigen Staaten mit metallischen Verkehrsmünzen völlig gleich standen.

Und die Menschen! Im Großen und Ganzen - Ausnahmen gibt es ja, namentlich in den Großstädten, überall - wie gut hielten sie sich! Man hatte fast durchweg den Eindruck, daß, besonders in den kleineren Städten und auf dem Lande, die Bevölkerung in einem zufriedenstellenden Wohlstande lebte, der sich von Jahr zu Jahr sichtlich hob. Auch war die Regierung bemüht, da wo es nottat, bessernd und helfend einzugreifen. Das ist ja auch in allen Kulturstaaten der Fall gewesen; namentlich war das in Italien und Spanien zu bemerken, wie sehr sich da in den letzten Jahren vor dem Kriege die Zustände gebessert hatten. Was ich hier Gutes von Deutschland sage, soll nicht nur von ihm allein gelten.

Und jetzt, ein Jahr, nachdem der Waffenstillstand geschlossen ist, wie sieht es da in Deutschland aus? Mit einem Worte: Verwahrlost! Man hat in den Kriegsjahren nicht die dauernd nötigen kleinen Arbeiten zur Instandhaltung der Bauten und Straßen in genügender Weise ausführen können und das machte sich bald überall fühlbar. Die Revolutionșzeit hat nun noch Schlimmeres dazu gebracht: Zerstörungen und Beschädigungen vieler öffentlicher Gebäude in den großen Städten, vor allem in Berlin. Die vielen Streiks, die zum Teil gerade dadurch verursachte Teuerung hindern, daß die Wiederherstellungsarbeiten alsbald und im nötigen Umfange ausgeführt werden, ebenso ist es aus demselben Grunde zur Zeit schwierig, die Reinhaltung der Straßen in der früheren Weise durchzuführen. In Berlin fällt dabei höchst abstoßend das Bekleben der Häuser, namentlich auch der öffentlichen Gebäude, mit Plakaten aller Art auf. Während der Vornahme der Wahlen geschah das geradezu in der unsinnigsten Weise. Und noch länger als ein halbes Jahr später fand man die zerfetzten 
Reste dieser Plakate überall. Kurzum, Berlin vor allem hatte ein unsauberes, beflecktes Kleid angezogen. Nur mit Trauer konnte man ansehen, was aus der früher so sauberen Stadt geworden war.

Auch in unserem Verkehrswesen war eine wesentliche Verschlechterung eingetreten. Zunächst eine große Erschwerung dadurch, da $B$ wegen Mangels an geschultem Personal, wegen der Kohlenknappheit und vor allem auch wegen der sich vielfach wiederholenden Streiks der bisherige Betrieb nicht aufrecht erhalten werden konnte. Briefe brauchten die doppelte, ja dreifache Zeit zur Beförderung im Inlande, nach dem Auslande eine noch mehrfache. Verspätungen der Bahnzüge oft um halbe, ja ganze Tage waren nicht Ausnahme, sondern Regel. Und da nun viel weniger Züge verkehrten, waren die laufenden sämtlich in einer kaum zu beschreibenden Weise überfüllt. Es verkehrte fast kein D-Zug, in dem nicht alle Gänge mit Reisenden und Paketen so besetzt waren, da $B$ man sich ka um darin bewegen konnte; in den einzelnen Abteilen fand man gar nicht selten die doppelte Zahl der Reisenden und darüber. Wenn das Reisen mit der Bahn überhaupt schon kein Vergnügen ist, so war es auf den vielbenutzten Strecken jetzt zur Qual geworden. Dazu kam, da B in manchen Abteilen der Wagen die Fenster gesprungen oder gänzlich zertrümmert waren; in Abteilen der ersten und zweiten Klasse fanden sich zerrissene und beschmutzte Polsterungen; die ganze früher so sorgfältig gewahrte Reinlichkeit ließ viel zu wünschen übrig. Da uns die Materialien und die erforderlichen Betriebskräfte fehlen, werden wir noch lange mit diesen Zuständen zu rechnen haben.

Ebensolche Stockungen und damit die Überfüllung der Wagen machten sich besonders auch in den großen Städten, vor allem in Berlin, geltend. Da waren es die Streiks des Personals der verschiedenen Verkehrsbetriebe selber: Stadtbahn, Untergrundbahn, Straßenbahn, dann die der Elektrizitätswerke und der Kohlenarbeiter, die bald den einen, bald den anderen Betrieb lahmlegten. War ein Betrieb gestört, so waren natürlich die anderen gleicher Art überfüllt in Anspruch genommen und wenn gar nur ein Verkehrsweg offen stand, so kamen Überfüllungen vor, die jeder Beschreibung spotten. Mehrere Male habe ich es unter solchen Umständen erlebt, da $B$ wir in einem Wagen der Untergrundbahn so dicht zusammengedrängt standen, da $B$ die Atembewegungen merklich erschwert waren. Ein 
anderesmal mußte ich sechs Bahnzüge vorüberfahren lassen, ehe ich endlich mit Mühe in dem folgenden Platz fand. Auch bediente man sich oft der Taktik, in einem Wagen der entgegengesetzten Richtung bis zum Endpunkte der Strecke zu fahren, um nun dort bei dessen Rückfahrt den Platz für die Fahrt, die man wünschte, sich verschaffen zu können.

Bei Behinderungen mehrerer Verkehrsarten kamen dann schnell die sogenannten ,wilden Wagen“, wie man sie nannte, auf, Gefährte aller Art, meist Markt- und Gütertransportwagen, die für hohe Preise sich dem Publikum zur Verfügung stellten. Meist verkehrten sie zwischen den einzelnen Bahnhöfen und waren fast stets gut besetzt. Man zahlte aber für die Strecken, die man mit der Straßenbahn oder Untergrundbahn für ro bis 20 Pfennige durchfahren konnte, 2 bis 3 Mark. Dabei ging's obne allerlei Streiterei, aber auch ohne den Humor, den der Berliner unter solchen Umständen immer noch zur Verfügung hat, nicht ab. So erregte es einmal große Heiterkeit, als ein solcher Marktwagen mit Reisenden, von denen ein Teil in der Mitte des Wagens aufrecht stand, von seinem Standplatze abfuhr und man auf der hinteren Wand in großen Buchstaben las: „Frischer Stangenspargel, I. Qualität.“

Nach und nach schwanden unsere schönen und bequemen Goldund Silbermünzen gänzlich aus dem Verkehr und wir sind zu Ende des Krieges völlig in die Papiergeldwirtschaft hineingekommen, ja noch tiefer gesunken, denn die einzelnen Städte waren genötigt, aus Mangel an Nickel- und Kupfermünzen Papierblättchen - anders kann man sie nicht nennen -, mit den Nennwerten von 50, 25 und Io Pfennigen auszugeben. Und wie schmutzig und zerrissen sahen schließlich die Scheine von kleineren Werten bis zu den 5 Markscheinen, die rasch durch viele Hände gingen, aus! Man scheute sich fast, sie in die Hand zu nehmen; sie waren, um ein berühmt oder berüchtigt gewordenes Wort zu gebrauchen, ein „Fetzen Papier“. Wer hätte das zu Anfang des Krieges für möglich gehalten, daß wir so weit herunter kommen würden!

Die große Teuerung, die sich auf alle Dinge erstreckte, hatte ibren Grund vornehmlich in den großen Mengen von Papiergeld, die alle kriegführenden Staaten herzustellen und auszugeben gezwungen waren. Deutschland und Österreich-Ungarn, als Unterlegene, wurden 
am schwersten davon betroffen. Um ein Bild davon zu geben, seien einige Preise genannt, die man im Winter r920 in Berlin zahlen mußte. Für ein Pfund Butter 30 Mark, für ein Ei 2 Mark bis 2,50 Mark, für eine I5pfündige Gans 200 Mark, für ein Paar Lederstiefel 300 Mark, für eineri wollenen Männeranzug rooo Mark. Für eine Flasche Rhein-oder Moselwein $\mathrm{I}_{5}-20-30$ Mark, für eine Flasche französischen Champagner $\mathrm{I} 8 \mathrm{0}$ bis 200 Mark. Aber auch die notwendigsten Lebensmittel mußten mit verhältnismäßig gleich hohen Preisen bezahlt werden, den IO- bis 20 -fachen des früheren.

Eine der schlimmsten Folgen des Krieges und vor allem der Revolution war die bald nach dem Sturz der bisherigen Regierung eintretende öffentliche Unsicherheit. Die letzten Kriegsjahre ließen schon die Anfänge erkennen, da eine größere Anzahl von Polizeimannschaften zum Kriegsdienste eingezogen wurde und kein genügender Ersatz zu beschaffen war. Ungleich größer aber stellte sie sich alsbald nach der Revolution ein. Kein Wunder, denn, wie bemerkt, war eine der ersten Sorgen der aufständischen Massen überall die Öffnung der Gefängnisse gewesen, aus denen dann auch die schwersten Verbrecher entkamen. Und es ist ja klar, daß, wenn die bisherige Autorität gestürzt wird, in allen bestehenden Ordnungen ein Nachla $B$ eintritt, bis die neue Obrigkeit sich völlig gefestigt hat. $\mathrm{Da} B$ auch die Entbehrungen und Teuerungen, die der Krieg uns gebracht hat, dazu beigetragen haben, Raub und Diebstahl zu fördern, soll nicht in Abrede gestellt werden. Das machte sich besonders bemerklich durch das häufige Verschwinden von Sendungen im Bahnund Postverkehr, vor allem solcher, in denen Lebensmittel oder Bekleidungsstoffe vermutet wurden. Schwerer wurden natürlich die vielen Einbrüche und Raubüberfälle empfunden; ganze Banden bildeten sich für diese Dinge. Auch die Zahl der Morde nahm in erschreckender Weise zu.

Über allen diesen beklagenswerten Übelständen schwebte das allgemein empfundene Gefühl, daß die neugebildete Regierung keinen Bestand haben werde. So lebte man in Deutschland unter dem Druck der harten Waffenstillstands- und Friedensbedingungen von außen und in dem Empfinden der Unordnung, Unbestimmtheit und Unsicherheit im Innern wahrlich in einem traurigen Zustande, der uns Älteren, die wir bessere Zustände gekannt hatten, auf die Dauer das 
Leben nicht mehr lebenswert erscheinen lassen konnte. $\mathrm{Zu}$ einem rein frohen, freien Aufblick konnte es selbst bei sonst recht freudigen Familienerlebnissen und im Freundeskreise nicht mehr kommen Wie ein trüber Schleier hing über dem allem das nicht weichende Bewußtsein unserer traurigen Gesamtlage.

Am schwersten aber, trotz der harten Friedensbedingungen und der durch die Teuerung verursachten Entbehrungsnöte noch Mut und Freudigkeit am Leben aufrecht zu erhalten, wurde es dadurch, daß man die Deutschen nicht als ein ,einig Volk von Brüdern“ aus dem Kriege hervorgehen sah. Meist pflegt doch ein gemeinsam zu tragendes Unglück die Menschen einander näher zu bringen; aber nichts von dem war in Deutschland zu bemerken. Und das ist mir als das Allertraurigste erschienen! Das alte Parteigezänk setzte sich in unserer neuen Nationalversammlung fort, die religiösen Gegensätze zeigten sich alsbald wieder wie bisher; der Partikularismus der einzelnen deutschen Staaten regte sich in unverminderter Weise nach wie vor. Da zeigte es sich klar, daß es zu einem starken deutschen Nationalbewußtsein, dessen sich unsere Gegner, die Engländer, Franzosen, Italiener und die Polen, letztere ungeachtet ihrer mehr als hundertjährigen Unterdrückung, erfreuen, noch nicht gekommen war, selbst nach der Errichtung des neuen deutschen Kaiserreiches. England, Frankreich und jüngst, vor den Augen von uns Älteren, Italien, sind auch, wie wir, aus früher selbständig bestehenden Einzelstaaten zusammengeschweißt worden und damit hat sich bei ihren Bewohnern das starke einheitliche Nationalgefühl entwickelt. Der Franzose ist in erster Linie Franzose und erst in zweiter Normanne, Bretagner, Provençale oder Gascogner und so bei den genannten Völkern überall. Bei uns ist es umgekehrt: da kommt der Bayer, der Preuße, der Sachse zuerst und dann der Deutsche.

Es wäre jetzt meines Erachtens wohl der Mühe wert, den schon gemachten Vorschlägen näher zu treten und dem Deutschen Reiche eine Organisation zu geben, wie sie die Vereinigten Staaten von Nordamerika besitzen. Demnach müßten die Staaten Preußen und Bayern als die ungebührlich großen verschwinden, ebenso die kleinsten, die mit anderen zusammengelegt würden. Preußen und Bayern müßten in einzelne Teile, die man mit dem guten alten Namen Gaue bezeichnen könnte, unter einem „Gaugrafen“ zerlegt werden, 
etwa einen Preußengau (Ostpreußen), Pommerngau, Westfalengau, Rheingau, Hannovergau, zu dem Braunschweig gelegt werden könnte, usw. Bayern wäre in 3 bis 4 Gaue zu zerlegen, Württemberg, Sachsen und Baden bildeten je einen Gau, ebenso Hessen mit Nassau. Der Thüringergau umfaßte die jetzige preußische Provinz Sachsen nebst einem Teile der kleinen thüringischen Fürstentümer, andere Gaue bildeten die beiden Mecklenburg zusammen und Schleswig-Holstein. Die einzelnen Gaue erhielten eine Selbständigkeit, etwa nach dem Muster der Einzelstaaten der Nordamerikanischen Union und wären einer starken Zentralgewalt, sei es mit monarchischer oder republikanischer Spitze, unterstellt, deren Sitz eine in der Mitte Deutschlands gelegene Stadt wäre, die mit ihrer näheren Umgebung eine ähnliche. Selbständigkeit wie Washington erhielte.

Man kann einwenden, da $B$ damit dem historisch Gewordenen eine arge Vergewaltigung geschähe. Das trifft aber doch nicht völlig $\mathrm{zu}$ und die Einigkeit Deutschlands würde am besten hergestellt, wenn die einzelnen, geschichtlich seit langem bestehenden deutschen Stämme jeder die größtmöglichste Selbständigkeit bekämen. Preußen ist erst viel später, teils durch Erbschaften, teils durch Eroberungen, teils durch Zuerteilung bei Verträgen aus dem brandenburgischen Kurfürstentum zu dem starken und bedeutenden Staate geworden, der ihm gestattete, die Vormacht im neuen deutschen Reiche zu bilden. Bleibt es in Deutschland bestehen, so wird bei den anderen deutschen Stämmen immer das Gefühl sich erhalten, Deutschland werde nicht von einer deutschen Zentralgewalt regiert, sondern von einer preuBischen. Will man ein starkes, einiges Deutschland haben, so muB, meiner Meinung nach, Preußen und auch Bayern ein Opfer bringen.

Man kann bis zu einem gewissen Grade den Vorgang der Einigung Italiens in Parallele bringen mit der Einigung Deutschlands, wie sie sich r87o vollzogen hat. Was Preußen damals für Deutschland war, war das Königreich Sardinien für Italien, was die Hohenzollern für Deutschland, das die Savoyer für Italien. Aber da war ein Unterschied: Preußen mußte vor dem südlichen Teile Deutschlands Halt machen, während Sardinien sich auch Süditalien mit der Waffe einverleibte und selbst vor Rom nicht stehen blieb. So ward Italien in der Tat ein einiges Reich und Volk, während Deutschland es nur scheinbar ward. Gewiß, schon I870 und als es im Jahre I9I4 zum Kriege kam, 
und die ganzen Kriegsjahre hindurch haben alle deutschen Staaten treu zu Preußen und später zu Kaiser und Reich gestander bis zum letzten Augenblicke; mir wenigstens ist von Sonderbestrebungen nichts bekannt geworden. Jetzt aber, nach dem Zusammenbruche der Kaiserlichen Reichsgewalt, machen sich die Sondergelüste wieder mehr geltend, zwar nicht für eine Lostrennung von Deutschland, wenigstens wird diese bis jetzt stets geleugnet, wohl aber von Preußen. Ob wir unter dem neuen Stande der Dinge, unter der Republik, den festen Zusammenhalt werden bewahren können, scheint mir zweifelhaft. Die preußische Eigenart, die Großes erreicht und geschaffen hat, hatte nur feste Wurzeln in den ostelbischen Teilen Preußens, im Westen ist sie nie völlig sympathisch gewesen und noch weniger in Südwestdeutschland. Preußen verstand zu erobern, aber nicht zu gewinnen! Mir scheint unter den gegenwärtigen Verhältnissen der bekanntlich schon von anderer Seite vorgeschlagene Weg, der der Schaffung der Vereinigten Staten Deutschlands, wie ich ihn angedeutet habe, der zum ersehnten Ziele führende. Es wird jedem Preußen- und Bayernherzen schwer werden, auf diesen Weg zu treten und Opfer zu bringen; aber es gilt einer großen, einer heiligen Sache, der Gewinnung eines einigen und starken deutschen Vaterlandes! Es gibt nur zwei Wege, diese feste Einheit zu erzielen: entweder den, welchen England, Frankreich und Italien gegangen sind, da $B$ einer der Teilstaaten, als der stärkere, die anderen unterwarf und sich einverleibte, oder da $B$, nach dem Muster der Vereinigten Staaten Nordamerikas, jede Vormacht ausgeschlossen wird und die einzelnen Teilstaaten jeder dem anderen möglichst gleichgestellt werden. Soweit ich die deutsche Geschichte und den deutschen Volkscharakter zu beurteilen imstande bin, scheint mir der zweite Weg der richtigere und aussichtsvollere. Gern werden die den seit altersher bestandenen deutschen Stämmen angepaßten Gaue ihre Eigenart bewahrt sehen und in dem Gefühl, da $B$ dieses nur bei festem Zusammenschluß unter einer Zentralgewalt in einem völlig einigen Deutschen Reiche möglich ist, vor allem sich als Deutsche fühlen lernen.

Was hielt nun mich und hält mich noch bei allen Erniedrigungen, Entbehrungen und Unbestimmtheiten unserer Gesamtlage aufrecht?

Das Vertrauen auf eine bessere Zukunft, die dem sichtlich noch nicht völlig politisch entwickelten deutschen Volke noch bevorsteht 
Fortschritte in Wissenschaft und Technik während meines Lebens. 393

der Halt, den ich an meinen Kindern und Enkeln und an den wenigen mir aus der Jugendzeit übrig gebliebenen lieben Freunden und Verwandten fand und finde, vor allem aber die Arbeit!

Ich hielt noch nach meinem Übertritt in den Ruhestand in jedem Semester eine Vorlesung abwechselnd über Anatomie des Nervensystems und über Entwicklungsgeschichte im Universitätsgebäude für Hörer aller Fakultäten und erfreute mich dabei einer ansehnlichen Hörerzahl; dazu verwaltete ich bis zum I. September I9I9 mein Amt als ständiger Sekretar der Akademie und führte den Vorsitz bei einigen Vereinen, war Mitherausgeber des Archivs für Anatomie und Physiologie und des Archivs für mikroskopische Anatomie und Entwicklungsgeschichte, sowie des seit $\mathrm{I} 842$ bestehenden, von Canstatt begründeten Jahresberichtes für die gesamten medizinischen Wissenschaften $\left({ }^{19}\right)$. Vor allem aber beschäftigen mich noch, während ich diese Erinnerungen niederschreibe, zwei wissenschaftliche Arbeiten, die zur Veröffentlichung bestimmt sind. Möge es mir vergönnt sein, sie noch im Druck fertig zu sehen, bevor ich meine Augen für immer schließe.

Arbeitslust und Arbeitskunst

Sind des Himmels höchste Gunst!

XV. Ka pit el.

Fortschritte in den Wissenschaften und in der Technik und deren Verwertung für unsere Lebensführung seit meiner Geburt. Schlußwort.

Hat man, wie ich, ein langes Leben hinter sich, so gewahrt man rückschauend, daß sich vieles im Laufe der Zeiten geändert hat. Unser Wissen hat sich, seit ich das Licht der Welt erblickte und am Lernen und Mitarbeiten teilnahm, beträchtlich vermehrt, ebenso unser technisches Können; beides hat auf unsere öffentliche und private Lebensführung großen Einfluß ausgeübt, vor allem auf unsere Verkehrseinrichtungen, ebenso aber auch auf unser Hausleben. Auch im Kunstleben und dessen Betätigung zeigen sich mannigfache Änderungen. Gewöhnlich pflegt man alle diese Wandlungen als „,Fort- 
schritte" zu bezeichnen, und ich habe diesen Namen auch in der Kapitelüberschrift gewählt. Verbindet man aber, wie meistens, mit dem Worte „Fortschritt“ den Begriff einer Wendung zum Besseren, so trifft das nicht immer zu; die Änderungen führen nicht selten auch zum Schlechteren, sind ,Rückschritte“.

Getreu meinem Plane, in diesen Lebenserinnerungen das Einst und Jetzt, wie es die Spanne eines längeren Menschenlebens umfaßt, miteinander $\mathrm{zu}$ vergleichen, soll diesen Änderungen und Wandlungen noch ein „Schlußkapitel“ gewidmet sein. Für die Fortschritte in unserem Wissen beschränke ich mich auf die Naturwissenschaften und beginne mit der Biologie.

Erst nach meiner Geburt wurde die Tatsache festgestellt, daß die gesamte Tier- und Pflanzenwelt einen einzigen gemeinsamen Baustein hat, die organische Zelle; zweifellos eine der bedeutsamsten Feststellungen, die jemals gemacht worden sind. Ferner wurde das Wesen dieses Elementarorganismus genauer ergründet und sein Eigenleben erkannt. Es wurde ermittelt, daß die schon seit längerer Zeit bekannten Keime, welche die Grundlage aller höheren Tier- und Pflanzenformen bilden, die männlichen Keime, die Spermien und die weiblichen, die Eier, in ihren wesentlichen Bestandteilen einfache Zellen sind.

Weiter wurde erwiesen, daß dieselben Zellen, welche die normalen Körperteile bilden, auch bei der Bildung von krankhaften Produkten, wie bei den krankhaften Neubildungen (Geschwülsten) und bei den Entzündungen und Eiterungen wesentlich beteiligt sind.

Hatte, drittens, schon vor meiner Zeit die Entwicklungsgeschichte der Organismen durch die Arbeiten von Döllinger, Pa nder und Karl Ernst v. Baer einen glänzenden Anlauf genommen, so gelangte sie doch erst in der Zeit meines Lebens zu der ungeahnten Blüte, in der sie gegenwärtig steht. Insbesondere ist in ihr jetzt ein ganz neuer Zweig auf wissenschaftlicher Grundlage entwickelt, die Vererbungslehre, wobei ich an die Aufstellung des Begriffes der Geschlechtszellen, an die genauere Erkenntnis des Befruchtungsvorganges mit wesentlicher Beteiligung der männlichen und weiblichen Zellkerne durch O. Hertwig, an die Entdeckung der Kernteilungsvorgänge und der bei Vererbungen obwaltenden Regeln, Mendelsche Regeln, erinnere ( ${ }^{\mathbf{2}}$ ). 
Im Bereiche der Beschreibenden Anatomie sind insbesondere im Gebiete des Nervensystems ganz außerordentliche Fortschritte zu verzeichnen, sowohl in der Erkenntnis des feineren Baues wie in der der gröberen Formbestandteile, sowie besonders in der Auffindung der Leitungsbahnen und der Lokalisation physiologischer Vorgänge im Gehirn. Zur Zeit meines Eintrittes ins Leben war, um nur eins zu erwähnen, von den Hirnwindungen und den Lokalisationen physiologischer Funktionen im Gehirn fast nichts bekannt. Hier begegnen sich nun große anatomische und physiologische Fortschritte. Für letztere muß auch an die großartigen Leistungen der in Rede stehenden Zeit auf dem Gebiete der tierischen Elektrizität erinnert werden. Ferner fällt in meine Lebenszeit die Entdeckung der anatonischen Endigungsformen der Muskelnerven und der Sinnesnerven, von denen vorher nur die des Sehnerven in der Netzhaut des Auges bekannt waren.

Hervorgehoben zu werden verdient nicht minder die Ausarbeitung einer echt wissenschaftlichen Forschungsmethode auf dem Gebiete der Vergleichenden Anatomie durch Karl Gegenbaur, welche erst dadurch festere Grundlagen gewann, ferner der befruchtende EinfluB, welchen die Deszendenzlehre und deren Ausbau durch Ernst Haeckel auf die gesamte Biologie ausübte. Man muß die Zeiten, in denen Darwin und Haeckel mit ihren Theorien auftraten, erlebt haben, um zu verstehen, wie diese Lehren belebend und fördernd wirkten, wenn auch vieles, selbst Grundsätzliches, der weiteren Erkenntnis nicht hat standhalten können. Hieran schließe ich als einen wesentlichen Faktor neuerer Forschung die methodische Einführung physikalischer Betrachtung mit experimenteller Arbeitsweise in die Gebiete der Morphologie und Entwicklungsgeschichte, von W. Roux als „Entwicklungsmechanik" bezeichnet.

Ein gänzlich neues Gebiet eröffnete sich im Rahmen der Anatomie und Physiologie mit der Entdeckung der Funktionen der Drüsen ohne Ausführungsgang, der früher sogenannten Blutgefäßdrüsen, jetzt als „,endokrine Drüsen" bezeichnet. Man erkannte, daß diese ihre Arbeitsprodukte, ihre Sekrete, neuerdings „Reizstoffe“, „Hormone“ genannt, direkt in die Blut- und Lymphbahnen abführen und so zu einer unmittelbaren Wirkung auf den Organismus gelangen, die selbst für ganz kleine Organe dieser Art eine sehr eingreifende sein kann. 
396 Fortschritte in Wissenschaft und Technik während meines Lebens.

Mehrere hierher gehörende Organe wurden neu entdeckt, die Funktion anderer schon bekannter erst festgestellt und gezeigt, daß auch Organe, deren Bedeutung man vollständig bekannt glaubte, wie die Geschlechtsdrüsen, auch noch besondere, bisher unbekannte Hormone liefern.

Nicht minder große Fortschritte sind im Gebiete der Physiologie der Sinnesorgane gemacht worden; ich erinnere nur an die unschätzbaren Arbeiten von Helmholtz über das Sehorgan und das Gehörorgan.

Fast gänzlich neu, kann man wohl sagen, entstand in meiner Lebenszeit das jetzt so weit bebaute Gebiet der physiologischen Chemie. Ich erwähne auch die Entdeckung der Gefäßnerven, die Erfindung des Kymographions und die der Spiegeluntersuchungen: Augenspiegel, Nasenspiegel, Kehlkopfspiegel u. a., welche sowohl für die Physiologie, wie für die Pathologie von größter Bedeutung geworden sind. Dazu kommen für die Untersuchung des Stoffwechsels die Respirationsapparate.

Andere technische Maßnahmen sind der beschreibenden und topographischen Anatomie zugute gekommen: das Korrosionsverfahren, das Gefrierschnittverfahren, die verschiedenen Konservierungsmethoden, die Aufbewahrung von Körperteilen in ihren natürlichen Farben, die Herstellung durchsichtiger Präparate, das Verfahren, Skelette in ihren natürlichen Formen aufzustellen. Ferner für die mikroskopische Technik die bedeutenden Verbesserungen der Mikroskope durch Einführung der Beleuchtungslinsen, der Immersionssysteme, der Dunkelfeldbeleuchtung, der Polarisationsvorrichtungen u. a., dann die Färbungsverfahren und die Metallimprägnationen, von denen bei meinem Eintritt in das anatomische Forschungsleben noch nichts bekannt war.

Die Anthropologie, namentlich in ihrem prähistorischen Zweige, wurde neu belebt durch die Auffindung menschlicher Körperreste, Skeletteile und Zähne, sowie Manufakte, vor allem der Steinwerkzeuge.

Auf dem Gebiete der Pathologie und der praktischen Medizin möchte ich nur kurz an die Begründung der Bakteriologie, an die Einführung der Antisepsis, der Asepsis und der Narkose er- 
Fortschritte in Wissenschaft und Technik während meines Lebens. 397

innern. Es genügt, diese Namen zu nennen, um zu zeigen, welche grundlegenden Umgestaltungen in der medizinischen Wissenschaft und Praxis während der Zeit meines Lebens vor sich gegangen sind. Von anderen Erwerben, die den biologischen Wissenschaften sowohl wie der praktischen Medizin zugute gekommen sind, wird noch die Rede sein.

Ich habe bei den anatomischen, entwicklungsgeschichtlichen, physiologischen und pathologischen Disziplinen länger verweilt, weil sie in den Bereich meiner Tätigkeit fallen. Alles, was ich da angeführt habe, bestand nicht in unserem Wissen und Können, als ich zur Welt kam; das meiste ist erworben in der Zeit, als ich bereits das Bewußtsein von der Bedeutung des neu Gewonnenen hatte und hat mir vielfache Anregung zu eigener Tätigkeit gegeben. Glücklich ist der zu preisen, der auf seinem Felde so viele Mitarbeiter findet, das gibt ein frisches, frohes Leben und Schaffen!

Ganz möchte ich aber auch die anderen Naturwissenschaften nicht übergehen, auf deren Gebiet vielleicht noch durchschlagendere Fortschritte von allgemeiner Bedeutung zu verzeichnen sind. Ich meine, daB hier wohl der Ph ysik die Palme gebührt: Der Ausbau der At omenlehre, die Aufstellung der Begriffe Elektron und Jon, überhaupt die Ausgestaltung der Lehre vom Elektromagnetismus, vom Licht und der Wärme, die Spektralanalyse, die Entdeckung der Röntgenstrahlen, die Quantentheorie Max Plancks und die Relativitätstheorie Albert Einsteins zeigen den großartigen Fortschritt, den die Physik in der letzten Zeit in Theorie und Praxis gemacht hat. Aber auch die Chemie ist nicht zurückgeblieben; ich erwähne nur die Herstellung so mancher Farbstoffe, vor allem des künstlichen Indigos, die Entwicklung der Chemie der Eiweißkörper, der Explosivstoffe, vor allem die Herstellung des Nitroglyzerins und der mit diesem bereiteten verschiedenen Dynamitformen. Die Bedeutung der Explosivstoffe ist kaum hoch genug einzuschätzen, wie schon das bekannte, volkstümlich gewordene Sprichwort von der Erfindung des „Pulvers“ zeigt. Sie sind transportable Kraftquellen, die entweder gewaltige Arbeit in einem Augenblicke leisten, die großen Nutzen bringt, wenn die dabei unvermeidlichen Zerstörungen unschädlich bleiben oder gar erzielt werden sollen, oder die, wenn es gelingt ihre Kräfte langsam zu entfesseln, große Arbeit ohne Zer- 
störung leisten können. Ich erwähne ferner die Entdeckung einer ganzen Reihe neuer chemischer Elemente, unter denen das Radium einen für die Chemie wie für die Physik gleich wertvollen Körper darstellt, dessen Bedeutung in theoretischer wie praktischer Beziehung kaum überschätzt werden kann. $\mathrm{Zu}$ beiden Gebieten, dem der Wissenschaft wie der Technik, gehört die Verflüssigung der atmosphärischen Luft und der meisten Gase.

So könnte ich auch aus den übrigen Naturwissenschaften, der Astronomie, der Geographie, der Geologie und Geognosie, der Zoologie und Botanik noch vieles anführen: An Stelle der wenigen bekannten Planeten, mit denen ich auf dem Gymnasium Bekanntschaft machte, sind jetzt mehrere hundert getreten, durch die Spektralanalyse ist uns vieles von der chemischen Konstitution der Himmelskörper und von ihrer Bewegung bekannt geworden; ein wichtiges Ergebnis ist die Erkenntnis der periodischen Schwankungen in der Lage der Erdachse und vor allem die Feststellung vom Vorkommen der Eiszeiten. Nicht vergessen sei, daß in dieser Zeit wohl die bisher unbekannten Flecke auf unserem Planeten, der Mutter Erde, bis auf wenige Stellen verschwunden sind und daß man sowohl den Nordpol wie den Südpol erreicht hat.

Die großen wissenschaftlichen Fortschritte haben nun auch hochbedeutende technische Fortschritte im Gefolge gehabt; ich nenne dic nicht hoch genug $\mathrm{zu}$ bewertende Photographie, die Kinematographie, den Phonographen, das Telephon und den Seismographen. Dann die für den landwirtschaftlichen Großbetrieb so wichtigen künstlichen Düngestoffe und Maschinen, die Säemaschine, die Mähmaschine, die Dreschmaschine und den Dampfpflug. Aber nicht nur für den Friedensdienst ist die Ernte der wissenschaftlichen Forschung eingetreten, sondern in hervorragender Weise auch für den Kriegsdienst. Vom Zündnadelgewehr durch das Chassepot gings zum Maschinengewehr und zur Handgranate; die gezogene Kanone brachte es zu Riesengeschützen, die auf viele Kilometerfernen noch mit genügender Sicherheit ihre Granaten feuerten. An die Stelle des Linienschiffes kam der Dreadnought und der Überdreadnought, und als ein Neues, eine der glänzendsten Leistungen der Technik, das Unterseeboot! Und jetzt ist gar das Sehnen der Menschen seit des Ikaros Zeiten erfüllt worden: wir fliegen durch das Luftmeer! 
Kurz berühre ich hier nur die Wandlungen in unseren Heizungsanlagen, bei denen die viel angenehmere Holzheizung durch die Steinkohlenheizung ersetzt ist. Die Wasser-, Gas- und Elektrizitätsleitungen sowie die Zentralheizungen bringen viel Vorteil; wenn sie jedoch wie jetzt öfters versagen, ist der Nachteil um so fühlbarer; doch ist unbedingt das Plus auf der Seite des Vorteils, vor allem bei den Wasserleitungen. Schließlich soll noch zweier zwar kleiner, aber ungemein wichtiger maschineller Hauseinrichtungen gedacht werden: der Schreibmaschine und der Nähmaschine.

Zwei Dinge möchte ich hier noch anführen, die für den Schutz der großen Städte und für ihren Handelsverkehr wichtig sind, es sind als Schutzmittel die Feuerwehr und für den Handel die großen Warenhäuser. Während die Feuerwehren sich als höchst segensreiche Einrichtungen bewährt haben, kann man in bezug auf die Warenpaläste noch im $Z$ weifel sein. Ich verzichte aber darauf, hier das Für und Wider zu erörtern.

An zwei besonders geeigneten Beispielen sei nun noch gezeigt, wie sich im Laufe von 80 Jahren gewaltige Änderungen in einer einzigen Einrichtung für den Bedarf des privaten und öffentlichen Lebens vollzogen haben; ich wähle das Beleuchtungs- und Verkehrswesen. Als ich ein Knabe war, hatte man überall, außer Kerzen, nur Lampen von der bekannten antiken Form, die auf einem stabförmigen, unten tellerförmig verbreiterten $F u ß e$ oben den Ölbehälter mit dem runden, etwa kleinfingerdicken Dochte trugen. Der Docht ragte aus dem einen schnabelförmig zugespitzten Ende des Ölbehälters, ohne Bedeckung durch einen Glaszylinder, frei hervor. Damit erträgliches Licht bestehen blieb, mußte er öfters von den sich ansetzenden sogenannten „,Schnuppen“, ,Schuppen“ oder ,Useln“ befreit werden. Dies war die Arbeitslampe. Die Kerzen dienten, wie auch noch heute, in den Kirchen und bei Festlichkeiten. Dann kamen die sogenannten Ku ppellampen auf, wo der platte breite oder röhrenförmig gestaltete Docht zunächst mit einem Glaszylinder bedeckt war, der die Flamme vor dem Einfluß von Luftschwankungen schützte und einen Luftzug von unten her wie in einem Schornstein begünstigte, so da $B$ mit gesteigerter Verbrennung ein helleres Licht erzeugt wurde. Der Zylinder war dann wieder mit einer Milchglasglocke bedeckt, aus deren oberer Öffnung er hinausragte. Das war ein großer Fortschritt; 
Zylinder und Kuppelglocke sind bei der heutigen Gasbeleuchtung noch geblieben. Bald wurden diese Kuppellampen als Moderateurlampen verbessert; bei diesen wurde das Öl durch ein Pumpwerk dem Docht zugeführt, so daß ein größerer, mehr Öl gebrauchender Docht verwendet werden konnte. Dann kamen die Petroleumlampen, dann die Gasbeleuchtung, die Spiritusglühlampen, die Nernstlampen und endlich die elektrische Beleuchtung! Eine scheinbar kleine, aber höchst wichtige Erfindung darf hier nicht'vergessen werden: die Streichzündhölzer. Wer, wie ich, noch in Zeiten gelebt hat, wo es keine gab, der weiß sie zu schätzen.

Was die Verkehrsanstalten anlangt, so waren wir anfangs auf dem Lande in Westfalen auf die natürlichen beiden Beine und auf Wagen und Pferde angewiesen; Poststraßen gab es nur wenige. Auf den Flüssen verkehrten aber schon Dampfschiffe und eine Eisenbahn mit Lokomotivenbetrieb für Güter- und Personenbeförderung bestand seit 7. Dezember 1835, also kurz vor meiner Geburt, in Deutschland zwischen Nürnberg und Fürth. Bekannt ist, da $B$ man sich in der Berliner Bürgerschaft zuerst ablehnend verhielt, als der König Friedrich Wilhelm III. den Bau einer Eisenbahn von Berlin nach Potsdam angeordnet hatte. Ich erwähnte vorhin, da $B$ ich erst als Vierzehnjähriger die erste Lokomotive in Fahrt zu sehen bekam und als Sechszehnjähriger meine erste Eisenbahnfahrt mitmachte. Jetzt sind wir im Begriffe, zur Luftschiffahrt überzugehen. An anderen Fuhrwerken haben sich das Aut omobil und die Ober-und Unterstra Benbahn eingestellt. In Berlin fand ich, als ich I86I hier einrückte, nur die Droschke vor, die der längst verschwundenen Droschke zweíter Klasse glich, und sehr langsam und bedächtig fuhr. Als ich einige Jahre später wieder eintraf, fand ich die Droschke erster Klasse, die mir sehr elegant vorkam, schneller, aber auch teurer fuhr. Sie ist jetzt die einzige Droschkenform, aber auch degeneriert, denn ihr Pferdematerial ist zur Zeit jämmerlich zu nennen. Auch die Oberstraßenbahn fuhr zunächst mit Pferden. Dann wurde der elektrische Betrieb eingerichtet und bald darauf die Unterstraßenbahn, gewöhnlich als Untergrundbahn bezeichnet, die mir als das beste Verkehrsmittel für den Stadtverkehr erscheint. Die Oberstraßenbahn wird gewöhnlich jetzt einfach als die "Elektrische" bezeichnet. Dazu kommen in den größeren Städten noch die „Stadtbahnen“, d. h. gewöhnliche Eisen- 
Fortschritte in Wissenschaft und Technik während meines Lebens. 401

bahnen, die den Personenverkehr im Inneren der Stadt und zu den Vororten besorgen und in kürzeren Zeitabschnitten fahren. Die von Pferden gezogenen Wagen, die gleichzeitig eine größere Anzahl von Personen auf dem gewöhnlichen Straßenpflaster befördern können, die sogenannten „Omnibus'“', sind noch nicht völlig verschwunden, doch fängt man an, sie mit Motoren zu betreiben. Überhaupt kann man sagen, die Zeiten, in die wir jetzt eingetreten sind, kennzeichnen sich als das Zeitalter der Elektrizität in der Wissenschaft wie in der Technik.

Der Briefverkehr kannte in der Zeit meiner Jugend noch keine Marken, man mußte jeden Brief auf die Post bringen und dort die Gebühr entrichten. Mit den Briefmarken kamen auch die Briefkästen auf. Als Telegraphen hatte man die Zeigertelegraphen, die aber ziemlich gut arbeiteten. Dann kam die elektrische Telegraphie, durch Gau B und Weber begründet, und man legte die Kabel durch die Ozeane. Weiterhin entwickelte sich die Telephonie. Diese habe ich zuerst in Amerika praktisch erlernt. Bei meinem ersten Besuche dort (IgOr) fand ich in meinem Gasthofszimmer keine Klingelschnur mehr vor, auch keinen Druckknopf für eine elektrische Zeichengabe, wohl aber an der Wand ein mir unbekanntes kastenförmiges Instrument. Ich ging, um mir etwas zu bestellen, auf den Flur, fand aber dort Niemanden vor. Mit einem Male ertönte aus dem mir unbekannten Kasten eine Glocke; ich sah hin, ging heran, mir ahnte, da $B$ das ein Telephon sei, war mir aber nicht klar, was ich nun mit dem Dinge anfangen sollte. Die Glocke lärmte weiter. Endlich beruhigte sie sich. Nach einiger Zeit kam ein Kellner, der mir sagte, es habe mich Jemand ans Telephon gerufen. Ich fragte, wo das sei. Der Kellner zeigte auf den' Kasten an der Wand und sagte, als er meine Unentschlossenheit bemerkte, es sei unten eine Telephonistin, die das besorgen könne. Ich ging hinab, fand das Fräulein, die mir das dort befindliche Telephor zeigte und sagte, ich möge nur den Betreffenden anrufen. Ich fragte, wie man das mache? Da lachte sie mich fröhlich aus; es war ihr noch Niemand vorgekommen, der nicht hätte telephonieren können. Das primitive Telephon, welches ich seiner Zeit in Straßburg gesehen hatte, hatte ich praktisch nicht erprobt, auch sonst bisher keine Gelegenheit zum Fernsprechen gefunden. Das Fräulein unterrichtete mich nun und so habe ich das Telephonieren in Amerika gelernt.

v. Waldeyer-Fartz, Lebenserinnerangen. 
Und nuun! Jetzt geht nach Marcon is glänzender Entdeckung der Ruf ohne festen Leitweg durch die Lüfte, die drahtlose Telegraphie, der Funkspruch! Wohin wird das führen? Führt es uns einmal zu den Gestirnen, die unserer Erde gleichen, zu den Planeten? Ich halte das nicht für ausgeschlossen. Zweimal habe ich schon mit Vorhersagen Recht behalten, als ich in Straßburg, Kundt gegenüber, das Telephon, und de Bary gegenüber, die Chromosomenentdeckung als wichtige Dinge bezeichnete. Sollte ich auch zum dritten Male richtig vorausgesehen haben?

Bevor ich die Schlußworte zu meinem Buche niederschreibe, gedenke ich noch dreier mir befreundeter Familien, die meine Jugendzeit mit meinem Lebensabend verknüpfen. Zwei entstammen dem Freundeskreise meiner Frau. Als junger Bräutigam wurde ich in Königsberg mit dem damaligen Oberstabsarzte, späteren Generalarzte Dr. H. Schickert und mit dem Leutnant, späteren Oberstleutnant Wit tcke bekannt, deren Frauen die besten Jugendfreundinnen meiner Braut waren. Ein günstiges Geschick fügte es, da $B$ beide Paare gleichzeitig mit uns in die neu gewonnenen Reichslande kamen und so die eingeleitete Bekanntschaft zur dauernden Familienfreundschaft sich entwickelte.

Jetzt bin ich freilich der einzige Überlebende der drei Paare; aber die Nachkommen haben das Band festgehalten: in Frankfurt a. M. die Familie des Generaloberarztes Dr. Ot to Schickert und in Erfurt die Familie des jüngst verstorbenen Generalleutnants Brosius, dessen Witwe die Tochter des Oberstleutnants Wittcke ist. In beiden Familien bin ich durch Enkelpatenschaft vertreten und in steter treuer Verbindung geblieben.

Das dritte freundschaftliche Verhältnis, welches meine jüng'eren Tage mit den älteren verknüpft, entwick lte sich durch Übernahme der Herausgabe des Archivs für mikroskopische Anatomie nach dem Tode Max Schultzes. Aus den geschäftlichen Beziehungen wurden bald echt freundschaftliche zu dem Verleger des Archivs, Friedrich Cohen senior. Es war mir jedesmal eine Herzensfreude, mit dem tüchtigen und trefflichen Manne zusammen zu sein, vor allem im Kreise seiner zahlreichen Familie, in der sich der lebhafte, stets schlagfertige Gatte und Hausvater und die stillwirkende, von ihm und ihren Kindern verehrte Hausfrau und Mutter so harmonisch 
ergänzten. Das Band, welches mich mit dem früh Geschiedenen einte, ist geblieben; treuen Dank dem Sohne, da $B$ er es mir ermöglichte, diese Erinnerungen meinem Freundes- und Bekanntenkreise vorzulegen.

Mit Betrachtungen, wie die im Vorstehenden gegebenen über die gewaltigen Fortschritte, welche Menschengeist und Menschenflei $B$ in der Spanne eines Menschenlebens errungen haben, beschäftige ich mich am Ende meiner Lebenserinnerungen, nicht mit dem Schweren und Betrübenden des vorletzten Kapitels. Mein Schlußkapitel soll Mut und Hoffnung wecken, da $B$ Deutschlands Söhne, die an erster Stelle mitgewirkt haben, das vorhin als wirklichen Fortschritt Dargelegte $\mathrm{zu}$ erreichen, auch weiterhin fortwirken werden als rüstige Arbeiter und Werkmeister am hohen Baue der Wissenschaft und der Weltwirtschaft, in allem Guten, Edlen und Schönen unterstützt von Deutschlands Frauen! Mag mein letztes Wort vom Fluge zu den Gestirnen überschwänglich erscheinen, - aber man kann sein Ziel nicht hoch genug stecken!

Ich werde diese glückliche Zukunft, in der unser teures Vaterland wieder in Ehren und im Frieden unter den Erdenvölkern dasteht, nicht mehr schauen; aber im festen Vertrauen, da $B$ sie uns komme, nehme ich ohne Bitterkeit Abschied von diesem Leben, welches mir so viel Liebes, Gutes und Schönes bot und schließe diese Erinnerungen mit dem Wunsche, da B Alle, welche sie lesen werden, noch die glücklichen Tage sehen mögen, von denen ich in dieser Stunde nur träumen kann.

Mein Morgenrot
Viel Schönes bot.
Mein Tag war hell,
Ein Lebensquell.
Auf Abends Matten
Fiel dunkler Schatten.
Nun kommt ganz sacht
Die stille Nacht. -
Ich zage nicht:
Durch Nacht zum Licht! 


\section{Anmerkungen, Zusätze, Litterarische Nachweise.}

(I) Die Weser ist deshalb der echteste deutsche Großstrom genannt, weil sie ihren ganzen Lauf durch echten deutschen Boden nimmt, einen Boden, der, soweit unsere Kenntnisse reichen, stets von rein germanischen Stämmen bewohnt gewesen ist, und an den sich die Erinnerungen der ersten historischen Freiheitskämpfe der Deutschen knüpfen.

(2) Der westfälische Dichter Friedrich Wilhelm Weber ist als Bauernsohn in dem kleinen Dorfe Alha usen bei Bad Driburg am 25. Dezember 1813 geboren. Das einfache bäuerliche Geburtshaus steht dem Hause meines verstorbenen Bruders Leonhard gegenüber. Nachdem Weber längere Zeit als Arzt in den beiden Badeorten Driburg und Lippspringe tätig gewesen war, folgte er einer Einladung des Freiherrn Guido v. Haxthausen, ganz seinen litterarischen und dichterischen Neigungen in $\mathrm{MuBe}$ auf dessen Schloß Thienhausen bei Steinheim zu leben. I887 übersiedelte er nach Nieheim in ein eigenes, hübsch gelegenes Haus, wo er 1894 starb. Weber ist ohne Frage einer der bedeutendsten unter den neueren Dichtern. Sein Hauptwerk „Dreizehnlinden", Paderborn bei F. Schöningh, hat über 50 Auflagen erlebt. Eine zweite herrliche Dichtung „Goliath" spielt auf norwegischem Boden, das Epos „Dreizehnlinden" in der westfälischen Heimat; es behandelt die Einführung des Christentums bei den sächsischen Westfalenstämmen. Ein paar Strophen aus dem einleitenden Teile dieses Epos mögen hier Platz finden:

Wonnig ist's, in Frühlingstagen Nach dem Wanderstab zu greifen Und, den Blumenstrauß am Hute, Gottes Garten zu durchschweifen.

Oben ziehn die weißen Wolken, Unten gehn die blauen Bäche;

Schön in neuen grünen Kleidern Prangen Wald und Wiesenfläche.

Auf die Bleiche bringt das Mädchen,

Was der Winterflei $\beta$ gesponnen, Und dem Hain erzählt die Amsel,

Was im Schnee sie still ersonnen.

Halbvergeßne alte Lieder

Wachen auf in meiner Seele:

Hätt' ich nur, sie auszusingen,

Wilde Amsel, deine Kehle!

Weber hatte sie aber, diese Kehle! Ich war mit ihm persönlich gut bekannt; als wertes Vermächtnis von ihm bewahre ich ein mit eigenhändiger. Widmung von ihm versehenes Exemplar seiner Goliath-Dichtung. 
(3) Broeder, Christian Gottlob, Verfasser einer derzeit vielgebrauchten lateinischen Grammatik. Er war Superintendent und Pastor zu Beuchte und Weddingen im Fürstentum Hildesheim. Nach Broeders Tode wurde das Werk neu herausgegeben von Ludwig Ramshorn, Professor am Gymnasium in Altenburg. Ich besitze die im Jahre 1836 erschienene 27. Auflage des Werkes. Der Ladenpreis der kleinen lateinischen Grammatik, eines Oktavbandes von 245 Druckseiten, betrug 8 Groschen!

(4) Wie die Kartoffelpflanze selbst, so ist auch der Erreger ihrer verheerendsten Kranklıeit, der zur Familie der Peronosporeen gehörige Pilz Phytophthora infestans, ein Geschenk Amerikas. Wenn auch bereits früher vereinzelt aufgetreten, breitete sich in Deutschland die durch den Pilz erzeugte Krankheit seuchenartig und schwer verderblich erst im Jahre 1845 aus. Sie ist niemals wieder gänzlich verschwunden, hat aber, wie das bei so vielen durch Pilze erregten Krankheitszuständen der Fall ist, ihre große Verbreitung und Gefährlichkeit verloren. Damit ist nicht gesagt, daß sie nun für immer ungefährlich bliebe.

(5) Haxthau sen, August, Freiherr v., geb. 2. März I792 zu Abbenburg, gest. 31. Dezember I866 in Hannover, wohlbekannt durch seine sozialpolitischen und nationalökonomischen Werke: Die Agrarverfassung und ihre Konflikte, Bd. I, Berlin 1829, Die ländliche Verfassung der Provinzen Ost- und Westpreußen, Königsberg 1839, Studien über die inneren Zustände, das Volksleben und insbesondere die ländlichen Einrichtungen Rußlands, 3 Bde., Hannover I 847 -52, Transkaukasia, 2 Bde., Leipzig I856 u. a. Im Auftrage der Preußischen Regierung bereiste er für die Abfassung der genannten Werke Ost- und Westpreußen, und im Auftrage der Russischen Regierung Rußland und den Kaukasus. Beim Kaiser Nikolaus I. war er sehr angesehen und beliebt. Er war ein origineller Mann mit vielen Interessen und Kenntnissen.

(6) Raabe, Wilhelm, Romanschriftsteller, geboren 8. September I83I zu Eschershausen im Herzogtum Braunschweig, gestorben hochbetagt in der Stadt Braunschweig. Verfasser der Erzählungen: „Die Chronik der Sperlingsgasse“, „Die Kinder von Finkenrode“, „Der Hungerpastor", „Der Schüdderump“" "Das Odfeld" und vieler anderer. Ein gesunder frischer Humor gesellte sich bei ihm zu reicher Phantasie und kräftiger, urwüchsiger Sprache. Was mir F. W. Weber als westfälischer Landsmann war, das hatte ich an Wilhelm Raabe als Braunschweigez.

(7) Man vergleiche über Henle das Buch seines Schwiegersohnes Fr. Merkel: Jacob Henle. Ein deutsches Gelehrtenleben. Nach Aufzeichnungen und Erinnerungen erzählt. Braunschweig, Friedrich Vieweg \& Sohn, 189I. Das Werk enthält eine große Zahl hochinteressanter Aussprüche Henles und wertvoller Zeitbilder. Ferner sei erwähnt mein Nachruf auf Henle im Archiv für mikroskopische Anatomie 1885 .

(8) Ich wähle Euterpe, die mit der Flöte dargestellte Muse, als die Beherrscherin der Musik, während Terpsichore wohl allgemein als die Muse des Tanzes aufgefaßt wird. Für die Musik käme auch Polyhymnia in Betracht. 
Übrigens bestanden die Meinungen über Beziehung der neun Musen $z \mathrm{u}$ bestimmten Wissenschaften und Künsten im klassischen Altertum noch nicht; sie sind erst später aufgekommen.

(9) Als Beispiel dieses Verwaltungsstiles, wie ich ihn nennen möchte und wie er noch 1836 üblich war, diene das nachstehende Privilegium, welches der König Maximilian Joseph von Bayern dem Verleger der Broederschen lateinischen Grammatil, Siegfried Lebrecht Crusius in Leipzig erteilte:

\section{Königlich Bayersches allergnädigstes}

Privilegium.

Wir, Maximilian Joseph, von Gottes Gnaden König von Bayern etc. Bekennen offentlich mit diesem Briefe und thun kund Jedermann, daß Wir auf allerunterthänigstes Bitten des Buchhändlers (folgt Name) Uns allergnädigst bewogen befunden haben, demselben ein ausschlieBliches Privilegium auf den Druck und Verkauf folgender Verlagswerke: (Namen) dergestalt in königlichen Gnaden zu verleihen, da $B$ es ihm freystehen solle, dic eben genannten Werke in Druck zu geben, feil zu bieten, und zu verkaufen, ohne daß Jemand, wer es auch sey, in Unsern sämmtlichen königlichen Erbstaaten dieselben nachzudrucken, oder nachdrucken zu lassen, sich unterstehen dürfe.

Befehlen hiernach allen in ermeldeten Unseren Staaten wohnenden Buchhändlern, Buchdruckern, Buchbindern oder Verlegern andurch allergnädigst, und wollen ernstlich, daß weder sie noch die Ihrigen sich beygehen lassen, die oben gedachten Werke, ohne vorgängige Einwilligung des rechtmäßigen Verlegers Siegfried Lebrecht Crusius, zu drucken, zu debitieren, oder zu verkaufen; Alles bey Vermeidung Unserer allerhöchsten Ungnade und einer Geld-Strafe von Ein Hundert Dukaten, wovon die eine Hälfte Unserm Fiscus, die andere Hälfte aber dem mehrerwähnten Verleger Crusius zukommen solle, - nebst Verlust des gegen diesen Unsern ausdrücklichen Befehl veranstalteten Nachdrucks - welchen der Impetrant mit Hülfe und Zuthun jeder Orts-Obrigkeit, wo man dergleichen finden wird, alsogleich aus eigener Gewalt, und ohne Jedermanns Hinderniß hinweg und zu sich nehmen, und damit nach Gefallen schalten könne und möge." Usw.

Die Probe wird genügen; den Schlußsatz habe ich als unwesentlich weggelassen, die Schreibweise und Interpunktion aber beibehalten. Was gemeint ist, darüber bleibt wohl kein Zweifel; das Auffallendste ist die Weitschweifigkeit und, ich möchte sagen, Ungelenkigkeit der Fassung und des Ausdruckes, während wir doch schon Lessing. Schiller und Goethe gehabt hatten.

(Io) Die alte Universität in Köln wurde $\mathrm{I}_{3} 88$ gegründet und bestand bis 1801, wo sie unter der Napoleonischen Herrschaft aufgehoben wurde. Sie hatte damals, wie manche andere deutsche Universität, die in dieser Zeit. aufgehoben wurde, ihre Bedeutung verloren.

(II) Fr. Merkel, Jacob Henle, ein deutsches Gelehrtenleben. S. II $7 /$ IIS. 
(I2) C. H. Becker, Gedanken zur Hochschulreform. Leipzig, Quelle \& Meyer, 1919 und O. L ubarsch, Zur Frage der Hochschulreform. Wiesbaden, J. F. Bergmann, rgrg.

(13) Diels, H., Frankreichs Führer im geistigen Revanchekrieg. I. Emile Boutroux. Internationale Monatsschrift für Wissenschaft, Kunst und Technil, I. Jahrg., B. G. Teubner, Leipzig und Berlin. S. 6I.

(r4) Unter ",karyokinetischen Kernteilungen" versteht man Teilungsvorgänge an tierischen und pflanzlichen Zellkernen, bei denen eigentümliche, ganz charakteristische Bewegungserscheinungen an diesen Kernen auftreten. Ein Teil der Kernsubstanzen sondert sich zu bestimmt geformten, gleich großen Stücken, den sogenannten „Chromosomen" für jede Tier- oder Pflanzenart von bestimmter Zahl. Jedes Chromosom teilt sich dann in zwei gleiche Hälften; das eine Halbstück wandert zu dem einen Kernpole, das zweite zum anderen, darauf teilt sich der Kern in seiner Mitte. Auf diese Weise erhält jede Kernhälfte die gleiche Masse von Chromosomensubstanz. Der Name Chromosom = Farbkörper bezieht sich auf den Umstand, da $B$ diese Körper sich in vielen bei den mikroskopischen Untersuchungen verwendeten Farbstoffen auffallend leicht und stark färben. Bei der Vererbungsfrage spielen diese Vorgänge eine wichtige Rolle.

(15) Bei dem hohen Interesse, welches die Äußerungen R. Virchows über seine Befunde an den vom Kronprinzen Friedrich stammenden, ihm zur Untersuchung übergebenen Stücken unstreitig haben, sei hier noch einiges Weitere mitgeteilt.

Virchow schreibt am I. Juli 1887 (Deutsche mediz. Wochenschrift, Nr. 28, S. 634, vom 14. Juli 1887) über ein zugesendetes, aus dem Kehlkopfe des Kronprinzen von Mackenzie exzidiertes Stück: ,Im Wesentlichen derselbe Befund wie früher; aber tiefere Gewebslagen waren nicht erreicht worden, nur Schleimhautteile waren gefaßt. Somit war nur wenig und schwierig zu behandelndes Gewebe vorhanden, an welchem ein Urteil über die Beschaffenheit der unterliegenden Teile zu gewinnen war."

„Dieses Gewebe ließ nirgends alveoläre Struktur, Einlagerung oder Eindringen epithelialer Massen wahrnehmen. Es bestand aus zartem Bindegewebe, welches nicht in der Tiefe, sondern nur in der Oberfläche vergrößerte und zum Teil in Proliferation begriffene Elemente enthielt. Nirgends erreichte diese Proliferation den Charakter selbständiger Herdbildung. Das exzidierte Stück hat sich daher in noch höherem Grade, als die bei der vorletzten Operation gewonnenen als eine von einer mäßig gereizten Oberfläche ausgegangene harte, zusammengesetzte Warze ergeben. Die Basis derselben hat auch nicht den entferntesten Anhalt für die Annahme einer in das Gewebe eindringenden Neubildung ergeben."

Abgesehen von dem hier streng betonten negativen Befunde, war wieder die positive Bezeichnung ,,Warze", mit der Jedermann den Begriff einer gutartigen Neubildung verbindet, geeignet, den Verdacht der deutschen Kliniker zu entkräften und Mackenzies Aussagen zu stützen. Dieser und sein Anhang ver- 
fehlten denn auch nicht, den ausgiebigsten Gebrauch davon zu machen. Dadurch wurde dann Virchow veranlaßt, sich abwehrend zu äußern. In einem Vortrage in der Berliner medizinischen Gesellschaft - s. Deutsche medizinische Wochenschrift Nr. 47 vom 24. November 1887 - faßt er seine Befunde noch einmal zusammen und sagt zu seinem Gutachten vom 9. Juni 1887 , welches im Text S. 332 wiedergegeben ist: ,,Sie sehen, ich habe damals, gewissermaßen über die mir gestellte Aufgabe hinausgehend, den ausdrücklichen Hinweis darauf gemacht, da $B$ eine solche partielle Untersuchung ein Urteil über ein Gesamtverhältnis, das im übrigen nicht vorliegt, nicht ergeben könnte. Ich glaube damit in der Tat das meinige getan zu haben, um Jeden, der das Gutachten las, aufmerksam zu machen, daß sich dasselbe nur bezog auf das, was wirklich vorlag, nicht auf Dinge, die nicht vorgelegen haben. Sie werden begreifen, daß ich in einem Gutachten, das unmittelbar bestimmt war auch den höchsten Personen des Staates vorgelegt zu werden, nicht etwa die Sache so fassen konnte, daß ich sagte: „Es ist möglich, daß daneben noch Krebs existierte. Technische Personen, die das Gutachten lasen, mußten sich sagen, da $B$ diese Möglichkeit nicht ausgeschlossen war. Ich mache diese Bemerkung, um ausdrücklich meine Stellung zu wahren, daß ich mein Gutachten beschränken wollte auf das Material, das mir übergeben worden war."

Virchow fügt hinzu, da $B$ er den Kronprinzen seit Ende des Winters, wo die Heiserkeit allerdings schon einen hohen Grad erreicht hatte, nicht mehr gesehen hätte. Virchow lehnt ferner die Versuche Mackenzies, ihm (Virchow) die Verantwortlichkeit für die Diagnose Mackenzies zuzuschreiben, ab. Er habe mit Mackenzie bis jetzt weder mündlich noch schriftlich während der ganzen Dauer der Krankheit des Kronprinzen in Verkehr gestanden.

In einem letzten Gutachten über ein aus San Remo gesendetes Stück vom 29. Januar 1888 - s. Deutsche mediz. Wochenschrift Nr. 8 vom Jahre I 888 , 23. Februar, S. 159 - heißt es: „Nur an dem aus einer fast harten Stelle herausgeschnittenen größeren Stücke, welches die Form und das Aussehen einer flachen Warze hatte und an welchem sich auf einem Durchschnitt schon mit bloßem Auge ein festerer, mehr weißlicher Kern und eine trübe, ziemlich dicke Deckschicht unterscheiden ließ, zeigten sich fast in jedem mikroskopischen Schnitte sogenannte Nester (Zwiebeln) von epidermoidalen, häufig ganz homogen gewordenen Zellen; regelmäßig lagen diese Nester in der Deckschicht oder doch in nächster Nähe derselben. Epidermiszwiebeln in tieferen Teilen und deutlich isolierte Alveolen habe ich trotz anhaltenden Suchens nicht gefunden. Nirgends fand sich ein Knorpelstück."

Ich gestehe, daß ich nach einem Befunde, wie nach dem hier von Virchow geschilderten, die Diagnose ,Krebs" ohne alle Bedenken gestellt haben würde. Virchow sagt ja selbst, daß die Nester (Zwiebeln) nicht nur in der Deckschicht, sondern auch in nächster Nähe dieser Schicht, also doch unterhalb derselben, gelegen hätten, also in die Schleimhaut eingedrungen waren, was er früher stets vermiBt hatte. 
(16) Hassenpflug, H. L., geboren am 26. Februar 799 in Hanau, machte als Freiwilliger den Feldzug von I813 mit, studierte die Rechte in Marburg und Göttingen, wurde 1832 kurhessischer Minister der Justiz und des Inneren und begann damals sofort die Arbeit zur Beseitigung der Verfassung von I83I. Nach seinem Rücktritte 1837 übernahm er die Leitung der Regierungsgeschäfte in Hohenzollern-Sigmaringen, wurde I839 Zivilgouverneur von Luxemburg, $x 8_{4} 1$ Obertribunalsrat in Berlin, $x 8_{4} 6$ Präsident des Oberappellationsgerichts in Greifswald, 1850 wieder kurhessischer Ministerpräsident. 1855 trat er in den Ruhestand und nahm seinen Wohnsitz in Marburg, wo er am Io. Oktober 1862 starb.

(17) S. über die Emser Depesche: Otto Fürstvon Bismarck, Gedanken und Erinnerungen, Stuttgart, Cottasche Buchhandlung, Bd. II, S. $87 \mathrm{ff}$.

(18) Ich zitiere den Namen, wie ich ihn in der Schrift Diego Barros Aranas, Histoire de la Guerre du Pacifique, Paris, J. Dumaine, I88I, gedruckt finde: "Grau", nicht „Gran", wie ich mich erinnere, ihn anderswo gelesen zu haben.

(19) Canstatt war Kliniker in Erlangen. Er gründete 1842 seinen ,. Jahresbericht über die Fortschritte der gesamten Medizin", soweit mir bekannt, als erstes Unternehmen dieser Art überhaupt. Später wurde der Bericht von Rudolf Virchow und August Hirsch und seit 1902 von Karl Posner und mir weiter geführt. Leider stellt sich jetzt heraus, daß die Kosten für Druck, Papier und besonders für die Beschaffung der ausländischen Litteratur so beträchtlich geworden sind, daß sie bei weitem den Erlös aus dem Vertrieb übersteigen. So muß bis zum Eintritt besserer Zeiten dies für die deutsche medizinische Literatur höchst ehrenvolle und wichtige Unternehmen ruhen.

(20) Gregor Mendel, Benediktinerpater in Brünn, stellte durch lange fortgesetzte Versuche an Pflanzen die gesetzmäßigen Regeln fest, nach denen sich die elterlichen Eigenschaften auf die Nachkommen bis in fernliegende Glieder vererben. Vgl. Mendel, Versuche über Pflanzenhybriden, I865 und 1869, neu abgedruckt in Ostwalds ,Klassiker der exakten Wissenschaften“" Nr. I2I, 1901; ferner Correns, Berichte der Deutschen Botanischen Gesellschaft, 18, 1900, und 19, I902, und „Die Vererbung und Bestimmung des Geschlechtes", Berlin I9I3.

(2I) (Nachtrag vom 3. Juli I920.) Inzwischen hat man, wie berichtet wird, nachgegeben, da $\beta$ die Verhandlungen vor einem deutschen Gerichtshofe geführt werden. Immerhin bleibt die Forderung eine unerhörte. Sollte man auf ihr bestehen, so müßte Deutschland verlangen, da $B$ auch diejenigen Fälle, in denen nach unserer Ansicht Offiziere und Mannschaften unserer Gegner sich schuldig gemacht hätten, in entsprechender Weise vor Gericht zur Aburteilung gebracht würden. 


\section{Namen-Register.}

A.

Abdul-Hamid, Sultan 304 Abeken, Legationsrat 275 Abel, K., Dr. med., Gynäkolog 289

Ancel, Anatom 257

Adler, Fr., Prof., Baurat 272, 275

Adam, Gebrüder, Institutsdiener $1_{4} 8,1_{49}$, I6I

Aeby, Chr., Prof., Anatom 159

Aehrenthal, Graf, Staatsminister 356

Ahlemeyer, Gymnasialdirektor $55,56,58,64$

Alexander II., russischer Zar 260

Alexander III., russischer Zar 28I

Alexander, König von Serbien 260

Althoff, Fr., Ministerialdirektor 105, 174, 175, I 76,185

Andrian-Werburg, Freiherr v., Anthropolog $242,25^{\circ}$

Argutinsky, Prof., Anatom 290

Arnswaldt, Freih. v. 88

Arnswaldt, Freifrau v. 88

Asquith, Staatsmann 229

Aubenas, Prof., Gynäkolog 144,147

AufseB, Freiherr v. 142

Auwers, Arthur v., Astronom $74,212,213,224$, 236,237

Aweng, Maire von Stieringen 349

B.

Bachmann, P., Prof., Mathem. 138, 244
Baer, K. E. v., Prof., |Bernouilli, Joh., Mathem. Anatom u. Zoolog 394

Baeyer, A., Prof., Chemiker ${ }^{4} 6$

Bardeleben, A. v., Prof., Chirurg 97, 98, I80, I90, 266, 330

Bardeleben, K. v., Prof., Anatom 256

Barkow, H. K. L., Prof., Anatom 127

Barlow, Sir Thomas, Kliniker 268

Barlow, Lady 269

Bartels, Max, Dr. med., Arzt 264

Bartels, Paul, Dr. med., Anatom 289

Bartling, Prof., Botan. 68 de Bary, Prof., Botan. I 46, I47, 238, 402

Bastian, A., Ethnolog 240 Baum, Prof.,Chirurg 68,8 I Bäumker, Fr., Gymnasialoberlehrer 50, 5I, 55, 56

Bäumker, Klemens, Prof., Philosoph 55, 56

Baumstark, Prof., Nationalökonom 91, 96

Becker, Präs. d. Akad. d. Künste 265

Becker, C. H., Prof., Ministerialdirektor 193,407

Benecke,Prof., Geolog 146

Benedetti, franz. Botschafter 343

Berendes, Jul. Dr. phil. $57,58,59$

Bergius, Hofrat 275

Bergmann, E. v., Prof., Chirurg I80, 227, 264, $266,278,282,285,324$, $325,326,327,328,329$, 330,331
275

Beseler, Prof., Jurist 272

Bethmann-Hollweg, v., Kultusminister 272

Betschler, Prof., Gynäkolog I 40

Bianchi, Prof., Anatom 232

Bier, A., Prof., Chirurg I8I

Binding, Prof., Jurist I 42, I 43

Biondi, D., Prof., Chirurg 232, 299

Bischoff, Th. W., Prof., Anatom 94, I75

Bismarck, Fürst 167,168 , $292,335,343,344,409$

Blaserna, Prof., Physiker $23 I$

du Bois-Reymond, Prof., Physiol. 103, 135, I 80, 2 II, 2 I 2

Bonhoeffer, Prof., Psychiater I8I

Bonin, v., General 252 Bonin, J. v., Oberstleutn. $253,303,357,368$

Bonin, Hedwig v., geb. v. Waldeyer-Hartz 153 , $245,267,293,294,297$. 298, 299, 300, 301, 367 Bonin, Irmgard v. $3 I_{7}$

Bötticher, v., Minister 266 Bouchard, Prof., Med., Paris 227

Bouin, Prof., Anatom, Nancy 257

Bourbaki, General 345

Boutroux, Prof., Philos., Paris 228, 229, 406

Bramann, Prof., Chirurg 326,328

Bramwell, Mrs. Lizzie 307 
Braun, Alex., Prof., Botaniker 275

Bremer, Ludwig, Arzt, St. Louis Mo. 313, 317

Brieger, L.,Prof.,Med. 28o

Broeder, Pfarrer, Grammatiker 405

Brösike, G., Prof., Anatom 289

Brosius, Generalleutnant 402

Bruch, Prof., Theolog I4I, ${ }_{4} 6$

Brüdern, Karoline, geb. Persuhn $4^{8}$

Brunn, Ferdinand v., Prof., Anatom I45, 288, 289

Brunner, Heinr., Prof., Jurist $I_{4} 6,179$

Brunton, Lauder 269

Bryce, Lord, Staatsmann 229

Buch, Leopold v., Geolog 2I7, 275

Buchholz, R., Zoolog 52

Buchwald, Prof., Inn. Medizin 138, 288

Budge, J., Physiolog 9I, 92, 93, 94, 95

Bülow, Fürst 23I, 302

Bumm, Prof., Gynäkolog I 8 I

Busch, D. W. H., Prof., Gynäkolog I 8I

Buse, Kaufmann, Paderborn 63

C.

Cambon, franz. Botschafter $35^{8}$

Canstatt, Prof., Med. 409

Caprivi, Graf, Reichskanzler 275

Carlos, König v. Portugal 260

Carmalt,Prof.,Chirurg 308

Carmer, Graf, Staatsmann 275
Carnot, Präsident 260

Carol I., König, Rumänien 306

Casper, J. L., Prof., Staatsarzneikunde 107, I08

Cassel, Konditor, Braunschweig 45

Cassel, Minette, geb. v. Hartz 45

Cervera, span. Admiral 354

Charpy, A., Prof., Anatom 257

Christian VIII., König v. Dänemark 336

Christoffel, Prof., Math. ${ }_{4} 6$

Cilimbaris, Anatom und Chirurg, Athen 290

Clémenceau, franz. Ministerpräsident 236

Cohen, Fr., Verlagsbuchhändler 402

Cohn, Ferdinand, Prof., Botaniker I 39, I 40

Cohnheim, J., Prof., Pathol. Anatom 135, 136, I 37

Cohnheim, Otto, Dr., Preisrichter 313

Coler, A. v., Generalstabsarzt 2 ro, 265

Conrady, Max, Arzt II4, I I 5 , I 38

Conway, Rev. S. J., Preisrichter $3 \mathbf{3}$

Corning, Prof., Anatom 290

Correns, Prof., Botan. 273

Cunitz, Prof., Theolog 146

Cunningham, D. J., Prof., Anatom 307

Curtius, Prof., Philolog 2 I 2

Cuvier, G., Prof., Zoolog 217

Czerny, A., Prof., Pädiater I8I
D.

Darboux, Prof., Mathem. 227

Darwin, Charles, Zoolog 395

Davis, Prof., Geograph 3 I 4

Dechend, Bankpräsident 275

Delbrück, Hans, Prof., Historiker 309

Diaz, Porfirio, Präsident, Mexiko 316

Dieckhoff, Gymnasialoberlehrer 55,56

Diels, H., Prof., Philolog 213, 229, 272, 407

Dilke, Sir Charles, Staatsmann 229

Dillenburger, ProvinzialSchulrat I I 5, I $8,1_{3} 8$, I 4 I

Dillenburger, Wilhelmine geb. Wichterich II5, I 4 I

Dillenburger, Agathe, verehelichte Gutsbesitzer Schröder 302

Dillenburger, Gertrud, verehelichte Major Peters 267

Dillenburger, Otto, Kaufmann, Mexiko 316

Disse, J., Prof., Anatom 289

Dohrn, Anton, Zoolog 133 , 302

Döllinger, Ignaz, Prof., Anatom 394

Dorner, Isaak, , Prof., Theolog 275

Dove, Prof., Physiker 275

Drake, Bildhauer 275

DröBler, Anatomiewärter Berlin 330

Droste-Hülshoff, Annette v. I4

Droste-Hülshoff, Max, Freiherr v. II 
Drumont, Journalist, Paris 226

Drüner, Dr. med., Generalarzt 210

Duncker, Prof., Historiker 272

Dwight, Prof., Anatom 3I0

E.

Ebstein, Dr. med., Prof., Inn. Kliniker I33

Edinger, L., Prof., Neurolog $157,158,229$

Eduard VII., König von England 228

Eggeling, $H$. v., Prof., Anatom 256

Ehlers, Ernst, Prof., Zoo$\log 8 \mathrm{I}$

Ehrenberg, Prof., Zoolog I I , I I 3,270

Ehrlich, Paul, Prof. d. Medizin 157, I 58,280 , 286

Ehrlich, Frau Professor 269

Eichhorn, Minister 275

Eickermann, Schafmeister, Abbenburg 35

Einstein, Prof., Physiker 397

Elisabeth, Königin, Rumänien 306

Ellenberger, Prof., Physiolog 159

Emmich, v., General 359

Encke, Prof., Astronom 275

Ernst Ludwig, Großherzog von Hessen 253

\section{F.}

Failly de, Marschall 343 Fischer, H., Prof., Chirurg $346,347,34^{8}$

Fischer, Wärter am Pathol. Inst. Berlin I37
Fischer, Kaplan I7

Flörcken, Gebrüder, Verwandte d. Verf. 6o

Flügge, Prof., Hygieniker I 81

Förster, W., Prof., Astronom 272

Förster, R., Prof., Ophthalmolog 138,252

Foster, Sir Michael, Physiolog 228

Franqueville, Comte de 335

Franz, Prof., Gynäkolog I8I

Frederick VII., König von Dänemark 336

Frerichs, Th. v., Prof., Inn. Kliniker 103, 106, 107. I10, 135, I 80, 280

Freund, W. A., Prof., Gynäkolog I40, I47, I 56

Friedmann, Franz, Prof., Mediz. 286

Friedrich I., König von Preußen 212

Friedrich II., König von Preußen 214, 215, 217 . 269, 36I, 362

Friedrich III., Deutscher Kaiser 282-320

Friedrich, Großherzog von Baden I 54, I 55

Friedrich Wilhelm I., König von Preußen 2 I 7 Friedrich Wilhelm III., König von Preußen 212,400

Friedrich Wilhelm IV., König von Preußen 320 Fritsch, Gustav, Prof., Anatom I40

Frohse, Fritz, Anatom 290

Froriep, R., Patholog. Anatom I 8I

Frossard, Marschall $34^{8}$
G.

Gambetta, franz. Staatsmann 345, 373

Garfield, Präsident der U. S. A. 260

GauB, Fr., Prof., Mathem. 217,401

Gautier, Prof., Chemiker 3I 3

Gegenbaur,K.,Prof., Anatom 395

Gellzuhn, Inspektor der Berliner Anatomie I77

Georg V., König, von Hannover $69,82,83$

Gerhardt, K., Prof., Inn. Kliniker 282, 323, 324, $325,329,33 \mathrm{I}$

Gerota, Prof., Anatom u. Chirurg 290, 307

Gleditsch, Prof., Botan. 275

Goldstein, Dr. med., Arzt 313

Golgi, C., Prof., Anatom 229

Goltz, v. d., Prof., Theo$\log 272$

Goltz, Fr., Prof., Physio$\log$ II7, I 43, I54, 252

Gomperz, Prof., Philolog 225,226

Göppert, H. R., Prof., Botan. I39, I40

Goßler, G. v., Kultusminister $252,265,284$

Goethe, J. W. v., Dichter 217

Goette, A., Prof., Zoolog I 46 , I 53

Gottstein, Prof., Laryngolog 59, 288

Graf, Dr. med., Arzt 264 , 265

Graefe, A. v., Prof., Ophthalmolog I 82, I $89^{\circ}$

Gramont, Duc de, franz. Minister 344

Grasnick, Generalarzt 2 Io 
Grau, Peruanischer Ad-|Haxthausen, August, miral 353, 409

Griesinger, Prof., Psychiater 189

Grohé, Fr., Prof., Pathol. Anatom 93

Groth, Prof., Mineralog $I_{4} 6$

Grube, Prof., Zoolog I 30, I39

Grünhagen, Prof., Physiolog 125

Gusserow, A., Prof., Gynäkolog I 47, I 54, I 56, I 80

Gwinner, v., Bankdirektor 273

\section{H.}

Haase, Prof., Philolog 237 Haeckel, E., Prof., Zoolog 395

Haeser, H., Prof., Geschichte d. Med. 9 I

Haller, Graf v., Assistent Anat. Inst., Berlin 290

Harnack, A. v., Prof., Theolog 218

Hartmann, R., Prof., Anatom $\mathrm{r} 77,243,270$, 289

Hartel, Prof., Philolog 223

v. Hartz, W. G., Kantor, Großvater d. Verfass. I, I5, I9, 43, 44

v. Hartz, Karoline, geb. Cassel, Großmutter des Verfassers 44

v. Hartz, A., Superintendent $3,4^{8}$

v. Hartz, Luise 47

Hasse, Prof., Inn. Kliniker 252

Hassenpflug, Minister $337,338,409$

Hausmann, Prof., Geolog 66,69

Haxthausen, Friedrich, Freiherr v. 2, 28
Freiherr v. 9, I7, 38, 405

Heffter, Prof., Jurist 275

Heffter, A., Prof., Pharmakolog I8I

Heidenhain, L., Chirurg 253

Heidenhain, R., Prof., Physiolog II 8,125 , I26, I28, I 38,139

Heim, Dr. med., Arzt in Berlin 270, 275, 276

Hein, F., Prof., Assistent Anat. Inst., Berlin 290

Heinecke, Prof., Chirurg IOI

Helmholtz, H., Prof., Physiolog 275, 396

Hempel, Porträtmaler 275

Henle, J., Prof., Anatom $67,68,76,77,78,79$, So, I 4 I, I 59, I 75, I88, 288, 405

Henoch, Prof., Inn. Kliniker 182

Henry, Mrs., geb. Lauder Brunton 269

Henschen, S. E., Inn. Kliniker, Stockholm 2.54

Herbette, franz. Botschafter 266

Hermann, Prof., Anatom 208

Hermes, R., Dr. med., Arzt 90, 107, I I 4

Hertwig, O., Prof., Anatom I8I, 201, 394

Herzog, Staatssekretär I68, 252

Heyl v. Herrnsheim, Freiherr 253

Hildebrand, A., Bildhauer I33

Hildebrand, O., Prof., Chirurg , I 8 I
Hildebrand, Schwedischer Reichsantiquar 254

Hindenburg, v., Feldmarschall 359,368

Hirsch, A., Prof., Geschichte d. Medizin I 79, I 80, 409

Hirsch, Prof., Inn. Kliniker, Königsberg I I 5

His, W., Prof., Anatom I 59, 229, 256, 286, 287 , 307

His, W.,Prof., Inn. Kliniker 181,287

Hoffmann, A., Prof., Inn. Kliniker 297

Hofmann, A. W., Prof., Chemiker 275

Höhndorf, Institutsdiener, Breslau I3o

Holtei, Karl v., Dichter 238

Homeyer, Prof., Jurist 275

Hosius, Prof., Mineralog 244

Hovell, Dr.med., Ar zt 330

Huber, K., Prof., Anatom 290

Hübner, Inspektor am Pathol. Inst., Berlin $33^{\circ}$

Humboldt, W.v., Sprachforscher, Staatsmann $212,219,220$

Huntington, Prof., Anatom 310

\section{J.}

Jablonowski, Dr. med., Assist. Anat. Institut, Berlin 289

Jacobson, H., Prof., Inn. Kliniker $\mathbf{1 2 4}$

Jacobson, J., Prof., Ophthalmolog 12 I

Jaffé, Reg.-Baumeister 265 
Jäger-Lüroth, Dr. med., Arzt, Straßburg (Els.) I 57

Janošik, J., Prof., Anatom 289

Jeanne de la Croix, Krankenschwester 349

Jeanne de Dieu, Krankenschwester 349

Jenner, Arzt $35^{\circ}$

Joachim, Joseph, Musiker 282

Johann Albrecht, Herzog von Mecklenburg 303

Johannessen, Axel, Prof., Pädiater, Generalsekretär der Norweg. Ges. d. Wiss. 230

Jolly, Fr., Prof., Psychiater I47

Joessel, G., Prof., Anatom $I_{44}, I_{45}, I_{4} 6, I_{54}$ Joessel, Frau Fanny, geb. Edel I45

Jüngken, Chr., Prof., Chirurg 103, 105, 107, 108, I 36, I37, 181

Jzquierdo, V., Prof., Anatom 159, 354

\section{K.}

Kahlcke, O., Kaufmann, Hamburg I03

Kahlcke, Frau Emma, geb. Waldeyer I03

Kallius, E., Prof., Anatom 95, 290

Kamón, K., Prof., Anatom, Kyoto 290

Kant, E., Prof., Philosoph $217,219,220$

Karl Theodor, Herzog in Bayern 266

Kayser, Albert, Dr. med., Arzt 72, 88, 90, I I 4, 244

Kayser, Heinrich, Dr. med., Arzt 72

Keibel, Fr., Prof., Anatom 290
Kern, v., Obergeneralarzt, Prof. 2 Io

Keitel, Generalarzt 2 Iо Killian, G., Prof., Laryngolog 181

Kirchhoff, A., Prof., Philolog 180

Klaatsch, H., Prof., Anatom 290

Klaproth, Prof., Chemiker 270

Klebs, E., Prof., Pathol. Anatom II3, 126, 128

Klebs,Dr., Königsberg 245

Klein, Apotheker, Staatsrat, Stra Bburg (Els.) I62

Klein, Fran Staatsrat I 64

Kleinert, Prof., Theolog 272

Kleinschmidt, Rechnungsrat 267

Klimsch, Bildhauer 335

Koch, Dr. med., Joseph, Arzt $67,72,73, I_{14}$

Koch, Robert, Prof., Hygieniker 139, 283 , 284,285

Koganëi, J., Prof., Anatom, Tokyo x 59, 289

Köhl, Dr. med., Arzt, Anthropolog 252

Köhler, Wolfgang, Privatdozent, Philosoph 22 I

Kohts, O., Prof., Polikliniker I47, I 53

Kolaczek, Prof., Chirurg 138, 288

Kölliker, A. v., Prof., Anatom 94, IO4, I59, 243,266

Kollmann, J., Prof., Anatom 256

Kopsch, Fr., Prof., Anatom 290

Köring, Chr., Pfarrer I7. I8

Körte, W., Prof., Chirurg I 57
Korte, Schäfer in Abbenlourg 36

Kostanecki, K. v., Prof., Anatom 290

Krafft-Ebing, Freiherr v., Prof., Psychiater I44, I 47

Kraus, Fr., Prof., Inn. Kliniker I 8I

Krause, H., Prof., Laryngolog 333

Krause, W., Prof., Anatom 289

Kraut, Prof., Jurist 66

Kreilos, Gärtner in Abbenburg 35

Kreimeyer, Fleischermei. ster in Abbenburg 25

Kriele, Fräulein, Königsberg I 8 , I I 9

Kroner, Dr. med., Arzt $24^{\circ}$

Krückmann, Prof., Ophthalmolog I7, I8I

Kuhn, A., Prof., Otiater I 44, I54

Kühne, Dr. med., Stabsarzt IIO, III

Kühne, Willy, Prof., Physiolog 135, 136

Kultschitzky, Prof., Anatom 290

Kundt, A., Prof., Physiker $146,147,238,282$, 283,402

Kurlbaum, Prof., Physiker 273

Kußmaul, A., Prof., Inn. Kliniker I47, I 54, I 55 . 252

\section{L.}

Laband, P., Prof., Jurist I 46

Lachmann, Prof., Philo$\log 275$

Landgraf, Generalarzt 325

Landois, H., Prof., Zoo$\log 244$ 
Landois, L., Prof., Physiolog 90, 94, Ir4, 244 , 252

Lange, Dr. med., Arzt, Breslau 132

Langemak, Ratmann, Berlin 275

Langenbeck, B. v., Prof., Chirurg I6, I05, I35, I 81

Langerhans, P., Prof., Anatom 297

Lannelongue, Prof., Chirurg 227

Lanterman, Dr. med. I 59

Laplace, Astronom 217

Laqueur, L., Prof., Ophthalmolog I44, I 54

Lassar, Prof., Dermato.gonolog 264, 267

Lauer, v., Generalstabsarzt 210,324

Lebert, H., Prof., Inn. Kliniker I 3 I

Lecointe, Astronom 3 I 3

Lehmann, Frederick, Anwalt $312,313,317$

Lehmann, Frau 312

Lehnert, Unterstaatssekretär 275

Lehnert, Universitätsrichter $\mathrm{IO}_{3}$

Leibniz, G. W., Philosoph 2I 2, 2I4, 219,220

Lessing, G. E., Dichter 217, 275

Lesser, E., Prof., Dermatogonolog $18 \mathrm{I}$

Leßmann, Gymnasialoberlehrer 52, 56

Leube, Dr., Apotheker 247

Leube, Prof., Inn. Kliniker 247

Leuthold, v., Generalstabsarzt 210, 327, 329

Lewald, Unterstaatssekretär 3I3, 3I7
Leyden, E. v., Prof., Inn. Kliniker I25, I44, I47, I 54, I80, 264, 266, 281

Lichnowsky, Fürst 269

Lichtenstein, Zoolog 275

Lieberkühn, N., Prof., Anatom, Marburg 8o, I 4

Liebermeister, Prof., Inn. Kliniker IoI

Liebreich, O., Prof., Pharmakolog II8, I8o Limburg-Stirum, Graf, Preisrichter 313

Lincoln, A., Präsident U. S. A. 260

Link, Prof., Botan. 270

Loeb, Dr. med., Prof., Preisrichter 313

Lohmann, Lehrer und Kantor in Hehlen I5, 44

Lohmann, Frau Doris, geb. v. Hartz 44, $4^{8}$

Lohmann, Karl, Kaufmann $4^{8}$

Long, Dr. med., Arzt, Breslau I 30

Longworth, Dr. med. I 59

Lorent, H., Dr. med., Assistent, Straßburg (Els.) 289

Lorentz, Prof., Physiker 236

Lotze, H., Prof., Philosoph 66

Loubet, E., Präsident, Frankreich 225

Lubarsch, Prof., Pathol. Anatom 407

Lubosch, W., Prof., Anatom 290

Lücke, A., Prof., Chirurg I 44, I 54, 29 I

Ludwig, K., Prof., Physiolog 287,288

Luxburg, Graf, Gesandt. 384

\section{M.}

Mackenzie, Sir Morell, Laryngolog 324,325 , $326,328,330,331,334$. 406, 407

Mac Kinley, Präsident der U. S. A. 260

Mac Mahon, franz. Marschall $34^{6}$

Madai, v., Polizeipräsident 275

Magnus, Prof., Physiker 275

Mall, Franklin P., Prof., Embryolog 309

Manteuffel, v., Feldmarschall I68, I69

Marconi, Physiker 402

Marées, Hans v., Maler I33

Marheineke, Neuphilolog 52,72

Marenzeller, v., Zoolog I33

Martin, A., Prof., Gynäkolog 263, 264

Martin, Ed., Prof., Gynäkolog 135

Marx, Prof., Inn. Medizin 69

Maurer, Fr.. Prof., Anatom 257

Maximilian Joseph, König von Bayern 406

Maximilian, Kaiser von Mexiko 3I 5, 340

Mendel, Gregor, Benediktinermönch 394, 409

Menzel, Adolf, Maier 282

Merkel, Fr., Prof., Anatom I 88, I93, 405

Meschede, Frz., Prof., Psychiater 253

Methner, Dr. med., Arzt, Breslau 132

Meyer, Lehrer u. Kantor, Allrode $4^{8}$

Meyer, Frau Friederike, geb. v. Hartz 47 
Meyer, Kuno, Prof., Sprachforscher 269

Meyer, Lothar, Prof., Chemiker I25, I38

Meyer, Osk. Emil, Prof., Physiker 138

Meyer, Paul, Dr. med., Arzt, Straßburg (Els.) $x_{57}$

Meyer, Rentmeister, Abbenburg 9

Michele, Diener der zool. Station, Neapel I33

Michelmann, Laboratoriumsdiener bei $W$.

Weber 70, $7 \mathrm{I}$

Middeldorpf, Prof., Chirurg 131

Mihalkovics, Geza v., Anatom I 45, I 58, 299 Minot,Ch.Sedgwick,Prof., Histolog 310

Möbius, Prof., Zoolog 270, 273

Morf, Prof., Romanist 272

Möller, v., Oberpräsident I67

Moltke, Helmuth v., Feldmarschall $\mathrm{I} 67, x 68,344$

Mommsen, Prof., Historiker 212, 223, 224

Montelius, Prof., Anthropolog 254

Mortara, Prof., Anatom, Perugia 297

Müller, Aug., Prof., Ana. tom II7, I22, $\times 24$

Müller, Fr., Prof., Inn. Kliniker 270

Müller, Johannes, Prof., Anatom $80,176,178$, I8I, 188

Mundy, Baron v. 244

Münter, Prof., Botaniker und Zoolog 93

N.

Nahmmacher, W., Dr. med., Assistent 289
Napier, Charles, Admiral 339

Napoleon III., Kaiser $339,340,343$

Neumann, K., Historiker I38

Nicolai, Chr. Fr., Buchhändler u. Schriftstell. 275

Nicolas, A., Prof., Anatom, Paris 257

Niederleitner, Dr. med., Arzt 97

Niemeyer, Felix, Prof., Inn. Kliniker 95, 96, I 29, 190

Nikolaus II., russ. Zar I 59, 233

Nobél, St. Petersburg 234

Nüesch, J., Anthropolog $25^{\circ}$

0.

Obersteiner, H., Neurolog 229

Olfers,v., Generaldirek tor der Museen 275

Orth, J., Prof., Pathol. Anatom I8I

Osman-Pascha,türkischer Feldherr 304

P.

Pander, Chr., Embryolog, Anatom u. Paläontolog 394

Passow, A., Prof., Otiater I8I

Paul, Chirurg, Breslau 132, 342

Peabody, Dr. med. 159

Penck, A., Prof., Geograph 273, 3I 4

Pernice, Prof., Gynäko$\log 98$, 99, 100

Persuhn, Lehrer u. Kantor, Holzminden 47

Persuhn, Frau Karoline, geb. v. Hartz 47
Perthes, General 273

Pertik, O., Prof., Pathol. Anatom I 59, 299

Pertz, Oberbibliothekar 275

Phelps, Botschafter 266

Piersol, Geo, Prof., Anatom 290, 309

Pistor, Geh. Med.-Rat 264

Planck, Max, Prof., Physiker 213, 236, 397

Posner, K., Prof., Urolog I57, 267, 409

Prenant, Prof., Histolog 257

\section{Q.}

Quincke senior, Prof., Mediziner IIO, I I I

R.

Raabe, W., Schriftsteller 45, 405

Rabl, K., Prof., Anatom 246

Radowitz,v., Botschafter 260

Rainer, Erzherzog 230

Ramler, K. W., Dichter 275

Ramón y Cajál,Prof.,Anatom 229, 257

Ramshorn, L., Gymnasialdirektor 405

Ranke, J., Prof., Anthropolog 24 I, 247

Rathke, H., Prof., Anatom 188

v. Recklinghausen, Prof., Pathol. Anatom 80, I25, I29, I4I, 144, 147 . $\mathrm{I}_{4} 8, \mathrm{I}_{49}, \mathrm{I}_{50}, \mathrm{I}_{53}, \mathrm{x}_{54}$, I59, 29 I

Reichert, K. B., Prof., Anatom 80, 94, 103, I04, 105, 107, 108, 109, I75, I $76,177,178,180$, 2 II, 270 
Rein, G. v., Prof., Gynäkolog I 59, 233, 234, $25^{8}$

Reinkens, Prof., Theolog I I 8,138

Remak, R., Prof., Mediziner, Embryolog 94, I 82

Renaut, Prof., Histolog I $56,257,357$

Renson, Dr. med. I 59

Renvers, Prof., Generalarzt 210

Retzius, G., Prof., Anatom 319,320

Retzius, Frau Anna Hjerta- 319

Reuleaux, Prof., Techniker 275

ReuB, Prof., Theolog $I_{4} 6$

Reye, Prof., Mathem. 146

Rheinstädter, A., Frauenarzt 107, II 2

Richet, Prof., Physiol. 266

Rocliell, J., Pfarrer 57,65

Rochs, Generalarzt 2 Io

Roeder, Baron v., Dipterolog +8

Roggenbach, Freiherr v. I. 40,144

Rohrbach, Lehrer I6, 58

Rokitansky, Prof., Pathol. Anatom I 50

Romberg, Prof., Inn. Kliniker I35, I 8 I

Römer, F., Prof., Geolog I 39, 243

Romiti, G., Prof., Anatom I 59, 232, 257, 297

Rönne, L., Geh. Bergrat 348,349

Roosevelt, Th., Präsident U. S. A. 308, 309, 354

Roeren, K., Gymnasialdirektor 56,57

Rosdjeschtwensky, Admiral $3^{1} 7$

Roethe, G., Prof., Germanist 213

Rothe, General 273

Rothenberg, B., Pfarrer 9o
Rothmann, M., Prof.,

Neurolog 221

Roux, W., Prof., Anatom 395

Rubner, Max, Prof., Physiolog I8I, 2I3

Rudeloff, Generalarzt 2 ro Rudolphi, K. A., Prof., Anatom 176, I 78,270 , 271,275

Rudorff, Prof., Jurist 275

Ruffini, A., Prof., Histo$\log 232$

Runge, Müllermeister in Abbenburg 9, I I, I 2

Rust, Prof., Chirurg 276

\section{S.}

Sabatier, Armand, Zoolog 257

Sámpson, Admiral, U. S. A. 354

Samson, Albert, Bankherr 22 I

Sartorius v. Waltershausen, Prof. Mineralog, 68,69

Schaafhausen, Prof., Anthropolog 243

Schadow, Architekt 275

Schaffer, Karl, Neurolog 229

Schickert, H., Generalarzt 402

Schiefferdecker, P., Prof., Anatom 289

Schjerning, v., Generalstabsarzt 210

Schimper, W., Prof., Paläontolog ${ }^{4} 6$

Schirmer, senior, Augenarzt, Prof. IoI

Schleinitz, v., Oberpräsident I3I

Schley,AdmiralU.S.A.354

Schloßberger, Chemiker, Prof. $\mathrm{IO}_{4}$

Schmidt, Gymnasialdirektor $5^{6}$
Schmidt, Erich, Prof., Germanist I 54

Schmidt, Karl, Prof., Physiol. Chemiker 194

Schmidt, Oskar, Prof.,

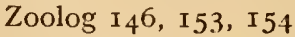

Schmiedeberg, Oswald, Prof., Pharmakolog I 44, I 47, I 57

Schmoller, G., Prof., Nationalökonom ${ }^{4} 4^{6}$

Schönlein, J. L., Prof., Inn. Kliniker I 8I

Schrader, Chr., Pfarrer I 8 Schrader, Dr. med., Oberstabsarzt 324

Schröder, K., Prof., Gynäkolog I 80

Schröter, Prof., Mathem. I 38,237

Schubert, Dr. med., Generalarzt 210

Schuchhardt, Prof., Anthropolog 240

Schulenburg, Graf v. d.

SchultheB, Theolog 275 I

Schultze, Aug. Sigismund Prof., Jurist I 46

Schultze, Bernh. Sigismund, Prof., Gynäko$\log 146$

Schultze, Max Sigismund, Prof., Anatom 8o, $\mathrm{IO}_{4}, \mathrm{I}_{4} \mathrm{O}, \mathrm{I}_{4} \mathrm{I}, \mathrm{I}_{4}$ h. I 59, I60, I 75

Schultze, Sigismund, Prof., Anatom $\mathbf{I}_{4} 6$

Schulze, Prof., Jurist I 40 Schütz, Prof., Berlin 240 Schützenberger, Prof., Inn. Kliniker, Straßburg (Els.) I 44

Schwalbe, G., Prof., Anatom $1_{46} 6,1_{53}, 1_{56}, 1_{57}$, 357

Schwarze, G., Dr. med., Arzt 90

Schweigger, K., Pıof,, Ophthalmolog I 80

v. Waldeyer-Hartz, Lebenserinnerungen. 
Schwubbe, Ferd., Gym- Strohl, Ed., Prof., Pharnasialoberlehrer 56

Seckel, Prof., Jurist 272

Seifert, Präparator 311 , 3 I 7

Selenka, Frau Professor 314,360

Seler, Prof., Archäolog, Amerikanist 316

Sengenwald, Obmann der Spitalskommission, Straßburg (Els.) I62

Skrzeczka, K., Prof. d. Staatsarzneikunde $\mathbf{2 4}$, 252

Smirnow, Prof., Anatom 290

Sobotta, J., Prof., Anatom 290

Socor, Prof., Physiolog 307

Solms-Laubach, Graf, Prof., Botaniker I 46 Sommer, Ferd., Prof., Anatom 92, 94, 252

Sorgius, Dr. med., Arzt 157 Spandow, Dr. med., Arzt $20_{4}$

Spiegelberg, O., Prof., Gynäkolog 8I, 82, 98, I25, I3I, I $32,138,140$, I 47,346

Springer, A., Prof., Kunsthistoriker I4I

Stephan, Generalpostmeister 275

Stern, Prof., Mathem. 66, 67,76

Sternecker, Admiral 244

Stiles, Wardell, Zoolog 309

Stilling, Benedikt, Arzt, Neurolog I 53

Stilling, Jakob, Ophthalmolog I 53, I 54

Stobbe, O., Prof., Jurist I 39

Stolberg-Wernigerode, Graf, Oberhofmarschall 3.30 makolog I 44, I 47

Struthers, John, Prof., Anatom I.59

Studemund, Prof., Philo$\log 1_{4} 6$

Stüler, Oberbaurat 275

Sucro, Oberdomprediger 275

Sulzer, Prof., Philosoph 275

Suzuki, Prof., Anatom 290

Swaen, Prof., Anatom 305

\section{T.}

Taguchi, Prof., Anatom 290

Teichmann, L., Prof., Anatom $74,78,79$

Tellgmann, Lehrer und Kantor 45, 47

Tellgmann, Frau Melusine, geb. v. Hartz 45

Temple, Miss, Preisrichterin $3 I 3$

Tenner, Dr. med., Leibarzt 155

Testut, Léon, Prof., Anatom 257

Thaer, Prof., Landwirtschafter 275

Therese, Prinzessin, zu Bayern $25^{\circ}$

Tilmann, O., Prof., Chirurg 94, 2 I I, 253, 303, 368

Tilmann, Frau Ilse, geb. v. Waldeyer-Hartz I $53,245,267,297,298$, 299, 301, 302, 303

Tobler, Prof., Romanist 272

Tobold, Prof., Laryngo$\log 324$

Togo, Japanischer Admiral 355

Traube, M., Prof., Inn. Kliniker $135, \quad 182$
Turner, Sir Wm., Prof., Anatom 266

Twesten, Prof., Theolog I03, 275

U.

Ulrich, Prof., Physiker 66

Umberto I., König von Italien 260

Unna, P., Prof., Dermatogonolog $157,{ }_{5}{ }^{8}$

\section{V.}

Vahlen, Prof., Philolog 213

Veit, Dr. med., Arzt III, I 12

Victoria, Kaiserin Friedrich $324,325,329,330$

Virchow, Hans, Prof., Anatom I 57, I 58, I96, 243, 289

Virchow, Rudolf, Prof., Pathol. Anatom I34. I 52, I 53, I 75, I80, I 8I, $224,239,240,241,242$, $244,246,247,250,25 \mathrm{I}$, $252,264,266,325,330$, $331,332,333,334,335$, $336,407,408,409$

Vogt, K., Prof., Zoolog 239

Volkmann, Alfred, Prof., Physiolog I25

Volkmann, Richard, Chirurg 125

Vollert, Verlagsbuch händler 273

Volta, Physiker 2 I 7

\section{W.}

Wagner, A., Prof., Chirurg, Königsberg I I5, I 7

Wagner, A., Prof., Nationalökonom 73

Wagner, R., Prof., Phy. siolog 73, 74 
Waitz, Prof., Historiker 272

Waldeck-Rousseau, franz. Minister 227

Waldeyer, Franz, Oheim des Verfassers $\mathrm{I}_{02}$, 103

Waldeyer, Friedrich, Bruder des Verfassers IO, II, 48, 49

Waldeyer, Friedrich, Neffe des Verfass. 368

Waldeyer, Johann Gottfried, Vater des Verf. I, 9, 10, I7, 20, 26, 27, $34,38,40,43,44,45$, 63,165

Waldeyer, Leonhard, Bruder des Verfassers $48,340,403$

Waldeyer, Philipp Heinrich, Großvater des Verfassers 3

Waldeyer, Philipp, Pfarrer, Stifter eines Familien-Stipendiums 3 , $3^{8}$

Waldeyer, Frau Wilhelmine, geb. v. Hartz, Mutter des Verfassers I, 3, 7, I4, 2I, 25, 32, $35,37,3^{8}$

v. Waldeyer-Hartz, Frau Emilie, geb. Dillenburger, Gattin des Verfassers II6, I4I, 243 , 297, 298, 299, 300, $301,302,322,327$, 329 v. Waldeyer-Hartz, Gerhard, Oberst, Sohn des Verfassers 302, 368

v. Waldeyer-Hartz, Frau Helene, geb. v. Wild 294

v. Waldeyer-Hartz, Hugo, Kapitän z. See, Sohn des Verfassers 367

Weber, F. W., Arzt und Dichter 33, 404

Weber, W., Prof., Physiker $66,70,7$ I , 76, 77, 40 I

Wegner, v., Generalarzt $323,325,330$

Weigert, K., Prof., Pathol. Anatom $x_{3} 8,157$, I 58,288

Weisbach, Prof., Kunsthistoriker 272

Weißmann, Oberlehrer $24 \mathrm{I}$

Weizsäcker, Prof., Historiker 272

Werner, Anton v., Maler I 79, 265

Werther, Chemiker I22

Westphal, K., Prof., Psychiater 180,272

Wickersheimer, Präparator 176,330

Wieger, Fr., Prof. der Medizin I44, I 47

Wilczek, Graf Hans 230, 244

Wilhelm I., Deutscher Kaiser 109, 320, 327, $329,336,343,344$
Wilhelm II., Deutscher Kaiser 215, 319, 320, $328,330,334,335,336$, $357,375,377$

Willdenow, Prof., Botan. 275

Winnecke, Prof., Astronom 146

Wittcke, Oberstleutn. 402 Wittich, W. v., Prof., Physiolog II 3, I I 4, I 2 I, I24, I25

Wittich, Else v. 2

Wöhler, Kaufmann, Braunschweig $4^{8}$

Wöhler, Fr., Prof., Chemiker 66,76

Wolff, Präsident d. Gesellsch. f. Natur- und Heilkunde $27^{\circ}$

Wöllner, Staatsminister 275

Wood, Preisrichter 3I 3

Wrangel, v., Feldmarschall 337

Wurmbrand, Graf 244

Z.

Zahn, Fr. W., Prof., Pathol. Anatom $\mathrm{I}_{4} 7, \mathrm{I} 53$

Ziemssen, Prof., Inn. Kliniker IOI

Zimmermann, Prof., Anatom 289

Zitzewitz, v., Oberst 347 , $34^{8}$

Zweifel, P., Prof., Gynäkolog I 53

Zweihoff, Kaplan I7 




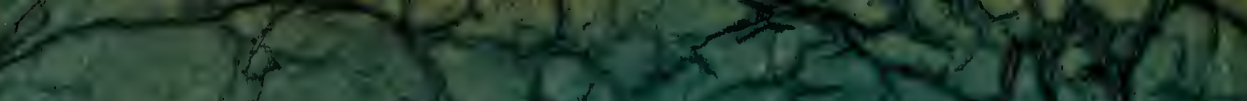

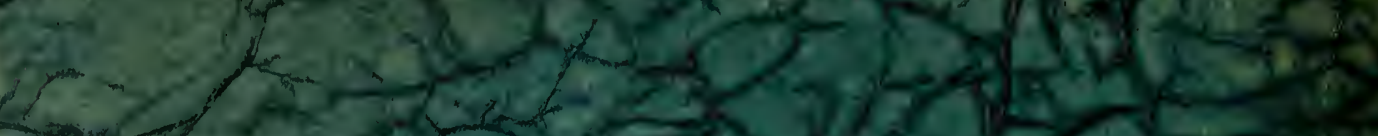
5 rs 12

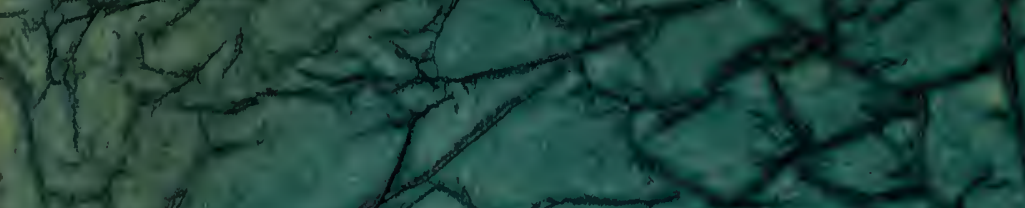
13

4.

experts

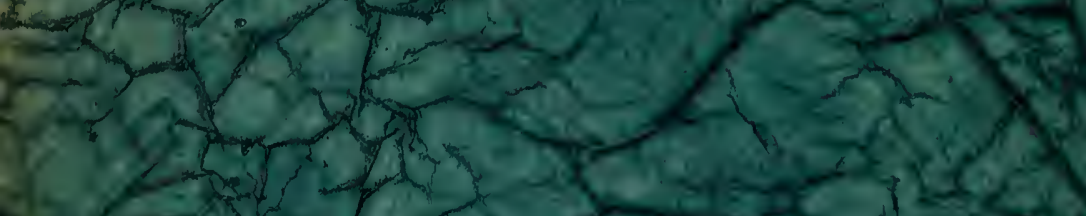

$\int_{-1}^{2}+\frac{1}{2}+2$ 2. As and

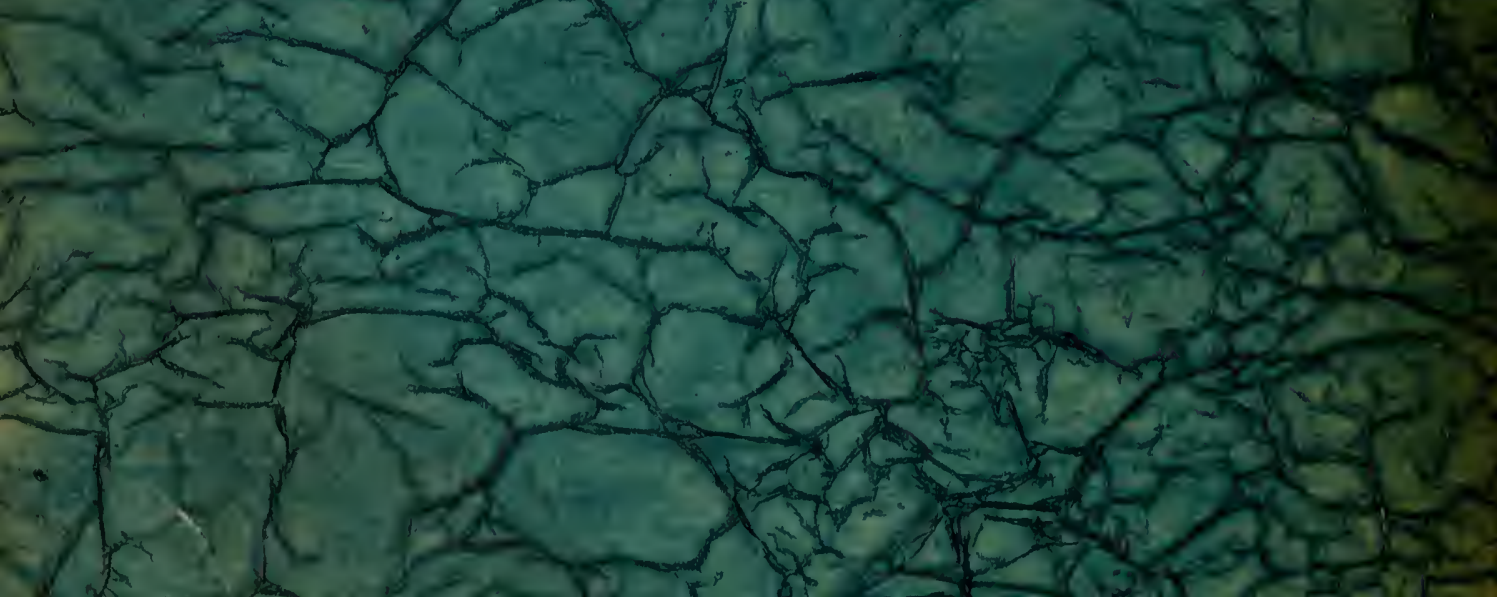

